UnIVERSIDAD NACIONAL DE LA PLATA

FACULTAD DE HUMANIDADES Y CIENCIAS DE LA EdUCACIÓN SECRETARÍA DE POSGRADO

\title{
Los significados de la desesperación
}

Las representaciones del suicidio en Buenos Aires (1868-1903)

\author{
Julián Arroyo
}

Tesis para optar por el grado de Doctor en Historia Directora: Dra. María Andrea Reguera (UNCPBA / CONICET) Codirectora: Silvia Mallo (UNLP / CONICET)

La Plata, 21 de marzo de 2018 


\section{Agradecimientos}

Esta tesis doctoral es el resultado de cinco años de intensa labor, enfrentando muchos desafíos y viviendo invaluables experiencias que me han hecho crecer tanto a nivel profesional como personal. Hoy, mirando el camino recorrido, estoy agradecido por cada uno de esos momentos y por las personas con las que transité los pasos que llevaron a la conclusión de esta etapa.

En primer lugar, quiero agradecer a la Dra. Andrea Reguera, mi directora, por formarme, con entusiasmo y dedicación, en el oficio de historiador, y por las sugerencias, observaciones y correcciones realizadas a las diferentes versiones previas de este trabajo. Gracias a ellas, pude presentar de forma más clara, ordenada y con una mejor y más sólida fundamentación las ideas que quería expresar en esta tesis. También quiero manifestar mi gratitud a la Dra. Silvia Mallo por acompañarnos, como codirectora, durante el desarrollo de mis estudios doctorales, y brindarnos sus consejos y recomendaciones.

Asimismo, deseo expresar mi agradecimiento a las instituciones que hicieron posible el desarrollo de mi formación de postgrado: a las autoridades y miembros del Centro de Estudios Sociales de América Latina (CESAL FCH UNICEN), mi lugar de trabajo, donde obtuve valiosas experiencias al participar de proyectos grupales y desarrollar mis tareas como becario; al Consejo Nacional de Investigaciones Científicas y Técnicas (CONICET), que durante cinco años me brindó el financiamiento necesario para llevar adelante mis estudios doctorales; y a todo el equipo del Programa de Doctorado en Historia de la Facultad de Humanidades y Ciencias de la Educación de la Universidad Nacional de la Plata. También quiero dar las gracias al plantel docente de los seminarios que cursé durante esta etapa formativa, en especial, a la Dra. Alejandra Mailhe, al Dr. Diego Pereyra, la Dra. María Angélica Corva y al Rabino Dr. Fishel Szlajen.

También quiero expresar mi agradecimiento a las instituciones que me abrieron sus puertas para llevar adelante esta investigación: Archivo General de la Nación, Hemeroteca "José Hernández" (Legislatura de la Ciudad Autónoma de Buenos Aires), Biblioteca Nacional "Mariano Moreno", Biblioteca Prebisch (Banco Central de la 
República Argentina), Biblioteca del Convento de Santo Domingo, Biblioteca Pública del Convento de la Merced, Biblioteca de la Legislatura de la Provincia de Buenos Aires, Academia Nacional de Medicina, Biblioteca de la Facultad de Medicina de la UBA, Biblioteca Rivadavia (Tandil), Biblioteca Central de la UNICEN, Biblioteca del Instituto de Estudios Histórico Sociales "Prof. Juan Carlos Grosso", Biblioteca Pública de la Universidad Nacional de La Plata, Biblioteca de la Academia Nacional de la Historia, Biblioteca Central "Prof. Augusto Raúl Cortázar". Quiero agradecer muy especialmente a los archivistas, bibliotecarios, personal y autoridades que trabajan en las instituciones antes mencionadas por atender con buena predisposición y paciencia mis consultas y solicitudes, en especial, al equipo de trabajo del Departamento de Documentos Escritos del AGN. Asimismo deseo dejar mi agradecimiento a quienes llevaron adelante la traducción de parte de la documentación consultada: Claudia Debernardi, Natalia D'Aquino, Tim Oliver Sander y Marina Brunotto.

En estas líneas, no puedo dejar de mencionar a los amigos que siempre están, a pesar de las distancias y de la vorágine del día a día, como Federico Sutter, Leonardo Distéfano, Belén Santillán, Juan Pablo Martínez, Nicolás Olmedo, Silvina Tamagni, Lucio Martinelli, Ariel Di Benedetto, Agustín Hidalgo, Leonardo Canciani, Josefina Irurzun y Dana Valente Ezcurra. Quiero darle las gracias a Ángel Henríquez por acompañarme en el día a día durante el último tramo de esta etapa como tesista. También quiero agradecer a Héctor García, compañero de apasionantes charlas, con el que siempre he podido compartir pensamientos, sentimientos, reflexiones y dudas existenciales. Santiago Ríos y Hugo Pouzo, además de honrarme con su amistad, me han recibido en sus hogares, cuando necesité salir de Tandil para cursar el doctorado y llevar adelante extensas jornadas de trabajo de campo. Ellos me acompañaron en muchos momentos de ansiedad e incertidumbre. En esos días, estuvieron para escucharme, darme consejos oportunos y palabras de aliento. Nunca olvidaré todo lo que han hecho por mí.

Asimismo, siempre recordaré con enorme gratitud las enseñanzas de mi maestro, el Yogacharya Sadeva Dharmanath, y los momentos compartidos con mis compañeros en la Escuela de Natha Yoga. En los últimos cuatro años, junto a los yoguis y yoguinis, aprendí a valorar y ver de una manera distinta cada una de las experiencias vividas hasta ahora. 
Para finalizar, quiero dedicar unas palabras a los miembros de mi familia, a quienes dedico esta obra, aunque no creo que haya suficientes palabras para expresar lo agradecido que me siento con ellos y lo mucho que los amo. En primer lugar, a mis padres, Sergio y Cecilia, que caminan conmigo desde que tengo memoria, y en cada nuevo desafío están ahí, junto con mis hermanos, Pablo, Felipe y Bernardo, para alentarme. Cuando pienso en el final de esta etapa, observando la tesis concluida, me siento dichoso y afortunado de estar compartiendo estos momentos con ustedes. Sonrío pensando en las charlas sobre la serie o película que miramos por la noche, las vacaciones en Necochea, los mates que tomamos en el patio por la tarde, o las risas mientras jugamos a las cartas o algún juego de mesa. También elevo mis comisuras al pensar en la próxima vez que nos juntemos a comer todos juntos, con mis tíos, Néstor y Laura, y mis primos, Román y Martín. Sin todos esos momentos, la vida no habría sido tan feliz como hasta ahora. El camino que recorrí mientras escribía esta tesis también habría sido muy diferente, mucho menos alegre y gratificante. Siempre conté con ustedes y los siento conmigo hoy, mientras imagino los días y los futuros proyectos que vendrán. Por último, quiero dejar unas palabras de gratitud a mis abuelos: Tito, Elsa, Dora y José. Sin sus pasos, hoy no estaría aquí, sintiendo cada uno de los míos. 


\section{RESUMEN Y PALABRAS CLAVE}

La presente investigación tiene como objetivo el estudio sociocultural de las representaciones del suicidio en la ciudad de Buenos Aires, durante el último tercio del siglo XIX. Mientras este asentamiento urbano crecía de forma acelerada, aparecieron una serie de problemas que las distintas ramas de la ciencia positivista trataron de explicar y prevenir, por ejemplo, las enfermedades, el delito, la propagación de los vicios y los comportamientos inmorales (como el juego o la prostitución), las patologías mentales y las muertes por mano propia. Una de las formas de representar el crecimiento de la tasa de suicidios era la de una epidemia contagiosa, producida por las características de la vida moderna y civilizada. En nuestro estudio, sostenemos, como hipótesis de trabajo, que el avance del paradigma científico sobre el tema no agotó la reflexión ética de los actores sociales. Así, consideramos que si bien los actos suicidas fueron objeto de estudio del saber médico legal y psiquiátrico, como discurso erudito y hegemónico sobre el fenómeno, seguía vigente, incluso entre los miembros de la elite cultural, un debate axiológico sobre la legitimidad o no de la muerte voluntaria en distintas circunstancias. En este sentido, entendemos que el suicidio era motivo de polémica, ya que comprometía ciertos valores sociales, como lo hace en el presente. De este modo, interpretamos los actos suicidas como acciones individuales que poseían un significado social, es decir, eran inteligibles a la luz de la cultura compartida por los suicidas, su red de vínculos y la sociedad en la que estos vivían. A partir de estos supuestos, nos planteamos las siguientes preguntas: ¿Qué principios morales se ponían en juego a la hora de pensar en la decisión de poner fin a la vida? ¿Cuáles eran las causas legítimas? ¿Cuáles tenían sentido para la sociedad porteña de las décadas finales del siglo XIX? ¿El suicidio podía ser un desenlace permitido, o hasta deseable y admirado en alguna situación? Para responder, al menos, de forma parcial, estos interrogantes llevamos adelante un estudio cualitativo de los casos de suicidio registrados en los sumarios judiciales disponibles y su repercusión en la prensa de la época. A partir del estudio de esta documentación, hemos encontrado diferentes tipos de narraciones, de acuerdo a la "causa determinante" que articulaba el recuento de lo sucedido. Estas explicaciones verosímiles tenían un valor moral específico para los habitantes de Buenos Aires en el período que abordamos.

\section{Palabras clave}

- REPRESENTACIONES DEL SUICIDIO

- REPRESENTACIONES DE LA MUERTE

- HISTORIA CULTURAL

- HISTORIA DE BUENOS AIRES

- MARCO AXIOLÓGICO 


\section{ÍNDICE}

\section{Los significados de la desesperación \\ Las representaciones del suicidio \\ en Buenos Aires (1868-1903)}

Agradecimientos .................................................................. 2

Introducción......................................................................... 10

Primera Parte - Marco teórico y metodológico ...................................... 21

1. El estudio cultural del suicidio desde la historia ............................. 22

1.1. Breve introducción de las perspectivas de análisis del suicidio en el mundo occidental .............................................................................26

1.1.1. El suicidio en la filosofía antigua ........................................... 26

1.1.2. La mirada del pensamiento cristiano .......................................... 30

1.1.3. La modernidad: despenalización y medicalización del suicidio ................. 32

1.1.4. La muerte voluntaria en el siglo XIX: el saber psiquiátrico ...................... 35

1.1.5. La interpretación social del fenómeno ........................................... 35

1.2. Corrientes de pensamiento en el mundo contemporáneo ...................... 42

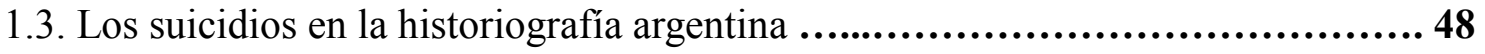

1.4. Consideraciones finales ......................................................59

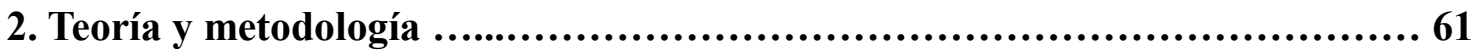

2.1. Aspectos teóricos y metodológicos ..........................................61 61

2.1.1. Las representaciones de la muerte por mano propia .............................. 64

2.1.2. La narración moral y el marco axiológico .........................................6 68

2.1.3. La red social de contención ..................................................... 72

2.1.4. El otro significativo y la acción comunicativa ................................. 76

2.2. Fuentes .................................................................. 79

2.2.1. Textos científicos y académicos ............................................... 79

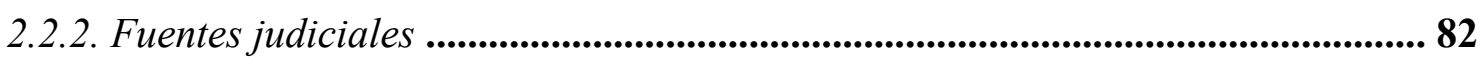

2.3. Consideraciones finales ....................................................... 86 
Segunda parte - Contexto histórico: aspectos culturales y transformaciones políticas, sociales y económicas

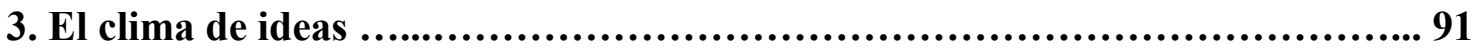

3.1. Auge del positivismo......................................................... 91

3.2. Los liberales reformistas y la "cuestión social" ................................ 96

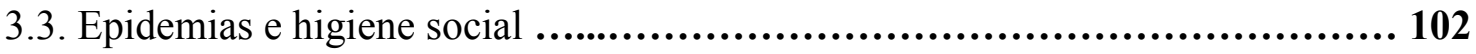

3.4. El pensamiento médico y las enfermedades mentales ........................... 105

3.5. De la Medicina Legal a la Antropología Criminal .............................. 109

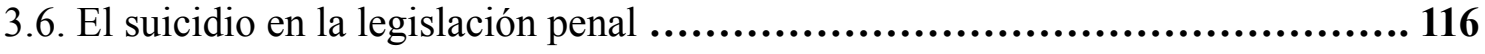

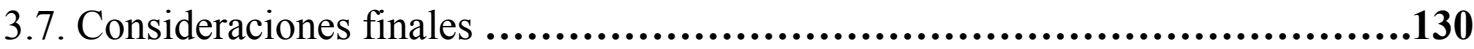

4. El proceso de modernización en la ciudad de Buenos Aires .....................132

4.1. Los escenarios y su transformación ................................................137

4.1.1. El puerto y los ferrocarriles ...........................................................................139

4.1.2. Palacios, unidades familiares y viviendas colectivas .............................141

4.1.3. Geografia higienista del organismo urbano ......................................151

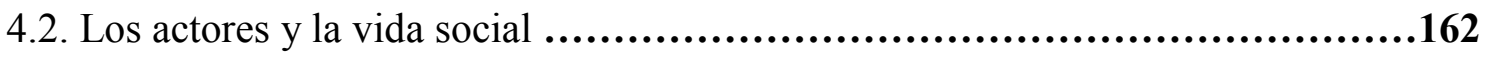

4.2.1. Nativos e inmigrantes ........................................................... 162

4.2.2. Una sociedad de clases en formación .............................................168

4.2.2.1. Clases trabajadoras ........................................................168

4.2.2.2. Clases medias ...........................................................174

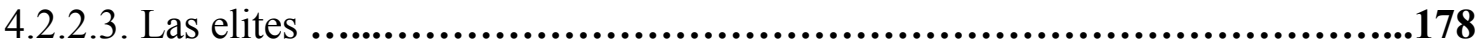

4.2.3. Hombres y mujeres ..............................................................................................189

4.3. Consideraciones finales .................................................... 199

Tercera parte - Los significados del suicidio ...................................201

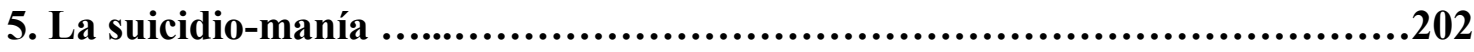

5.1. Las ideas científicas sobre el suicidio ...................................... 204

5.1.1. Una epidemia inquietante... .................................................. 204

5.1 .2 En la frontera entre la razón y la locura ....................................... 214

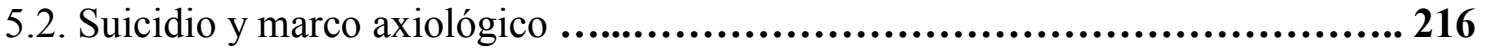

5.2.1. Pasión, ambición y vicio .................................................216 
5.2.2 El acto suicida como final estoico...........................................218

5.2 .3 El suicidio de Leandro N. Alem ...............................................222

5.3. Consideraciones finales ......................................................229

6. Medir la desesperación ...................................................234

6.1. Los suicidas a la luz de las estadísticas ........................................236

6.2. Las formas de la autodestrucción .............................................241

6.3. Un lugar para morir .........................................................244

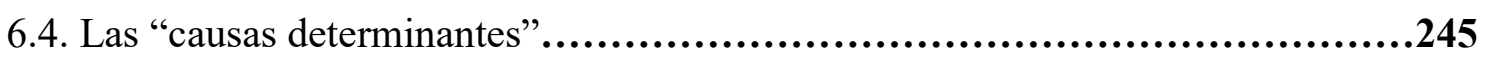

6.5. Los "cansados de la vida" ...........................................................251

6.6. El silencio de los desesperados ............................................258

6.7. Consideraciones finales .....................................................265

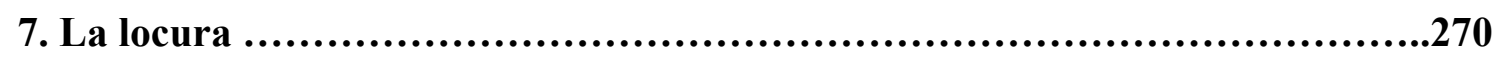

7.1. Los suicidas alienados .....................................................272

7.1.1. La monomanía del suicidio .....................................................279

7.1.2. Perseguidos hasta la muerte ... .................................................281

7.1.3. La ambigüedad de la tristeza ...............................................282

7.2. Los indicios de la ausencia del juicio ........................................284

7.3. La responsabilidad y la memoria del suicida .................................291

7.4. Luchar contra la locura estoicamente .......................................298

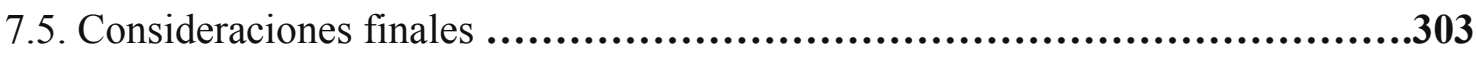

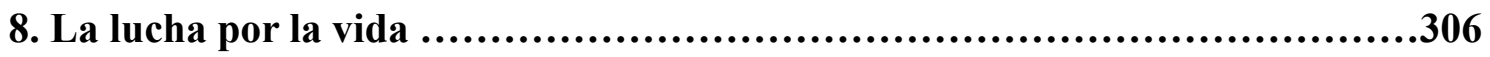

8.1. La "suprema desesperación" ...............................................308

8.2. Asistencia material y últimas voluntades.......................................314

8.3. La contención afectiva y el pedido de auxilio................................321

8.4. Consideraciones finales .......................................................326

9. Las pasiones desenfrenadas ................................................331

9.1. Mujeres sensibles y jóvenes románticos...................................333

9.2. Los suicidas apasionados ................................................342

9.2.1. El Desengaño .............................................................342

9.2.2. Sentimientos prohibidos ....................................................347

9.2.3. Celos e infidelidad ..........................................................353 
9.3. Consideraciones finales.................................................372

10. Honor y sufrimiento moral .............................................375

10.1. El deber, la vergüenza y la desesperación ......................................376

10.2. El lenguaje de la honra y la defensa de la reputación............................387

10.3. Limpiar la mancha y legar un buen nombre .....................................396

10.4. Consideraciones finales ..................................................408

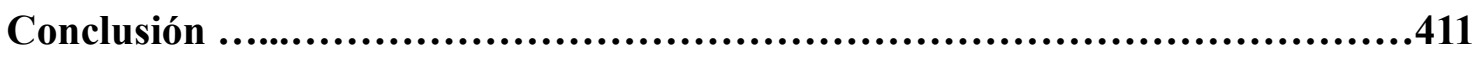

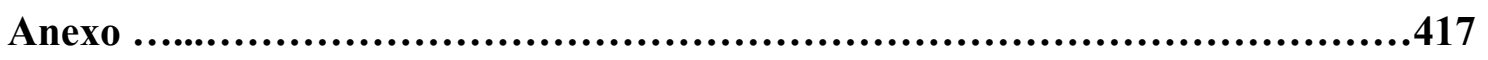

Referencias bibliográficas ....................................................449 


\section{Introducción}

La presente investigación fue llevada a cabo con el objetivo de realizar un aporte al conocimiento de las representaciones de la muerte en Buenos Aires durante la segunda mitad del siglo XIX. En Argentina, desde fines del siglo XX hasta la actualidad, nuevas investigaciones han abordado el estudio cultural de la muerte en distintos períodos de la historia y de acuerdo con distintos enfoques (véase, entre otros, GODOY y HOURCADE, 1993; PEREYRA, 1999; LÓPEZ MATO, 2002; CARETTA y ZACCA, 2007, 2010 y 2011; GAYOL, 2012 у 2016; GUERRA, 2010a y b, 2014 у 2015; KESSLER y GAYOL, 2015; DAL CASTELLO, 2014 y 2016; CARETTA, 2015; FIQUEPRON, 2015). Estos estudios abarcaron aspectos y perspectivas diversas tales como los cambios en la sensibilidad hacia los muertos, los lugares de entierro y las prácticas funerarias (LÓPEZ MATO, 2002; CARETTA y ZACCA, 2007 y 2010; GUERRA, 2010a y b); las representaciones de la muerte en la infancia (JÁUREGUI, 1993); la difusión de las ideas médico-higienistas durante el siglo XIX (PEREYRA, 1999; GUERRA, 2014, DAL CASTELLO, 2014 y 2016); los funerales de figuras políticas destacadas de las elites y el significado cultural de las movilizaciones convocadas por estos funerales (CARETTA y ZACCA 2010 y 2011; GAYOL, 2012 y 2016; CARETTA, 2015). Los importantes avances realizados por los trabajos hasta aquí mencionados no agotan el tema de la muerte y el morir. En este sentido, existen temáticas menos trabajadas, por ejemplo, los significados de las muertes violentas (homicidios, ejecuciones, etc.), en distintos contextos históricos. Por esta razón, decidimos estudiar las formas de representar las muertes por mano propia.

El paradigma científico actual contempla los actos suicidas dentro de las preocupaciones de la salud pública. En el mundo contemporáneo, las tasas de suicidio son un motivo de alarma a nivel mundial. Más allá de las distorsiones que las cifras puedan tener (por el ocultamiento de muchos casos o por situaciones que pasan por accidentes, cuando no lo son), en 2000, se calculaba que cerca de 1.000 suicidios ocurrían por día en el mundo; es decir, cada 40 segundos se producía un suicidio en algún lugar del planeta, de acuerdo a las estimaciones de la Organización Mundial de la Salud [OMS]; así, la alarmante cifra anual estimada ascendía a más de 800.000 
suicidios (COHEN AGREST, 2007: 37). ${ }^{1}$ Según la OMS, en 2012 un número similar de personas se quitaron la vida (803.900) y muchas más intentaron hacerlo. De acuerdo con sus estimaciones, en muchos lugares, más gente muere a causa de suicidios que en conflictos armados, homicidios o accidentes de tránsito. Por otra parte, el suicidio es la segunda causa de muerte, a nivel mundial, de la población de entre 15 y 29 años. Así, en algunos países, el número de casos en los jóvenes ha crecido más, en términos relativos y absolutos, que las tasas correspondientes a la población de mayor edad, que siempre han sido las más altas. ${ }^{2}$ En la actualidad, se estima que las cifras no han variado mucho. ${ }^{3}$

La preocupación por el aumento de los suicidios impulsó, desde el siglo XIX y hasta la actualidad, el desarrollo de investigaciones científicas que apuntan a comprender el fenómeno de la muerte violenta auto-infligida. Así, la interpretación y la comprensión de los actos suicidas, en general, es objeto de estudio de distintas disciplinas, tales como la psiquiatría, la psicología y la sociología, entre otras. El interés por el tema llevó a conformar un campo de estudios multidisciplinario específico, a mediados del siglo XX, a partir de los trabajos e iniciativas impulsadas, entre otros, por el psicólogo norteamericano Edwin Shneidman, fundador de la Asociación Americana de Suicidología.

El enfoque científico sobre el tema es bastante reciente, si se compara su trayectoria con la larga historia de acalorados debates éticos y filosóficos que el suicidio ha impulsado en el mundo occidental. Según el sociólogo Jack Douglas (1967), en el marco del saber erudito, el siglo XIX fue el escenario de un cambio en la comprensión de los actos suicidas. Hasta entonces, el suicida era comprendido principalmente desde sus caracteres esenciales (virtuoso, cobarde, desesperado, melancólico, loco, alienado, apasionado, romántico, etc.), así existían elementos sustanciales y constitutivos del individuo que lo caracterizaban como tal y daban cuenta del suicidio. Al mismo tiempo, el acto suicida hablaba de las cualidades del individuo, de su estado moral. La comprensión interdisciplinaria actual de los mismos hace hincapié en una combinación de elementos esenciales y situacionales, dependiendo de la perspectiva de la disciplina

\footnotetext{
${ }^{1}$ Disponible en: http://www.who.int/mental health/media/en/382.pdf [Consultado el 12/11/2014].

${ }^{2}$ Véase, Preventing suicide: a global imperative (2014), World Health Organization. Disponible en: http://apps.who.int/iris/bitstream/10665/131056/1/9789241564779 eng.pdf?ua=1 [Consultado el 13/07/ 2017].

${ }^{3}$ Disponible en: http://www.who.int/mental_health/suicide-prevention/suicide-infographic-es.pdf?ua=1 [Consultado el 13/07/2017].
} 
que estudie el tema. En este sentido, los estudios del campo científico actual han presentado un sujeto situado y condicionado por su propia configuración biológica y psicológica, así como por su entorno familiar, laboral, social y cultural. Así, el espacio de la decisión personal y del libre albedrío se ven fuertemente limitados desde los discursos académicos actuales.

Por otra parte, el debate ético y filosófico sobre el suicidio es mucho más antiguo. En el pasado, el suicidio era comprendido como un problema moral. Desde nuestra perspectiva, la muerte voluntaria interpela a toda la sociedad, más allá de cualquier contexto temporal y geográfico. No hay una idea de orden posible si todos podemos disponer de nuestras vidas libremente. Por ello, las diferentes sociedades han pautado normas y códigos, de acuerdo a los comportamientos que buscaban promover en sus integrantes. Así, una serie de valores (positivos o negativos) es la base de lo que llamamos marco axiológico, es decir, el conjunto de principios que dan autoridad y legitimidad, o que, por el contrario, reprueban las acciones de los miembros de una sociedad. ${ }^{4}$ En otras palabras: ¿Qué actitudes eran enaltecidas? ¿Cuáles reprobadas? ¿Con qué discurso eran legitimadas o descalificadas? Ninguna sociedad ha permanecido indiferente al respecto. En la actualidad, la reflexión moral del tema parece reducida al ámbito de los problemas bioéticos. ${ }^{5}$ Así, los debates en el mundo contemporáneo, que han vuelto a poner sobre la mesa las viejas discusiones filosóficas sobre el suicidio, están vinculados con el derecho a la eutanasia y a una muerte digna, que no prolongue la vida artificialmente (dejando de lado la voluntad del difunto y su sufrimiento).

Sin embargo, los problemas relacionados con los pacientes terminales no agotan las dimensiones éticas y existenciales que nos plantea el tema de los suicidios. De acuerdo con las ideas de Scott Fitzpatrick (2011, 2014a y b), las narraciones de las personas que intentaron quitarse la vida, o de los familiares y amigos del suicida, parten de un conjunto de supuestos axiológicos o existenciales. Los deudos elaboran un relato, una narración para dar cuenta de lo sucedido y para procesar los intensos sentimientos y emociones con los que cargan. Hoy sabemos más acerca del dolor y el padecimiento de

\footnotetext{
${ }^{4}$ La categoría marco axiológico fue elaborada en base a las ideas presentadas en la investigación llevada adelante por el Rab. Dr. Fernando Szlajen, quien analizó la reflexión filosófica sobre el suicidio en el pensamiento occidental, y en la filosofía judía, sin reducir el fenómeno a su aspecto psiquiátrico o patológico, tomando como eje el análisis de la muerte voluntaria como problema ético y existencial (SZLAJEN, 2012).

${ }^{5}$ Véase, por ejemplo, COHEN AGREST (2007) y SZLAJEN (2012).
} 
los familiares y seres queridos del suicida, los llamados "sobrevivientes". Así como existen programas de prevención y de atención a los suicidas antes, durante y después de una autoagresión, también hay instituciones y grupos dedicados a contener a las personas que están atravesando el duelo, luego del suicidio de un otro significativo (COHEN AGREST, 2007: 315-318). Narrar lo sucedido en estos espacios permite reconstruir los eventos traumáticos para aceptar la muerte del ser querido y seguir viviendo. Siguiendo lo estudiado por Fitzpatrick, la trama elaborada por los miembros de la red social familiar y afectiva del suicida combina un conjunto de elementos esenciales y situacionales, con el objetivo de trabajar con la culpa y la responsabilidad por lo sucedido. Estas narraciones también contienen referencias a las creencias, principios y valores de los sujetos que las enuncian, los cuales forman parte de una cultura compartida.

"No hay más que un problema filosófico verdaderamente serio: el suicidio. Juzgar que la vida vale o no vale la pena de que se la viva es responder a la pregunta fundamental de la filosofía". Así da comienzo la reflexión de Albert Camus en "El Mito de Sísifo". Camus entendía el suicidio como el punto de partida de toda axiología existencial. Es decir, la pregunta por el suicidio nos lleva a la cuestión fundamental de todo ser humano: el valor de la vida y el sentido de esta (o de quitársela). De este modo, preguntarnos por la muerte voluntaria nos lleva al interrogante sobre aquellos valores que sirven como fundamentos de la acción. Son los axiomas que dan sentido y coherencia a nuestros actos, o que permiten que otros los interpreten. Por esta razón, la pregunta por el suicidio pone en tensión los valores que sustentan la vida en sociedad: ¿Tengo derecho sobre mi vida? ¿En qué circunstancias? Cada grupo humano estableció su versión sobre este asunto, de acuerdo a un marco axiológico general establecido históricamente. Por ello, a la cita de Camus añadiríamos que no se trata sólo de un problema filosófico, sino también de una cuestión histórica y cultural.

A fin de encarar el tema desde esta perspectiva en la historia argentina, la investigación que presentamos aborda el período que va de 1868 a 1903. Esta demarcación cronológica responde a ciertos cambios en la legislación argentina. Consideramos dichas modificaciones del marco legal como sucesos emergentes dentro de un proceso de larga duración en el mundo occidental: la despenalización del suicidio. El inicio del recorte temporal seleccionado toma como referencia la presentación del 
Proyecto de Código Penal elaborado por Carlos Tejedor. El 5 de diciembre de 1864 el Gobierno Nacional encargó a Tejedor la tarea de elaborar un proyecto de código penal para el naciente estado argentino en proceso de consolidación. Su autor entregó una primera parte el 30 de diciembre de 1865 y una segunda el 31 de enero de 1868 (LAPLAZA, 1978: 77). ${ }^{6}$ En esta última entrega, estaban incluidas las disposiciones referidas a los crímenes y delitos en particular, entre otros, el suicidio. En el proyecto de código penal de Carlos Tejedor el suicidio aparecía tipificado como un delito de acción privada, dentro de la división de los crímenes y delitos contra las personas (junto con el homicidio simple, el asesinato, el parricidio, el aborto, el infanticidio y el duelo), y estaban pautadas una serie de sanciones. En la parte 2a, Libro I, Título I, prf. 6, figuraban tres artículos al respecto. El primero dejaba sin efecto el testamento del que se hubiera quitado la vida; el segundo establecía que aquel que hubiera intentado suicidarse sería encerrado y vigilado por un cierto lapso de tiempo, de uno a tres años; y en el tercero, Tejedor proponía la pena para aquellos que hubieran participado de un suicidio, ya fuera instigando al que se había quitado la vida o ayudándolo en su propósito de darse muerte. De estos tres artículos, sólo el tercero quedó incluido en el Código de la Provincia de Buenos Aires, sancionado por ley en 1877. La legislación nacional, aprobada en 1886, no incluyó directamente ninguna mención sobre el suicidio. Años más tarde, tomando el precedente del proyecto de reforma presentado en 1891, por la ley 4189 del 20 de agosto de 1903, se incluyó en el Código Nacional, de nuevo, la normativa sobre la instigación o ayuda al suicidio. La única variación, desde entonces, fue la cantidad de años para la pena en estos casos. Según el informe que presentaron los integrantes de la comisión de legislación en el senado nacional, en 1903:

El inciso $6^{\circ}$ del proyecto pena severamente al que instiga o ayuda a otro al suicidio cuando este tiene lugar. Es una disposición nueva. El proyecto Tejedor había erigido el suicidio en delito imponiendo como pena la anulación de las disposiciones de última voluntad, y al autor de tentativa de suicidio la sujeción a una rigurosa vigilancia por uno a tres años. Estas disposiciones fueron suprimidas conservándose sólo la de cooperación al suicidio en el proyecto adoptado interinamente, o sea en el Código Tejedor. La ley actual no consigna prescripción alguna sobre este punto. Hubo razón en suprimir la infundada

\footnotetext{
${ }^{6}$ Sobre este tema, véase, entre otros, BLASCO FERNÁNDEZ DE MOREDA (1962); GARDELLA (1968); LAPLAZA (1978); DONNA (1999: 94) y DI GRESIA (2014: 455, 457, 458-461, 794-797, 799$803,805-810)$.
} 
prescripción del proyecto Tejedor con sus penas ridículas e ineficaces, pero no hubo razón para guardar silencio sobre la instigación y la cooperación al suicidio, a las que puede procederse por malignidad, por mal entendida misericordia o por interés. ${ }^{7}$

La inclusión del artículo propuesto por Tejedor tenía como uno de sus objetivos poner un límite a la "mal entendida misericordia". En este sentido, dejaba explícito que había un acto que estaba fuera de toda discusión: la eutanasia. Sobre este asunto, José Ingenieros se mostró intransigente en un artículo publicado en 1911:

Se podría discutir el "derecho a la muerte" en los suicidas, pero es evidente que su responsabilidad es intransferible; es inadmisible que el médico pueda convertirse en instrumento de suicidio ajeno. [...] Con nuestra moral presente, estamos obligados a considerar como delito cualquier acto que abrevie la existencia de un enfermo, sea cual fuere su gravedad.

En síntesis, la incorporación del artículo antes omitido dentro del código penal marcaba la frontera de lo permitido, la negación de la eutanasia estaba fuera de discusión. Al mismo tiempo, en 1903, la idea de castigar a los suicidas ya no poseía fundamento o legitimidad.

Asimismo, el período seleccionado reviste un especial interés por las nuevas ideas que se difundieron sobre los actos suicidas durante esos años, sobre todo, en el ámbito científico y académico porteño. Los cambios económicos, políticos y sociales del último tercio del siglo XIX y principios del XX promovieron la reflexión de los contemporáneos sobre un conjunto de problemáticas. Mientras los asentamientos urbanos crecían aceleradamente, aparecieron una serie de problemas que las distintas ramas de la ciencia positivista trataron de explicar y prevenir, como las enfermedades, el delito, la propagación de los vicios y los comportamientos inmorales (como el juego o la prostitución), las patologías mentales o las muertes por mano propia. En este marco, como han mostrado trabajos anteriores (OTERO, 1991 y 2004), los suicidios fueron descubiertos en la ciudad de Buenos Aires como fenómeno social, cuyo aumento acelerado en la población despertaba preocupación. Una de las formas de representar el crecimiento de la tasa de suicidios era la de una epidemia contagiosa, una suicidio-

\footnotetext{
7 Congreso Nacional, Diario de Sesiones de la Cámara de Senadores, período 1903, Buenos Aires, Establecimiento Tipográfico "El Comercio", 1904, pp. 131-132.
} 
manía, producida por las transformaciones de la vida moderna y civilizada. El higienismo, la psiquiatría alienista, la medicina legal y la criminología, desde diferentes ángulos, se ocuparon de estudiar los suicidios en Buenos Aires. Dada la atención prestada por los contemporáneos a los sucesos de este tipo en la capital del estado argentino, optamos por estudiar estos casos y cómo fueron representados por los actores sociales de la época.

En este sentido, consideramos como punto de partida la siguiente premisa: los suicidios son acciones sociales que ponen en tensión los principios morales de una sociedad, es decir, el marco axiológico. En primer lugar, cabe señalar que entendemos a los suicidas como sujetos inmersos en una red compuesta por diversos vínculos (familiares, afectivos, etc.). Así, el que se quita la vida interpela a ciertos individuos que considera sus otros significativos. Como veremos, el suicida expresaba en sus notas lo que sentía y deseaba a los miembros de su red familiar y afectiva, y, en muchos casos, buscaba condicionar al entorno con sus últimas palabras y su autoagresión. Dicho de otro modo, los que llevaban adelante un acto suicida no estaban aislados, eran actores sociales permeados por esquemas culturales e inmersos en una trama de lazos vinculares que los asistían y/o condicionaban.

En segundo lugar, como ya mencionamos, al entender los suicidios como acciones éticas que siempre ponen en tensión los valores de una sociedad, como hipótesis de trabajo consideramos que el avance del paradigma científico sobre el tema de la muerte por mano propia no agotó la reflexión ética de los actores sociales. Así, estimamos que si bien el suicidio fue objeto de estudio del saber médico legal y psiquiátrico, como discurso erudito y hegemónico sobre el fenómeno, y era asociado, en nuestro período, a la enfermedad, el delito y, en especial, a la locura, sostenemos que seguía vigente, incluso entre los miembros de la elite cultural, un debate axiológico sobre la legitimidad o no de la muerte voluntaria en distintas circunstancias y para ciertos actores. En este sentido, entendemos que el suicidio seguía siendo motivo de polémica, ya que comprometía ciertos valores sociales, como lo hace en el presente. Como veremos, los familiares, amigos y conocidos del suicida, a partir de sus esquemas culturales y su experiencia particular, debían procesar lo sucedido y comunicar a las autoridades su visión de lo ocurrido. Estas interpretaciones eran articuladas como relatos morales, narraciones que ponían el énfasis en determinar la responsabilidad en los eventos que llevaron al trágico desenlace, a partir de una serie de variables, causas o 
motivaciones verosímiles. Estas últimas, según nuestra consideración, no eran valoradas de la misma forma por los actores sociales del período. Por ejemplo, la narración difundida en los medios gráficos cumplía la función de fábula moral, que exaltaba o condenaba las actitudes de los suicidas, de acuerdo con las circunstancias. De igual modo, el suicida dejaba testimonios, en las notas y escritos legados a los deudos y a los agentes del estado, que daban cuenta de sus valores culturales, del marco axiológico que tenía como referencia.

A partir de los supuestos ya mencionados, nos planteamos los siguientes interrogantes: ¿Qué valores aparecían como importantes en el análisis axiológico del suicidio? ¿Qué principios morales se ponían en juego a la hora de pensar en la decisión de poner fin a la vida? ¿Cuáles eran las causas legítimas? ¿Cuáles tenían sentido para la sociedad de la segunda mitad del siglo XIX? ¿Qué vidas valían la pena ser vividas y cuáles no? ¿El suicidio podía ser un desenlace permitido, o hasta deseable y admirado en alguna situación?

Atendiendo a estas preguntas, hemos llevado adelante la investigación que presentamos a continuación. La primera parte está constituida por dos capítulos. En el primero, exponemos las diferentes actitudes y perspectivas éticas que el mundo occidental ha adoptado ante las prácticas suicidas en la historia. Asimismo, introducimos el estado de la cuestión sobre el tema, una síntesis general del vasto campo de estudios que abordan el suicidio como objeto de estudio, para así determinar dónde situamos nuestra investigación: la perspectiva sociocultural. En el segundo capítulo, nos dedicamos a presentar el diseño de la investigación y las fuentes documentales consultadas. Así, explicamos cómo se abordaron las representaciones del suicidio y las principales herramientas conceptuales utilizadas para ello (tipo narrativo, red social, acción comunicativa, etc.). Por otro lado, introducimos la documentación analizada a lo largo de esta obra, tales como textos científicos y académicos, sumarios judiciales, medios gráficos, literatura, censos y anuarios estadísticos.

La segunda parte está orientada a presentar el contexto histórico general del período de estudio. Así, en el capítulo 3, presentamos un balance del clima de ideas de la época. En la exposición, abordamos, entre otros temas, el auge y la expansión de las disciplinas científicas, la preocupación por la cuestión social y los problemas que emergieron luego de la llegada de la población inmigrante. En el ámbito académico porteño, los actos suicidas eran comprendidos a partir de la integración de los saberes 
del paradigma alienista con los de otras áreas, como higienismo y salud pública, demografía, medicina legal y criminología. En el cuarto capítulo, por otra parte, introducimos el marco social y cultural de la ciudad de Buenos Aires durante el último tercio del siglo XIX e inicios del XX. Por esta razón, describimos, de forma general, las principales transformaciones del paisaje urbano como resultado de la llegada masiva de inmigrantes extranjeros. Las reformas urbanas y edilicias, encaradas para resolver los problemas vinculados con la salud pública y el embellecimiento de la ciudad, cambiaron la fisonomía del asentamiento, dejando atrás la Buenos Aires de mediados del siglo XIX. Por otra parte, el arribo de los inmigrantes superó toda planificación por parte de las autoridades, generando espacios hacinados y carentes de toda higiene e intimidad. Estos conventillos y viviendas colectivas, habitados por la mayoría de los miembros de las clases trabajadoras, eran el escenario donde ocurrían muchos de los episodios de suicidio. Asimismo, en este capítulo, presentamos a los principales actores sociales que convivían y transitaban por el espacio urbano en constante transformación. Por último, también exponemos los diferentes horizontes de expectativas, de acuerdo con el género de los sujetos históricos de la época.

La última parte de la tesis está dedicada a analizar las representaciones de los suicidios ocurridos en Buenos Aires durante el último tercio del siglo XIX, a partir de los casos relevados en los textos académicos, los medios gráficos $\mathrm{y}$, sobre todo, los sumarios judiciales.

En el quinto capítulo, diferenciamos las interpretaciones que generó el aumento de la tasa de suicidios entre los intelectuales positivistas del período. Además de presentar las principales corrientes de pensamiento y la información estadística conocida en la época, nuestro objetivo fue abordar la lectura moral del tema que hacían los miembros de la elite cultural. Estos últimos buscaban promover el ideal del pensamiento moderno y positivista: formar ciudadanos que fueran capaces de hacer uso de su razón y que civilizaran sus pasiones románticas y violentas.

En el capítulo 6, exponemos, de manera general, la información estadística disponible sobre los suicidios en la ciudad de Buenos Aires durante el período de estudio. Al mismo tiempo, buscamos presentar el conjunto de causas y motivos verosímiles que figuraban en los anuarios estadísticos y los testimonios registrados en la documentación judicial. Por último, estudiamos el significado de una causa ambigua que figuraba en muchos relatos: el "hastío de la vida". Consideramos que la ausencia o 
desconocimiento de la causa en una gran cantidad de expedientes, como las explicaciones ambiguas esbozadas en muchos otros, contribuían a ocultar lo sucedido al público y reservar la intimidad del individuo y su familia. El suicidio era considerado un acto vergonzoso y escandaloso, que, en la mayoría de los casos, comprometía la reputación del suicida y su entorno familiar. Así, si la condena legal y el castigo al suicida habían dejado de estar presentes, pervivía el estigma social, el miedo a ser juzgado por aquellos que observaban lo sucedido.

En el séptimo capítulo, presentamos los casos en los que el suicida era caracterizado como un loco. Así, analizamos los relatos de los suicidas alienados y comparamos esta caracterización con la idea de locura del saber erudito y académico. Consideramos que la representación popular del suicida alienado respondía a una serie de ideas previas sobre el comportamiento de los sujetos anormales o dementes. Así, las enfermedades mentales estaban limitadas a un conjunto de casos, en los que podían ser reconocidos dichos indicios. Esto limitaba el espectro de enfermos mentales que el sentido común podía percibir, a diferencia del saber alienista de la época, que consideraba una amplia tipología de cuadros y categorías para clasificar los casos de alienación. Al mismo tiempo, entendemos que las patologías mentales, como elemento de la narración, modificaban la interpretación moral del acto suicida. En este sentido, la locura disculpaba al suicida y a los deudos por lo ocurrido.

En el capítulo 8, abordamos aquellas narraciones protagonizadas por suicidas que manifestaban un profundo sentimiento de desesperación, producto de la miseria, la enfermedad y el aislamiento; y centramos nuestra mirada en los casos de inmigrantes desempleados, con el objetivo de observar las características de su red vincular. El ámbito familiar del suicida era considerado uno de los elementos situacionales claves a la hora de explicar una muerte por suicidio. Cuando estaba presente y no había peleas internas de por medio, la red familiar era representada como un soporte, un ámbito de contención frente a los desafíos de la lucha por la vida. En varios casos, la situación de los inmigrantes era caracterizada como dificultosa por la falta de una adecuada inserción en el tejido social receptor. Asimismo, consideramos que existían roles diferentes, de acuerdo al género, entre los sujetos que lo asistían. Mientras que los hombres eran representados como los receptores de los pedidos de auxilio material y destinatarios de las últimas disposiciones, las mujeres eran descriptas como las que brindaban la contención emocional al suicida. 
En el noveno capítulo, exploramos los casos en los que el suicida era representado como individuo apasionado. En este sentido, encontramos que la mayoría de estos casos estaban asociados con temas vinculados al amor y las relaciones de pareja. Al mismo tiempo, en muchos de estos relatos, el suicida llevaba adelante su acto como una acción comunicativa regulativa agresiva. Es decir, buscaba condicionar y agredir a sus otros significativos. Consideramos que era frecuente, sobre todo entre jóvenes e individuos de género femenino, representar al suicida como un sujeto apasionado, preso de intensas emociones y sentimientos exacerbados y $\sin$ frenos. Dentro de este tipo de esquemas narrativos, los celos y el desengaño amoroso eran las emociones que permitían explicar los intentos de autoagresión y/o las acciones violentas contra terceros por parte del suicida. Así, sostenemos que este modo de narrar lo sucedido presentaba las relaciones de pareja como vínculos posesivos y exclusivos, en los que los celos no eran infrecuentes. En el caso de los sujetos suicidas, su obsesión y sus pasiones amorosas eran un reflejo anormal de sentimientos que podían ser reconocidos en muchos otros que no se quitaban la vida.

Por último, en el décimo capítulo, reflexionamos a partir de los casos en los que el suicida representaba su autoagresión como un modo de salvar o defender su reputación personal. De este modo, consideramos que los actos suicidas también podían ser presentados como sacrificios o acciones defensivas para salvaguardar la honra personal y el recuerdo que construirían los deudos. Cabe destacar que no sostenemos la existencia de un código social que determinara situaciones en las que los individuos debían suicidarse. Sin embargo, sí resultaba comprensible y verosímil que algunos sujetos consideraran suicidarse frente a una deshonra pública con consecuencias intolerables. Para algunas personas, era un acto de coraje y valor que hablaba de la calidad personal del sujeto que descargaba la violencia sobre sí mismo. Como argumentamos a lo largo de la tesis, los suicidios no eran valorados de la misma forma en todas las circunstancias. Ciertas situaciones generaban un sentimiento ambiguo, asociado con el carácter positivo que podía tener la defensa del honor, de acuerdo con el marco axiológico de la época. 


\section{Primera Parte}

Marco teórico y metodológico 


\section{Capítulo 1: El estudio cultural del suicidio desde la historia}

A lo largo del siglo XX, trabajos realizados desde diferentes disciplinas de las Ciencias Sociales dieron los pasos iniciales en el estudio sobre la muerte en las sociedades del mundo occidental en distintos períodos. En un primer momento, estos trabajos estuvieron relacionados con las investigaciones sobre religión en el marco de los estudios etnográficos, siendo la dicotomía buena/mala muerte y los rituales de pasaje vinculados a ella los principales ejes de análisis (GAYOL y KESSLER, 2011: 53-54). La muerte, como objeto de estudio, permitió a investigadores como Malinowski acceder al complejo mundo de la diversidad religiosa, entendiendo las prácticas de los distintos cultos como respuestas culturales a este hecho biológico ineludible. Esta interpretación cultural del morir trazaba la línea entre una buena o mala muerte para los miembros de cada sociedad. Otros autores, como Arnold Van Gennep y Robert Hertz, prestaron atención a las prácticas funerarias como instancias de cambio para la sociedad y como uno de los momentos claves de socialización de la vida de los individuos (GAYOL y KESSLER, 2011: 54-56).

Sin embargo, no será hasta mediados del siglo XX cuando la muerte se convierta en tema de interés para la sociología y la historia. En un contexto global donde, entre otras cosas, se hizo más evidente la mercantilización de los servicios funerarios, así como la aparición de tratamientos hospitalarios que permitían prolongar la vida de una persona de una forma que era percibida como deshumanizada, apareció un nuevo interés por la reflexión sobre la muerte en el mundo occidental. A partir de estos trabajos -como el realizado por la psiquiatra suiza Elisabeth Kübler-Ross con enfermos terminales o incurables, o la obra de B. Glaser y A. Strauss, Awarennes of Dying, realizada a través del trabajo de campo en una unidad de cuidados intensivos-, las nuevas formas de entender y experimentar el proceso de morir fueron analizadas y estudiadas (GAYOL y KESSLER, 2011: 57-58).

En el caso de la historia, los estudios más influyentes durante este período fueron los realizados por la historiografía francesa. Ésta, a partir de los años sesenta, empezó a dar mayor relevancia al estudio de las mentalidades y la cultura, dejando en un segundo plano a las estructuras económicas y sociales, que, hasta ese entonces, habían sido el objeto privilegiado de las investigaciones históricas (BURKE, 1990). 
Este nuevo impulso de los estudios culturales fue un interés compartido por varios de los integrantes de la llamada tercera generación de Annales. Si bien Marc Bloch y Lucien Febvre habían planteado la necesidad de abordar "la mentalité" dentro del estudio de la historia social como historia total, el estudio de las mentalidades había sido eclipsado y dejado en un segundo plano, con las excepciones de trabajos y casos aislados, hasta los años sesenta. Durante los años anteriores, la historia se había centrado en estudios demográficos y socioeconómicos, es decir en el "sótano", en oposición al "desván” o "granero" que representaban los fenómenos mentales, culturales o superestructurales. En este sentido, desde fines de la década de los cincuenta la historiografía de la muerte estuvo relacionada, sobre todo, con el estudio de la mortandad, en un sentido demográfico, tratando de establecer los vínculos entre las defunciones, la base material y las relaciones sociales (BURGUIÈRE, 2009). Más allá de algunos trabajos aislados, realizados en años anteriores, como la obra de Alberto Tenenti sobre la iconografía de la muerte a finales de la Edad Media (La vie et la mort à travers l'art du XVe siècle), las investigaciones desde la historia cultural o de las mentalidades relacionadas con la muerte no fueron numerosas hasta fines de los años sesenta y década del setenta (AZPEITÍA MARTÍN, 2008). De los estudios realizados durante esos años, las investigaciones de Philippe Ariès y Michel Vovelle fueron las que más se destacaron, siendo, en la actualidad, referentes ineludibles para quienes estudian las representaciones de la muerte en Argentina. ${ }^{8}$

El trabajo de Philippe Ariès (2000 y 2011) fue un intento ambicioso de estudiar, en la larga duración, las diferentes actitudes ante la muerte en el espacio europeo (en especial en Francia), desde el fin de la antigüedad hasta las últimas décadas del siglo XX. La preocupación central de Ariès era comprender el tabú de la muerte en la sociedad de su tiempo. Observaba que, en los hospitales, ésta era ocultada a quienes estaban a punto de morir, entrando éstos en un estado de aislamiento respecto de sus familias y amigos. Al mismo tiempo, los médicos y trabajadores de la institución sanitaria eran quienes decidían y regulaban el proceso a partir de la internación. Según Ariès, esta actitud ante el hecho de morir, esta "muerte salvaje", contrastaba con el

\footnotetext{
${ }^{8}$ En Argentina, desde fines del siglo XX hasta la actualidad, nuevas investigaciones han abordado el estudio cultural de la muerte en distintos períodos de la historia y de acuerdo con distintos enfoques. Véase, entre otros, GODOY y HOURCADE (1993); PEREYRA (1999); LÓPEZ MATO (2002); CARETTA y ZACCA (2007, 2010 y 2011); GUERRA (2010a y b, 2014 y 2015); GAYOL (2012 y 2016); DAL CASTELLO (2014 y 2016) KESSLER y GAYOL (2015); CARETTA (2015).
} 
modo de encarar el fin de la vida en épocas anteriores, como en la Edad Media, período en que la muerte era una experiencia muy diferente. Quien iba a morir estaba acompañado por su familia y los miembros de su comunidad y sabía (al igual que los que presenciaban su fin), la actitud, los gestos y cómo desenvolverse en ese momento crucial. No se ocultaba la situación (ni al difunto ni a los niños), hablaban abiertamente de ella.

Si bien Norbert Elias (2009) criticó la visión romántica e idealizada que Ariès tenía de la vida en la Edad Media, donde la violencia, el dolor y las epidemias marcaban el momento de morir, también identificó el tabú de la muerte en la sociedad de fines del siglo XX. El aumento de la esperanza de vida, el avance del conocimiento científico y médico para prolongar la existencia, la mayor pacificación interna como resultado del monopolio de la coerción de los estados modernos y el avance de una mayor conciencia individual de los miembros de la sociedad, al tiempo que permitieron olvidar la idea de que la muerte era algo inevitable, la asociaron con la enfermedad, la vejez y la soledad. Como resultado de este proceso, el morir se convirtió en un tema tabú, a diferencia de la situación en sociedades pasadas, donde el mismo era tratado con un mayor grado de cotidianidad y familiaridad (ELIAS, 2009: 36-37). Por otra parte, Elias criticó la falta de una mayor claridad en la explicación del proceso que había dado Ariès. Según el sociólogo, el cambio fundamental que ocurrió a lo largo de la historia, hasta el presente, fue el paso de fantasías de inmortalidad colectivas y fuertemente institucionalizadas a otras privadas e individuales. Es decir, un avance del proceso de secularización de las representaciones de la muerte (ELIAS, 2009: 66-67).

Por su lado, Michel Vovelle (1985) prestó atención, en sus trabajos, al proceso de secularización y descristianización. Así, el declive del temor ante la muerte y la angustia por la salvación (representado por el decrecimiento de las peticiones de misas, los legados a las cofradías e, incluso, el peso de las velas en los funerales solicitados por los difuntos al testar) era un signo de conciencias cada vez más secularizadas, producto de la influencia del clima de ideas de la Ilustración. Mediante el análisis serial de los testamentos, su fuente principal, Vovelle buscó identificar las fórmulas usadas por los difuntos a la hora de testar y la modificación de la práctica testamentaria en Francia. Este énfasis en el análisis cuantitativo de la documentación lo diferenció de Ariès, quien era partidario de un enfoque más cualitativo. Las críticas que Vovelle le hizo a este último giraron sobre todo alrededor del concepto del inconsciente colectivo, empleado 
por Ariès para comprender el cambio social y cultural. Para Vovelle, el proceso de transformación de las actitudes ante la muerte no podía ser entendido sin prestar atención a la base material de la sociedad, así como a las corrientes de pensamiento e ideología de un período. Dicho de otro modo, el estudio de las mentalidades no debía ser separado de la historia social, ya que el inconsciente colectivo no poseía independencia y autonomía respecto de la realidad social. De ahí que al elaborar su tipología para el análisis de la muerte, Vovelle la dividiera en tres niveles: la muerte sufrida -el impacto desigual de la muerte según parámetros tales como la edad, el sexo y la estratificación social en las curvas demográficas-; la muerte vivida -la sensibilidad y subjetividad intrínseca en la red de gestos y ritos que los actores llevan adelante hasta la muerte, que forma parte del inconsciente colectivo-; y el discurso sobre la muerte -la elaboración más transparente y explícita.

Más allá de los matices, posturas e interpretaciones particulares, los trabajos de Ariès y Vovelle buscaron explicar una serie de cambios en la actitud ante la muerte, producto de la conformación de las sociedades modernas desde el siglo XVII, pero sobre todo a partir de la segunda mitad de los siglos XVIII y XIX. Con la consolidación de los estados-nación modernos, la formación de una sociedad capitalista (donde el mercado condicionó la vida de la población) y el avance del proceso de secularización, surgieron cambios en la sensibilidad y, en consecuencia, en la forma de encarar la muerte. Los estudios clásicos de la historia cultural sobre el tema buscaron entender esas transformaciones y dejaron sentado una serie de problemas que fueron retomados posteriormente por otros investigadores (como el estudio de las prácticas funerarias y sus cambios, las características de los cementerios, la aparición de una sensibilidad higienista hacia los cuerpos, etc.). También cabe destacar que hubo temáticas que no fueron trabajadas por estos autores. En este sentido, una de las que ha sido menos profundizada, salvo por menciones acotadas, es el de las actitudes ante las muertes violentas (homicidios, ejecuciones, etc.). Como ha señalado Minois (1995), el suicidio no fue uno de los temas privilegiados por los estudios clásicos de la historia cultural de la muerte. Estos prestaron atención, en palabras de Ariès, a la muerte esperada por todos, la que llegaba más allá de la voluntad de los individuos, mientras que en el suicidio había una acción individual del sujeto que interrumpía la vida de forma deliberada, lo que le daba un significado distinto y lo diferenciaba de otras formas de morir. 
Los suicidios han sido valorados y comprendidos por distintas disciplinas científicas a lo largo de la historia. Fueron y son objeto de estudio de la medicina, la psicología, la psiquiatría, la antropología, el derecho y la historia, entre otras. Por esta razón, creemos que es importante hacer un breve recorrido por las distintas interpretaciones que hicieron las sociedades del mundo occidental sobre el fenómeno. Esto nos permitirá entender, con mayor profundidad, las características originales del período que estudiamos, los diálogos entablados con las tradiciones del pasado y las continuidades con el proceso de formación del mundo moderno. Así, este breve recorrido por las ideas y la cultura sobre la muerte voluntaria en occidente, nos permitirá presentar un panorama general, en el cual podremos integrar, de forma

particular, la información sobre las representaciones del suicidio en Buenos Aires durante el último tercio del siglo XIX.

En este sentido, nuestro objetivo es realizar un aporte al estudio cultural del quitarse la vida. Cabe destacar que las representaciones del suicidio han sido un tema poco investigado por la historiografía argentina. Por esta razón, también hemos tomado en cuenta los estudios realizados en otras regiones de América Latina, Europa y el mundo anglosajón, para reflexionar sobre las diferentes posibilidades teóricas y metodológicas a la hora de encarar el estudio histórico de los suicidios. Por otra parte, las investigaciones socioculturales realizadas por distintas ramas de las ciencias humanas, nos abre una serie de problemas y ejes que creemos importante retomar a fin de avanzar en nuestra investigación.

\subsection{Breve introducción de las perspectivas de análisis del suicidio en el mundo occidental}

\subsubsection{El suicidio en la filosofia antigua}

El suicidio ha sido un problema para las sociedades del mundo occidental desde hace mucho tiempo. En el pasado, antes de ser un fenómeno estadístico o una preocupación de la salud pública, o un objeto de estudio de las ciencias de la salud mental (como la psiquiatría) y las investigaciones sociales y culturales, el suicidio fue, y continúa siendo, un problema axiológico, es decir, una situación límite que compromete 
los valores de la sociedad. Reflexiones en torno a este problema, las podemos encontrar, al menos, desde la antigüedad greco-romana. Por ejemplo, las tramas de las obras de los poetas trágicos mostraban el suicidio como una opción ante las desgracias, en especial, frente a una vida sin proezas (SZLAJEN, 2012: 58). Sin embargo, como sucede en las obras de Eurípides, abandonar la vida por falta de fortaleza de espíritu era considerado algo deshonroso y motivo de vergüenza. De modo similar, para Menandro (344-292 a.c.), la buena muerte consistía en no morir innoblemente, sin adelantar la propia muerte, pero tampoco viviendo de forma frívola, en otras palabras, vivir con virtud, con gracia (SZLAJEN, 2012: 65).

El pensamiento filosófico de Pitágoras, por otra parte, consideraba el suicidio como un crimen del hombre hacia su dios, ya que estaría terminando anticipadamente con su vida, alterando el ciclo de reencarnación de las almas o metempsicosis (SZLAJEN, 2012: 66). Para Platón, quien retomó la tradición pitagórica, el alma se encontraba prisionera en el cuerpo, estando prohibido para los hombres darse muerte para liberarse de él antes de tiempo. Por otra parte, para este filósofo, la conveniencia de la vida de un individuo radicaba en la importancia que tuviera para la comunidad en la que vivía (SZLAJEN, 2012: 67-68). Es decir, aprobaba la eutanasia social en aquellos individuos que representaban una carga para el colectivo y el estado y, por ende, no valía la pena ni resultaba provechoso mantenerlos con vida. Sólo los ciudadanos bien constituidos debían ser auxiliados frente al malestar de sus cuerpos o de sus almas (SZLAJEN, 2012: 69). Así también, en casos de enfermos terminales o imposibles de curar, o para ciertos crímenes, Platón sugería el suicidio como una salida más decorosa. Por otro lado, el quitarse la vida estaba prohibido para quien tuviera un deber como miembro de la polis, es decir, para todos los ciudadanos, salvo ciertas excepciones (SZLAJEN, 2012: 70). Entre estas últimas, el pensamiento de Platón contemplaba quitarse la vida frente a una desgracia en extremo dolorosa o bien para resarcir un crimen o una falta que no tuviera solución y fuera imposible seguir con la vida por la deshonra que traía. En este sentido, quitarse la vida por flojedad o cobardía no era un acto digno del miembro de una polis, según Platón. En síntesis, la comunidad era la que tenía el poder legítimo para decidir sobre la vida y la muerte de los individuos que la integraban.

Para Aristóteles, a su vez, el suicida era un débil vencido por el sufrimiento y el dolor que recurría a una forma de evasión o escape. Partiendo de la misma preeminencia 
del bienestar de la polis, este filósofo condenaba el suicidio en estos casos, considerándolo un crimen contra la propia comunidad de ciudadanos (SZLAJEN, 2012: 74-75).

Mas allá de las posturas de estos pensadores, muchos ciudadanos de la polis cometían suicidio y no había una pena o castigo formal para los hombres libres que ponían fin a su vida, siendo muy distinto el caso del suicidio de esclavos (un atentado contra la propiedad) o de soldados que intentaban quitarse la vida y fallaban (que eran castigados) (MINOIS, 1995: 63).

En este sentido, otras corrientes filosóficas se mostraron menos inflexibles respecto de la muerte por mano propia de los jurídicamente libres. Para Epicuro no se debía buscar prolongar la vida si ésta se tornaba insufrible, siendo la muerte una solución a las desgracias. Sin embargo, no consideraba válido quitarse la vida por hastío, tedio u odio hacia ésta, o por miedo a la muerte. El sabio, para este filósofo, era aquel que, incluso, en las situaciones de mayor escasez podía permanecer feliz, es decir, alcanzar la imperturbabilidad del alma, la ataraxia, en la vejez.

Quienes fueron los más permisivos respecto de la posibilidad del suicidio en el mundo antiguo fueron los estoicos. Crisipo de Solos (280-207 a.c.), discípulo de Zenón de Citio (334-260 a.c.), fundador de la escuela estoica, hablaba de la eutanasia para referirse a la buena muerte, entendida como la muerte en estado de perfección ética, es decir, de virtud. El suicidio, para esta escuela, sería una salida en caso de no poder envejecer o vivir en este estado de virtud. Dentro del estoicismo romano, tanto Cicerón (106-43 a.c.) como Séneca (4-65 d.c.) y Epicteto (55-135 d.c.), se expresaron en favor del suicidio, solitario o asistido, ante determinadas circunstancias que atentaran contra la dignidad del individuo (SZLAJEN, 2012: 82-85). Frente al deterioro de las facultades mentales, físicas o la calidad de vida en general, o ante la necesidad de cumplir con el deber, terminar con la propia vida era aprobado por estos pensadores. Desde la perspectiva de los estoicos, no era necesario retener la vida, sino vivir bien. Así, la puerta estaba siempre abierta para dejar la vida cuando el sujeto lo creyera necesario. Sin embargo, esto no avalaba el quitarse la vida por odio o hastío hacia la misma, o por miedo. La decisión debía estar fundada en las causas que hacían que el sujeto no encontrara significado para seguir viviendo, una decisión tomada por medio del pensamiento (el logos universal) en estado de imperturbabilidad y no de la influencia de las pasiones (dolor, placer, temor). La muerte podía ser un supremo refugio, un 
instrumento libertario y de afirmación de la libre voluntad. Con el suicidio no se perdía ni se dañaba nada en el cosmos, era parte del reciclado de los seres vivientes (SZLAJEN, 2012: 89). Lo reprobable para el estoicismo no era el suicidio en sí, sino vivir de forma contraria a la ética estoica, es decir, vivir de forma vergonzosa, cobarde y deshonrosa, de manera contraria a la naturaleza, sin las facultades de la razón, en detrimento de la virtud y consumido por el vicio. Epicteto señaló, desde el estoicismo, algunos ejemplos de muertes justificadas: discapacidad, mutilación o amputación que impidiera el desempeño de facultades naturales, una enfermedad terminal en su fase final, alguien que sin posibilidad de salvamento o socorro moriría de hambre o sed, o quien padeciera las inclemencias irreversibles del dolor, sufrimiento, deterioro físico o mental. Sólo el miedo y el vicio podían robar la integridad moral del individuo, pero no la muerte (SZLAJEN, 2012: 91-92).

Tanto el estoicismo como el epicureísmo fueron las doctrinas predominantes en el final del período de la República romana y los inicios del Imperio (SZLAJEN, 2012: 85). Tras el declive del estoicismo, por otra parte, la ética con respecto al suicidio empezó a endurecerse. Si bien hasta ese momento sólo los esclavos tenían prohibido suicidarse y los ciudadanos podían disponer de sus vidas sin penas o castigos, con el paso del tiempo la condena se generalizó de forma más amplia. Durante la crisis que atravesó el Imperio Romano, los gobernantes reforzaron las penas contra los suicidas; el estado no podía darse el lujo de perder mano de obra y soldados para sus ejércitos (MINOIS, 1995: 71-72).

El mundo antiguo dejó como legado las historias de muertes por mano propia heroicas, que expresaban el ideal estoico. En el año 65, el filósofo Lucius Annaeus Séneca murió por orden del Emperador Nerón. En el pasado, Nerón había recibido el consejo y la instrucción de este pensador, que contaba con la protección de la madre del César. Los detalles de la muerte de Séneca fueron relatados por Cornelius Tacitus en sus “Annales” (CANCIK, 1997: 111). Acusado de cómplice en un complot contra la cabeza del imperio, Séneca recibió una carta con su condena a muerte. Era la hora de la cena, allí estaban también su esposa Pompeia Paulina y dos amigos. El final de la existencia de Séneca emula el de Sócrates, narrado por Platón; representa la última resistencia contra la injusticia de un régimen tiránico, la actitud ante la muerte: con serenidad y coraje, Séneca tomó la cicuta y puso fin a su vida voluntariamente. No dejó que Nerón lo ejecutara, pero tampoco escapó del castigo arbitrario impuesto por éste. Entre vivir 
sin virtud y morir como un ciudadano libre, el filósofo se decidió por la última opción. Muertes como las de Séneca eran idealizadas por los miembros de las elites intelectuales a partir del surgimiento de la modernidad en el siglo XVI. Como veremos, esta admiración perduró hasta el siglo XIX.

\subsubsection{La mirada del pensamiento cristiano}

El cristianismo, una vez declarada religión oficial del imperio, contribuyó a legitimar la condena sobre la muerte voluntaria. Esta situación se combinó con el temor que se tenía a los muertos en el mundo antiguo (ARIÈS, 2000). Debido a esto último, los lugares de entierro estaban fuera de los asentamientos de los pueblos y ciudades. A su vez, la inhumación de los restos de los que se quitaban la vida era realizada según rituales específicos como, por ejemplo, clavar una estaca en el pecho del difunto antes de enterrarlo de forma invertida. Esto se hacía para impedir que el alma del muerto permaneciera vagando en el mundo de los vivos (MINOIS, 1995: 61-63 y 70-72).

Si bien la muerte fue "domesticada" en la transición al mundo medieval, según Ariès $(2000: 7,28,35)$, la muerte voluntaria fue asociada a la idea de homicidio de uno mismo. Siguiendo la tendencia de los años finales del imperio romano, el suicidio pasó a ser considerado un pecado en cualquier circunstancia, ya que la condena provenía de la conciencia del sujeto que la llevaba adelante más allá del acto en sí. Quitarse la vida no sólo era un acto pecaminoso, sino uno muy grave y, por ello, se negaba al suicida el entierro en campo santo. Esta condena de la muerte por mano propia fue sistematizada en el derecho canónico en el siglo XII. Uno de los principales representantes de esa doctrina fue Santo Tomás de Aquino. Para éste, el suicidio era un pecado por atentar contra la vida, propiedad de Dios, que, además, no daba lugar ni a la penitencia ni al arrepentimiento, lo cual agravaba la situación del pecador ante su creador (COHEN AGREST, 2007: 83-89).

Tomás de Aquino retomó argumentos de las ideas de Agustín de Hipona sobre el tema. Basándose en la interpretación del quinto mandamiento ("no matarás"), y en línea con otros teólogos cristianos, como Clemente de Alejandría (150-215) u Orígenes (185-254), Agustín de Hipona (354-430) postulaba que matar a otro hombre era pecado y que matarse a sí mismo también lo era (SZLAJEN, 2012: 109). El criterio elegido por 
Agustín estuvo en línea con las codificaciones civiles posteriores, como la Lex Romana Visigothorum (del siglo VI), o las codificaciones canónicas de los Concilios de Arlés, Braga y Auxerre. Como señala Szlajen (2012), el criterio que guió los juicios de este teólogo sobre el tema fue diferente al empleado por los antiguos. Mientras que en situaciones de extrema deshonra, el marco axiológico de la antigüedad permitía el suicidio como una salida, en el caso del cristianismo, el criterio para aprobar o no una acción era la conciencia del propio individuo y su relación con la divinidad, sin tener mayor importancia el código social. Desde esta perspectiva, el suicidio era siempre un pecado contra el mandato divino. Sólo a Dios estaba asignado el dar o quitar la vida, la cual era un don sagrado entregado a los hombres, estando prohibido que estos le pusieran fin con sus actos. Como contrapartida, el suicidio o las acciones que llevaran a la propia muerte de forma deliberada sólo podían ser justificados por ese mismo imperativo sagrado (como en el caso de los personajes bíblicos célebres y los martirios de los fieles cristianos).

Asimismo, el pensamiento cristiano del mundo medieval representaba al suicida como un desesperado, de allí la gravedad del pecado cometido. Cabe destacar que la desesperación, como concepto, no aludía a estados mentales o emocionales. Se tratada de un calificativo que hacía referencia a una actitud pecaminosa, la pérdida de la fe en la divina providencia. Así, el desesperado era un sujeto que cuestionaba con sus actos la misericordia y la voluntad de Dios, un alma carente de esperanza que había sido tentada por el diablo (SCHMITT, 1976: 4-5). Este término era el más utilizado para referirse a los actos suicidas en el mundo medieval. ${ }^{9}$

A la fuerte condena moral y religiosa que pesaba sobre el suicidio en la Edad Media, se sumaban los rituales que maltrataban y exponían el cadáver y la confiscación de los bienes del difunto por parte de nobles y monarcas. Por otra parte, si bien las condenas eran severas en la letra, en la práctica se buscaba ocultar lo más posible del dominio público este tipo de situaciones que podían afectar a la familia del difunto, en especial si se trataba de un miembro del clero o de la nobleza. Así, el secreto y la discreción fueron la pauta seguida por los deudos (MINOIS, 1995: 50).

Según Alejandro Morin (2001), en el caso de las Partidas de Alfonso X antecedente jurídico medieval clave para el mundo colonial hispanoamericano y fuente

\footnotetext{
${ }^{9}$ Sobre el suicidio en el mundo medieval, véase, también, MURRAY (1998).
} 
de autoridad hasta los procesos de codificación de cada nación (durante el siglo XIX)la situación de los desesperados sólo era penada en un caso: cuando el suicida trataba de escapar de la condena de un delito que había cometido. En ese marco, de manera similar a lo que planteaba el derecho romano, la ley secular desconocía las últimas voluntades del desesperado y confiscaba sus bienes. En síntesis, la legislación alfonsina sobre el suicidio lo definía como un crimen, pero no aplicaba pena en caso de locura, dolor o enfermedad, pérdida de poder o riqueza (MORIN, 2001: 193-194). Por otro lado, el derecho canónico sí definía sanción para los suicidas en general: la privación de sepultura eclesiástica. Sin embargo, contemplaba ciertas excepciones para la aplicación de la pena: la enajenación mental, la falta de intención de quitarse la vida o el arrepentimiento por la ofensa cometida a Dios manifestado antes de morir (SEOANE, 2006: 55).

\subsubsection{La modernidad: despenalización y medicalización del suicidio}

La modernidad trajo consigo un cambio de paradigma en cuanto a la interpretación del suicidio. Con el paso de los siglos, y en el marco de las transformaciones económicas, sociales y culturales de la época moderna, un nuevo clima de ideas (que empezó a manifestarse en el pensamiento moral, filosófico y literario), modificó las concepciones sobre el suicidio vigentes desde la Edad Media. La propia historia de la palabra "suicidio" nos da una idea del complejo proceso de transformación que la mirada sobre la muerte voluntaria atravesó desde la antigüedad clásica, pasando por el mundo medieval, hasta alcanzar la modernidad (COHEN AGREST, 2007: 51).

Hasta bien entrado el siglo XVII, se recurría a diferentes expresiones para aludir al acto suicida, y al sujeto que lo cometía, pero no había un término que designara el fenómeno de manera general. En las polis griegas y en Roma, por ejemplo, se hablaba de "morir por mano propia". Así, el latín clásico desconocía el vocablo suicidio, si bien sus raíces son latinas. Tampoco en las obras escritas durante la Edad Media se encuentra el vocablo "suicidium". Recién a mediados del siglo XVII, el término apareció, por primera vez, en la obra del inglés Thomas Browne, Religio Medici, escrita en 1635 y publicada en 1642 (COHEN AGREST, 2007: 72). La intención en el uso del vocablo era 
diferenciar los nobles suicidios de los hombres de la antigüedad (suicidium) del acto condenado por el cristianismo (self-murder, self-killing). A partir de esta primera aparición, el uso del término se expandió entre los países europeos. En la lengua española, la primera referencia a la palabra apareció en el Diccionario de la Real Academia Española en 1817 como sustantivo y, más tarde, en 1822, el mismo vocablo figuró como sustantivo y adjetivo (COHEN AGREST, 2007: 75). La aparición del término "suicidio" fue el emergente de un cambio de paradigma en el mundo occidental sobre la muerte voluntaria. A fines del siglo XVI y principios del XVII, nuevas miradas comenzaron a relacionar las prácticas suicidas con la melancolía, la enfermedad y la locura (MINOIS, 1995: 166-167). Así, médicos, juristas e intelectuales humanistas iniciaron el debate acerca de la concepción medieval sobre la muerte voluntaria. De las posturas sobre el tema durante la modernidad, queremos detenernos en las ideas de John Donne (1572-1631).

Este metafísico, poeta, y, posteriormente, clérigo anglicano, en su Biathanatos, la obra más importante y exhaustiva sobre el suicidio escrita en la modernidad (COHEN AGREST, 2007: 97), postuló que este acto no estaba necesariamente en contra de la naturaleza, de la razón, de la ley social o de la autoridad divina, como señalaban Tomás de Aquino y la teología cristiana. ${ }^{10}$ Este autor, en primer lugar, señaló que el cristianismo había permitido, a lo largo de la historia, diversas formas de autoanulación, tales como la pena capital, las matanzas en las guerras, como las cruzadas, y los martirios de sus fieles, llegando, inclusive, a plantear que la muerte de Jesús en la cruz se trató de un suicidio. Si estas formas de eliminación de la vida humana eran acordes a la ley de la naturaleza, el suicidio también lo era. De igual modo, si dejar la propia vida era un acto contra la justicia divina y secular, por abandonar el puesto designado por Dios, también sería un pecado prestar servicio militar al Estado (no pudiendo permitir que éste dispusiera de una vida que no le pertenecía) o abandonar los cargos públicos, ambas situaciones no eran condenadas por el derecho canónico. Para Donne, no era la ley natural sino la vida en comunidades humanas la que fue generando estrategias a través de las cuales impedir o disminuir la cantidad de muertes autoinfligidas (a través de la civilización, la cultura y el estado) (SZLAJEN, 2012: 134-135). En este sentido, Donne presentó ejemplos de legislación antigua, donde se permitía o se

\footnotetext{
10 Cabe destacar que el pensamiento de este autor es rescatado, en el presente, por quienes apoyan propuestas a favor de la muerte digna, la eutanasia y el suicidio asistido (SZLAJEN, 2012: 128-129).
} 
prohibía el suicido de acuerdo a las circunstancias, pero sin postular una condena general del acto en sí mismo. En síntesis, para este autor el suicidio no era un acto pecaminoso a priori, sino que dependía de las circunstancias y motivos del hecho o tentativa (SZLAJEN, 2012: 143).

Otros filósofos posteriores plantearon argumentos en el mismo sentido, como David Hume, quien abogaba por la finalización de la penalización que caía sobre quienes ponían fin a sus vidas. Sin embargo, la condena moral del suicidio se mantuvo en filósofos como John Locke o Imannuel Kant. Para el primero, se trataba de un daño a la propiedad divina dada en usufructo al ser humano por Dios; y, para el segundo, el suicidio representaba una violación del imperativo categórico (ya que no constituía una acción que pudiera ser considerada una ley universal). Así, si bien casi ningún filósofo moderno hacía apología del suicidio, cada vez era más amplio el consenso en favor de la despenalización del acto y en contra de la confiscación de los bienes por parte del estado y los castigos y rituales que humillaban a la familia del suicida.

En paralelo a este proceso de despenalización, el suicidio empezó a ser asociado con la locura y la melancolía. En este sentido, cabe mencionar la obra de Robert Burton, médico inglés, precursor de las interpretaciones científicas sobre el suicido. En su obra Anatomía de la melancolía, de 1621, destacó que la melancolía, lejos de ser un mal traído por el demonio, y, por ende, motivo de castigo, era una enfermedad que aquejaba, en especial, a las personas dedicadas a actividades intelectuales, que podían caer en pensamientos mórbidos constantes. Por otro lado, ciertas características fisiológicas (un exceso de bilis negra), astrológicas (la influencia de Saturno) y del medio social (situaciones de pobreza), podían contribuir a promover este mal. La cura propuesta por Burton consistía en diversificar las actividades (abandonar los libros y frecuentar más a las mujeres y otras prácticas que alegraran el corazón) (COHEN AGREST, 2007: 162163). Lo enunciado por Burton es considerado uno de los primeros intentos por despenalizar el suicidio y entenderlo desde el paradigma de las enfermedades mentales (MINOIS, 1995). ${ }^{11}$

\footnotetext{
${ }^{11}$ Sobre el proceso de medicalización del suicidio, véase, también, MACDONALD (1989).
} 


\subsubsection{La muerte voluntaria en el siglo XIX: el saber psiquiátrico}

Durante el siglo XIX, este proceso de apropiación del fenómeno por parte del saber médico se profundizó. En la primera mitad del siglo, los trabajos de los psiquiatras de la escuela francesa fueron la explicación más difundida sobre el fenómeno. El estudio del suicidio pasó a estar relacionado con el de la alienación mental.

A partir de los trabajos de Philippe Pinel (renombrado médico del hospital de la Salpêtrière de París entre fines del siglo XVIII y primeras décadas del XIX), se puso en cuestión que el suicidio fuera una enfermedad propia de los ingleses (como se creía popularmente hasta ese entonces), ya que había frecuentes casos en Francia (HABIF, 2005: 18). En su obra, Traité médico-philosophique sur l'alienation mentale ou la manie, Pinel planteaba el suicidio como resultado de una conducta mórbida, un estado de debilidad de espíritu que hacía que el sujeto exagerara los eventos desafortunados de su vida (MINOIS, 1995: 366). Para combatir esta actitud, el saber de la psiquiatría proponía el uso de un "tratamiento moral", basado en castigos (que iban desde las amenazas, el aislamiento, la sed, el hambre, duchas repentinas, sillas giratorias y otras prácticas de represión) (MINOIS, 1995: 367).

$\mathrm{Su}$ discípulo, el médico alienista Jean Étienne Dominique Esquirol (17721840), elaboró, con una mirada clínica y patológica global, la primera teoría psiquiátrica del suicidio (FALK, 2011: 9). Según Esquirol, todos los suicidios eran el efecto de una enfermedad o de un delirio agudo. Para este médico psiquiatra, estos trastornos mentales eran resultado del efecto de las pasiones humanas (ambición, venganza, orgullo, ira, temor, remordimientos, amores contrariados, etc.), que podían terminar en una crisis de afección moral. En síntesis, la medicina de principios del siglo XIX tendió a caracterizar a la melancolía depresiva y a la propensión al suicidio como formas de alienación mental, producidas por una debilidad moral y un exceso de las pasiones.

\subsubsection{La interpretación social del fenómeno}

En la segunda mitad del siglo XIX, el problema pasó a ser analizado, en el ámbito europeo, desde una mirada social. Lentamente, apareció una interpretación en 
clave sociológica, que se dio en paralelo con un mayor registro de las cifras estadísticas. El aumento de los casos de suicidio fue una preocupación de la elite cultural, no sólo en Argentina, sino en el mundo occidental que atravesaba el proceso de consolidación de sus estados nacionales modernos y el avance de la economía capitalista de mercado. En este marco, según Michel Foucault (2008: 131), no era sorprendente que los suicidios se volvieran objeto de estudio de investigaciones sociológicas: el suicidio "hacía aparecer en las fronteras y los intersticios del poder que se ejerce sobre la vida, el derecho individual y privado de morir". En medio de una sociedad donde el poder político se proponía la administración de la vida, para responder a la necesidad de abastecer de mano de obra al mercado, el suicidio aparecía como un hecho inquietante. Varios pensadores buscaron explicar lo que ocurría y cuál era la relación entre los suicidios y la transformación de la sociedad moderna, con la consolidación de los estados nacionales y la evolución y expansión del capitalismo.

Así, por ejemplo, en 1846, Karl Marx publicó una extensa reseña sobre el Informe de Jacques Peuchet, archivista de la policía de París. La mayor parte del artículo consistía en extractos de dicho informe traducidos por Marx para su publicación. Sirviéndose de lo relatado por Peuchet, fue presentando una serie de casos concretos, situaciones que retrataban la vida privada y las relaciones interpersonales en el mundo burgués. Entre los extractos, el que será el autor del Manifiesto Comunista pocos años más tarde, va haciendo comentarios y acotaciones, re-apropiándose del texto original para fundamentar sus ideas. Así, Marx expone los casos relatados por Peuchet para dar cuenta de "lo contradictorio y anti-natural de la vida moderna, no sólo en las relaciones entre clases particulares, sino en todos los circuitos y figuras del intercambio cotidiano de hoy" (MARX, 2011: 63). La argumentación buscaba rebatir la postura de sectores reformistas, que creían que bastaba con mejorar las condiciones materiales de los trabajadores para solucionar las contradicciones del mundo capitalista. "Como si los únicos en soportar las condiciones sociales actuales fueran los trabajadores, como si en lo que respecta al resto de la sociedad, el mundo existente fuera el mejor de los mundos posibles..." (MARX, 2011: 64). Por esta razón, encontramos el suicidio en todas las clases sociales, incluidos los ricos, los artistas y los políticos. En Peuchet, Marx encontró la crítica a las relaciones de propiedad, pero también a las relaciones familiares y a la vida privada en general. En este sentido, uno de los objetivos era mostrar la opresión de la mujer en la sociedad burguesa. En uno de los relatos, una mujer de clase 
media se suicida tras padecer los ataques violentos de celos de su marido, quien además la tenía prisionera en el interior de su domicilio. Esto último era posible con la ayuda del código civil y el derecho de propiedad: "Base de las diferencias sociales que vuelven al amor independiente de los libres sentimientos de los amantes y permitía al marido celoso encerrar a su esposa con los mismos cerrojos con los que el avaro cierra los baúles de su cofre. La mujer es parte del inventario" (MARX, 2011: 83).

Además de las cuestiones familiares y del ámbito privado, en el texto original, Peuchet se detenía a hablar de las causas, regularidades e influencia de las carestías y el desempleo. Así, presentaba los casos de suicidio como un síntoma de la organización defectuosa de la sociedad moderna, ya que su cantidad aumentaba cuando había hambre, escaseaba el trabajo y ocurrían bancarrotas en serie (MARX, 2011: 66). En este sentido, para Marx-Peuchet, si bien el suicidio no era algo antinatural, "es natural a nuestra sociedad el dar a luz a muchos suicidas [...]" (MARX, 2011: 68). Estas observaciones llevaban a Marx a concluir que, fuera de una reforma total del orden social actual, todos los intentos de cambio serían inútiles.

La influencia de la organización de la sociedad (y sus defectos) sobre la tasa de suicidios fue uno de los ejes que ordenó el debate en torno al suicidio a fines del siglo XIX. La polémica dividió las posturas entre aquellos que creían más apropiado hablar de "suicidio" en singular y las que partían de pensar en "los suicidios", es decir, estudiar las clases del mismo fenómeno en plural. Es decir, había una tensión entre los teóricos que veían en los suicidios fenómenos individuales y aquellos que buscaban entenderlos desde una perspectiva social (COHEN AGREST, 2007: 166).

Émile Durkheim (2004 [edición original de 1897]), por su parte, se opuso a la corriente individualista, indagando la relación entre el suicidio y la sociedad moderna. A diferencia de aquellas teorías, que ponían el énfasis en las patologías mentales o factores ambientales, este sociólogo buscó las causas sociales del suicidio. Según el autor de $E l$ Suicidio, no se debía ver a un loco en cada suicida, ya que las personas que no presentaban monomanías también se suicidaban.

Para Durkheim, el aumento de las tasas de suicidio en las sociedades urbanas modernas estaba vinculado con la pérdida de fuerza de los lazos que habían mantenido cohesionados a los sujetos en los distintos grupos sociales. Es decir, en la sociedad moderna, el excesivo grado de individualismo era el que provocaba una alta tasa de suicidios, al haberse debilitado el grado de cohesión que la sociedad religiosa, el grupo 
familiar y la comunidad política ejercían sobre el sujeto. La religión ejercía un efecto protector, por ser un ámbito de vinculación entre los hombres como grupo social (no por el contenido de la doctrina religiosa en sí). El libre examen de conciencia, identificado en el protestantismo, llevaba al individualismo religioso, a la búsqueda de libertad. Esto daba como resultado, en la mirada de Durkheim, una iglesia menos cohesionada que la católica o la comunidad judía. El hombre, en estos contextos, era más propenso a quitarse la vida porque la sociedad religiosa de la que formaba parte había perdido cohesión (no había una mirada homogénea, un corpus, sino múltiples formas de pensar). La sociedad familiar también tenía un efecto protector contra el suicidio. La importancia de la densidad familiar (la cantidad de miembros, en especial, de hijos), estaría dada por el incremento del sentir colectivo, de la vida en común, que daría una mayor cohesión. Del mismo modo, el sentido de pertenencia a una misma comunidad política también tendría un efecto cohesionador. Así, las crisis políticas o nacionales que encendían pasiones hacían bajar la tasa de suicidios. En síntesis, cuando el "yo" individuo se afirmaba excesivamente frente al yo social, aparecía un estado de egoísmo desmedido. Según Durkheim, los sujetos que sólo vivían teniendo como horizonte sus deseos individuales, sin contar con algo mayor a ellos mismos, podían caer en una falta de sentido en sus vidas, lo que los predisponía a quitárselas. Este tipo de suicidio es el que denominó como "egoísta".

En contrapartida, una falta de autovaloración por parte de los sujetos puede provocar que pierdan de vista el cuidar su propia vida y, por ello, la entreguen sin oponer demasiada resistencia. Este tipo de suicidio es el que Durkheim denominó como "altruista", el propio de sociedades más tradicionales, donde el individuo se haya fuertemente cohesionado, sujetado y vigilado por la comunidad. En estas sociedades, los individuos se suicidaban porque tenían la obligación de hacerlo. La enorme cohesión grupal provocaría que el individuo fuera absorbido por el grupo, haciendo que la personalidad individual no tuviera peso. Sin embargo, este tipo de suicidio, si bien no era el predominante, existía en algunos ámbitos de las sociedades modernas. El ejército nacional de los estados modernos, con su férrea disciplina y sometimiento al grupo, era un ámbito donde los sujetos entregaban su vida individual al colectivo. La fidelidad y obediencia eran la norma que guiaba el desempeño de los soldados. En ese marco, también había una pérdida de la valoración individual. 
Además del alto grado de individuación, había otro fenómeno que Durkheim identificaba en las sociedades modernas. En palabras del autor:

La sociedad no es únicamente un objeto que atrae hacia sí, con una intensidad desigual, los sentimientos y la actividad de los individuos. La sociedad es también un poder que los regula. Entre la manera en que se ejerce esta acción reguladora y la tasa social de los suicidios hay una relación (DURKHEIM, 2004: 321).

Es decir, también era importante prestar atención a cómo la sociedad regulaba y ejercía poder sobre estos. En este sentido, la única autoridad que podía poner un límite moral a las pasiones individuales era la sociedad. Los frenos que la vida social imponía a cada individuo de acuerdo a su función, regulaban y delimitaban las expectativas y los deseos. Esto ocurría en un marco de reglas que pautaban el ascenso social y el lugar que cada individuo ocupaba en la sociedad. En la perspectiva de Durkheim, las personas no podían ser felices si los medios no se adecuaban a sus necesidades. Si se les exigía más de lo que podían dar, o algo diferente, padecerían sufrimiento. La acumulación de tendencias insatisfechas y atrofiadas contribuía, de este modo, a minar la tendencia a vivir. En el hombre, las necesidades no estaban delimitadas, en su mayoría, por una dependencia con el cuerpo, o lo estaban en un grado diferente al de los animales. Es decir, si bien los seres humanos requerían, por ejemplo, de alimentos, sus necesidades iban más allá, de la mano de las libres combinaciones de sus deseos. Estos deseos, reconocidos por la mente humana, llevaban a los hombres a buscar las condiciones para realizarlos, generando necesidades ilimitadas: la sensibilidad era un vacío sin fondo que nada podía llenar. Más allá del placer que el hombre pudiera experimentar al moverse, al actuar, al esforzarse, era necesario que contara con un objetivo. Para Durkheim, perseguir un fin inaccesible era vivir en un estado de eterna insatisfacción. Desde su perspectiva, el hombre necesitaba percibir que avanzaba hacia un fin alcanzable (DURKHEIM, 2004: 331-333).

El freno de las pasiones que la regulación de la sociedad imponía en los sujetos, se debilitaba en crisis económicas (ya fueran prósperas o desfavorables). En estas situaciones, las escalas de valores se trastocaban, aparecía un estado de anomia. La riqueza podía traer como consecuencia la búsqueda de ascenso social. Este contexto de prosperidad llevaba a la competencia y a la frustración cuando estas aspiraciones eran 
obstaculizadas. Según Durkheim, el rol de la religión en sociedades anteriores era poner un límite a los deseos de los hombres, efecto que fue desapareciendo en las sociedades modernas. Por esta razón, frente al utilitarismo industrialista, no había un freno a las pasiones de los seres humanos, ya sea desde las instituciones religiosas o desde el Estado. Este último, según el sociólogo francés, estaba sumido en la ola de enriquecimiento económico.

En síntesis, la anomia surgía de la ausencia de control y regulación de las pasiones por parte de la sociedad, cuando un cambio, por ejemplo, una crisis en la economía (ya sea por la prosperidad o por la miseria que conllevaba), alteraba las expectativas y no había una moralidad social legítima que pusiera freno a los deseos individuales. Este fenómeno daba lugar a una tercera clase de suicidio, el anómico. El suicidio egoísta y el anómico tenían mucho en común. Ambos provenían de la ausencia de la sociedad en la vida de los individuos. Pero la esfera de la que estaban ausentes no era la misma en los dos casos. En el suicidio egoísta estaba ausente de la actividad colectiva (no había un objetivo o significado). En el suicidio anómico, estaba ausente de las pasiones individuales, dejándolas sin el freno que las regulaba. Es decir, más allá de los puntos en común, son dos tipos independientes el uno del otro. Según Durkheim, devolver a la sociedad todo lo social y colectivo no implicaba el saber limitar nuestros deseos; sin ser un egoísta se podía vivir en un estado de anomia, e inversamente (DURKHEIM, 2004: 343-349).

El último tipo de suicidio que Durkheim identificó se oponía al anómico (del mismo modo que el suicidio egoísta y el altruista se oponían entre sí), el fatalista: "Es el que resulta de un exceso de reglamentación; el que cometen los sujetos cuyo futuro no tiene ninguna salida, cuyas pasiones están violentamente sometidas por una disciplina opresiva". Tenía poca importancia para Durkheim en su presente, aunque el sociólogo francés señalaba que podría tener una relevancia histórica, por ejemplo, en los casos de suicidio en sujetos sometidos a un régimen de esclavitud (DURKHEIM, 2004: 374).

En síntesis, en el análisis de Durkheim, las causas sociológicas explicaban el aumento del número de suicidios. Los aspectos que eran tomados en cuenta en el análisis demográfico de la población (como el sexo, la franja etaria, las estaciones), estaban relacionados con las variaciones de la actividad social: "si el suicidio aumenta de enero a junio para disminuir a continuación, es porque la actividad social atraviesa las mismas variaciones estacionales” (DURKHEIM, 2004: 406). Según Durkheim, 
había corrientes que arrastraban a los individuos con una fuerza determinada, fuerzas análogas a las estudiadas por la química, la física y otras ciencias. El estado general del medio social (formado de ideas, creencias, hábitos, tendencias comunes), que existía de manera independiente a los individuos, constituía la tendencia colectiva al suicidio, de la que derivaban las tendencias particulares. Para Durkheim, no había ideal moral que no combinara, en proporciones variables, según las sociedades, el egoísmo, el altruismo y una cierta anomia. Si una de las tres se salía de equilibrio predisponía una tendencia suicidógena al individualizarse (DURKHEIM, 2004: 410-437).

En el análisis de Durkheim, podemos ver el punto de llegada de una serie de estudios que buscaron entender el aumento de la cantidad de suicidios que se dio en paralelo con los cambios en las sociedades occidentales durante el siglo XIX. Sin embargo, la interpretación social del fenómeno fue cuestionada durante el siglo XX, entre otros, por el historiador Jean Baechler. Según Philippe Ariès, sociólogos, demógrafos y antropólogos han asociado el suicidio a la modernidad, como un rasgo de ésta y como un indicador del malestar social del período industrial. Esto fue puesto en duda por Baechler, quien realizó su tesis doctoral sobre los suicidios en 1975, bajo la dirección de Raymond Aron. El autor destacó la singularidad de los suicidios, como actos propiamente individuales, proponiendo dejar atrás las interpretaciones clásicas para alcanzar una verdadera suicidiología (GARDETTE, 2001). Así, este historiador redujo a su mínimo exponente la naturaleza histórica y social del suicidio. Desde su perspectiva, lo que dependía de la sociedad era el mito del suicidio:

La literatura del siglo XIX, desde la mejor hasta la peor, muestra una verdadera obsesión por el suicidio, más que por el crimen. Las ciencias sociales nacientes se precipitan sobre el fenómeno y le dedican estudios que han sido indefinidamente retomados sin haber sido nunca demostrados, incluido el libro de Durkheim. Ahora bien, por fuerza hay que reconocer que el suicidio no es más que un mito colectivo, pues aunque los hechos demuestran que efectivamente hay suicidios, aquí como en todas partes, y que tal vez han aumentado, aunque lentamente a lo largo del siglo, este aumento no permite prever la proximidad del apocalipsis (ARIÈS, 1996: 249-250). 


\subsection{Corrientes de pensamiento en el mundo contemporáneo}

En la actualidad, a fin de organizar las distintas corrientes de pensamiento sobre el tema, podríamos dividir los diferentes tipos de investigación en tres, estudios desde la psiquiatría, desde el psicoanálisis y la psicología y los socioculturales.

Respecto a los primeros, en el campo de la medicina psiquiátrica, el suicidio es considerado un fenómeno cuyas causas son múltiples, un acto multifactorial, siendo decisivos distintos trastornos que se van asociando y llevan a quienes los padecen a quitarse la vida. Entre los factores tomados en cuenta están: los trastornos psiquiátricos (depresión, esquizofrenia, abuso de alcohol), los trastornos asociados con la drogadependencia, factores biológicos y genéticos (bajas concentraciones de serotonina en ciertas regiones del cerebro, por ejemplo) y trastornos somáticos (enfermedades físicas, por ejemplo, cáncer) (COHEN AGREST, 2007: 191). Desde esta perspectiva, se han llevado a cabo autopsias psicológicas de quienes fallecieron por un suicidio (las autopsias consisten en entrevistas a familiares, amigos, médicos, etc.). Los resultados mostraron que la mayoría de las personas que se quitaron la vida padecían algún trastorno psiquiátrico, en su mayor parte trastornos depresivos y de personalidad (COHEN AGREST, 2007: 192). A su vez, desde las teorías neuroquímicas y genéticas, el foco está puesto en comprender el papel que el metabolismo de la serotonina tiene en los casos de suicidio, como expresión de los factores genéticos que contribuyen a explicar el fenómeno (HABIF, 2005: 38).

En cuanto a los estudios desde el psicoanálisis y la psicología, este tipo de explicaciones ponen el énfasis en las fuerzas psíquicas conscientes e inconscientes del individuo. Si bien el psicoanálisis ha aportado una serie de herramientas teóricas y conceptuales para comprender las prácticas suicidas, poco ha dejado Sigmund Freud (1856-1939) escrito sobre el tema del suicidio en particular. En La aflicción y la melancolía (obra publicada en 1917), Freud veía en el suicidio la agresión de un sujeto sobre sí mismo, tras afrontar la pérdida del objeto de deseo y haber dirigido su hostilidad hacia éste. Cuando el sujeto sufría, por ejemplo, un desengaño o una ofensa por parte de la persona amada, la libido, en lugar de dirigirse a otro objeto podía volverse hacia el yo, generando la identificación entre el yo y el objeto perdido. Para el Freud de esta obra, sólo era posible que el sujeto se suicidara si podía tratarse a él mismo como a un objeto, es decir, si podía dirigir la hostilidad referida a un objeto 
exterior de sí mismo, por ejemplo, mediante el auto-castigo (COHEN AGREST, 2007: 174). Más tarde, Freud asoció el tema con la pulsión de muerte (Thanatos) y la acción del Superyó en el sujeto. Esta noción, junto con la de Eros (la pulsión libidinal), fue enunciada en su obra Más allá del principio del placer (1920). Cuando el sujeto está melancólico y es atacado por un Superyó patológico (tiránico, sádico e hipercrítico), esta situación puede empujar al Yo a la muerte. Obras posteriores, como El hombre contra sí mismo de Karl Menninger (1893-1990), retomaron las ideas y los conceptos centrales de Freud. Menninger, además, propuso que la agresividad desplazada hacia el yo en las sociedades modernas hacía, por un lado, ascender el número de suicidios, y, por el otro, descender las tasas de homicidios (COHEN AGREST, 2007: 179).

Una segunda línea de interpretación de la perspectiva psicológica tiene su origen en la obra del estadounidense Edwin Shneidman (1918-2009). Este psicólogo es considerado uno de los pioneros de la suicidología moderna (CHÁVEZ-HERNÁNDEZ y LEENAARS, 2010 y BRAZ SARAIVA, 2011) y promotor de las autopsias psicológicas como metodología para conocer las variables que influyen en los casos de muerte por mano propia. En sus obras ("The definition of suicide" (1985), "Suicide as psychache" (1993) y "The suicidal mind" (1996), estudia los suicidios como actos propios de individuos que padecían un dolor psicológico insoportable o "psychache", es decir, el suicidio era el resultado de una crisis psicológica. Los trabajos de Shneidman fueron la base de estudios posteriores relacionados con la evaluación del comportamiento suicida, el análisis de las notas póstumas, el desarrollo de las autopsias psicológicas y los procesos de contención y atención de los familiares y personas vinculadas con el suicida (también conocidos como "sobrevivientes"), entre otras líneas de investigación (CHÁVEZ-HERNÁNDEZ y LEENAARS, 2010: 357-358).

Por último, los estudios socioculturales hacen hincapié en los factores sociales y en los aspectos culturales del fenómeno (cómo fue valorado a nivel religioso, filosófico, intelectual o popular). Partiendo de las hipótesis y reflexiones expuestas por Durkheim, algunos trabajos posteriores continuaron avanzando en esta línea, o matizaron algunas de sus ideas. En este sentido, cabe destacar la obra de Maurice Halbwachs, quien, en 1930, publicó Les causes du suicide, estudio donde revisó algunos puntos de la teoría de Durkheim (como la relación entre las crisis económicas y los suicidios) (HABIF, 2005: 32-33). 
Por otra parte, autores como Jack Douglas (1967) y el ya mencionado Jean Baechler (1975) cuestionaron las ideas del paradigma durkhemiano sobre el suicidio. En sus obras, ambos retoman las premisas expresadas por Max Weber sobre la acción social para elaborar su modelo teórico. Para Douglas, los actos suicidas son acciones cargadas de significado subjetivo, que pueden ser interpretados tanto por el que se quita la vida como por aquellos que interactúan con el suicida o los testigos de lo sucedido. Así, lo esencial, desde esta perspectiva, sería reconocer aquellas formas de representar los suicidios por parte de los actores sociales que comparten una misma cultura. Para comprender estos significados culturales en la sociedad occidental, Douglas proponía estudiar casos particulares de suicidios, en situaciones concretas, en lugar de recurrir a las cifras estadísticas, como en el enfoque metodológico de Durkheim o Halbwachs. Por esta razón, este sociólogo propuso analizar, desde una perspectiva sociocultural, los informes elaborados por los psiquiatras en las autopsias psicológicas. En este sentido, partía de considerar que los actos suicidas tenían una variedad de significados que podían ser reconocidos tanto por aquellos que se quitaban la vida como por los que formaban parte de su red de otros significativos. Para Douglas, estas representaciones eran las que permitían reconstruir las "causas" del suceso a los deudos y al propio suicida; por ejemplo, posibilitaban reconocer aquellos elementos de la situación externa del sujeto o de la realidad interna de éste que daban sentido a lo sucedido, es decir, que resultaban más verosímiles.

Baechler también tomó como punto de partida la teoría social weberiana. Desde su perspectiva, los suicidios eran acciones estratégicas cargadas de sentido, es decir, de significados que podían ser interpretados por los actores sociales que compartían una misma cultura. En lugar de apelar a un análisis estadístico del fenómeno, como en los estudios inspirados en la obra de Durkheim, este cientista social abogó por un estudio profundo e interdisciplinario de los casos particulares, para lograr avanzar en el desarrollo de una auténtica suicidología, como ya mencionamos. A partir de los datos relevados en la bibliografía e investigaciones que consultó, Baechler estableció una tipología de acciones suicidas, de acuerdo con el fin u objetivo estratégico perseguido por el que se quitaba la vida (el para qué), de forma consciente o inconsciente. Algunos de estos significados, estaban institucionalizados en distintas sociedades, es decir, eran imaginables o verosímiles en ciertas situaciones particulares. La clasificación propuesta incluía cuatro categorías generales (suicidio "escapista", 
"agresivo", "oblativo", "lúdico") y sus subtipos, totalizando once tipos ideales de actos suicidas. Así, del "escapista" (caracterizado por la acción orientada a la huida de una situación específica), se desprendían las variantes del acto suicida denominadas "fuga" (escape de una situación insoportable para el sujeto), “duelo" (la evasión del dolor producido por la muerte de un ser querido o la pérdida de algún elemento del plan de vida del individuo) y "castigo" (el suicidio como un modo de expiar una pena o una falta real o imaginaria). Las variantes del "agresivo" (el acto suicida como un medio de agredir a un otro) eran "venganza" (quitarse la vida para generar remordimiento a través de la condena de la comunidad), "crimen" (suicidarse para arrastrar a otros hacia la muerte), "chantaje" (la autoagresión como un medio para condicionar las decisiones de un tercero), "llamado" (el intento de autolesión para pedir auxilio al entorno a modo de señal de alarma). De igual modo, los suicidios oblativos (interpretados como una ofrenda o sacrificio) podían ser subdivididos en "sacrificio" (morir para salvar un valor considerado más importante que la vida personal) y "pasaje" (suicidarse para acceder a un estado considerado más deseable para el sujeto, por ejemplo, una vida después de la muerte). Por último, los suicidios lúdicos podían ser clasificados en "ordalía" (atentar contra uno mismo para ponerse a prueba o buscar el juicio de una realidad superior o divina) y "juego" (arriesgar la vida con el objetivo de jugar con ella). En cuanto a las causas o factores que influían en el aumento o descenso de los suicidios (el porqué), Baechler reconocía tres: las características genéticas, psiquiátricas y familiares del sujeto que se suicidaba.

Otros estudios han encarado cómo han sido valorados los suicidios en la historia y en diferentes culturas. ${ }^{12}$ El estudio de la muerte voluntaria se presenta hoy como un campo de cuestiones y problemas donde los conocimientos de las ciencias humanas pueden aportar elementos para la discusión. Problemas de bioética, como el derecho a una muerte digna o la interrupción de embarazos, están relacionados con diversas propuestas legislativas que generan polémica entre los integrantes de la sociedad. En el interior de estos debates, se encuentran representaciones y discursos sobre la muerte, en general, y sobre la muerte voluntaria, en particular. El análisis de las actitudes y sus cambios permiten pensar, en el presente, ciertas situaciones donde la

\footnotetext{
${ }^{12}$ Un ejemplo célebre de este tipo de estudios es el ensayo de Maurice Pinguet (1987), La muerte voluntaria en Japón. En dicha obra, su autor realizó una comparación de las distintas formas de comprender el suicidio entre dicha región de oriente y el mundo occidental.
} 
muerte voluntaria puede ser considerada un derecho legítimo, en oposición a los estigmas sociales que han acompañado a los suicidios en el mundo occidental a lo largo de los siglos. Un ejemplo de esto último lo encontramos en el trabajo de Diana Cohen Agrest (2007), Por mano propia, que está orientado al análisis de las ideas entre las diferentes corrientes de pensamiento que han abordado el tema a lo largo de la historia y los debates que la muerte voluntaria ha suscitado y los que plantea en el presente. Otro trabajo, que participa del mismo debate, es el del Rab. Dr. Fishel Szlajen. En el primer tomo de su obra, Suicidio y Eutanasia: en la filosofia occidental y en lo normativo y filosófico judio (2012), Szlajen realiza un recorrido del problema del suicidio y la eutanasia desde una perspectiva ética y axiológica. Alejándose de las cuestiones relacionadas con la salud mental y prestando atención a los valores, argumentos y motivos que tuvieron sentido en el mundo occidental para avalar o condenar la decisión de poner fin a la vida, Szlajen recorre el pensamiento desde los filósofos griegos y los poetas trágicos hasta el mundo contemporáneo.

Por último, cabe mencionar algunos trabajos recientes que provienen del campo de la suicidología. ${ }^{13}$ Estos comprenden a los suicidios como sucesos cargados de significado individual, aunque también social y cultural. Por esta razón, estas investigaciones toman en cuenta el marco con el que interactuaba el que se agredía a sí mismo: cómo interpelaba a los otros con los que se relacionaba, de qué manera transmitía su mensaje a su red social. Al mismo tiempo, estos estudios hacen hincapié en el conjunto de valores culturales que guían las acciones del suicida. Del mismo modo, dan cuenta también de las distintas formas de narrar lo sucedido por parte de los deudos y los sobrevivientes a una tentativa de suicidio, es decir, las diferentes maneras de representar al que llevó adelante un acto suicida. Así, estas investigaciones consideran que las acciones de los otros significativos ante un llamado de auxilio, o la forma en la que estos representaban al que se suicidaba, también estaban condicionadas por valores morales y creencias del sentido común. En el capítulo 2, desarrollaremos con más detalle estas ideas.

\footnotetext{
${ }^{13}$ Véase, entre otros, HJELMELAND (2010); HJELMELAND y KNIZEK (2011); FITZPATRICK (2011; 2014a y b); OWENS y LAMBERT (2012); OWENS et al (2012); SWEENEY, OWENS y MALONE (2015).
} 
Volviendo a los tipos de estudios acerca de los actos suicidas, los trabajos emprendidos desde la historia se ubican dentro de este tercer grupo: las investigaciones socioculturales de los suicidios, ya sea porque intentan comprender los factores sociales que intervienen en los casos de muerte voluntaria o porque buscan entender las representaciones de estos en la cultura. Como destacamos en un principio, hemos encontrado pocos trabajos que aporten a la comprensión del suicidio desde la historia en Argentina. La historiografía latinoamericana, por ejemplo, o la del mundo europeo y anglosajón, cuenta, por otra parte, con varias obras que abordan el tema de los suicidios en diferentes periodos y regiones. ${ }^{14}$ Uno de los trabajos que brinda un panorama general sobre la cuestión es el de Georges Minois (1995), que analizó las representaciones del suicidio en Europa. En su obra, Histoire du suicide. La société occidentale face à la mort volontaire, llevó adelante un recorrido de larga duración desde el Imperio Romano hasta finales del siglo XIX y principios del XX, con mayor énfasis en el tratamiento de los casos de Francia e Inglaterra. Minois utilizó, para su investigación, diversas referencias de la historia del pensamiento del mundo occidental, así como diferentes trabajos históricos sobre el suicidio. Como queda planteado en su estudio, las prácticas suicidas han sido objeto de reflexión en diversos contextos socioculturales a lo largo de la historia. Si bien abordó algunos aspectos de las mentalidades colectivas, de forma similar a los estudios clásicos de la historiografía francesa, el centro de la obra fueron las ideas provenientes de la filosofía, la literatura, el pensamiento científico y jurídico, en una vía más similar a la seguida por estudios como el de Cohen Agrest o Szlajen, ya mencionados.

Las pocas investigaciones existentes realizadas en Argentina utilizaron diferentes enfoques para abordar el estudio cultural de la muerte voluntaria, en diversos recortes temporales y geográficos. A continuación, reflexionaremos sobre estos trabajos, presentándolos de forma cronológica. Para enriquecer el análisis, haremos dialogar las ideas de estos estudios con las sostenidas en investigaciones históricas argentinas referidas a la muerte en general.

\footnotetext{
${ }^{14}$ Como ejemplos de este tipo de trabajos en la historiografía latinoamericana, podemos mencionar, entre otros, LOPES (1998 y 2003); CASTILLO TRONCOSO (2001); FERREIRA (2004); FERNÁNDEZ LABBÉ (2004 y 2006); ISAIS CONTRERAS (2005, 2007 a y b); FALK (2011); ALZATE (2015 a y b); BELTRÁN ABARCA (2015); FABREGAT (2015 a y b); CHÁVEZ y OVALLE (2015); FLORES (2015); BELMAR (2015 a y b). Para el mundo europeo y anglosajón, sin hacer una exposición exhaustiva, podemos mencionar, entre otros, SCHMITT (1976); VEYNE (1981); MACDONALD (1986 y 1989); CHESNAIS (1992); MINOIS (1995); MURRAY (1998); MARTÍNEZ PÉREZ (2001); WEAVER (2009); SNYDER (2010); PLUMED y ROJO MORENO (2012).
} 


\subsection{Los suicidios en la historiografía argentina}

La primera obra que hemos encontrado referida al tema del suicidio en la historia argentina es la de Lidia Parise y Abel González, La fin del mundo (1971). En su estudio, los autores destacan el clima de época durante el Centenario de 1910, momento en que la población de Buenos Aires se preguntaba si el paso del Cometa Halley contaminaría la atmósfera de la tierra y terminaría con la vida. En esa situación, se suicidaron muchas personas, dejando, en algunos casos, en sus "mensajes de adiós", referencias no sólo a esta situación, sino también a muchas otras que angustiaban a hombres y mujeres de la época.

Si el trabajo de Parise y González estuvo enfocado en el análisis de los casos anónimos que daban cuenta de la sensibilidad romántica y decadentista (estar viviendo el final de los tiempos) de fines del siglo XIX y principios del XX, el trabajo de Jimena Sáenz (1973), que apareció publicado en la revista Todo es Historia, estuvo centrado en los casos de suicidio de algunas personalidades de la elite cultural y política que permanecieron en la memoria colectiva. En este artículo, la autora realizó un recorrido por los casos particulares de ciertas figuras reconocidas de diferentes ámbitos de la historia argentina -Leandro N. Alem, Alfonsina Storni, Leopoldo Lugones, Lisandro de la Torre, entre otros-, que terminaron con sus vidas. Sáenz sólo dio cierta información biográfica de algunas figuras célebres, sin avanzar en un análisis sistemático y riguroso de las representaciones, la sensibilidad o los discursos relacionados con el quitarse la vida. Estos casos, por tratarse de individuos destacados y conocidos de la población, habían sido el centro de debates y habían abierto, en distintos momentos, la discusión sobre los valores y el marco axiológico, implícito y explícito, que compartían quienes presenciaban el hecho.

El tema permanecería ausente en la historiografía argentina hasta 1991, año en el que Marcelo Otero publicó su tesis de licenciatura, referida al discurso médico sobre el suicidio en el ámbito intelectual porteño de entre siglos. ${ }^{15} \mathrm{Sin}$ adscribir abiertamente a un enfoque foucaultiano, su investigación puso el foco de atención en las tesis médicas y artículos sobre el tema del suicidio en la ciudad de Buenos Aires. Para ello, problematizó los análisis realizados desde el Círculo Médico Argentino y otras instituciones, en los que identificó la preocupación que provocó el aumento sostenido de

\footnotetext{
${ }^{15}$ Véase, también, OTERO (2004).
} 
la tasa de suicidios. Antes de que la obra de Durkheim, El suicidio (1894), fuera publicada, los médicos discutían distintos enfoques sobre el problema, debatiendo sobre las causas y factores que influían en la tasa de suicidios. En estas discusiones, aparecía la idea de que el suicidio era una enfermedad moral relacionada con el grado de civilización alcanzado por la sociedad. Los científicos, mediante su conocimiento, sentían el deber de avanzar en el estudio de estos fenómenos para continuar con la línea del progreso sin límites en la que todavía se creía a fines del siglo XIX. El interés por el suicidio comenzó a decaer en 1910, momento en que las investigaciones sobre el tema eran cada vez más infrecuentes, hasta los años treinta, período en que dicho interés, según Otero, volvió a resurgir. En su trabajo, para el análisis de los discursos y la mirada médica sobre la muerte voluntaria, utilizó algunos artículos e investigaciones que aparecieron editados entre 1880 y 1910 en publicaciones como los "Anales del Círculo Médico Argentino", la revista "La Semana Médica", “Archivos de Psiquiatría y Criminología" y algunas de las tesis de medicina de la Facultad de Ciencias Médicas de la Universidad de Buenos Aires, de ese mismo período.

Cabe señalar que el análisis de los discursos científicos e intelectuales nos permite conocer las formas hegemónicas de entender distintos fenómenos de la cultura de un período determinado. En este sentido, los estudios sobre la muerte han dado cuenta del proceso de legitimación del saber médico y científico, así como de la figura de los profesionales de la salud, en especial, en la época que estudiamos.

Durante la segunda mitad del siglo XIX, en paralelo con el crecimiento de los asentamientos urbanos, las epidemias de diferentes enfermedades preocuparon a la población en general, que padecía sus efectos. En este marco, ocurrieron cambios en la sensibilidad ante la muerte, $\mathrm{y}$, en especial, en el trato con los cuerpos, una posible vía de contagio, y de las prácticas funerarias, alejando los cementerios de los cascos urbanos, para evitar el intercambio promiscuo y antihigiénico entre vivos y muertos. ${ }^{16}$ La lucha

\footnotetext{
${ }^{16}$ En la perspectiva de Philippe Ariès, el traslado de los cementerios del centro de las ciudades hacia las afueras, como consecuencia del cambio de sensibilidad ante los cadáveres, fue un momento relevante en el proceso de formación del tabú de la muerte en el siglo XX. En el siglo XIX, muchas prácticas funerarias cambiaron junto con la transformación de la sensibilidad hacia los cadáveres y el avance del proceso de secularización. A medida que ganaba peso una concepción ilustrada e higienista de los cadáveres, perdía legitimidad la autoridad religiosa en ciertas esferas, como el entierro de los muertos. En este sentido, una de las prácticas que desapareció fue el entierro en las iglesias. Esto dio como resultado el traslado de los cementerios a lugares alejados de los centros urbanos y la prohibición de enterrar en el interior de los templos religiosos. Esta transformación de las prácticas funerarias estuvo lejos de ser un proceso lineal, por el contrario, tuvo avances lentos y sinuosos e irregulares en el tiempo, hasta que conquistaron una legitimidad en sectores amplios de la población y no sólo entre ciertas fracciones de la
} 
antiepidémica fue el marco en el que los profesionales de la salud consolidaron su posición como actores políticos y sociales, lo que dio legitimidad a su discurso sobre distintas esferas de la vida, entre ellas, la muerte.

Un trabajo que da cuenta de este avance de la autoridad médica, para el caso de la ciudad de Córdoba, es el de Liliana V. Pereyra (1999). En su obra, La muerte en Córdoba a fines del siglo XIX, destacó, como uno de los cambios que aparece en el final del siglo XIX, el aumento constante del peso y la legitimidad otorgado al discurso médico en cuestiones relacionadas con la muerte, en paralelo con el proceso de consolidación del estado. Si bien, según la autora, la Iglesia conservó el monopolio de la entrada a la otra vida (de acuerdo a la ritualización, lugares y servicios que eran ofrecidos en la época), a la hora de la muerte actuaban tres discursos: el médico, el estatal y el religioso. Cuando era necesario determinar la defunción de un miembro de la comunidad, el médico era la persona autorizada para confirmar que había ocurrido una muerte, a través de la observación de los signos vitales correspondientes. Por otra parte, el especialista en medicina moderna pasó a cumplir funciones dentro del aparato estatal, como impulsor y administrador de medidas orientadas a garantizar una vida higiénica en la población. Como señala Pereyra (1999: 99): "El discurso del médico actúa en dos planos: uno, casi autónomo, frente a cada muerte, como profesional en ejercicio de su disciplina; y el otro, lo ubica frente a todas las muertes desde su creciente inserción en el aparato del Estado".

Para nuestra investigación, creemos importante retomar el discurso médico y científico sobre el suicidio, a fin de observar lo que era considerado verosímil sobre el tema y los valores que los médicos ponían en juego a la hora de reflexionar sobre la muerte voluntaria. El estudio de los saberes en boga durante la segunda mitad del siglo XIX nos puede brindar un primer acercamiento a las representaciones del suicidio por parte de las elites políticas y culturales y los intentos de difundir esta mirada al resto de la sociedad. Nos parece interesante, también, reflexionar sobre la circulación de este discurso por fuera del espacio de sociabilidad laboral y profesional de los médicos,

elite. Algunos trabajos han analizado este proceso en diferentes lugares del territorio argentino (LÓPEZ MATO, 2002; NIEVES SOSA, 2005; CARETTA y ZACCA, 2007 y 2010; AYROLO, 2009; GERÉS, 2011). Como señalan estos estudios, las representaciones del período colonial pervivieron durante largo tiempo y los cambios no fueron ni profundos ni afectaron a todos los sectores de la sociedad hasta bien avanzado el proceso de modernización. Para un análisis de los monumentos funerarios y las características de los cementerios en Argentina y Brasil en el período que estudiamos, véase, también, DILLMANN (2014). 
sobre otras lecturas y otras formas de interpretar el fenómeno. Al mismo tiempo, cabe destacar que los profesionales de la salud, siguiendo lo expuesto por Otero, eran seguidores atentos de la prensa, una de las fuentes principales que les aportaba información sobre lo relacionado con el suicidio en la ciudad de Buenos Aires, en el territorio nacional, y en el resto del mundo. En este sentido, encontramos estimulante la comparación del discurso intelectual de las elites con los enunciados aparecidos en diarios y periódicos, a fin de observar la circulación de las ideas desde el ámbito académico hacia un público más amplio. ${ }^{17}$

También nos parece relevante recuperar las influencias intelectuales que los médicos recibieron de los centros hegemónicos a nivel mundial y cómo resignificaron esos discursos eruditos. ${ }^{18}$ Esto último es algo que Otero no desarrolló en su tesis sobre el suicidio en Buenos Aires, al igual que los espacios de sociabilidad y producción de esos saberes, es decir, los vínculos que ligaban a los intelectuales en una red de colegas, discípulos y alumnos, y sus roles como funcionarios políticos y como profesores en las cátedras de la Universidad de Buenos Aires. Si bien Otero encontró que había una dimensión moral en el análisis del suicidio por parte de los profesionales de la salud, no profundizó el análisis del marco axiológico implícito, siendo que su objetivo era mostrar las similitudes de las ideas de los médicos de entre siglos y el pensamiento de Durkheim. En nuestra investigación, por otra parte, ese será el lente con el que

\footnotetext{
${ }^{17}$ En esta línea de interpretación están los trabajos de Fabio Henrique Lopes, en los que analizó la influencia del discurso médico en el imaginario de la sociedad brasileña durante el siglo XIX e inicios del XX. En su primer trabajo, O suicídio sem fronteiras: entre a razão e a desordem mental (1998), Lopes realizó un análisis del tratamiento del suicidio en la prensa de Campinas. Por medio de la elaboración de series temáticas, en base a lo publicado en el Diario de Campinas, organizó los discursos vinculados con el suicidio. El autor destacó que el objetivo de la publicación no era sólo informar, sino también interpretar, orientar y divertir. En su trabajo, Lopes (1998: 5) abordó las tres décadas finales del siglo XIX, período de importancia por la intensa actividad de la prensa local, tanto como por la constancia y la diversidad de temas y secciones. Entre estos discursos, pudo identificar el del saber médico, que integraba el suicidio al universo de las enfermedades mentales. Junto a este discurso, también encontró otros relacionados con lo ficcional, lo popular y lo místico. En su estudio, además, buscó demostrar cómo la prensa jugaba un rol central en convertir los suicidios en elementos del cotidiano de la ciudad.

${ }^{18}$ En su segunda obra, A experiência do suicídio: discursos médicos no Brasil, 1830-1900 (2003), Lopes se concentró, principalmente, en las tesis médicas como fuentes. La información encontrada en las mismas sobre las representaciones del discurso médico fue ordenada en cuatro series temáticas. En la primera, agrupó las referencias sobre el suicidio como enfermedad mental. La segunda serie fue elaborada reuniendo los enunciados que mostraban al suicidio como el resultado de pasiones excesivas del mundo urbano. A través de la tercera, López analizó las diferencias a la hora de explicar los casos de suicidios en hombres y mujeres. Por último, identificó una serie sobre los efectos que la literatura ejercía en los jóvenes, que, en algunos casos, podía sugestionarlos, provocando epidemias de suicidios. Además de analizar el discurso de los profesionales de la salud en Río de Janeiro, Lopes indagó las referencias intelectuales presentes en estos. Así, encontró una fuerte influencia de la psiquiatría francesa, y, en especial, de las ideas de Esquirol.
} 
revisaremos los escritos producidos por estos intelectuales. ${ }^{19}$ Más allá de analizar su rol como miembros de la elite cultural del período, buscaremos entenderlos como parte de la sociedad de la época, es decir, permeados por los valores y el código social presentes durante el proceso de formación de la Argentina moderna.

Mientras que los trabajos de Otero estuvieron centrados en diversas fuentes referidas al saber médico producido en la ciudad de Buenos Aires, la investigación de Diana Duart y Carlos Van Haubart buscó indagar las representaciones del suicidio en los expedientes judiciales del Departamento Capital de la Provincia de Buenos Aires. ${ }^{20}$ Estos les permitieron avanzar en un análisis de la sensibilidad de la población, a través de las notas de despedida de quienes decidieron quitarse la vida y de los testimonios de los que fueron interrogados por la policía. Dos conceptos se repetían en la mayoría de las cartas y declaraciones, honor y fidelidad. En este sentido, los testimonios relevados daban cuenta de elementos que formaban parte de las representaciones de la honra masculina y femenina a fines del siglo XIX y principios del XX. Este tipo de trabajos aportan elementos para comparar las fuentes producidas por las elites e identificar los puntos de acuerdo y las diferencias a la hora de expresar lo que era verosímil y otorgarle un valor.

En este sentido, creemos importante destacar las variantes que adquiere la representación de la muerte, del comportamiento seguido, de acuerdo a la clase, el género y la edad, dentro del análisis más general de la sociedad en un período. Como señala Jacques Le Goff (1995), el nivel de las mentalidades o de lo cultural está vinculado, de forma íntima, con las características de la estructura social, con la vida material y las relaciones al interior de cada estrato y con otros grupos y actores de la sociedad de la época. Para ejemplificar estas cuestiones, nos parece oportuno presentar

\footnotetext{
${ }^{19}$ En este sentido, si bien Jackson André da Silva Ferreira reconoció la importancia de interpretar estos discursos en los períodos estudiados, en su trabajo sobre el suicidio en Bahía (Brasil), durante la segunda mitad del siglo XIX, relativizó el alcance del poder de los médicos en la sociedad (FERREIRA, 2004: 6). Para este autor, no sólo era importante la influencia que estos tenían en los grupos y actores sociales de la época, sino que también era fundamental pensar cómo la lectura de la prensa, entre otras cosas, construía la mirada de los profesionales de la salud. Otro punto interesante en el trabajo de Ferreira fue la atención prestada al discurso religioso sobre la muerte voluntaria. El autor recurrió a publicaciones religiosas para rescatar el punto de vista de los católicos y otros cultos en relación al tema de la muerte voluntaria y así comparar el discurso desde el punto de vista religioso con la moral del saber médico. Esto permitió a Ferreira plantear que, en las tesis médicas, además de las ideas científicas, había una fuerte influencia de concepciones morales, a veces similares a las de los discursos religiosos (FERREIRA, 2004: 10).

${ }^{20}$ Desafortunadamente, los trabajos de Duart y Van Haubart no se encuentran en poder de sus autores y, al día de hoy, no hemos podido acceder a una copia de los mismos. Lo único que queda es un breve artículo disponible en la Biblioteca de la Universidad Nacional de Mar del Plata.
} 
los trabajos de Andrea Jáuregui y Lilian Diodati y Nora Liñan, aparecidos en la compilación de Cristina Godoy y Eduardo Hourcade, La Muerte en la Cultura (1993). Jáuregui abordó, por un lado, las pinturas de los Salones Nacionales entre 1911 y 1945 , y, por el otro, los elementos iconográficos de las sepulturas en el Cementerio de la Recoleta. Entre los aspectos destacados por la autora en las series icónicas, encontró que la muerte del otro (retomando la tipología de Ariès) era uno de los temas más frecuentes en las pinturas, en tanto la muerte de los hijos era una de las más sufridas y, por ello, representada con mayor dramatismo. Esto también aparecía en las bóvedas del cementerio de la Recoleta dedicadas a la memoria de los hijos por parte de aquellos padres que habían encargado su construcción (JÁUREGUI, 1993: 81). Esto contrastaba con la forma en que había sido vivida la muerte durante la mayor parte del siglo XIX, como señalan Diodati y Liñan (1993). Estas abordaron el tema desde la historia de la sensibilidad colectiva y las mentalidades, centrando su análisis en el espacio rioplatense de la primera mitad del siglo XIX. Entre las particularidades que encontraron, destacaron las actitudes ante la muerte de los niños. El "velorio del angelito" constituía una fiesta y una ceremonia de gran importancia, tanto para los pobladores de la campaña como para los habitantes del mundo urbano. Entre los primeros, por ejemplo, era común que los asistentes tomaran mate y bebieran, jugaran a los naipes, tocaran la guitarra, bailaran alegremente, cocinaran pasteles, mientras velaban el cuerpo del niño (que estaba vestido de blanco). La fiesta duraba toda la noche y, al día siguiente, los padres del niño podían prestar el angelito a un vecino para continuar con el velorio un par de días más. Estas prácticas festivas se daban (con sus particularidades) entre los miembros de las elites (que en lugar de bailar el gato danzaban alegres minuetos). Si bien había diferencias a la hora de velar un notable o un miembro de los sectores populares rurales o urbanos, para todos los integrantes de la sociedad, más allá de su origen social, la muerte de un niño (un alma sin los pecados de los adultos) era algo que merecía ser recordado. Este tipo de prácticas (con matices, sincretismos y resignificaciones) están vigentes en ciertas comunidades, como Corrientes. Este caso fue estudiado por César Iván Bondar (2012a y b). ${ }^{21}$ Por otra parte, Diodati y Liñan

\footnotetext{
${ }^{21}$ En su trabajo, Bondar analiza las prácticas en torno a los angelitos en el presente como el resultado de un proceso de mestizaje y re-semiotización dentro de la religiosidad popular. A diferencia de los velorios narrados por los viajeros abordados por Diodati y Liñan (1993), en el caso de la provincia de Corrientes no hay festividades de varios días. Por otra parte, Bondar sí ha encontrado diferencias en los velorios y las tumbas (el uso de ciertos colores y la presencia de exvotos relacionados con la muerte en la niñez) de los
} 
(1993) hacen hincapié en la violencia cotidiana, propia de la situación social, política y material del siglo XIX, y cómo ésta se enlaza con las representaciones de la muerte (con la imagen de la sangre y el cuchillo), ya que era una experiencia más cotidiana y presente en la vida de los pobladores, tanto urbanos como rurales. Estos estudios muestran distintas representaciones de acuerdo a la franja etaria del difunto, el grupo social al que pertenecía, a su lugar de residencia, o a la identidad de género del que moría; de manera similar, en nuestra investigación, también tendremos en cuenta este tipo de matices, de acuerdo con las características del difunto, que permitían establecer interpretaciones diferentes en los casos de suicidio.

Si bien la posibilidad de recuperar la voz y la vida de las clases populares, aunque sea de forma fragmentaria, a través de los expedientes judiciales, resulta atractiva, no es menos interesante analizar las representaciones de los suicidios de miembros de las elites y otros personajes referenciados en el ámbito público. Así, en la actualidad, hay investigaciones en curso que buscan comprender el rol de la muerte y las prácticas funerarias en los procesos políticos. Un ejemplo de este tipo de enfoque, lo encontramos en los trabajos de Gabriela Caretta e Isabel Zacca (2010 y 2011) sobre los funerales del Gobernador Martín Miguel de Güemes en Salta. Los restos enterrados, originalmente, en la capilla de Chamical (20 kilómetros fuera de la ciudad), fueron exhumados para ser trasladados al templo principal de la ciudad de Salta, por encargo del Gobernador Gorriti. Éste buscaba, por medio de este acto simbólico, por un lado, que los miembros de la elite salteña (opositores y partidarios del caudillo, gobernador y militar de la independencia) se reconciliaran y, por el otro, legitimar a la elite ante el resto del pueblo. Así, el cuerpo de Güemes fue depositado en uno de los lugares de mayor prestigio de la ciudad, frente al altar de la catedral, resaltando sus méritos y servicios prestados. ${ }^{22}$

Otro estudio que analiza el rol político de los funerales de los "grandes hombres" es el trabajo de Sandra Gayol (2012). Gayol muestra cómo las ceremonias funerarias de ciertos ciudadanos ilustres en Buenos Aires fueron una oportunidad, para el estado, de reafirmar la legitimidad de su poder. El contexto del Centenario de 1910 dio lugar a múltiples eventos conmemorativos (visitas al cementerio de la Recoleta,

angelitos, así como ciertas prácticas de actualización de la memoria sobre estos, como las llevadas adelante anualmente el $1^{\circ}$ de noviembre (BONDAR, 2012a y b).

${ }^{22}$ Gabriela CARETTA (2015), en un trabajo más reciente, ha estudiado los funerales políticos de Manuel Dorrego, Alejandro Heredia y Facundo Quiroga. 
colocación de estatuas, inauguración de monumentos, acuñación de monedas y medallas con la efigie del homenajeado). Este tipo de conmemoraciones formaron parte del proceso de consolidación del estado-nación y la creación de símbolos que cimentaran su legitimidad. Los años previos y posteriores a 1910, entre 1906 y 1914, fueron, además de un período de fuerte fervor conmemorativo, años marcados por la muerte de varias figuras célebres del elenco político: Bartolomé Mitre, Francisco Uriburu, Manuel Quintana, Carlos Pellegrini, Juan Agustín García y Alberto Casares en 1906, Luis Sáenz Peña en 1908, Miguel Juárez Celman en 1909 y Roque Sáenz Peña, Julio Argentino Roca y José Evaristo Uriburu en 1914. Gayol prestó atención a las acciones desplegadas, por parte del estado, para llevar adelante los funerales oficiales, haciendo hincapié en la relevancia política e ideológica de los mismos y su rol en la construcción simbólica de la memoria y la identidad nacional. Las ceremonias religiosas, las procesiones multitudinarias al cementerio, los protocolos, los discursos pronunciados en el entierro, confluían en lograr un mismo objetivo: reafirmar la legitimidad del partido gobernante al conmemorar a los hombres que habían construido y consolidado el estado y, por ende, encarnaban a la nación.

Así como la muerte de estos personajes, en circunstancias convencionales, no pasaba desapercibida, y era motivo de actos y manifestaciones excepcionales, el suicidio de ciertas figuras, como los presentados en el artículo de Sáenz (ya mencionado), tampoco era pensado y entendido en los mismos parámetros que los de las clases populares y anónimas. Este fue el caso de Lisandro de la Torre, estudiado por Eduardo Hourcade (1993). El autor analizó el suicidio de este destacado político e intelectual, ocurrido en 1939, y los momentos previos a este. Su muerte fue comparada con la de Leandro N. Alem (en el cual de la Torre se inspiró al tomar la resolución de quitarse la vida). En sus últimos años, de la Torre estuvo abocado al debate de cuestiones religiosas, siendo su principal adversario en las polémicas Monseñor Franceschi (en las páginas de "Criterio"). En sus últimos trabajos, este integrante de la clase política se dedicó a exponer sus argumentos panteístas y materialistas en contra de la autoridad religiosa, en especial, en abierta oposición al catolicismo. Por otra parte, en estos escritos aparecía un de la Torre cargado de profundo pesimismo -como liberal progresista, laico y racionalista, frente a la crisis del liberalismo-, que anunciaba su trágico final. El objetivo de Hourcade fue rescatar las representaciones con las que de la Torre se "preparó" para la muerte y que, tal vez, pueden ser adscriptas a un mundo de 
sociabilidad históricamente especificado (HOURCADE, 1993: 180).

Como balance, podemos destacar que la muerte y el suicidio eran una experiencia diferente para distintas clases sociales. En este sentido, la historiografía sobre la muerte, la clásica y la producida en Argentina, en época más reciente, ha dado algunas respuestas sobre los mecanismos de diferenciación en los rituales funerarios en diversos períodos. Algunos de los aspectos que estos trabajos han tenido en cuenta son los espacios, los rituales de enterramiento y las prácticas anteriores a la muerte física (elaboración del testamento), así como las posteriores al enterramiento (misas de difuntos, visitas al cementerio, etc.).

Un fenómeno que modificó las modalidades de las prácticas funerarias fue la conformación de un mercado de consumo a fines del siglo XIX y principios del XX. Los rituales relacionados con la muerte han sido utilizados por distintas sociedades como formas de diferenciación, para marcar el estatus del difunto y el prestigio del grupo al que pertenecía y, así, reafirmar el orden establecido. Esto último fue estudiado, para el período colonial y tardo colonial, por Isabel Zacca y Gabriela Caretta, en el caso de Salta, ${ }^{23}$ y por Hilda Zapico, en el de Buenos Aires. ${ }^{24}$ Una novedad que apareció hacia finales del siglo XIX fue la aparición de empresas y personal que se encargaban de ofrecer los servicios necesarios para la despedida del difunto, algo que destacó Pereyra

\footnotetext{
${ }^{23}$ En las sociedades anteriores al advenimiento de la modernidad, los lugares de entierro estaban ubicados dentro del espacio de la vida cotidiana de la comunidad, los muertos estaban integrados al mundo de los vivos. En este sentido, los trabajos de Gabriela CARETTA e Isabel ZACCA (2007 y 2010) abordaron estas cuestiones para el período de la segunda mitad del siglo XVIII y primera del XIX en la ciudad de Salta. En sus trabajos, además de destacar que el cementerio estaba integrado al espacio cotidiano de la población, las autoras buscaron mostrar los lugares de entierro como sitios cargados de sentido y de representaciones de la compleja trama social. A través del estudio de los registros de entierros, en los templos y sus patios, Caretta y Zacca explicaron cómo los muertos continuaron bajo la jurisdicción de la Iglesia, donde los clérigos mantenían el control sobre los espacios y sus registros, creando un vínculo entre el acto de morir, el entierro en espacio sagrado y el destino en el más allá. En este sentido, la negación de la sepultura resultaba un fuerte dispositivo de poder por parte de los clérigos sobre la población. Las autoras también observaron cómo a cada muerto le correspondía un sitio diferencial en el cementerio de acuerdo a su lugar social.

${ }^{24}$ Como señala Hilda R. ZAPICO (2005a y b), en las sociedades de Antiguo Régimen, la reproducción del orden social encontraba en las honras fúnebres una oportunidad significativa, porque reiteraba, a través del ritual, las diferencias y legitimaba el orden estatuido. Acontecimientos como los fallecimientos regios y las consiguientes entronizaciones, daban lugar a manifestaciones ceremoniales de carácter general para todo el reino, donde se ponía de manifiesto la adhesión a una dinastía y, más ampliamente, a la institución monárquica, en tanto suponía la participación activa de todo el tejido social. En sus trabajos, Zapico explicó que las elites de la sociedad colonial de Buenos Aires concebían las honras fúnebres como una forma de mostrarse de manera pública y notoria. La desaparición física significó para la elite mucho más que el mero hecho de la transmisión de bienes, implicaba, entre otras prácticas, misas por el alma del difunto, bienes simbólicos, donaciones al clero y el entierro en espacios privilegiados, por ejemplo, bajo el altar de las iglesias. Así, las ceremonias y los rituales tenían, en el Antiguo Régimen, un rol en la configuración de una conciencia colectiva de pertenencia a una misma comunidad política y reafirmaban las jerarquías sociales.
} 
(1999), para la ciudad de Córdoba. El poder adquisitivo del difunto y su grupo familiar determinaban las características del velatorio, el coche que llevaría el cuerpo, el cajón y el lugar donde serían depositados los restos. La aparición de publicidades ofreciendo estos bienes y servicios fue una de las fuentes que consultó Diego Fernando Guerra para explorar los cambios que provocó el proceso de modernización en las prácticas funerarias. ${ }^{25}$

Las prácticas funerarias y su sentido cambiaron durante la modernización de la sociedad argentina y variaron de acuerdo al grupo de pertenencia de los difuntos. Del mismo modo, el suicidio era una experiencia diferente para las personas de acuerdo a la clase a la que pertenecieran, a su género, a la franja etaria o el lugar donde vivieran. Al mismo tiempo, las formas de poner fin a la vida tenían un sentido y un significado distinto que podía ser vinculado con la identidad del que se suicidaba. Otras circunstancias, como el día de la semana, la hora o la época del año, también podían tener un sentido dentro del contexto social y cultural en el que vivía la persona que se quitaba la vida, como ya había señalado Durkheim.

Inspirado por el sociólogo francés, Daniel Caminotti (2000 y 2010) estudió los casos de suicidio en el territorio de Neuquén entre 1903 y 1957, utilizando para ello los expedientes judiciales disponibles. ${ }^{26} \mathrm{Si}$ bien tomó fuentes similares a las utilizadas por

\footnotetext{
${ }^{25}$ En sus trabajos, Diego Fernando GUERRA (2009 y 2010a y b) combinó los conocimientos de los estudios históricos y los de la historia del arte en la interpretación de registros visuales: fotografía y publicidad. Así, logró avanzar en el conocimiento sobre algunos aspectos de la temprana modernización de los servicios funerarios en Argentina, entre finales del siglo XIX y principios del XX, y sobre el modo en que la consolidación de una cultura de masas y el surgimiento de los primeros medios masivos ilustrados -"vehículos privilegiados" de los valores y discursos de la sociedad de consumo-, contribuyeron a transformar las actitudes ante la muerte y las prácticas del rito fúnebre, a medida que lo posicionaban como un ítem de la oferta de bienes y servicios. Por otra parte, Guerra abordó, a través de los consumos funerarios, la aparición del tabú de la muerte. En este sentido, su estudio estuvo centrado en la desaparición, durante la primera mitad del siglo XX, de las fotografías y los retratos de difuntos, elementos habituales durante el siglo XIX. Este tipo de fenómenos, como los abordados por los estudios clásicos, pueden darnos las claves para interpretar la aparición, en la sociedad en general, de un tabú de la muerte.

${ }^{26}$ Un trabajo similar al de Caminotti fue el de Pedro Federico FALK (2011). En su estudio, realizó un análisis de las representaciones y prácticas relacionadas con el suicidio durante los años veinte en la ciudad de Recife (Brasil). Su objetivo fue poner a prueba las hipótesis de Durkheim sobre el suicidio. Si bien analizó los discursos médicos, religiosos y jurídicos, el eje central de su trabajo fue poner a prueba los efectos del debilitamiento y desregulación de las antiguas instituciones (familia, iglesia, comunidad), producto de los cambios sociales y culturales de la modernidad. Así, el objetivo principal de Falk fue mostrar cómo estos fenómenos habían jugado un rol central en el aumento de la tasa de suicidios, aún en tiempos de bienestar económico (como fueron los años 20 en la ciudad de Recife), pero de cambios profundos (como consecuencia de la modernización), tanto en términos cuantitativos (la cantidad de suicidios y las cifras según parámetros como la edad, el sexo, el estado civil, etc. de los casos relevados en el Diario de Pernambuco), como en términos cualitativos (las representaciones de los suicidios en los discursos, la prensa y los documentos policiales y judiciales).
} 
Duart y Van Haubart (1999), además de observar las causas verosímiles, presentes en los mensajes de adiós y las declaraciones, y su relación con la identidad de quienes se quitaban la vida, en su análisis, también interpretó otras circunstancias de los casos de suicidio. Así, su objetivo fue destacar aquellos aspectos de la sociedad de la época que se relacionaban con los casos: diferencias entre la vida urbana y el mundo rural, entre hombres y mujeres, según las nacionalidades, los medios utilizados para suicidarse, las edades, los días y las estaciones.

Este tipo de análisis nos permite reflexionar sobre los cambios y continuidades que el proceso de modernización trajo en la vida de los habitantes. Por un lado, nuevas formas de quitarse la vida estaban disponibles, por ejemplo, a través de la circulación de venenos y sustancias químicas; o por la llegada de los rieles, en los que algunos se situaban para suicidarse. Por otra parte, los viejos medios, como el uso de armas de fuego (resabio de una sociedad que había vivido para la guerra durante muchos años), continuaban presentes y contrastaban con las prácticas en otros lugares del mundo, más "civilizado", como Francia, donde las formas más habituales de suicidarse eran el ahorcamiento por suspensión, o la asfixia por sumersión, luego de tirarse al río (BIALET MASSÉ, 1885: 232). Todo esto aparecía relatado en las páginas de los diarios y periódicos de la época. Los medios de comunicación, como el telégrafo, daban a conocer los casos de suicidio de muchos lugares del territorio argentino y del globo, volviéndolos un hecho conocido y familiar. La vida de los trabajadores en el mundo moderno también modificaba la forma de percibir el tiempo y sus experiencias cotidianas: los días y las semanas, los meses y las estaciones eran experimentadas a través de las ocupaciones que los hombres desempeñaban en sus trabajos, o como administradores de negocios y empleados del estado. Al mismo tiempo, el significado social del suicidio estaba atravesado por un conjunto de valores y creencias, relacionados con los roles que los habitantes debían desempeñar de acuerdo a su identidad de género. En este sentido, consideramos relevante mencionar el trabajo de Donna Guy (2014), sobre los suicidios de las prostitutas de Buenos Aires entre 1880 y 1910. Apelando, entre otras fuentes, a los sumarios judiciales, la autora reconstruyó el relato de los suicidios de algunas mujeres que se dedicaban al comercio sexual. ${ }^{27}$ Entre

\footnotetext{
${ }^{27}$ Sobre el uso de los sumarios judiciales como fuentes históricas, véase, también, los trabajos de FABREGAT, CHÁVEZ y OVALLE, FLORES y BELMAR, incluidos en el Dossier coordinado por Mario Fabregat (2015) para la revista "Historia y Justicia".
} 
otras cuestiones, Guy destacó el rol de las redes de contención en las historias analizadas. Según lo observado en los casos que estudió, las mujeres que vivían en burdeles tenían una mayor cantidad de vínculos a los que recurrir cuando sentían tristeza, depresión o encontraban dificultades. Asimismo, Guy prestó atención a cómo fueron narrados los suicidios de las prostitutas en algunos medios gráficos de la época. En algunos casos, los diarios construían una fábula moral, que mostraba el desdichado final que les esperaba a las que se dedicaban a esta actividad; al mismo tiempo, alertaba sobre las consecuencias negativas que implicaba el ejercicio de la prostitución en la ciudad, por ejemplo, la trata de mujeres traídas con engaños desde el otro lado del Atlántico.

\subsection{Consideraciones finales}

Luego de exponer, de forma breve, algunas de las principales posturas que las elites culturales adoptaron con respecto al suicidio en el mundo occidental, podemos observar que la polémica sobre el derecho de los seres humanos a quitarse la vida ha dado lugar a diferentes salidas e interpretaciones a lo largo de la historia. El suicidio es y ha sido un problema moral en diferentes contextos socio-históricos. Cada sociedad ha planteado una actitud particular y una manera de abordar el dilema ético de los actos suicidas. Como han señalado otros autores, el que un miembro de una comunidad decidiera morir voluntariamente pone en tensión aquellos principios, normas e ideales que permiten sostener el régimen vigente y que son compartidos por los integrantes de una sociedad en un momento dado. Como ya mencionamos, no hay sociedad posible que se sostenga en la muerte voluntaria de todos sus miembros. De allí que cada una regule de distinta forma las situaciones en las que avala o reprueba la muerte voluntaria de sus miembros, ya sea desde el código social, filosófico, jurídico o religioso. En este sentido, como señala Cohen Agrest (2007: 79), las ideas sobre el suicidio y la muerte voluntaria son un espejo de la ideología de cada espíritu epocal.

Por esta razón, consideramos que el análisis de los casos de suicidio nos puede dar elementos para comprender el sentido que diferentes actores daban a la muerte autoinfligida, lo que resultaba verosímil, y los distintos valores, expectativas y creencias de los habitantes de la ciudad de Buenos Aires durante el último tercio del siglo XIX. 
Como veremos en el próximo capítulo, la utilización de diferentes tipos de documentación nos permitirá alcanzar distintos objetivos. Por un lado, reconocer las distintas formas de representar a los suicidas entre los médicos higienistas, los psiquiatras alienistas o los criminólogos positivistas. Por otro, observar la circulación de las ideas y principios morales de estos miembros de las elites culturales en los medios gráficos. Por último, Si bien existía un discurso hegemónico sobre los actos suicidas, también creemos relevante explorar las ideas y los valores sobre la muerte voluntaria de otros actores, desde un punto de vista que recupere el aspecto ético-moral, y que podemos observar, aunque sea de manera fragmentaria, en los indicios que quedan del pasado en las fuentes disponibles, sobre todo, en los sumarios judiciales. Allí podemos encontrar las declaraciones de los miembros de la red social del que se quitaba la vida y los escritos de los suicidas que han quedado adjuntados en los expedientes. 


\section{Capítulo 2: Teoría y metodología}

En el capítulo anterior, expusimos de forma general los distintos enfoques utilizados por las disciplinas científicas para articular el estudio de los suicidios de forma interdisciplinaria: el psiquiátrico, el psicológico y el sociocultural. A partir de esta última perspectiva, como ya mencionamos, desarrollamos nuestra investigación. En este punto de nuestra exposición, consideramos oportuno mencionar algunas precisiones conceptuales y metodológicas que tuvimos en cuenta a la hora de analizar las representaciones del suicidio. Asimismo, el presente capítulo estará dedicado a introducir las fuentes principales que fueron utilizadas como referentes empíricos en nuestro estudio: los textos académicos y los sumarios judiciales.

Como hemos fundamentado, consideramos los suicidios como acciones sociales y comunicativas. En este sentido, pensamos que el acto suicida era interpretado por el propio suicida y los distintos actores sociales que presenciaban los hechos desde una perspectiva ética. Esta última se expresaba en un relato moral que mencionaba características esenciales del suicida y/o elementos situacionales del contexto, de acuerdo con lo que resultaba verosímil. Dicho de otro modo, estimamos que el mensaje final del que se quitaba la vida y los testimonios de los deudos estaban permeados por los principios morales del marco axiológico vigente durante el período en estudio.

\subsection{Aspectos teóricos y metodológicos}

Los suicidios constituyen una situación límite, la acción final de un individuo que no encuentra más alternativas en la vida. En este sentido, según Vladimir Jankélévitch (2006: 91-93), existe un vínculo estrecho entre la desesperación y el quitarse la vida:

La desesperación, en el sentido literal, la ausencia total de esperanza, es decir, la renuncia total al porvenir, es un sentimiento apenas soportable, que la mayor parte de los hombres no ha conocido, y que no existe sino en los libros, o entre los románticos que no son sinceros; "desesperado" como puede estarlo un poeta o un músico romántico... pero cuando se está verdaderamente desesperado, 
entonces no queda otra cosa que meterse una bala en la cabeza. La situación del hombre desesperado es una situación irrepresentable, inconcebible. [...] Aquel que aún vive guarda siempre una esperanza: vivir un segundo más. Es propio de la vida. La esperanza está clavada en el hecho de ser. [...] Hay entonces entre la desesperación y el suicidio un vínculo inmediato, directo, la única solución que es la ausencia de solución. Un desesperado no puede tener necesidad sino de matarse.

Si bien la experiencia de alguien que está por suicidarse implica un intenso sufrimiento personal, también nos parece importante tener presente que el que padece el sentimiento de desesperación forma parte de una sociedad y entiende el mundo a partir del sistema cultural en el que vive. Dicho de otro modo: ¿Qué significaba la desesperación en un contexto socio-histórico específico?

En este sentido, este trabajo propone analizar los casos de suicidio ocurridos durante la segunda mitad del siglo XIX, en la ciudad de Buenos Aires, desde una perspectiva sociocultural. Siguiendo lo expresado por Heidi Hjelmeland (2010), frente a una tendencia a descartar o minimizar la influencia de toda variable que no sea la biológica, consideramos relevante contemplar los aspectos culturales y sociales en torno a las muertes por mano propia, más allá de los factores individuales, físicos y mentales. Así, conocer el suicidio en diferentes contextos históricos, nos permite pensar con mayor amplitud la realidad de nuestro propio entorno social. Por ejemplo, entender en qué situaciones y por qué era considerado un tema tabú en el pasado, nos ayuda a reflexionar sobre nuestros propios preconceptos de los actos suicidas en el presente.

También, cabe aclarar que entendemos el suicidio como un fenómeno multidimensional. Por esta razón, retomando lo expuesto por S. J. Fitzpatrick (2014a), creemos central contemplarlo en su complejidad, más allá de las cuestiones relacionadas con la salud mental. Es decir, recuperar las dimensiones moral, temporal, relacional, existencial y ontológica del acto suicida. En primer lugar, cuando nos referimos a los aspectos morales, estamos poniendo énfasis en las creencias implícitas sobre la "buena" y "mala" vida (o muerte, en este caso) de una sociedad, y los valores que delimitan lo que se considera "permitido" y "prohibido". Desde nuestra perspectiva, la vida moral, no es un asunto exclusivo de debates éticos, jurídicos o filosóficos, sucede en el acontecer cotidiano de la experiencia social de los sujetos históricos. En este sentido, y vinculado con lo anterior, entendemos que los suicidios han sido interpretados en 
diferentes sociedades y distintos contextos espaciales y temporales. Como vimos en el capítulo 1, en algunas épocas, el mundo occidental toleró los actos suicidas y, en algunos casos, hasta los exaltó (por ejemplo, la concepción estoica de la muerte por mano propia como supremo refugio), mientras que la sociedad medieval condenó los suicidios de manera general, como un pecado grave hacia Dios y la cristiandad. Si bien la modernidad, por su parte, ha llevado adelante un proceso de medicalización en su interpretación de las muertes voluntarias, entendemos, en línea con Fitzpatrick (2014), que también mantuvo su propia mirada moral del tema. Lo mismo acontece en la actualidad cuando reflexionamos sobre la legitimidad de disponer de la propia vida.

En relación con lo anterior, nos parece importante resaltar la dimensión relacional e interactiva del suicido. Así como podemos analizar los casos a partir de las características biológicas y psicológicas individuales del que lleva adelante el acto suicida, entendemos que estos acontecimientos no ocurren en el vacío. Se trata de actores sociales, que están vinculados con los sujetos que integran su red social y que interactúan con otros para construir el significado que dan a sus propias vidas y a los lazos que construyen. Así, el sentido que cada individuo da a su existencia, en el mundo moderno estaba relacionado, de forma íntima, con los roles que desempeñaba como parte del colectivo; al mismo tiempo, otorgaba a las personas, objetos, lugares, acontecimientos y acciones que llevaba adelante diferentes significados, que son a la vez individuales y sociales. Dicho de otro modo, la forma en la que representaban el mundo los sujetos históricos que analizamos no estaba desvinculada de la sociedad en la que participaban y la cultura que construían como colectivo.

Así, reflexionar desde una perspectiva cultural implica tomar en consideración el entorno social en el que sucedieron los acontecimientos, es decir la construcción de significado en determinados grupos sociales, y dentro de un marco histórico y espacial específico, a partir de la interacción de los sujetos que lo componen. En este sentido, el estudio cualitativo de casos particulares, a partir de un enfoque hermenéutico, nos permite encontrar indicios de la vida del individuo que llevó adelante un proceso suicida y las interacciones que mantuvo con su entorno; es decir, nos brinda información para comprender cómo percibían estos individuos su mundo interno y relacional. Así, la prioridad es comprender el fenómeno desde la propia perspectiva de aquellos que tuvieron la vivencia. Asimismo, resulta enriquecedor, dentro de este enfoque, la 
comparación de diversas realidades, según el género, la edad, la clase social y las características de la red vincular del suicida. En síntesis, más que un estudio del suicidio en sí, nuestro objetivo es identificar la forma en la que era interpretada la autoagresión por las personas que compartían un medio social y vivían en un mismo contexto histórico.

\subsubsection{Las representaciones de la muerte por mano propia}

A partir de lo que hemos expuesto, nos parece conveniente precisar uno de los conceptos clave que hemos utilizado en el desarrollo de nuestro estudio, el de representación. Entendemos a las representaciones como el conjunto de mediaciones, basadas en los valores, ideas y creencias de una sociedad, que permiten a los sujetos interpretar sus vivencias, es decir, sus experiencias individuales (la relación con el propio cuerpo y la subjetividad) y colectivas (la relación con un “otro", con los grupos y actores sociales). ${ }^{28}$ De esta manera, las representaciones guían la forma de pensar, de sentir y de actuar, así como la relación con otros miembros de una misma comunidad humana. Es decir, lejos de tener una función pasiva, o ser un reflejo de la realidad percibida, las representaciones influyen en la forma de actuar de los sujetos en el mundo.

A su vez, las representaciones son creadas en la vida social, dicho de otro modo, son construcciones sociales. En sus interacciones, los seres humanos generan representaciones variadas sobre diferentes contenidos, como el sexo, el cuerpo, el poder, el tiempo, el espacio, la muerte, entre otros. Este conjunto de significados está vinculado entre sí y forma un sistema de representaciones, o cultura. ${ }^{29} \mathrm{El}$ conjunto de

\footnotetext{
${ }^{28}$ El concepto de representación que definimos en este apartado fue elaborado a partir de las ideas expuestas por Henri Lefebvre, La presencia y la ausencia. Contribución a la teoría de las representaciones (2006). Según este autor, la representación está en el intervalo entre la presencia (vivencia) y la ausencia (que moviliza la re-presentación de lo ausente), resultado del movimiento dialéctico de lo vivido y lo concebido. En palabras del autor: "Las representaciones nacen perpetuamente. En cada momento, a partir de un fondo (ni sustancia ni instancia) sin fundamento asegurado -mi cuerpo, mi cerebro, mis nervios, mi memoria, las palabras de que dispongo- se genera el proceso que va de la energía elemental y burda de las 'pulsiones' a las proposiciones sutiles, de los afectos a las representaciones sofisticadas" (LEFEBVRE, 2006: 104-106). Sobre el concepto de representaciones, véase, también, entre otros, MOSCOVICI (1979); CHARTIER (1992); ABRIC (2001) y PIÑERO (2008).

${ }^{29}$ Dentro de las representaciones, Lefebvre (2006) distingue tres categorías. En primer lugar, el concepto, materia prima de la ideología y del discurso filosófico e intelectual, es decir producto de un proceso de razonamiento y análisis crítico que permite discernir entre representaciones que ocultan y disimulan de
} 
significados que la integran es el resultado de la experiencia de los individuos en el medio social (de su relación con los otros y la realidad fenoménica), así como de la interpretación de su vida interior (pensamientos, emociones, sensaciones), es decir, de su experiencia humana. En este sentido, creemos conveniente remarcar, siguiendo a Peter Burke (2004), que estas construcciones simbólicas, creadas por los miembros de una sociedad, incluyen no sólo la "alta cultura", sino también la cultura de la vida cotidiana, las costumbres, los valores y los modos de vida. Es decir, entendiendo a la cultura en el sentido etnográfico y antropológico amplio. ${ }^{30}$

La percepción de los seres humanos está condicionada por el uso del lenguaje, que es aprendido en el medio social; por esta razón, a través de los discursos, conceptos y palabras utilizadas por los actores en determinada época, podemos acceder al complejo entramado simbólico que compone su cultura. ${ }^{31}$ Así también, la identidad que cada individuo construía en la sociedad que estudiamos era el resultado de una compleja microfísica de vínculos y acciones desarrollada en el espacio público y en el ámbito familiar. Cada persona, al participar de los diferentes grupos sociales y cumplir los distintos roles que le tocaba desempeñar (los "yo" que integraban un mismo sujeto: hombre, ciudadano, hijo, esposo, hermano, trabajador, etc.), interiorizaba, a lo largo de la vida, un conjunto de creencias y principios (o axiomas). ${ }^{32}$ Dicho de otro modo: "Lo cotidiano se programa por la convergencia de las representaciones" (LEFEBVRE, 2006: 223). A su vez, eran estos esquemas culturales los que sostenían el orden social.

En este sentido, entendemos que la cultura de una sociedad configura el sentido

las que tienden a ir más allá de lo posible. El concepto se diferencia de las representaciones cotidianas. Estas últimas están más cerca de la experiencia de los sujetos, de la vivencia. Por último, el autor hace hincapié en el potencial de la creación artística, que, al rescatar la vivencia, construye con representaciones obras que superan el acto de representar el mundo.

30 Como señala Clifford Geertz (1991), ésta puede ser definida como "un esquema históricamente transmitido de significaciones representadas en símbolos, un sistema de concepciones heredadas y expresadas en formas simbólicas por medio de los cuales los hombres se comunican, perpetúan y desarrollan su conocimiento, y sus actitudes frente a la vida" (GEERTZ, 1991: 88). Sobre el concepto de cultura véase, también, entre otros, WILLIAMS (2000).

${ }^{31}$ Más allá de las operaciones que construyen la vinculación entre el significado y el significante (como la metáfora o la metonimia), son las normas y valores sociales las que dan un sentido a las palabras y su significado dentro de un discurso. Dicho de otro modo, la construcción de las representaciones no es sólo un fenómeno lingüístico, en éste intervienen el marco de creencias y principios que dan sentido y cohesión al discurso en una sociedad (LEFEBVRE, 2006: 51-52).

32 Coincidimos con Lefebvre (2006: 59) en que "toda representación implica un valor, sea que el sujeto valore lo que se representa, el objeto ausente; sea que lo desvalore". A su vez, para que algo sea valorado necesita ser representado. Aquellas representaciones que están asociadas con ideas o creencias valoradas se consolidan: "Se vuelven éticas o estéticas; guían la acción, suscitan conflictos durante los cuales aumentan de intensidad y aun de evidencia -o desaparecen" (LEFEBVRE, 2006: 100). 
común de sus miembros. Por esta razón, en cada discurso enunciado por alguno de sus integrantes, podemos identificar un conjunto de significados construidos socialmente. Vale aclarar que estos no son compartidos de igual forma o grado por todos los actores o grupos sociales. Cómo señala Burke (2004), el pensar en una circulación cultural, entre dos culturas parcialmente diferenciadas, una popular y otra erudita, en interacción, transformación y diálogo, puede sernos de utilidad para no caer en una visión demasiado homogénea de la misma. Así, creemos más adecuado para nuestra investigación sobre las representaciones del suicidio, pensar de esta forma la relación entre la cultura popular y la de la elite, buscando, además de las diferencias, el marco general compartido, sin establecer una separación tajante o una oposición binaria entre ambas. $^{33}$

Es decir, nuestro objetivo es identificar las representaciones que constituían el sentido común sobre el suicidio en los habitantes de la ciudad de Buenos Aires durante la segunda mitad del siglo XIX; en otras palabras, reconocer aquello que era verosímil para quienes vivían en una urbe en proceso de transformación, así como los principios y valores que aparecían expresados a la hora de reflexionar sobre el tema. En esta construcción del deber ser, del marco axiológico, ${ }^{34}$ había una esfera privilegiada, la de la elite cultural, que manifestaba su interés de moralizar a la población y civilizar el comportamiento de los hombres y mujeres del organismo social, transmitiendo un código social de matriz higienista y positivista. Éste aparecía, por ejemplo, en los discursos de la época sobre el aumento de la tasa de suicidios como fenómeno. Al mismo tiempo, los principios morales y creencias de los habitantes de la ciudad de Buenos Aires, y lo que consideraban verosímil acerca de las muertes por mano propia, puede ser indagado a partir de los testimonios registrados en los sumarios judiciales. En estos, hemos encontrado ideas sobre una serie de valores, como el amor, el valor o el honor, o representaciones de lo femenino y lo masculino que eran compartidas por una parte más amplia de la población, más allá de los círculos sociales y académicos de las élites.

\footnotetext{
33 Según LEFEBVRE (2006: 66), las representaciones, dentro de una estructura social, constituyen la imagen que un grupo o clase construye de sí, para sí, y que, por otro lado, también transmite a los demás miembros de la sociedad en su conjunto. Los dominados interiorizan estos valores e imágenes, modificando su contenido de acuerdo a sus posibilidades de cuestionar lo establecido.

${ }^{34}$ Esta categoría fue elaborada en base a las ideas presentadas en la investigación llevada adelante por SZLAJEN (2012: 31, 34, 46, 52-55).
} 
Para interpretar estos significados, hemos estudiado las representaciones del suicidio presentes en los discursos a partir de cinco ejes o dimensiones: el suicidio (fenómeno colectivo), el suicida, la causa / motivo determinante, la red de contención y la comunicación con el otro significativo. En la primera dimensión, hemos agrupado los enunciados producidos por distintos actores de la elite cultural sobre el suicidio y su aumento como fenómeno general del mundo civilizado, que circularon en la opinión pública y contribuyeron a formar el sentido común. Entre las variables que componen esta dimensión, creemos relevante destacar el discurso presente en textos científicos y académicos de la época. Asimismo, hemos recolectado los enunciados referidos al sujeto que se quitaba la vida. En este sentido, las diferentes situaciones individuales generaban una polémica que nos permite entrever aquellos valores que estaban firmemente interiorizados y los hechos que despertaban cuestionamientos. Los datos sobre estos casos han sido organizados en base a la distinta apreciación ética sobre los mismos. En la dimensión “causa / motivo determinante", reunimos los enunciados sobre las distintas explicaciones verosímiles elaboradas tanto en el mundo académico y los medios gráficos, como en los testimonios de las personas vinculadas con el suicida, para dar cuenta de las acciones que lo llevaron a tomar el camino de la muerte por mano propia (pobreza / miseria, enfermedad, cansancio / hastío de la vida, alienación mental, remordimiento, desengaño amoroso, mal estado de los negocios, etc.). También consideramos relevante registrar los discursos referidos a las acciones de los miembros de la red de contención (familiares, amigos, "conocidos" y desconocidos) y su interacción con el suicida. Así, en los expedientes, encontramos información de cómo se identificaban los sujetos que habían entablado algún vínculo con el suicida. Al mismo tiempo, en algunos casos, también encontramos datos e indicios de cómo representaba, el que se quitaba la vida, a los que interpelaba con su acción, a los otros significativos de su entramado vincular. Estos enunciados fueron agrupados en la dimensión "otro significativo".

En síntesis, a partir de la combinación de los datos organizados en estas cinco dimensiones del concepto general "representaciones del suicidio", nos proponemos reconstruir lo que los actores de este período consideraban verosímil sobre los suicidas y las formas de quitarse la vida, así como el discurso ético sobre la muerte voluntaria. 


\subsubsection{La narración moral y el marco axiológico}

Una forma de comprender las representaciones del suicidio es a partir de las narraciones de los familiares y miembros de la red vincular del que se quitó la vida. Como señala Fitzpatrick (2011), el grupo familiar y los lazos afectivos del que lleva adelante un acto suicida elaboran un relato de lo sucedido, a modo de una herramienta que permite comprender la situación experimentada. Asimismo, el que sobrevive a su propio intento de autoagresión también narra los eventos en un intento de dar sentido a sus acciones.

¿Qué hacer cuando el devenir de la vida rutinaria es detenido y trastocado luego de este suceso? ¿Cómo imaginar, a partir de ese momento, la relación con el otro, que intentó quitarse la vida? ¿Cómo reelaborar la propia identidad en el caso del que lleva adelante el acto suicida y la de los integrantes de la red social? En síntesis, ¿quién era la persona que se quitó la vida (o intentó hacerlo) y por qué tomó esa determinación?

En este sentido, la narración de lo sucedido es el recuento de los hechos que llevaron a un quiebre en la vida de los individuos que estaban vinculados con el difunto / herido; y en el caso del que intentó autoagredirse sin éxito, es un modo de dar cuenta a los otros significativos de sus acciones, aunque no sea sencillo explicar su experiencia o las motivaciones que lo llevaron a caer en la desesperación y la autoaniquilación. Esto representaba un desafío para los narradores al contar lo sucedido. En primer lugar, si sentían afecto hacia el suicida, debían buscar la manera de salvar una imagen positiva de éste, en un contexto en el que la muerte por mano propia era considerada, en la mayoría de los casos, un acto escandaloso y/o vergonzoso. En segundo lugar, debían elaborar el duelo y la culpa, es decir, realizar un balance acerca de la responsabilidad de lo sucedido, ya fuera por parte del suicida o de los miembros de la red social del sujeto que se autoagredió. En este sentido, los relatos, al mismo tiempo que preservaban la memoria o la reputación del suicida, también servían a quienes los contaban para reelaborar la propia forma de entenderse y verse a sí mismos. Al trabajar con el duelo y la responsabilidad por lo sucedido, por ejemplo, los testigos podían presentar al suicida como héroe o como víctima de otros externos; este era un modo de evadir el asunto de la culpa o de las acciones que no encuadraban con el rol de soporte y cuidado esperados. 
Así, cada individuo articula una narración de los hechos que le permite ordenar la experiencia y procesar de alguna forma un evento traumático. Si bien incluye su punto de vista individual, dotan de significado a lo relatado a partir de un conjunto de tramas y géneros narrativos que forman parte de su bagaje cultural. Para lograr esto, familiares y deudos recurren a un conjunto de imágenes, metáforas, motivos y representaciones simbólicas, que forman parte de la red de significados que constituye la cultura colectiva.

Nuestro objetivo no es saber lo que realmente aconteció, sino aquello que los sujetos reconstruyeron, aquellas representaciones socio-culturales que dotaban de sentido a la experiencia y que eran reelaboradas a partir de los hechos vivenciados. Por esta razón, la subjetividad del discurso no resulta un obstáculo en este tipo de análisis, ya que nuestro objetivo es indagar lo que resultaba verosímil.

A la hora de realizar el análisis discursivo de los relatos, debemos prestar atención a la información relacionada con la dinámica de los acontecimientos y el contexto en el que ocurrieron. Por ejemplo, dónde empieza el relato, el orden cronológico de los eventos, la forma en la que están articulados los acontecimientos y cómo era interpretada la relación de causalidad entre los mismos. En este sentido, es clave diferenciar cuáles eran los eventos significativos de la trayectoria biográfica del suicida que daban sentido a lo relatado, en especial, aquel suceso disruptivo que irrumpía en el mundo cotidiano y marcaba el inicio de la desintegración de la vida tal como la conocía el sujeto, una situación límite, que rompía con su horizonte de expectativas. También identificamos, en la lectura de las fuentes, si se hacía hincapié en el desarrollo de la historia o en las emociones / estado mental del que se quitó la vida, es decir, si se ponía más énfasis en cómo se sentía el desesperado (más expresivo), o si la narración hacía hincapié en explicar la sucesión de eventos. Asimismo, nos pareció relevante registrar los datos referidos a la interacción del suicida con los miembros de su red vincular, las acciones comunicativas.

Cabe destacar que consideramos que, en cada narración de eventos, podemos encontrar un discurso moral acerca de la experiencia vivida, explícito o implícito. Las historias cumplen una función. Estos relatos están en el vértice entre lo social y lo individual; en este sentido, los narradores se posicionan con respecto a las normas morales acerca del suicidio y las respuestas adecuadas hacia este fenómeno, ya sea para 
adherir o rebatir los valores y creencias establecidos sobre el tema. De este modo, en su discurso, encontramos indicios no sólo del modo en que imaginaban al que se quitó la vida, sino también de las acciones y actitudes del entorno, sobre el rol que los vínculos debían llevar adelante, es decir, los integrantes de la red social en la que se encontraba inmerso el sujeto que sufría la desesperación. Más allá del loco / alienado, que padece una enfermedad mental, según el paradigma científico, los relatos e historias de los deudos presentan un amplio repertorio de imágenes, símbolos y representaciones que corresponden a diversos tipos de personaje teatral (por ejemplo, locos, apasionados, desesperados, valientes, cobardes, deshonrados), es decir, los relatos contribuyen a construir estereotipos sobre los suicidios y las circunstancias que los rodean. Así, por ejemplo, el difunto podía ser presentado como su propio verdugo o como víctima, dependiendo del contexto. No podemos conocer las actitudes genuinas, ni lo que realmente aconteció, pero sí podemos entrever lo que resultaba verosímil y lo que debía hacerse, de acuerdo al criterio individual, pero también de acuerdo con el marco axiológico socialmente aceptado y legitimado.

Hemos clasificado los enunciados y discursos encontrados en las fuentes consultadas a partir de una serie de temas. Estos surgieron como resultado de un trabajo de investigación previo (ARROYO, 2015). Por un lado, de la lectura de la bibliografía especializada y, por el otro, del propio trabajo inductivo con las fuentes, clasificando los expedientes según la causa / motivo verosímil principal identificado. En este sentido, privilegiamos la mirada de los propios actores sociales. Como veremos más adelante, existía una serie de factores, variables y circunstancias ("causas determinantes") creíbles para imaginar un suicidio posible dentro del marco del sentido común y del saber científico de la época. Por ejemplo, la creencia de que un suicidio podía responder a las características patológicas de la mente del individuo que llevó adelante el acto suicida; asimismo, también era verosímil imaginar que el daño grave a la reputación personal generaba, en un individuo, un dolor y un padecimiento desesperantes, en especial, si afectaba a su familia. A partir de este eje, las causas verosímiles, ordenamos la presentación de los casos estudiados por medio de los sumarios judiciales y las ideas rescatadas de los textos académicos.

Al mismo tiempo, en los casos agrupados por temas, el objetivo fue encontrar los tipos narrativos recurrentes. Podemos definir un tipo narrativo como la historia 
general que subyace dentro de un relato específico. En este sentido, una misma narración puede hacer referencia a más de un tema / causa determinante, aunque uno de ellos sea el que predomina. Así, nos propusimos encontrar, en el conjunto de los testimonios relevados, diferentes modelos de narración. Es decir, reconocer diferentes formatos de historia verosímil, a partir de los elementos en común, dicho de otro modo, los núcleos centrales de cada modelo narrativo; por ejemplo, un tipo de narración puede estar centrado en los sufrimientos internos del sujeto que padece la enfermedad; otra, orientado al sentimiento de honra del individuo que se quitó la vida. Cabe destacar que, al elaborar esta tipología, dimos mayor relevancia a la mirada moral sobre el que se quitaba la vida y sus motivos. Es decir, la interpretación moral es la característica principal que permite identificar cada tipo narrativo.

Al mismo tiempo, como veremos, los relatos pueden diferir según el sexo, la edad y el grupo socio-profesional del que se quitaba la vida. De todos modos, en general, hemos identificado que predomina el género como criterio para diferenciar las historias en su conjunto y los roles de los individuos que participaron en el desarrollo de los acontecimientos. Así, había formas de narrar los hechos que predominaban al hablar de los suicidios de los hombres (por ejemplo, que la causa fuera el "mal estado de los negocios", usando un arma de fuego) y otras tramas para explicar lo sucedido a las mujeres (que se sintiera "cansada de la vida" por algún desengaño amoroso). Al mismo tiempo, los guiones sobre los suicidios verosímiles y adecuados a cada género modelaban el comportamiento suicida e influían en el modo de construir el recuerdo del suicida por parte de los deudos. Por esta razón, dimos relevancia al análisis de la construcción de la masculinidad y la femineidad en estas fábulas morales. En segundo término, encontramos variantes de lo narrado de acuerdo con la franja etaria y la ocupación del individuo implicado en los hechos. En este sentido, la experiencia vivida por los jóvenes y los adultos mayores era diferente; por ejemplo, en estos últimos, los problemas expresados eran los dolores causados por la enfermedad, la soledad y la falta de medios para su subsistencia. Asimismo, no era la misma realidad la de un individuo desempleado o sumido en la pobreza y el hacinamiento, que la de comerciantes o propietarios de clase media. Por último, en el contexto de inmigración masiva de la segunda mitad del siglo XIX en Argentina, no dejamos de considerar el factor étnico a la hora de analizar los discursos y elaborar los modelos narrativos que presentamos en 
este trabajo. Sin embargo, consideramos que existían valores y creencias compartidos entre los hombres y mujeres que integraban la sociedad de la época y que, a partir de ese marco axiológico, eran generadas variantes de los diferentes relatos.

Es decir, nuestro objetivo es rescatar los testimonios de los sujetos vinculados a un suicida, y el de este último, para observar cómo se posicionaban unos y otros desde su rol con el otro, con el que interactuaban, y qué valores y creencias morales expresaba la narración que enunciaban. Dicho de otro modo, nos preguntamos: ¿Qué valores morales reflejaba ese discurso / relato? ¿Cómo se representaba el sujeto que lo enunció? ¿Cómo describía la relación con el otro significativo al que apelaba? ¿Cómo se posicionó dentro del contexto social en el que vivía? ¿Qué elementos del marco axiológico colectivo emergían al narrar los eventos? ¿En qué medida reflejaba los valores culturales dominantes de la época?

En síntesis, el análisis cualitativo de los relatos morales nos permite entrever indicios de cómo era comprendida la muerte violenta por mano propia en el contexto cultural en el que estas ocurrieron. Asimismo, podemos identificar algunas características del entorno afectivo y vincular del suicida a una escala micro social. Todos los testimonios, los relatos, fueron elaborados desde el lugar que la persona ocupaba en la vida del difunto / herido, es decir, del tipo de relación social que tenían.

\subsubsection{La red social de contención}

Según Christabel Owens y otros autores (2012), las investigaciones en el campo de la suicidología muestran que las personas que atentan contra sí mismas comunican sus intenciones de diversos modos y a diferentes personas con las que están vinculadas. El mensaje puede ser transmitido de forma directa o indirecta (ironía, pistas, insinuaciones, metáforas, etc.) a los miembros de la red social del suicida. Las formas indirectas son las que pueden confundir a los miembros de la red de contención, que, en algunos casos, no pueden traducir con claridad los signos y señales que perciben. Al tratarse de un asunto incómodo, quien siente que está al borde de la desesperación y de llevar adelante su autoaniquilación suele expresarse de forma ambigua sobre el tema en la interacción social con los otros significativos. En otros casos, el mensaje es transparente y directo, aunque a veces no es tomado en cuenta con seriedad por el 
entorno, por ejemplo, si el sujeto se encuentra bajo el efecto de bebidas alcohólicas. El suicida puede comunicar sus pensamientos, sentimientos, intenciones, amenazas o detalles del plan que piensa llevar adelante para quitarse la vida. Como veremos más adelante, además de encontrar diferentes matices en los significados del suicidio de hombres y mujeres, en los relatos hallamos distintas formas de representar la interacción de acuerdo con el género del que pide auxilio y el de quien recibe el mensaje o provee la asistencia material y emocional.

En este punto de nuestra exposición, nos parece oportuno presentar cómo entendemos el concepto de "red social" y la forma de abordar los distintos lazos que encontramos en las fuentes estudiadas. Podemos definir a la red como el conjunto de vínculos que conectan a diversos individuos en un espacio social y en un período temporal determinado. ${ }^{35}$ Entendemos este entramado relacional como los lazos que vinculan a una serie de actores y grupos sociales entre sí, que permite intercambios materiales e inmateriales, la circulación de información, el otorgamiento de ayuda mutua y el establecimiento de alianzas. Inspirados en el juego de escalas propuesto por los estudios microhistóricos, nos parece relevante una mirada que nos permita conocer las estrategias, las prácticas posibles y las diversas tentativas ensayadas por los actores sociales en diversas situaciones concretas, aportando, de este modo, a la construcción de una mirada dinámica y activa de las acciones de los sujetos, que contemple la comprensión de sus valores y motivaciones. ${ }^{36}$ Es decir, pensar en las experiencias de los sujetos históricos que modelan sus conciencias y analizar las representaciones con las que estos se identificaban al llevar adelante interacciones en contextos diferentes. Como planteó Carlo Ginzburg (2004), buscaremos los indicios, las pistas y las huellas que nos permitan reconstruir las distintas formas de vinculación que establecen los sujetos entre sí. En este sentido, nos proponemos tomar distancia de una imagen determinista y mostrar actores que despliegan estrategias para evitar un desenlace nunca predeterminado, un final trágico y lamentado que podía ocurrir en distintas circunstancias.

\footnotetext{
${ }^{35}$ Para una síntesis y una reflexión teórico-metodológica de los usos del concepto de "red" en Ciencias Sociales, véase, entre otros, RAMELLA (1995); IMIZCOZ (2004); GONZALEZ y BASALDUA (2007); BERTRAND (2016) y REGUERA (2017).

${ }^{36}$ Sobre microhistoria, véase, entre otros, LEVI (1990); REVEL (1995) y GINZBURG (2004).
} 
Cabe aclarar que nuestra intención no es realizar un análisis de estructura de las redes de acuerdo a ciertos parámetros (densidad, centralidad, distancia, etc.) sino, más bien, concentrarnos en identificar la diversidad de los lazos y las acciones de los sujetos históricos en un contexto espacial y temporal definido. ${ }^{37}$ En este sentido, consideramos que lo que el sujeto representaba estaba condicionado por la clase, el género y la franja etaria a la que pertenecía y su insatisfacción con el mundo que experimentaba sucedía en el marco de una serie de relaciones sociales. Por ejemplo, en una parte del capítulo 8, hemos circunscripto el análisis al conjunto de casos referidos a hombres desempleados. Dentro de este subgrupo, seleccionamos los expedientes que relatan los suicidios de los varones extranjeros para estudiar las características de su red de contención. Estos testimonios permitieron entrever diversas estrategias y acciones que los individuos tenían, en primer lugar, para hacer frente a los períodos en los que quedaban sin empleo $\mathrm{y}$, en segundo lugar, las actitudes y prácticas del que sufría la desesperación, las formas de pedir auxilio y las respuestas del entorno frente a estas señales de riesgo.

También cabe destacar que las redes no estaban activas de manera permanente. Ciertos momentos y coyunturas específicas activaban una determinada clase de lazos. En nuestro estudio, buscamos abordar una situación particular. En este sentido, nos interesa observar lo que ocurría con aquellos individuos que trataron de quitarse la vida: a quiénes recurrían, qué estrategias utilizaron para pedir auxilio, cómo respondió el entorno frente al peligro inminente de que uno de los integrantes de su red vincular estuviera al borde de cometer una "resolución extrema", o lo que ocurría luego de sucedido el acto de autoagresión por parte del ego. Así, nos proponemos analizar la red afectiva de contención, es decir, identificar el conjunto de lazos que entraban en juego al momento de que uno de los actores sociales cayera en situación de desesperación frente a la ausencia de alternativas. En esta coyuntura crítica, buscamos identificar una serie de vínculos que brindaban apoyo material y emocional.

Al indagar las acciones del entramado vincular del sujeto, no pretendemos cargar con el peso y la responsabilidad de lo sucedido a los familiares, conocidos y amigos del individuo que llevó adelante un acto suicida. En este sentido, partimos de entender el suicidio como un desenlace posible, no determinado en ningún caso por un

\footnotetext{
${ }^{37}$ Así, cabe aclarar que no pretendemos llevar adelante un análisis del tipo realizado por Mark S. Granovetter (1973), sino identificar y organizar las distintas clases de relaciones que estableció el sujeto que se quitó la vida con personas de su entorno.
} 
factor en particular; pensamos, más bien, que se trata de hechos en extremo complejos en los que confluían variables individuales del sujeto (por ejemplo, las características físicas y psicológicas individuales), y su situación material, además del contexto cultural y social del que se quitaba la vida. Esto no nos lleva a desconocer el rol que la red de vínculos tenía antes, durante y luego de una muerte por mano propia. Las acciones de estos individuos buscaban preservar la vida del otro o, por lo menos, no perseguían como objetivo alentar la muerte voluntaria del que estaba desesperado. Así, encontramos una trama de acciones desplegadas para atender las dificultades, volver más soportable el sufrimiento y encontrar una solución al obstáculo. Una mirada a escala micro nos permite entrever acciones potenciales, derroteros originales y prácticas recurrentes. Existían situaciones verosímiles para el uso de la violencia en general y para la agresión propia; frente a estas situaciones, un conjunto de actores, vinculados de distinto modo con el ego padeciente, buscaba eliminar o aminorar el dolor para hacer más vivible una experiencia que conducía a muchos al agotamiento, el hastío, la locura, el desengaño y la frustración. ¿Cuántos de estos terminaron con la vida? ¿Cuáles fueron los que llevaron adelante su "extrema resolución"? Estos interrogantes escapan a las posibilidades de este estudio. Pero sí podemos entrever las estrategias de familiares, compañeros de trabajo, agentes del estado, del sistema de salud mental e higiene, los amigos y aquellos que apenas o casi nada conocían al que terminaba con su vida. $\mathrm{O}$, al menos, aquello que los testigos consideraban adecuado contar en el momento de comunicar la narración de los hechos a las autoridades, en retrospectiva, algo que no debemos perder de vista al analizar el relato de lo sucedido y que el policía dejó asentado en el sumario. Es decir, lejos de darnos una visión acabada de lo que ocurrió, estos testimonios nos dicen más sobre lo que resultaba verosímil para los contemporáneos (FRADKIN, 1999: 598; MAYO, 1999: 585). Más allá de cuáles fueron los hechos que efectivamente sucedieron, lo interesante es analizar qué situaciones hipotéticas tenían sentido tanto para los testigos que los mencionaban, como para quienes las registraban por escrito. Si bien no podemos comprobar la sinceridad de su narración y de la información brindada, si se trataba de mentiras, éstas, al menos, debían resultar creíbles para quienes las escuchaban, o no serían efectivas; dicho de otro modo, eran relatos posibles para el sentido común de la época, más allá de que estos fueran verdaderos o no (GRINBERG, 2009: 128-129). 


\subsubsection{El otro significativo y la acción comunicativa}

Siguiendo con lo expuesto, entendemos el suicidio como un hecho individual, pero, al mismo tiempo, social. Es decir, una acción que responde a las representaciones del sujeto como individuo y a la manera de representar a los que forman parte de su red social. Según Pierre Moron (1980), la autoagresión y la heteroagresividad (dirigida a un tercero) están conectadas. En este sentido, los suicidios y los significados que les otorgan los que se quitan la vida, en general, estarían relacionados con el vínculo con el prójimo. Según Moron, el motivo esencial es la reivindicación afectiva, es decir: "El sentido del deseo de autodestrucción es esencialmente hacer al prójimo responsable de la muerte: auto y heteroagresividad están indisolublemente ligadas" (MORON, 1980: 125).

Desde nuestra perspectiva, y a partir de lo estudiado en las fuentes, la intencionalidad puesta en el acto suicida implica otras posibilidades. Además de la revancha o venganza, a través de la culpa, consciente o inconsciente, que el suicida busca generar en el otro significativo, las situaciones que hemos observado en la documentación analizada, desde una mirada cultural, son más variadas, así como las intenciones / motivos verosímiles manifestados. Por ejemplo, en algunos casos, el otro significativo carecía de una forma específica, se trataba de alguien indefinido o colectivo, y la intención que manifestaba en la nota que dejó el que se quitaba la vida era la de expresar el sufrimiento. Por otra parte, sí consideramos que la relación con el otro significativo, la persona a la que apela el sujeto con su acción suicida (o su llamado de auxilio), debe ser tomada muy en cuenta a la hora de analizar los testimonios de los actores sociales. Así, interpretamos los suicidios y los mensajes dejados por los suicidas como interacciones con el entorno, ya sea para lograr una respuesta o una actitud en particular, para comunicar / exteriorizar dolor, o para lograr la trascendencia individual a partir del recuerdo de los que integran la red vincular del que se quita la vida. En este mismo sentido, interpretamos los pedidos de auxilio y las interacciones que el sujeto entabló con su red de contención, previo a llevar adelante el acto suicida. En palabras de Moron (1980: 28): "El suicida en potencia da señales de su intención de suicidarse, da avisos, a menudo directos, e incluso explícitos de autodestrucción”. El hombre o mujer 
desesperado/a recurría a los vínculos disponibles para pedir auxilio, apelando a diversas formas de comunicar su sufrimiento.

Por esta razón, encontramos estimulante pensar las muertes por mano propia a partir de la teoría de la comunicación, en línea con lo que plantean autores como Birthe Loa Knizek y Heidi Hjelmeland (2011). Desde esta perspectiva, los suicidios son analizados como acciones comunicativas. Se parte de entender que todo lo que el ser humano hace transmite un mensaje a los demás individuos que forman parte de su contexto social, influyendo en ellos. En este sentido, al lastimarse, los que se agreden a sí mismos están comunicando algo a la red social que integran, o al colectivo. Desde este punto de vista, las muertes por mano propia son fenómenos duales: afectan al que se suicida y a los otros significativos a los que apela. Estos últimos reconstruyen luego de lo sucedido diálogos previos e interacciones. En cierta medida, la muerte por mano propia es ubicada como desenlace y encadenada con la serie de eventos previos. Como señalan Knizek y Hjelmeland (2011), la teoría de la comunicación es pertinente para pensar los suicidios en diversos contextos culturales. En este sentido, el significado de la violencia dirigida hacia uno mismo y de las muertes por mano propia puede ser diferente en distintas sociedades, así como la forma de transmitir las necesidades y los sentimientos a los otros significativos que integran la red social de contención. Hjelmeland (2010) diferencia, al seguir la tipología de L. Qvortrup, cinco categorías para clasificar los actos suicidas desde la perspectiva cultural y comunicativa, de acuerdo con el mensaje que transmiten y el interlocutor al que está dirigido: emocional hacia uno mismo, emocional hacia otros, regulativa hacia otros, regulativa hacia uno mismo y declarativas. En primer lugar, las acciones emotivas dirigidas hacia uno mismo son aquellas en las que el eje del mensaje transmitido por medio del suicidio está vinculado con la imagen negativa del propio individuo, lo que expresa una baja autoestima y falta de amor hacia uno mismo; el mensaje, en la segunda forma de expresión (emocional hacia otros), incluye las manifestaciones hacia los otros significativos y hace mayor hincapié en comunicar el malestar a los que están relacionados con el que se quita la vida. En tercer lugar, las acciones regulativas hacia otros tienen una finalidad retórica e imperativa, es decir, el suicidio es visto como un modo de condicionar a los miembros del entorno relacional; por otra parte, las regulativas hacia sí mismo, son actos característicos de personas que sienten no poder 
cumplir con las demandas de su red social o de su comunidad como colectivo, e, incluso, llegan a castigarse a sí mismos. Por último, las declarativas no implican datos o información sobre los motivos o razones para quitarse la vida, tampoco hay una intención explícita de influir en el entorno, el sujeto, en estos casos, se limita a declarar que ha decidido morir.

El modelo descripto en el párrafo anterior fue desarrollado en un período muy reciente. Nuestro objetivo, a partir de la clasificación de las distintas situaciones narradas en los sumarios judiciales, es el armado de una clasificación que se ajuste a los patrones culturales de la Buenos Aires de la segunda mitad del siglo XIX. Para ello, tomamos la tipología mencionada a modo de hipótesis con el fin de corroborar qué tipo de acciones comunicativas encontramos en los relatos analizados y cuáles predominaban en las notas suicidas abordadas y en las declaraciones de los heridos, según los diferentes temas (locura, amor, honor, etc.) y tipos narrativos identificados. Asimismo, nos proponemos identificar quiénes son los otros significativos a los que dirige su mensaje la persona que se quita la vida de acuerdo con los diferentes roles (madre, padre, hijo/a, pareja, compañeros de trabajo, etc.), y cómo los representaba en las notas y cartas que dejaba. Al mismo tiempo, al clasificar las acciones comunicativas de los actos suicidas estudiados, nos proponemos interpretar las implicancias morales de los mismos y de la actitud que adoptaban los emisores (disgusto / hastío, remordimiento, tristeza, cansancio, temor, etc.). Por ejemplo, en los suicidios relacionados con el sentido de la honra, en qué circunstancias los mensajes regulativos eran hacia uno mismo (expresión de remordimiento) o hacia los otros (denuncia o exposición de una situación considerada injusta).

En síntesis, el que se agredía a sí mismo, en cierta medida, interpelaba al mundo en el que vivía y a los otros con los que interactuaba. A partir de esta perspectiva, consideramos los casos de muerte por mano propia a través de la comunicación que el individuo sin esperanzas intentaba establecer con su red social, y, dentro de esta, con los que identificaba como otros significativos. La forma de acercarse y transmitir su mensaje estaba permeada por un conjunto de principios; dicho de otro modo, estas creencias comunes daban significado a la representación de sí mismo que construía el sujeto y la imagen que tenía de las personas con las que estaba vinculado. De forma análoga, las acciones de los otros significativos ante su llamado de auxilio, o 
la forma en la que estos representaban al que se quitaba la vida, estaban condicionadas por los valores morales del sentido común.

\subsection{Fuentes}

Al estudiar la documentación para llevar adelante nuestra investigación, privilegiamos un enfoque cualitativo, así como la interpretación global dentro del recorte temporal seleccionado. Nuestro objetivo principal fue el relevamiento y análisis crítico de los documentos encontrados a través del paradigma interpretativo, es decir, intentar comprender el sentido que los actores le han dado a sus acciones para "recuperar la perspectiva de los participantes y comprender el significado de la acción en un marco de relaciones intersubjetivas" (VASILACHIS de GIALDINO, 1993: 48).

El trabajo realizado estuvo basado en el análisis de dos fuentes principales: textos científicos y académicos y sumarios judiciales; si bien hemos usado de forma auxiliar otras fuentes, como medios gráficos, censos, literatura, estadísticas de la época, etc. Creemos relevante señalar algunos de los principales aspectos metodológicos que tuvimos en cuenta al emplearlas. En primer lugar, la justificación de los referentes empíricos utilizados (cómo se relacionan con la hipótesis de trabajo y el objetivo de la investigación), la información disponible en cada caso, los usos posibles (tomando en cuenta las investigaciones anteriores sobre el tema) y los problemas y los límites de lo que nos pueden aportar.

\subsubsection{Textos científicos y académicos}

Como vimos en el capítulo anterior, el pensamiento científico (en especial, el médico), en sus distintas vertientes (higienismo, alienismo, criminología, medicina legal), se consolidó como marco de interpretación de los casos de suicidio, entre otros fenómenos del proceso de urbanización de la segunda mitad del siglo XIX. Teniendo en cuenta el creciente prestigio y la legitimidad que tuvieron estos discursos durante el período que analizamos (en especial entre los miembros de las elites), creemos importante consultar las principales publicaciones académicas y tesis universitarias, a 
fin de rescatar la mirada del pensamiento positivista sobre la muerte voluntaria. ${ }^{38}$ Como ya señalamos, además de entender la grilla conceptual de la elite porteña, indagar estos discursos nos permitirá extraer elementos del marco axiológico de quienes los enunciaban.

Ahora bien: ¿qué aspectos deberíamos tener en cuenta al trabajar esta fuente? En primer lugar, nos parece importante prestar atención a los distintos espacios de formación y difusión de estos discursos, así como a la sociabilidad que implicaban. Las relaciones entre los médicos se daban en diversas instituciones (académicas, como las cátedras de la Facultad de Medicina, y gubernamentales, como el Departamento Nacional de Higiene, por mencionar un ejemplo) y en ámbitos de producción de conocimiento científico (como en publicaciones y congresos). A su vez, los vínculos establecidos eran diversos. En algunos casos, se trataba de colegas de una misma institución; en otros, había una línea de maestros y discípulos (en las cátedras y en las residencias en distintas instituciones para acceder al título de grado). También podía darse el caso de que esas vinculaciones aparecieran en el equipo de redacción y asesoramiento de algunas publicaciones. Éste fue el caso de la revista "Archivos de Psiquiatría, Criminología y Medicina Legal”, dirigida por José Ingenieros, que tenía un equipo editorial integrado, entre otros, por el maestro de éste, José María Ramos Mejía (personaje que ocupó cargos claves en la universidad y el estado). Por otra parte, cabe destacar el rol que tuvieron los higienistas al formar a muchos de los médicos que luego tuvieron que realizar los informes médico-legales tras los casos de suicidio. También podemos pensar en la influencia que las ideas expresadas en sus publicaciones pudieron tener, en especial, entre los miembros de las elites en la ciudad de Buenos Aires.

En segundo lugar, acercarnos a estas publicaciones nos sirvió para identificar la presencia del pensamiento hegemónico a nivel mundial (criminología positivista, psicología de las multitudes, alienismo, etc.) y medir el grado de influencia en la elite intelectual porteña. Tanto en los artículos como en las tesis aparecían referencias a distintos profesionales e instituciones (por ejemplo, a la obra del criminólogo Césare Lombroso), que dan cuenta de la recepción que tuvo la escuela italiana en Argentina y América Latina. En este sentido, los saberes de la medicina legal producidos en Francia

38 Varios de los textos médicos que abordaremos en el desarrollo de nuestra investigación fueron utilizados por Marcelo OTERO (1991). En nuestro trabajo, además de volver sobre estas fuentes desde una perspectiva diferente, hemos consultado otras nuevas, como la revista Criminología Moderna. 
y España o los de la psiquiatría francesa, fueron una fuente clave para los profesionales de la salud a la hora de comprender el cambiante y dinámico proceso de modernización.

En tercer lugar, y vinculado con lo anterior, si bien es importante prestar atención a las influencias y a los préstamos intelectuales de los centros hegemónicos a nivel mundial, no debemos perder de vista los desarrollos autónomos y las reelaboraciones del ámbito local. Intelectuales argentinos como José Ingenieros o José María Ramos Mejía eran muy respetados por sus trabajos a nivel internacional y, lejos de repetir, de forma acrítica, el discurso de los referentes europeos, se apropiaron de estos y les hicieron agudas observaciones. Como veremos más adelante, estos científicos elaboraron sus interpretaciones, adaptando los conocimientos producidos en Europa a la realidad local, para enseñarlas y difundirlas, por ejemplo, en los cursos de medicina legal dictados en la universidad.

Con respecto a los límites y a las dificultades en el uso de esta fuente, cabe señalar que esta mirada no es la de toda la sociedad en su conjunto, sino de cierta parte de la elite comprometida con el proceso de modernización de la economía, la sociedad y el estado en el territorio argentino. Es decir, queda por analizar más en profundidad otras interpretaciones e imágenes. En este sentido, creemos válido preguntarnos: ¿hasta qué punto el discurso producido en el ámbito científico y académico era compartido por el resto de la sociedad? ¿Cómo era reelaborado por otros actores? ¿Con qué otras interpretaciones entraban en diálogo o en conflicto? Para responder, al menos, de forma parcial e inicial a estos interrogantes, hemos consultado, por un lado, los sumarios judiciales de la ciudad de Buenos Aires durante la segunda mitad del siglo XIX. Asimismo, también hemos consultado algunos ejemplares de los diarios "La Prensa" y "La Nación", a fin de observar los discursos que circulaban en los medios gráficos dirigidos a un público de lectores más amplio que el de los textos científicos y académicos. ${ }^{39}$

39 Durante las décadas finales del siglo XIX, la cantidad y variedad de medios gráficos tuvo una destacada expansión. De acuerdo con el Censo de la Ciudad de Buenos Aires del año 1887, en la época circulaban 102 periódicos. Una parte de estos estaba compuesta por la prensa política del período, cuyo objetivo principal era promocionar la candidatura o las ideas de un determinado agrupamiento partidario. Por otra parte, algunos órganos de la prensa porteña presentaban un híbrido más moderno entre el panfleto político decimonónico y los diarios de las capitales europeas y las ciudades norteamericanas (ALONSO, 1997: 37-50). Así, estos diarios buscaban mantener una mayor cuota de imparcialidad e impersonalidad a la hora de dar sus opiniones, es decir, estaban más orientados a informar noticias locales, regionales e internacionales. Entre estos, La Nación y La Prensa eran los que tenían la tirada 


\subsubsection{Fuentes judiciales}

La documentación judicial puede ser utilizada con fines diferentes. Los estudios de la historia social de la justicia han empleado este tipo de documentos para reflexionar y comprender cómo ha funcionado la justicia en distintos períodos y regiones, así como las principales transformaciones ocurridas desde la conformación de las instituciones judiciales hasta el presente. Quienes han estudiado estas fuentes desde esta perspectiva han buscado entender la relación entre la justicia y la sociedad, indagando las prácticas y el imaginario de los actores en diferentes períodos (BARRENECHE, 1999; PALACIO, 2005; DI GRESIA, 2011). Así, combinando el análisis cuantitativo y cualitativo de los fondos documentales han contribuido a reconstruir las representaciones de los delitos y las distintas acciones llevadas adelante por las instituciones estatales, prestando atención a la voz de los propios actores que intervenían en estos procesos judiciales. Otro uso posible es la búsqueda arqueológica de significados culturales sobre distintos temas, por fuera de lo relacionado con la justicia y el delito, así como la dinámica de los conflictos en la vida cotidiana. De esta forma emplearemos los expedientes en este trabajo.

Por otra parte, si bien no será el centro de nuestra investigación el accionar de la policía y la justicia ante una muerte violenta, tendremos muy en cuenta estos aspectos de cara a la lectura e interpretación de los documentos. En este sentido, cabe aclarar que

\footnotetext{
diaria más numerosa, 18.000 ejemplares cada uno y, por ende, eran los que tenían mayor circulación (ZIMMERMANN, 1998: 2-3). La Prensa, fundado en 1869 por José C. Paz, representaba claramente esta transición. Aunque no disimulaba sus preferencias políticas, los contenidos que informaba no se agotaban en brindar un apoyo a un determinado candidato o grupo político. En este sentido, La Prensa ofrecía información sobre sucesos nacionales e internacionales, gracias al moderno sistema telegráfico que poseía y a sus corresponsales extranjeros. En 1887, imprimía 18.000 ejemplares por día. Si bien estaba más orientado al perfil político, La Nación, fundado por Bartolomé Mitre en 1870, durante las décadas de 1880 y 1890, también mostró una serie de cambios y novedades análogos a los de La Prensa. No había lugar a dudas de sus alineamientos políticos de las opiniones expuestas en sus columnas, pero también estaba entre sus objetivos el brindar información nacional e internacional. Asimismo, tenía una de las secciones literarias más prestigiosas. Como señala Gayol (2007: 70-71), en general, tanto los periódicos de orientación partidaria, como aquellos que tenían una perspectiva más general, incluían, en sus páginas, información cada vez más diversa relacionada con los intereses de los lectores, por ejemplo, la crónica social y policial. Así, las secciones de diarios como La Prensa y La Nación estaban pobladas de sucesos tales como homicidios pasionales, asesinatos, duelistas, robos profesionales o suicidios publicados bajo los subtítulos "noticias de policía", "Noticias", etc. Para un análisis de las características de los periódicos del período, véase, entre otros, ALONSO (1997); ZIMMERMANN (1998) y GAYOL (2004 y 2007). Sobre el uso de la prensa y los medios gráficos como fuentes para la investigación histórica, véase, entre otros, SAÍTTA (1998); GIRBAL-BLACHA y QUATROCCHI-WOISSON (1999) y LUCA (2008).
} 
el suicidio, en este período, no era penado por la ley. ${ }^{40}$ La legislación argentina sobre este tema pasó por una serie de cambios a lo largo de la segunda mitad del siglo XIX, en los que terminó por primar la tendencia a eliminar las penas para quienes se hubieran quitado la vida o para los que hubieran fallado en su intento.

Sin embargo, aunque el suicidio no fue castigado por la justicia, hasta que no se demostrara que no se trataba de un homicidio, las autoridades judiciales y los agentes de la policía debían investigar las causas de una muerte violenta. De allí la existencia de expedientes judiciales que contienen la investigación sumaria y las declaraciones en casos de suicidio. Estos también incluían, en general, un informe realizado por el médico de policía que establecía la causa de la muerte, si ésta ya se había consumado, o, en las tentativas, determinaba el estado de salud mental del sujeto, además de informar sobre las características y la gravedad de las heridas.

En este trabajo, hemos utilizado los sumarios judiciales de este tipo que tienen información sobre casos ocurridos en la ciudad de Buenos Aires. Los mismos fueron encontrados en el fondo "Tribunal Criminal" de la ciudad de Buenos Aires, disponibles en el Archivo General de la Nación [en adelante, AGN]. ${ }^{41}$

Como toda fuente documental, el trabajo con los expedientes requiere de cierta precaución a la hora de leer e interpretar los testimonios que contienen (GRINBERG, 2009: 122-128). En primer lugar, debemos tener presente el objetivo perseguido en la construcción y producción de la documentación consultada, así como la mediación y el sesgo de los agentes de la policía. Estos eran los que realizaban el interrogatorio y enunciaban las preguntas contestadas por los testigos; y, de acuerdo a sus valores, intuiciones y al rol que cumplían como autoridades, tomaban sus decisiones. Al mismo tiempo, también podía haber tratos diferenciados de acuerdo a los vínculos que el difunto tuviera con la institución policial o el grupo social del que procediera. En este sentido, creemos que algunos habitantes podían evadir el informe médico o hacer figurar como accidente los casos que pudieran pasar desapercibidos. Al mismo tiempo, quienes declaraban sabían que estaban delante de un representante de la autoridad, que indagaba la posibilidad de un asesinato, del que podrían resultar sospechosos si sus

\footnotetext{
${ }^{40}$ Véase, DONNA (1999: 94). También, BLASCO FERNÁNDEZ DE MOREDA (1962); GARDELLA (1968); DI GRESIA (2014: 455, 457, 458-461, 794-797, 799-803, 805-810).

${ }^{41}$ Parte de este material fue consultado por Donna Guy (2014), para estudiar los casos de suicidio de las prostitutas de la ciudad de Buenos Aires entre 1880 y 1900.
} 
respuestas no eran las esperadas.

Por otra parte, si tenemos en cuenta estas precauciones, el uso de estas fuentes presenta una serie de posibilidades muy ricas. En primer lugar, encontramos información sobre el difunto (edad, género, oficio, nacionalidad, estado civil) y su entorno (familiar y, en muchos casos, laboral). Las fuentes judiciales también nos aportan datos para entender esa compleja red de vínculos en la que estaba inmerso el sujeto, como hombre y mujer en su comunidad; o como padre / madre, esposo/a, hijo/a, etc., al interior del grupo familiar.

En segundo lugar, los expedientes judiciales presentan una polifonía de voces: testigos, autoridades, médicos y, en algunos casos, hasta el propio individuo que se había quitado la vida, dejaban su versión de los hechos. Cada uno de los testigos, las autoridades, los médicos, etc. proponía una visión de lo sucedido, de las circunstancias y sus causas. En este sentido, este tipo de documentación nos aporta información sobre lo que era verosímil para los contemporáneos (MAYO, 1999: 585; FRADKIN, 1999: 598). Como ya mencionamos, más que averiguar lo que realmente sucedió, nos proponemos indagar las hipótesis verosímiles imaginadas por los que declaraban y las apreciaciones de los miembros de la autoridad que las sentaban en el sumario. En este sentido, si los enunciados no eran creíbles, no serían tomados en cuenta; por esta razón, las versiones declaradas debían respetar el sentido común de la época. En síntesis, los sumarios judiciales nos proveen de narraciones posibles de casos de suicidio para los que vivían en el contexto histórico y cultural estudiado.

Otra ventaja que poseen las fuentes judiciales es la posibilidad de recuperar aspectos de la vida diaria en el pasado. Como señala Carlos Mayo (1999: 584), estos documentos estatales incorporan la esfera privada. En su interior, muchas veces, quedaban cartas, inventarios, libros de cuentas, que nos abren la puerta al mundo cotidiano y personal de los actores sociales. Éste es el caso de los escritos dejados por aquellos que se quitaron la vida. A este tipo de documentos se los conoce en los estudios sobre suicidios como "mensajes de adiós" o "notas suicidas". Si bien suelen ser pocos (comparados con el total de los expedientes), y descifrar la letra de sus autores, en muchos casos, es todo un desafío, estos escritos nos permiten acceder al complejo mundo de las representaciones de diferentes actores y a la dinámica de los conflictos en la vida cotidiana. Como señala Yonissa Marmitt Wadi (2008: 120-121), en estos 
mensajes aparecía una especie de autobiografía. De estos textos podemos extraer distintos elementos que hacen a la identidad del sujeto que ha decidido poner fin a su vida (por ejemplo, ciertos aspectos relacionados con su género o sus vínculos personales, afectivos y laborales). En estas cartas, también aparecían enunciadas las diversas motivaciones de sus autores, por ejemplo, el deseo de trascender la propia vida, de no ser olvidados, la intención de culpar a los destinatarios de su muerte o de denunciar una injusticia.

Por otra parte, también consideramos relevante observar cómo fueron expuestos los eventos narrados por los testigos y la policía en las páginas de la prensa. Cabe mencionar que los medios gráficos daban una gran difusión a los casos de suicidio en este período. En la sección "noticias" o "noticias de policía", tanto "La Prensa" como "La Nación” informaban los casos de suicidio en la capital del estado argentino, de otras partes del país y, algunas veces, de otras regiones del mundo. La cantidad y el tipo de información en cada situación variaban. En algunas noticias aparecían detalles sobre la motivación, el medio utilizado, datos referidos al difunto y su entorno, la investigación policial y el diagnóstico médico, llegando incluso a publicar las cartas y mensajes dejados por quienes se quitaban la vida. En otros, la información era más escueta. Además de ciertos aspectos de las historias de vida de los suicidas, y las circunstancias en que estos hechos habían ocurrido, las noticias nos aportan elementos sobre cómo era presentado a la sociedad. Esto nos permite pensar y reflexionar sobre lo que resultaba verosímil para los lectores y la imagen que los medios construían sobre el suicidio. En este sentido, al difundir estos datos, la prensa transmitía su versión de las historias de quienes ponían fin a su vida. Por ejemplo, cuáles eran los medios más comunes para suicidarse o si había formas de hacerlo asociadas con lo masculino y lo femenino. Por otra parte, las ideas manifestadas por los cronistas de diarios y periódicos nos permiten observar los valores y las creencias de estos y el marco axiológico compartido con otros miembros de la comunidad. Examinar cómo se presentaba la información (el tono, la valoración más o menos negativa del suceso, las acotaciones sobre el medio utilizado y las causas expuestas), qué era mencionado u omitido, y comparar estas narraciones con las presentes en los sumarios judiciales, puede proporcionarnos una perspectiva de las distintas formas de representar la muerte voluntaria por parte de distintos actores sociales, así como el impacto que los actos suicidas tenían en la opinión pública. 
En síntesis, teniendo siempre en cuenta las particularidades que hacen a la elaboración de los sumarios judiciales, creemos que trabajar con los mismos nos aporta valiosa información sobre las categorías que usaban distintos actores para entender el suicidio, cuáles eran las explicaciones verosímiles para la sociedad de la época que estudiamos y qué valores explícitos e implícitos estaban en juego a la hora de reflexionar sobre la muerte voluntaria de un miembro de la comunidad.

\subsection{Consideraciones finales}

En este capítulo, nos propusimos realizar una exposición de los aspectos metodológicos y empíricos generales de nuestra investigación. En la primera parte, nos ocupamos de presentar las ideas y conceptos claves que articulan la metodología empleada en este trabajo. Como destacamos en un principio, nuestra principal inquietud fue analizar las características de las representaciones relacionadas con el suicidio en Argentina durante el último tercio del siglo XIX, tomando como caso la ciudad de Buenos Aires. Lejos de entender estas ideas y creencias como un reflejo pasivo de la realidad en las conciencias, las pensamos como un elemento activo que intervenía en las decisiones de los actores sociales que estudiamos. Dada la poca investigación previa sobre el tema, el énfasis en el desarrollo de los capítulos estará puesto en la descripción de estas representaciones, por medio de una lectura más cualitativa que cuantitativa del material empírico.

Tras una muerte violenta por mano propia, las personas vinculadas al suicida debían procesar lo sucedido, transitar por emociones aflictivas y, al mismo tiempo, dar cuenta de lo sucedido a las autoridades. Como mencionamos al principio, pocos tienen la experiencia de padecer la más intensa desesperación; explicar este sentimiento era un desafío para los que debían contar la biografía del suicida. Además, encontraban la dificultad de rescatar la memoria del ser querido y de elaborar el balance sobre la responsabilidad propia en lo sucedido. Llevar adelante la narración de los hechos era una acción discursiva que buscaba dar un significado a una situación límite que rompía con la vida cotidiana de los afectados. En los documentos estudiados encontramos historias que se cruzan, fábulas morales que nos hablan de los ideales que guiaban la vida de hombres y mujeres durante la segunda mitad del siglo XIX. Diversos temas 
podían ser abordados en estas narraciones (de acuerdo con la "causa determinante" imaginada). Los que consideramos más relevantes y representativos fueron los que utilizamos para clasificar y agrupar las distintas historias relevadas. A su vez, en cada unidad temática, nos propusimos identificar los diferentes tipos narrativos que subyacen en la diversidad y variedad de tramas particulares. En este sentido, el criterio que permitió diferenciar los distintos modelos de narración fue el papel de los valores morales y las creencias manifestadas por los actores sociales, es decir, los elementos del marco axiológico manifestados, de forma explícita o implícita, en los discursos enunciados.

Ninguna persona que pasaba por la experiencia de la desesperación y la vivencia final de quitarse la vida transitaba su existencia aislada; participaba de la vida colectiva, formaba parte de una red social. Esta podía actuar como medio de contención, material y/o afectiva, según el caso. Asimismo, el suicida recurría a los integrantes de este entramado vincular, para manifestar sus problemas, su sufrimiento o sus intenciones de terminar su vida por medio de la auto-agresión. Los relatos, a veces, dejaban huellas, indicios, de las interacciones llevadas a cabo antes del acto suicida.

Dentro de la red social de contención, se encontraban los otros significativos a los que apelaba el que se quitaba la vida en sus cartas. Entendiendo los suicidios como acciones humanas, que, además de implicar un intenso dolor individual, tienen un mensaje implícito para algunos de los miembros de la red social del suicida, nos propusimos identificar estos vínculos y analizar la relación entre la actitud del que se quita la vida (hastío, tristeza, temor, etc.) y los principios morales de la sociedad de la época.

Para alcanzar estos objetivos, hemos recurrido a dos fuentes que cubrieron diferentes necesidades en el desarrollo de nuestro estudio, éstas fueron el eje de la segunda parte de este capítulo. En primer lugar, los textos que difundían las ideas del saber médico, psiquiátrico y criminológico que nos aportan una primera serie de discursos sobre el suicidio en nuestro período. Como analizaremos en los capítulos siguientes, estos enunciados tenían una importante legitimidad en la época, en especial, entre los miembros de las elites comprometidos con el proceso de modernización. Como ya mencionamos en el capítulo anterior, creemos que dentro de las ideas higienistas había un conglomerado de valores y creencias compartidos por una amplia cantidad de 
miembros de las elites porteñas. Por otra parte, estos discursos tenían su influencia no sólo en la formación de profesionales de la salud, sino también en los agentes de la policía y el poder judicial, entre los que había médicos también. Si bien no es nuestro objetivo central analizar y medir el grado de influencia alcanzado entre los miembros de las instituciones del estado, debemos tener presente que este discurso circulaba entre estos en la época, sobre todo, por la exigencia del informe del médico de policía en los sumarios. Esto no implica desconocer la importancia de una reflexión sobre otro grupo de argumentaciones, como las enunciadas desde el ámbito religioso, o las discusiones desde el punto de vista jurídico. Creemos importante comparar estas ideas sobre la muerte voluntaria provenientes de discursos que se encontraban en diálogo, ya sea por sus coincidencias o por aquello que los enfrentaba. En este sentido, la consulta de legislación y publicaciones jurídicas, así como de prensa religiosa y documentación eclesiástica, nos puede aportar cierta información sobre cómo entendían la Iglesia y la Justicia a la muerte voluntaria. Estos estudios quedarán pendientes para trabajos futuros, si bien haremos alguna referencia a la postura de las autoridades religiosas y judiciales.

Para recuperar el testimonio de otros actores, sin el filtro de la mirada de los miembros de las elites, aunque sea de forma parcial y fragmentada, recurrimos al uso de los expedientes producidos por las instituciones policiales y judiciales durante los sumarios. Como destacamos antes, estos documentos nos permiten acercarnos al mundo más cotidiano de quienes ponían fin a sus vidas. Así, podemos leer los testimonios de familiares, amigos, compañeros de trabajo; analizar las explicaciones, las especulaciones y los intentos por adentrarse en las emociones de los que habían decidido darse muerte por mano propia; rescatar el sentido y la valoración otorgada a los distintos casos de suicidio entre diferentes actores. Si bien raros y dificultosos en su interpretación, creemos que valió la pena detenerse en las notas suicidas, ya que nos dejaron conocer algunos fragmentos de la vida, las emociones y los valores que daban sentido a las acciones de los que decidían quitarse la vida. Cabe remarcar que nuestra perspectiva de análisis de la muerte voluntaria estuvo enmarcada en una mirada social y cultural, no entrando en un enfoque psicológico del tema. De este modo, nuestro objetivo, al consultar estos casos, fue la búsqueda de aquellas representaciones que quienes se suicidaban compartían con sus grupos sociales de pertenencia y con la sociedad en su conjunto. 
En síntesis, de la documentación consultada relevamos aquellos discursos y enunciados que tenían el peso suficiente para aparecer invocados como justificaciones en las acciones de aquellos que decidían poner fin a su vida, o de aquellos que trataban de explicar dichos actos. Como destacamos, lejos de entender las razones reales que llevaron a suicidarse a muchos individuos, nuestra intención fue entender lo que era verosímil para los hombres y mujeres de Buenos Aires en las décadas finales del siglo XIX y las características del marco axiológico durante el avance de la modernización.

En los capítulos siguientes, expondremos, de forma general, este proceso y su impacto en la estructura urbana de la capital del estado argentino y en la vida de sus habitantes. Al mismo tiempo, también introduciremos aquellos elementos del clima de ideas que estaban relacionados con la comprensión de los suicidios desde un punto de vista científico y jurídico. 


\section{Segunda Parte}

Contexto histórico: aspectos culturales y transformaciones políticas, sociales $y$ económicas 


\section{Capítulo 3: El clima de ideas}

No podremos entender las interpretaciones del suicidio (como fenómeno social e individual, o como problema axiológico) sin presentar antes, de manera breve, el entramado ideológico de la época que estudiamos.

En paralelo a la pérdida de autoridad del saber religioso, la ciencia se convirtió en el marco interpretativo legítimo de la realidad. Las décadas finales del siglo XIX, en especial, fueron un momento de auge del cientificismo. Las disciplinas científicas no sólo explicaban los fenómenos biológicos, sino que también ambicionaban alcanzar la comprensión del funcionamiento de la sociedad como organismo. Las distintas ramas del saber, como la higiene pública, el alienismo o la criminología buscaron dar explicaciones de los cambios en el mundo urbano, entre otros, del creciente aumento de la tasa de suicidios.

Conocer los elementos principales de estos discursos, así como el ámbito en el que fueron producidos, nos permitirá abordar el contexto intelectual en el que los suicidios se volvieron motivo de preocupación y objeto de reflexión por parte de la elite cultural.

\subsection{Auge del positivismo}

El siglo XIX fue un período de expansión del conocimiento científico. Ésta no surgió en el vacío, fue parte de un proceso que puede rastrearse, al menos, desde el Renacimiento en el siglo XVI (GALAFASSI, 2001). Los avances en astronomía de Nicolás Copérnico, Johannes Kepler, Galileo Galilei; el pensamiento de filósofos como René Descartes o Francis Bacon; o los descubrimientos de Isaac Newton son buenos ejemplos de cómo los modernos trataron de comprender los fenómenos naturales. Estos científicos y pensadores tenían como objetivo entender las causas de la realidad, encontrar sus regularidades y formular leyes. Para el siglo XVIII, ya había, entre los hombres ilustrados, un consenso sobre una serie de principios: la fe en la razón por encima de cualquier conocimiento heredado del pasado; la convicción de que los hombres serían capaces de dominar la naturaleza; y la confianza de que los seres humanos lograrían perfeccionarse hasta lograr la felicidad. Un ejemplo de este espíritu liberal ilustrado fue Alexander Von Humboldt, quien viajó por América del sur recabando información geográfica, botánica, zoológica, geológica, social y cultural del 
continente (ETTE, 2000). Los aportes de estos naturalistas también alimentaban esta perspectiva optimista sobre el destino de la humanidad y la capacidad de la ciencia para sostener un progreso sin límites.

Esta ideología alcanzó un consenso pleno durante el siglo XIX. A ello contribuyeron en buena medida las ideas de la revolución francesa, los desarrollos científicos y técnicos, los logros de la revolución industrial, el aumento del bienestar, la comodidad y la seguridad de las elites, el liberalismo, la alfabetización y la educación, y los avances de la democracia. Como señala Jacques Le Goff (2005), estos adelantos de la ciencia generaron, primero, un gran entusiasmo en la sociedad decimonónica, luego, su aceleración provocó un cierto temor, hasta que su estancamiento hizo decaer la fe en el saber científico durante el cambio de siglo. Sin embargo, mientras duró el auge del cientificismo, éste llegó a englobar a todas las esferas del conocimiento, inclusive, el saber sobre los seres humanos y la sociedad.

La aparición de las ciencias sociales fue una ampliación de los objetos estudiados por medio del método científico. En este sentido, la ciencia era una sola y, por ende, el punto de partida era el mismo. De este modo, estas disciplinas tomaron como modelo a las ciencias naturales y se plantearon como objetivo el relevamiento de datos empíricos para encontrar leyes. Por ejemplo, Auguste Comte imaginó a la sociología como una física de lo social.

La doctrina de Comte fue una referencia entre los intelectuales latinoamericanos. Como destacó Charles Hale (1991: 14-15), este paradigma cognitivo no era novedoso para el siglo XIX, salvo por el propio término "positivismo" y su enunciación de forma explícita y ordenada, aparecida en el Cours de philosophie positive. Según esta forma de entender el mundo, para construir un conocimiento verdadero había que llevar adelante una observación objetiva y la experimentación en la realidad empírica, siguiendo los pasos del método científico, para alcanzar leyes generales. En el camino que iba de las ciencias simples a las más complejas, el estudio de la física social, la sociología, era una de las ambiciones del pensamiento positivista. Para Comte la sociedad era entendida como un organismo en el que los sujetos estaban determinados por el medio material y social. La metáfora organicista de lo social se combinó con el concepto de evolución. Así, existía la convicción de que las sociedades evolucionaban hacia mayores grados de civilización. 
Durante el siglo XIX, el evolucionismo ganó adeptos, ocupando un lugar privilegiado dentro de la cosmovisión de los intelectuales de la época. Hasta entonces, había dominado la perspectiva del "fijismo", que veía en la naturaleza una creación divina, la que no modificaba su esencia, y sólo bastaba describirla y clasificarla, como hizo en sus estudios el naturalista sueco Carl von Linneo (1707-1778). Para las posturas transformistas, por otra parte, el cambio tenía un valor positivo. Un ejemplo de este punto de vista lo encontramos en la obra del naturalista francés Jean Baptiste de Monet, caballero de Lamark (1744-1829), quien propuso pensar en los cambios de los seres vivos como una forma de superar los obstáculos del medio (GALAFASSI, 2001).

La teoría más influyente sobre la evolución, y que mantiene su prestigio hasta el día de hoy, fue la de Charles Darwin. En su primera obra, El origen de las especies (1859), estudió la biología evolutiva de plantas y animales. Para explicar los cambios en los seres vivos, apeló a la combinación de una serie de variables: la variación en las características particulares, la herencia de algunas de las cualidades de una generación a la siguiente, el cambio en las condiciones ambientales (el medio) y el proceso de selección natural. Sólo los que resultaban más aptos sobrevivían en la competencia por los recursos que ofrecía el medio y transmitían sus atributos a las generaciones siguientes. Darwin estuvo inspirado en las ideas de Thomas Malthus, quien sostenía que la población crecía más rápido que los alimentos necesarios, lo que llevaba a una lucha por la vida, en la que sólo sobrevivían los más fuertes (GALAFASSI, 2001).

El concepto de evolución enunciado por Darwin contribuyó a sostener la ideología del progreso, que alcanzó un alto grado de legitimidad entre 1840 y 1890, en paralelo con el despegue económico e industrial del mundo occidental (GALAFASSI, 2001; LE GOFF, 2005). Sin embargo, el naturalista británico no aplicó sus teorías a los fenómenos sociales. Sería Herbert Spencer quien enunciaría el marco teórico de la evolución para el estudio de las sociedades humanas. Según su teoría del cambio social, los grupos humanos evolucionaban desde organizaciones simples y primitivas, atravesaban una serie de estadios, y las llevaban, de forma lineal, al punto más civilizado, como ejemplo se presentaba el caso de la Inglaterra del siglo XIX. Cada sociedad era un organismo biológico, con estructuras y funciones; la lucha por la vida era sinónimo de progreso social. De la teoría de Spencer provenía un concepto que aglutinaba las preocupaciones y problemas que aparecían en los diagnósticos y proyecciones de los intelectuales sobre la realidad latinoamericana: la raza. Este término reunía dos dimensiones principales. Por un lado, contemplaba las características 
culturales de las sociedades humanas (costumbres, prácticas religiosas, instituciones políticas, por ejemplo), así como las propiedades físicas y biológicas heredadas de generación en generación en cada grupo humano. Estos caracteres, entre otros (como la historia, la literatura, la lengua y la geografía), eran los que permitían explicar el avance o el atraso de las sociedades en su proceso de evolución hacia la civilización europea. Muchos ensayos o análisis de la realidad latinoamericana estuvieron dedicados a los problemas sociales y políticos que ponían en riesgo el correcto proceso evolutivo de la raza. Así, la interpretación spenceriana de la evolución para analizar las formaciones sociales fue muy influyente en los ensayos sobre la realidad socioeconómica y política de América Latina en la segunda mitad del siglo XIX (HALE, 1991: 26).

En síntesis, el creciente prestigio de las ciencias naturales, de las teorías evolucionistas y del pensamiento de intelectuales europeos, como Comte o Spencer, contribuyó a crear la representación de la sociedad como un organismo social, que avanzaba en el camino hacia la civilización. Durante la segunda mitad del siglo XIX, el pensamiento de las elites en el poder, en América Latina, estuvo guiado por el ideario liberal. Sin embargo, como señala Hale (1991), paulatinamente, el liberalismo, sin perder todavía su prestigio y hegemonía, fue dejando lugar a otras ideas, como las del pensamiento de cuño positivista. Junto con la sensación de estar experimentando el fin de los tiempos, característica del decadentismo del final del siglo XIX, el auge de la ciencia positivista fue el marco desde el cual los intelectuales pensaron el conjunto de cambios sociales, políticos y económicos que la realidad latinoamericana estaba experimentando.

La elite política y cultural argentina también fue influenciada por este clima de época. ${ }^{42}$ Así, participaron del mismo entusiasmo y espíritu cientificista. Esto fue alentado por los desarrollos científicos en las décadas de 1870 y 1880 por parte de figuras destacadas como Florentino Ameghino. Los fenómenos sociales también fueron interpretados a partir del biologismo: los hechos del organismo social eran, en última instancia, de la misma naturaleza que los biológicos, sólo que más complejos. Si no había diferencias entre la realidad estudiada por las ciencias, el método era el mismo para las disciplinas naturales y las que estudiaban a la sociedad y la cultura, y ambas tenían el mismo horizonte: enunciar leyes generales. Estos principios también habían

\footnotetext{
${ }^{42}$ Para un estudio de las ideas científicas, políticas y sociales en Argentina durante las décadas finales del siglo XIX y las primeras del XX, véase, entre otros, SOLER (1968); BIAGINI (1985); HALE (1991); BOTANA y GALLO (2007) y TERÁN (2010).
} 
estado presentes en la generación del '37, pero el contexto era diferente. Mientras que los románticos habían dedicado sus esfuerzos a fines prácticos y políticos (la construcción y consolidación del estado), los miembros de la generación del '80 tuvieron un perfil más académico y universitario y, en cierta medida, pudieron dedicar más tiempo al desarrollo de las ciencias.

Como señaló Ricaurte Soler (1968), el positivismo en Argentina fue una etapa cultural que influyó tanto en la actividad científica como en la artística y cultural en general. En este sentido, los autores literarios también fueron imbuidos por el cientificismo e inspirados por el naturalismo francés. Más que las consignas políticas de Émile Zolá, los autores naturalistas en el Río de la Plata imitaron las técnicas y las formas para describir las escenas y los espacios, en los que por momentos aparecían elementos de una sensibilidad romántica que todavía perduraba (AVELLANEDA, 1980: 145-146). El rasgo central de la novela naturalista era su vocación de dar un relato que pudiera destacarse por su objetividad y realismo en la narración de los hechos. Debido a la influencia de las ideas científicas en boga (en especial de las ciencias naturales), las obras naturalistas tendían a presentar a los sujetos determinados por el medio ambiente, en particular, por el mundo urbano finisecular. Al igual que en los estudios médicos de la época, los personajes de las obras estaban determinados por las leyes de la herencia, por sus instintos y tendencias, y no podían escapar de la influencia ineludible y aplastante del medio. Por esta razón, al realizar una descripción minuciosa de las situaciones ponían mucho cuidado, como si se tratase de un experimento científico; el relato, al recrear las condiciones que habían generado los hechos narrados, servía como una prueba o evidencia para justificar la interpretación de la realidad observada y presentada en la obra.

No hay dudas de que el evolucionismo gozaba de un importante grado de aceptación por parte de los positivistas argentinos. Sin embargo, la forma de interpretar la evolución no era la misma en todos los especialistas. En este sentido, según Soler (1968), hubo una serie de autores que representaron una corriente de positivismo rioplatense original, alejada tanto de las ideas del comtismo como del modelo teórico de Spencer. Intelectuales como Carlos O. Bunge o José Ingenieros expusieron la importancia de la experiencia individual y colectiva en el desarrollo de la evolución de las sociedades nacionales, sin apelar al intelectualismo o al determinismo mecanicista. Así, la concepción individualista del evolucionismo social de Spencer no era el marco de referencia que seguían estos renombrados científicos y escritores. Otros, como José 
María Ramos Mejía, interpretaban la transformación de las sociedades a lo largo de la historia argentina de una forma más similar a la del reconocido intelectual inglés. Por ejemplo, en Las multitudes argentinas (1899), al igual que en la obra de Spencer, las metáforas organicistas eran frecuentes, refiriéndose a la multitud como el protoplasma que podía sobrevivir y regenerarse si alguna de sus partes moría o desaparecía (ya que, sin ser ninguno de los dos, tenía la resistencia de los sólidos y la fluidez de los líquidos). También, de manera análoga al individualismo metodológico spenceriano, Ramos Mejía explicaba la fisiología de la multitud partiendo del "hombre carbono", esa unidad mínima que se agrupaba para conformar las revueltas, las turbas y las agitaciones ocurridas a lo largo del pasado argentino. En este sentido, desde una mirada determinista, entendía el proceso histórico como resultado de las acciones individuales no planificadas, dejando en segundo plano los efectos del colectivo como totalidad.

Más allá de estas particularidades, los intelectuales argentinos de fines del siglo XIX compartían la adhesión a los postulados generales del evolucionismo e imaginaban a la sociedad como un organismo que había cambiado a lo largo del tiempo. La metáfora organicista estuvo presente en los estudios sociales de la época, que intentaron comprender los problemas que surgieron como consecuencia del creciente aumento demográfico, el progreso material y el acelerado proceso de urbanización.

\subsection{Los liberales reformistas y la "cuestión social"}

El proceso de modernización, iniciado en la década de 1860, trajo sus consecuencias en el Río de la Plata, como en el resto del globo. Entre ellas, tras la llegada masiva de un número creciente de inmigrantes, se desencadenaron los problemas, producto del proceso de urbanización, como la necesidad de acceso a la vivienda, la cobertura de atención médica y la búsqueda de medidas para garantizar la salud pública en general. Cabe recordar, para dimensionar la magnitud del fenómeno, que Buenos Aires pasó de 187.100 habitantes en 1869 a tener una población de 1.575.000 en 1914 (SURIANO, 2004: 3). Tanto para la elite política como para los intelectuales y profesionales, el impacto de los cambios demográficos y sociales planteó un serio desafío en varios campos, que iban desde la salud pública al aumento del delito y la protesta de la clase obrera. La expresión "cuestión social", lanzada a fines del siglo XIX, fue utilizada para referirse a estos disfuncionamientos que se habían producido con la transformación socio-económica del país (LOBATO, 1996: 13). 
En paralelo con los cambios y transformaciones de la segunda mitad del siglo XIX, el estado nacional consolidó una serie de instituciones (sanitarias, educativas, militares, policiales, etc.), encargadas de administrar los asuntos públicos y el ejercicio de la coerción. Para ponerlas en funcionamiento, las autoridades atrajeron a diferentes profesionales -abogados, médicos, ingenieros y profesores universitarios-, que ingresaron en las instituciones públicas; algunos, muy reconocidos por sus carreras en el campo profesional, académico e intelectual, como José María Ramos Mejía y Emilio Coni (en la Asistencia Pública de Buenos Aires), Augusto Bunge (en la Sección de Higiene Industrial del Departamento Nacional de Higiene), José Ingenieros (en el Instituto de Criminología de la Penitenciaría Nacional), José N. Matienzo y Marco M. Avellaneda (los dos primeros presidentes del Departamento Nacional del Trabajo, quienes promovieron la incorporación de graduados de la Facultad de Derecho en esa área) (ZIMMERMANN, 1995: 72). Otros profesionales ingresaron a las instituciones por sus contactos, por ejemplo, con diferentes profesores de las cátedras universitarias. La formación de funcionarios especializados, poseedores de un cierto saber para el manejo administrativo, surgió como producto de las necesidades de las nacientes instituciones estatales. A medida que finalizaba el siglo XIX y comenzaba el XX, entre los profesionales implicados en estas ramas de la administración pública, comenzaron debates que giraban alrededor de los problemas relacionados con la llamada cuestión social (ZIMMERMANN, 1995: 35). Tras la crisis de 1890, el diagnóstico de la situación elaborado por estos intelectuales, funcionarios y políticos, apuntó al grave deterioro moral que estos identificaban en la sociedad de su época. Desde su perspectiva, la cuestión social estaba vinculada con el supuesto resquebrajamiento de la moral pública, que no permitía la constitución de un sistema político "sano". Para solucionar esta situación, académicos de diferentes áreas proponían la reforma moral, política y social de la nación (ZIMMERMANN, 1995: 68-70).

Entre estos profesionales circulaban las ideas de las ciencias sociales del período (como la criminología, la higiene social y la sociología), que estaban en línea con el pensamiento evolucionista, que ponía énfasis en los conceptos de raza y herencia biológica. En su mayoría, eran (en términos políticos) liberales conservadores a favor del parlamentarismo y contrarios a cualquier clase de reforma radical o revolucionaria. Para resolver los problemas relacionados con la vivienda, la salud pública, la criminalidad urbana, las movilizaciones obreras y las corrientes ideológicas consideradas problemáticas, en especial, el anarquismo, estos intelectuales pensaban en 
un mayor intervencionismo estatal sin llegar por eso a una revolución armada o a un cambio rápido y profundo en el corto plazo (ZIMMERMANN, 1995: 15-17). Por otra parte, los conocimientos de los científicos positivistas no sólo los legitimaron ante el estado, o sirvieron para comprender el fenómeno de las epidemias, la inmigración, la locura y el delito, sino que también fueron una fuente de autoridad ante las elites económicas como los estancieros, por ejemplo, frente al ingreso, para mejorar la calidad de sus rebaños, de animales que sufrían de tuberculosis. La bacteriología, en este sentido, fue el principal saber que consolidó, como empleados y funcionarios estatales, a los profesionales de la salud (SALESSI, 1995: 47), sobre todo si tenemos en cuenta el impacto que las epidemias tuvieron en los cuerpos y el imaginario de la población durante la segunda mitad del siglo XIX.

Los médicos, como otros profesionales, no se limitaron a interpretar los problemas sociales, también interpelaban a las autoridades y a las instituciones del estado para que intervinieran y solucionaran los asuntos relacionados con la salud de la población. Si, por un lado, estaban vinculados con el mundo de la elite, buscaban convertirse en la voz de los más necesitados (VEZZETTI, 1985: 37). En este sentido, su perfil solía combinar un costado político y otro relacionado con la participación en asuntos relacionados con el bienestar del colectivo. En muchos casos, durante la segunda mitad del siglo XIX, varios profesionales de la salud fueron también funcionarios públicos $\mathrm{y} / \mathrm{u}$ ocuparon cargos políticos, además de continuar con su actividad académica. Por ejemplo, Eduardo Wilde, desde posiciones claves de la burocracia estatal, promovió una ideología y una política higiénica, fue un escritor prolífico, que difundía su pensamiento en la prensa de la época o en las Cámaras del Congreso (SALESSI, 1995: 80), al tiempo que dictaba clases en la Facultad de Medicina. Si bien el estado requería de la asistencia de los médicos, al mismo tiempo, la profesión médica, durante la segunda mitad del siglo XIX, dependió, para su legitimación, en gran medida, del poder del estado. Mediante negociaciones y conflictos, la elite de médicos diplomados contribuyó a la creación y consolidación de instituciones públicas, al tiempo que afirmaba su posición y su legitimidad ante la clase gobernante y la sociedad (GONZÁLEZ LEANDRI, 1996: 27). En un contexto donde predominaban esos otros sin títulos habilitantes, los llamados curanderos y curanderas, y escaseaban los médicos diplomados; donde había una reducida demanda de la medicina científica fuera del pequeño reducto de la elite en el mundo urbano; y otros grupos, como los farmacéuticos, pugnaban por el prestigio y la influencia, el 
reconocimiento de la corporación médica estuvo vinculado a la construcción y consolidación del estado y sus necesidades. Con su credo higienista y antiepidémico, los médicos participaron de la incipiente policía sanitaria de gobiernos nacionales, provinciales y municipales no muy afianzados, con atribuciones confusas y superpuestas y carentes de los medios materiales y organizativos necesarios (GONZÁLEZ LEANDRI, 1996: 33-34).

La segunda mitad del siglo XIX fue un período de expansión de la actividad estatal en materia de higiene y salud pública (ZIMMERMANN, 1995: 101). Tras la caída de Juan Manuel de Rosas, las nuevas autoridades de la provincia de Buenos Aires crearon una serie de instituciones que debía reflejar el progreso que llevaban por bandera. Estas fueron la Facultad de Medicina, el Consejo de Higiene (luego denominado Departamento Nacional de Higiene) y la Academia de Medicina. Al Consejo de Higiene Pública le fueron asignados "el control de vastas áreas consideradas de incumbencia médica y de cuestiones que respondían a sus intereses más específicos, como la vigilancia del ejercicio médico y farmacéutico y la persecución del curanderismo" (GONZÁLEZ LEANDRI, 1996: 29). Sin embargo, en el tercer cuarto del siglo XIX, el estado todavía tenía poca capacidad para llevar adelante políticas concretas en relación con el tema de la salud y el ejercicio de la medicina. El crecimiento y desarrollo de las facultades de inspección y control de organismos estatales en estos temas se dio, en especial, luego de las epidemias de fiebre amarilla (1871) y de cólera (1867-1868 y 1886-1887). Sin embargo, las principales estrategias y posibilidades aparecieron a partir de 1880 , cuando la influencia de la esfera estatal en estos asuntos inició el camino de la consolidación (GONZÁLEZ LEANDRI, 1996: 26). ${ }^{43}$ Un ejemplo de esto fue la creación de la Asistencia Pública en 1883, tras la federalización de la ciudad de Buenos Aires. Esta institución fue pensada para velar por la salud de la población y encarar las situaciones que atentaran contra la higiene en el ámbito de la ciudad de Buenos Aires (GONZÁLEZ LEANDRI, 2006: 49). Otro ejemplo fue la concreción, entre 1874 y 1892, de grandes obras sanitarias (relacionadas con la circulación de agua potable y los desechos, así como reformas en el puerto) en Buenos Aires, que requirieron importantes inversiones de capital, que el estado financió con endeudamiento externo (SALESSI, 1995: 21). Las obras públicas emprendidas por

\footnotetext{
${ }^{43}$ Aunque no debemos olvidar que la salud de la población era atendida tanto por instituciones públicas (la principal, la Asistencia Pública de Buenos Aires), como por iniciativas privadas o filantrópicas (entre ellas, las asociaciones de inmigrantes o las instituciones de la iglesia) (ZIMMERMANN, 1995: 105).
} 
compañías privadas, primero, y por la Comisión de Obras de Salubridad, después (más tarde Obras Sanitarias de la Nación), lograron un efecto positivo en las condiciones higiénicas de la ciudad de Buenos Aires. Esto se vio reflejado en la caída de la tasa de mortalidad, en especial, en las muertes por enfermedades infecciosas (ZIMMERMANN, 1995: 101-102). Detrás de estos proyectos estuvieron médicos como Guillermo Rawson, José María Ramos Mejía o Emilio Coni. Éstas no fueron las únicas iniciativas en las que participaron los profesionales de la salud. Su intervención tuvo impacto en la reforma y modernización del ejército, la policía, la educación y las instituciones de la salud mental, entre otras ramas de la administración pública.

Otras instituciones contribuyeron a canalizar las aspiraciones profesionales de los médicos y sus demandas respecto de la producción y enseñanza de los conocimientos en los espacios de formación académica. Las carreras de Emilio Coni, Lucio Meléndez, Ramos Mejía o Samuel Gaché, entre otros, se dio dentro del marco de instituciones estatales (como la Asistencia Pública o el Departamento de Higiene), aunque también a través de la participación en sociedades médicas, como el Círculo Médico Argentino, o la producción de artículos y ensayos publicados en revistas especializadas, como la "Revista Médico Quirúrgica” (GONZÁLEZ LEANDRI, 2004: 239-241), que desde 1875 se presentaba como el "órgano de los intereses médicos argentinos" (VEZZETTI, 1985: 31). ${ }^{44}$

Hacia fines de siglo, dos sociedades médicas, el Círculo Médico Argentino y la Asociación Médica Argentina, se disputaban el prestigio y el liderazgo. La primera fue, en sus orígenes, una institución que promovió, a comienzos de la década de 1870, los cambios en la estructura y sociabilidad médicas y la renovación de los conocimientos en las instituciones académicas (GONZÁLEZ LEANDRI, 2004). Nucleados alrededor de la figura de José María Ramos Mejía, su fundador y primer presidente, egresados y estudiantes de la Facultad de Medicina realizaban, desde el Círculo, actividades académicas, como, por ejemplo, el dictado de cursos, la elaboración de publicaciones y la organización de concursos y eventos. Los conflictos con varios profesores de la Facultad llevaron a que estos fundaran, en respuesta, la Asociación Médica Argentina (OTERO, 1991: 45-46). Según González Leandri (2004: 241), el Círculo “podía al mismo tiempo impugnar con contundencia a los académicos, contentar las expectativas

\footnotetext{
${ }^{44}$ Entre las temáticas que preocupaban a los médicos, y aparecían en la Revista Médico Quirúrgica, estaban las epidemias, las campañas de vacunación, los cementerios, la limpieza de las calles, la reglamentación de la prostitución, la ética médica y los movimientos demográficos (VEZZETTI, 1985: $31)$.
} 
de prestigio y ascenso colectivo de los estudiantes y doctores jóvenes e incluir por goteo a sus dirigentes dentro del estrecho marco de los notables de la Facultad de Medicina". En paralelo, durante las décadas del ' 80 y el '90 del siglo XIX, la institución, a través de su militancia positivista y sus vínculos con la elite liberal en el poder, logró posicionar a algunos de sus miembros, en especial, a José María Ramos Mejía, en lugares claves para crear y dirigir las más importantes instituciones sanitarias.

Además de este rol de promoción de sus miembros y defensa de intereses corporativos, estas organizaciones tenían una actividad académica y de producción científica. Por ejemplo, el Círculo Médico inició la publicación de su revista, “Anales del Círculo Médico”, para la cual formó comisiones encargadas de diferentes temáticas: higiene, medicina nacional, ciencias naturales, patología y clínica, terapéutica y farmacología, anatomía y fisiología, y estadística (VEZZETTI, 1985: 18). Del mismo modo, las distintas áreas del estado en las que se insertaban los profesionales de la salud producían alguna clase de publicación en la que difundían su pensamiento, aprovechando los recursos logísticos y el financiamiento estatal. Ramos Mejía, presidente del Departamento Nacional de Higiene entre 1892 y 1898, además de ocuparse de proyectos relacionados con la salubridad en el territorio nacional, se dedicó a difundir las ideas higienistas al fundar una nueva publicación, los "Anales del Departamento Nacional de Higiene" (SALESSI, 1995: 23).

Como funcionarios estatales y escritores universitarios, los profesionales de la salud, a través de sus revistas, libros, artículos y reseñas, dieron a conocer su pensamiento. Para ello, al utilizar los medios de las instituciones estatales en las que participaban, lograron difundir sus ideas en América y Europa (SALESSI, 1995: 128). ${ }^{45}$ Uno de los casos más conocidos tal vez sea el de José Ingenieros y la revista "Archivos de Psiquiatría y Criminología”. “Archivos” era una revista mensual, de sesenta páginas, que contaba con lectores europeos y americanos. Allí, intelectuales como Ramos Mejía, de Veyga e Ingenieros publicaban historias clínicas de pacientes particulares y de alienados observados en el marco de instituciones policiales o académicas. Así, de la información surgida de instituciones, como la Sala de Observación de la policía y el Instituto de Medicina Legal, se elaboraban artículos para ser publicados en los

\footnotetext{
${ }^{45}$ De Veyga, por ejemplo, pudo participar de las clases de Charcot en la Salpêtriére durante su estadía en Europa entre 1891 y 1896 . Años más tarde, publicaría sus trabajos en los Anales del Departamento Nacional de Higiene (entre 1896 y 1900); publicación en la que trabajó junto a su maestro Ramos Mejía, durante los últimos años en los que éste estuvo a cargo de la presidencia del Departamento y de los Anales (SALESSI, 1995: 128).
} 
“Archivos". Años más tarde, en 1907, cuando Ingenieros fue nombrado director del Instituto de Criminología, fundado en la Penitenciaría Nacional de Buenos Aires, los "Archivos" fueron publicados en el presidio nacional, siendo este transformado en una gran imprenta, en la cual trabajaban los presos (SALESSI, 1995: 173). También publicaban en los "Archivos" escritores, intelectuales y científicos argentinos y extranjeros, como Nina Rodríguez, Miguel de Unamuno o Enrique Ferri. Entre otros contenidos, la revista incluía traducciones de libros, selecciones y reseñas de obras de reciente publicación. Al igual que el contenido que presentaba, su público era amplio. Era leída por intelectuales argentinos y extranjeros, profesionales de la ley y la medicina, docentes, estudiantes y otras personas interesadas en la temática (SALESSI, 1995: 172-173). Uno de los temas de los que se ocupó este tipo de publicaciones del ámbito médico y científico fueron los casos de suicidio, cuyo aumento generaba preocupación a fines del siglo XIX en Buenos Aires.

\subsection{Epidemias e higiene social}

Uno de los primeros fenómenos relacionados con la cuestión social que inquietó a los intelectuales desde mediados del siglo XIX fueron las epidemias. Estos episodios marcaron a la sociedad de la época. En la década de 1850, ocurrió el primer aviso de importancia relacionado con las consecuencias de las enfermedades para la población, la epidemia de fiebre amarilla de 1858. El origen de la peste fue asociado con los miasmas, agentes causantes de las enfermedades y su contagio. La epidemia de cólera de fines de 1867 y principios de 1868 representó un punto importante de reflexión sobre el tema. Los problemas identificados en este caso fueron la falta de un servicio de recolección de basuras apropiado y la ausencia de una adecuada fuente de provisión de agua potable, así como la situación de la vivienda entre los sectores populares y los inmigrantes, los llamados "corralones". Así, la cuestión de los focos de infección ganó cada vez mayor atención (GONZÁLEZ LEANDRI, 2004: 225-227). La epidemia de fiebre amarilla de 1871 aceleró los debates entre los higienistas y en el seno de la sociedad en general. Por su carácter extremo (murieron 13.725 personas de un total de 190.000 en la ciudad de Buenos Aires, más del 7\% de la población), la epidemia paralizó la actividad productiva y comercial durante varios meses (GONZÁLEZ LEANDRI, 2004: 229). Ante la falta de conocimientos precisos sobre las causas de la enfermedad, los principales factores destacados por el saber médico fueron la falta de 
separación entre aguas servidas y fuentes de agua potable, los desechos de mataderos y saladeros, los enterramientos en los cementerios y, antecedente temprano de las décadas siguientes, los barrios de inmigrantes (donde familias enteras vivían en cuartos reducidos y oscuros), viviendas que eran vistas como "focos" de infección (SALESSI, 1995: 49 у 76). ${ }^{46}$

Como señala Mirta Lobato (1996: 14), "la cuestión social fue el medio que facilitó la intervención de diferentes profesiones en la búsqueda de soluciones, así como promovió el debate de ideas entre quienes buscaban promoverlas". En un contexto de creciente prestigio a nivel mundial del higienismo -que se consolidaría entre $1875 \mathrm{y}$ 1885, tras los descubrimientos en bacteriología y vacunación por parte de Lister y Pasteur-, las amenazas de las epidemias alentaron la reflexión de médicos como Guillermo Rawson, Eduardo Wilde, Pedro Mallo y Emilio Coni (LOBATO, 1996: 12). De este modo, los estragos causados por estas enfermedades en la población trajeron, entre otras consecuencias, el descubrimiento de la enfermedad como problema social dentro de "una suerte de ideología urbana articulada en torno a los temas del progreso, la multitud, el orden, la higiene y el bienestar" (ARMUS, 2000: 510). De la mano de los médicos higienistas de entre siglos, la enfermedad empezó a ser interpretada desde una perspectiva social, es decir, haciendo referencia a la situación en el contexto urbano, por ejemplo, las características de las viviendas y del ámbito laboral, los hábitos cotidianos, la situación de los inmigrantes y las multitudes en las ciudades. Con cada epidemia se iniciaba un ciclo de pánico y denuncias, junto a la conmoción y las numerosas muertes, que dejaba en evidencia la ausencia de los medios para hacer frente al azote de la enfermedad en la población (ARMUS, 2005: 192-193). En paralelo, la higiene pública pasó a formar parte de la formación regular de los médicos en la Facultad de Medicina a cargo de Guillermo Rawson. Rawson, Eduardo Wilde y Emilio Coni fueron de los primeros en plantear la necesidad de pensar la higiene y la salud desde una perspectiva colectiva, que tuviera en cuenta la salud física y moral de la población, proponiendo una mayor intervención del estado en estos asuntos y un límite a las acciones individuales que afectaban a la sociedad en su conjunto (ZIMMERMANN, 1995: 102).

\footnotetext{
46 A diferencia de años posteriores, las causas de la enfermedad y los problemas sanitarios eran identificados en las características del ámbito local y no entre los inmigrantes en sí (SALESSI, 1995: 78). En las décadas finales del siglo XIX, la población extranjera sería el centro de las explicaciones del aumento del delito y los efectos no deseados, como la locura y los suicidios.
} 
En este sentido, las preocupaciones de los médicos abarcaban un espectro muy amplio. Por ejemplo, uno de los temas que más inquietó a los higienistas fue la circulación separada y ordenada de las corrientes de agua pura y las de los desperdicios y posibles contaminantes, asunto vital para garantizar el saneamiento de las ciudades. Tras la epidemia de fiebre amarilla, las distintas instancias gubernamentales estuvieron de acuerdo en la necesidad de construir una red de circulación de agua potable y desagües de aguas servidas (SALESSI, 1995: 15-16). El objetivo era evitar que los líquidos de mataderos y saladeros, así como el contenido de los pozos ciegos, pudieran contaminar las napas de agua. De esta manera, las obras públicas debían garantizar la circulación de flujos en las ciudades, organismos de los gobiernos liberales. Del mismo modo, otro tema que despertó creciente preocupación tras la epidemia de fiebre amarilla fue el tratamiento de los cadáveres en los cementerios. La situación extrema vivida en este contexto, además de fortalecer la legitimidad de las ideas higienistas, reforzó la imagen de los cuerpos como vehículos de contagio de enfermedades peligrosas y, en consecuencia, dio más argumentos en contra de la presencia de los cementerios dentro del radio urbano (asociados con la promiscuidad entre vivos y muertos). La acumulación masiva de cadáveres en el cementerio sur llevó a la apertura de uno nuevo en la llamada Chacarita de los colegiales, antiguo espacio de recreación de jóvenes de la elite como Miguel Cané (SALESSI, 1995: 40 y 53). Junto con estas cuestiones puntuales, los médicos tenían un interés en los problemas relacionados con la vivienda, instituciones hospitalarias y un sistema de atención médica gratuita para los más necesitados (ZIMMERMANN, 1995: 102).

Por otra parte, la preocupación de los profesionales de la salud también se orientó a las "plagas sociales", como el alcoholismo, la tuberculosis y las enfermedades venéreas (LOBATO, 1996: 14). En el pensamiento higienista, el análisis de la realidad estaba articulado en la antinomia salubre / insalubre. Producto de la experiencia vivida con las epidemias, se consolidó, en el imaginario, la idea de la enfermedad, en un sentido amplio (tanto física como moral, individual o colectiva), como el nuevo enemigo a vencer (SALESSI, 1995: 14). En la mirada higienista, el vicio y la inmoralidad eran una peste, tanto o más peligrosa que las enfermedades infectocontagiosas, que atentaban contra la población (VEZZETTI, 1985: 42).

Así, las problemáticas sociales eran entendidas en términos de patologías frente a las cuales había que intervenir e interponer medidas de prevención (por ejemplo, la creación de instituciones especializadas) (RUIBAL, 1996: 193-194). Para pensar la 
nación, el desarrollo de una economía capitalista y el proceso de urbanización, la matriz de pensamiento de la época combinaba una perspectiva biológica en paralelo con una social, que se mezclaban para comprender las problemáticas tras la llegada masiva de inmigrantes, la aparición de la prédica anarquista y los problemas tras el acelerado crecimiento de las ciudades, consecuencias imprevistas en el proyecto modernizador.

En este sentido, a fines del siglo XIX, el pensamiento médico-higienista apuntaba, muchas de sus propuestas, a la masa anónima desposeída y a los trabajadores urbanos, a fin de lograr la medicalización de la conducta ciudadana, con la intención de fabricar un hombre argentino, una nueva raza (VEZZETTI, 1985: 12-13 y 43). Así, con el avance de la segunda mitad del siglo XIX, las ideas y los problemas de la higiene social se entrelazaron con los del estudio de las patologías mentales y el delito en el mundo urbano.

Como veremos más adelante, una de las formas de representar el crecimiento de la tasa de suicidios era la de una epidemia contagiosa, una suicidio-manía producida por las transformaciones de la vida moderna y civilizada. Desde la perspectiva de los miembros de la elite intelectual, los suicidios tenían un significado ambivalente: por un lado, eran hechos lamentables y no deseados; por el otro, eran sinónimo de que se estaba en camino de alcanzar un alto grado de progreso. Las exigencias de la lucha por la vida eran una de las características de las sociedades adelantadas en la escala evolutiva. En estas, según los profesionales de la salud, las presiones cotidianas agotaban los cerebros y las fuerzas físicas de los habitantes y los que no podían soportarlas se quitaban la vida. A esto se sumaba el desequilibrio presente en la sociedad-organismo rioplatense entre el avance del desarrollo material y el deficiente progreso moral de la población, que generaba un creciente número de suicidios y enfermedades mentales.

\subsection{El pensamiento médico y las enfermedades mentales}

En las décadas finales del siglo XIX, con el aumento de la inmigración y el crecimiento demográfico de los habitantes en las ciudades, los profesionales de la salud se interesaron también por la situación de las patologías mentales y las instituciones encargadas de este tipo de casos. Si el higienismo tuvo su principal preocupación en las epidemias de enfermedades infectocontagiosas, el alienismo se ocupó de la locura y de las epidemias psíquicas. En este sentido, al igual que en el caso de los médicos 
higienistas, la ambición de la naciente psiquiatría era mejorar las cualidades de los ciudadanos, a través de la psiquiatrización de la vida cotidiana, y garantizar un mejor control y gobierno de las masas (VEZZETTI, 1985: 132-133). Así, los focos de su preocupación fueron el malestar urbano y la masa inmigrante.

Según Hugo Vezzetti (1985: 43), el dispositivo psiquiátrico (basado en el alienismo, los manicomios, el tratamiento moral de los locos), al igual que el criminológico, nació a partir de 1880, después de la creación de cátedras dedicadas a las enfermedades mentales en la Facultad de Medicina y con los textos de José María Ramos Mejía y Lucio Meléndez, ambos influidos por las ideas del alienismo francés. ${ }^{47}$ Meléndez, a cargo de la cátedra de Psiquiatría a partir de 1886, ya venía poniendo en práctica las ideas de los principales representantes de la escuela alienista francesa, como Esquirol y Pinel, en la dirección del Manicomio de Hombres desde 1876. En este tipo de instituciones, por ejemplo, el trabajo era utilizado como un medio moral de tratamiento para reformar a los enfermos mentales. Así, en el taller del Hospicio de Mujeres, las alienadas, por ejemplo, cosían para el ejército, y, a cambio, obtenían ciertas recompensas (salidas, ropa, mate, cigarros). En estas instituciones, el camino de la observación metódica y el seguimiento cuidadoso de la evolución del alienado, sugeridas por Pinel, fueron la pauta seguida por los alienistas como Meléndez. Desde la perspectiva del médico psiquiatra francés, la práctica asilar, característica del alienismo, puesta en marcha por este especialista en patologías mentales en instituciones como el asilo de Bicêtre y la Salpêtrière, debía combinar un método de gobierno que no dejara de incluir tanto la ilustración como el terror, a fin de lograr en el loco un control moral de la conducta (VEZZETTI, 1985: 50). Así, los tratamientos propuestos por este psiquiatra incluían el uso del chaleco de contención, baños con chorros de agua, sugestión por medio de la palabra, etc. El alienista tenía un rol multifacético: juez y policía, padre y director de conciencia. Años más tarde, Domingo Cabred, sucesor de Meléndez, impulsaría una modificación en la práctica de aislamiento, implementando el

\footnotetext{
${ }^{47}$ Este alienista se preocupó muy especialmente por la situación de la locura y la patología mental en los delincuentes, proyectando, años más tarde, pabellones especiales, destinados a estos casos en particular. Como especialista en psiquiatría, además, tuvo una importante participación en espacios académicos nacionales e internacionales. En 1884, la Academia de Medicina creó nuevas cátedras, entre ellas la de Patología Mental. Meléndez concursó y ganó el cargo de profesor titular en 1886, disputándolo con Eduardo Pérez y José María Ramos Mejía. También tuvo una importante producción de artículos en publicaciones especializadas como la Revista Médico-Quirúrgica. El método de trabajo de Meléndez estuvo basado en la observación y comparación clínica rigurosa de sus casos, la investigación terapéutica y la estadística epidemiológica (STAGNARO, 1997). Según Vásquez, Meléndez decía: "cada loco es un libro nuevo que se me abre al estudio y a la observación”. Véase, CUTOLO (1968: t. IV: 512).
} 
sistema de puertas abiertas, puesto en marcha en la Colonia Nacional de Alienados Open Door (1889). Este sistema buscaba dar a la institución mental el aspecto de un pueblo y mayor libertad al loco dentro de su reclusión (VEZZETTI, 1985: 79). ${ }^{48}$

¿Cómo entendían las enfermedades mentales los médicos alienistas? Las pasiones humanas (opuestas al entendimiento), producto del desorden propio de la civilización y la vida en el mundo urbano, donde los medios de subsistencia eran más difíciles de conseguir (a diferencia del espacio rural), eran el origen de la alienación mental (VEZZETTI, 1985: 82). Éstas se manifestaban en comportamientos que la psiquiatría establecía como anormales, siendo catalogados como neurosis, locuras parciales, ocultas en las conductas del sujeto. Esquirol resumió en un concepto la forma que adoptaba la locura en su tiempo: la monomanía. Ésta era una perturbación intelectual, afectiva o instintiva-, que no afectaba a las demás facultades, era la enfermedad mental de la civilización, del progreso, que llevaba al hombre hacia fuera de forma excesiva; una exaltación desmedida, anormal, desviada de las pasiones y emociones o de obsesiones (sexuales y criminales). Por ejemplo, erotomanía (necesidad de amor), megalomanía (exaltación del yo), dipsomanía (adicción a las bebidas), cleptomanía, piromanía, suicidiomanía, etc. (VEZZETTI, 1985: 127-129). En síntesis, la locura era ante todo un estado apasionado del individuo.

Este discurso, lejos de limitarse al ámbito personal o privado de los pacientes, buscaba abordar cuestiones de "orden público" (gobierno de las masas), por ejemplo, el consumo de alcohol, la sífilis, los matrimonios, la instrucción y el trabajo, los caracteres psíquicos y raciales de la población, la condenación de todos los excesos y el control de las pasiones (VEZZETTI, 1985: 49-50). La preocupación de una psiquiatría social se enlazaba con el estudio de la locura en las multitudes y en los hombres célebres de cara a pensar el destino nacional de un pueblo virtuoso y trabajador. En este sentido, el alienismo, como el higienismo y la criminología, buscó constituir un sujeto moral que conformara un colectivo social. En este sujeto moral, la ética del trabajo, sumada a un proceso de modelado de las pasiones populares en la dirección de la estabilidad y la mesura, contribuiría a mantener el orden (VEZZETTI, 1985:13,14). Desde esta perspectiva, la locura, como concepto del discurso médico más general, abarcaba mucho más que los aspectos que hoy consideramos parte de la salud mental: entre el ochenta y el centenario, el análisis de lo patológico alcanzaba espacios tan diferentes como el

\footnotetext{
${ }^{48}$ Sobre la Colonia Nacional de Alienados de Open Door, véase, entre otros, MARQUIEGUI (2012 y 2014).
} 
trabajo o la sexualidad, las funciones de gobierno o los negocios. La armonía familiar, el matrimonio y la educación, o la religión (si no se trataba del fanatismo) eran los pilares destacados para seguir el camino de la "salud mental" y eran los opuestos de la ociosidad, el vicio y el descontrol de las pasiones (VEZZETTI, 1985: 85-87).

En el discurso de los alienistas argentinos, había dos variables sociales principales para explicar la locura, la inmigración y el consumo de alcohol (VEZZETTI, 1985: 83-84). El alcoholismo era un signo del vicio y la vagancia que requería la intervención policial. Por otra parte, los inmigrantes eran el centro de la preocupación de los especialistas en enfermedades mentales, llegando a constituir un estereotipo, el loco inmigrante (VEZZETTI, 1985: 21). Éstos eran proclives a caer, tras padecer los pesares domésticos, el amor y los celos, los reveses de la fortuna, el miedo o la pérdida de personas queridas. Pero, sobre todo, el papel del dinero entre los inmigrantes era visto como la principal falla moral, productora de una brecha en la virtud ciudadana. En la mirada de los alienistas, los manicomios estaban poblados de estos inmigrantes que perseguían la riqueza material. En su mayoría, eran hombres italianos, dedicados a oficios manuales (jornaleros, labradores, albañiles, zapateros, changadores, cocineros), entre 20 y 40 años de edad (VEZZETTI, 1985: 47).

Por otra parte, muchos sujetos marginados, alcohólicos e indigentes eran catalogados como locos por la policía, muchas veces de forma arbitraria, que los detenía y enviaba al hospicio, situación que Meléndez denunciaba. En este sentido, la práctica alienista encontraba un problema fundamental: cómo definir objetivamente cuándo se trataba de locura y cuándo no, más aún, teniendo en cuenta el limitado espacio y recursos con que contaban las instituciones (VEZZETTI, 1985: 64).

La sociedad de la época, como veremos, también se preguntaba por los límites entre la razón y la locura. En este sentido, para algunos médicos, el suicidio era siempre el resultado de una patología mental, sólo esta podía explicar la capacidad de violar el instinto de autopreservación. Otros profesionales consideraban que había sujetos que se suicidaban en uso de sus facultades mentales, pero arrastrados por una pasión desmedida. Los debates giraban entre estas dos posturas y si bien había situaciones donde era más evidente para todos que el sujeto no tenía uso de su razón, en otras no era tan sencillo determinar si el que se quitaba la vida estaba loco.

La dificultad para diferenciar las situaciones donde las facultades mentales estaban alteradas, por otra parte, estaba vinculada con otro dilema, el de identificar la responsabilidad de los criminales en sus delitos. En este sentido, el discurso de la 
medicina mental preparó la aparición del criminológico (VEZZETTI, 1985: 49-50). Este diálogo entre la psiquiatría y la criminología fue facilitado en Argentina por la lectura de Pinel y Esquirol, en paralelo con la introducción de otros autores posteriores, como Lombroso, por ejemplo, que buscaba conocer al criminal nato (VEZZETTI, 1985: 132).

\subsection{De la Medicina Legal a la Antropología Criminal}

En paralelo con la discusión sobre la cuestión social, creció la influencia de una disciplina, la Medicina Legal. ${ }^{49}$ Durante la segunda mitad del siglo XIX, el trabajo con cadáveres por parte de higienistas y médicos forenses se volvió cada vez más frecuente. En el marco de las epidemias, eran necesarias las autopsias para confirmar las causas de las muertes y corroborar que se trataba de defunciones producidas por enfermedades. Asimismo, los médicos forenses eran requeridos para la elaboración de informes en causas civiles y criminales. Eduardo Wilde, en este sentido, condensó ambas miradas del estudio de los cadáveres desde la cátedra de Higiene (creada en 1873) y como profesor titular de Medicina Legal (desde 1875) (SALESSI, 1995: 82).

Este campo intermedio entre los conocimientos del derecho y la medicina surgió también como respuesta a la preocupación por identificar si quienes cometían un delito tenían sus facultades mentales alteradas. En estos casos, los detenidos eran librados de la culpa por sus acciones y sometidos a tratamientos en instituciones especializadas. Tanto los criminólogos como los alienistas buscaron que los enfermos mentales (quienes padecían alguna monomanía, la melancolía o alguna otra forma de alteración de sus facultades) fueran librados de toda pena por sus actos, ya que no podían ser considerados responsables de estos. De allí la importancia de las pericias médicas para reconocer la presencia de la locura en los procesos judiciales. Por ejemplo, si bien los casos de suicidio no eran delitos, cuando alguien atentaba contra su vida, y fallaba en su intento, intervenía un médico de la policía que hacía la pericia para diagnosticar si su razón había estado alterada por alguna patología. Tras estas indagaciones, en algunos casos, se los derivaba a hospitales e instituciones dedicadas al cuidado y tratamiento de los alienados.

\footnotetext{
${ }^{49}$ Sobre la cuestión social en Argentina, durante las décadas finales del siglo XIX, véase, entre otros, VEZZETTI (1985); SALESSI (1995); ZIMMERMANN (1995); LOBATO (1996); SURIANO (2004); PLOTKIN y ZIMMERMANN (2012).
} 
La medicina legal, una prolongación de los alcances del saber médico, fue, a fines del siglo XIX, un primer espacio de la criminología. A las ideas de los alienistas, difundidas en instituciones de encierro y en las cátedras de la Universidad, se sumó esta nueva disciplina que estudiaba el delito y la locura como parte de un mismo grupo, los anormales. Éstos eran identificados por la peligrosidad (entendida como cierta configuración morfológica y psíquica) que su existencia representaba para el colectivo social (VEZZETTI, 1985: 21). Con la consolidación de la criminología positivista, la brecha entre el crimen y la locura sería apenas una diferencia de grado en cuanto a los caracteres fisiológicos y psíquicos considerados normales. Según Vezzetti, el criminólogo era un alienista que desplazaba su objeto fuera de los asilos, hacia la población más marginal. En este sentido, en la mirada de ambas disciplinas, el loco y el delincuente debían ser recluidos para su observación.

El pensamiento criminológico en Argentina estuvo fuertemente vinculado con las ideas de la escuela positivista italiana, cuyos principales referentes fueron Cesare Lombroso, Raffaele Garófalo y Enrico Ferri. Ésta tuvo su declaración de principios con la obra de Lombroso, L'uomo delinquente (1876). Los partidarios de esta corriente de pensamiento entendían al delito como una patología social o biológica, según el caso, cuyo estudio empírico debía llevarse a cabo dejando de lado las nociones clásicas de libre albedrío y responsabilidad individual, características del derecho penal más tradicional. Según Lombroso, había ciertos rasgos, observables empíricamente, en los criminales (ciertos tipos de mandíbulas, frentes y orejas, por ejemplo), correspondientes con el típico uomo delinquente, cuya predisposición al delito era innata. Al tratarse de factores que escapaban a la decisión de los individuos, en lugar de castigar a los criminales por la responsabilidad de la falta, la comunidad debía aplicar instrumentos para la defensa social de la misma (ZIMMERMANN, 1995: 127-128). Es decir, este énfasis en el determinismo biológico o social en los orígenes de la conducta criminal, implicaba que el delito y su pena ya no se medían en términos de pecado o culpa, sino en el potencial riesgo que el sujeto anormal representaba para la sociedad. El encierro era un medio para evitar daños a la comunidad, no para castigar, y para observar el comportamiento y los rasgos de los delincuentes.

Esta corriente de pensamiento tuvo una importante influencia en la filosofía del derecho, la sociología, la psiquiatría y la medicina legal (VEZZETTI, 1985: 173). En Argentina, profesionales de la salud y juristas adoptaron estas ideas para entender la cuestión social. Sus adherentes, a fines de la década del '80, fundaron la Sociedad de 
Antropología Jurídica. Entre sus miembros se encontraban José María Ramos Mejía (director de la asistencia pública), José Nicolás Matienzo (a cargo del Departamento de Trabajo, años más tarde) y Rodolfo Rivarola (luego director de la "Revista Argentina de Ciencias Políticas”). Los trabajos de Luis María Drago (Los hombres de presa, de 1888) y Antonio Dellepiane (Las causas del delito, de 1892) fueron los primeros que presentaron las ideas de la escuela italiana en Argentina. El diálogo entre los intelectuales de ambos países fue estrecho. Por ejemplo, Lombroso, además de ser corresponsal de publicaciones argentinas, tradujo y prologó la obra de Drago y escribió el prólogo del libro de Cornelio Moyano Gacitúa, La delincuencia argentina ante algunas cifras y teorías (1905); y Ferri, por su parte, dictó algunas conferencias en su paso por Buenos Aires (ZIMMERMANN, 1995: 129).

Producto de la difusión de este pensamiento en Argentina, surgieron publicaciones relacionadas con el estudio de la realidad en Buenos Aires a finales del siglo XIX y principios del XX. La primera revista que apareció fue "Criminología Moderna", dirigida por Pietro Gori, abogado anarquista y jurista italiano. Gori se había exiliado en Argentina tras ser condenado a 21 años de prisión en su país de origen acusado de participar como impulsor de sublevaciones populares. Su estadía en Buenos Aires dio un importante empuje a la difusión de la criminología positivista en Argentina. En 1902, este intelectual abandonó el país para regresar a Italia. La figura de Gori actuó como puente entre los principales referentes de la escuela en Italia y los adherentes locales de sus ideas (ZIMMERMANN, 1995: 128).

Entre los temas abordados en la publicación había artículos sobre derecho y procedimiento penal, legislación y jurisprudencia; aportes desde la medicina legal, la sociología y la antropología criminal; análisis de diferentes casos de criminales o temas de actualidad a la luz de la mirada criminológica; datos estadísticos e información sobre el funcionamiento del sistema judicial y carcelario. De manera análoga a la variedad de temas y enfoques eran los colaboradores con los que contaba la publicación. Dentro del cuerpo de redacción estaban incluidos, entre otros, el Director de la Oficina Antropométrica de la Capital (Guillermo Achával), el Presidente de la Comisión de Cárceles y Casas de Detención (Julián Aguirre), abogados, profesores del Colegio Nacional (el escritor uruguayo Víctor Arreguine, por ejemplo), el Director de la Penitenciaría de Sierra Chica (Miguel Costa), docentes universitarios, políticos, jueces, autoridades de instituciones policiales y psiquiátricas, por ejemplo, Juan Vucetich (jefe de las Oficinas de Estadística e Identificación Antropométrica de la Policía de la 
provincia de Buenos Aires). Entre los corresponsales en el exterior había profesores universitarios y académicos especialistas en derecho penal, antropología criminal y medicina legal de varias ciudades del mundo, aunque, en su mayoría, eran del ámbito intelectual italiano del que provenía Gori (Lombroso, Morselli, Garófalo y Ferri). Cabe destacar que los primeros trabajos de intelectuales argentinos que tendrían mayor trascendencia en años posteriores, como José Ingenieros o Francisco de Veyga, aparecieron en esta publicación, cuyos veinte números se publicaron entre 1898 y 1900. Con la aparición de "Criminología Moderna" comenzó el auge de la corriente positivista de antropología criminal en Argentina.

Esta publicación fue el antecedente de la célebre "Archivos de Psiquiatría y Criminología", revista fundada por Francisco de Veyga y dirigida por José Ingenieros, entre 1902 y 1913. Como director y escritor de "Archivos", Ingenieros contó, además de su formación en medicina, psicología y derecho penal, con un importante archivo sobre delincuentes y presos, resultado de su actividad en el Instituto de Criminología y Penitenciaría Nacional y del Depósito de Contraventores de la Policía. A partir de su nombramiento como director del mencionado Instituto de Criminología, en 1907, la publicación de la revista especializada, "Archivos de Psiquiatría, Criminología y Ciencias Afines", pasó a editarse en sus instalaciones. Como objetivo de su programa, esta proponía el estudio científico de los anormales (el homicida, el genio, el mentiroso, el pederasta, el filántropo, el avaro, el alienado, el ladrón, el apóstol, el sectario, el enamorado, el vagabundo, la prostituta).

Según Salessi (1995: 127 y 133), la influencia de la criminología no se limitó a una serie de principios o marcos teóricos, éstos modelaban una serie de prácticas dentro de las instituciones estatales. En este sentido, cabe destacar que, entre 1890 y 1910, oficiales y cirujanos del ejército, como Falcón y Veyga, y médicos psiquiatras y criminólogos, como Ingenieros y Ramos Mejía, colaboraron en la modernización del ejército argentino y la policía de la Capital Federal.

En los análisis de estos intelectuales había una suerte de continuidad con las ideas higienistas y alienistas. Los sistemas de control, los modelos de análisis y el vocabulario del higienismo del siglo XIX fueron retomados por los criminólogos y sociólogos durante el comienzo del siglo XX. Las preocupaciones frente a las enfermedades venidas del exterior se transformaron en inquietudes respecto al delito. El crimen era comprendido como una enfermedad psicológica y moral que amenazaba la salud del colectivo (SALESSI, 1995: 115). Así, continuaron pensando la sociedad en 
analogía con los organismos vivos, tratando de entender la dinámica y las leyes de su evolución. Una diferencia que encontraban con lo ocurrido en la naturaleza se relacionaba con la adaptación y la lucha por la vida. Mientras que en el mundo natural sólo sobrevivían los más aptos, esto no ocurría en el mundo social, dando como resultado la supervivencia de seres improductivos o degenerados. Las ideas sobre la degeneración, seguidas por los criminólogos de entre siglos (como De Veyga e Ingenieros), estaban emparentadas con las de Benedict Augustin Morel. Éste pensaba que "las degeneraciones son desviaciones morbosas del tipo humano normal, hereditariamente transmisibles y sujetas a evolución progresiva hacia la decadencia" (VEZZETTI, 1985: 155). En este sentido, la degeneración de la raza era un obstáculo para la evolución de la nación, la antítesis del progreso económico, social y cultural indefinidos. ${ }^{50}$ Para contener el aumento del crimen era necesaria una higiene social, con sus respectivas medidas profilácticas, que redujeran los efectos causados por la herencia, el temperamento, las lesiones, o factores como el medio social. En este sentido, era imposible preservar a la población de un proceso degenerativo sino se contaban con condiciones morales, laborales, sanitarias y habitacionales orientadas a regular la calidad de vida en el mundo moderno y sus efectos negativos, como el consumo de alcohol o la prostitución (ZIMMERMANN, 1995: 107-108).

Los inmigrantes, los marginados y los trabajadores eran el blanco de estas interpretaciones. En paralelo a la necesidad de desterrar las enfermedades infecciosas del cuerpo social, los médicos veían la necesidad de expulsar a los individuos indeseables, que podían infectar al colectivo con sus conductas desviadas, patológicas, peligrosas y anormales, definidas bajo la expresión "la mala vida" (ZIMMERMANN, 1995: 107). Según Alejandro Korn, en su tesis doctoral, la depravación física y moral era transmitida de padres a hijos, entre los sectores sociales bajos, en el caso argentino, gauchos e inmigrantes (VEZZETTI, 1985: 144). Las estadísticas indicaban un aumento de la criminalidad, y quienes aparecían como responsables, en su mayoría, eran españoles e italianos. Este fue uno de los datos, junto a prejuicios y percepciones de la elite política y científica, que llevó a asociar delito con inmigración. En realidad, más

\footnotetext{
${ }^{50}$ El concepto "raza" trascendía las barreras ideológicas y carecía de precisión en su definición. En general, era utilizada para marcar diferencias entre razas "superiores" e "inferiores", resaltando la diferencia de jerarquías entre distintos grupos humanos, pero el criterio de demarcación oscilaba entre un énfasis en distintos factores: biológicos, climáticos, históricos, culturales, geográficos, llegando a ser no poco frecuente el uso de raza y nación como sinónimos. Al mismo tiempo, también se utilizaba el término raza para hablar de los caracteres fisiológicos de la población que debían preservarse de la degeneración (ZIMMERMANN, 1995: 110).
} 
que la tendencia nata criminal de los inmigrantes, estos datos reflejaban el peso de la población extranjera en la ciudad de Buenos Aires que, en 1914, representaba más de la mitad de la población, siendo en su gran mayoría italianos y españoles (ZIMMERMANN, 1995: 130). En este contexto, la inmigración y la protesta obrera fueron asociadas al anarquismo y al delito, que debían ser combatidos en post de la defensa social frente a su peligrosidad para la salud del colectivo (ZIMMERMANN, 1995: 142-143).

La difusión del discurso de la criminología italiana planteó otros interrogantes: ¿existía un "suicida nato”? ¿Había más suicidas entre los inmigrantes que entre los nativos? ¿La degeneración y los vicios que identificaban los criminólogos y alienistas tenían alguna relación con el aumento de la tasa de muertes por mano propia? ¿Qué medios profilácticos podían ser efectivos para disminuir el número de suicidios? Estas fueron algunas de las cuestiones que los artículos publicados en "Criminología Moderna" y "Archivos de Psiquiatría..." trataban de responder. La presencia de trabajos enfocados en este fenómeno da cuenta de la preocupación que el aumento de estos casos provocaba en la población y en la comunidad científica de fin de siglo. En el primer número de "Criminología Moderna", en un artículo sobre un caso de doble homicidio y rapto, el autor destacó:

El mes transcurrido ha sido trágicamente fecundo en hechos de sangre excepcionales perpetrados en distintos puntos de la Republica y de que se ha ocupado extensamente la prensa diaria.

Desde luego se nota entre esos hechos el considerable predominio de los suicidios cuyo incremento ha tomado en el país las mas alarmantes proporciones, hasta el punto de haber preocupado seriamente la atención de los escritores y las autoridades. ${ }^{51}$

De los estudios aparecidos en las dos revistas sobresalen dos autores que sintetizan las principales discusiones sobre la muerte voluntaria durante el final del siglo XIX y los inicios del XX: Fermín Rodríguez y Víctor Arreguine. Ambos intelectuales presentaron sus ideas en el Primer Congreso Científico Latino-Americano celebrado en Buenos Aires en 1898. El primero fue un destacado discípulo de Ramos Mejía, que planteaba la influencia decisiva del consumo de alcohol en el incremento de los casos de suicidio en el espacio urbano. Este fue el tema de la tesis que le permitió acceder al grado de doctor

\footnotetext{
${ }^{51}$ Criminología Moderna, $\mathrm{n}^{\circ} 1,1898$, p. 25.
} 
en 1897. Con el correr de los años, continuaría publicando otros trabajos sobre el tema, enfocando el problema desde otras variables, como la franja etaria, el género y el estado civil.

La colaboración de especialistas en diferentes áreas, fuera del ámbito médico y jurídico, fue común tanto en "Criminología" como en "Archivos". En ambas, fue incorporada la mirada de otras disciplinas y puntos de vista (jurídico, policial, pedagógico y penitenciario). Así, aunque entre sus colaboradores predominaron los profesionales de la salud, la revista recibió los aportes de actores diversos (profesores, académicos -locales y extranjeros-, abogados, políticos, miembros del ámbito educativo, de la fuerza policial, del mundo penitenciario y funcionarios del estado) (MAILHE, 2013: 4). Es el caso, por ejemplo, de Juan Vucetich, quien participó en ambas publicaciones, y en “Archivos” presentó un artículo en el que detallaba las cifras estadísticas de suicidios en la provincia de Buenos Aires durante el período 1891-1901.

Otro caso de colaboración por fuera del ámbito médico o jurídico fue el de Víctor Arreguine, periodista y escritor de origen uruguayo. ${ }^{52}$ Sus reflexiones sobre el aumento de los suicidios se expresaron por primera vez en el Primer Congreso Científico Latino-Americano, en 1898, y más tarde en el primer número de “Criminología Moderna”. Según la redacción de esta publicación, Arreguine había recibido las más elogiosas críticas cuando presentó su trabajo en este congreso. Al año siguiente, en su obra Estudios Sociales (1899), apareció publicado el ensayo sobre el suicidio que, posteriormente, en 1905, también vería la luz en "Archivos". La reaparición de este ensayo en varias oportunidades y distintos ámbitos intelectuales nos da una idea de la buena recepción que tuvo en su época. En este trabajo, Arreguine planteaba la heterogeneidad étnica, resultado de la inmigración, y la falta de solidaridad que traía como consecuencia, como la principal causa de los suicidios en Buenos Aires.

Si bien los criminólogos incluían a los suicidas entre los sujetos anormales analizados en sus publicaciones, estaba claro que sus actos no eran sancionados por las leyes. Como ya mencionamos, la legislación argentina sobre este tema pasó por una serie de cambios a lo largo de la segunda mitad del siglo XIX, en los que terminó por primar la tendencia a eliminar las penas para quienes se hubieran quitado la vida o para los que hubieran fallado en su intento.

\footnotetext{
52 Víctor Arreguine (1863-1924), educador y periodista uruguayo. Desde 1892, pasó a residir en Buenos Aires. Allí, tuvo una importante actuación docente, además de su actividad como escritor. Véase, CUTOLO (1968, t. I: 242-243). También, el artículo "Víctor Arreguine ante el progreso humano", de Fernando Pablo VILARDO, disponible en: http://www.cecies.org/articulo.asp?id=102
} 


\subsection{EI suicidio en la legislación penal}

Antes de 1887 no hubo un código penal nacional que unificara de forma sistemática la legislación sobre los delitos y sus penas en las provincias de la República Argentina. Mientras tanto, los jueces y juristas letrados apelaron a un conjunto de textos de diversas fuentes: en primer lugar, las leyes y normativas coloniales españolas anteriores a 1808 (las Leyes de Partidas, la Nueva Recopilación de Leyes de Indias de 1567, el Fuero Real, la Novísima Recopilación de los Reinos de Indias de 1680, etc.), que continuaron siendo mencionadas en la documentación judicial. ${ }^{53}$ En segundo término, las normas sancionadas, sin seguir forma alguna de sistematización, por las autoridades provinciales y nacionales durante el período precodificador, a partir de 1810. Distintas iniciativas surgieron con el correr del siglo XIX por parte de profesores de derecho de las Universidades del país. Entre estas, la de mayor trascendencia fue la de Carlos Tejedor, cuyo proyecto sirvió de base para los códigos sancionados en cada provincia, y más tarde para la elaboración del texto de la legislación nacional, aprobado en 1886. La propuesta del Código Penal diseñada por Tejedor, por encargo del gobierno nacional, fue presentada en 1868, y estuvo basada en el Curso de Derecho Penal, publicado por este jurista en años anteriores. Sin embargo, la evaluación de la comisión encargada de analizar el proyecto demoró su respuesta hasta 1881, momento en el que dieron a conocer su propuesta, que fue descartada por el congreso nacional, pero que se convertiría, en 1882, en el Código provincial de Córdoba. Asimismo, la sanción de un código nacional se demoró algunos años más. Es decir, desde la presentación original del proyecto de Tejedor, por casi dos décadas no hubo una legislación penal unificada para el territorio nacional (DI GRESIA, 2014: 453-455).

Durante ese período, las autoridades provinciales impulsaron la aprobación de proyectos legislativos para cada provincia, de forma provisional, mientras se esperaba la sanción de un código para todo el territorio de la nación. Así, la legislatura bonaerense debatió entre 1876 y 1877 una propuesta basada en el Código elaborado por Tejedor. Entre los temas que generaron discusión, en la cámara de diputados, estuvieron los artículos referidos a los casos de suicidio.

En el proyecto del código penal de Carlos Tejedor, el suicidio aparecía tipificado como un delito de acción privada, dentro de la división de los crímenes y

53 Para un análisis de la muerte por mano propia en las Leyes de Partidas, véase, MORIN (2001). 
delitos contra las personas (junto con el homicidio simple, el asesinato, el parricidio, el aborto, el infanticidio y el duelo), y estaban pautadas una serie de sanciones para los suicidas, los que intentaran quitarse la vida y también aquellos que instigaran o ayudaran a otro a suicidarse. En la parte $2^{\mathrm{a}}$, Libro I, Título I, prf. 6, figuraban tres artículos sobre el asunto. El primero dejaba sin efecto el testamento del que se hubiera quitado la vida:

El que se quite voluntariamente la vida incurre por el mismo hecho en la privación de los derechos civiles y las disposiciones últimas que hubiese hecho se tendrán por nulas y de ningún valor (TEJEDOR, 1866: 271-272).

El artículo segundo establecía que aquel que hubiera intentado suicidarse, sería encerrado y vigilado por un cierto lapso de tiempo, de uno a tres años:

Si el culpable de tentativa de suicidio fuese detenido en la ejecución del crimen por circunstancias independientes de su voluntad, y no por un arrepentimiento espontáneo, será conducido a lugar seguro, y sometido a una vigilancia rigurosa por un año al menos y tres a lo más (TEJEDOR, 1866: 273).

Por último, en el tercero, Tejedor proponía la pena para aquellos que hubieran participado de un suicidio, ya fuera instigando al que se había quitado la vida o ayudándolo en su propósito de darse muerte:

El que a sabiendas preste a otro medios para que se suicide, será castigado con uno a tres años de prisión. El que lo ayude a la ejecución del homicidio cooperando personalmente, sufrirá el minimum del presidio o penitenciaría (TEJEDOR, 1866: 273).

En el proyecto presentado por la comisión de legislación en la cámara de diputados de la legislatura bonaerense, desde el vamos ya se proponía, entre otras modificaciones, eliminar el primero de los artículos relacionados con el suicidio. Sobre este punto, Tejedor citaba el Código Sardo como antecedente y señalaba que no era injusto, ya que "el que atenta a su vida se hace por este hecho indigno de reglar él mismo su sucesión" y "sus herederos entrarán a heredar según el orden establecido por la ley". Tejedor se 
oponía al trato dado a los suicidas en la Edad Media, que incluían la exposición y maltrato de los cadáveres, la confiscación de los bienes por parte de la monarquía y la negación de sepultura sancionada por el derecho canónico (TEJEDOR, 1871 [1860]: 224-227). Sin embargo, desde su perspectiva, el considerar al suicidio como delito tenía la ventaja de actuar como una "lección” o "advertencia para los pueblos”: "¿Quién sabe si esta saludable reprobación no desvía de su cumplimiento a algunos espíritus momentáneamente extraviados? Y bastaba que impidiese una sola muerte para que la ley ya no fuese inútil” (TEJEDOR, 1866: 272-273). Además, si se castigaba un hecho que no era considerado delito, para Tejedor había una falta de coherencia dentro de la legislación, como ocurría en los códigos de otros países, que no penaban el suicidio, pero sí la asistencia al mismo (TEJEDOR, 1866: 274).

El debate en la cámara de diputados provincial, ocurrido el 20 de septiembre de 1876, nos permite entrever las razones que llevaron a eliminar este primer artículo, así como el segundo (referido a las tentativas), del Código para la provincia de Buenos Aires, sancionado en $1877 .{ }^{54}$ Luego de aprobar en general el proyecto presentado por la comisión de legislación, los legisladores pasaron a debatir cada una de las modificaciones particulares.

El primero en tomar la palabra al pasar a debatir los artículos relacionados con el suicidio fue Adolfo Saldías (1849-1914). Saldías destacó que no estaba de acuerdo con las penas a los suicidas, ya que estas recaían sobre un cuerpo sin vida, o sobre los deudos del suicida. Según este diputado y abogado, esto estaba en línea con las legislaciones más adelantadas de Europa. Por la misma razón, estaba de acuerdo con la supresión del artículo primero, pero también proponía quitar el segundo, referido a las tentativas, apoyándose en las mismas ideas de la legislación de los países europeos. Para Saldías, los suicidios no podían ser considerados un crimen, ya que no afectaban los intereses de terceros, sólo dañaban al sujeto que se daba muerte por mano propia y a sus deudos (familiares y amigos). Tejedor en su proyecto fundamentaba que:

[...] es justo y humano que el culpable sea colocado bajo la vigilancia activa y benéfica de la sociedad. Dejándole libre y abandonado a sus inspiraciones fatales podría volver a comenzar un acto que sólo le impidió ejecutar una circunstancia fortuita. Colocado por el contrario, en una casa especial, por un tiempo más o menos largo y bajo una vigilancia saludable, podrá volver sobre sí mismo y renunciar para

\footnotetext{
${ }^{54}$ Diario de Sesiones de la Cámara de Diputados de la Provincia de Buenos Aires, Buenos Aires, Imprenta de "El Nacional", 1876, pp. 770-790.
} 
siempre a toda idea de concluir con sus días. Hay más crueldad en abandonar a un hombre después que ha tentado matarse, que en detenerlo por algún tiempo, para conservarlo así a su familia y a sus amigos (TEJEDOR, 1866: 272-273).

Saldías no compartía este punto de vista y argumentaba que si los suicidios no eran delitos, tampoco podía considerarse como tales las tentativas, y que resultaría muy complicado, ineficaz y poco conveniente mantener preso, vigilado y alejado de su familia a un individuo en "ese estado". ${ }^{55}$ Para Saldías, la situación mental y moral de un suicida parecía estar comprometida, si bien no aclaraba si consideraba que se trataba de un estado apasionado o de los efectos de una alienación, por lo cual no estaba de acuerdo en castigar al que trataba de quitarse la vida. Asimismo, desconfiaba de la eficacia de la medida.

Roque Sáenz Peña (1851-1914), abogado, tomó la palabra para argumentar en contra de lo expresado por Saldías. Para este diputado, estaba fuera de discusión, según los debates filosóficos y morales, que el suicidio fuera un delito. La justicia encontraba la dificultad de castigar a los suicidas, ya que no era efectivo hacer cumplir una pena a un cuerpo sin vida, incapaz de sentir o percibir los efectos del castigo. ${ }^{56}$ Por otra parte, para el legislador, no era una razón para no hacerlo cuando resultara oportuno, como en el caso de las tentativas:

\footnotetext{
${ }^{55}$ Íbid, pp. 785-786.

${ }^{56}$ La explicación dada por Sáenz Peña sobre los problemas e inconvenientes para sancionar a los suicidas retomaba debates que no eran nuevos en la época. En este sentido, en el renombrado ensayo jurídico, $D e$ los delitos y de las penas, escrito por el italiano Cesare Bonesana, marqués de Beccaria (1738-1794), aparecían los principales aspectos del debate enmarcado en la perspectiva legal. Según este pensador y jurista milanés, si bien el suicidio era una falta que podía ser castigada por la divinidad, no era un delito que pudiera ser sancionado adecuadamente por los hombres: "El suicidio es un delito que parece no poder admitir penas propiamente dichas, pues ellas recaerían tan sólo sobre inocentes o sobre un cuerpo frío e insensible" (BECCARIA, 1955: 273). Aclaraba que el suicidio era una acción que no tenía consecuencias graves para la comunidad, si se lo comparaba con un individuo que dejaba el país: "El que se quita la vida ocasiona a la sociedad un mal menor que el de quien sale para siempre fuera de los confines de su país, puesto que aquél deja en él todos sus bienes, mientras éste transporta con la propia persona parte de su fortuna” (BECCARIA, 1955: 273). Este ilustrado italiano consideraba que sólo la divinidad tenía la capacidad de castigar a los que se quitaban la vida, y cualquier sanción humana sería poco efectiva y afectaría más que nada a personas inocentes, es decir, a los familiares del suicida. Beccaría era intransigente sobre esta cuestión: "Si alguien me objetara que tal pena puede, sin embargo, contener al hombre determinado a matarse, le responderé que quien renuncia tranquilamente al bien de la vida y odia la existencia terrena hasta el punto de preferir la eternidad desventurada, no será movido, en absoluto, por la consideración, menos eficaz y más distante, hacia hijos y parientes" (BECCARIA, 1955: 277). Algunos juristas argentinos como Tejedor y Sáenz Peña, creían que ciertas penas podían tener un efecto protector y disuasorio sobre los potenciales suicidas.
} 
Es preciso, señor Presidente, que al discutirse este punto, que al tomarse en consideración el suicidio, se considere más bajo el punto de vista legal que bajo el punto de vista filosófico. El señor diputado Saldías no puede negar que el suicidio es y será siempre un delito. ${ }^{57}$

Sáenz Peña, creía conveniente la retención del suicida, para evitar que este se quitara la vida: "la ley es benigna y benéfica, puesto que tiende a impedir el atentado". Es decir, prevenía una acción criminal más que castigar al que la llevaba adelante:

Si la ley propone penar a este, es porque evidentemente nada haría la autoridad ni las medidas represivas para impedir la reincidencia del delito, y el suicidio se consumaría si se lo dejara en completa libertad, puesto que no hay razón ninguna para suponer que se había estinguido aquel sentimiento superior a la razón, que movió el brazo de un individuo para disparar el arma sobre su cabeza. ${ }^{58}$

Si Sáenz Peña proponía concentrarse en la perspectiva jurídica del problema, el diputado Enrique B. Moreno (1846-1923), ${ }^{59}$ por el contrario, llamó al resto de los legisladores a tener presentes las cuestiones filosóficas y éticas del asunto, que todavía eran motivo de debate entre pensadores y moralistas. En este sentido, Moreno destacaba que todavía no estaba claro si el suicidio debía o no ser considerado un delito. Al igual que Saldías, Moreno destacaba que "el suicida está en condiciones morales especialísimas que lo dejan ajeno a la reflexión, y es imposible que hiciera efecto sobre su espíritu una disposición penal de esta naturaleza". ${ }^{60}$ Dicho de otro modo, el que intentaba quitarse la vida no podía reflexionar con uso de razón sobre sus actos, por ende, era inmune a la influencia que pudiera ejercer la existencia de leyes penales referidas al suicidio. Además, este legislador señalaba que según las estadísticas de los países que castigaban a los suicidas, estas medidas no habían sido efectivas para hacer descender el número de casos. En este sentido, Moreno también destacó la ineficacia de la pena en los casos de una tentativa de suicidio frustrada; el que buscaba suicidarse encontraría el modo de lograr su cometido, incluso recluido: "se dejaría morir de

\footnotetext{
${ }^{57}$ Diario de Sesiones de la Cámara de Diputados de la Provincia de Buenos Aires, Buenos Aires, Imprenta de "El Nacional", 1876, p. 785.

58 Íbid., p. 786.

${ }^{59}$ Moreno había integrado los batallones de guardias nacionales, poseía formación en el conocimiento bélico y se había desempeñado como profesor de historia y geografía en la Escuela Militar; también había sido instruido en filosofía en la universidad. Los datos biográficos de los diputados que intervinieron en el debate provienen, entre otros, de CUTOLO (1968) y DE LUCA (2008).

${ }^{60}$ Diario de Sesiones de la Cámara de Diputados de la Provincia de Buenos Aires, Buenos Aires, Imprenta de "El Nacional", 1876, p. 786.
} 
hambre, por que además del sentimiento depresivo que lo domina, se agregarían las penas que los señores diputados sostienen, la de verse arrojado de la sociedad, la de verse alejado de su familia y la de verse sumido en un calabozo". ${ }^{61}$

Por otra parte, en su argumentación, Moreno resaltó otro aspecto del problema, el suicida no solía pertenecer a los estratos inferiores de la sociedad; en muchos casos se trataba de "hombres que están en perfectas condiciones sociales", comerciantes y padres de familia, que al fracasar en su tentativa serían encerrados, sumando motivos para que reincidieran en su intención de quitarse la vida. En línea con lo expresado por Moreno, según el diputado Julio Fonrouge (1848-1908), abogado, dada la extracción social de los suicidas, los castigos serían inaplicables en la realidad y se pasarían por alto en la práctica: "Nosotros tenemos leyes que rigen el suicidio; esas leyes no se cumplen, y así sucedería con este artículo si se aceptase". ${ }^{62}$ Por otra parte, Fonrouge consideraba el suicidio como un delito, pero su argumentación no dejaba de resultar ambigua: "Mientras las pasiones de los hombres subsistan ha de haber suicidio, el suicidio es un delito, yo por lo menos lo creo así; pero un delito digno de las almas grandes, como decía Napoleón". ${ }^{63}$ Para Sáenz Peña, estos argumentos eran inaceptables; el juez debía hacer valer lo establecido por ley. Fonrouge replicó: "El señor diputado olvida que el legislador es hombre, que el juez que va a aplicar la ley es también hombre y que todos los hombres tenemos pasiones y sentimientos, como los tiene toda la humanidad". ${ }^{64}$

Esta última declaración escandalizó a Sáenz Peña: “¿Es posible que se pronuncien en esta Cámara palabras de justificación de este crímen, cometido por un hombre porque no le ha ido bien en un negocio?". 65 Para Sáenz Peña, la extracción social de los suicidas (la mayoría, personas que habían sufrido "quebrantos en sus negocios") no era motivo suficiente para dejar de considerar los suicidios como actos delictivos. Mientras los diputados Moreno y Fonrouge negaban a Sáenz Peña estar "santificando el suicidio", un legislador que no había pronunciado palabra alguna hasta ese momento hizo su única intervención durante la sesión, Rafael Hernández (18401903), agrimensor y periodista, hermano del autor del Martín Fierro. Este diputado exclamó que el suicidio, lejos de ser un delito, era "un derecho". ${ }^{66}$

\footnotetext{
${ }^{61}$ Íbid., p. 786.

${ }^{62}$ Íbid., p. 787. Es probable que Fonrouge hiciera referencia a la legislación de la monarquía española que continuó vigente tras la independencia, hasta la sanción de los códigos provinciales.

${ }^{63}$ Íbid.

${ }^{64}$ Íbid.

${ }^{65}$ Íbid., p. 788.

${ }^{6}$ Íbid.
} 
En ese momento, intervino Santiago M. Bengolea (1825-1890), para tratar de moderar la discusión, y propuso recortar el tema dejando de lado cuestiones filosóficas y metafísicas, y circunscribir el debate al terreno legal. Asimismo, este hacendado católico manifestó estar de acuerdo con el castigo de aquellos que intentaran quitarse la vida, ya que serviría de ejemplo moralizador, aunque fuera poco frecuente su aplicación. Para Bengolea "es cuestión abstracta la de si un hombre tiene o no el derecho para suicidarse"; por otra parte, este diputado pensaba que la preservación de la vida era un principio incuestionable y evidente, reconocido por la "legislación universal" y las leyes de todos los países. El diputado Fonrouge le corrigió haciendo referencia a los datos presentados por Tejedor en el proyecto de código penal: el único caso que penaba a los suicidas, y a los que habían sobrevivido a una tentativa, era el código penal sardo, que había servido como antecedente a Tejedor sobre el tema de los suicidios. Fonrouge también agregó que sólo desde un punto de vista religioso podía argumentarse la condena y las penas para los que se quitaban la vida. Enrique Moreno, por su parte, volvió a insistir que los castigos a los suicidas no servían para disuadir o prevenir el aumento de las muertes por mano propia, dadas las condiciones morales en las que estaba el que trataba de quitarse la vida; y agregó que los casos de suicidio, lejos de ser una mera discusión abstracta, eran una "cuestión social".

Como quedó explicitado, del debate sobre los artículos relacionados con los suicidios participaron especialistas en leyes (Saldías, Sáenz Peña, Fonrouge), pero también legisladores con otro perfil socio-ocupacional: un hacendado (Bengolea), un agrimensor (Hernández) y un militar (Moreno). Sin embargo, las posiciones que tomaron en la discusión no coincidían con esta clasificación. Los juristas letrados estaban divididos en sus puntos de vista, al igual que los que no eran abogados. Esto implica que había un dilema que iba más allá de lo estrictamente jurídico.

Por un lado, los legisladores no se ponían de acuerdo si el suicidio era o no un delito. Para algunos (Sáenz Peña, Bengolea), se trataba de un crimen que era difícil de castigar en la mayoría de los casos. Esta postura estaba más en línea con una concepción religiosa del tema, que consideraba el quitarse la vida como una falta grave hacia Dios, y con las posturas filosóficas que lo entendían como un atentado hacia la comunidad. Si se consideraba inconveniente castigar a los que se habían quitado la vida era para evitar prácticas incivilizadas (maltrato del cuerpo del difunto, exposición del mismo, negación de sepultura), que sólo recaían en un cadáver y perjudicaban a los deudos. En este sentido, si bien consideraban el suicidio como un delito, no estaban de acuerdo con este 
tipo de penas, al igual que Tejedor, que lo dejaba aclarado de forma explícita en las notas de su código.

Otros, como Saldías o Moreno, planteaban que no se trataba de un delito, o que, por lo menos, no podía ser catalogado como tal en todos los casos; en muchos, los suicidas se encontraban en un estado mental y emocional que no les daba la posibilidad de un razonamiento con total discernimiento. Este argumento estaba más en línea con los discursos científicos y médicos que asociaban a los suicidios con la alteración total o parcial de las facultades mentales, y con el malestar de la vida en el mundo civilizado, la "cuestión social". La muerte por mano propia era un desenlace trágico, e indeseado, pero no se trataba de un crimen.

Por último, aparecieron algunas concepciones más ambiguas: Fonrouge expresaba que desde su punto de vista el suicidio era un delito digno de las "almas grandes"; y Rafael Hernández irrumpía de forma provocadora al exclamar que se trataba de un derecho. Este tipo de argumentos estaban vinculados con la admiración que despertaban algunos personajes históricos célebres, como los de la antigüedad grecoromana, que por medio de su razón tomaban la firme determinación de quitarse la vida, sin mostrar signos de cobardía. En este sentido, algunos miembros de la elite defendían una concepción estoica sobre el tema, y entendían que existía una pequeña minoría de casos en los que el suicidio era un derecho, e incluso, un "supremo refugio".

En suma, de acuerdo con estos puntos de vista, el suicida podía ser considerado un delincuente, un loco moral o alguien digno de respeto y hasta de admiración. Como veremos más adelante, estas posturas también eran debatidas por las elites intelectuales.

En segundo lugar, más allá de definir si la muerte por mano propia era un delito o una acción válida, los legisladores debatieron si tenía algún sentido establecer penas para estos actos, aunque sólo fuera como un medio de prevenir y disuadir a los que trataban de quitarse la vida. En esta dirección apuntaba Tejedor con los artículos presentes en el proyecto y así lo destacaban Sáenz Peña y Bengolea. Si bien consideraban el suicidio como una acción delictiva, también hacían hincapié en el espíritu preventivo y protector del artículo referido a las tentativas. El resto de los legisladores no compartió su punto de vista, ya que consideraban ineficaz y/o contraproducente establecer medidas punitivas o de reclusión para los que intentaran quitarse la vida. Finalmente, se votó la moción del diputado Moreno, y se decidió sacar el artículo $1^{\circ}$ y $2^{\circ}$ del título referido a los suicidios del proyecto de Código Penal de la Provincia de Buenos Aires. En la sesión del 27 de octubre de 1877, los miembros del 
senado provincial aprobaron el código con las modificaciones propuestas sin mayores reparos. ${ }^{67}$ El tema que abrió la polémica, en este caso, fue el de los delitos que atentaban contra la religión. ${ }^{68}$ Así, de los tres artículos referidos a las muertes por mano propia propuestos por Tejedor, sólo el tercero quedó incluido en la legislación sancionada en 1877, en el artículo 220:

El que a sabiendas preste a otro medios para que se suicide, será castigado con uno a tres años de prisión.

El que lo ayude a la ejecución del homicidio cooperando personalmente, sufrirá el mínimun de presidio o penitenciaria. ${ }^{69}$

¿Por qué no fueron tomadas en cuenta las propuestas de Tejedor sobre el tema? Creemos que el clima de época ya no era favorable para establecer penas a los suicidas, más allá de que estas fueran pensadas con un carácter preventivo. Los castigos dispensados a los que se quitaban la vida eran un ícono del oscurantismo medieval. En una época de floreciente fe en la ciencia, el progreso y la civilización, conservar este tipo de sanciones en la legislación penal no despertaba simpatías en la mayoría. Además, las leyes de los países europeos no contenían disposiciones similares a las propuestas por Tejedor. Asimismo, el prestigio de las disciplinas científicas, como el alienismo, estaba en auge. El discurso del saber médico restaba capacidad de agencia a la mayoría de los individuos que se daban la muerte por su propia mano; estos episodios eran considerados, en la mayoría de los casos, como el producto de estados apasionados anormales o de enfermedades mentales. La creciente legitimidad de las ideas médicas y

\footnotetext{
${ }^{67}$ Diario de Sesiones de la Cámara de Senadores de la Provincia de Buenos Aires, año 1877, Buenos Aires, Imprenta Rivadavia, 1877, pp. 859-872.

${ }^{68}$ Sobre este punto, véase, entre otros, BASALO (1998) y DÍAZ COUSELO (2014). Como señalan ambos autores, el proyecto presentado en 1876 por el diputado Carlos L. Marenco en la legislatura bonaerense suprimía todos los artículos propuestos por Tejedor en el título $4^{\circ}$ ("De los crímenes y delitos contra la religión"). En este último, figuraban cinco artículos. El primero planteaba las penas para quienes intentaran abolir o variar la religión católica, apostólica, romana; en el segundo, se establecía el castigo para los que "celebraran actos públicos de un culto que no sea el de la religión católica, apostólica, romana"; el tercero estaba relacionado con la sanción de hechos relacionados con atentados a las prácticas del culto católico (profanación de la eucaristía, de las imágenes, vasos y otros objetos sagrados; interrupción de ceremonias públicas; difamación de los ritos del catolicismo); el artículo cuarto contemplaba las penas para aquellos que ofendieran o maltrataran a los miembros del clero; por último, el quinto artículo planteaba sanciones para los que exhumaran cadáveres con el propósito de mutilarlos o profanarlos (DÍAZ COUSELO, 2014: 49-55). Estos enunciados fueron reemplazados en la propuesta de Marenco, y en el Código aprobado en 1877, por un único artículo que establecía: "Todo acto de irreverencia cometido en lugares destinados al culto católico o el de cualquier otra religión autorizada, será penado con arresto que no baje de 15 días, ni exceda de tres meses, siempre que el acto no asuma el carácter de alguno de los delitos previstos y penados en este Código, en cuyo caso se aplicará la pena del delito que el acto importe".

${ }^{69}$ Código Penal de la Provincia de Buenos Aires, 1996 [1877], Madrid, A-Z Editora.
} 
alienistas y la tendencia a la despenalización en el mundo occidental restaron fuerza a los argumentos de los que estaban a favor de castigos ejemplificadores y de penas preventivas para los suicidas. Por otra parte, no es casual que en la discusión surgiera el ejemplo del hombre de negocios y padre de familia que, frente a la quiebra y la deshonra, se suicidaba. A diferencia de los otros delitos, el perfil verosímil del suicida, para los diputados que participaron del debate, era este sujeto de género masculino que había perdido su posición económica y social; así lo imaginaban tanto aquellos que estaban a favor de las penas para los casos de suicidio, como los que argumentaban en contra. Es probable que varios legisladores sintieran empatía con este tipo de hechos, y tuvieran amigos y conocidos que habían pasado por eventos desafortunados similares, e imaginaban las penosas circunstancias (el sufrimiento emocional y el escándalo público) que debería atravesar el individuo que había intentado quitarse la vida y sus familiares. Es decir, para muchos resultaba comprensible, y digna de compasión, la trágica y difícil situación que pasaba este hombre público, jefe de familia, que por un golpe infortunado del destino quedaba en la ruina y veía comprometido su buen nombre. Por esta razón, más allá de que se estuviera a favor de la reclusión del que había intentado suicidarse o de dejarlo al cuidado de sus seres queridos, la prioridad de los legisladores no era el castigo, sino preservar la vida del que, en ese momento, veía nublada su capacidad de decidir con libertad y evitar padecimientos a su familia y amigos.

La versión del Código Penal de Buenos Aires fue la base que tomaron algunas provincias para elaborar sus legislaciones provisionales, mientras el Congreso Nacional sancionaba un código para todo el territorio argentino. Así ocurrió en las provincias de Entre Ríos (1878), San Juan (1878), Corrientes (1878), San Luis (1878), Catamarca (1878), Mendoza (1879), Santa Fe (1880), Salta (1880) y Tucumán (1881). En Jujuy y Santiago del Estero, los debates legislativos sobre el tema no prosperaron. Las autoridades de La Rioja, por su parte, aprobaron, en 1876, antes de que Buenos Aires se definiera sobre este asunto, el proyecto Tejedor sin introducir modificaciones, incluyendo así todos los artículos referidos a los suicidios. La provincia de Córdoba fue la única que no tomó como base ni el código propuesto por Tejedor, ni el de la provincia de Buenos Aires. Los legisladores cordobeses optaron por adoptar, en 1882, el proyecto de Código Nacional elaborado por Sixto Villegas, Andrés Ugarriza y Juan Agustín García, agregando algunas modificaciones. Entre estas, incluyeron el artículo referido a 
las tentativas de suicidio del proyecto escrito por Tejedor. ${ }^{70}$ En el texto presentado por Villegas, Ugarriza y García al Congreso de la nación, en 1881, el único artículo referido a los suicidios era el que estaba incluido en el código penal bonaerense sobre la ayuda o colaboración personal. ${ }^{71}$

Los códigos penales provinciales estuvieron en vigencia hasta que fue sancionado el aprobado por el Congreso Nacional, en 1886. Si bien la legislación nacional respetó, en líneas generales, lo estipulado por el proyecto de Tejedor, hubo algunas modificaciones. Como señala Di Gresia (2014: 459): "Las dos grandes diferencias fueron, por un lado, eliminar los delitos contra la religión como forma tipificada de delito, y, por el otro, eliminar el delito de suicidio de los delitos contra las personas". La legislación nacional, aprobada en 1886, directamente no incluyó ninguna mención sobre el suicidio. ${ }^{72}$

Sin embargo, el código nacional fue el blanco de críticas y cuestionamientos, en especial, por parte de los representantes de la Escuela Positiva, un grupo de juristas que estaban nucleados en la Sociedad de Antropología Jurídica. Fundada en 1888, entre sus integrantes estaban Francisco y José María Ramos Mejía, Rodolfo Rivarola, Norberto Piñero, José Nicolás Matienzo (DI GRESIA, 2014: 462). Los últimos tres fueron los integrantes de la comisión que en 1890 fue designada para reformar el Código Penal. En junio de 1891, presentaron un proyecto con una serie de reformas, aunque éste nunca fue debatido en el parlamento. Entre los cambios que proponían estaba la inclusión de un artículo referido a la ayuda o colaboración en suicidios de terceros, similar al que estaba presente en el código provincial bonaerense de 1877. Así, en su artículo 114, rezaba: "el que instigare a otro al suicidio o le ayudare a cometerlo, será reprimido, si el suicidio tuviere lugar, con la pena de uno a cuatro años de penitenciaría". Quienes elaboraron este proyecto, destacaron que había sido adecuado eliminar las penas que Tejedor había establecido en su propuesta para los suicidas. Lo

\footnotetext{
${ }^{70}$ Sobre este tema, véase, entre otros, BASALO (1998).

${ }^{71}$ Los miembros de la Comisión encargada de revisar el proyecto de Código Penal (Sixto Villegas, Andrés Ugarriza y J. A. García), en la carta dirigida al Ministro de Justicia, Culto e Instrucción Pública, que acompañaba el proyecto de 1881, señalaban: "En el capítulo relativo al suicidio, se ha adoptado la doctrina sancionada por la Provincia de Buenos Aires al aceptar el proyecto del doctor Tejedor". Véase, Sixto Villegas, Andrés Ugarriza y Juan Agustín García, Proyecto de Código Penal, Buenos Aires, Imprenta El Nacional, 1881, p. XXXVII, de la carta que antecede al proyecto. El Artículo 216 del mismo (p. 95) decía lo siguiente: "El que a sabiendas preste a otro medios para que se suicide será castigado con prisión media. El que lo ayude a la ejecución del suicidio, cooperando personalmente, sufrirá penitenciaria menor".

72 Código penal reformado y leyes complementarias de la República Argentina en vigencia desde el 1 de marzo de 1887 (1919), Buenos Aires, M. A. Rosas, pp. 40 y 41. En esta edición, se especifica la introducción de los “delitos contra la vida" a partir de la ley 4189 de 1903.
} 
equivocado era "guardar silencio sobre la instigación y la cooperación al suicidio, a las que puede procederse por malignidad, por mal entendida misericordia o por interés" (GARDELLA, 1968: 953).

El tratamiento de la reforma recién se dio a comienzos del siglo XX. Tras la sanción de la Ley $\mathrm{N}^{\circ} 4189$ (en 1903), se incluyó, entre los delitos contra las personas, un subgrupo que aglutinaba a los delitos contra la vida (DI GRESIA, 2014: 462-464); entre estos últimos, estaba la ayuda / instigación al suicidio. Así, la reforma del código retomó lo planteado en el proyecto de 1891. Lo que cambió fue la pena: "tres a seis años de penitenciaría" ${ }^{73}$ La única variación, desde entonces, fue la cantidad de años de la sanción prevista para estos casos. El proyecto de 1906, por ejemplo, proponía, en su artículo 87, uno a cuatro años de prisión para quien instigare a otro al suicidio o le ayudare a cometerlo, si este tuviera lugar (GARDELLA, 1968: 953).

Las penas pensadas por Tejedor para los casos de suicidio no habían sido bien recibidas y eran consideradas como uno de los desaciertos de su proyecto de código penal. Sin embargo, al momento de encarar las reformas, los legisladores optaron por volver a incluir un artículo referido a los casos de ayuda e instigación al suicidio. ¿A qué se debió esta medida? Como mencionamos en la introducción de esta investigación, la eutanasia o cualquier tipo de asistencia para poner fin a la vida de una persona no era avalada por los juristas. En este sentido, el artículo incluido en la reforma servía para disuadir este tipo de acciones y diferenciar estos casos, movidos por una "mal entendida misericordia", de los homicidios.

Por otra parte, tenemos algunos indicios de otras situaciones de muerte violenta, que podían generar un dilema a la hora de juzgar a los implicados y que hacían necesaria la aclaración en el código penal sobre los casos de ayuda / instigación al suicidio. En este sentido, uno de los fenómenos que despertaban la curiosidad, la denuncia y el rechazo de varios intelectuales era el llamado "doble suicidio", en el cual dos enamorados decidían poner fin a sus vidas. Si en un caso de suicidio doble alguno de los implicados llegaba a sobrevivir, quedaba planteado un dilema: ¿era un homicidio o se trataba de un suicidio asistido? En ese caso, ¿debía considerarse un crimen, si el suicidio no lo era? Para Eduardo Wilde (1917: 82), profesor de Medicina Legal de la Universidad de Buenos Aires entre 1875 y 1890, si bien no era un delito quitarse la vida, poner fin a la de otro sí debía ser penado, aunque este diera su consentimiento. Por

${ }^{73}$ Véase, Código penal reformado y leyes complementarias de la República Argentina en vigencia desde el 1 de marzo de 1887 (1919), Buenos Aires, M. A. Rosas, pp. 3-6. 
esta razón, consideraba que se trataba de un homicidio, de características particulares, que debía ser castigado. Según Juan Bialet Massé (1885: 229.), profesor de la cátedra de Medicina Legal de la Universidad de Córdoba, a la hora de aplicar las leyes a los casos particulares, la justicia francesa parecía mostrarse contemplativa con respecto a las tentativas de suicidio doble, tanto si sobrevivía uno de los amantes o los dos. Ejemplos de estas situaciones aparecían en los manuales de medicina legal de autores como el español Pedro Mata y el francés Legrand du Saulle, ya que, al tratarse de zonas intermedias entre la razón y la locura, generaban problemas a la hora de ser evaluados por la justicia y los peritos médicos. Para Mata (1866: 1015), si el que sobrevivía había actuado con sus facultades mentales alteradas, sería considerado inocente del cargo de homicidio, si, por otro lado, había permanecido en un estado apasionado, pero sin estar alienado, quedaría en manos de la justicia. De este modo, si alguno de los miembros de la pareja sobrevivía, el examen de las facultades mentales tendría un rol más decisivo, ya que de este dependería la absolución o la condena del que había quedado con vida. Pero para juzgar al que quedaba con vida era necesario contar con alguna clase de legislación que contemplara la posibilidad de ayuda o instigación al suicidio. Sin esta distinción se estaba sancionando a alguien por un delito que no estaba contemplado en el código penal, el suicidio, o se lo clasificaba dentro de la figura de homicidio, que implicaba otras circunstancias y penas más severas.

En síntesis, los artículos propuestos por Tejedor, que establecían sanciones para los que se quitaran la vida, no encontraron el suficiente apoyo entre los miembros de la elite como para ser incluidos en la normativa que fue aprobada en 1877, y en las legislaciones posteriores. En un clima de ideas positivista, para muchos miembros de la elite intelectual, resultaba anacrónico y poco efectivo castigar a los suicidas, como proponía Tejedor. Este tipo de medidas eran asociadas con el oscurantismo medieval y la superstición religiosa. El pensamiento moderno entendía al suicidio desde un punto de vista científico, dentro del universo de las alienaciones mentales, y consideraba poco efectivo y nada ventajoso reprimir a personas que, en la mayoría de los casos, no tenían conciencia de sus actos. Además, se consideraba que si se detenía o recluía a aquellos que buscaban quitarse la vida, probablemente volverían a reincidir en sus intentos.

Más allá de los argumentos puntuales esgrimidos por legisladores y juristas, creemos que la eliminación de los artículos del proyecto de Carlos Tejedor referidos a los suicidios nos habla de un avance del proceso de secularización de las conciencias, 
que alcanzó un nuevo umbral durante el siglo XIX. ${ }^{74}$ En este sentido, la secularización no sólo implicó un impulso de la laicización de diferentes instituciones y esferas de la vida social. Esto último ocurrió en paralelo con la separación de una esfera de lo religioso, que se diferenció de otros ámbitos como la ciencia, la economía, la política, etc., en constante recomposición y relocalización (DI STEFANO, 2011: 3). Este proceso de separación de la religión como una zona específica dentro de la cultura, se dio en un marco de pérdida de legitimidad de la autoridad religiosa y de una mayor individuación de las creencias. De este modo, puede hablarse de una secularización de las instituciones y otra de las conciencias que ocurrieron en paralelo. ${ }^{75}$

Si bien no todos los legisladores estaban de acuerdo en considerar al suicidio como un delito, todos tenían en cuenta el estado mental y moral del individuo que se quitaba la vida. Incluso los que planteaban las sanciones para los suicidas, como lo hacía Tejedor, resaltaban el carácter protector de las mismas, más que su lado punitivo, ya que este tipo de medidas carecían de toda legitimidad, eran consideradas "ridículas" e "ineficaces", además de ser inexistentes en la legislación de la mayoría de los países "civilizados"; al mismo tiempo, eran asociadas con los abusos del antiguo régimen, del fanatismo religioso y la sociedad medieval. En este sentido, todos fundamentaban que la prioridad era la protección de la vida individual del suicida para preservarlo a su familia y amigos y ninguno hacía hincapié en la sanción del que cometía dicho acto.

Por otra parte, como se desprende de los argumentos de los legisladores de la provincia de Buenos Aires en 1876, el avance del proceso de secularización y el desarrollo de conocimientos científicos sobre la salud mental no habían terminado con

\footnotetext{
${ }^{74}$ El proceso de secularización, cuyo inicio, en el caso hispanoamericano y en el Río de la Plata, se puede marcar durante las reformas ilustradas del siglo XVIII, llega a un primer umbral, según Di Stéfano, para mediados del siglo XIX. Para ese momento había temas que ya no eran motivo de discusión para el clero o para la clase política: la concepción secular de la soberanía y la ciudadanía, la tolerancia de la pluralidad religiosa de los "disidentes", la reforma de las estructuras eclesiásticas. Al terminar la primera mitad del siglo XIX, había un acuerdo general "para crear una esfera específica para 'encerrar' dentro de ella a la religión, que en época colonial ha impregnado todas las manifestaciones de la vida colectiva, y crear de tal modo espacios relativamente autónomos para otras esferas en proceso de conformación" (DI STÉFANO, 2011: 14). Un nuevo grado de secularización alcanzó la sociedad y el estado argentino en el período que va de 1880 a 1930, en el que las áreas de influencia estatal se ampliaron. En este sentido, las décadas finales de la segunda mitad del siglo XIX fueron un momento de avance de la laicización de diferentes esferas de la vida social. En este período, las autoridades sancionaron las leyes de registro civil, matrimonio y educación común, ocupando el estado el lugar de instituciones como la Iglesia. Este tipo de medidas avivaron los enfrentamientos entre católicos y liberales.

75 Como contraparte de la consolidación de los estados nacionales y modernos y el proceso de secularización y laicización en la segunda mitad del siglo XIX, las autoridades eclesiásticas en Roma buscaron estrechar lazos con los miembros del clero en los territorios americanos. A este proceso de centralización del poder de la jerarquía romana se lo ha denominado proceso de romanización. Sobre este tema véase, entre otros, DI STÉFANO y ZANATTA (2000) y GALLARDO y MARTINS (2014).
} 
el debate ético de fondo: ¿Era válido, en ciertas circunstancias, quitarse la vida? ¿Era siempre el resultado del extravío mental de un individuo? ¿O podía ser considerado un derecho, como exclamó el diputado Hernández en el calor de la discusión?

\subsection{Consideraciones finales}

Mientras que a mediados del siglo XIX ya habían alcanzado legitimidad, incluso dentro del clero, ideas como la soberanía popular y la necesidad de establecer marcos institucionales autónomos para el funcionamiento del clero y el estado, las décadas finales del siglo XIX y las primeras del XX fueron un período de nueva definición de los límites entre lo religioso y lo secular. Las reformas liberales de los gobiernos conservadores tendieron a desligar al clero y a la Iglesia de ciertas funciones (educación, registro de los nacimientos, defunciones y casamientos), que habían desarrollado por largo tiempo. Estas medidas fueron un reflejo de un contexto donde las conciencias habían alcanzado un nuevo umbral de secularización que permitió llevar adelante ciertos cambios. En este sentido, la legislación sobre el suicidio fue un signo claro de que condenas como las del derecho canónico de la época medieval eran intolerables para la elite conservadora liberal, que eliminó los artículos del proyecto de código penal de Carlos Tejedor. En síntesis, en el período que estudiamos continuó la definición de una esfera de la cosa pública y otra de lo privado, donde los miembros de la clase gobernante consideraban que es donde debían estar las creencias religiosas.

En paralelo con el declive de la autoridad eclesiástica, el conocimiento científico se volvió la norma y el criterio para determinar lo verdadero y lo legítimo. El auge del positivismo alcanzó su clímax durante la segunda mitad del siglo XIX, época de fe en el orden, la razón, el progreso, entendido como la evolución de la humanidad en la senda de la sociedad occidental europea. El creciente prestigio de las ciencias naturales, de las teorías evolucionistas y del pensamiento de intelectuales europeos, como Comte o Spencer, contribuyó a crear la representación de la sociedad como un organismo social que avanzaba en el camino de la civilización.

A partir de esta concepción, analizaron los cambios de la población y las prácticas de los habitantes, mientras los asentamientos urbanos crecían aceleradamente. Esto último trajo una serie de problemas que las distintas ramas de la ciencia positivista trataron de explicar y prevenir, como las enfermedades, el delito, la propagación de los 
vicios y los comportamientos inmorales (como el juego o la prostitución), las patologías mentales o las muertes por mano propia.

El higienismo, la psiquiatría alienista, la medicina legal y la criminología, desde diferentes ángulos, se ocuparon de estudiar los suicidios en Buenos Aires a medida que avanzaba la segunda mitad del siglo XIX. El mismo optimismo de los intelectuales positivistas argentinos los impulsaba a buscar las causas de esta suicidiomanía, o epidemia de suicidios, y los medios para prevenir futuras muertes.

Las ideas expresadas en los textos elaborados por los miembros de la elite cultural sólo pueden entenderse a la luz del contexto en el que fueron producidos. Las transformaciones económicas, políticas y sociales de la segunda mitad del siglo XIX y principios del XX despertaron la reflexión de los contemporáneos sobre una serie de fenómenos, entre estos estaban los suicidios. Desde nuestra perspectiva, la forma de representar las muertes por mano propia por parte de los miembros de las elites estuvo vinculada con las características del marco axiológico y los esquemas culturales de la época. De los cambios y continuidades de la vida material, social y moral durante el proceso de modernización, nos ocuparemos en el capítulo siguiente. 


\section{Capítulo 4: El proceso de modernización en la ciudad de Buenos Aires}

En el capítulo anterior expusimos las principales corrientes de pensamiento que interpretaron los suicidios durante las décadas finales del siglo XIX. Estas ideas eran enunciadas en un intento por comprender las transformaciones dinámicas que estaban sucediendo en la capital del estado argentino. En este capítulo, por otra parte, presentaremos de forma general las características y los cambios de la vida social y material de la ciudad de Buenos Aires, nuestro caso de estudio, en el último tercio del siglo XIX y principios del XX. Estos elementos fundamentales del contexto nos servirán para interpretar, en profundidad, las diferentes historias de los suicidas que analizaremos en los capítulos posteriores.

En primer lugar, cabe destacar que, desde mediados del siglo XIX, la economía argentina inició un agudo proceso de inserción en el mercado mundial. ${ }^{76}$ Los países capitalistas europeos entraron en un nuevo período de expansión, en el que integraron a otras regiones a su esfera de influencia, promoviendo el intercambio comercial (productos manufacturados por materias primas), la inversión directa de capital y los préstamos internacionales. El creciente desarrollo de las principales áreas industrializadas (Gran Bretaña, Francia, Alemania y Estados Unidos), trajo como consecuencia un aumento de la demanda de alimentos y materias primas. Así, la producción argentina ingresó de forma plena al mercado internacional de los intercambios comerciales. Si bien desde la primera mitad del siglo XIX se exportaban cueros, carne, tasajo y otros productos, el impulso definitivo ocurriría en la segunda mitad, en especial, a partir de 1880. Durante las últimas décadas del siglo XIX y comienzos del XX, la economía argentina experimentó un crecimiento inédito: mientras que la población se triplicó, la riqueza generada se multiplicó por nueve (ROCCHI, 2000: 19). Desde 1840 a 1880, la lana fue el producto más rentable en el mercado mundial. ${ }^{77}$ A principios del siglo XX, en cambio, las carnes (primero envío de ganado en pie, luego carne congelada y, más tarde, enfriada) y los cereales serían los que darían los mayores réditos a los productores rurales y a las casas de comercialización. ${ }^{78} \mathrm{La}$

\footnotetext{
${ }^{76}$ La bibliografía sobre el período de auge de la economía agroexportadora (fines del siglo XIX y comienzos del XX) es muy amplia; entre otros, véase, GALLO y CORTÉS CONDE (1984); CORTÉS CONDE (1979, 1992, 2000); ROCCHI (2000); REGUERA (2006a); MÍGUEZ (2008).

77 Sobre este tema, véase, entre otros, SABATO (1989).

${ }^{78}$ Para optimizar el proceso de engorde de los animales y mantener la fertilidad del suelo, los estancieros de la zona, a partir de 1890, empezaron a combinar el cultivo de forrajeras (maíz, por ejemplo, y más
} 
unidad de producción dominante fue la estancia: grandes extensiones de tierra dedicadas, en su mayoría, a la actividad pastoril. ${ }^{79}$ Así, Argentina se insertó como proveedora de materias primas para el mercado internacional. Al mismo tiempo, recibió del resto del mundo mano de obra y capitales, que le permitieron llevar adelante la transformación productiva y el salto en la escala de producción. Los países europeos tenían un excedente de población, y, al mismo tiempo, los salarios y las posibilidades de ascenso social que ofrecía el migrar a América del Sur, tentó a muchos italianos, españoles, franceses, entre otros, a dejar sus lugares de origen para mejorar su situación. Con el aumento demográfico local, la llegada de migrantes internos y de países limítrofes, $\mathrm{y}$, sobre todo, el arribo masivo de inmigrantes, fueron cubiertas las necesidades de mano de obra y se conformó un mercado de trabajo. En el Río de la Plata, dos factores de producción eran más escasos: mano de obra y capital. Mientras la tierra había sido el factor abundante durante la mayor parte del siglo XIX, la economía carecía de suficientes brazos. Al mismo tiempo, eran necesarias inversiones para impulsar las actividades productivas y las obras que volvieran rentable la producción para su exportación, por ejemplo, reducir los costos de transporte. Entre 1880 y 1889 , hubo un flujo constante de capitales extranjeros. ${ }^{80} \mathrm{En}$ su mayoría, estos fondos fueron destinados a la construcción de la red ferroviaria. ${ }^{81}$

Para lograr el éxito de la expansión agroexportadora, los intelectuales y la clase gobernante argentina estaban convencidos de la necesaria intervención del estado para resolver una serie de obstáculos. En este sentido, las acciones de las autoridades estuvieron orientadas a reducir los costos de transporte, atraer mano de obra y terminar con la inestabilidad en la frontera. Para captar capitales y trabajadores inmigrantes, las elites buscaron garantizar la seguridad, salvaguardar el respeto de la propiedad privada

tarde alfalfa), con la cría de ganado (GALLO Y CORTÉS CONDE, 1984; SESTO, 1999; ROCCHI, 2000; ZEBERIO, 2000; REGUERA, 2006a).

${ }^{79}$ Sobre el funcionamiento de los establecimientos ganaderos de la zona y sus características, véase, entre otros, ZEBERIO (2000) y REGUERA (2006a y 2013).

${ }^{80}$ La mayoría de los capitales invertidos fue inglés. Los principales compradores de los bonos del estado y los que construyeron los ferrocarriles fueron empresas de Inglaterra. Otros países también invirtieron en la economía argentina, entre ellos, Francia, Bélgica, Alemania, Italia, Estados Unidos. Algunos de los fondos fueron usados para respaldar el sistema monetario. También se utilizaron para financiar la construcción de obras públicas (como la ciudad de La Plata, por ejemplo, además de puertos, obras de salubridad, etc.). También hubo una serie de inversiones privadas destinada a medios de comunicación (telégrafos, teléfonos) y otras formas de transporte (tranvías) y negocios (compañías de tierras y seguros, y bancos, entre otros) (GALLO y CORTÉS CONDE, 1984: 38).

${ }^{81}$ La mayoría de las inversiones fue británica. El estado las incentivó a través de ciertas concesiones, como las garantías de rentabilidad ofrecidas a las empresas ferrocarrileras o el otorgamiento de una franja de tierras al costado de las vías férreas. La administración pública, por otra parte, encaró la construcción de aquellos trayectos que no eran atractivos para las empresas privadas. 
y unificar el marco político y jurídico. Es decir, era necesario lograr la consolidación del poder del estado. ${ }^{82}$

Dos hechos contribuyeron a afianzar la autoridad estatal en el territorio nacional. En primer lugar, los avances militares sobre las tierras ocupadas por los indígenas durante el siglo XIX. ${ }^{83}$ En el último tercio, las campañas del general Julio A. Roca en 1879 y las avanzadas militares en el Chaco y la Patagonia, terminaron de consolidar la dominación del estado y pusieron fin a un largo período de convivencia violenta y pacífica- entre los descendientes de europeos y las poblaciones de indios con prácticamente la desaparición de éstos. Tras el final de la campaña, fueron incorporadas 15.000 leguas $^{2}$ de tierra y sometidos 14.000 indígenas (GALLO y CORTÉS CONDE, 1984: 42-44).

Por otra parte, el estado central sólo estableció su dominio incuestionable luego de reprimir las rebeliones de las facciones de la elite, tanto en el interior como en la provincia de Buenos Aires. El levantamiento de 1880, encabezado por Carlos Tejedor, fue la última de las revueltas que cuestionaron seriamente la hegemonía de las autoridades del gobierno nacional. Los autonomistas porteños, que no se habían unido al Partido Autonomista Nacional (PAN), vieron frustradas sus acciones para impedir la federalización de la ciudad de Buenos Aires y fueron derrotados por las fuerzas del ejército nacional al mando del general Roca. Este último sería el sucesor de Nicolás Avellaneda en el cargo de presidente. Ambos eran políticos del interior y contaban con el apoyo de las elites provinciales y grupos de influencia en Santa Fe, Entre Ríos, Tucumán y Cuyo. Así, Roca sumaba, a su prestigio como líder militar, el respaldo político del resto de las provincias. Una facción de los miembros de las elites porteñas se oponía a su elección como presidente y al proyecto de federalizar Buenos Aires. La derrota de estos consolidó la autoridad del gobierno nacional (LOBATO, 2000a: 179-

\footnotetext{
${ }^{82}$ Lejos de ser un estado que no intervenía en asuntos económicos, como sostenía el credo liberal ortodoxo, el gobierno argentino de estas décadas participó activamente, por ejemplo, en la gestión de las concesiones de los ferrocarriles, en la creación de instituciones bancarias (como el Banco de la Nación Argentina en 1891), y protegió, por medio de aranceles, con cierto pragmatismo político, la producción de algunas regiones, como la zona azucarera de Tucumán. El estado también intervino para establecer una política cambiaria que beneficiara a los sectores que exportaban su producción. Había dos tipos de moneda. El peso moneda nacional y el peso oro. El primero, se devaluaba con cada emisión y no estaba sujeto a ningún tipo de cambio, el segundo, estaba atado al precio de la divisa en el mercado internacional. En la época, se hablaba del "premio del oro" para referirse a los sectores de la economía que recibían el pago por sus productos en oro y abonaban, en pesos devaluados, los salarios y otros costos de la producción en el mercado interno. Así, tanto la política cambiaria como la fiscal benefició a los grandes productores rurales y a las casas de exportación (ROCCHI, 2000: 39, 63-65).

${ }_{83}$ Para una síntesis del proceso de expansión de la frontera en la provincia de Buenos Aires, véase, entre otros, MANDRINI (1992) y CANCIANI (2013).
} 
184). Los sucesos de 1880, por otra parte, no fueron el fin de la construcción del aparato estatal, sino el inicio de una etapa en la que creció su presencia en las distintas regiones y se amplió la planta de funcionarios y empleados de la administración pública. ${ }^{84}$

Este proceso de modernización económica y política, que venimos describiendo de forma general, tuvo como efecto la transformación de la estructura y el paisaje urbano de la ciudad de Buenos Aires, así como las características demográficas de su población. La ciudad funcionaba como el nodo central para la comercialización de la producción del territorio nacional. Al ser exportada a través de su puerto, Buenos Aires funcionó como punto de recepción y acopio de los bienes primarios producidos en el interior. A partir de este circuito se estructuró la red ferroviaria que los trasladaba hacia allí. Al mismo tiempo, sus instalaciones portuarias fueron la vía de entrada de la población extranjera que arribaba y los productos importados que llegaban desde el mercado externo. Como señalan Scobie y Ravina (2000a: 19):

Cualquier expansión de las exportaciones, fuera en madera aserrada del Chaco, maíz de Santa Fe, cuero de Entre Ríos, lana de la Patagonia, harina de los molinos del Litoral, o carnero congelado o enfriado, o vacuno de los frigoríficos de la zona sur de la ciudad, impulsaba el crecimiento porteño más y más. [...] Y las importaciones, vinos finos y especialidades alimenticias de Francia, encajes y tejidos de Bélgica, artículos de Inglaterra, muebles y equipo agrícola de los Estados Unidos, pasaron por cuentagotas al campo y a las ciudades secundarias argentinas después de haber saciado la demanda de Buenos Aires y de haber dejado un beneficio respetable en los bolsillos de los porteños.

\footnotetext{
${ }^{84} \mathrm{El}$ estado necesitaba funcionarios para llevar adelante las tareas administrativas y burocráticas. Había una gran heterogeneidad en cuanto a la procedencia y la instrucción de gran parte de la burocracia. Sin embargo, en los cargos más altos, eran designados jóvenes egresados de las carreras de derecho y medicina de las universidades de Córdoba y Buenos Aires. Ambas profesiones eran prestigiosas y podían ser una vía de ascenso social o un camino para desarrollar una carrera política. También eran voces autorizadas para diagnosticar y analizar el organismo social, en un contexto de auge de las ciencias y su legitimidad. Al compás de la expansión de la planta de funcionarios públicos, creció el presupuesto para mantenerlos. Este pasó de 13,1 millones de pesos oro, gastados entre 1864 y 1869, a 187,4 millones entre 1910 y 1914 (LOBATO, 2000a: 187). Para sostener esta burocracia estatal, y pagar los servicios de la deuda externa, la mayoría de los ingresos del erario público provenía de los impuestos indirectos a las importaciones, pagados por todos los consumidores, sin diferenciar su nivel de ingresos. En menor medida, había impuestos a la exportación, sin embargo, la recaudación fiscal fue, en muchos casos, ineficiente, lo que condujo al endeudamiento externo para sostener los ingresos estatales. Es decir, como señala Lobato (2000a), el sistema tributario, en este período, era regresivo, ya que no era aplicado otro tipo de instrumentos fiscales, como los impuestos a la riqueza o a las ganancias para sanear las finanzas públicas.
} 
También cabe mencionar que la ciudad siguió albergando a las autoridades gubernamentales, así como a las diferentes dependencias estatales. Como capital de la nación, Buenos Aires atrajo hacia sí la actividad comercial, las inversiones, las obras públicas (puerto y ferrocarriles) y una gran cantidad de población extranjera. Al mismo tiempo, llegaron también políticos, comerciantes, abogados, educadores y propietarios del resto del territorio argentino, más tarde, conocidos como la "generación del 80", integrantes de las elites que compartían un mismo entusiasmo por el avance del progreso y de las ciencias (SCOBIE y RAVINA, 2000b, 167). Además, estaban asentadas allí las casas comerciales, las instituciones bursátiles, bancarias y financieras. La Bolsa de Comercio, ubicada en Plaza de Mayo, generó una intensa dinámica de actividad emprendedora y especulación, clima febril de los negocios retratado en "La Bolsa” de Julián Martel y “Quilito” de Carlos María Ocantos. Esto llevó a enriquecerse a algunos y también a terminar en la ruina a otros, como sucedió durante la crisis de 1890.

En síntesis, durante la segunda mitad del siglo XIX, la ciudad consolidó aún más el perfil comercial y administrativo que la caracterizaba desde la época en que era la capital del Virreinato del Río de la Plata. Por otra parte, la creciente actividad mercantil y burocrática, y el incremento demográfico acelerado, motivaron una serie de reformas, muchas veces a destiempo, para adecuar la infraestructura urbana a las necesidades de la economía y la población que la habitaba.

Así, en este capítulo, presentaremos aquellos cambios que transformaron la "gran aldea" de mediados del siglo XIX, y convirtieron a Buenos Aires en la "París de América del sud", como era caracterizada, ya como urbe moderna, hacia el centenario de la Revolución de Mayo, en 1910. De este modo, nos proponemos presentar, de forma general, las principales modificaciones del espacio, a partir de las reformas urbanas (obras sanitarias, parquizaciones, trazado de calles y avenidas), la modernización de los medios de transporte, los cambios en la estética de las construcciones, la variación de las características de la población, la alteración de los patrones de asentamiento de diferentes grupos sociales, los contrastes relacionados con la desigualdad social, en especial, entre el estilo de vida de las elites y la situación de las clases trabajadoras. En este sentido, también expondremos los distintos aspectos relacionados con la experiencia vital de los diversos actores sociales que habitaban la ciudad. De este modo, nuestro objetivo es distinguir las diferentes realidades que vivían los sujetos históricos, de acuerdo con su clase, género y etnia. Esto nos permitirá comprender el marco en el 
que tuvieron lugar los suicidios que estudiamos en los próximos capítulos.

\subsection{Los escenarios y su transformación}

Antes de 1870, como señala Scobie (1991: 202), las ciudades latinoamericanas despertaban poco interés en los visitantes europeos o norteamericanos que transitaban por la región, más impresionados por los paisajes naturales del nuevo mundo. Estos asentamientos concentraban la mayor parte de su movimiento en las manzanas cercanas a la plaza central; alrededor de ella estaban situados los principales edificios dedicados a las actividades administrativas, comerciales y religiosas. Cerca de allí, también estaban las residencias de las familias de mayor poderío y renombre de la elite colonial, construidas de acuerdo con el estilo hispánico. Asimismo, en el espacio próximo a la plaza estaban ubicados la mayoría de los mercados, oficinas, almacenes, clubes, teatros, iglesias y escuelas. La mayor parte de la población vivía lejos del centro administrativo y comercial, en viviendas construidas con los materiales más baratos disponibles, su aspecto era modesto al igual que la dieta de los que las habitaban (basada en uno o dos alimentos). A pesar del incremento de la actividad comercial, hasta el último cuarto del siglo XIX no dejarían de ser espacios en los que reinaba la falta de ruido y movimiento, salvo por hechos aislados (la llegada de embarcaciones al puerto, el tránsito de empleados domésticos que debían cumplir algún encargo, el ruido de caballos o carruajes, las mujeres que iban a misa), que irrumpían en el silencioso entorno. En las calles abundaban el polvo y los desechos de los habitantes. En las noches, éstas permanecían oscuras, sólo transitadas por aquellos pocos que se atrevían a deambular en las sombras, interrumpidas por las lámparas de algunos edificios (SCOBIE, 1991: 204205).

Buenos Aires no era la excepción, compartía características similares a las del resto de las ciudades de América Latina: estaba orientada hacia la plaza principal, el radio de su actividad y el terreno edificado no superaba 15 cuadras a la redonda, tomando como centro lo que hoy conocemos como la Plaza de Mayo. Allí se concentraban los edificios políticos principales y las residencias de las elites. Así, lo que hoy es la Plaza de Mayo estaba dividida en dos por una antigua arcada (que había sido erigida a fines del período colonial), conocida como La Recova Vieja, donde estaban ubicados los puestos y tiendas de algunos vendedores y artesanos, por ejemplo, sastres, 
zapateros y pasteleros. La mitad más cercana al río era llamada Plaza 25 de Mayo, a su alrededor estaba el antiguo Fuerte, transformado, por aquel entonces, en sede del poder ejecutivo nacional y de sus ministros. Alrededor de la plaza también se encontraban los edificios del Congreso Nacional y el primer Teatro Colón (obra del arquitecto Carlos Pellegrini). La segunda mitad de la plaza, situada más hacia el oeste, era denominada Plaza de la Victoria. Allí, entre algunos árboles y bancos, estaba el monumento que conmemoraba los hechos relacionados con la Revolución de Mayo, la Pirámide. Alrededor de la Plaza de la Victoria estaban los edificios donde funcionaban la Corte Suprema (situada en el antiguo Cabildo), el Concejo Municipal, el Cuartel General de Policía, la Catedral, la sede de la Curia y el Arzobispado.

En 1870, fuera de la actividad desarrollada en los muelles y calles, donde estaban ubicados los principales comercios, la ciudad permanecía silenciosa y tranquila (SCOBIE, 1977: 57-58). Con respecto a la higiene en el espacio urbano, como señala Scobie (1977: 71):

La acumulación de basura, la falta de un sistema de desagüe y el desborde frecuente de excusados convertían a muchas calles en algo más que cloacas abiertas. En los días calurosos de verano el olor de los desechos humanos y de los desperdicios en la calle Chile podía tornarse insoportable.

Fuera del sector de manzanas consolidadas cercanas a las dos plazas, se extendía una segunda zona con muy poca o ninguna edificación continua. Por último, la última franja que marcaba los límites del territorio de la ciudad correspondía a un sector de quintas pequeñas, que no superaban las veinticinco hectáreas, estas llegaban, aproximadamente, hasta lo que hoy es la avenida Boedo (CARIDE BATRONS, 2011: 40). Así, la población de la ciudad, 180.000 habitantes (SCOBIE, 1977: 58), habitó, hasta 1887, el territorio limitado hacia el sur y el este, por el Riachuelo y el estuario; hacia el oeste, por las calles Entre Ríos y Callao. El límite norte de la ciudad, siguiendo por Florida, era la Plaza de Marte (San Martín). Lo que sería conocido como Barrio Norte no había sido edificado; recién a partir de 1880, y durante la primera década del siglo XX, aparecerían los petits hotels y las residencias de las elites (SCOBIE, 1977: 83). También cabe mencionar que, a partir de 1887, se anexaron los terrenos del partido de Flores y Belgrano al territorio de la ciudad (SCOBIE y RAVINA, 2000b: 167). En 1870, estos 
estaban ocupados por las quintas y residencias de los miembros de la clase alta, local y extranjera, que podían afrontar el alto costo del pasaje en ferrocarril para trasladarse al centro de la ciudad. Por aquellos años, San José de Flores tenía reputación de espacio saludable, lugar ideal para el veraneo de las elites y, más tarde, como espacio para sus residencias.

\title{
4.1.1 El puerto y los ferrocarriles
}

Este paisaje se vería modificado durante las últimas décadas del siglo XIX en las principales urbes de América Latina. En el caso de Buenos Aires, fue necesario realizar una serie de transformaciones para favorecer el funcionamiento dinámico de las actividades productivas y atender a las necesidades del comercio de exportación. En este sentido, era fundamental modernizar los medios de transporte y las instalaciones portuarias. El creciente movimiento del puerto motivó la reforma de este. Como destaca Scobie (1977: 89):

\begin{abstract}
En 1870 la ciudad carecía de muelles sobre la costa. Las pequeñas naves, especialmente las encargadas del comercio costero podían entrar en el Riachuelo y anclar a lo largo de la ribera en la Boca y Barracas. Pero la orilla barrosa y baja, que algunas veces no alcanzaba una profundidad mayor de metro y medio, a un kilómetro y medio de la costa, obligaba a los grandes transatlánticos y barcos de vela que entonces pasaban de 400 toneladas y que calaban hasta 16 pies, a fondear a varios kilómetros de la costa en pleno estuario. Desde allí, la carga y los pasajeros bajaban o subían en una serie de etapas: primero a barcazas, luego a lanchas o a las carretas de altas ruedas que entraban en el río y finalmente a los muelles respectivos.
\end{abstract}

En la década de 1870 , se barajaban dos alternativas con respecto al puerto. La primera era instalarlo en la zona sur, utilizando como base el puerto de pescadores del Riachuelo (Proyecto del Ing. Luis A. Huergo); un segundo proyecto, presentado por un influyente comerciante de la ciudad, planteaba la construcción de las instalaciones al este de la Plaza de Mayo. Esta fue la visión que triunfó. A fines de septiembre de 1882 e inicios de octubre, el congreso dio su apoyo a esta segunda propuesta. La sección sur se inauguró en enero de 1889 y ese año se le dio el nombre formal de "Puerto Madero". El resto de las obras se completó en los años siguientes, a pesar de contratiempos y retrasos 
provocados por los efectos de la crisis financiera de 1890. Los diques primero y segundo en 1891, el tercero en 1892, el cuarto, junto con la dársena norte del puerto, en 1897. La obra se completó en 1898, luego del dragado final del canal norte, lo que permitió abrir, de forma completa, el sistema (SCOBIE y RAVINA, 2000a: 20-22). El puerto era la vía de salida de la producción de materias primas (lana, ganado en pie y, más tarde, carne congelada y granos) y la entrada de los productos importados.

En segundo lugar, para atender a los requerimientos de la economía primaria exportadora en expansión fue necesaria la instalación de una red ferroviaria que conectara las unidades de producción con el puerto. Buenos Aires fue el epicentro del sistema de vías férreas. Las líneas ferroviarias empezaron a marcar el crecimiento del asentamiento hacia tres polos: oeste, sur y norte (SCOBIE, 1977: 59- 61). En dirección a Plaza Once, lugar de llegada de las mulas y carretas y mercado de ventas al por mayor. A su alrededor comenzó a crecer un conjunto de manzanas. En Once, estuvo ubicada la terminal del primer ferrocarril del país, el Oeste, inaugurado en 1857. Este recorría un trayecto de diez kilómetros hasta el poblado de Flores y en 1870 llegó a la zona triguera de Chivilcoy. El Ferrocarril del Sur, a partir de 1865, comunicaba Chascomús, pasando por Barracas y la Boca, con la terminal, situada en Plaza Constitución (principal mercado mayorista del sur). Por otra parte, la expansión del Ferrocarril del Norte conectó el centro, desde la terminal ubicada en Retiro, con asentamientos pequeños, como Belgrano, San Isidro y San Fernando. En un principio, la gestión de la construcción de los ferrocarriles era con capitales locales y estatales. La expansión de las redes continuó, sobre todo durante las décadas de 1890 y 1900, guiadas por las directivas de las compañías británicas. Así, el Ferrocarril de Buenos Aires al Pacífico, conectó la capital federal con las provincias de San Luis, Mendoza y San Juan y, en 1910, alcanzó Chile. El Central Argentino conectó Buenos Aires con Rosario y con las provincias del centro y norte. El Ferrocarril del Oeste avanzó por las zonas agrícolas trigueras más ricas de la provincia de Buenos Aires y por la provincia de La Pampa. El sur, el más extenso de los cuatro, comunicó las zonas vinculadas con la ganadería vacuna y ovina, actividad que se había ido trasladando hacia el sur bonaerense y la Patagonia (SCOBIE y RAVINA, 2000a: 26-28).

Por otra parte, los rieles también fueron el escenario de sucesos trágicos, las muertes de los desesperados más pobres. Tirarse sobre las vías, cuando el tren estaba por pasar, era un nuevo modo de quitarse la vida, sobre todo para los que no tenían dinero ni para comprar un revólver, como mencionaron algunos cronistas. Muchos de 
ellos eran extranjeros que habían llegado al país con sueños y ambiciones de ascenso social. Para algunos, quizás, resultara triste, paradójico y desconcertante leer en los periódicos y diarios noticias sobre los suicidios de inmigrantes, que se quitaban la vida dejándose aplastar por las locomotoras, símbolos del progreso. Para otros, los suicidios eran un signo de que se dejaba atrás el pasado de barbarie, su multiplicación era un problema de los países adelantados.

\subsubsection{Palacios, unidades familiares y viviendas colectivas}

La modificación del paisaje y la estructura urbana de Buenos Aires también resultó de una adaptación a la llegada masiva de población extranjera y a los nuevos problemas asociados con las epidemias de enfermedades contagiosas. En este sentido, las consecuencias del brote epidémico de fiebre amarilla, durante la primera mitad del año 1871, llevaron a un punto de inflexión que abrió el debate sobre las cuestiones higiénicas a resolver. Durante el verano lluvioso de ese año, las grandes cantidades de mosquitos propagaron la enfermedad. Al principio, en los barrios de San Telmo y la Boca y, días después, se expandió a otras áreas. A comienzos del mes de marzo, reinaba el pánico: unas 100 personas morían por día. Las zonas afectadas empezaron a ser evacuadas y los cuerpos eran enterrados sin demora, antes de las seis horas de la defunción. En el mes de abril, las autoridades municipales habilitaron un cementerio nuevo para atender las emergencias, el Cementerio de la Chacarita. Al mismo tiempo, se limitaron las procesiones funerarias y se prohibió arrojar desperdicios a los ríos. Quienes podían hacerlo, salían de la ciudad para escapar de la peste; así lo hicieron entre 50.000 y 100.000 personas (SCOBIE, 1977: 157-159). Mientras la epidemia duró, la vida comunitaria e institucional se desarticuló. Los servicios religiosos y la actividad administrativa de las oficinas públicas cesaron, al igual que las patrullas de la policía y la recolección de residuos. El comienzo del invierno fue el momento de culminación de la epidemia. En cuatro meses, 13.000 habitantes murieron (cerca del 8\% de la población). Esta cifra de defunciones era inédita, sobre todo si se la comparaba con el número de muertes generado por brotes epidémicos anteriores. Los porteños ya habían padecido los efectos desastrosos del cólera (1867) y la fiebre tifoidea (1869) y episodios de viruela y difteria durante la década de 1860 . La clase gobernante y los habitantes de Buenos Aires sintieron el impacto y tomaron mayor conciencia de lo sucedido, 
quedando guardado en la memoria colectiva. Según los diarios, las causas de lo ocurrido eran: los desperdicios de los saladeros en el riachuelo, la situación de los conventillos hacinados de extranjeros y sucios, la falta de higiene de las barracas y los hospitales, el inadecuado modo de tratar los desechos humanos. ${ }^{85}$ Para construir una ciudad moderna debían llevarse adelante medidas que actuaran sobre estos problemas y pusieran fin a los desastres traídos por las epidemias de este tipo (ARMUS, 2000: 509).

Por otra parte, algunos empezaron a notar que la enfermedad no había afectado a los que habitaban en la zona de Belgrano y Flores; esto hizo subir el valor de los terrenos, así como el de los alquileres. Hasta ese momento, estos lugares eran destinados a retiros veraniegos, debido al clima menos húmedo y al aire más puro que allí se respiraba (SCOBIE, 1977: 155-156). Los comerciantes extranjeros, ingleses en su mayoría, habían adoptado como espacio de residencia las zonas alejadas de la ribera y de allí venía el origen de algunas localidades que se habían creado a medida que se extendía el tendido de la línea del Ferrocarril del Norte. Las elites locales tomaron el ejemplo y optaron por pasar los veranos y fines de semana en las quintas, apartadas del centro. En un principio, en dirección a Flores (SCOBIE, 1977: 159). En este sentido, a partir de la epidemia, el traslado de las elites hacia la zona norte tomó un mayor impulso, en busca de espacios más saludables. Desde los años cincuenta, las familias de renombre habían empezado a dejar su antigua área de residencia, al sur de la Plaza de Mayo, cerca de la "Manzana de las Luces", el Mercado Central y las tiendas elegantes de la calle Victoria. Los nuevos miembros de las elites, políticos provincianos, profesionales, comerciantes y banqueros se instalaron en el lado norte de la plaza, en particular, sobre las calles San Martín y Florida. Ésta última, al sur, era sinónimo de establecimientos comerciales para las elites (como los que vendían moda francesa, muebles o perfumes) (SCOBIE, 1977: 80-81); del otro extremo, era la sede para las residencias de las familias más acomodadas. Con el tiempo, el perfil comercial de Florida se consolidó y las residencias de las elites se situaron en el Barrio Norte y al noroeste de la Plaza San Martín (SCOBIE, 1977: 161-162). Con el cambio de locación, las elites también dejaban atrás los estilos más austeros y tradicionales de sus viviendas (conjuntos de ambientes que se desplegaban alrededor de patios centrales y sucesivos, en un lote rectangular). A partir de 1880, y durante la primera década del siglo XX, aparecerían los petits hotels y las residencias ostentosas de la zona norte (SCOBIE,

${ }^{85}$ Se desconocía que el verdadero transmisor del mal era un mosquito, recién se lo descubrió en 1900 (SCOBIE, 1977: 157-158). 
1977: 83). Según Scobie (1977: 84):

Estas casas de nuevo tipo eran altas y estrechas. Sus tres pisos aprovechaban mejor el terreno, cada vez más costoso, y proporcionaban mayor ventilación y luz que las casas bajas de uno y dos pisos. Un gran hall de entrada y recepción ocupaban casi todo el primer piso; en el segundo estaban el comedor, el escritorio y algunos saloncitos, mientras que el tercero se reservaba para los dormitorios. Las habitaciones de servicio y la cocina ocupaban el subsuelo.

Como señala Jorge Liernur (2000: 430), la vivienda era un modo de diferenciación para los miembros de las elites y la llamada "gente decente", era un elemento clave de la construcción de su identidad como grupo. Además del lujo de la ornamentación y su mobiliario y el acceso a servicios (red de agua y cloacas), la característica distintiva de estas residencias era la especialización de las funciones en los ambientes que las componían. Así, las habitaciones tenían formas diversas y estaban destinadas a actividades específicas: dormitorio, boudoir, baño, escritorio, salón de fumar, sala, halles, vestíbulos, cuartos de niños, cuartos de servicio, lavaderos, etc. (LIERNUR, 2000: 429).

Mientras que las familias de mayor alcurnia edificaban palacios monumentales, las clases medias, por su parte, emulaban este tipo de vivienda con espacios especializados en una dimensión menor. Si Flores y Belgrano se volvieron espacios de residencia para las elites, con la expansión de los medios de transporte, áreas como Villa del Parque, Villa Devoto o Villa Catalinas se convirtieron en suburbios de los empleados con salarios más altos y los profesionales, quienes podían pagar el costo de transporte en tren, y más tarde, tranvía. En estos barrios en formación, fueron edificadas casas suburbanas de diversa tipología. La opción más modesta y utilizada era la secuencia de cuartos sucesivos con galería lateral. Los que tenían un mayor poder adquisitivo edificaban una variante del hotel particular, con una forma más reducida, comprimida y alargada, para adaptarse a los límites de los lotes (LIERNUR, 2000: 430).

En general, la mayoría de los suicidas, como veremos, optaba por quitarse la vida en sus domicilios, buscando un ambiente de soledad e intimidad. Esto último era más factible en las casas de las clases medias y las elites. Allí, por ejemplo, algunos hombres se suicidaban en sus escritorios. En otros, las más de las veces, los actos suicidas eran llevados adelante en los dormitorios de la casa, donde había mayor 
privacidad, y menos posibilidades de ser interrumpido.

En varios casos, las viejas casas de las elites fueron ocupadas por la población extranjera que comenzó a arribar de forma masiva durante las décadas finales del siglo XIX. Así, estas residencias de la "gente decente" se convirtieron en conventillos; por ejemplo, así ocurrió con la de la "virreina vieja", construida a finales del siglo XVIII, en la esquina de Perú y Belgrano, y habitada por el Virrey Joaquín del Pino a principios del siglo XIX, y luego por su viuda. Del mismo modo, una vivienda de la familia Ramos Mejía (ubicada en la calle Bolívar №553) fue adaptada para funcionar como casa de inquilinos, albergando en su interior a 14 grupos familiares o más, en diferentes períodos (CICERCHIA, 2001: 168). Como señala Scobie (1977: 72), estos edificios estaban bastante deteriorados y, por esta razón, en la década de 1850, muchos habían empezado a convertirlos (luego de unas pocas reformas) en inquilinatos, lo que daba importantes ganancias a sus propietarios. A partir de la epidemia de fiebre amarilla y la llegada masiva de inmigrantes, este proceso se aceleró, lo cual generó el surgimiento de más conventillos al sur de la Plaza de Mayo. A estos, se agregaron edificios construidos con el objetivo de funcionar como inquilinatos baratos, destinados a los trabajadores de bajos ingresos (SCOBIE, 1977: 189). Para ello, se empleaban los materiales más económicos disponibles: chapas de cinc, tablas y tirantes de madera, otros elementos usados o de descarte y, en algunos casos, muros de mampostería (LIERNUR, 2000: 433-434). En 1880, existían alrededor de 1.800 conventillos, de los cuales 300 habían sido construidos con ese fin, tendencia que seguiría creciendo en los años siguientes. En las 24.000 habitaciones que los componían, vivían alrededor de 52.000 personas. En su mayoría, estaban ubicados en los barrios de Concepción, Piedad, Socorro, San Nicolás, Balvanera y San Telmo (CICERCHIA, 2001: 165). En 1887, alrededor de una tercera parte de la población que vivía en el centro residía en conventillos (SCOBIE, 1977: 150). A fines de la década del ochenta, cerca de 94.000 inquilinos ocupaban 37.600 cuartos. Así, la cantidad de estas casas de inquilinato creció constantemente hasta la década de 1890. Desde entonces, el número se mantuvo constante (2.500 viviendas colectivas), aunque aumentaron la cantidad de ocupantes dentro de cada una de estas (SCOBIE, 1977: 198-200). Si en 1880 el índice promedio de ocupación era de 2,16 personas por habitación, este pasó a ser de 2,49 en 1890 y 3,7 en 1913. Esta tendencia continuó durante las primeras décadas del siglo XX. Según Liernur (2000: 434), en 1917, el 88\% de los grupos familiares de las clases trabajadoras todavía vivía en hogares que constaban de una sola habitación. 
Los conventillos estaban construidos siguiendo una planta rectangular. Debido a como estaban divididos los lotes, el largo de los terrenos eran de 3 a 6 veces el ancho de los mismos. En general, los existentes entre 1870 y 1910 tenían las siguientes características edilicias: patio interior, alrededor del cual estaban dispuestas las habitaciones, una sola puerta de entrada desde la calle, habitaciones de 4 x 4 metros y una altura de 4,25 metros. Al final del patio, había algunos escasos retretes y piletones (LIERNUR, 2000: 433-434). En estos cuartos, vivían desde familias enteras hasta grupos de hombres solos de un mismo origen étnico y/o de un mismo sector ocupacional. Por ejemplo, en el edificio ubicado en la calle Potosí $\mathrm{N}^{\circ} 7$ :

Los 207 inquilinos de este conventillo ocupaban 30 habitaciones: el mismo espacio destinado a una familia acomodada de 10 a 15 miembros con 5 a 10 sirvientes. Algunas unidades familiares vivían en las habitaciones individuales: una lavandera española de 60 años con sus cuatro hijos, la mayor de los cuales era viuda y vivía allí con su hijo de seis años nacido en la Argentina; un zapatero italiano con su mujer y sus tres hijos, todos nacidos en Italia; un albañil francés con su mujer, lavandera, y sus cuatro hijos, todos porteños; una lavandera española viuda y sus cinco hijos, los tres mayores nacidos en Uruguay y los dos menores en Buenos Aires. Más común era el grupo de hombres, algunos solteros y otros casados, cuyas mujeres se habían quedado en Europa, que se unían para alquilar una habitación. Varios grupos así conformados vivían en aquella casa de la calle Potosí: seis españoles, cuatro de ellos, peones, y dos serenos; cuatro peones y cuatro serenos españoles; tres peones, tres serenos, dos vendedores de cigarrillos y un cocinero, también españoles: otros nueve de la misma nacionalidad, de los cuales siete eran peones y dos serenos. Con frecuencia, la unidad familiar y los grupos de hombres solos se combinaban: 11 españoles, incluido un carpintero, un sastre, dos sirvientes, un peón con su esposa y cuatro hijos, y una lavandera de 19 años; un cordobés y 15 españoles, incluidos tres matrimonios; ocho españoles y un matrimonio italiano (SCOBIE, 1977: 73).

Como se aprecia en la descripción anterior, la población en su gran mayoría era extranjera, lo que se expresaba en el vestuario, el acento, la comida y el lenguaje que hablaban sus residentes (SCOBIE, 1977: 85, 87, 88). En general, entre los inquilinos de un conventillo, predominaba una sola nacionalidad. Vivían más hombres que mujeres, todos dedicados, en general, a ocupaciones manuales no especializadas. Había una importante población infantil y cabe mencionar que los de diez años o mayores, en su mayoría, trabajaban. En general, las parejas estaban casadas, aunque había algunos que vivían en concubinato (SCOBIE, 1977: 73-74). 
Como señala Scobie (1977: 192), la vida del conventillo no dejaba demasiado espacio para la privacidad: "Cada unidad o habitación disponía de alguna intimidad mientras la puerta permaneciera cerrada y una cortina cubriera la única ventana que daba al patio". Esta cortina de paja también servía para protegerse de las moscas. Para cocinar, los inquilinos recurrían a braseros a carbón, colocados en un cajón o repisa a la entrada de las habitaciones o, algunas veces, adentro. En las hornallas, estaban la pava para el mate, la olla del puchero o la sopa, dependiendo la ocasión (CICERCHIA, 2001: 169). Los que ocupaban el cuarto disponían de alguna palangana para lavar o recolectar la basura y los desechos. Los muebles que se encontraban en cada pieza eran escasos y rudimentarios: una cama de dos plazas o algunos elásticos que servían como lecho (ocupados de forma alternada por los hombres que vivían en la misma habitación), una mesa, algunas sillas o bancos, algún baúl viejo $\mathrm{y}$, tal vez, alguna máquina de coser. En este sentido, cabe mencionar que algunos talleres funcionaban en las habitaciones: talabarteros, planchadoras, tacheros soldadores, costureras y modistos, entre otros, desarrollaban sus oficios en los cuartos (CICERCHIA, 2001: 169). Las piezas eran iluminadas por la escasa luz natural que entraba por la ventana y la puerta; por la noche, se utilizaba una lámpara de querosene o gas $\mathrm{y}$, años más tarde, alguna lamparilla eléctrica. Decoraban las paredes imágenes diversas (desde retratos de héroes populares hasta la imagen de alguna virgen o santo) o alguna fotografía de los familiares que habían quedado del otro lado del Atlántico (SCOBIE, 1977: 192).

Existían varias razones que motivaban a los extranjeros para residir en estos espacios precarios. En primer lugar, el ahorro que implicaba no gastar en transporte hasta sus empleos, muchos de ellos en la construcción de las nuevas obras públicas y edificios ubicados en el centro: bulevares, plazas, parques, empedrados, teatros, los palacios, bancos, juzgados, etc. Así, la mayor parte de las integrantes de las clases trabajadoras vivía cerca del lugar donde estaba colocado, o trabajaba en su propio domicilio. De manera análoga, las mujeres de los trabajadores (artesanos, jornaleros, etc.) se empleaban como lavanderas, planchadoras o costureras en residencias cercanas al domicilio del grupo familiar. En segundo lugar, los inmigrantes buscaban estar cerca de sus compatriotas. Dentro de un mismo barrio solía predominar un mismo grupo social y/o étnico. Del mismo modo, había conventillos en los que preponderaba alguna nacionalidad, aunque el barrio en sí contaba con la presencia de grupos de diferentes etnias (SCOBIE, 1977: 73-74). Al mismo tiempo, al permanecer en el centro de la 
ciudad, aunque fuera en condiciones muy precarias, la población extranjera podía disfrutar de los servicios y oportunidades allí disponibles, por ejemplo: el acceso a las escuelas y hospitales; los entretenimientos (escuchar música, bailar, compartir espacios de sociabilidad con sus connacionales, asistir a los circos, parques, carreras, riñas, etc.) o las mayores posibilidades de encontrar pareja (LIERNUR, 2000: 412-413).

Los conventillos albergaban a un cuarto o un tercio de la población que moraba en el centro de la ciudad (SCOBIE, 1977: 187). El resto de los habitantes del radio céntrico, en su mayoría (60 o $70 \%$ ), se alojaba en pensiones, departamentos con alquileres bajos, o casas de dos pisos en las que vivían dos o más grupos familiares. En estas viviendas, las condiciones no diferían mucho de las que brindaba el conventillo en cuanto al tamaño de las piezas, la situación de hacinamiento y los servicios disponibles (SCOBIE, 1977: 187). Por ejemplo, Scobie (1977: 76) menciona que existían en el centro:

[...] varios departamentos ocupados por un carrero italiano, su esposa de la misma nacionalidad y dos hijos; un grupo de cuatro solteros -dos italianos y dos españoles- dos de los cuales trabajaban como carreros, uno como peón y otro como tonelero; un zapatero italiano, su esposa lavandera, también italiana, y tres hijos; finalmente, en una habitación vivía sola una viuda alemana de 80 años.

Algunos artesanos, tenderos y empleados públicos, que disponían de mayores recursos, podían vivir en mejores condiciones: en residencias de tipo familiar o en pensiones menos hacinadas. En algunos casos tenían uno o dos sirvientes. Por mencionar un ejemplo, en la calle México, entre Bolívar y Perú, en una residencia vivía: "un comerciante de 45 años con su esposa, dos hijos mayores que ayudaban en el negocio familiar, cuatro hijos más, una tía soltera, una mucama y la cocinera" (SCOBIE, 1977: 74). Otros vivían en sus negocios: como los almaceneros, los dueños de tiendas y talleres artesanales, los propietarios de los cafés y despachos de bebidas, entre otros.

Como veremos, muchas de las historias que narraremos a lo largo de nuestro trabajo tuvieron como escenario los conventillos y diversas modalidades de casas de inquilinato o pensiones, en las que vivían varios individuos en una misma habitación. Hallar la posibilidad de suicidarse en soledad no era factible muchas veces. Así, encontramos relatos de suicidas que se hirieron delante de sus familiares, compañeros y/o amigos, mientras estos dormían, por ejemplo. En otros casos, mediante alguna 
excusa, el desesperado buscaba quedarse a solas en el cuarto. La ausencia prolongada o el estruendo del revólver atraían al resto de los vecinos hacia el lugar donde estaba el cuerpo del suicida o del moribundo. Si se había herido con un arma de fuego o un objeto cortante, encontrarían al muerto rodeado de un charco de sangre. Si, por otra parte, se había envenenado, hallarían los restos del veneno y el olor del mismo, como en el caso de los fósforos diluidos en agua. Por otra parte, había algunos actos suicidas que acontecían a plena vista de todos, en el espacio más expuesto de la casa: el patio. El mismo ámbito de la sociabilidad de los ocupantes, en algunas oportunidades, fue el escenario de estos sucesos trágicos, escandalosos y sangrientos.

La población más empobrecida y marginada, por otra parte, debía recurrir a un conjunto de alternativas de vivienda aún más precaria que las habitaciones del conventillo. Algunos vivían en ranchos de adobe y paja o en casillas fabricadas con materiales rudimentarios y baratos (madera y chapa de cinc). Estas últimas eran de un solo ambiente, de rápido armado y de fácil traslado (algo relevante en un contexto de venta de terrenos y expansión de las zonas edificadas), lo que permitía cambiar la ubicación de las casillas con mayor frecuencia. Este tipo de vivienda era característica del Barrio de la Boca y el Barrio de las Ranas (cerca de los basurales). Estas eran construidas sobre pilotes (en sus inicios), ya que eran edificadas en terrenos bajos (los más baratos). Algunos se instalaban en este tipo de alojamiento como una alternativa a los conventillos. Así, la construcción rápida del primer ambiente permitía el traslado de los inquilinatos superpoblados, llevando las pocas pertenencias y agregando, luego, nuevos ambientes con el correr del tiempo. Entre los más pobres y marginados estaban los llamados "atorrantes", personas sin residencia fija, vagabundos que deambulaban por la ciudad trabajando o dedicándose al ocio, de acuerdo con las imágenes de los medios gráficos. Estos buscaban refugio para dormir por las noches en las entradas de los teatros y las iglesias. La imagen estereotipada era la del extranjero sin dinero, domicilio o vestuario, caído en desgracia (LIERNUR, 1992: 110-114).

En síntesis, para la mayoría de los trabajadores asalariados y artesanos urbanos la posibilidad de una vivienda familiar propia estuvo fuera de su alcance durante las décadas finales del siglo XIX; en cambio, según Cicerchia (2001: 158), ser inquilino constituyó una parte central entre las experiencias que constituyeron la mentalidad de la gran mayoría de la población urbana de Buenos Aires durante este período, y lo siguió siendo en las décadas siguientes. Recién con la electrificación y ampliación de la red de 
tranvías, a partir de 1907, los descendientes de los obreros inmigrantes pudieron aspirar a un terreno propio donde edificar su hogar en las afueras (SCOBIE, 1977: 204; LIERNUR, 2000: 436-437). La posibilidad de tener una casa propia, de una a tres habitaciones, se volvió una posibilidad de movilidad ascendente para aquellos obreros que pudieron ahorrar, con la ayuda de todos los integrantes del grupo familiar, y acceder a la compra de un lote donde edificar el ambiente inicial, a partir del cual serían levantados los siguientes. En lotes de 9 metros de ancho y 36 a 45 de largo, a la primera habitación, que se convertía en cocina y comedor, se anexaban los dormitorios (SCOBIE, 1977: 229-231). Así, se formaron las nuevas áreas residenciales suburbanas, como Nueva Chicago, Villa Santa Rita o Villa Crespo, Villa Malcom y Villa Alvear, a partir del tendido que conducía hacia el cementerio de la Chacarita, y que, en 1910, se convirtieron en zonas urbanizadas (SCOBIE y RAVINA, 2000b).

Por otra parte, los recelos y la polémica acerca de la vivienda popular no mermaron en todo el período en estudio. Así, los alojamientos de los trabajadores estuvieron en el centro del debate vinculado con la llamada "cuestión social", del que participaron maestros, curas, moralistas, empresarios, especuladores, médicos, abogados, políticos y periodistas (LIERNUR, 2000: 437). Desde la ola de muerte provocada por la fiebre amarilla, las casas hacinadas que ocupaban los inmigrantes despertaban inquietud entre las elites. El diario "La Prensa" del 10 de abril de 1871, decía lo siguiente:

Viene haciéndose una convicción profunda: el que la gente pobre, que vive hacinada en las casas de inquilinato suministra al terrible flagelo que nos diezma, el combustible más favorable.

Cálculos sensatos hechos por personas que han visitado en estos días dichos lugares, estiman en un cincuenta por ciento, por lo menos, el número de víctimas que hace la fiebre entre esa gente [...] Si los conventillos son una amenaza de muerte para el resto de la población; si la gente pobre que vive en ellos estimulada por una codicia criminal permanece desafiando los furores del flagelo; si a pesar de las amplias y generosas ventajas que les ofrece la previsión oficial en la construcción de viviendas fuera de la ciudad no quieren aun esos inquilinos abandonar los focos terribles de infección, no queda más camino que obligarles a desalojarlos. ${ }^{86}$

Con el paso de las décadas, la preocupación por el potencial foco de enfermedades que

\footnotetext{
${ }^{86}$ La Prensa, 10 de abril de 1871, cit. por CICERCHIA (2001: 166).
} 
representaban los inquilinatos no mermó. A mediados de la década de 1890, Guillermo Rawson, por ejemplo, destacaba lo siguiente:

\begin{abstract}
Entremos con ellos a ese recinto oscuro, estrecho, húmedo e infecto donde pasan sus horas, donde viven, donde duermen, donde sufren los dolores de la enfermedad y donde los alcanza la muerte prematura: y entonces nos sentiremos conmovidos hasta lo más profundo del alma, no sólo por la compasión intensísima que ese espectáculo despierta, sino por el horror de semejante condición. De aquellas fétidas pocilgas, cuyo aire jamás se renueva y en cuyo ambiente se cultivan los gérmenes de las más terribles enfermedades, salen esas emanaciones, se incorporan a la atmósfera circunvecina y son conducidas por ella tal vez hasta los lujosos palacios de los ricos. ${ }^{87}$
\end{abstract}

Así, las epidemias pusieron en la mira de los profesionales de la salud a los conventillos, como potencial foco de contagio. De allí en adelante, las autoridades ensayaron reglamentos poco realistas, en los que se proponía, por ejemplo, que el máximo de ocupantes por habitación fuera de dos personas. Las sucesivas normativas posteriores buscaron imponer un límite de tres camas por habitación, una inspección municipal de los establecimientos con más de cuatro piezas (1875), la no utilización de materiales precarios (1883), la provisión de al menos una ducha para mujeres y otra para hombres (1893), y sólo en 1904 se determinó la cantidad de retretes y otros aspectos sanitarios básicos de acuerdo a la población que habitaba cada vivienda colectiva (LIERNUR, 2000: 435). La demanda de vivienda por parte de una población en constante crecimiento hacía difícil reglamentar las condiciones de vida de los habitantes de los conventillos (SCOBIE, 1977: 196-197). Por esta razón, las condiciones higiénicas de estas viviendas colectivas no mejoraron hasta comienzos del siglo XX. A partir de entonces, los servicios básicos, como agua corriente, cloacas y recolección de desperdicios, se garantizaron con más frecuencia y de manera más efectiva. En el centro de la ciudad esto ocurrió antes; en los suburbios, en cambio, la precariedad continuó por más tiempo (SCOBIE, 1977: 198-200).

${ }^{87}$ Guillermo Rawson, Estudio sobre las casas de inquilinato de Buenos Aires, cit. por CICERCHIA (2001: 167). 


\subsubsection{Geografia higienista del organismo urbano}

En este sentido, como señala Zimmermann (2000), las medidas iban a destiempo con los procesos de expansión urbana de la capital del estado argentino, en un proceso de evolución demográfica que superó las expectativas de las elites políticas e intelectuales. Si en 1869, alrededor de 1.737 .000 argentinos vivía en ciudades (el $28,6 \%$ ), en 1914 , el $52,7 \%$ de la población total (alrededor de 7.800 .000 habitantes) residía en asentamientos urbanos. En el marco de este proceso de revolución urbana, la población de la ciudad de Buenos Aires creció de forma acelerada y fuera de toda proyección, producto, sobre todo, de la llegada constante de inmigrantes: de los 187.100 habitantes que residían en 1869, la ciudad paso a albergar 1.575 .800 en 1914 (LIERNUR, 2000: 411-412). Los que estaban asentados en las ciudades enfrentaban los devastadores efectos de las enfermedades infectocontagiosas y gastrointestinales. Entre las primeras estaban la fiebre tifoidea, el cólera, la fiebre amarilla y la difteria. Las víctimas de este tipo de patologías decrecieron a medida que se desarrollaron los sistemas de aguas corrientes y las redes de cloacas, entre otras mejoras en las pautas de higiene urbana. En el caso de la viruela, la cantidad de personas afectadas disminuyó como resultado de las campañas de vacunación. Las enfermedades gastrointestinales y la tuberculosis, por otra parte, continuaron causando una creciente cantidad de defunciones en la ciudad de Buenos Aires. De estos males, las epidemias causadas por las infectocontagiosas eran más visibles y afectaban directamente el funcionamiento y el ritmo de la vida en la ciudad. Por este motivo, fue necesario llevar adelante reformas para adaptar las características del espacio urbano al nuevo contexto de actividad comercial y a las inéditas dimensiones de la población que vivía en las ciudades del territorio argentino. De este modo, los episodios de escarlatina, fiebre amarilla, cólera, fiebre tifoidea, peste bubónica, disentería, viruela, sarampión, difteria, ocurridos en la segunda mitad del siglo XIX, fortalecieron la legitimidad y la autoridad de los profesionales de la salud y de las políticas públicas vinculadas al estado sanitario de las ciudades (ARMUS, 2000: 518-521).

Dentro del pensamiento higienista, que cambió con el correr de las décadas, la preocupación por la ciudad y su normal funcionamiento para garantizar el progreso de la nación tuvo un rol central como idea rectora. Los higienistas (en su mayoría, médicos) aportaron su saber sobre bacteriología para atender los problemas de las 
epidemias. Pasado el peligro inminente de estas enfermedades, con el avance de las obras públicas, su atención se orientó a otras problemáticas como la pobreza y la asistencia social (ARMUS, 2000: 513). Desde las instituciones creadas por estos, se promovió la realización de obras sanitarias y la difusión de hábitos y conductas saludables (ARMUS, 2000: 513-516).

Desde este paradigma, inspirado en las ciencias naturales de la época, la ciudad era entendida como un organismo vivo, que podía evolucionar y progresar, o, por el contrario, degenerar y enfermar. Al recordar los sucesos ocurridos como resultado de la propagación de la fiebre amarilla en 1871, Paul Groussac comparaba la situación de la ciudad de Buenos Aires con el estado de un cuerpo enfermo: un organismo al que se le estaba agotando la vitalidad, cuyos órganos ya no respondían de manera armoniosa y adecuada. Tras la epidemia, la idea de un "cuerpo urbano" se popularizó y se volvió una metáfora frecuente en el discurso de las elites políticas e intelectuales. Así fue utilizada por el presidente D. F. Sarmiento en su discurso inaugural, el 4 de julio de 1871, en el que mencionaba la necesidad de garantizar aquellas obras públicas que constituirían el organismo de las ciudades, para referirse a la red de agua potable. Prueba de la fuerza retórica de esta analogía biologicista era su utilización para pensar la nación como un organismo (CARIDE BARTRONS, 2011: 37-38; 42). Así, las décadas finales del siglo XIX y las primeras del XX fueron un período de reflexión sobre la ciudad, como un cuerpo ordenado que necesitaba ser correctamente administrado y normado para asegurar su correcto funcionamiento. En este sentido, el pensamiento higienista argentino, adaptación de las ideas europeas más prestigiosas, prestaba especial atención a dos cuestiones. Por un lado, todo aquello que resultara del amontonamiento de ciertos elementos que representaban un potencial peligro: las personas en las viviendas colectivas, los difuntos en los cementerios, los animales en los mataderos. Por otro, garantizar la circulación de los insumos vitales indispensables, como el agua y el aire. Por esta razón, daban mucha relevancia a la construcción de la red hídrica y al sistema de cloacas, a la apertura de grandes avenidas, por las que circularan corrientes de aire puro, y a la creación de parques y plazas, que actuaran como pulmones urbanos (ARMUS, 2000: 527, 529-530). Así, la ciudad fue pensada como un organismo vivo, con una serie de áreas y partes que actuaban como un todo ordenado, en el que era fundamental asegurar el correcto desarrollo de las diferentes funciones y procesos (alimentación, eliminación de desechos, oxigenación, circulación, etc.). 
Guiados por las ideas de este paradigma higienista, la clase política diagramó una serie de reglamentaciones y encaró una serie de medidas para atender las cuestiones relacionadas con la higiene pública en las ciudades, con el objetivo de avanzar en la senda del orden y el progreso, en línea con el pensamiento positivista en boga.

Según este ideario, era de vital importancia regular los flujos de agua y desechos para garantizar un crecimiento y desarrollo sano e higiénico de los habitantes, por ejemplo, mediante el correcto funcionamiento del sistema de agua potable, la instalación de la red de cloacas y la regulación del tratamiento de los residuos, así como de las pautas de enterramiento en los cementerios, ubicados lejos de las zonas comerciales y residenciales. Antes de la instalación de la red de agua potable, la provisión era cubierta recurriendo al Río de la Plata, por intermedio de los aguateros, a los arroyos (el Riachuelo y el Maldonado, por ejemplo), a pozos poco profundos o a los aljibes abastecidos por agua de lluvia (en estos dos últimos casos, en permanente contacto con los pozos ciegos, que recibían los desechos y residuos de los habitantes). El sistema de agua potable fue encargado en 1874 al ingeniero Juan F. Bateman, cuya construcción se puso en marcha tras la federalización de la ciudad de Buenos Aires en 1880. Las plantas de potabilización fueron instaladas en Palermo y el primer gran tanque de agua potable fue edificado en la Plaza Lorea. Sobre todo, a partir de 1883, la red empezó a expandirse con más velocidad y continuidad. Si a comienzos de la década del ' 80 , unas 5.000 casas eran abastecidas por la red (una cuarta parte de la ciudad), en 1909, el 50\% de las viviendas (más de 111.000) accedían al agua potable, mientras que otras 30.000 seguían recurriendo a los pozos comunes de las primeras napas y otras carecían de servicio alguno. El proceso de extensión de la red de aguas corrientes de la ciudad culminó en 1915 (ARMUS, 2000: 522; SARRAILH, 2006: 412-413).

En el caso de la red cloacal, la expansión de la cobertura se demoró varios años más. Las obras se iniciaron en 1874, sin embargo, aún en 1890 sólo el 10\% de las viviendas tenía dicho servicio. Desde 1888 a 1910, el avance fue más contundente en el área céntrica, mientras que en los barrios más nuevos llegó recién en 1913. En 1920, la cobertura no alcanzaba al 40\% de los hogares porteños (ARMUS, 2000: 522-523; LIERNUR, 2000: 432; SCOBIE y RAVINA, 2000b: 179, 182-183; SARRAILH, 2006: 412-413).

Con respecto al tratamiento de los residuos, este también estuvo en el centro de la agenda pública, sobre todo, luego de los estragos del ciclo epidémico de 1871. Hasta 
entonces, era frecuente tirar basura en los jardines de las casas, en la parte trasera de sus terrenos; otros, depositaban los desperdicios en baldíos o directamente los arrojaban a la calle. Como precaución para evitar otras epidemias, la Comisión Municipal, a partir de 1874, organizó el servicio de recolección de basuras (CARIDE, 2011: 43). Los desechos fueron tirados en las afueras de la ciudad, en las áreas cercanas a los cementerios, hospitales y asilos. A partir de la década de 1880, los desperdicios fueron trasladados a la zona sur cercana al Riachuelo, donde se estableció el Barrio de las Ranas. Allí, sobrevivían alrededor de 2.000 hombres, mujeres y niños en condiciones de extrema pobreza, revolviendo los desechos urbanos. En 1911, el basurero fue relocalizado en Nueva Chicago, cerca del matadero municipal (SCOBIE y RAVINA, 2000b: 179, 182183).

Los estragos de las epidemias también llevaron a ampliar los espacios de entierro disponibles en la ciudad y produjeron nuevas formas de llevar adelante las prácticas funerarias, como señala Maximiliano Fiquepron (2015: 229). En 1868, para hacer frente a la epidemia de cólera de ese año, se autorizó la apertura del Cementerio del Sur, ubicado en el actual Parque Ameghino (en el barrio de Parque Patricios). Ese mismo año, también se sancionó un nuevo reglamento para los cementerios. Este reemplazaba las normativas dictadas en la década de 1820 por el gobierno de Martín Rodríguez. Las grandes cantidades de defunciones provocadas por la fiebre amarilla en 1871 superpoblaron el Cementerio Sur y este debió ser clausurado. Como reemplazo, las autoridades habilitaron un nuevo espacio de entierro en los terrenos de la Chacarita de los Colegiales y el Cementerio del Oeste, ubicados en el poblado de Belgrano, a siete kilómetros del centro de Buenos Aires. Durante las epidemias de cólera y fiebre amarilla, las autoridades municipales dictaminaron que los cuerpos debían ser enterrados antes de pasadas las seis horas de la defunción, sin ceremonias o procesiones fúnebres, el acompañamiento estaba limitado y, más tarde, directamente prohibido. La policía y comisiones de vecinos estaban designadas para llevar adelante las tareas de traslado y entierro. Dado el apuro por alejar los cadáveres, potenciales focos de contagio, se dispuso del ferrocarril para trasladar los cuerpos de los difuntos. Así, el cementerio general quedó establecido en Chacarita y el traslado de los cuerpos pasó a partir de 1875 a manos privadas. El Ferrocarril del Oeste, a través de la empresa que lo administraba, se encargó, desde entonces, del traslado de los cuerpos de los difuntos y sus deudos. Con el paso de los años el cementerio se expandió. Al predio inicial, se le 
anexaron unas 95 hectáreas, lo que le daba una dimensión más similar a la que tiene en la actualidad (FIQUEPRON, 2015: 229, 231-232, 240, 243). Hasta 1893, Chacarita no tuvo un área destinada a bóvedas, sepulcros y panteones. Esto último, así como la lejanía del centro urbano, formaban parte de las pautas higienistas para el tratamiento de los cadáveres. Desde su creación, se había estipulado que "toda inhumación en el nuevo Cementerio, debe verificarse en la tierra [subrayado en el original], a la profundidad y en las condiciones que el Consejo de Hijiene [sic] determine" (FIQUEPRON, 2015: 242). Así, el Cementerio del Oeste sería destinado, principalmente, como lugar de reposo de los miembros de las clases trabajadoras de la ciudad y, más tarde, para los integrantes de las clases medias en expansión. El traslado, a través del servicio ferroviario, trastocaba las prácticas funerarias típicas de los habitantes de menores recursos: el velorio y el entierro quedaban separados en el espacio y el tiempo. Además, al tratarse de un espacio lejano y de instalaciones precarias, las nuevas condiciones del lugar de entierro iban en detrimento de las visitas de los deudos al cementerio, algo que estaba más a la mano de quienes tenían a sus muertos enterrados en el Cementerio del Sur, el protestante o el de la Recoleta (FIQUEPRON, 2015: 245).

Este último consolidó su perfil como espacio mortuorio de las familias de mayor alcurnia y renombre (SCOBIE y RAVINA, 2000b: 183). La Recoleta no fue un cementerio exclusivo de las elites durante buena parte del siglo XIX, aunque sí poseía una jerarquía de lugares y áreas: existía el espacio para las tumbas vendidas a perpetuidad y las bóvedas; la mayoría, por otra parte, era enterrada al ras del suelo, y los más pobres eran inhumados en las fosas comunes, al igual que los cadáveres de los desconocidos encontrados en la vía pública. Originalmente, se había pensado cerrar los cementerios de los protestantes y el de la Recoleta. Los que tenían terrenos a perpetuidad alegaron el derecho de inhumar a sus muertos allí; de este modo, este cementerio quedó destinado como espacio de entierro de las elites y de las figuras políticas, culturales e intelectuales de biografía destacada y área de la arquitectura funeraria monumental (FIQUEPRON, 2015: 241).

La epidemia de cólera de 1886 trajo otra novedad, la creación de los primeros crematorios, utilizados para tratar los cadáveres de los fallecidos por enfermedades contagiosas. La construcción de un crematorio fue promovida por algunos renombrados profesionales de la salud, como José María Ramos Mejía, Pedro Mallo, Telemaco Susini y José Penna, que incidieron con su punto de vista en las decisiones de las autoridades 
nacionales y municipales. Así, en 1886, se instaló un crematorio en la Casa de Aislamiento (actual Hospital de Enfermedades Infecciosas Francisco Javier Muñiz) y en el cementerio de la Chacarita, en los cuales se cremaron, ese mismo año, 1.184 muertos por cólera. Este tipo de tratamiento de los cadáveres quedaría reservado para los muertos por enfermedades infectocontagiosas (FIQUEPRON, 2015: 243). En 1903, se inauguró oficialmente el Crematorio de Buenos Aires en el Cementerio del Oeste. Una ordenanza, del mismo año, pautaba las normas a seguir en la cremación de los cuerpos. La incineración podía ser obligatoria para los cadáveres que podían transmitir alguna enfermedad, o voluntaria, aunque la práctica cremacionista no empezó a despertar mayor interés antes de 1920 (DAL CASTELLO, 2014: 169). ${ }^{88}$

Otras medidas destinadas a proteger la salud del cuerpo / organismo social estaban orientadas a la creación de parques, jardines, plazas, etc., que actuaran a modo de pulmones del espacio urbano, garantizando la limpieza y pureza del aire, así como su circulación, a través de calles y avenidas más amplias. Como señala Gayol (2000: 76):

En un contexto en donde la salud y la higiene social son objeto de discursos y prácticas, cuando se utiliza la metáfora de la sociedad como un organismo que funda un conjunto de representaciones que asocian la salud -física y moral- a los caracteres permanentes de la nación, los parques, paseos al aire libre y plazas rebasan ampliamente la vocación estetizante del gobierno e invocan aspiraciones sanitarias, educativas y regeneradoras.

Los parques y las plazas cumplían variadas funciones, las cuales fueron cambiando con el paso del tiempo (LIERNUR, 2000: 419). En este sentido, por un lado, eran un espacio para la pedagogía, orientada a la construcción de una identidad nacional en formación; por el otro, un medio para promover la salud en la población y prevenir futuras epidemias; como así también lugares para el ocio y el esparcimiento y un escenario de expresión estética. En el caso de Buenos Aires, uno de los ejemplos más emblemáticos de este tipo de equipamientos verdes fue el Parque Tres de Febrero, inaugurado en 1875. Desde comienzos de la década del ochenta, la construcción de paseos, parques y plazas fue constante, si en 1887 había 28 espacios verdes, en 1896 esta cifra ascendía a 56 y en 1906 a 77 (GAYOL, 2000: 78).

La ornamentación y diseño de estos lugares tenían por objetivo mostrar una

\footnotetext{
${ }^{88}$ Sobre las practicas funerarias durante la segunda mitad del siglo XIX en Buenos Aires, véase, entre otros, DAL CASTELLO (2014 y 2016) y FIQUEPRON (2015).
} 
imagen de progreso y esplendor a los visitantes del mundo "civilizado". Durante la intendencia de Torcuato de Alvear (entre 1880 y 1887), se dejaron sentadas las líneas principales que seguirían los emprendimientos de las gestiones posteriores para embellecer y cambiar el paisaje urbano de la ciudad de Buenos Aires. Estas acciones, por parte de las elites, tuvieron como foco el centro de la ciudad. En este sentido, una de sus principales y emblemáticas obras fue la unión de las dos plazas en una sola, luego de eliminar la vieja Recova, galería que dividía el área que ocupa en la actualidad la Plaza de Mayo. La Pirámide fue preservada gracias a la intervención de actores de la elite política como Sarmiento, Mitre y Avellaneda, quienes se opusieron a su destrucción (SCOBIE y RAVINA, 2000b: 168). Así, la Plaza de Mayo conservó su preeminencia. A su alrededor, se concentraron las novedades, desarrollos y servicios característicos de la modernización (agua, cloacas, iluminación a gas y, más tarde, eléctrica). Además, siguiendo la tradición de la época colonial y el siglo XIX, la plaza era el espacio que articulaba las principales actividades urbanas. Esto último se acentuó todavía más luego de 1880, con la federalización de la ciudad (SCOBIE y RAVINA, 2000b: 167). Asimismo, se embellecieron otras plazas y parques: la Plaza de Marte (actual San Martín), del Parque (Lavalle), Vicente López, Lorea (Congreso) y Constitución. En ellas, se plantaron árboles y arbustos, se edificaron masas de cemento, piedra y adornos de hierro forjado, también se trazaron senderos y "grutas" en algunas, como en el Parque Tres de Febrero, en Palermo (SCOBIE, 1977: 142).

Otras de las obras públicas que fue realizada en este período fue la pavimentación de las calles. A mediados del XIX, las calles carecían de nivelación e higiene. Los emprendimientos para limpieza y pavimentación tomaron impulso a partir de 1880. Al mismo tiempo, la autoridad municipal ensanchó algunas calles y creó otras en las que construyó bulevares. Los primeros fueron proyectados en la Avenida de Mayo, la Avenida Alvear y la calle Entre Ríos-Callao (LIERNUR, 2000: 419). El trazado y la edificación de la Avenida de Mayo fueron hechos en 1884. En 1889, empezaron las obras y en 1894, las 14 cuadras que componían la Avenida habían sido edificadas. Los edificios más modernos y suntuosos se construyeron en ella, por ejemplo, la Municipalidad, la sede del diario "La Prensa", los establecimientos de las grandes tiendas "A la ciudad de Londres" y "Gath y Chaves", o el edificio del "Grand Hotel". Estos tenían los servicios más modernos y habían sido construidos con materiales más nuevos y resistentes, como el hormigón armado (SCOBIE y RAVINA, 
2000b: 168). En el extremo opuesto de la Avenida de Mayo, fue erigido el nuevo edificio del Congreso Nacional, allí se trasladaron las autoridades en 1906. Las reformas urbanas de este tipo estuvieron inspiradas en las desarrolladas por George Haussman en París (SCOBIE, 1977: 165).

Junto con la eficiencia y el utilitarismo, la belleza también era sinónimo de progreso. Los miembros de las elites en América Latina eligieron seguir los cánones estéticos europeos, sobre todo franceses, para encarar el diseño de paseos y parques, así como la edificación de edificios gubernamentales y la construcción de monumentos conmemorativos. Estos últimos, además de un fin estético, tenían como objetivo fortalecer el proceso de formación de una identidad nacional en los ciudadanos de estados recientemente consolidados. Así, el paisaje urbano, además de responder a los ideales de la visión higienista, transmitía un mensaje a los habitantes de Buenos Aires y a los visitantes extranjeros, esos “ojos imperiales", siguiendo a Mary Louise Pratt (2011), que observaban e interpretaban mientras transitaban por la ciudad. En 1910, los que habían estado en la capital del estado argentino, como Georges Clemenceau (político francés), Joseph Antoine Bouvard (urbanista parisiense), o el criminólogo Enrico Ferri, entre otros, coincidían en destacar las coincidencias entre la apariencia de Buenos Aires (su infraestructura urbana y sus características edilicias) con la de París. Sus avenidas, la decoración y los adornos de los edificios públicos, las tiendas elegantes dispuestas sobre la Avenida de Mayo, captaban la atención de los observadores foráneos (SCOBIE, 1977: 28).

El proyecto urbano higienista no sólo se proponía generar un ambiente sano para impedir la difusión de las epidemias de enfermedades infectocontagiosas, sino también la higiene social, en este sentido, miraba con recelo otros espacios y prácticas anti-higiénicas, además de los conventillos, es decir, aquellos males sociales que corrompían la salud, la eficiencia y la respetabilidad de los trabajadores, como el alcoholismo y las enfermedades de transmisión sexual, en especial, la sífilis (ARMUS, 2000: 545).

Estas últimas estaban vinculadas con el ejercicio del comercio sexual y la presencia de los prostíbulos en el espacio urbano. ${ }^{89} \mathrm{La}$ alta demanda de la prostitución por parte de los hombres de Buenos Aires se explica, en parte, por el alto índice de

\footnotetext{
${ }^{89}$ Sobre el tema de la prostitución en este período, véase, GUY (1994 y 2014).
} 
masculinidad de la población, lo que condicionaba la posibilidad de encontrar pareja. Al mismo tiempo, el entretenimiento sexual gozaba de popularidad, tanto entre las elites como entre las clases populares, y había burdeles para diferentes estratos sociales. Hasta 1936, los hombres de todas las clases sociales solían iniciarse sexualmente en un cabaret (GUY, 1994: 64). Muchas de las mujeres que allí ejercían su actividad eran extranjeras, la mayoría de las veces venían de Polonia (Varsovia, Cracovia y Lvoff), ciudades afectadas por la pobreza y la falta de recursos para sostenerse. Llegaban a Buenos Aires, vía Montevideo, y ya en manos de los importadores eran subastadas, como si se tratara de esclavos (CICERCHIA, 2001: 184-185). Estas se sumaban al conjunto de mujeres nativas que se dedicaban al comercio sexual, legal o clandestino, en la ciudad. La prensa demostraba la preocupación por lo que sucedía entre los jóvenes, que eran atraídos a las casas de prostitución. Los varones de la elite, que se iniciaban sexualmente con las prostitutas, estaban en peligro de ser contagiados por males como la sífilis. En este sentido, el discurso médico abogaba por una vigilancia de las prostitutas y por controles y visitas médicas para evitar la propagación de enfermedades venéreas. Los médicos higienistas alentaban, además, a que se respetaran las pautas higiénicas en los prostíbulos, habilitados en lugares ventilados y limpios, con baño y toilette, y señalizados con carteles en los que se advertían los síntomas de las enfermedades de transmisión sexual y tuberculosis (GUY, 1994: 79). Estos objetivos motivaron la elaboración de las ordenanzas municipales que buscaban regular la actividad de las prostitutas y los establecimientos donde la ejercían, como la promulgada el 5 de enero de 1875, que habilitaba el ejercicio de la prostitución bajo una serie de condiciones. Allí quedaba establecido que las prostitutas podían permanecer en los burdeles o trabajar por su cuenta; las regentas debían pagar las revisaciones médicas, dos veces por semana (miércoles y sábados), de las mujeres que trabajaban para ellas, y hacerse cargo de los embarazos de éstas. Asimismo, la ordenanza delimitaba las áreas donde podría desarrollarse el comercio sexual. En enero de 1889, por intermedio de las autoridades municipales, fue abierto un dispensario y sifilocomio, donde se realizaban los exámenes de salud a las mujeres que ejercían la prostitución (GUY, 1994: 75).

Las autoridades también aspiraban a ocultar de la vista las casas de prostitución, mantenerlas a distancia de los templos y escuelas y expulsarlas del centro de la ciudad. La gestión de Torcuato de Alvear, además de intentar implementar la revisación médica de forma efectiva, se propuso expulsar a las prostitutas de la zona 
céntrica (GUY, 1994: 73). Como señala Guy (1994: 73), "el plan de embellecer la ciudad y extirpar las enfermedades venéreas estaba asociado con la idea de esconder o alejar a la población marginal”. Así, la policía se encargó de clausurar negocios y desalojar prostitutas clandestinas. Por otra parte, las autoridades reclamaban a los agentes que sólo se limitaran a lograr que las prostitutas no se expusieran por fuera de las casas y que no se abrieran nuevos locales en el área (GUY, 1994: 73). Así, las tácticas usadas por las autoridades municipales y la policía, para regular el comercio sexual fracasaron: "En una ciudad con tantos hombres solteros y tantas mujeres pobres, las reglamentaciones para los burdeles nunca podían erradicar la prostitución, sino apenas ocultar sus manifestaciones más obvias" (GUY, 1994: 77). Al mismo tiempo, de acuerdo con los datos relevados por los higienistas, entre 1889 y 1893, de las 3.984 mujeres registradas, sólo 744 llevaban adelante la revisación médica semanal (GUY, 1994: 85). Además, se suponía que junto al comercio sexual legal existían muchas otras mujeres que ejercían la prostitución de manera clandestina, sin pagar impuestos ni ser examinadas por los profesionales de la salud. En este sentido, debe tenerse en cuenta que la patente que pagaban para ejercer su actividad de forma legal era muy onerosa.

En síntesis, los burdeles no podían ser ocultados. Estos no estaban ubicados en un área específica del espacio urbano, estaban esparcidos en diferentes zonas y a ellos asistían públicos diferenciados. Por ejemplo, en 1870:

\footnotetext{
Los más próximos a Plaza de Mayo estaban agradablemente amueblados, con salones para jugar a las cartas y conversar, y sus mujeres eran francesas, italianas, alemanas, jóvenes y atractivas. Hacia el norte por 25 de Mayo, en cambio, las mujeres que se encontraban eran de más edad, y a menudo con fuerte mezcla de sangre negra o india, por lo que era evidente que se las destinaba a marineros, peones y obreros en general (SCOBIE, 1977: 85).
}

Otras áreas asociadas con el ejercicio del comercio sexual eran el paseo de la Alameda (hoy Leandro N. Alem), el popular "Pasaje de los Suspiros" (el actual cruce de Viamonte y Suipacha, donde funcionaba el café Cassoulet), la "calle del pecado" (en el barrio de Monserrat) y, hacia el norte, la llamada "Tierra del Fuego" (situada en las manzanas delimitadas por las avenidas Pueyrredón, Las Heras, Coronel Díaz y Libertador); en la esquina de Lavalle y Junín (donde estaban los prostíbulos de la "gente decente"); en las calles Brandsen, Suárez, Olavarría y Necochea de la Boca, casas de 
prostitución de los trabajadores y sectores marginados, al igual que los ubicados en Nueva Pompeya y Puente Alsina, donde estaban los bailongos, reñideros y bares populares (GUY, 1994: 64; CICERCHIA, 2001: 184-185). Recién en 1908, se reglamentó la creación de una zona específica para las actividades del comercio sexual, fuera del centro (CICERCHIA, 2001: 39).

Se suponía que las prostitutas frecuentaban academias de baile y otros lugares de sociabilidad y entretenimiento popular, como los despachos de bebidas. Así, en algunos cafés y bares también se ejercía la prostitución clandestina, tolerada por las autoridades (GUY, 1994: 87). La cantidad de despachos de bebidas y cafés creció durante todo el período. En 1870, existían 523 establecimientos, en 1878, la cantidad de locales llegaba a más de 600, y en 1914 se contabilizaban 1.097. La mayoría estaban distribuidos en las calles adyacentes a la Plaza de Mayo y en el centro de la ciudad, los lugares más poblados del asentamiento urbano. Por ejemplo, en 1878, cerca de la plaza estaban radicados más del $75 \%$ de los locales existentes. A pesar de que entre 1887 y 1909, la proporción de la población que vivía en el área céntrica disminuyó, ésta concentró la mayor parte de los cafés y despachos de bebidas (GAYOL, 2000: 35-37). Algunos eran frecuentados por las elites, otros atraían una población más heterogénea, de inmigrantes y nativos, de clases trabajadoras y medias. Estos ámbitos de encuentro también eran observados con cierta reserva por parte de las autoridades y los higienistas. Así, desde esta visión, los despachos de bebidas eran el espacio de reunión de prostitutas, vagos, marginados y una población de clase social y nacionalidad heterogéneas. Estos promovían actitudes y conductas contrarias al trabajo, propiciando los vicios como el alcoholismo, el juego y la prostitución (GAYOL, 2000: 67). En este sentido, la presencia femenina en estos lugares era sinónimo de comercio sexual. En 1903, la municipalidad se propuso combatir estos ámbitos que propagaban las enfermedades venéreas, alejando a los hombres de actividades útiles para el colectivo (GUY, 1994: 87). La ordenanza promulgada ese año obligaba a revisar la salud de las que trabajaban como camareras en estos negocios, sospechosas de ejercer la prostitución. Así, los despachos de bebidas, donde también era moneda corriente el juego y la prostitución, eran la antítesis de los lugares saludables, los espacios verdes (GAYOL, 2000: 79-81). Los parques, paseos y plazas eran un contrapeso de aquellos lugares antihigiénicos, como los conventillos, los prostíbulos o los despachos de bebidas. La asistencia a estos, a los teatros o a otros eventos y festividades populares, 
como el carnaval, eran las formas de ocio legítimas y sanas, los cafés y bares, en cambio, eran caracterizados como formas de entretenimiento y sociabilidad negativos (GAYOL, 2000: 75-76).

En síntesis, no es extraño, como mencionamos en el capítulo anterior, que en el presente contexto de transformaciones urbanas y de estragos causados por los ciclos epidémicos, los miembros de las elites hayan interpretado los suicidios como una epidemia social, un síntoma de los cambios ocurridos en la ciudad de Buenos Aires, representada como un organismo urbano. En medio de un clima de auge del positivismo y del higienismo, en un momento de crecimiento y desarrollo de la actividad en la urbe, también surgían nuevos problemas que eran analizados por las elites. Los guardianes de la higiene social tuvieron una activa campaña denunciando los males que corrompían a la sociedad y la alejaban del progreso y el avance de la civilización, así como una promoción de hábitos y prácticas higiénicas entre la población para combatir los estragos de las epidemias. Como veremos, la difusión dada en la prensa a los casos de suicidios contribuyó, en buena medida, a construir esta imagen de una plaga moral que se expandía de forma acelerada. Del mismo modo, las cifras estadísticas que empezaron a ser relevadas también dieron argumentos a quienes querían encontrar la epidemia de actos suicidas que crecía de manera inquietante. En los distintos espacios del cuerpo urbano, ocurrían las muertes violentas de individuos de las clases populares y medias y también de los miembros de las elites. Así, los conventillos, las pensiones, los domicilios particulares, los negocios y talleres de productos manufacturados $\mathrm{y}$ artesanales, las plazas y parques, las vías férreas, los prostíbulos y los cafés; espacios higiénicos, focos de contagio y lugares del vicio y la corrupción moral, todos fueron, en mayor o menor medida, los escenarios de los suicidios que aparecían publicados en las páginas de la prensa porteña en los principales diarios, como "La Prensa" o "La Nación”. En los textos que narraban estas noticias escandalosas encontramos la inquietud que esta nueva plaga, propia de un mundo "civilizado", despertaba entre la gente decente.

\subsection{Los actores y la vida social}

\subsubsection{Nativos e inmigrantes}


Según José Luis Romero (2010), el rasgo distintivo de la sociedad argentina de la segunda mitad del siglo XIX y, sobre todo, a partir de 1880, fue su carácter aluvial. La organización del estado nacional promovió la llegada de población inmigrante, que contribuyó, con su trabajo, al desarrollo y crecimiento del sistema productivo y las bases materiales del país y conformaron un mercado de trabajo. Asimismo, la entrada de este flujo poblacional también modificó, de manera profunda, las características de la vida social y cultural en el territorio argentino, en especial, el litoral y la pampa húmeda. En este sentido, del conjunto de población nativa e inmigrante surgieron los sectores medios y las clases trabajadoras, que crecieron aceleradamente entre las décadas finales del siglo XIX e inicios del XX.

Para hacernos una idea de la dimensión del proceso, entre 1869 y 1895 , Argentina experimentó un crecimiento demográfico extraordinario: de 1.736.923 habitantes, la población total pasó a ser de 3.954.911. ${ }^{90} \mathrm{La}$ mayor parte de este crecimiento fue debida a la constante llegada de población inmigrante de origen europeo que ingresaba por el puerto de la ciudad de Buenos Aires. ${ }^{91}$ Esta creció de una forma vertiginosa: si en 1869 había 181.838 habitantes; en 1914, estos eran más de un millón y medio (GALLO, 1992: 45). Desde mediados del siglo XIX, y hasta la década de 1870, la cantidad de extranjeros ascendió de forma más gradual. A partir de entonces, el número de inmigrantes venido de zonas mediterráneas y orientales de Europa se multiplicó. Cabe mencionar que entre 1880 y 1910 arribaba un promedio de 85.000 personas por año. Así, entre 1870 y 1915, llegaron en total alrededor de 7 millones de migrantes europeos, en su mayoría italianos y españoles, de los cuales el 58\% volvió a sus lugares de origen. Entre 1869 y 1895, los italianos representaron el 50\% de los que ingresaron, mientras que los españoles fueron alrededor del $20 \% .{ }^{92}$ De 1895 a 1915 , la tendencia se invirtió, los venidos de distintas regiones de España sumaron el 41,2\%, mientras que los provenientes de Italia representaron el 35,7\% (LATTES, 1975: 61, 64). Muchos eran atraídos por la afinidad cultural y las características religiosas, climáticas,

\footnotetext{
${ }^{90}$ Datos tomados de los Censos Nacionales de 1869 y 1895 , respectivamente.

91 Sobre este tema existe una abundante bibliografía; véase, entre otros, LATTES (1973 y 1975); GANDOLFO (1992); CIBOTTI (2000); FALCÓN (2000); DEVOTO (2000 y 2005); DE CRISTÓFORIS y FERNÁNDEZ (2008); LATTES, ANDRADA Y CAVIEZEL (2010); CEVA (2012).

92 En las décadas iniciales del proceso inmigratorio, la mayoría de los italianos provenía de las zonas del centro-norte de Italia: Piamonte, Liguria, Lombardía, Emilia y Toscana. Con el correr de la segunda mitad del siglo XIX, llegaron trabajadores y campesinos del sur y de Sicilia. En el caso de los españoles, los primeros migrantes provenían del País Vasco, Cataluña y Madrid; a partir de 1880, los gallegos se constituyeron en el principal grupo regional (FALCÓN, 2000: 492-493).
} 
lingüísticas, y, sobre todo, por las oportunidades de ascenso social. En general, estos declaraban ser agricultores (20\%) o jornaleros $(70 \%)$. De acuerdo con el proyecto de la generación romántica de 1837, los inmigrantes, trabajadores laboriosos que pondrían en producción la tierra, vendrían del norte de Europa (GALLO y CORTÉS CONDE, 1984: 54-55). En cambio, Argentina recibió, en su mayoría, inmigrantes de la región meridional europea. Aunque también llegaron de otras zonas, como franceses, ingleses, rusos, turcos, austro-húngaros, alemanes, portugueses, suizos, belgas y holandeses (CIBOTTI, 2000: 367).

En 1855, en Buenos Aires había una importante proporción de población extranjera (34,5\%), que creció con el correr de las décadas. En 1869, los inmigrantes representaban el 49,6\% de los habitantes y en 1885 este porcentaje ascendió al 52,3\% (FALCÓN, 2000: 489; LATTES, ANDRADA y CAVIEZEL, 2010: 128-131, 138-146). En 1895, en la Capital Federal, frente a un 48\% de población nativa (muchos, en parte, descendientes de los primeros inmigrantes), había un $27 \%$ de habitantes italianos, alrededor de un $12 \%$ de españoles y un $8 \%$ de extranjeros provenientes de otras regiones del viejo mundo (CIBOTTI, 2000: 393-394). Este fenómeno se acentuaba en el caso de la población masculina: los hombres extranjeros que en 1855 representaban el 47,7\% del conjunto de los varones, tres décadas más tarde eran alrededor del 61,1\%. En 1914, los inmigrantes representaban entre el 60 y el 70 por ciento de la población activa mayor de 14 años: los ocupados en el comercio y en la industria eran el 72,5\% y el $68,8 \%$, respectivamente; y el $72 \%$ de los trabajadores y empleados porteños tenía origen extranjero (GALLO, 1992: 46,48; CIBOTTI, 2000: 368).

Diferentes factores alentaron estos movimientos poblacionales masivos hacia el territorio argentino. En primer lugar, la situación en los países de origen y las perspectivas de ascenso social. En este sentido, las coyunturas económicas tuvieron un efecto determinante en la cantidad anual de migrantes (GALLO y CORTÉS CONDE, 1984: 52). Así, por ejemplo, en 1889 entraron alrededor de 260.000 personas y emigraron unas 40.000. Luego de la crisis, los saldos favorables se invirtieron: en 1891, llegaron unas 50.000 personas y partieron 80.000 , aproximadamente. En este sentido, en algunos casos, quien migraba ya venía con un contrato de trabajo desde su país de origen. A su vez, los contactos entre los primeros pioneros y sus connacionales atrajeron a otros a probar suerte en el Río de la Plata. Así, las cadenas migratorias jugaron un rol importante en la atracción de nuevos habitantes hacia Argentina. A esto se sumó el clima favorable para la recepción de inmigrantes, promovida por el propio estado, a 
partir de la Ley de Inmigración y Colonización de 1876 y de la política de subsidiar pasajes y promocionar las oportunidades del país en el exterior (CIBOTTI, 2000: 368).

Los inmigrantes transformaron la estructura poblacional en muchos niveles. La cantidad de población extranjera que llegó modificó la proporción de los sexos y las franjas etarias, la distribución demográfica regional y la estructura ocupacional (GALLO y CORTÉS CONDE, 1984). La mayor parte (alrededor del 90\%) se instaló en las provincias del litoral y la región pampeana; en especial, Santa Fe, Capital Federal y la provincia de Buenos Aires (FALCÓN, 2000: 489). Esta zona recibió también la llegada de migrantes de las provincias del interior, en especial, del noroeste. A esta última, como contrapunto, no llegaron gran cantidad de inmigrantes. El ingreso de una alta cantidad de varones en edad activa alteró las proporciones en cuanto a género y edad de la población total. En general, la mayoría de los que llegaban eran hombres jóvenes de entre 20 y 30 años, solteros y no cualificados (LATTES, ANDRADA y CAVIEZEL, 2010: 128-131, 138-146). Las mujeres casadas viajaban con los hijos, pasado un cierto tiempo, luego de la llegada del esposo. En general, los inmigrantes tendieron a formar pareja y contraer matrimonio con miembros de su grupo étnico. Sin embargo, dada la mayor proporción masculina de los migrantes, era frecuente que muchos hombres se casaran con mujeres argentinas. Las extranjeras, como contrapartida, en general, se casaban con personas de su misma nacionalidad (CIBOTTI, 2000: 372-373).

Inicialmente, los inmigrantes europeos venían para trabajar la tierra, pero muchos terminaron asentándose en Buenos Aires, en algunos casos, luego de una o varias experiencias en el mundo rural. Muchos de los migrantes que llegaron, una tercera parte, se insertaron en las actividades rurales. Sin embargo, la diferencia entre trabajadores rurales y urbanos puede ser engañosa, ya que había un constante movimiento de población en los establecimientos agropecuarios. Los cambios estacionales en la demanda de trabajadores favorecían una circulación de mano de obra desde el ámbito rural a los poblados, a otros partidos del territorio bonaerense, o hacia la ciudad de Buenos Aires; y también en el sentido inverso, de los núcleos urbanos a los establecimientos agrícolas y ganaderos de la provincia. En este sentido, no es infrecuente encontrar en los medios gráficos de la época las noticias de las muertes violentas de individuos que no podían ser reconocidos por los habitantes del lugar o que eran identificados como provenientes de otros partidos.

Las transformaciones sociales, tanto en el campo como en la ciudad, generaron 
incertidumbre y confusión en los que vivieron el proceso. En el espacio rural la llegada masiva de extranjeros despertó sentimientos xenófobos en ciertos sectores de la población nativa. Los inmigrantes, a su vez, fueron uno de los principales temas de debate entre la elite política e intelectual de la época. Si en un principio primó el optimismo hacia los recién llegados, esta actitud cambió y se transformó en recelo. En este sentido, la llegada de este aluvión migratorio fue recibida con desconfianza por los miembros de la clase gobernante. Lejos de formar una ciudadanía comprometida con el desarrollo de la nación, los inmigrantes eran, desde su perspectiva, hombres ansiosos de conseguir riqueza y dinero.

Testigos de la época, como Domingo F. Sarmiento, promotor de la modernización y la llegada de inmigrantes para poblar el "desierto", no dejaban de manifestar su desilusión ante las transformaciones de la sociedad. Desde su perspectiva, los extranjeros no venían con intenciones de participar en los asuntos de gobierno o en cuestiones de bien público; sólo querían solucionar su situación de bienestar económico (CIBOTTI, 2000: 405).

Médicos (Samuel Gaché, Manuel Blancas, José María Ramos Mejía) e intelectuales (Víctor Arreguine) observaban este creciente culto a lo material con desconfianza. Para ellos, la vida orientada por las ambiciones egoístas, entre otras pasiones sin freno, eran el origen de muchos de los suicidios, fenómeno que crecía de manera alarmante, al compás de la civilización. Entre los contemporáneos, era frecuente diferenciar entre un progreso material y uno moral, caracterizado por la difusión de valores cívicos, solidarios y altruistas, que guiaran las acciones de los individuos. La falta de estos principios, o el atraso de su desarrollo en la sociedad, era la clave que les permitía a algunos explicar el aumento de la cantidad de muertes por mano propia.

En este sentido, Víctor Arreguine pensaba que además de la tendencia de la población a dejarse arrastrar por sus ambiciones, el problema estaba en la falta de homogeneidad cultural de los habitantes. Esto último generaba, entre otras cosas, un crecimiento de la tasa de suicidios. Según Arreguine (1898: 6):

Los que emigran de su país por no suicidarse, ya traen el germen, la sugestión del suicidio; y si al llegar aquí no encuentran la realización de sus sueños de ventura, si siguen sintiéndose desgraciados, impotentes y perseguidos por una para ellos ineludible fatalidad; si contemplan el cuadro de sus miserias y la fácil opulencia de muchos de sus compatriotas, es natural que algunos hagan en América lo que hubiesen hecho en Europa: matarse. Y resulta tanto más justificada 
esta tesis, si a una serie de fracasos, a la nostalgia, a los compromisos a que no pueden dar cumplimiento, al despacho, a la falta de amistades, se agrega a la carencia de homogeneidad social: vínculos políticos, religiosos, idiomáticos, etc., que siempre facilitan la vida de relación, y que determinan con mayor energía la ayuda mutua, extendiendo a la vez la esfera de la simpatía.

Arreguine, como otros miembros de la elite cultural, también miraba con cierta desconfianza a algunos inmigrantes que ya traían cierta predisposición a quitarse la vida. Era necesario generar un vínculo de solidaridad entre los ciudadanos. La multiculturalidad y la falta de una mayor integración de la población eran la principal causa de los problemas que aparecían con la modernización, y no la civilización en sí.

Así, era necesario buscar mecanismos que integraran a los extranjeros. La educación impartida a partir de la sanción de la Ley 1420 fue uno de los instrumentos de nacionalización más eficaces ideados por la elite argentina. ${ }^{93}$ Los hijos de los inmigrantes terminaron por adoptar como identidad la del país en el que habían nacido. Este proceso de integración no fue automático. Las colectividades más importantes, como la italiana, buscaron preservar su idioma, costumbres y tradiciones, por ejemplo, al fundar escuelas dedicadas a formar niños en la herencia cultural de las comunidades de origen de sus padres. A esto se oponía firmemente Sarmiento en sus discursos y en las columnas que aparecían en la prensa de la época (CIBOTTI, 2000).

Ideas similares fueron gestadas en las décadas siguientes y alcanzarían un mayor nivel de consolidación hacia el primer Centenario de la Revolución de Mayo. La creación de una identidad nacional parecía ser la solución para problemas como el aumento del delito, los casos de suicidio, los movimientos políticos o los reclamos sociales, encabezados por anarquistas y socialistas. La visión de un país sin ciudadanos generaba inquietud entre la clase gobernante, que apostó a la educación patriótica y a los símbolos nacionales para forjar el crisol de razas. ${ }^{94}$ El vínculo generado de este

\footnotetext{
${ }^{93}$ Sobre el rol de la educación en la configuración de un modelo de ciudadanía en Argentina, véase, entre otros, LIONETTI (2005 y 2007). Con respecto a los debates en torno a la cuestión nacional, podemos mencionar, entre otros, a los trabajos de BERTONI (1992; 1996 y 2001).

94 Según algunos autores (GALLO y CORTÉS CONDE, 1984: 78 y ROMERO, 2010), en las décadas finales del siglo XIX, la mentalidad colectiva estuvo orientada por la búsqueda del éxito económico y la especulación, mientras que los valores ciudadanos quedaron en un segundo plano. Desde esta perspectiva, el extranjero era un sujeto que añoraba el regreso a su patria y, por ello, sólo consideraba al país donde residía como un lugar de paso, para alcanzar fortuna y luego volver a su tierra, lo que no despertaba un mayor compromiso político. Según GALLO y CORTÉS CONDE (1984: 79): "La pasividad política de una población deslumbrada por las oportunidades que se le abrían en la vida material se constituyó de esta manera en el principal sostén del grupo gobernante". Para los autores, esta actitud pasiva frente a los asuntos políticos se veía alterada en los momentos en que el ciclo expansivo de la economía se
} 
modo entre los habitantes del territorio argentino permitiría la cohesión del organismo social y fortalecería las virtudes propias del progreso moral, que ansiaban políticos e intelectuales de la elite.

Si la clase gobernante se veía como el bastión de la ciudadanía y la nación argentina, los inmigrantes, por otro lado, eran motivo de preocupación creciente. Era necesario encontrar medios para generar vínculos de cohesión en una población heterogénea y sin conciencia ciudadana. Para la elite política y cultural esta era la causa de muchos de los males, como el delito, la conflictividad social, el vicio, la falta de un freno para las pasiones desmedidas y el crecimiento de los casos de suicidio.

\subsubsection{Una sociedad de clases en formación}

\subsubsection{Clases trabajadoras}

Tanto en el espacio rural como en el mundo urbano ocurrió un cambio en las relaciones sociales. Esta reestructuración social estuvo relacionada con la conformación de un mercado de trabajo, proceso que se desarrolló en la segunda mitad del siglo XIX, y que se aceleró con la llegada masiva de población extranjera, dispuesta a vender su fuerza de trabajo a cambio de un salario. Los inmigrantes se integraron a los trabajadores criollos, indígenas, mulatos y afroargentinos que ya existían en la ciudad de Buenos Aires; con el paso del tiempo, la comunidad negra tendió a ser invisibilizada. Las remuneraciones eran lo suficientemente altas como para atraer a migrantes, que elegían la Argentina antes que Estados Unidos o Canadá. A medida que el ritmo del crecimiento se hizo más lento, los ingresos se redujeron y la posibilidad de estar desempleado fue mayor. Asimismo, las crisis económicas periódicas también ponían en

interrumpía. Sin embargo, la realidad parecía ser más compleja. Muchos inmigrantes tenían sus espacios de participación tanto en la organización de la sociedad civil como en la política de la época. En este sentido, el movimiento asociacionista y mutualista fue muy importante en este período: se formaron sociedades de ayuda mutua, clubes, instituciones recreativas, hospitales, escuelas y órganos de prensa. En cuanto a su participación política, la prensa de las colectividades, como la italiana, intervenía en los debates parlamentarios y otros asuntos de la sociedad civil. Así, si bien los extranjeros no tenían derechos políticos, esto no significó la apatía o la ausencia de actividad como parte de la opinión pública o del ejercicio de la libertad de reunirse o asociarse. En este sentido, las movilizaciones dirigidas desde las organizaciones de ayuda mutua, como señaló CIBOTTI (2000: 382-397) para el caso de los italianos en Buenos Aires, jugaron un papel importante a la hora de apoyar o vetar las iniciativas de la clase gobernante que los afectaban directamente. Por ejemplo, cuando fue debatida una propuesta de nacionalización automática de los extranjeros (en 1890), o en temas más generales, como la enseñanza religiosa en las escuelas o el descanso dominical. Sobre las instituciones y asociaciones creadas por colectivos de inmigrantes en la provincia de Buenos Aires, véase, entre otros, IRURZUN (2014). 
riesgo los niveles salariales y las tasas de empleo. Además, la demanda de trabajadores no calificados fluctuaba de forma estacional y era mayor en las épocas de más actividad en el sector primario. Por esta razón, era frecuente la movilidad de los trabajadores desde las áreas más dinámicas de la economía rural hacia el espacio urbano. Así, de peones temporales en las cosechas pasaban a ser albañiles en las ciudades como Buenos Aires o Rosario.

Una tercera parte de los trabajadores estaba ocupada en las actividades del sector primario (LOBATO, 2000b: 472). Las relaciones sociales de producción eran diferentes en distintas regiones. Mientras que en la zona de Santa Fe florecieron las colonias agrícolas, en la provincia de Buenos Aires predominó la gran propiedad rural, la estancia, basada en la subdivisión en pequeñas unidades de producción, trabajadas por arrendatarios. Los inmigrantes tenían una gran capacidad para adaptarse al cambio de trabajo, pasando de uno a otro, y a la movilidad del campo a la ciudad. En el espacio rural, algunos se insertaron como arrendatarios, colonos agrícolas, peones (permanentes, estacionales u ocasionales). Los trabajadores rurales vendían su fuerza de trabajo a chacareros, comerciantes, dueños de maquinaria agrícola, transportistas y ganaderos. Los salarios eran heterogéneos y dependían de la tarea y el área en el que estuvieran empleados. La actividad en los campos era intensa y no quedaba mucho tiempo para el ocio (REGUERA, 2006a: 154). Los peones y puesteros eran asignados con múltiples tareas por el mayordomo del establecimiento. Estas incluían: el sembrar y cosechar cereales y forrajeras, trillar y limpiar los granos para embolsarlos; actividades ganaderas (por ejemplo, hacer recuentos de animales, bañar y esquilar ovejas, preparar la lana para su traslado al puerto, poner en condiciones a los animales para las exposiciones y ferias); a estás, se sumaban otras labores como trabajos de herrería, carpintería, albañilería, alambrado de los terrenos, colocación de tranqueras, artesanía con cueros, carneada de animales, traslado de la producción desde diferentes puntos de la estancia (REGUERA, 2006a: 152).

La exigencia física de las labores podía ser compensada por la expectativa de un futuro promisorio. La mayoría de los inmigrantes que lograron alcanzar, en alguna medida, el ascenso social, empezaron trabajando como peones en los establecimientos rurales o como arrendatarios y medieros. Para muchos trabajadores extranjeros, el paso por los empleos fijos o estacionales era una forma de alcanzar una mejor situación material para luego volver a su tierra; las circunstancias desfavorables que parecían truncar este horizonte de seguro generaban malestar y desánimo. Si algunos lograron 
prosperar, otros no alcanzaron el éxito anhelado. Fueron muchos también los que volvieron sin modificar su situación. Otros tantos no regresaron a sus países y no pudieron lograr una movilidad social ascendente. Las oportunidades para conseguir empleo eran numerosas, si los individuos estaban dispuestos a trasladarse por los campos de la provincia, los asentamientos y la ciudad de Buenos Aires. Sin embargo, si a la falta de perspectivas de mejorar la calidad de vida se sumaba la ausencia de suficiente fuerza en el organismo y un escenario de miseria y penuria en el corto plazo, esto minaba los posibles alicientes para continuar luchando. Otros trabajadores no resistían el agotador desafío y terminaban afectados por distintos fenómenos de malestar psíquico, que los contemporáneos aglutinaban en la confusa categoría de la locura. Para el tratamiento de este tipo de patologías había pocas e incipientes instituciones en el territorio provincial o en la Capital Federal, como el Hospicio de las Mercedes. Estas eran algunas de las situaciones que aparecían narradas en la prensa. Entre los hechos informados, había episodios de suicidios y muertes violentas ocurridos en los establecimientos rurales de la provincia de Buenos Aires. En los galpones y silos, en las viviendas de los puestos, recurriendo a los elementos de uso cotidiano -como los venenos para tratar los cueros y curar la sarna de las ovejas u objetos cortantes, como cuchillos y tijeras de esquilar- o a las armas de fuego disponibles (revólver o escopeta), hubo hombres y mujeres que de esta manera se quitaron la vida. ${ }^{95}$

Si no tenían éxito en las labores rurales, o no había demanda de mano de obra en el campo, la expansión del consumo en el ámbito urbano ofrecía nuevas posibilidades en las actividades comerciales. De este modo, la llegada de la población extranjera impulsó el proceso de urbanización; en este sentido, una parte considerable de la población pasó a residir en los núcleos urbanos grandes y medios. Así, entre 1895 y 1914, la proporción de los que vivían en las ciudades superó el 50\% de la población total (GALLO, 1992: 45). Como ya mencionamos, con el proceso de urbanización acelerado, vinieron nuevos problemas en distintas áreas, que incluían, entre otros, la salud pública, las medidas de higiene para prevenir epidemias, la necesidad de viviendas, el crecimiento del delito, el alcoholismo, la prostitución, la pobreza, la marginalidad y el desempleo. Los cabarets y los despachos de bebidas eran un espacio compartido por trabajadores y por otros individuos que llevaban una "mala vida", los denominados "malvivientes": mendigos, ladrones rateros, estafadores, malevos. Según

\footnotetext{
${ }^{95}$ Sobre este tema, véase, ARROYO (2015).
} 
Adamovsky (2012: 66-67), era frecuente el contacto entre ambos mundos y, en varios casos, el pasaje de uno a otro en distintos momentos de la trayectoria biográfica de un obrero. $^{96}$

Al mismo tiempo, las ocupaciones en el espacio urbano también se diversificaron y muchos hombres pasaron a insertarse en trabajos que antes no existían. En este sentido, los distintos grupos de trabajadores asalariados fueron los que más crecieron en el último cuarto del siglo XIX y las primeras décadas del XX. Estos se insertaron en las fábricas y talleres y en las actividades del sector del comercio y servicios. Así, muchos inmigrantes se asentaron como trabajadores de la industria de la alimentación, de emprendimientos en domicilios particulares, trabajando por cuenta propia o en talleres pequeños (como zapateros, panaderos, carpinteros, etc.), o en las actividades relacionadas con el transporte: ferroviarios, conductores de carros y vehículos, portuarios, etc. (LOBATO, 2000b: 472). Otros se dedicaron a actividades no manuales, como dependientes de comercio, secretarias, empleados bancarios, telefonistas, capataces, supervisores, cadetes, etc. Si en 1869, en todo el territorio argentino había 12.000 empleados y dependientes, en 1914, estos eran alrededor de 95.000 (ADAMOVSKY, 2012: 37). También creció la cantidad de empleados públicos: barrenderos, personal de maestranza, oficinistas, técnicos, funcionarios, docentes, etc. Por su parte, muchos otros se insertaron como peones en diferentes rubros: el transporte, la carga y descarga de envíos y la construcción. Las nuevas obras públicas (bulevares, las plazas, los parques, los empedrados), las ostentosas residencias de las elites, y otras obras de infraestructura como los edificios de los teatros, bancos, y edificios estatales generaban una importante demanda de mano de obra y trabajadores con diferentes oficios. Así, en 1869, de los 9.000 albañiles, 14.000 carpinteros y 1.100 pintores que fueron registrados en el censo nacional, un tercio estaba radicado en la ciudad de Buenos Aires (FALCÓN, 2000: 488). A su vez, la expansión de la actividad constructora también estimuló la de otros artesanos y trabajadores especializados: por ejemplo, los herreros, yeseros y marmoleros. Sin embargo, el grupo de trabajadores que más creció fue el de los "sin oficio", peones y jornaleros que se insertaron en el desarrollo de las obras públicas, como la infraestructura sanitaria y la red ferroviaria (FALCÓN, 2000: 499). Asimismo, también hubo quienes fueron contratados como empleados domésticos en las casas de la alta sociedad porteña y los hogares de clase media más prósperos.

\footnotetext{
${ }^{96}$ Sobre este tema, véase, GUTIÉRREZ (2000b).
} 
Las condiciones de trabajo y la calidad de vida de las clases trabajadoras fueron variables; sin embargo, en general, la mayoría vivió en ambientes precarios, sin estabilidad ni derechos laborales. ${ }^{97}$ Los salarios eran pagados de forma bastante irregular; en muchos casos, se retribuía por día trabajado (es decir, por jornal). El salario mensual era poco frecuente, salvo en ciertos ramos como el comercio. En otros, el pago por pieza, a destajo o por trabajo terminado era muy frecuente. El cobro en todos los casos podía ser bastante irregular y no existían muchas formas de hacer un reclamo por parte de los trabajadores. Las jornadas diarias no eran menores a las 10 horas, los accidentes de trabajo eran frecuentes, el sábado era un día laborable y no existían indemnizaciones por despido, vacaciones pagas, aguinaldo o un sistema jubilatorio general. Sobre este último punto, los primeros ensayos fueron las pensiones recibidas por funcionarios y empleados estatales, maestros y militares. Las de este tipo para trabajadores de otros sectores, como los ferroviarios, no fueron anteriores a 1916. Con respecto a la estabilidad, los que gozaban de una situación más segura eran los obreros más calificados y los trabajadores del comercio. Estos últimos, los llamados "esclavos blancos", por otra parte, vivían y comían en sus lugares de trabajo, en los almacenes y las tiendas, muchas veces sufrían maltrato y recibían una paga inferior a la de los trabajadores manuales, aunque los dependientes y empleados de este ramo mantuvieran un mayor prestigio. Al mismo tiempo, como ya mencionamos, las condiciones de hacinamiento y carencia de higiene en los conventillos y viviendas colectivas, donde vivían trabajadores manuales y dependientes de comercio, eran alarmantes. A esto se sumaba el alto costo de los alquileres, un 140\% más caro que en Alemania o Inglaterra y un 200\% más que en Francia (ADAMOVSKY, 2012: 55). El alquiler de una habitación, entre 5 o 6 hombres, consumía, por lo menos, una quinta parte del salario de un trabajador no especializado. Si a todo esto se suman los efectos de una crisis económica, como la de 1873, las circunstancias podían llevar a la desesperación a muchos extranjeros que venían con expectativas de amasar una fortuna para volver a sus tierras (SCOBIE, 1977: 175-176).

No restaban tiempo o dinero para ser invertidos en actividades ociosas, salvo por la asistencia a los teatros o algún circo, donde los espectadores podían disfrutar de pruebas de trapecio y las presentaciones de gimnastas, contorsionistas, prestidigitadores,

\footnotetext{
${ }^{97}$ Sobre las condiciones de vida de los trabajadores en el mundo urbano durante la segunda mitad del siglo XIX, véase, entre otros, FALCÓN (2000: 496-509); LOBATO (2000b) y ADAMOVSKY (2012: 51$67)$.
} 
animales amaestrados y clowns. Sin embargo, la mayoría de las veces el escaso "tiempo libre" era pasado en los "despachos de bebidas", en los cafés y los almacenes. Allí, los hombres se reunían a jugar al truco, al mus, a la brisca o al tute cabrero, conversaban, reían y discutían mientras bebían un trago (vino o caña). En algunos bodegones, también se podía jugar a las bochas o a la taba; en otros, también tenían lugar las riñas de gallos. Había quienes bailaban, por ejemplo, algún tango, danza que surgió en los ambientes marginales de maleantes y prostitutas, en la década de 1880, y se volvió más popular en cafés, bares y pistas de baile del centro y algunos barrios de trabajadores hacia el final del siglo XIX. ${ }^{98}$ En estos espacios, a partir de la recreación, se podían refugiar y evadir del hacinamiento y la precariedad de las condiciones de vida en los conventillos y casas de inquilinatos, las preocupaciones relacionadas con la falta de empleo, las extenuantes jornadas laborales y los problemas familiares (como las enfermedades de los hijos) (TRONCOSO, 2000: 97). A comienzos del siglo XX, el fútbol adquirió popularidad entre las clases trabajadores y con el paso de los años serían fundados los primeros clubes en los barrios obreros del sur.

Las clases trabajadoras construyeron su identidad a partir de una serie de asociaciones mutuales y organizaciones gremiales. Entre las primeras, se encuentran las sociedades de socorros mutuos que agrupaban a individuos de acuerdo con su nacionalidad, profesión o religión. El ejemplo más temprano de este tipo es el de la Sociedad Tipográfica Bonaerense, creada el 25 de mayo de 1857. Fue fundada con el objetivo de brindar ayuda a enfermos o personas que ya no pudieran trabajar y garantizar las condiciones laborales y salariales de los empleados en dicha profesión. En la década de 1870, ya existían otras sociedades similares, como las de albañiles, panaderos, trabajadores de la construcción, sastres y carpinteros (FALCÓN, 2000: 500501). Por otra parte, las asociaciones de este tipo más grandes fueron las vinculadas a las colectividades extranjeras, como la "Unione e Benevolenza", establecida a partir de la iniciativa de inmigrantes italianos. Otros grupos étnicos (franceses, españoles, gallegos), encararon organizaciones similares. En 1914, había en Buenos Aires alrededor de 255.000 socios agrupados en 214 asociaciones de socorros mutuos. La mayoría de los asociados estaban nucleados en instituciones multinacionales $(51,4 \%)$, otra parte importante, en mutuales que aglutinaban a personas del mismo origen nacional y los menos, en asociaciones de argentinos nativos (10,6\%) (GALLO, 1992:

\footnotetext{
${ }^{98}$ Sobre la sociabilidad masculina en los cafés y bares, véase, GAYOL (2000).
} 
52). Los gremios, por otra parte, fueron espacios con más libertad para que los trabajadores pudieran manifestar y hacer sus demandas. Hubo muchas organizaciones obreras de acuerdo con el oficio o rama de actividad y el tiempo que permanecieron en funcionamiento también varió. En este sentido, si hubo gremios de duración efímera, otros perduraron y alcanzaron una gran influencia, como los ferroviarios y trabajadores portuarios. Si eran pocos los afiliados, se unían los trabajadores de varios rubros, alquilaban una habitación donde hacer las reuniones y editaban un periódico (LOBATO, 2000b: 493-495). En estas publicaciones, los militantes expresaban sus puntos de vista sobre temas variados, como las acciones estatales, la situación del capitalismo mundial, cuestiones nacionalistas, problemas como la desocupación, etc. Así, los trabajadores en el espacio urbano formaron las primeras organizaciones obreras. ${ }^{99}$ Este proceso se aceleró a partir de 1890 y, con el tiempo, desembocó en la aparición de federaciones que aglutinaban a varios gremios.

La elite conservadora no tuvo la rapidez o la eficacia para responder a las demandas de los trabajadores. Si bien hubo intentos de encarar una política reformista por parte de algunos miembros del elenco gobernante, como Joaquín V. González y su proyecto de legislación nacional para regular el trabajo, estas no prosperaron. Sumado a esto, en general, los gobiernos durante el régimen conservador tendieron a tomar una política represiva frente a los reclamos, como ocurrió con las huelgas de 1902, que tuvieron por desenlace la declaración de estado de sitio y la sanción de la Ley de Residencia. A comienzos del siglo XX, como señala Lobato (2000b), los trabajadores se habían convertido en una presencia más que inquietante para la clase gobernante.

\subsubsection{Clases medias}

La llegada de los inmigrantes no sólo fue clave en la conformación de un mercado de trabajo capitalista, también contribuyó al crecimiento de los sectores medios (en los servicios, el comercio, la educación, la industria y la administración pública) (ZIMMERMANN, 2000). Durante la segunda mitad del siglo XIX tuvo lugar un

\footnotetext{
99 Sobre las luchas y organizaciones de las clases trabajadoras en el período que estudiamos, véase, entre otros, FALCÓN (1984 y 2000); LOBATO (2000); GUTIÉRREZ (2000) y ADAMOVSKY (2012).
} 
proceso de cambio de la estructura social tradicional, dividida en dos estratos bien diferenciados, la "gente decente" (militares, funcionarios, estancieros, comerciantes, dueños de saladeros y curtiembres, curas, abogados, médicos y otros sujetos dedicados al trabajo "intelectual") y la "gente de pueblo" (gauchos, peones, esclavos, indios, trabajadores domésticos, artesanos, vendedores ambulantes, pulperos, acopiadores de cuero, carniceros, los que se dedicaban al transporte de carretas, servicio doméstico, prostitutas, lavanderas, etc. ). Al mismo tiempo, en la sociedad tradicional existía una jerarquía racial: ser "decente" era sinónimo de ser "blanco"; ser parte de la plebe tenía implícito el ser negro, indio, mestizo o mulato. ${ }^{100}$ Los integrantes de cada una de estas categorías compartían ciertos antecedentes familiares, ocupación y nivel de ingresos. Las diferencias de riqueza eran menores si se comparan con la desigualdad entre ricos y pobres a fines del siglo XIX. Por otra parte, no había una "clase media", se era o no “decente". Al mismo tiempo, la pertenencia a una u otra era bastante rígida y estática desde el nacimiento de los sujetos, sin grandes posibilidades de cambio. Por esta razón, los sectores medios eran escasos, la mayoría pertenecía a las clases populares. Por otra parte, en la sociedad de clases, estaba abierta la posibilidad de progreso económico y ascenso social. Como señala Eduardo Zimmermann (2000: 140-141), las oportunidades de enriquecimiento, la llegada masiva de población extranjera y el avance de la urbanización transformaron las ciudades del Litoral, como Buenos Aires:

[...] el surgimiento de importantes sectores medios, facilitado por un fenomenal proceso de movilidad social ascendente, fue acompañado por una creciente diversificación en la composición tanto de los sectores nuevos como de los estratos más tradicionales. El surgimiento de una clase media urbana vinculada a la expansión del sector terciario de la economía, al comercio, la industria, el aparato administrativo del Estado, y el sistema educativo, fue paralelo a la transformación en los sectores populares, en los que los nuevos trabajadores urbanos también adquirieron mayor peso numérico frente a los trabajadores rurales y las formas más tradicionales del artesanado.

Si en 1869, los sectores medios equivalían al 12 o 15\% de la población argentina, en 1895 representaban cerca del 25\% y en 1914 el 35 o 40\% (GALLO y CORTÉS CONDE, 1984: 174-175; GALLO, 1992: 47-48). Así como el resto de las ciudades del

\footnotetext{
${ }^{100}$ Para una síntesis del proceso de cambio social en Argentina durante el siglo XIX, véase, entre otros, MALLO (2000) y ZIMMERMANN (2000).
} 
Litoral, Buenos Aires concentró muchas de las nuevas oportunidades de crecimiento. Allí estuvieron radicados la mayoría de los profesionales, empleados y comerciantes, en el período que estudiamos (ADAMOVSKY, 2009: 45). Por otra parte, los grupos que más crecieron fueron los asalariados en tareas no manuales: dependientes de comercio, secretarias, empleados bancarios, telefonistas, capataces, supervisores, cadetes, etc.

Entre los sectores medios las realidades vividas eran muy disímiles. Por un lado, existía una jerarquía de estatus diferenciada. Así, un funcionario público estaba por encima de cualquier asalariado, en términos de prestigio personal, mientras que otros trabajos estatales tenían menos prestigio: por ejemplo, los oficinistas de poco renombre o los obreros manuales encargados de recolección de residuos. Asimismo, un empleado bancario era más estimado que uno de una tienda, y éste, a su vez, más que un dependiente de almacén. Por otra parte, el prestigio que cada ocupación tenía no siempre estaba relacionada con el salario percibido o las características de sus viviendas. El salario de un empleado bancario muchas veces no difería del pagado a los obreros manuales (el promedio del primero no era mayor a 250 pesos y el de los segundos de 150 pesos), pero aquel podía llegar a ascender a puestos sucesivos en los que los montos podían ser considerables, como en el caso de los gerentes ( 1.000 o 2.000 pesos) (ADAMOVSKY, 2012: 60-61). Del mismo modo, había empleados de comercio, que más allá de gozar de un mayor nivel de "decencia" por su empleo, era común que vivieran y comieran en sus lugares de trabajo, en almacenes y tiendas; al mismo tiempo, su paga era inferior a la de los trabajadores manuales. No era lo mismo trabajar en una tienda elegante que desempeñar la misma función en un almacén. Al mismo tiempo, entre los comerciantes, las realidades eran diversas: la de los comerciantes "respetables" y prósperos, dueños de negocios más grandes, no era la de los pequeños almaceneros o verduleros (de cuestionable respetabilidad), que tenían ingresos similares a los de los asalariados.

El crecimiento de estos sectores implicaba, a su vez, un aumento de las posibilidades de ascenso social, que fue la trayectoria de muchos inmigrantes que mejoraron su situación con respecto a la que tenían en sus países de origen. Un peón podía ser ascendido a oficial luego de recibir la apropiada formación o un dependiente de comercio que lograba volverse un pequeño comerciante por cuenta propia. Como señala Adamovsky (2012: 32), los que más aprovecharon las oportunidades de ascenso fueron los extranjeros: 
[...] de cada 100 habitantes de origen popular en 1895, 31 de los que eran inmigrantes habían ascendido a los sectores medios, mientras que sólo 10 de los nativos de la Argentina habían tenido la misma suerte (y debe tenerse en cuenta que los hijos de los inmigrantes ya figuraban en los censos como "nativos", de modo que los propiamente "criollos" que lograron ascender deben haber sido muchos menos).

En 1895, en Buenos Aires había 350.000 extranjeros. De estos, 8.000 eran propietarios de industrias, 91\% de los de este ramo. Asimismo, de los 12.731 propietarios de comercios, 87\% eran extranjeros (KORN, 2000: 58). Los nativos, en cambio, eran mayoría en la administración pública, la justicia y la instrucción: representaban el 91\% de los militares, el 62\% de los empleados de la administración pública, el 63\% de los que de una manera u otra impartían justicia, el 73\% de los educadores (KORN, 2000: 59). Las redes de contactos y el nivel de calificación eran claves en las estrategias de ascenso social.

Al mismo tiempo, las oportunidades no fueron las mismas para los que llegaron más tempranamente. Los ejemplos de ascenso social más sobresalientes fueron los de los inmigrantes de la primera hora, los que arribaron antes de finalizar el tercer cuarto del siglo XIX. La trayectoria de Pedro Vasena es un caso de este tipo. Vasena (italiano de la ciudad de Lecco) llegó a Buenos Aires en 1865 y empezó a trabajar como herrero. Tras desempeñarse como obrero durante algunos años, puso su propio taller. Con el tiempo, abrió un nuevo establecimiento y años más tarde compró una fábrica en la ciudad de La Plata. El emprendimiento de Vasena fue responsable de grandes obras, como puentes de hierro, instalaciones de luz y gas, construcción de edificios (como el Mercado del Abasto de la ciudad de Buenos Aires) (KORN, 2000: 55 y 58). Así, más que ocuparse de la acción gremial y política, la búsqueda del ascenso social guió a los inmigrantes. Los más exitosos ascendieron socialmente y se transformaron en miembros de las clases medias en conformación y algunos llegaron a formar parte de las elites terratenientes e industriales. De una generación de pequeños comerciantes, la siguiente podía aspirar a un cargo en la burocracia o llegar a desempeñarse en las profesiones liberales. No debemos olvidar que muchos nativos eran también hijos de inmigrantes. Algunos de estos estudiaron y accedieron a cargos como docentes. La trayectoria de Pablo Pizzurno y sus hijos es un ejemplo de esto último. Pizzurno, soldado genovés, llegó a Buenos Aires en 1848. Empezó como vendedor itinerante de ropa; tiempo después puso una tienda y almacén. De los ocho hijos que tuvo con su esposa, tres (Pablo, Juan y Carlos) estudiaron magisterio y ocuparon importantes puestos dentro del 
sistema educativo (KORN, 2000: 62). A medida que terminaba el siglo XIX y comenzaba el XX, las posibilidades de ascenso social se volvieron cada vez más infrecuentes.

De este modo, una parte de los inmigrantes logró aprovechar, en mayor o menor medida, las posibilidades que ofrecía el contexto de expansión económica y territorial y mejorar su situación material (al acumular bienes y capital para volver a sus países), así como su posición en la escala social, con respecto a la que tenían en su lugar de origen (por ejemplo, llegar a ser propietarios de la tierra que trabajaban, establecer una casa de comercio o alcanzar el éxito en los pequeños emprendimientos manufactureros y comerciales). Así, fueron muchos los inmigrantes que lograron ascender socialmente y pasaron a formar parte de las clases medias urbanas y rurales, mientras que los nativos predominaron en la cima (como grandes propietarios) o entre la clase trabajadora en el campo. Por otra parte, las historias que abordamos en este trabajo, en general, nos muestran las dificultades que debían enfrentar muchos de los que migraban y que viendo cercados los caminos para lograr sus objetivos, en algunos casos (no podemos generalizar este desenlace), terminaban quitándose la vida. Por ejemplo, muchos de los trabajadores rurales y urbanos vivían cambiando de espacios y ocupaciones. Si bien, en general, había una alta posibilidad de obtener empleo en los períodos de cosecha o esquila y los salarios eran altos (en comparación con los pagados en el ámbito rural europeo), la demanda era fluctuante, lo cual los exponía a períodos de inestabilidad laboral. No es difícil imaginar que para muchos esta situación era angustiante, en especial, en los momentos de crisis económica. No podemos saber cuántas personas pasaron por situaciones similares, tampoco es nuestro objetivo. Lo que nos interesa destacar, como veremos más adelante, es que, para los contemporáneos, era verosímil que muchos de los que se suicidaban lo hicieran por ver frustradas sus expectativas de ascenso social.

\subsubsection{Las elites}

Los sectores más prósperos de las clases medias, comerciantes e industriales, ansiaban formar parte de los círculos sociales de las elites. La alta sociedad de Buenos Aires era un grupo heterogéneo. Una parte de sus miembros provenía de familias porteñas tradicionales, es decir, cuyos orígenes eran anteriores a la Revolución de Mayo 
y podían ser rastreados en el período colonial (Alvear, Anchorena, Casares, Unzué, Álzaga). Al mismo tiempo, había entre las elites sujetos de origen inmigrante que habían logrado triunfar en el terreno económico, como Ramón Santamarina. ${ }^{101}$ Otros grupos familiares que integraban la alta sociedad venían del interior (los Roca, Urquiza, Avellaneda, Uriburu, Juárez, Gallo); a partir del proceso de consolidación del estado nacional se habían asentado en Buenos Aires y entablado relaciones con la "gente decente" porteña. En este sentido, la conformación política del PAN tuvo éxito en cristalizar la alianza entre un sector de las elites de Buenos Aires y los grupos dirigentes de otras provincias, aglutinados en la llamada "Liga de Gobernadores".

En este período, quienes se dedicaban a la actividad política formaban una oligarquía. Este último término, muy polisémico, como señala Lobato (2000: 190), puede resultar apropiado para caracterizar a la elite política, si la pensamos como un grupo minoritario que se consideraba superior al resto de los habitantes y mantenía un control del acceso a los cargos de gobierno, restringiendo la intervención de otros actores. $^{102}$ Así, al hablar de una oligarquía hacemos referencia a los mecanismos utilizados por la elite para concentrar el poder político y monopolizar el control de las instituciones estatales. De este modo, a la toma de decisiones sólo accedían algunos, ya fuera por su poder económico, su prestigio personal, el ser parte de ciertos espacios de sociabilidad (como tertulias, cafés, banquetes, asociaciones, etc.), o la educación que habían recibido. Las amistades, forjadas en lugares selectos de socialización (como el Club del Progreso, en un principio, el Jockey Club y el Círculo de Armas, el más selecto de todos) o en la universidad (en especial, la Facultad de Derecho), tuvieron un rol importante a la hora de establecer vínculos entre los miembros de la elite. ${ }^{103}$ En este sentido, las redes y los contactos interpersonales tenían un papel clave en el acceso a los cargos y los gabinetes del elenco gobernante.

Así, la dinámica política continuó pasando por canales informales y mecanismos tradicionales, como las redes familiares y particulares que controlaban los hilos de los caudillos locales. En este sentido, la elite administraba las reglas del juego por medio del fraude y la elección de los gobernantes a nivel provincial y nacional. La máquina electoral, montada alrededor de caudillos regionales para controlar las listas de electores y ejercer presión en las mesas donde se votaba, fue efectiva para mantener los

\footnotetext{
${ }^{101}$ Para un análisis de la trayectoria biográfica de Ramón Santamarina, véase, REGUERA (2006). 102 Sobre este tema véase, entre otros, ANSALDI (2004).

103 Sobre los espacios de sociabilidad de las elites porteñas, véase, entre otros, LOSADA (2006, 2008 y 2009).
} 
resortes del poder en un grupo reducido. Las agrupaciones no tenían un programa político claro, eran formaciones coyunturales que basaban la adhesión de sus miembros en el prestigio de ciertas personalidades y en la eficacia de las prácticas clientelares para mantener la lealtad de los líderes locales. Más allá de los rasgos peculiares de la cultura política, el acto electoral era un requisito para mantener la imagen de un orden republicano (LOBATO, 2000: 199). Es decir, representar la elección de los gobernantes por parte de los ciudadanos resultaba indispensable para garantizar la legitimidad de la elite en el poder. La clase política de la época, en su mayoría, tenía una perspectiva conservadora acerca de las masas o multitudes. Sin embargo, no dejaban de pensar el orden en términos de una república. Como veremos, había expresiones y referencias que usaban para compararse con los célebres ciudadanos del mundo antiguo.

Desde un punto de vista económico, los terratenientes de la pampa húmeda eran la fracción más poderosa de las elites porteñas. Durante buena parte del siglo XIX, si bien habían invertido en la compra de tierras y en la exportación primaria, tenían diversificadas sus inversiones en comercio y finanzas. ${ }^{104}$ De manera gradual, la elite económica consolidó su perfil terrateniente, proceso que culminó hacia finales del siglo. Si bien podemos identificar la emergencia de una elite industrial, durante la segunda mitad del siglo XIX, la fracción de los grupos económicos más poderosos pertenecía al sector de los grandes productores rurales. Gracias a la demanda externa de materias primas y al aumento exponencial de los precios de estas en el mercado internacional, los grandes terratenientes de la pampa húmeda alcanzaron una cantidad de riqueza inédita, que alejó su situación material de cualquier otro sector de la sociedad de la época. El éxito alcanzado por estos estancieros llevó a revalorizar lo rural como parte de su identidad. Tener estancia se transformó en sinónimo de prestigio, riqueza y poder. ${ }^{105}$ Los miembros de la elite terrateniente alternaban su vida entre la ciudad de Buenos Aires y las propiedades rurales. Muchos de ellos tenían desinterés por el mundo político y no tenían experiencia en el juego electoral. Así, la mayoría no tenía los medios y las bases para sostener las redes clientelares que sí disponían los miembros de la elite política.

Los distintos actores y grupos que componían la alta sociedad de Buenos Aires estaban unidos por lazos de parentesco y compartían ciertas prácticas comunes, así como ciertos espacios de sociabilidad. Estos últimos variaban de acuerdo al sexo. De

\footnotetext{
${ }^{104}$ Acerca de esto último, véase, entre otros: SÁBATO (1987).

105 Sobre este punto, véase, entre otros, REGUERA (2006a y 2013).
} 
esta manera, la casa y el espacio privado, así como las instituciones de beneficencia y caridad, se constituyeron en espacios de interacción femeninos y eran gestionados por mujeres. Los hombres se vinculaban entre sí en los clubes, así como en ciertos ámbitos intelectuales, agrupaciones políticas y corporaciones económicas, como la Sociedad Rural Argentina o el Club Industrial (fundados en 1866 y 1875, respectivamente). El mundo del club era el ámbito de las relaciones masculinas. Entre estos, se destacaron, durante la segunda mitad del siglo XIX y primeras décadas del XX, el Club del Progreso y, más tarde, el Jockey Club. El primero fue fundado en 1852, y su sede estaba ubicada en las actuales calles de Hipólito Yrigoyen y Perú (la Casa Muñoa), allí estuvo radicado hasta 1900. Fue epicentro de la alta sociedad porteña entre 1850 y 1880. Allí, sus socios podían encontrar un espacio para pasar el tiempo libre: mesas de juego, sala de armas, biblioteca, bailes. Los espacios masculinos más prestigiosos en las décadas posteriores fueron el Jockey Club (1882), que abrió su sede social en 1897 en la calle Florida, y el Círculo de Armas (1885), situado en Corrientes al 600. El primero fue fundado en 1882 por una facción del roquismo interesada en el turf y la cría de caballos de carrera, actividades asociadas al prestigio y la riqueza (LOSADA, 2009: 165-166). La institución representaba la revalorización de lo rural y las actividades productivas vinculadas a ello, así como el creciente reconocimiento de los grandes terratenientes de la pampa húmeda en el proceso de auge de la economía agroexportadora. Asimismo, su creación tuvo como uno de sus principales objetivos dotar de una mayor sofisticación a las elites y promover un ocio refinado entre sus miembros. La cocina francesa, la práctica de la esgrima, la visita a la biblioteca, o la apreciación de obras artísticas formaban parte de las distinguidas actividades que los socios podían disfrutar en su sede. De este modo, en los clubes, además se transmitían las pautas de refinamiento europeas a sus miembros, orientadas a promover modos de comportamiento que apuntaran a la civilización de las pasiones entre los miembros de la "aristocracia" / "patriciado". En este sentido, para formar parte de la alta sociedad, además del dinero, era necesario contar con el capital cultural y simbólico.

Así, los bienes consumidos y el estilo de vida de las elites pasaron por un proceso de europeización. Esto fue visible, por ejemplo, en el vestido, la comida, la adquisición de obras de arte, las actividades de ocio, como el turf, los estilos arquitectónicos, la música lírica o los bailes (el vals, las cuadrillas y mazurcas en lugar de minués y contradanzas, de la primera mitad del siglo XIX) (LOSADA, 2009: 175). 
Al mismo tiempo, los años que estudiamos fueron un período en el que la sencillez de la vida de las elites coloniales y decimonónicas fue dejada de lado y la ostentación se afianzó como la norma en las prácticas relacionadas con el ocio y el consumo. Fue la época de los largos viajes por el viejo mundo, de la edificación de portentosas viviendas, los petit hotels y palacios (donde serían celebradas las reuniones sociales más exclusivas y los bailes de la alta sociedad), del veraneo en las lujosas residencias ubicadas en las estancias, de los paseos en fastuosos carruajes por Palermo (que tenían lugar los jueves y domingos por la tarde), donde hombres y mujeres iban vestidos elegantemente haciendo gala de su status y riqueza. En este sentido, las prácticas y el consumo de ciertos bienes y servicios apuntaban a marcar la distinción con el resto de la sociedad. Asistir a las funciones en los teatros era una forma. Del mismo modo, los integrantes de la alta sociedad asistían a una serie de cafés que actuaban como espacios de sociabilidad, recreación y entretenimiento exclusivos (por ejemplo, la confitería del Águila, situada en la calle Florida), en los que había espectáculos, conciertos o actos musicales; y que contaban, en algunos casos, con jardines.

La austeridad cedió lugar a la pompa también en los rituales de paso. Mientras las misas perdieron peso como espacio de encuentro, los funerales y bodas se cargaron de una enorme ostentación materialista y mundana. ${ }^{106}$ La sociedad se volvió más consumista, lo que generó rechazo en algunos observadores que habían presenciado el paso de la "gran aldea" a la "ciudad cosmopolita" (ROCCHI, 2000: 17-18). Las publicidades de nuevas mercancías se multiplicaron en la prensa y los medios gráficos de la época; y momentos de la vida, como la muerte o los enlaces matrimoniales, se convirtieron en demandas potenciales para empresas comerciales, que ofrecían todo lo necesario para garantizar un servicio de calidad, de acuerdo con los ingresos de cada cliente (ROCCHI, 2000: 52). ${ }^{107}$ Las prácticas funerarias y el luto, por ejemplo, generaron una nueva demanda de servicios (armado de la capilla ardiente, traslado del cuerpo) y bienes (cajones, velas, tarjetas, indumentaria negra, pianos silenciosos, etc.). Así, los rituales funerarios eran grandes representaciones y puestas en escena, en las que se invertían importantes sumas de dinero, al igual que en las bóvedas y panteones edificados en el cementerio de la Recoleta, que representaban el lujo, la opulencia y la ostentación de las elites en su máxima expresión. Aquellos con suficiente poder

\footnotetext{
106 Sobre las prácticas funerarias en este período, véase, entre otros, FIQUEPRON (2015) y DAL CASTELLO (2014 y 2016).

107 Sobre este tema, véase también, entre otros, ROCCHI (1999).
} 
adquisitivo, podían edificar suntuosos monumentos funerarios en mármol. La nueva era de riqueza, por ejemplo, había posibilitado que grandes estancieros o personas que se habían enriquecido con las nuevas actividades comerciales construyeran mausoleos en los cementerios. Julio, el protagonista de La Gran Aldea (capítulo XII, p. 122), se preguntaba por el mérito y la justificación de estos ostentosos homenajes para personas que no habían sido próceres, soldados o grandes intelectuales. Esta mercantilización de los rituales funerarios era percibida por los contemporáneos, que a fines del siglo XIX remarcaban su contracara, el declive de la visita de los deudos al cementerio (GUERRA, 2010a: 3). Este tipo de consumo era una forma de exteriorizar el status alcanzado entre los miembros de la alta sociedad, amigos y familia, pero también hacia el resto de la sociedad (LOSADA, 2008: 217). Como contraparte, la jerarquía y el afecto de los que conocían al muerto estaba en relación directa con la concurrencia y el tamaño de la procesión de carros, que acompañaban el traslado del difunto a "su última morada", donde serían pronunciados los discursos antes del entierro. Si se trataba de miembros destacados del ámbito político e intelectual, dirigentes de asociaciones y autoridades políticas acompañaban la procesión. En cambio, la muerte en soledad, un entierro al que no asistían los miembros de la comunidad, los amigos y familiares, sin un velorio, que nadie visitara la tumba, ser enterrado en una fosa común, eran características de un destino triste en el imaginario de los porteños de fines del siglo XIX y principios del XX, es decir, eran signos claros del olvido del difunto por parte del colectivo o los seres queridos.

Los diarios y periódicos de la época, como "La Prensa” y "La Nación”, cubrían los eventos relacionados con la vida de la alta sociedad, entre otros, las muertes y los rituales funerarios de sus miembros. Muchas necrológicas llevaban adelante la construcción de una biografía celebre y heroica del fallecido, con una clara intención pedagógica y de adoctrinamiento político y moral para la sociedad (FIQUEPRON, 2015: 235). Como señala Andrea Reguera (2006a), los valores resaltados por unos hombres acerca de otros, sobre todo, en los casos de una vida "ejemplar", nos dan una idea de aquellos aspectos que volvían prestigioso a un individuo entre sus contemporáneos. De acuerdo con la concepción de la masculinidad, había una serie de atributos que volvía a un hombre meritorio del respeto de sus pares y del resto de la comunidad: virilidad, fortaleza, perseverancia, decisión, trabajo, iniciativa, esfuerzo propio fueron las cualidades que el diario "La Nación” resaltó en la necrológica 
publicada con motivo de la muerte de Ramón Santamarina (REGUERA, 2006a: 23). Las circunstancias de su defunción estuvieron ausentes en ese breve bosquejo de su biografía, que lo caracterizaba como un poderoso y prestigioso estanciero. ${ }^{108}$ Santamarina, uno de los destacados miembros de la elite terrateniente, respetado por el resto de las elites de la Capital Federal, ${ }^{109}$ recibió homenajes en su memoria, tanto en la ciudad de Buenos Aires como en la comunidad de Tandil, donde había vivido y amasado buena parte de su fortuna, aunque hacía tiempo que no residía en dicha localidad. El día de su muerte (23 de agosto de 1904), "La Nación" publicaba una necrológica sobre este reconocido miembro de la elite porteña. ${ }^{110}$ Según el cronista, había sido un "patriarca", un "anciano viril”, cuya muerte había tomado por sorpresa a sus familiares, seres queridos y amigos más cercanos. Su vida había sido, además, el ejemplo del trabajo y del sacrificio, un hombre que se hizo a sí mismo, empezando desde abajo: "El veterano del trabajo ha caído a plomo en el reposo eterno". La necrológica se concentra en marcar la lucha de un joven inmigrante que construyó un enorme patrimonio por sus propios méritos individuales, como producto de la dedicación al trabajo duro, arriesgando su vida, recorriendo con su carreta los caminos que erran el territorio de los indígenas. Su fortuna, amasada por el ahorro invertido en el comercio y en su estancia, era un ejemplo a enaltecer. Según la información del diario, la casa en la que fue velado estaba concurrida, y en la capilla ardiente, adornada con coronas de flores, el cuerpo era acompañado por quienes venían a despedirlo.

Santamarina era el símbolo del hombre que gracias a su trabajo había ascendido socialmente. Representaba, siguiendo los valores de la época, la fortuna

\footnotetext{
${ }^{108}$ Ramón Santamarina se suicidó en 1904. Para un análisis de la biografía de este estanciero gallego, véase, entre otros, REGUERA (2006a). Mediante testimonios de los descendientes, la autora pudo acceder a importantes datos referidos a las circunstancias de la muerte de este acaudalado terrateniente y empresario.

${ }^{109}$ Ramón Santamarina llegó a Buenos Aires, huérfano y sin dinero. Su viaje lo llevó a Tandil en 1844, como arreador de bueyes en una tropa de carretas. En el campo de Ciriaco Gómez trabajaría como peón. A partir de entonces, daría comienzo su carrera en los negocios, dedicándose al transporte de cueros desde Tandil a Buenos Aires en carretas, desde donde traía mercaderías para abastecer al pueblo. Este servicio era necesario en una época en la que el ferrocarril no llegaba a la zona. A partir de 1863, empezaría a comprar tierras, aprovechando la acumulación de capital lograda gracias a su actividad como comerciante, dando inicio a la carrera meteórica que lo llevó a la acumulación de un patrimonio que superaba los 10.000.000 de pesos al momento de su muerte, ocurrida en 1904. Los títulos de los campos que adquirió en Tandil fueron un beneficio de la política de tierras del Estado. En aquel entonces, eran ofrecidas a la venta privada, en un contexto donde el peligro de los malones continuaba vigente, lo que las volvía menos atractivas. Los datos aquí presentados fueron tomados de REGUERA (2007). La autora ha trabajado el caso de Santamarina como empresario, comerciante y terrateniente de la región pampeana, teniendo en cuenta las redes sociales y políticas que le permitieron consolidar su inmensa fortuna y legarla a sus descendientes (REGUERA, 2006a).

${ }^{110}$ La necrológica del diario La Nación fue presentada en REGUERA (2006a).
} 
construida con esfuerzo, el éxito luego de atravesar por los desafíos de la "lucha por la vida". Así también era presentado en la necrológica publicada por el diario "La Prensa" (24/08/1904); en esta se destacaban el aprecio y la admiración que Santamarina despertaba con su ejemplo: hombre que había amasado fortuna con esfuerzo, perseverancia y trabajo arduo, sin otro capital que su "deseo de luchar contra la suerte". Asimismo, el cronista destacaba que la familia guardaba en la estancia "Bella Vista" la carreta con la que este patriarca había forjado su fortuna (adquiriendo tierras a buen precio que años más tarde se valorizaron). También se destacaba que el difunto, ese "viejo luchador", había sido un esposo y padre modelo, así como un generoso contribuyente en causas humanitarias y obras de caridad. Por otro lado, no se mencionaban detalles relacionados con su defunción.

Según los datos biográficos presentados por Andrea Reguera (2006a: 78), Santamarina se quitó la vida, luego de caer en una profunda depresión, el 23 de agosto de 1904, a los 77 años, tras consolidar una inmensa fortuna y volverse un nombre prestigioso entre la elite porteña. El suicidio ya había marcado su vida antes de cruzar el Atlántico. Siendo todavía un niño, el padre de Santamarina, José, se había suicidado en España delante de su hijo (REGUERA, 2006a: 18). Si bien las necrológicas de "La Nación” y "La Prensa" no brindaban detalles sobre la forma en la que murió, es probable que su suicidio fuera un secreto a voces en la época.

No creemos que el suicidio de Ramón Santamarina fuera el único que fue ocultado en el período que estudiamos. Dado el escándalo que estos sucesos provocaban en la sociedad, asociados con la locura, en el mejor de los casos, es probable que los deudos buscaran ocultar lo sucedido al público. ¿Qué consecuencias ocurrían cuando esto no era factible y las circunstancias no podían ser encubiertas o disimuladas? Por un lado, el difunto no podría participar de ningún tipo de ritual religioso, como la misa de cuerpo presente; por otra parte, ya no existía peligro de que no se autorizara la sepultura. En 1863, Bartolomé Mitre, como consecuencia de un pleito con autoridades de la Iglesia por no autorizar el entierro de Blas Agüero (un francmasón ateo que se negó a recibir los sacramentos antes de morir), decretó que se diera sepultura en el cementerio "a los cadáveres de todos los individuos que hubieren fallecido perteneciendo a la religión católica sin haber hecho de ella abjuración pública y notoria, no obstante cualquiera prevención que en contrario hiciere la autoridad eclesiástica" (PEÑA, 1960: 162). 
Incluso antes, ya existían ciertos argumentos para eludir la administración de los enterramientos por parte del clero. El 24 enero de 1856, a las seis de la mañana, Juan Cornet, un "antiguo y honrado" comerciante se suicidó en la puerta de su tienda, situada en la calle Federación. Según el cronista de "El Nacional" (24/01/1856), Cornet mantenía con su hijo un cierto conflicto, que habría sido la causa que lo habría llevado al suicidio. Al día siguiente, se publicó un ensayo titulado "La comunidad de la Tumba", cuyo autor era Domingo Faustino Sarmiento. En este texto, Sarmiento mencionaba los contratiempos que habían tenido lugar para llevar adelante el entierro de Cornet:

El desgraciado Cornet, que se suicidó anteayer, fué enterrado en el cementerio común por disposición del gobierno, contra la negativa de sepultura que imponía la autoridad eclesiástica.

Aplaudimos esta medida que evita que en adelante se introduzca también en el sepulcro la persecución y la deshonra de los cadáveres. $\mathrm{Ni}$ la religión, ni la sociedad tienen nada que ver con los restos inanimados de lo que fue hombre. El delito o la herejía son obras del alma; el cuerpo inanimado es inocente de todo cargo. ${ }^{111}$

Sarmiento se oponía a los castigos y penas relacionadas con la privación de sepultura de los suicidas. En este sentido, destacaba que el carácter sagrado del cementerio no dependía exclusivamente de la bendición eclesiástica, ya que este era un atributo dado desde la legislación romana, que consideraba este espacio como la morada de los restos de los antepasados. Al mismo tiempo, las leyes de las partidas no impedían el entierro de un suicida, salvo que este se quitara la vida para escapar del castigo de un delito por el que se lo había condenado. Así, los locos y aquellos que padecían de alguna dolencia o sufrimiento insoportable no podían ser privados de sepultura. Sarmiento también resaltaba que el cementerio era una institución civil, más allá de la consagración del mismo dada por la iglesia, y su edificación y cuidado dependían de las autoridades seculares; las atribuciones de los miembros del clero se reducían a las tareas administrativas del mismo. En síntesis: "El gobierno, por tanto, es juez del cementerio".

\footnotetext{
${ }^{111}$ SARMIENTO (1951 [1856]: 308-309).
} 
En este ensayo, Sarmiento también destacaba el correcto y humanitario accionar seguido por las autoridades, que pidieron el asesoramiento de Dalmasio Vélez Sarsfield, resaltando sus conocimientos sobre los temas relacionados con la Iglesia y el Derecho Canónico. En su escrito, Vélez (1971 [1856]) retomaba argumentos de diferentes tradiciones jurídicas para rebatir la postura del obispo, que había decidido privar de sepultura a Cornet. De acuerdo con el derecho romano, el suicidio sólo era un delito cuando el suicida estaba acusado y esperando condena por un crimen. Por otra parte, las leyes heredadas del antiguo régimen, las Partidas, establecían que sólo se condenaba a aquellos suicidas que hubieran cometido algún delito; así, no había pena alguna para los que se quitaban la vida movidos por un gran dolor o por efecto de la locura. Si bien el Derecho Canónico establecía que debía privarse de sepultura a los suicidas, también contemplaba que esto no aplicaba para los casos de individuos afectados por sus facultades mentales o por una enfermedad. En síntesis, la privación de sepultura no debía ser aplicada si no podía probarse que se trataba de una acción premeditada y deliberada:

Bastará pues que Su Señoría Ilustrísima, el Señor Obispo Diocesano exija para concederle sepultura eclesiástica, alguna información de los deudos del muerto que acredite que el suicidio no ha sido absolutamente voluntario, sino efecto de alguna enfermedad física o moral; y ésta, Señor, ha sido la práctica seguida en Buenos Aires por otros Obispos o por los Gobernadores de la Iglesia en Sede Vacante.

Soy pues de dictamen que Vuestra Excelencia diga a su Señoría Ilustrísima que las leyes civiles que nos rigen y la práctica observada en casos de suicidio, como las mismas leyes en la Iglesia, no le permiten privar de la sepultura en los Cementerios públicos a todo suicida, generalmente hablando, como lo exije Su Señoría Ilustrísima sin examen, sin proceso previo de las causas que han motivado la muerte, causas valoradas y de resultados jurídicos, según el derecho civil que rige a Buenos Aires (VÉLEZ, 1971 [1856]): 317).

El alegato de Vélez logró revertir la situación. "El Nacional” (26/01/1856) informaba que Cornet había sido enterrado luego de 48 horas de espera, mientras se resolvía la situación planteada por las autoridades eclesiásticas. En vista de la los argumentos legales, el Obispo había determinado que daría marcha atrás y permitiría la inhumación del suicida. El cronista destacaba: "Aplaudimos en esto la conducta obtemperante de la autoridad eclesiástica en evitar colisiones que no hacen más que perturbar las conciencias, y suscitar animosidades". Lo sucedido en este episodio puso en evidencia el avance del proceso de secularización de la administración de los cementerios, 
institucionalizado luego por el mencionado decreto de 1863 y más tarde con la sanción de un nuevo reglamento de cementerios en 1868. A partir de 1880, el avance de la laicización de diferentes esferas de la vida social cobraría mayor impulso (con la sanción de las leyes de registro civil, matrimonio y educación común) y las áreas de influencia estatal se ampliaron. Así, mientras que el estado y sus áreas de incumbencia crecieron, las instituciones religiosas perdieron una serie de funciones de las cuales se habían ocupado durante la época virreinal y luego de la independencia.

En síntesis, a medida que avanzó la segunda mitad del siglo XIX, resultó cada vez más anacrónico e intolerable la privación de sepultura a los suicidas, así como cualquier clase de castigo o sanción dirigida hacia aquellos. Como ya mencionamos, la legislación argentina sobre este tema pasó por una serie de cambios a lo largo de la segunda mitad del siglo XIX, en los que terminó por primar la tendencia a eliminar las penas para quienes se hubieran quitado la vida o para los que hubieran fallado en su intento. ${ }^{112}$ Sin embargo, una muerte por mano propia no dejaba de poner en cuestión la reputación y el buen nombre del que se quitaba la vida. Como veremos, los suicidios tenían un significado polémico y podían ser interpretados de diversas maneras. En el escrito de Vélez Sarsfield ya mencionado, este jurista destacaba que, si bien no estaba de acuerdo con la privación de la sepultura, una pena infamante que afectaba más a la familia del suicida que a este último, sí consideraba preferible catalogar los suicidios como delitos, aunque no fuera posible sancionar la falta, a fin de dejar "una advertencia moral para los pueblos" y disuadir a los más predispuestos a llevar adelante tales actos indeseados. El castigo para los suicidas no podía ser otro que la mancha de la "deshonra pública” (VÉLEZ, 1971 [1856]): 316). En este sentido, como mencionaba el autor de "La Gran Aldea" (2003[1884]: 106), Lucio Vicente López, los suicidios estaban entre los principales escándalos de la comunidad junto a raptos, seducciones, adulterios y duelos.

Para los miembros de la sociedad porteña, tan obsesionada con la preservación de la reputación personal, un suicidio era un suceso escandaloso que los exponía en público, sobre todo, si los detalles de lo sucedido circulaban en las páginas de la prensa. Diarios renombrados y de gran tirada, como "La Prensa" y "La Nación", y los periódicos con un orientación política y partidaria más definida, incluían información

\footnotetext{
112 Véase, DONNA (1999: 94). También, BLASCO FERNÁNDEZ DE MOREDA (1962); GARDELLA (1968) y DI GRESIA (2014: 455, 457, 458-461, 794-797, 799-803, 805-810).
} 
cada vez más diversa entre sus páginas, por ejemplo, secciones en las que publicaban las cartas y solicitadas de sus lectores con contenidos relacionados con la honra y la reputación de estos. ${ }^{113}$ La presentación en público de estos escritos, por parte de un autor reconocido, era un modo de silenciar los rumores maliciosos que circulaban de forma oral. En este sentido, por ejemplo, desmentir los chismes relacionados con el malestar en los negocios de algún individuo. Otras secciones novedosas eran las dedicadas a la crónica social y policial. Los suicidios también eran informados a través de estos medios gráficos. Los suicidas, y sus familias, asimismo eran el blanco de las murmuraciones y juicios lanzados por el “tribunal de la opinión”. Estos hechos serían comentados en las conversaciones casuales de las elites, en sus espacios de encuentro y sociabilidad, por ejemplo, las mujeres durante las visitas a las casas de sus amigas; los hombres al conversar en el club, o en algún café. Sin embargo, no creemos que fueran los únicos que participaran del cotilleo. En los patios de los conventillos, pensiones, almacenes, despachos de bebidas, fondas y pulperías, hombres y mujeres de seguro también comentaban los escándalos y las miserias del resto de los habitantes del barrio, la ciudad e incluso de otras regiones del territorio argentino. Este circuito de murmuraciones podía afectar la reputación y el prestigio individual. Si bien los espacios urbanos creaban ámbitos de mayor anonimato, donde escapar al ojo vigilante que juzgaba las acciones de cada uno, en el microcosmos del barrio y la cuadra, el rumor y la mirada del otro tenían un gran poder cuando se compartían los mismos espacios en público. Por esta razón, se buscaba mantener el secreto y la reserva, cuando esto era posible, solicitando a algún médico de confianza que mantuviera ocultas las circunstancias de la muerte al público.

Por otra parte, como veremos más adelante, para aquellos suicidas de la alta sociedad que no podían ser ocultados, los cronistas de la prensa ensayaron formas discursivas alternativas, orientadas a enaltecer al muerto y solapar la forma en que había fallecido, destacando ciertas circunstancias del acto suicida (el estado mental frío y sereno, la determinación de su decisión, sin duda ni cobardía, etc.) o el "cursus honorum" del difunto. Así, algunos suicidas fueron coronados con los rituales y el discurso de la "buena muerte".

\subsubsection{Hombres y mujeres}

${ }^{113}$ Sobre este asunto, véase, entre otros, GAYOL (2007). 
Como mencionábamos antes, la llegada masiva de extranjeros tendió a aumentar el índice de masculinidad y la proporción de personas jóvenes en la población total. Este desequilibrio entre la cantidad de varones y mujeres generó realidades diferentes a la hora de conseguir pareja para ambos sexos. En este sentido, los inmigrantes tendieron a casarse con personas de su misma nacionalidad. Esta elevada tasa de endogamia no implicó la ausencia de matrimonios entre extranjeros y nativos. Esto último era más frecuente entre los hombres. En una sociedad con alto índice de masculinidad, no era extraño que buscaran compañeras fuera de su grupo étnico, aunque prefirieran a las de su misma región de origen. Más infrecuente fue lo inverso: mujeres extranjeras casadas con hombres nativos (DEVOTO, 2000: 103). Al mismo tiempo, las mujeres tendieron a casarse tempranamente, mientras que los varones podían permanecer por más tiempo solteros, debido a la poca cantidad de posibles candidatas con las cuales formar una familia.

Esta no era la única diferencia en la vida de los sujetos de sexo masculino y femenino en la ciudad de Buenos Aires. Si bien es cierto que hubo posibilidades para el ascenso social, por medio del trabajo en diferentes actividades, esta fue una realidad para los varones: en 1895, sólo el 15,7\% de la mano de obra industrial de toda la Argentina era de sexo femenino, empleadas en fábricas del rubro textil, confección, vestido y tocador, químico, gráfico y alimentación (LOBATO, 2007: 75). Así, las mujeres, en su mayoría, estuvieron excluidas del mundo laboral, como señala Lobato (2000b: 470), y, en su mayoría, siguieron ocupadas como tejedoras, modistas, domésticas, cocineras, planchadoras, lavanderas, costureras $\mathrm{y}$, en algún caso, vendedoras de cigarrillos. Mientras que las mujeres de la alta sociedad porteña o de la "gente decente" permanecían recluidas en el mundo del hogar, muchas de las de las clases populares debían salir a la calle a ganar el sustento para vivir. Algunas también se dedicaron a ejercer la prostitución. Las que llevaban adelante labores análogas a las de los hombres eran consideradas mano de obra barata, al igual que los niños, y por esta razón cobraban un salario bastante menor que los varones. Como señala Lobato (2007: 78), la cultura dominante estigmatizaba el trabajo femenino, sobre todo en los establecimientos fabriles. Existía un preconcepto de lo femenino que lo asociaba con el honor, suavidad, belleza, atributos que no eran los de la condición obrera. En el siglo XIX, había un sólo oficio respetable para la mujer, por fuera de su rol en las tareas del 
hogar, el de educadora. Si trabajaban, las mujeres lo hacían mientras eran solteras o recién casadas, cuando estaban embarazadas y cuidaban de los niños se retiraban del mercado laboral. Volvían más tarde cuando estos habían crecido.

En general, la mayoría de las mujeres aparecía empleada como parte del servicio doméstico, en las residencias de las elites y en los hogares de algunas familias de los sectores medios. En Buenos Aires, en 1887, había 29.870 trabajadores “domésticos", y la mayoría eran mujeres (LIERNUR, 2000: 430). ${ }^{114}$ En ese mismo año, la cantidad de empleadas domésticas era similar a la del conjunto de costureras, modistas y tejedoras (LOBATO, 2007: 59). En las ciudades del litoral, las empleadas domésticas eran mujeres europeas y migrantes del interior, aunque en 1895 todavía había criadas negras y mulatas. Francesas, españolas e italianas eran más requeridas y tenían un mejor salario. Mientras que los varones se dedicaban a cuidar las caballerizas y a realizar tareas en las cocinas, tarea compartida con el servicio femenino, las mujeres se dedicaban a hacer de amas de leche, lavar y planchar ropa, limpiar el hogar, cuidar de los niños, comprar los alimentos. Había una relación paternalista, aunque sin olvidar mantener la disciplina, entre patrones y servicio doméstico. No era infrecuente que fueran considerados como parte de la familia, que figuraran en las disposiciones testamentarias o que los jefes del hogar fueran padrinos o madrinas en los matrimonios de sus empleados domésticos. Este vínculo se volvió cada vez más impersonal a medida que avanzó el siglo XX (LOSADA, 2008: 98-99). Si bien muchos criados y criadas fueron recordados con cariño, por otra parte, también se dieron casos de relaciones sexuales forzadas y violaciones de las empleadas domésticas. Estas, a veces, eran objeto de abusivas costumbres masculinas, algo que no fue insólito entre las familias adineradas (LOBATO, 2007: 24; ADAMOVSKY, 2012: 78).

También existían muchas mujeres dedicadas a trabajar de modistas, en sus domicilios, en las habitaciones de los conventillos y casas de inquilinos. En las últimas décadas del siglo XIX, se popularizó el uso de las máquinas de coser (CICERCHIA, 2001: 162). A partir de entonces, empezaron a atender los encargos que provenían del

\footnotetext{
${ }^{114}$ En las casas de las familias de la alta sociedad y de las clases medias había empleados domésticos. Estos, muchas veces, eran niños y niñas de entre 7 y 14 años, que eran cedidos por sus padres, por medio de un contrato, a comerciantes y vecinos notables de la comunidad, con el compromiso de que los jóvenes fueran educados, vestidos y alimentados hasta alcanzar la mayoría de edad. A cambio, éstos debían servir como personal doméstico. En esta situación, podían llegar a sufrir malos tratos, por parte de sus patrones/tutores, que los llevaban a huir; en algunos casos, a buscar el auxilio de alguna prostituta; en otros, como veremos, a quitarse la vida.
} 
ejército y la marina, de talleres, de industriales o de tiendas. Podían dedicarse a confeccionar ropa (pantalones, sacos, corbatas, chalecos, trajecitos para niños, bombachas, ropa interior para negocios y familias particulares), camisas para los uniformes militares (coser puños y cuellos era más complejo y trabajoso que otros tipos de indumentaria), o bolsas de arpillera (destinadas a las labores agrarias). Otras mujeres trabajaban como lavanderas y planchadoras (en las ventanas de los conventillos uno podía toparse con algún letrero que rezaba "planchadora"). Ambas eran consideradas ocupaciones femeninas. El planchado era una actividad que requería de cierto talento para lograr un trabajo prolijo en mangas y cuellos, pantalones y otras prendas, que eran entregadas dobladas de forma impecable los días sábados (LOBATO, 2007: 32). Para ello, utilizaban una plancha sin carbón, esta era calentada a base de una lengua de hierro que estaba al rojo vivo (puesta en un horno que funcionaba a base de coke) y era insertada en la plancha (CICERCHIA, 2001: 168). Para sostenerse con los ingresos de este tipo de actividad, una planchadora debía trabajar no menos de 10 horas por día. Las mejores en el oficio trabajaban para las casas de las elites. Otras mujeres se dedicaban a la venta ambulante de cigarros, que fabricaban en las habitaciones que alquilaban. El trabajo a domicilio en los conventillos, como el de las costureras y fabricantes de cigarrillos, era por demás insalubre. Al mismo tiempo, allí se mezclaba lo laboral con la vida familiar (LOBATO, 2007: 96).

Además, las mujeres que trabajaban por un salario fuera de su hogar o las que lo hacían en sus domicilios no dejaron de ocuparse de sus grupos familiares: limpiaban, cocinaban y cuidaban de los niños y enfermos. El trabajo femenino en el hogar era intenso y acelerado, empezaba muy temprano (cuatro y media de la mañana, en verano, seis, en invierno) y terminaba por la noche (pasadas las veintidós horas). Estas labores no estaban orientadas por un horario específico (se trataba de un quehacer constante), aunque los ritmos los marcaban los tiempos de la escuela y de los trabajos de sus compañeros. Así, coordinaban sus actividades para tener lista la comida a determinadas horas, por ejemplo, a las 11:30hs, cuando los trabajadores volvían momentáneamente a sus hogares y era el momento de almorzar (LOBATO, 2007: 104-105). De este modo, muchas mujeres fueron doblemente explotadas: se encargaron de las labores domésticas de forma gratuita, mientras que ganaban salarios menores que los de los hombres. El rol femenino en la reproducción de la mano de obra fue clave para la expansión del capitalismo, como señala Adamovsky (2012: 74). Todas las tareas que desempeñaron 
madres y esposas (limpiar, comprar y cocinar los alimentos, criar a los hijos y enviarlos a la escuela, lavar, planchar y remendar la ropa), posibilitaron que los hijos y maridos pudieran dedicarse a jornadas laborales de no menos de 10 horas diarias, en la mayoría de los casos, y si el salario de estos no rendía lo suficiente, llevar adelante actividades para generar ingresos extra para el grupo familiar. Así, de acuerdo con el marco axiológico vigente y el horizonte ideal femenino, la mujer estaba abocada a convertir el hogar en refugio, en espacio de felicidad. Desde niña era preparada para cocinar, lavar, planchar, limpiar, coser junto a las otras mujeres de la familia. Esta orientación también era transmitida en la escuela. Como contrapartida, durante el último cuarto del siglo XIX, se consolidó la idea de que el trabajo de las mujeres fuera del hogar, a cambio de un salario, era peligroso para la raza, la sociedad y el hogar, ya que tenía un potencial degenerador (LOBATO, 2007: 315).

Así, se consolidaron dos ideales de género. Por un lado, uno masculino, asociado con la actividad en los espacios públicos y la función de productor, proveedor y actor político. Lo femenino, por otra parte, fue vinculado con el hogar y la maternidad, actividad clave en la reproducción sana de los miembros de la raza y la nación. Así se conformaba el ideal de madre de familia: esta reina y señora del hogar, ama de casa eficiente y madre ejemplar, debía garantizar la armonía y la tranquilidad del mismo, para que los hombres pudieran reponer fuerzas luego de la actividad agitada del espacio público, en el trabajo, la política y los negocios. De acuerdo con el ideal dominante de la época, la mujer era consoladora, daba animo a los demás, protegía a los desamparados, llenaba de belleza y vitalidad la existencia (LOBATO, 2007: 63). Al mismo tiempo, era la madre la encargada de enseñar aquello que no se aprendía en el colegio, una sólida instrucción religiosa. La familia era imaginada como un ámbito de contención, un refugio frente a las turbulencias de la vida moderna (LOBATO, 2007: 13, 105). Las calles eran espacios públicos de sociabilidad masculina, las mujeres sólo las transitaban acompañadas. Sólo las prostitutas andaban por la vía pública solas. El resto de las mujeres permanecía en el ámbito del hogar y la sociabilidad familiar. A partir del matrimonio, la vida social femenina se reducía y se centraba en sus roles de madre, esposa y anfitriona. Dentro del espacio privado, las señoras de la alta sociedad porteña también tenían el rol de organizar los eventos y reuniones sociales. Para ello habían sido criadas desde niñas: su formación incluía clases de canto, idiomas, piano, es decir, las habilidades de una mujer de salón, agradable y culta. Cabe destacar que su 
educación formal no iba más allá del nivel secundario (para llegar a ser maestras). Asimismo, las jóvenes eran entrenadas para mantener un trato cortés y sostener conversaciones entretenidas, en las que hicieran gala de su juicio, intelecto y buen gusto con respecto al arte y la literatura. Al mismo tiempo, para llevar adelante las reuniones sociales, las anfitrionas contaban con un ejército de sirvientes que cocinaban, servían el té, hacían las compras y limpiaban la vajilla.

Por otra parte, esto no implicaba, de forma necesaria, una actividad exclusiva en el espacio privado y hogareño para todas las mujeres de la ciudad de Buenos Aires. Los cargos públicos o la posibilidad de votar no estaban dentro de las posibilidades de las mujeres en este período y el discurso de las elites tendía a ubicar su rango de acción en la esfera privada, como madre y esposa. Sin embargo, las mujeres de las elites (las esposas de hombres destacados por su poder económico y político), tuvieron ámbitos de participación en el espacio público, por ejemplo, administrando las instituciones de beneficencia, a través de sus redes de vínculos familiares y sociales. Así, había mujeres que cubrían con sus acciones roles esenciales para el estado, como la incipiente asistencia social llevada adelante desde las organizaciones filantrópicas de las que participaban, por ejemplo, La Sociedad de Beneficencia y la Comisión Auxiliar de Damas del Patronato de la Infancia. En este sentido, las "esposas y madres de los ciudadanos" participaban, desde un lugar diferente al de los varones, en la sociedad civil. Si por un lado las actividades caritativas y filantrópicas eran otra forma de expresar el perfil maternal promovido en la educación de las mujeres (LOSADA, 2008: 132), la beneficencia fue también una herramienta política no estatal implementada por las mujeres de las elites que ocuparon esferas que el estado todavía no tomaba a su cargo, ya fuera por falta de medios o por la legitimidad que los habitantes otorgaban a la delegación de este tipo de asuntos en los particulares (DE PAZ TRUEBA, 2010).

Así, de acuerdo con el horizonte ideal femenino, las mujeres debían convertirse en madres y esposas de los ciudadanos, guardianas de las virtudes republicanas en el hogar, y estar dispuestas a acatar la autoridad del padre, y más tarde, del marido. Los discursos eruditos, moralistas y religiosos hegemónicos apuntaban a una sexualidad controlada, que privilegiaba y fomentaba la castidad, la pureza y la preservación de la virginidad femenina (CICERCHIA, 2001: 179). Así, existía un rechazo de la sensualidad de la mujer por parte de la iglesia y las ideas morales de la época (LOSADA, 2008: 122). Por esta razón, las jóvenes debían ser protegidas de la 
influencia perniciosa y pornográfica de los folletines europeos, publicados en los diarios porteños, que alentaban actitudes inapropiadas. Por otra parte, las solteras asistían a los bailes, donde podían conocer a sus pretendientes y lograr su objetivo: el matrimonio. En este sentido, las madres promovían que las mujeres se relacionaran con gente y tuvieran una intensa vida social, que sostuvieran buenas relaciones con amigas y se desenvolvieran con soltura ante los demás. La formación religiosa femenina no buscaba aislar a las mujeres, sino integrarlas evitando que se desarrollara una sensualidad peligrosa e inconveniente (LOSADA, 2008: 125).

La antítesis de esta imagen ideal era la "mujer pública", la prostituta, que había perdido su honra. No es casual que la forma más agraviante para insultar a una mujer fuera llamarla "puta". La presencia de las prostitutas era una realidad inquietante para médicos e higienistas, aunque también era considerada inevitable, dado el alto índice de masculinidad que no favorecía la búsqueda de pareja. La mayoría de las prostitutas registradas entre 1889 y 1901 provenía de Europa del este, Francia, Italia y ya se dedicaban a esta actividad antes de venir a América. Al mismo tiempo, un 25\% de las 6.413 mujeres de Buenos Aires, relevadas en los datos de los médicos higienistas, eran argentinas (GUY, 1994: 28-29). Se suponía que la actividad legal sólo era la punta del témpano. En los interrogatorios, la mayoría no declaraba una profesión o actividad previa al ejercicio del comercio sexual, las que sí lo hacían mencionaban que habían trabajado como empleadas domésticas, lavanderas y modistas. En este sentido, muchas de las mujeres que optaban por ejercer la prostitución no contaban, como mencionamos antes, con muchas otras alternativas, frente al desempleo y la falta de oportunidades laborales que les aportaran lo necesario para sostener a sus familias, en especial, si su ingreso era el único con el que contaban. Quedaba claro que muchas de las mujeres que se prostituían eran las que habían quedado por fuera de los trabajos capitalistas en las fábricas, del otro lado del Atlántico. Como señala Donna Guy (1994: 85):

Trabajos como el de vendedora de cigarrillos o camarera de café no llevaban a las mujeres a las casas de prostitución; tampoco los trabajos en el sector público. [...] El desempleo y el trabajo doméstico mal pago, y no los empleos fuera del hogar, llevaban a las mujeres a la prostitución.

Podemos destacar también, retomando lo expuesto por Guy (2014: 121-122) en un 
trabajo más reciente, que la prostitución no era la principal actividad de las mujeres suicidas: aunque compartían con el resto de los suicidas de sexo femenino similares condiciones habitacionales (vivían en piezas alquiladas), padecían de enfermedades físicas y /o mentales, y sufrían la ausencia de redes de contención suficientes. Como señala la autora, podría aventurarse que las que trabajaban en burdeles tenían mayores vínculos a los que recurrir para afrontar las dificultades que las mujeres que ejercían la actividad solas y en la clandestinidad.

Si el lugar en el mercado de trabajo y en la esfera pública era distinto, las formas de ganar estatus y sostener una reputación también eran diferentes para las personas según su sexo. En este sentido, el uso de la violencia no era sólo una forma de protegerse, formaba parte de la propia identidad masculina. Un hombre como tal debía estar dispuesto a jugarse la vida para defender su honor. Este era un valor compartido tanto por los inmigrantes como por la población nativa. A la hora de dirimir conflictos entre dos hombres, frente a alguna ofensa, estos podían resolver sus diferencias como asuntos privados, recurriendo a la agresión física, por medio de armas de fuego, cuchillos o golpes a mano limpia. No responder el desafío era una cobardía, un acto vergonzoso. Un insulto o un comentario injurioso podían dar pie para que los contendientes se trabaran en combate. En este sentido, llamar a alguien "ladrón" era una ofensa grave. Ponía en tela de juicio la confianza hacia dicho individuo, lo cual comprometía su capital de honor, que le permitía, por ejemplo, solicitar préstamos a otros miembros de la comunidad, basados en el conocimiento mutuo y la palabra dada, o conseguir un empleo.

En este sentido, la segunda mitad del siglo XIX y las primeras décadas del XX, fueron un período de apogeo y crisis de ciertas actitudes hacia el honor. Ideales de moralidad y nobleza surgieron como reacción al pragmatismo reinante durante el proceso de modernización. La cultura del honor, que pervivió hasta la segunda década del siglo XX, fue erosionada por la propia realidad del mundo urbano, donde, con el tiempo, se hicieron presentes problemas y deseos más mundanos y materiales. Mientras el culto a la honra estuvo vigente, una de las prácticas más visibles fueron los duelos: "El duelo, un gesto romántico, pueblerino, sobrevivió integrando estas tradiciones a las prácticas innovadoras que un contexto de transformaciones estructurales imponía. El duelo fue, en definitiva, una costumbre mortal y grotesca de la primera época moderna" (CICERCHIA, 2001: 52). Este tipo de prácticas, ajustadas al código de honor, fueron comunes entre los miembros de la elite durante el siglo XIX. Eran parte de la cultura 
burguesa de estos actores, como ir a la ópera al Teatro Colón, el gusto por las artes, las ciencias, etc. Los duelos eran una forma de resolver conflictos, permitían construir la reputación y, de este modo, legitimar el rol ocupado en la sociedad. El desuso de prácticas como los lances entre caballeros fue un reflejo del declive de la mentalidad del honor (CICERCHIA, 2001: 24).

Como señala Sandra Gayol (2000), si bien los que se batían, siguiendo las normas formales, eran los miembros de las elites, el resto de la sociedad también poseía una noción de honor. ${ }^{115}$ Ésta formaba parte del vocabulario de los propios actores, era un valor que permitía explicar las acciones propias o las de otros. Según Gayol (2000: 185): "El honor describe lo que se debe hacer y lo que es creíble, pero también articula los diálogos entre actores, los comentarios y las obras de ficción contemporánea”. El honor formaba parte de las experiencias pasadas y los esquemas culturales de la población, tanto la extranjera como la nativa. La honra, o su contracara, la vergüenza, eran sentimientos que tenían una doble dimensión. Por un lado, eran categorías que servían a los individuos para representarse a sí mismos, de otorgarse un valor moral, para llevar adelante ciertas acciones o para reprimirlas. Por otra parte, este accionar individual formaba parte de la vida social, es decir, estaba dentro de ciertas pautas de comportamiento colectivas. El objetivo perseguido por cada sujeto era el reconocimiento de los pares (el prestigio, la reputación). Así, cada uno era aspirante a la honra en público y, al mismo tiempo, formaba parte del tribunal que juzgaba las acciones de los demás. Las formas de preservar la honra y la reputación variaban de acuerdo con el género y la clase social de cada uno. Sin embargo, como señala Gayol (2008), era un valor al que todos, de acuerdo con los ideales republicanos, podían aspirar.

Para un hombre de honor era importante demostrar su hombría, tanto en términos psicológicos como sociales (GAYOL, 2000: 222). Era un elemento constituyente de la subjetividad masculina. Por otra parte, daba prestigio y reconocimiento entre los pares, del cual dependía el lugar y el desempeño individual en la esfera pública. Honor era sinónimo de valentía, fuerza física, virilidad y honradez (honestidad en los negocios comerciales y desempeño profesional). Apelativos tales como "ladrón", "cobarde", "inútil” (la falta de habilidad o incapacidad para realizar ciertas tareas) o "cornudo" eran insultos que dañaban la reputación masculina. Para ser

115 Sobre el honor en la cultura durante el proceso de formación de la Argentina Moderna, véase, entre otros, GAYOL (2000 y 2008) y CICERCHIA (2001). 
hombre de honor, había que demostrar la predisposición a poner en juego la vida para defender la honra. Esto no implicaba actuar de una manera violenta y agresiva sin fundamento, también era importante demostrar un control de las pasiones, actuar con moderación y templanza. La lucha por las cuestiones de honor podía tener como escenario preliminar ciertos espacios de sociabilidad, como despachos de bebidas o cafés. Allí ocurría el intercambio de insultos y agresiones previas a los enfrentamientos físicos entre individuos, que se desarrollaban en la vía pública. Este tipo de conflictos era asunto privado y no correspondía que nadie interviniera o llamara a la autoridad.

El honor masculino también podía resultar afectado por el comportamiento femenino. La honra de los hombres dependía de la conducta sexual de las mujeres (hijas, madres y esposas). Por siglos, el cristianismo instituyó un código moral tendiente a regular la sexualidad de los fieles, varones y mujeres. En el caso de las personas de sexo femenino, las pautas eran la virginidad y la fidelidad. La reputación de la mujer también podía ser puesta en duda si los otros observaban un comportamiento poco habitual (salir sola o presentarse en espacios públicos). Sin embargo, si bien la sexualidad de las mujeres afectaba su propia honra, deshonraba también al esposo / padre / hermanos con su accionar. Si la esposa le ponía los cuernos a su marido, por ejemplo, era signo de falta de virilidad por parte de éste, que no la satisfacía de forma completa. Como contraparte, era un acto de cierto prestigio el conquistar a las mujeres de otros, una actitud viril. La falta en estos casos era de la mujer que engañaba. Los hombres debían saber controlarlas y evitar conductas inmorales y desviadas que dañaran el capital de honor familiar (la confianza basada en la reputación y las buenas relaciones que lesionaban las burlas y comentarios injuriosos) (GAYOL, 2000: 188-201).

Según Julian Pitt-Rivers (1999: 242), las formas de matar, o inclusive de suicidarse, podían tener un significado honorífico en cada cultura. Así, por ejemplo, en algunas sociedades, morir por la pérdida de sangre era más honroso que perder la vida asfixiado. Si el medio de quitar la vida podía ser un símbolo de prestigio o de deshonra, como veremos más adelante, los motivos que alegaba el que se suicidaba también podían afectar su reputación en la comunidad. Las cuestiones de honor fueron parte de la construcción de las identidades femeninas y masculinas de la época y como tales eran motivos verosímiles para los que buscaban explicar los casos de suicidio. En algunos, los mismos individuos que se habían suicidado dejaban sentado en sus cartas frases y enunciados en los que hacían referencia a la importancia de su honra y la de su grupo familiar. Proteger la respetabilidad de la familia era de importancia, era un mandato 
central. Las acciones de hombres y mujeres, de generación en generación, construían a partir de la reputación legada. Por esta razón, entre la "gente decente", los retratos de los padres eran adornos valorados y exhibidos en las piezas y salas principales de la casa (LOSADA, 2008: 104). Así, los méritos y las virtudes, o en su defecto, los vicios y faltas de cada uno de los miembros del grupo familiar repercutía en el conjunto: el apellido podía ser portador de virtud o deshonra. En este sentido, los individuos, en cada situación, estaban siendo evaluados por el tribunal de la opinión pública, como veremos, incluso cuando decidían quitarse la vida.

\subsection{Consideraciones finales}

La ciudad de Buenos Aires, durante el último tercio del siglo XIX, fue el escenario de un proceso dinámico de transformaciones económicas y sociales. Entre los signos que los testigos de la época alcanzaban a divisar, junto a las muestras claras de progreso material (la llegada de inmigrantes, la extensión de la red ferroviaria, el crecimiento económico), otros aspectos de la realidad denotaban viejos y nuevos problemas que requerían atención. Preservar la higiene física y moral de la población era la fórmula que englobaba todas las dificultades del organismo social, incluido ese nuevo fenómeno: la epidemia de suicidios.

No es casual que la cantidad de actos suicidas haya aumentado en este período como detectaron los médicos porteños, ni que muchos de los que se quitaron la vida fueran hombres inmigrantes jóvenes; todo esto respondía a la evolución demográfica acelerada de la ciudad que dejaba atrás su pasado como gran aldea. La llegada masiva de extranjeros modificó las características de la población de la urbe. El arribo constante de nuevos habitantes sobrepasó toda previsión por parte de la clase gobernante. Así, los recién llegados habitaron espacios hacinados y carentes de toda higiene e intimidad. En estos conventillos, ocurrían muchos de los episodios de suicidio que narraremos en los capítulos siguientes. Las familias de clase media podían acceder a otros tipos de viviendas, constituidas por varios cuartos, con ambientes especializados. Estas residencias también fueron el escenario de muchos otros actos suicidas. Los menos, optaban por espacios públicos (las calles, plazas, parques o las vías del tren) o de sociabilidad (cafés, despachos de bebidas, prostíbulos). En este paisaje urbano en transformación, tuvieron lugar los suicidios de extranjeros y nativos, que fueron 
observados por los que convivían y transitaban por esos mismos espacios.

Al mismo tiempo, junto a los cambios sociales y demográficos, los esquemas culturales románticos y heroicos perduraron en el imaginario de las elites, combinados con la fe en la ciencia y la razón, pilares del positivismo. Asimismo, la obsesión por la honra y el cuidado de la reputación eran un rasgo común de la cultura de la época (compartido por inmigrantes y nativos). El poder de las miradas estaba presente en muchos momentos de la vida diaria de los sujetos, que dependían de la confianza de sus pares para lograr sus objetivos, aprovechar oportunidades para amasar fortuna y lograr ascender socialmente, anhelo de muchos de los inmigrantes que deseaban regresar a sus lugares de origen. Por otro lado, así como la vida social, el acceso al mercado laboral y los roles en el espacio público eran diferentes para hombres y mujeres, del mismo modo, las formas de ganar o perder prestigio a los ojos de los demás eran distintas para los individuos según su sexo.

Los rumores y los comentarios sobre los vecinos, que atentaban contra su capital de honor, circulaban por las páginas de la prensa y en diversos espacios de sociabilidad, desde fiestas y reuniones, hasta las conversaciones casuales e informales en cafés, casas de tolerancia o visitas a los domicilios particulares. Desde nuestra perspectiva, quienes se quitaban la vida no eran la excepción y también eran sometidos al juicio moral de la sociedad de la época, a la luz del marco axiológico compartido. 


\section{Tercera parte}

Los significados del suicidio 


\section{Capítulo 5: La suicidio-manía}

\begin{abstract}
Para el alma que no tiene el calor de esa Fé, que hace creer al candor de los creyentes tantas cosas, sino verdaderas, cuando menos muy bellas algunas; para los que creen que la vida futura es simplemente un mito consolador, muy moral pero poco probable, el suicidio no puede ser sino un refugio supremo en las grandes e irreparables tribulaciones, en que hay que optar entre la muerte civil o moral producida por una lapidación pública, y la muerte física, que es una simple degradación de la materia, según los adoradores de la Fuerza. Hay que fijarse bien en que digo grandes e irreparables desgracias, y no las pueriles causas que encierra la estadística indiferente bajo el vago y conceptuoso calificativo de hastio de la vida. ${ }^{116}$
\end{abstract}

En el transcurso del siglo XIX, un fenómeno llamó la atención de una parte de los intelectuales y eruditos del mundo occidental: el crecimiento de la cantidad de suicidios entre la población de las naciones civilizadas. La influencia de la organización social (y sus defectos) sobre la tasa de muertes violentas fue uno de los ejes que ordenó el debate en torno al suicidio a fines del siglo XIX (COHEN AGREST, 2007: 166). Como ya mencionamos, Émile Durkheim (2004 [edición original de 1897]), en su obra "El Suicidio", encaró, de este modo, el estudio de la relación entre el suicidio y la sociedad moderna. Para Durkheim, el aumento de las tasas de suicidio en el mundo urbano estaba vinculado con la pérdida de fuerza de los lazos que habían mantenido cohesionados a los sujetos en los distintos grupos sociales. Es decir, en la sociedad moderna, el excesivo grado de individualismo era el que provocaba una alta tasa de suicidios al haberse debilitado el nivel de cohesión que la sociedad religiosa, el grupo familiar y la comunidad política habían proporcionado al sujeto. Al mismo tiempo, este tipo de organización social tenía problemas para regular las acciones y deseos de sus integrantes. Como ya dijimos, desde la perspectiva durkhemiana, la única autoridad que podía poner un límite moral a las pasiones individuales era la sociedad. Los frenos que la vida social imponía a cada individuo de acuerdo a su función, regulaban y delimitaban las expectativas y la ambición. Esto ocurría en un marco de reglas que

\footnotetext{
116 José María RAMOS MEJÍA, "La tentación del suicidio", Anales del Departamento Nacional de
} Higiene, año VII, n 23, Buenos Aires, 1896, p. 381. 
pautaban el ascenso social y el lugar que cada sujeto ocupaba en la vida colectiva. Así, el rol de la religión en el pasado había sido poner un límite a los deseos de los hombres, efecto que desapareció en las sociedades modernas. Por esta razón, frente al utilitarismo industrialista, no había un freno a las pasiones de los seres humanos, ya sea desde las instituciones religiosas o desde el Estado.

Para el historiador francés Jean Baechler (1975), la idea de una epidemia de suicidios en expansión ha sido un mito occidental moderno, que vuelve a resurgir en tiempos convulsionados y de cambio, en los que los observadores prestan más atención a los suicidios como una forma de proyectar su propia incertidumbre, angustia y malestar frente a la transformación de la sociedad y el mundo en el que viven. En estas coyunturas, los suicidios pasaron a ser interpretados como el signo de un mal profundo que se expandía en paralelo al declive moral de la población. Según Baechler fue esta convicción en la crisis de la sociedad occidental la que llevó a recolectar los datos y analizar las cifras, y no a la inversa. Es decir, las estadísticas no fueron el indicio que condujo a pensar en la crisis moral; fue la imagen de una sociedad decadente, construida por los propios observadores, a partir de sus inquietudes, la que llevó a revisar los datos disponibles y a elaborar nuevas fuentes de información estadística. De este tipo de estudios, por ejemplo, surgió la preocupación por la pérdida del sentimiento religioso en el mundo moderno, y sus consecuencias para el organismo social, así como la búsqueda de alternativas para solucionar estos trastornos.

Sin adentrarnos en el debate de la construcción de las estadísticas sobre suicidios, nos parece estimulante preguntarnos, como Baechler, los motivos por los cuales, en ciertos momentos, algunas ideas fueron difundidas por canales de comunicación y espacios muy diversos. En este sentido, la representación de los suicidios como una epidemia que se extendía por el mundo moderno, circulaba más allá de las instituciones académicas europeas, hasta las cátedras universitarias argentinas. En este capítulo, nuestro objetivo es mostrar que la "suicidio-manía" era una representación cultural construida por las elites intelectuales, en un clima de optimismo y fe en el progreso, pero también de cambios dinámicos y acelerados que generaban incertidumbre. La existencia de una epidemia de suicidios ilustraba las consecuencias de la ausencia de frenos para las pasiones en el mundo civilizado (tras el declive de las creencias religiosas). Al mismo tiempo, era un argumento más para fundamentar la necesidad de una educación moral en los habitantes de los estados modernos, es decir, una instrucción que permitiera moderar la sensibilidad (exaltada por el romanticismo), 
las ambiciones materiales y los deseos egoístas, causas principales del crecimiento de la locura, los suicidios y los delitos. Estas ideas circularon por distintos canales (publicaciones científicas, la enseñanza en las universidades y los medios gráficos, entre otros). Como veremos, esto fue posible, a pesar de observar y reflexionar sobre realidades diferentes, debido a que los médicos e intelectuales porteños y los especialistas europeos en el tema compartían un mismo marco axiológico positivista, pues estaban comprometidos con el avance del progreso y la civilización del comportamiento de cada uno de los integrantes del organismo social.

\subsection{Las ideas científicas sobre el suicidio}

\subsubsection{Una epidemia inquietante...}

El diagnóstico de la sociedad moderna presentado por Durkheim en su obra fue el punto de llegada de un conjunto de investigaciones que habían aparecido a lo largo del siglo XIX, centradas en la evolución demográfica de la población y su interpretación (BAECHLER, 1975: 18-19). Por ejemplo, antes de la aparición del estudio realizado por el sociólogo francés, Enrico Morselli, psiquiatra y sociólogo italiano, había publicado en italiano (1879) y en inglés (1882) una obra sobre el tema: "Il suicidio. Saggio di statistica morale comparata". Para abordar el tema, proponía el uso de las estadísticas disponibles. El análisis de éstas, a partir de un enfoque sociológico, haría desaparecer las variaciones individuales y permitiría observar el comportamiento del suicidio en el organismo social. Los datos, según Morselli, mostraban una situación inquietante: "From statistics collected up to this time is demonstrated this most painful fact, that suicide has increased from the beginning of the century, and goes on continually increasing in almost all civilized countries of Europe and of the world" (MORSELLI, 1882: 15). Luego de analizar los registros estadísticos de los suicidios en diferentes países europeos, Morselli llegaba a la siguiente conclusión:

In the agregate of the civilized States of Europe and America, the frequency of suicide shows a growing and uniform increase, so that generally voluntary death since the beginning of the century has increased and goes on increasing more rapidly than the geometrical augmentation of the population and of the general mortality (MORSELLI, 1882: 29). 
Para este representante de la criminología positivista, el suicidio era el resultado de influencias sociales; más concretamente, del avance de la civilización. Haciendo referencia al pensamiento de Charles Darwin, Thomas Malthus y Herbert Spencer, Morselli explicaba el aumento de los suicidios como una consecuencia de la creciente intensidad que había adquirido la lucha por la vida en los países civilizados (aquellos más adelantados en su desarrollo tecnológico y de mayor complejidad en las formas de asociación entre sus habitantes). El proceso de evolución y selección natural en las naciones civilizadas exigía un enorme esfuerzo a nivel intelectual, que comprometía el funcionamiento del cerebro y el sistema nervioso. Al mismo tiempo, la vida social se había tornado más compleja y habían aumentado las ambiciones y las expectativas de forma generalizada entre la población, lo que volvía más intensa la competencia por los recursos disponibles en cada sociedad. ${ }^{117}$ De este modo, la multiplicación de casos de locura y suicidio era una consecuencia del aumento de las exigencias de la vida moderna y los deseos de los habitantes en los países más adelantados en la carrera del progreso y la evolución. ${ }^{118}$ En la introducción de su obra, Morselli destacaba el rol de los estados europeos pioneros (Francia, Prusia, Noruega, Austria), que durante el siglo XIX habían llevado adelante la elaboración de registros estadísticos, dando cuenta, entre otros datos, de los casos de suicidio detectados en el territorio nacional. Esta información había sido la base para la elaboración de las primeras obras que trataban el análisis de las muertes voluntarias y su relación con el estudio de la población, por ejemplo, las de los estadísticos Adolphe Quetelet y André-Michel Guerry. Morselli también resaltaba el importante legado dejado por las investigaciones de los médicos alienistas y especialistas en medicina legal, entre otros, Jean-Étienne Dominique Esquirol, Jean-Pierre Falret, Pierre Egiste Lisle y Alexandre Brierre de Boismont.

Así, la aparición de un análisis en clave sociológica de los suicidios ocurrió en paralelo al proceso de construcción de las categorías y conceptos del saber alienista y médico legal y el desarrollo de los sistemas de registro de las cifras estadísticas del fenómeno. En este contexto, el aumento de los casos de suicidio se transformó en una

\footnotetext{
${ }^{117}$ Morselli también se volvió célebre por su concepción del suicidio como el desenlace de una agresión interna, cuya manifestación final adquiría múltiples formas. Esta idea fue más tarde retomada por Freud, asociando la tasa de homicidios y suicidios como parte de un fenómeno único relacionado con la agresión del sujeto que perdía su objeto de deseo.

${ }^{118}$ Según MORSELLI (1882: 116), los países europeos estaban a la cabeza en la escala de la civilización, ya que fueron los primeros en impulsar una legislación relacionada con el respeto de las libertades individuales, de acuerdo a los ideales de la razón y de la justicia; también eran pioneros en el desarrollo del conocimiento científico y su aplicación en la producción de manufacturas, el comercio y la salud pública.
} 
preocupación de la elite cultural en el mundo occidental. Varios pensadores buscaron explicar lo que ocurría y cuál era la relación entre las muertes voluntarias y la transformación de la sociedad moderna, tras la consolidación de los estados nacionales y la expansión del capitalismo. En este sentido, en el marco del estudio de las llamadas estadísticas morales, la cantidad de suicidios y hechos delictivos despertaron un gran interés entre los científicos e intelectuales. A través de su análisis, se buscaba diagnosticar la presencia o ausencia de virtud en las poblaciones de las naciones civilizadas. Estos estudios partían de entender que la variación en la cantidad de los casos de suicidio era un indicador del malestar y la corrupción del mundo urbano, espacio de las pasiones, el vicio y la vida desenfrenada. Desde su perspectiva, era esta crisis moral la causante de una creciente epidemia de muertes voluntarias en los países desarrollados.

Esta forma de comprender los suicidios tuvo su correlato en Argentina. En este sentido, la interpretación de las muertes por mano propia realizada por los censistas y demógrafos argentinos era diferente a la concepción determinista que estos aplicaban para estudiar el resto de las defunciones. En la explicación de la evolución demográfica de las muertes naturales, sólo apelaban a la intervención de factores físicos y biológicos, como el efecto de las estaciones. ${ }^{119}$ En cambio, a la hora de pensar los suicidios, estos integrantes de la elite intelectual consideraban otras variables. Francisco Latzina, importante referente de los estudios estadísticos, apostaba por una interpretación holística de la tasa de suicidios que, además de prestar atención a los factores relacionados con el clima y la estacionalidad, o los datos valorados por la antropología criminal (la forma de los cráneos o el funcionamiento del cerebro), vinculara las cifras de las muertes voluntarias con la información disponible sobre la edad, el sexo, el estado civil, la ocupación, el grado de instrucción, la nacionalidad, o la situación económica y material de los que se quitaban la vida. Desde su perspectiva, las muertes voluntarias eran un "fenómeno social", y, por ende, debían tenerse en cuenta a partir de los datos antes mencionados, los aspectos sociales y culturales, a la hora de reflexionar sobre las mismas. Así, las características de la vida colectiva promovían o desalentaban, según el caso, la generación de los suicidios en el organismo social y, en estas cifras, aparecían regularidades que fascinaban a los especialistas del saber estadístico en

\footnotetext{
$119 \mathrm{Si}$ bien poco relevantes en términos cuantitativos, tanto la longevidad como el suicidio abrían la posibilidad de reflexionar sobre temas profundos y estimulantes para los miembros de la elite intelectual; el problema de los "límites de la vida humana" o el del "libre albedrío" (OTERO, 2006: 387).
} 
Argentina (OTERO, 2006: 395-396). ${ }^{120}$ Para intelectuales como Latzina, los suicidios eran un mecanismo de la sociedad para eliminar impurezas, que, al mismo tiempo, permitía medir el grado de malestar / enfermedad del colectivo. Éste era consecuencia del crecimiento del alcoholismo y el consumo de otros vicios, la injusta organización social, la creación de necesidades ficticias y la multiplicación de actitudes egoístas en paralelo al declive de los sentimientos religiosos (LATZINA, 1896: 8). Es decir, a diferencia de lo planteado por otros autores, como Morselli, el aumento de los suicidios para Latzina (1896: 3-4) no era un signo del incremento del progreso. ${ }^{121}$ La tasa de actos suicidas, más bien, era un indicador para diagnosticar el estado del ambiente moral en la población, al igual que las cifras relacionadas con los delitos:

El estado de la agricultura, del comercio y de la industria, así como el de la cultura intelectual, señalan de un modo muy aproximado el grado de civilización que ha alcanzado un pueblo, y se ha observado, al mismo tiempo, que entre ésta y la frecuencia de los suicidios existe un marcado paralelismo, es decir, que en las comarcas económicamente más avanzadas son los suicidios más frecuentes que en las pobres y atrasadas. La cosa la explica esa caza incesante del dinero en la que los competidores se hacen una guerra sin piedad; todos los sentimientos nobles se debilitan a expensas de uno solo que paulatinamente absorbe y reemplaza a todos los demás, el egoísmo (LATZINA, 1896: 12).

Como mencionamos antes, los especialistas en medicina legal y psiquiatría argentinos también hicieron su aporte al análisis del suicidio y la interpretación de su crecimiento en las sociedades civilizadas, retomando la matriz de pensamiento científica positivista, readaptada para comprender la realidad local. ${ }^{122}$ Como ya mencionamos en el capítulo 3, estas ideas eran difundidas en las cátedras de medicina legal de la época en

\footnotetext{
${ }^{120}$ El objetivo buscado con el análisis de las estadísticas era la enunciación de leyes generales, siguiendo el ideal de la ciencia positivista, a partir de las regularidades observadas y su relación con otros factores, por lo general biológicos, como la edad (por ejemplo, "ley estadística de la tendencia al suicidio con el aumento de la edad") o el sexo (OTERO, 2006: 430).

${ }^{121}$ Según Hernán OTERO (2006: 395), Latzina, funcionario estadístico de renombre entre los censistas y demógrafos argentinos, citaba, en sus análisis de los datos relacionados con los suicidios, a Morselli, aunque cuestionando su interpretación de los suicidios como resultado de la lucha por la vida y la selección natural. Por otra parte, no mencionaba la obra de Durkheim.

${ }^{122}$ Los estudios médico-legales llamaron la atención de los profesionales de la salud a medida que avanzaba el siglo XIX, en especial durante la segunda mitad, en el marco de los debates por los problemas englobados dentro de la llamada "cuestión social", como ya hemos indicado. El trabajo con los cuerpos, durante los episodios de epidemias y la participación de los forenses en causas civiles y criminales, impulsó el desarrollo de este campo intermedio entre el derecho y la medicina. Sobre la cuestión social en Argentina entre 1880 y 1910, véase, entre otros, VEZZETTI (1985); SALESSI (1995); ZIMMERMANN (1995); LOBATO (1996); RUIBAL (1996); SURIANO (2004).
} 
Argentina. En la Universidad de Buenos Aires, Eduardo Wilde brindaba a los estudiantes los conocimientos generales sobre la jurisprudencia y las consideraciones técnicas necesarias en las pericias que incluían los aspectos vinculados con las patologías mentales. ${ }^{123}$ En este sentido, una de las cuestiones que surgía, a la hora de explicar lo relativo al suicidio en las clases, era si se trataba de un acto patológico, si era producto de una monomanía o de una locura, o, por el contrario, si se trataba de un acto voluntario tomado por un individuo en pleno uso de sus facultades mentales. De acuerdo con las notas de Wilde, ambas situaciones eran posibles. En algunos, se trataba de una alienación, y, en otros, era el resultado de una acción voluntaria y apasionada. Las personas débiles (y carentes de la suficiente capacidad intelectual), los cobardes, las mujeres vírgenes y aquellos que hubieran sufrido algún desengaño eran más proclives a dejarse arrastrar por sus pasiones. Pruebas de ello quedaban en las cartas y mensajes que dejaban antes de quitarse la vida, como mostraban las evidencias presentes en las investigaciones de la psiquiatría francesa. Según Wilde (1917: 80-82), en algunos pocos casos, estos documentos mostraban la frialdad con que algunos tomaban su determinación y ponían fin a su existencia. Sin embargo, para el prestigioso titular de la cátedra de Medicina Legal, en la mayoría de los casos, la causa de los suicidios era el resultado de la exaltación de las pasiones, promovida por el avance de la civilización y la vida en el mundo urbano.

Partiendo de premisas similares, Samuel Gaché (1859-1907), presidente del Círculo Médico Argentino, escribió un artículo publicado en los "Anales" de la institución, interpretando el suicidio como un mal social (OTERO, 1991). Gaché, que ya había incursionado en el estudio de las enfermedades mentales en una obra previa, La locura en Buenos Aires (1879), también dedicaría dos capítulos de su tesis, Estudio de Psicopatología (1886), donde ampliaría lo ya desarrollado en su artículo inicial de 1884. En "Patogenia del Suicidio en Buenos Aires" (1884), el presidente del Círculo Médico propuso interpretar los suicidios como el resultado del avance de la civilización. ${ }^{124}$ Una de las variables que permitía medir el desarrollo alcanzado era la

\footnotetext{
${ }^{123}$ Apuntes para un Tratado de Jurisprudencia Médica, fue el título que recibió el cuarto tomo de las Obras Completas (1917) de Eduardo Wilde. En este volumen, fueron compiladas las notas que utilizaba para dictar sus clases en la Facultad de Ciencias Médicas.

${ }^{124}$ Algunos de los textos médicos que abordaremos fueron utilizados por Marcelo Otero en su trabajo sobre el suicidio en la ciudad de Buenos Aires. Otero utilizó la producción científica de la época para mostrar que ideas similares a las de Durkheim estaban siendo gestadas en Buenos Aires, antes de la llegada de El Suicidio a la Argentina. Como señala Otero, desde principios de la década de 1880, los profesionales de la salud venían analizando el fenómeno como un problema social, consecuencia de la vida en el mundo urbano y moderno. Si bien Otero mencionó el estigma que recaía sobre ciertas
} 
presencia de la ciencia, las artes, las industrias, la política, el comercio como actividades centrales en la vida de la población (GACHE, 1884: 559). Otro aspecto que servía para medir el progreso de la nación era el movimiento inmigratorio. En este sentido, las regiones que tenían una menor actividad comercial y una corriente migratoria poco numerosa tenían una menor proporción de suicidios, como Bolivia, Paraguay, Perú y Chile (GACHE, 1884: 566-567).

El incremento de estos hechos en el mundo urbano era asociado con los cambios que el proceso de modernización había traído a la vida de los habitantes. Mientras que en las sociedades sumidas en la barbarie el suicidio era producto de la ignorancia o de un culto religioso fanático, en el mundo civilizado, era el resultado de las pasiones desenfrenadas y de los estados nerviosos que provocaba la "lucha por la vida", en especial entre los inmigrantes que llegaban al territorio argentino (GACHE, 1884: 561).

La vida en el mundo urbano se combinaba con la predisposición que muchos individuos tenían para ser sugestionados e imitar los hechos publicados en la prensa, o en las obras de la literatura de los folletines, o por las patologías nerviosas que los afectaban, algo de lo que también advertía Wilde (1917: 140). En su Código de higiene y medicina legal (1891), Emilio Coni, otro prestigioso médico de la época, además de lamentar el aumento de los casos de suicidio en todos los países del mundo, proponía que los diarios y los medios gráficos dejaran de difundir hechos contrarios a la moral o a la salud pública, como una forma de prevención para el contagio por imitación (CONI, 1891: 632-633). En las resoluciones de la primera reunión del Congreso Científico Latino Americano, celebrado en Buenos Aires del 10 al 20 de abril de 1898, quedarían establecidas una serie de propuestas con respecto al creciente aumento de los suicidios y las medidas profilácticas recomendadas para evitar que continuara la expansión del contagio. Estas fueron difundidas en los "Anales del Departamento Nacional de Higiene". La sección de ciencias médicas del evento se expresó a favor de que "las asociaciones de la prensa de los países latinoamericanos interpongan su influencia a fin de que los diarios de las respectivas naciones no den publicidad a los relatos de los suicidios y demás crímenes”.

conductas que eran patologizadas, como el consumo de alcohol, no se detuvo a extraer los valores que los médicos e intelectuales ponían en juego a la hora de elaborar sus producciones. En nuestro estudio, volveremos sobre estos textos, y otros nuevos, para analizar el marco axiológico que estaba implícito en el discurso científico de entre siglos. 
Si bien el poder de sugestión de los periódicos y diarios, así como de la literatura "romántica" o "folletinesca", se mantendría como factor que el pensamiento científico consideraba en la explicación, la causa principal eran los fenómenos y transformaciones sociales que afectaban a los organismos particulares en su funcionamiento. En este sentido, había una dimensión individual y una social para explicar los suicidios. Gaché planteó que estos se habían convertido, en la ciudad de Buenos Aires, en "una epidemia social”, fundamentado en el análisis de las primeras estadísticas confeccionadas y en la comparación de los datos de las capitales de América y Europa. En Buenos Aires, al igual que en muchas regiones del globo, habían crecido dos fenómenos, la locura y el suicidio. Si bien entendía que, en muchos casos, se trataba de personas con sus facultades mentales alteradas, Gaché, en línea con las ideas que eran transmitidas desde la cátedra de Medicina Legal, negaba que todos los suicidas fueran locos, como lo había postulado el discurso de los alienistas. Desde el Círculo Médico, Gaché llamó a la comunidad científica y a los profesionales de la salud para que impulsaran la investigación del suicidio como un problema social y así implementar medidas profilácticas y preventivas.

Como señala Otero (1991), podemos encontrar cierta similitud entre este tipo de discurso y lo que expondrá Emile Durkheim años más tarde. En primer lugar, sobre la influencia de las pasiones en las sociedades modernas y la necesidad de frenos para éstas. Otra idea común que aparecía era la necesidad de separar a los locos de los apasionados, perspectiva que acercaba este pensamiento a una mirada social y limitaba el peso de las patologías mentales en la explicación del incremento de los casos de suicidio. Si bien no habían leído al sociólogo francés, el clima de ideas en Europa ya estaba dejando de lado las hipótesis de corte más alienista y empezaba a esbozar nuevas explicaciones sobre el suicidio. Por ejemplo, además del pensamiento de la higiene social, los médicos tenían presente las ideas de especialistas en medicina legal, como el español Pedro Mata o el francés Legrand du Saulle (citados por Wilde en sus clases), que fueron las referencias que Gaché usó para separarse del pensamiento del alienista Jean Étienne Esquirol. Mata, uno de los médicos españoles más prestigiosos de la época, destacaba en su Tratado de Medicina y Cirugía Legal:

El suicidio es muy común; síntoma en cierto modo del estado de los espíritus de un pueblo, acaso anuncia a los ojos del filósofo observador llagas sociales. [...] Acaso es un error grave considerar al suicida como una hoja que se desprende del árbol social, sin relación 
con el árbol entero (MATA, 1866: 1014).

Al referirse a este asunto, Mata citaba al médico francés Alexandre Jacques François Brierre de Boismont. Según Plumed y Rojo Moreno (2012: 151-152), las ideas de este intelectual fueron citadas por médicos españoles para sostener que el suicidio no siempre se trataba de un estado de locura y que su aumento se debía a la influencia de la civilización, entendida como el avance de la secularización y la sensibilidad romántica. La vida civilizada producía hastío en los habitantes del mundo urbano, al no tener un freno para sus pasiones, lo que provocaba un aumento de los casos de suicidio. En palabras de Mata:

[...] los progresos de la civilización han aumentado el número de suicidios, y esto lo podría probar también con datos estadísticos. Como consecuencia lógica de ese hecho lamentable, no solo presentan mayor número de suicidas las naciones más civilizadas o de más movimiento social, sino sus capitales y ciudades más populosas. Cuanto mayor es la población, más suicidas, y no es porque haya más gentío, sino porque en ella reinan más, la mayor parte, por no decir todas, las causas, en especial morales del suicidio (MATA, 1866: 1028).

También era citado por los médicos argentinos con la misma intención. Dentro de su vasta obra dedicada al tema ( Du Suicide et de la Folie Suicide, 1865 [1856]), en el capítulo V, "Du suicide dans ses rapports avec la civilisation", Brierre de Boismont encaraba el análisis y la interpretación de los datos disponibles sobre la tasa de suicidios en los distintos países de Europa y otras regiones del globo. En su exposición, destacaba que las características del entorno social eran fundamentales para comprender la expansión de la cantidad de suicidios en las naciones civilizadas del mundo. Junto con el avance de los conocimientos de la ciencia y la técnica, el progreso traído por la civilización había tendido a exacerbar la sensibilidad. Ésta podría ser definida como el grado de exaltación de las pasiones de una sociedad, que era directamente proporcional al estado de las almas en una época determinada (es decir, de acuerdo con las ideas, el pensamiento, el arte, la religión y la moral predominantes en un cierto período); esto hacía variar la cantidad de suicidios a lo largo de la historia y en las distintas regiones del mundo (BRIERRE de BOISMONT, 1865: 463-464). Mientras que en el mundo antiguo los suicidios crecían como consecuencia de las ideas religiosas y filosóficas (en especial las místicas y panteístas); en el mundo medieval, la presencia del cristianismo 
en la religión y la filosofía habían contribuido a hacer descender este tipo de hechos. En la modernidad, y sobre todo en el siglo XIX, para Brierre de Boismont el aumento de los suicidios se debía a la propagación de la duda, la exaltación del orgullo, el exceso de amor por uno mismo, el escepticismo, la búsqueda desenfrenada de alcanzar los objetivos e intereses materiales y el ideal democrático (BOISMONT, 1865: 485). Para este médico alienista, la irreligiosidad de su época era un factor muy importante para comprender la ausencia de un freno a las pasiones, era la fuente de la melancolía moderna; el hombre ya no recurría a la fe para entrever su destino, ante la tristeza y la falta de voluntad para vivir, parecía que el hombre melancólico sólo encontraba como única salida el suicidio (BOISMONT, 1865: 481-482). Goethe era quien mejor expresa esta sensación, según Brierre de Boismont. En este sentido, los modelos eran los jóvenes como Werther, ícono de la sensibilidad romántica, cuyo prototipo reconocía en el Hamlet de Shakespeare. Este estado exacerbado de la sensibilidad parecía predominar en las ciudades, en comparación con las cifras en las áreas rurales, donde eran más intensos los efectos del progreso. Si bien celebraba los logros de la civilización para mejorar la calidad y la duración de la vida humana, no dejaba de exponer los defectos o problemas que aquejaban a la población de los estados europeos, como la locura, el suicidio o el delito (BOISMONT, 1865: 485).

En síntesis, los médicos e intelectuales porteños tomaron en cuenta el diagnóstico de sus pares europeos que celebraban el progreso material y lamentaban la decadencia moral de las sociedades civilizadas, para explicar el crecimiento de los suicidios en el Río de la Plata. Tanto en los artículos como en las tesis, aparecían referencias a distintos profesionales e instituciones que daban cuenta de la recepción que tuvo el saber académico europeo acerca del suicidio en Argentina. En este sentido, los conocimientos sobre la medicina legal y la psiquiatría, producidos del otro lado del Atlántico, fueron una fuente clave para los profesionales de la salud a la hora de comprender el cambiante y dinámico proceso de modernización.

El trabajo de Gaché generó un importante impacto, fue publicado íntegro en el diario "La Prensa" el 20 de mayo de 1884. Esto da cuenta del interés que despertaba el tema entre los actores sociales de la época. Durante las décadas finales del siglo XIX y principios del XX, los suicidios volvieron a llamar la atención de distintos observadores que reflexionaron sobre el aumento de los casos o analizaron las cifras. Para dar un ejemplo, por fuera del ámbito de los profesionales de la salud, cabe mencionar al policía 
Alberto Méndez Casariego (1888). Este elevó una memoria al jefe de la Policía de Buenos Aires, conteniendo un informe sobre los delitos y suicidios ocurridos en la capital del estado argentino durante el año 1887. Al comparar las cifras disponibles, Casariego daba cuenta del aumento de los actos suicidas en Buenos Aires. El año 1882 representó, para Casariego, una "verdadera epidemia de suicidios", dentro de una tendencia más gradual hacia el aumento de las muertes por mano propia (MÉNDEZ CASARIEGO, 1888: 46).

En 1905, el crecimiento de los suicidios era un asunto ya conocido y familiar para los contemporáneos. Así lo expresaba el diario "La Prensa" (4/3/1905) al informar sobre el contenido de la pastoral de cuaresma, escrita por el Arzobispo de Buenos Aires, Mariano Espinosa. Esta versaba "sobre un tema que, a pesar de haberse tratado muchas veces, ofrece siempre interés: el suicidio". La pastoral de Monseñor Espinosa también fue reseñada en la edición de "La Nación" del domingo 5 de marzo de 1905. Esta autoridad eclesiástica decidió dedicar el sermón de cuaresma a un tema que preocupaba por su constante aumento: el suicidio (ESPINOSA, 1905). ${ }^{125}$ Frente a este terrible fenómeno, el clérigo detallaba medidas para prevenir su expansión. Según Espinosa, las causas del suicidio eran, en primer lugar, la irreligiosidad. Y aclaraba, "así lo entienden los más distinguidos sociólogos y médicos”. Decía el arzobispo:

En los pueblos en que el catolicismo disminuye y se debilita por lo tanto la verdadera fe religiosa, donde los placeres y goces físicos constituyen la única aspiración y suprema felicidad; cuando las inteligencias se embotan, oprimidas por la materia y no alcanzan a ver más allá de la tumba; se comprende que al cruzar el hombre los eriales de la desgracia y verse desterrado de los dominios de la fortuna, sucumba bajo el peso de la desesperación y se suicide (ESPINOSA, 1905: 222).

El que tenía fe y creía en una vida después de la muerte, por otra parte, no perdería las esperanzas y podría afrontar todos los obstáculos que aparecieran en el transcurso de su existencia. Espinosa también se sumaba a la cruzada de los médicos contra cierto periodismo de mala calidad y las obras literarias y espectáculos con contenido inmoral. Los problemas familiares, producto de la falta de una moral cristiana en el hogar, también eran otro factor que el obispo mencionaba, así como la miseria entre los pobres.

125 En 1915, Espinosa volvió a referirse al tema del suicidio en una de sus pastorales, ésta, como la anterior, fue publicada en la Revista Eclesiástica. 
En este sentido, el obispo elogiaba la actividad de las asociaciones cristianas encargadas de la asistencia social y llamaba al clero a predicar las enseñanzas del cristianismo para contribuir a la disminución del número de suicidios.

\subsubsection{En la frontera entre la razón y la locura}

Como mencionamos en el capítulo 3, durante el último tercio del siglo XIX, mientras algunos profesionales de la salud se interesaron por la propagación de las enfermedades infectocontagiosas, otros estudiaron las patologías mentales en las instituciones psiquiátricas. Así, los alienistas se ocuparon de las epidemias psíquicas. La experiencia de los que observaban casos de suicidio en instituciones de encierro difería de las situaciones que analizaban los peritos médicos, algo que estos últimos les recalcaban a los especialistas en enfermedades de la mente. Así, mientras que algunos profesionales de la salud hacían mayor hincapié en las variables sociales y ambientales del fenómeno (en el poder de las pasiones y la falta de un freno moral), otros ponían más énfasis en la alteración de las facultades mentales de los suicidas.

En su tesis (defendida en 1883), Alejandro Korn, por ejemplo, estudió las diferentes patologías mentales entre los delincuentes que observó en la Penitenciaría. Para Korn, la melancolía era la forma de locura que más promovía conductas delictivas o criminales en los individuos. Ésta tenía como rasgo característico la tristeza producida por el decaimiento de las capacidades intelectuales. Las oscuras reflexiones que nublaban el juicio del sujeto lo volvían sensible a cualquier acontecimiento adverso y podían conducirlo a sentir un fuerte hastío hacia la vida, aunque no padeciera delirio o alucinaciones. Si el estado melancólico avanzaba en su desarrollo, podía desencadenar acciones violentas en los individuos afectados, como el homicidio o el suicidio (KORN, 1883: 45-47). Éste último, según Korn, siempre era el resultado de un "estado mental alterado". Sólo una alienación podía explicar que un individuo pudiera desviarse del instinto de auto-preservación, presente en los humanos en condiciones normales, y en los seres vivos en general.

Otros médicos hablaban directamente de la existencia de una monomanía suicida, retomando las ideas de Esquirol, como José Vásquez, quien presentó el 28 de febrero de 1891, en la Facultad de Ciencias Médicas, su tesis sobre el tema (OTERO, 1991). Vásquez era un alienista que había realizado su residencia en el Hospicio de 
Alienados de la Capital Federal y en el Instituto Frenocomio Modelo, en los cuales obtuvo las referencias y el material empírico necesarios para su trabajo. Fue dirigido por el mencionado alienista argentino, el Dr. Lucio Meléndez.

La intención explícita de este estudiante de medicina era encuadrar los suicidios dentro del campo de las patologías mentales, definiendo el fenómeno como una suicidiomanía: "tratándola como una entidad mórbida perfectamente definida, para que ocupe alguna vez su lugar en el cuadro nosológico de las enfermedades de la mente" (VÁSQUEZ, 1891: 10).

Vásquez asociaba las prácticas suicidas con las enfermedades mentales, de allí que sus principales referentes intelectuales fueran Jean E. Esquirol y Philippe Pinel. En su tesis celebró el fin del oscurantismo medieval gracias a las ciencias naturales y la medicina. En este sentido, Pinel y Esquirol eran los héroes que habían terminado con la ignorancia sobre las patologías mentales. Sin embargo, estos no eran los únicos autores que aparecían citados en su tesis. Además de los médicos psiquiatras, como Charcot, también eran mencionados, como fuentes de autoridad, especialistas en medicina legal, como Legrand du Saulle, Tardieu o Brouardel (decano de la Facultad de Medicina de París), o de la criminología positivista, como Césare Lombroso y Edward Taylor, así como los principales referentes del evolucionismo natural, Charles Darwin, y social, Herbert Spencer. Como señala Vezzeti, las obras del alienismo en Argentina fueron leídas en diálogo con el pensamiento de otros intelectuales que habían escrito en un período posterior.

Por esta razón, en el desarrollo de su exposición, el autor hacía explícita la discusión en torno al suicidio durante la segunda mitad del siglo XIX. Para ciertos pensadores británicos, como Spencer, había que diferenciar los suicidios de la locura, o, al menos, de la monomanía suicida. Para el pensamiento de la psiquiatría francesa, que seguía a Esquirol, los suicidios eran consecuencia de alteraciones de las facultades mentales. En este punto, Vásquez se preguntaba por la existencia de una especie de zona de frontera, que separaría a los alienados de quienes hacían uso de sus facultades mentales en libertad, donde estarían los locos morales o semialienados. Allí ubicó el fenómeno del suicidio, en el límite entre la locura y la razón.

Si bien partía de un marco alienista para interpretar el suicidio, Vásquez no dejó de pensar la relación de estas patologías con el mundo civilizado en expansión (VÁSQUEZ, 1891: 64). En este sentido, en su tesis aparecía la intención de combinar la perspectiva del alienismo con las ideas sobre el suicidio como problema social: 
"Efectivamente, el eretismo nervioso en que viven las sociedades modernas en continua masturbación intelectual, por el enorme consumo de fuerza nerviosa, el nerviosismo contemporáneo, como le llama Charcot, ejerce generalmente su influencia en el cerebro del hombre civilizado que habita las populosas capitales" (VÁSQUEZ, 1891: 15).

Al igual que Blancas y Gaché, Vásquez relacionaba el aumento de los casos de suicidio con el avance de la civilización y las características en el mundo urbano. Contemplaba, en su explicación, el aspecto social del problema y las presiones que la lucha por la vida en el mundo urbano imponía a los hombres. El autor citado sobre este punto era el ya mencionado médico psiquiatra francés, Brierre de Boismont (VÁSQUEZ, 1891: 63-64).

\subsection{Suicidio y marco axiológico}

\subsubsection{Pasión, ambición y vicio}

Por otra parte, nos parece interesante rescatar de la interpretación general aquellos valores que los profesionales de la salud ponían en juego en la producción de sus discursos. Como señala Vezzetti (1985: 13-14), en los análisis de los médicos higienistas y alienistas había una comprensión de la enfermedad que iba más allá de lo físico o biológico, también había un diagnóstico moral de las conductas de los habitantes, ya que se buscaba modelar un nuevo sujeto social.

Según el profesor suplente de la cátedra de Medicina Legal, el Dr. Manuel Blancas (1823-1906), al que Gaché pidió su opinión sobre lo planteado en su trabajo acerca del suicidio,

En el combate con la vida, el hombre no se resigna o se resigna mal en frente de sus ambiciones contrariadas; entonces su vida flaquea, comete actos réprobos, se desarrolla un instinto perverso, y por último atenta contra su vida, ya porque desea y no alcanza, ya por haber gozado mucho y no poder seguir gozando, ya porque siente o presiente que se embota o estingue el sentimiento, ya en fin, porque se considera como el héroe de Goëthe condenado al eterno suplicio de no poder amar (BLANCAS, 1884: 571).

El profesor de la cátedra de Medicina Legal de la Universidad de Córdoba, Juan Bialet Massé, planteaba algo similar. En su obra, Lecciones de medicina legal: aplicada a la 
legislación de la República Argentina (1885), expresaba que el debilitamiento del sentimiento religioso y la falta de una educación moral eran los factores más evidentes para comprender el aumento de los suicidios en la población (BIALET MASSÉ, 1885: 230). ${ }^{126}$

En Wilde, Blancas, Bialet Massé y Gaché, como en otros médicos de la época, aparecía una crítica a lo que era identificado como una exaltación excesiva de ciertas pasiones (la pérdida del honor, el deseo de acumular riquezas o los desengaños amorosos), aumentado por la influencia de los medios gráficos y la literatura. La pasión, desde esta mirada, debía ser controlada para que no nublara el juicio de la razón, en una fuerte oposición a los valores del romanticismo, que exaltaba las emociones y los sentimientos. Así, desaprobaban la conducta de quienes eran dominados por sus sentimientos, como el amor, la desesperación y el miedo (frente a la miseria o la deshonra). Por otro lado, los suicidios producidos por la degradación que traía el vicio (las bebidas alcohólicas, por ejemplo), también eran reprobados por estos académicos. En síntesis, las personas que ponían fin a sus vidas representaban, para estos médicos, cuando no se trataba de casos de locura, ejemplos de vidas no virtuosas, consumidas por la búsqueda del lujo y los placeres, los negocios, el materialismo o la ambición desmedida.

En este sentido, antes de pasar a reflexionar sobre el incremento de los casos, Blancas destacó que toda su vida había sido un fuerte moralista y que por ello había tratado de cobardes a los suicidas, aunque contemplara interpretaciones similares a las de Gaché en el momento que escribía su carta. Bialet Massé también planteaba la idea de que los suicidas carecían de valor. Al hacer una crítica a las ideas materialistas que eran más permisivas con el derecho del hombre a poner fin a su vida, este definía al suicidio como un acto de "cobardía moral", producto de la falta de una educación de las facultades necesarias, que quedaba reservada a los intelectuales, y dejaba excluida a la mayoría de los habitantes. Según Bialet Massé (1885: 230), la cobardía moral no podía ser entendida como una enfermedad o como el resultado de una alienación mental en todos los casos.

Así, estos profesionales no descartaron la posibilidad de que la decisión de quitarse la vida pudiera estar fundamentada de forma racional y no por emociones

\footnotetext{
${ }^{126}$ La obra de Bialet Massé fue premiada en 1884, en el Gran Concurso Nacional de Ciencias Médicas, organizado por el Círculo Médico Argentino, y fue declarada texto oficial para la formación impartida en la Universidad Nacional de Córdoba.
} 
desenfrenadas o trastornos de las facultades mentales. Quienes se mataban, según Gaché (1884: 556), podían no ser enajenados, estando en la "plenitud de su razón" pero sumidos en "una pasión profunda y violenta". Si bien no eran locos, estos suicidas tenían bloqueada su libertad moral. Quienes también tenían su capacidad ética de decisión limitada eran los que no tenían trabajo o no tenían alguna ocupación en la que concentrar sus energías. Estos padecían el "taedium vitae":

\footnotetext{
Respecto del fastidio, la gran calamidad que aflije a muchos, diremos que se le encuentra en los individuos que no tienen ocupaciones habituales, y que por consiguiente su sistema nervioso sin actividad regular, los pone fácilmente en condiciones de malestar físico y moral, de donde se ha deducido el principio general de que todo hombre que permanece inactivo es desgraciado, y que para librarse del fastidio es necesario entregarse al trabajo (GACHÉ, 1886: 107).
}

Estos casos, los cansados y hastiados de la vida, como los apasionados, a su vez, se diferenciaban de aquellos que, con plena conciencia y haciendo uso de su libre voluntad, ponían fin a su existencia, distinción que también planteaba Bialet Massé. Estos eran los casos de los hombres que para salvar su honor -y "sin pasiones melancólicas", ni ambiciones desmedidas o "exaltaciones orgánicas"-, tenían la virtud de saber cuándo morir. Como veremos, otros profesionales de la salud también contemplaron esta posibilidad.

\subsubsection{El acto suicida como final estoico}

Una interpretación alternativa era la de José María Ramos Mejía (1849-1914) Este renombrado e influyente médico estaba entre quienes consideraban el suicidio como un mecanismo de selección natural del organismo social. En 1896, Ramos Mejía expresaba, en un artículo de los "Anales del Departamento Nacional de Higiene", que, partiendo del concepto moderno de suicidio como fenómeno social, lo entendía como un medio para prevenir los posibles trastornos mentales de las generaciones futuras, al hacer partir, voluntariamente, a muchos seres de estructura mental débil (OTERO, 1991: 65). De manera similar a Vásquez, planteaba que los cerebros modernos, sometidos a constantes y renovadas presiones en la lucha por la existencia, podían volverse inadaptables al medio social, ya sea por ser débiles desde el nacimiento o conmovidos por determinados efectos sociales. Dos salidas quedaban para quienes no eran capaces 
de adaptarse: el suicidio o la locura.

Sin embargo, había algunas situaciones que estaban por fuera del universo de las patologías mentales. Para Ramos Mejía, había ciertos casos en los que los hombres estaban justificados para disponer de sus vidas: el hombre que ve venir la locura, el militar que ha perdido sus genitales, eran situaciones extremas que podían justificar el quitarse la vida (RAMOS MEJÍA, 1896). Como señala Otero (1991: 77), Ramos Mejía reservaba para un grupo selecto el derecho de quitarse la vida.

Los ejemplos de estos últimos, hechos admirables o dignos de compasión, contrastaban con los cansados y hastiados de la vida, y con los suicidios de los jóvenes enamorados, descriptos en Las multitudes argentinas: "El suicidio por amor, bellísimo ejemplo de regresión social hacia la época werteriana del paquete romántico, ¿dónde lo encontraréis sino en esa inocente pareja de guaranguitos, en quienes la inervación emotiva desencajada de su justo equilibrio, ha perdido el gobierno de su pensamiento?" (RAMOS MEJÍA, 1952: 317-318). Estos casos podían generar un dilema ético y práctico para los peritos médico-legales. Si alguno de los miembros de la pareja sobrevivía, el examen de las facultades mentales tendría un rol más decisivo, ya que de este dependería la absolución o la condena del que había quedado con vida. Pero, además, el suicidio de las parejas de enamorados era un ícono de los valores del romanticismo, un ejemplo de las pasiones sin freno y sus resultados. La referencia a la obra de Göethe, cuyo protagonista era uno de los estereotipos más comunes del suicidio romántico, estaba en línea con el clima de ideas de la época, el auge del positivismo, en el que la razón individual era considerada la herramienta necesaria para frenar y contener las emociones y los sentimientos de jóvenes como Werther, que el romanticismo había exaltado.

Para Ramos Mejía, la civilización y el progreso implicaban una mayor complejidad y una aceleración de la vida social. Junto con esto, venía un aumento de los goces, de la actividad intelectual, de las pasiones y de las ambiciones, que traían, como consecuencia, una sobre-excitación cerebral. Este nuevo contexto de exigencia de las facultades mentales provocaba patologías. Sólo aquellos que pudieran adaptarse a la nueva situación podrían sobrevivir y salir victoriosos en la lucha por la vida y el proceso de selección natural.

En Ramos Mejía, aparecía, de forma más evidente, la influencia de Gustave Le Bon y su teoría sobre la psicología de las multitudes. Para el autor de Las multitudes argentinas, la multitud era el producto de la evolución desde la colonia hasta llegar al 
final del siglo XIX, donde la novedad era la influencia de la masa de extranjeros sobre la población ya asentada en el Río de la Plata. El principal defecto entre la población de inmigrantes estaba en su relación con el dinero. El afán por enriquecerse era un tipo de pasión que podía alterar las facultades mentales, y, por ende, generar distintos tipos de locura. Sin embargo, estos inmigrantes aparecían en la mirada de Ramos Mejía como seres infantiles, que más allá de sus imperfecciones, podían ser transformados en ciudadanos virtuosos, por ejemplo, a través de la educación. La formación basada en los valores de la familia y el trabajo transformaría en ciudadanos respetables a esta multitud -femenina y apasionada, puro inconsciente-, que era vista como la antinomia de la elite virtuosa, de los grandes hombres, que hacían uso de la razón.

Nos llama la atención la similitud del pensamiento de este autor con el del mundo antiguo, en especial, con la concepción de los estoicos. ${ }^{127}$ Para Ramos Mejía, existían situaciones en las que el suicidio podía ser permitido y hasta recomendado:

El Suicidio podrá ser un simple fenómeno social, como la prostitución, el pauperismo y la delincuencia; un resultado inevitable y previsto de la selección de la lucha por la existencia, pero quedan esas excepciones numerosas que dejamos mencionadas, en que es el término preparado de un proceso intelectual relativamente libre, consciente y reflexivo; un acto voluntario hasta donde el mecanismo hombre lo puede verificar: el producto lógico de una situación moral dada, cuyo desarrollo necesario -casi diría mecánico- lleva fatalmente a este fin, refugio de una conciencia alarmada; pero no meticulosa ni cobarde (RAMOS MEJÍA, 1896: 380).

Cuando se hacía frente a la muerte, de manera consciente y sin cobardía, para eludir un destino de sufrimiento o una agonía dolorosa o atroz; en los casos de suicidios políticos, donde era elegido el fin de la existencia al estigma de una circunstancia aleatoria y desafortunada, es decir, frente a las "grandes e irreparables tribulaciones", en que había que optar entre el final de la vida biológica y la muerte civil o moral, producida por la pérdida del honor en el espacio público, el suicidio era un supremo refugio (RAMOS MEJÍA, 1896: 381). Hacia el final del artículo, Ramos Mejía tomaba como ejemplo de estos casos los suicidios de los estoicos y figuras históricas célebres, que no debían ser confundidos con los alienados y criminales.

\footnotetext{
127 Para los estoicos, la muerte podía ser un supremo refugio, un instrumento libertario y afirmación de la libre voluntad. En este sentido, lo reprobable para el estoicismo no era el suicidio en sí, sino vivir de forma contraria a la ética estoica, es decir, vivir de forma vergonzosa, cobarde y deshonrosa, de manera contraria a la naturaleza, sin las facultades de la razón, en detrimento de la virtud y consumido por el vicio. Véase, SZLAJEN (2012: 89-91-92).
} 
Esta separación que establecía entre unos casos, los cansados y hastiados de la vida, y los hombres que eran dueños de su razón y defendían su honra expresaba la síntesis del código social de la época. La locura era el equivalente a la pérdida de las facultades mentales, la razón, condición básica para una existencia digna. La mutilación de los genitales representaba la pérdida de la virilidad, atributo esencial de la identidad masculina. Por último, el honor demostrado en el espacio público, en especial, el de aquellos que participaban del juego político, era una cualidad muy apreciada por los miembros de la elite, como Ramos Mejía.

Estos principios axiológicos eran sostenidos por sus discípulos, como Fermín Rodríguez, y por intelectuales que se distanciaban de la interpretación del suicidio como un mecanismo de la selección natural, como el escritor Víctor Arreguine, en revistas como "Criminología Moderna” o "Archivos de Psiquiatría y Criminología”.

En sus trabajos, Rodríguez, además de insistir con sus reflexiones sobre el consumo de alcohol, y de analizar las franjas etarias y el estado civil donde predominaba el suicidio, indagó sobre el sexo y aquellas circunstancias que predisponían el quitarse la vida a la población.

Al igual que otros profesionales de la salud, para Rodríguez, el perfil del suicida promedio era un hombre, entre 16 y 25 años, sin empleo, o, en segundo lugar, de alguna profesión liberal y soltero. Los jóvenes eran los más propensos a dejarse llevar por las pasiones desenfrenadas y más proclives, por ejemplo, a dejarse influenciar por la lectura de folletines y novelas románticas. En el caso de los profesionales, por ejemplo, un médico que identificara que sus facultades mentales estaban siendo alteradas, y que el manicomio y la locura estaban cerca, podía llegar a optar por terminar con su existencia. En estas situaciones, para Rodríguez era entendible que aquellos que estuvieran al límite en la lucha por la vida, la abandonaran para terminar con el sufrimiento. Desde su punto de vista, estos hechos no atentaban contra el bienestar del organismo social.

De manera similar, interpretaba las enfermedades incurables o que traían dolores extremos. En esas situaciones, además, el enfermo resultaba una carga para los familiares. Frente a una vida deshonrosa, tanto para él como para sus seres queridos, era verosímil, para Rodríguez, que el balance moral del que padecía la enfermedad se inclinara hacia el suicidio.

El honor era un asunto delicado, que afectaba no sólo al hombre como padre. Sus acciones también marcaban a su esposa y a sus hijos. En este sentido, Rodríguez 
señalaba que, si alguna situación había manchado el honor de un hombre, sin merecerlo, éste último podía continuar viviendo, aunque la sociedad lo juzgara injustamente. Sin embargo, podía esperarse que el jefe de familia, frente a la vergüenza y el escándalo que sus actos podían hacer caer sobre sus hijos y su esposa, pusiera fin a su vida para callar al "tirano social". En esas circunstancias, el suicidio era "un supremo refugio" (RODRÍGUEZ, 1905: 387-388).

Por otro lado, las mujeres no estaban exentas del peligro de perder su honra y sus consecuencias. La joven que había quedado embarazada antes del matrimonio era víctima de un estigma social muy fuerte en la época. Según Rodríguez,

\begin{abstract}
El abandono por parte del hombre, la represión, a veces sangrienta, de parte de su familia, la miseria y la vergüenza, llevando en brazos al hijo, frecuentemente odiado desde los primeros síntomas del embarazo, amasan esa pasta de la que abandonará, en algunos casos, la existencia, para escapar a las penalidades físicas y morales de una maternidad intolerable, si no se libra ella por el aborto criminal o el infanticidio, cuya idea es insinuada por alguna compañera práctica en esos achaques de las consecuencias del amor clandestino, si acaso no lo es por las narraciones de los diarios, tan pródigos en lecciones de inmoralidad (RODRÍGUEZ, 1904 : 14).
\end{abstract}

El honor femenino, si bien en un lugar más secundario, también era considerado a la hora de pensar las causas y la legitimidad de los suicidios. En este sentido, el autor también se preguntaba si, frente a un caso de incesto, la mujer deshonrada estaba en su derecho de quitarse la vida. Así, el honor de hombres y mujeres daba sentido a los casos de suicidio que estaban fuera de las patologías mentales o de las enfermedades morales.

\title{
5.2.3 El suicidio de Leandro N. Alem
}

Al igual que otros de los intelectuales de la época, Rodríguez quería separarse de la psiquiatría alienista francesa. Si bien, en muchos casos, podría tratarse de una patología o de los efectos del alcoholismo, retomando lo postulado por su maestro Ramos Mejía, había otros donde el suicidio era digno de piedad y en algunos hasta de admiración. En este sentido, uno de los ejemplos que desarrolló fue el de Leandro N. Alem. En el artículo, el autor hacía un repaso de los hechos más destacados de la vida del líder radical. En su recorrido, Rodríguez se proponía mostrar que la idea del suicidio había estado presente en varios momentos de su biografía. Sin embargo, Alem no era 
presentado como un alienado o un melancólico. Este no había puesto fin a su vida en un ataque de locura, tampoco llevado por pasiones románticas, por ambición o cobardía. "El tribuno", como lo habían apodado, había vivido como un auténtico ciudadano de la república, que llevaba una vida virtuosa, de entrega intransigente a sus convicciones políticas. Rodríguez interpretó el suicidio de esta eminente figura política, de este luchador infatigable, como el resultado de un balance moral, de la comprensión de que su tarea ya había sido cumplida, y que su nombre pasaría a la historia sin mancha y cargado de honores otorgados por el pueblo. Con "solemne recogimiento" y la serenidad de una mente elevada, Alem puso fin a su vida. En este sentido, Rodríguez, citando a su maestro, afirmaba que este tipo de suicidios eran dignos de piedad y admiración y no merecían "la injuria, el castigo de las leyes o de la Iglesia" (RODRÍGUEZ, 1903: 267).

El suicidio de Alem ( $1^{\circ}$ de julio de 1896$)$ no sólo conmocionó a la opinión pública en la capital, sino que fue un hecho que tuvo gran impacto en todo el territorio argentino. ${ }^{128}$ Los medios gráficos de la época dieron cobertura del velatorio y las pompas fúnebres en honor del líder de la oposición al partido gobernante. ${ }^{129} \mathrm{La}$ información relacionada con la muerte de Leandro N. Alem era un hecho sensacional de proporciones sólo comparables a los funerales de otras figuras del elenco político, como el de Bartolomé Mitre, una década más tarde. ${ }^{130}$

Según la información que dieron "La Prensa" y "La Nación" sobre los detalles del mismo, en su residencia familiar, el cuerpo de Alem recibió la visita constante de

\footnotetext{
${ }^{128}$ Según los testimonios de La Prensa y La Nación (los días posteriores al $1^{\circ}$ de julio de 1896), Alem había citado a sus amigos en su casa para celebrar una reunión. Allí asistieron Domingo Demaría, Oscar Liliedal, Adolfo Saldías, Enrique de Madrid, Francisco A. Barroetaveña y Martín M. Torino. Mientras sus invitados ya estaban en su domicilio, buscó encerrarse en su escritorio, pero encontró a los doctores Torino y Demaría, por ello se suicidó en su carruaje, mientras éste se dirigía al Club del Progreso. Durante el recorrido, Alem se dio un disparo en la sien derecha con un arma de fuego. Fue encontrado por el cochero al llegar a destino. En un primer momento, fue velado dentro del club, donde las autoridades prepararon un cuarto especial para exhibir el cuerpo, que fue depositado en un cajón de ébano, rodeado de cirios y de aquellos que venían a verlo. Más tarde, fue trasladado al domicilio de la familia donde fue visitado por una gran cantidad de hombres y mujeres que iban a despedir al apreciado ciudadano, patriota, defensor de la república y la democracia argentina.

${ }^{129}$ Dado que se trataba de la muerte de un diputado del Congreso de la Nación, el ministerio del interior se expidió decretando los honores fúnebres correspondientes al diputado Leandro N. Alem, "siendo un deber del gobierno honrar la memoria de este distinguido ciudadano" (La Nación, 04/07/1896). La bandera nacional sería izada a media asta en todos los edificios públicos de la nación y los costos del ceremonial y del entierro saldrían de los fondos del estado nacional, designándose a cuatro diputados que representarían a los miembros de la cámara y acompañarían el cuerpo hasta el cementerio. Además, los batallones de infantería le rendirían los honores militares por orden del ejército. Estos deberían realizar tres salvas, una al pasar el cortejo, que trasladaría el cuerpo, otra al bajarlo y una última como saludo al depositar el cuerpo en la tumba.

${ }^{130}$ Sobre este tema, véase, entre otros, GAYOL (2012).
} 
muchos que se acercaron a despedirlo y a rendirle homenaje. ${ }^{131}$ El 4 de julio, el cortejo fúnebre fue llevado adelante como había sido programado. Las delegaciones se organizaban para emprender la marcha al cementerio. Autoridades políticas, diplomáticos, miembros de los comités nacional, provincial y de otras partes del territorio, comisarios y tropas se hicieron presentes para emprender la procesión al Cementerio del Norte. ${ }^{132}$ Más atrás, como estaba planificado, iban las agrupaciones de ciudadanos de las distintas parroquias de la ciudad. "La Nación” señalaba: "la multitud era inmensa, incalculable". ${ }^{133}$ A la una y media empezó la movilización al compás de las marchas fúnebres de las bandas militares. La gente se agolpaba para ayudar a subir el cajón al carro fúnebre; sobre el féretro, las familias que vivían en la misma calle habían lanzado pétalos de flores. Otro vehículo similar transportaba las coronas. Este último iba a la cabeza de la procesión y tenía escrito en letras doradas: "Gratitud nacional, Valor, Virtud, Patriotismo". Atrás, iba el coche fúnebre tirado por nueve caballos. Lo acompañaban, llevando los cordones del féretro, su hijo, Leandro, Hipólito Yrigoyen, Roque Sáenz Peña, el coronel Martín Irigoyen, el capitán Pereyra Rosas, Manuel Ruiz Moreno y amigos cercanos, como Liliedal y Saldías, entre otros. Los seguían los diputados nombrados para participar del cortejo y la multitud que avanzaba por las calles, que estaban atestadas de gente que miraba desde las aceras, las ventanas, las

\footnotetext{
${ }^{131}$ El cajón se encontraba en la capilla ardiente, rodeado de tres hachones dorados. A su lado, había dos banderas, una era regalo de las damas de Córdoba y la otra de las damas de Tucumán, que le había sido dada como presente cuando el caudillo radical pasó en campaña política por el interior. El féretro estaba rodeado de coronas de flores y el cuerpo cubierto con una mortaja de raso blanco. Alrededor, permanecían familiares y los más íntimos y cercanos amigos. Junto al catafalco, los deudos permanecían en silencio, algunos lloraban, otros rezaban en voz baja. Personalidades políticas, amigos, miembros del partido radical y una "compacta masa popular" expresaban sus condolencias. A la casa del difunto llegaron, además, tarjetas y telegramas de diferentes partes del país; los diarios dejaban sentado esto último y quiénes eran los remitentes. No sólo en la Capital Federal, sino también en la Plata y en múltiples puntos del territorio argentino se expresaron muestras de duelo y se enviaron mensajes con las condolencias y lamentos por la pérdida del líder de la fuerza opositora mayoritaria, designándose representantes para asistir al entierro. En las habitaciones y en la calle, afuera de la casa, había una numerosa muchedumbre. Esta multitud aumentaba en número a medida que pasaba el día. Según La Nación: "frente a ese cadáver desfiló ayer considerable parte de la población de Buenos Aires". Hombres y mujeres, ricos y pobres, jóvenes y niños, seguidores y adversarios políticos. Algunos manifestaban su dolor sin pudor: "un joven alto, rubio, mal vestido, entró en seguida y como poseído de un repentino ataque lo llamaba entre gemidos. Hubo que sacarlo de allí". Otros, en cambio, le acariciaban la barba, le besaban la cara o depositaban su mano sobre la frente del cuerpo. Más de 5.000 personas esperaban afuera de la casa de Alem, según "La Nación". Los que estaban afuera pedían entrar para ver al tribuno por última vez.

${ }^{132}$ El cortejo partió cerca de las 13:35hs y se dirigió por Callao hasta Avenida República y por esta calle hacia el cementerio de la Recoleta, al que llegaron alrededor de las 14:00 horas. Una vez descendido el cajón, fue depositado en el centro del patio del cementerio, donde fue rodeado con coronas de flores. Era "un verdadero desborde humano". La Prensa habla de unas dos mil personas en la calzada del cementerio. Los árboles y las azoteas fueron dos de los lugares desde donde muchos presenciaron los eventos en la Recoleta. El ataúd fue depositado en el mausoleo donde descansaban los restos de los caídos en la revolución de 1890, una vez que terminaron los discursos de los asistentes.

${ }^{133}$ La Nación, 05/07/1896.
} 
puertas y azoteas de las viviendas. Muchos, para observar, se subían a los árboles. Reinaba el silencio. Por lo menos 30.000 personas acompañaban el cadáver y unas 100.000 habían asistido a ver el desfile, según "La Nación". ${ }^{134}$ Estos eran los signos de una "buena muerte", digna de un hombre apreciado por los contemporáneos, que recibió, además de coronas y tarjetas, la presencia de una concurrencia masiva para acompañar el traslado de sus restos, lo que no ocurría con frecuencia en la capital.

Tanto opositores como partidarios, no dejaban de reconocer la carrera política de Alem y veían su muerte como la pérdida de una figura del elenco político clave, entendiendo que no merecía este abrupto desenlace. Así lo manifestaban los oradores que hablaron en el Cementerio de la Recoleta, antes de que el cajón fuera depositado en el mausoleo, donde descansaban los restos de los caídos en la revolución de 1890. En esa ocasión, el encargado de hablar como representante del comité radical de la Capital fue el Dr. Adolfo Saldías, un hombre muy cercano al difunto líder del radicalismo. Para Saldías, Alem era la representación de la virtud y la justicia, necesarias para que las instituciones republicanas pudieran consolidarse en la nación argentina. Algo similar planteó Bernardo de Irigoyen en su discurso. Éste fue publicado tanto por "La Prensa" como por "La Nación", y estuvo orientado a rescatar los principales hitos del cursus honorum de Alem, además de enaltecer el ejemplo de sus virtudes cívicas y ciudadanas para las futuras generaciones. En sus palabras, remarcó que Alem era un hombre que había afrontado las dificultades por sí mismo: gracias a sus capacidades intelectuales y morales, de una situación más que precaria, sin favores ni influencias, estudió derecho y se recibió de abogado, fue un militar que participó de batallas en el ejército y logró desarrollar una destacada labor política y parlamentaria. Irigoyen, además, destacaba su papel en la formación del partido radical: Leandro N. Alem era un hombre de actitud integra, austera y altruista, que había ganado la legitimidad del pueblo a lo largo del territorio nacional. Por todas estas razones, Irigoyen consideraba que el líder radical bajaba a la tumba rodeado de honores. Este discurso dejaba de lado la forma en la que había muerto Alem y se concentraba en resaltar aquellos aspectos de su biografía, personal y política, que lo habían hecho un ciudadano virtuoso. ${ }^{135}$

El discurso de Francisco Barroetaveña tuvo un tono diferente y las partes seleccionadas para ser publicadas por los medios de prensa también fueron diferentes.

\footnotetext{
134 Ibid.

${ }^{135}$ La Nación, 05/07/1896; La Prensa, 05/07/1896.
} 
En la versión publicada por "La Nación” el 5 de julio de 1896, este miembro de la UCR destacaba que "uno de sus patricios excelsos, con mano firme y temeraria, ha puesto fin a su noble vida", resaltando la valentía y la determinación del suicidio llevado adelante por Alem (recordemos que el valor era un rasgo de virilidad apreciado por la elite y la sociedad de la época). Por otra parte, señalaba que el acontecimiento generaba un antecedente peligroso para los hombres públicos a la hora de enfrentar los obstáculos y problemas en sus vidas: "séame permitido condenar el suicidio como el procedimiento más estéril y atentatorio". Si bien resaltaba las cualidades viriles, su alma varonil y virtudes ciudadanas, condenaba el suicidio como el resultado de la desesperación, el desenlace de una mente "excitada por un enfermizo romanticismo". No quedaban otras explicaciones para entender su suicidio: no era pobre, no pesaba sobre él calumnia alguna ("el hombre público argentino menos calumniado"), por el contrario, era un ejemplo de la virtud. Para Barroetaveña, en Alem se habían combinado un "alma byroniana" (romántica), con la belleza de las "virtudes de Catón el Antiguo", y era su carácter lo que permitía entender lo que lo había llevado a quitarse la vida. Al mismo tiempo, desautorizaba los adjetivos con los que Alem se describía en su testamento: “deprimido", "inútill", "estéril”. Nada más alejado del hombre noble, virtuoso y brillante que era el tribuno. No había explicación para el suicidio del líder radical. Se trataba de un hecho causado por los oscuros pensamientos de un "momento psicológico". Terminaba su discurso llamando a los jóvenes a continuar con la obra del "tribuno de fuego", el "demócrata del pueblo", siguiendo el horizonte marcado por su testamento político. "La Prensa" publicó el discurso de Barroetaveña, pero omitió todas las referencias que impugnaban el suicidio de Alem como un acto reprobable y cuasi romántico (el periódico aclaraba, por las dudas, que por cuestiones de espacio sólo publicaba fragmentos de lo pronunciado por los oradores). ${ }^{136}$

El discurso de Jorge L. Dupuis presentaba el suicidio de Alem desde una perspectiva diferente. ${ }^{137}$ Para este representante de la UCR de la provincia de San Juan, el difunto líder del radicalismo había sido un hombre de una estoicidad espartana, un "varón bíblico", hecho de la misma materia que los del mundo antiguo. Su suicidio había sido el resultado de una meditación serena por parte de su espíritu: "Todos sus actos llevan el sello de la entereza consciente y reflexiva". Era un sacrificio para salvar a la sociedad argentina de su corrupción: “creyó que su sangre derramada por su propia

${ }^{136}$ La Prensa, 05/07/1896.

${ }^{137}$ La Nación, 05/07/1896. 
mano, cayendo gota a gota sobre la frente del pueblo, sería su redención y se la dio". Para Dupuis, este "asceta del civismo" sólo podía ser juzgado por la historia.

Un espíritu similar tenía el discurso de Joaquín Castellanos, abogado y político que había participado en las revoluciones de 1890 y 1893 :

Todos sus actos llevan el sello de la entereza consciente y reflexiva. Su propia muerte es el resultado de la severa unidad que dió a su vida; a semejanza del Hércules antiguo, él mismo preparó su pira funeraria y él mismo recostó en ella su cuerpo dilacerado para despertar inmortal después de su martirio. ${ }^{138}$

El discurso más duro y condenatorio de los publicados en "La Prensa" fue el de Mariano Varela, quien había abandonado el partido radical hacía algunos años: “Al contemplar esta masa compacta de pueblo, que llega hasta aquí siguiendo los despojos de un suicida, hay derecho para que cada uno de nosotros se pregunte: ¿Somos un pueblo de cobardes?". Luego de reafirmar el valor como rasgo del pueblo argentino, y de resaltar las virtudes cívicas, el orador condenó abiertamente, y sin matices, en pleno funeral, el suicidio de Alem:

Cobardía he llamado a su muerte, y no me arrepiento ni retiro la palabra, porque mi maestro es Cristo, dejándose clavar en una cruz por sus doctrinas, y no aquellos espíritus de la antigüedad, que no teniendo valor para sobrellevar las contrariedades de la vida, aceptaban como gracia el darse muerte por sus propias manos, abriéndose las venas en baños perfumados. ${ }^{139}$

El diario no aclaró la repercusión de este discurso, pero entendemos que debe haber resultado chocante, en especial para quienes estaban presentando el suicidio de Alem como un hecho de carácter estoico y de un ciudadano sacrificado.

Los dos periódicos que hemos consultado también tenían discursos diferentes sobre la muerte del caudillo radical y las características de su personalidad. El artículo publicado al día siguiente de su muerte en "la Prensa" (02/07/1896), expresaba enfáticamente: “No debió morir así!”. Alem era presentado como un hombre que:

${ }^{138}$ La Prensa, 05/07/1896.
${ }^{139}$ La Prensa, 05/07/1896. 
Había nacido para la lucha. Las tendencias geniales de su espíritu, los atributos de su inteligencia, las generosidades ingénitas de su alma, el temple de sus virtudes cívicas, su altivo desdén por la fortuna, la intensidad de sus afectos, el fuego de sus pasiones, el ardimiento de su palabra de tribuno y la fortaleza incontrastable de todo su ser, constituían una de esas personalidades excepcionales, hijas genuinas de las democracias meridionales, cuya vida resplandece en el seno agitado de las luchas perennes y cuyo cuerpo sólo debe caer envuelto en la bandera de su credo.

Alem murió por su propio brazo, sin entenderse muy bien las razones de su "suprema y dolorosa decisión". Esta había sido un evento que el difunto había reflexionado fríamente, según "La Prensa", "con mente serena”. Así, había saltado a "los abismos del no ser, con viril y acentuada altivez”. El tribuno había sido un hombre viril, un ciudadano virtuoso y un patriota. Su presencia había inspirado a los jóvenes, que vivían en una era de "materialismo enervante", corruptor, y del utilitarismo que parecía eterno, en palabras de "La Prensa".

Las palabras del diario "La Nación" tenían un tono y un mensaje diferente. A la hora de enaltecer la figura de Leandro N. Alem se destacaban el "aprecio y la gratitud de sus conciudadanos", sus cualidades de líder político, su apasionada oratoria y su capacidad de movilizar y agitar a las masas reunidas en clubs y parlamentos. Se refería a él como el tribuno popular, el agitador, el hombre de leyes, el intelectual, el caudillo, "el de la palabra vibrante y perentoria" (su capacidad de orador se confundía con ciertos rasgos físicos que resaltaban su carácter viril), el de las largas barbas plateadas, "el de los ojos vivos y fulgurantes", "el hombre de la calle y de la plaza pública", que podía guiar a las multitudes cuando les hablaba; que tenía un "altruismo extraño", un rostro ascético. Entre líneas, el mitrismo aprovechaba para señalar que, sin intención, debilitó a la Unión Cívica al dividirla y formar la Unión Cívica Radical; sus intentos revolucionarios chocaron con la tendencia a la evolución según el cronista. El viernes 3 de julio, en una editorial titulada "Otros tiempos, otros hombres", el diario daba su punto de vista sobre "el último caudillo del día presente", que había puesto fin a su vida. Más allá de las ideas con las que había diferencias, era un hombre necesario, admirado por los pobres y olvidados, encarnaba el avance de una democracia que todavía estaba naciendo. Para "La Nación", su muerte sepultaba una época de la vida política argentina. Era el paso de la "energía brava" al razonamiento frío, representado por Aristóbulo del Valle. Su intransigencia es lo que la nación no dejó de recriminar de forma velada entre los halagos a su figura. El difunto líder del radicalismo era 
presentado como un hombre que no podía debatir en épocas de calma, de temperamento más bien romántico (“en el buen sentido"), había sido un hombre de acción. El presente, desde la perspectiva de "La Nación", era la hora de los hombres de gobierno y Alem había sido el hombre de la tribuna y el atrio, el caudillo popular. ${ }^{140}$ Es decir, era un líder político de multitudes, pasional, que había ocupado su rol en la época de convulsiones (el siglo XIX), pero opuesto al raciocinio que propiciaba la evolución hacia la que se dirigía la Argentina.

En este sentido, el suicidio de Alem fue presentado de forma similar a como Ramos Mejía, y otros intelectuales, entendían esos suicidios admirables, que podían ser comparados con los grandes hombres de la antigüedad, los que habían puesto fin a la vida a través de la fría meditación, frente a la caída en la arena política o una grave desgracia. Ramos Mejía escribió su artículo antes de este suceso, pensando en el caso del presidente chileno, José Balmaceda, ${ }^{141}$ pero, de nuevo, se aplicaban las mismas categorías, como señalaba Fermín Rodríguez, su discípulo, quien hizo referencias al caso del líder radical. En su testamento, Alem exponía que "había pensado, meditado y reflexionado mucho en un solemne recogimiento". Esta aclaración no era accidental, la diferencia entre un suicidio romántico, en el buen o en el mal sentido, y la ética estoica predicada en la época, era precisamente esta decisión producto de la razón. El suicidio meditado y razonado era la diferencia entre los grandes hombres de la virtud y los seres llevados por sus pasiones, románticas o políticas. El tribuno estoico había hecho uso de su derecho a morir. Esto lo posicionaba como mártir de la decadencia política para sus aliados y los partidarios de la reforma de las instituciones republicanas.

\subsection{Consideraciones finales}

El aumento de los casos de suicidio fue uno de los problemas identificados por los miembros de la elite cultural, que empezaron a estudiar las consecuencias del

\footnotetext{
${ }^{140}$ El 7 de julio de 1896, "La Nación" publicó la nota de un lector que buscaba esclarecer el sentido de algunos de los discursos que se referían al líder radical como un "caudillo". En respuesta a uno de los oradores del funeral, que reprobaba la comparación de Alem con "obscuros caudillejos locales", F. Uzal señalaba que caracterizar al político radical comparándolo con Adolfo Alsina, caudillo popular, era una forma elogiosa de presentar al difunto. Esto nos da la pauta de que el término "caudillo" tenía un significado ambiguo para la elite, aunque había comparaciones y ciertos usos del término que no eran necesariamente despectivos. Sin embargo, era evitado por los discursos más elogiosos expresados sobre el difunto líder del radicalismo.

${ }^{141}$ Sobre el suicidio del presidente chileno José Balmaceda, ocurrido en la legación argentina de Chile el 19 de septiembre de 1891, véase, entre otros, BLAKEMORE (1992) y SAN FRANCISCO (2006).
} 
proceso de modernización y las transformaciones en la ciudad de Buenos Aires. En nuestro recorrido por los trabajos producidos en el campo científico, encontramos referencias a diferentes corrientes de pensamiento del mundo occidental, resignificadas para comprender la realidad particular que estudiaban los profesionales de la salud. El discurso positivista tomó, para su interpretación del suicidio, una mezcla de diferentes disciplinas y marcos interpretativos del mundo europeo: los de la medicina legal, la psiquiatría alienista y la antropología criminal.

La población del mundo urbano, las masas de inmigrantes, trabajadores y marginados fueron el principal objeto de estudio de estos discursos. Una de las hipótesis que estuvo en el centro de las reflexiones fue la imitación de los suicidios en el mundo urbano. La posible sugestión de los individuos, la imitación de las prácticas suicidas fue un factor que, si bien no era la principal causa de los suicidios, explicaba el porqué de la utilización de los mismos medios y circunstancias. Como señaló Otero (1991), los médicos pensaban que, más allá de las facultades mentales alteradas de los individuos o su potencial para ser sugestionados, las características de la organización social, de la civilización, eran la clave para entender la tendencia al aumento de los casos de suicidio. Esto no implicó el abandono de la mirada de la psiquiatría alienista sobre el tema, que mantuvo su prestigio entre los intelectuales de fin de siglo. Así, conceptos como monomanía, neurosis y otros términos e ideas relacionados con las patologías mentales, continuaron siendo utilizados en la explicación de los suicidios.

Si bien no había acuerdos generales en cuanto a las formas de poner en práctica medidas profilácticas (la educación, la promoción del matrimonio, por ejemplo), o el peso de algunos factores (como el consumo de alcohol), en general, todos entendían que, en la mayoría de los casos, se trataba de personas con sus facultades mentales alteradas o en un estado nervioso o apasionado anormal, producido por la vida en el mundo moderno y civilizado, asociado con la ciudad y opuesto a la vida en el campo. La otra cuestión que parecían compartir estos profesionales, escritores y científicos, era la necesidad de diferenciar la gran mayoría de los casos (los alienados y anormales), de aquellos que habían sido llevados a cabo motivados por una evaluación racional de la situación.

En los trabajos sobre el suicidio, encontramos distintos discursos que se entrecruzan, se suman, discuten, dialogan, y, en su lectura, aportan elementos para entender la grilla mental de las elites porteñas, y sus matices, a la hora de reflexionar sobre los casos de suicidio. En medio del devenir de conceptos e ideas de las disciplinas 
científicas, en el debate sobre el suicidio, aparecía una discusión ética, que iba más allá del problema de la salud mental, tal como lo entenderíamos hoy. Lejos de indagar sólo las causas del fenómeno o de describir e interpretar sus variables demográficas, la reflexión de los médicos de fin de siglo combinaba los argumentos y conceptos del pensamiento moderno europeo con valores que filiaban de forma deliberada con la ética antigua y estoica, en la mayoría de los casos, haciendo explícita referencia a los episodios de suicidios de personajes históricos célebres, por ser ejemplos de vidas virtuosas, que estaban enfrentados al vicio del mundo urbano y popular de fin de siglo y principios del siguiente. Así, el pensamiento médico y científico finisecular retomó, para su análisis ético de las prácticas suicidas, valores como la honra de hombres y mujeres.

Al mismo tiempo, en la ética del higienismo y la ciencia positivista también había, en el fondo, un discurso utilitarista, que censuraba el placer y las conductas hedonistas, mientras exaltaba la entrega al bien del organismo colectivo. Siguiendo las concepciones del evolucionismo social de Spencer, entendían que las personas debían estar al servicio de la sociedad, y si no podían sostenerse en la lucha por la vida, seguían su destino natural: la muerte o la locura.

Asimismo, este discurso se oponía también a los valores que asociaba con el ideal del romanticismo y con las ideas de la Iglesia Católica que había condenado a los suicidas y a sus familias en el pasado. Por otra parte, si se separaban de las condenas religiosas, también buscaban poner un freno a la sensibilidad romántica. La ética positivista en este período era una reacción hacia el romanticismo, y el suicidio era un símbolo de este último, en especial cuando se trataba de una pareja que ponía fin a su vida. La defensa de la libre expresión de los sentimientos y las emociones no era el valor central a defender por esos intelectuales; la razón y la ciencia eran el norte que los guiaban.

A pesar de enmarcar muchos de los casos dentro del universo de las patologías mentales, el pensamiento científico de fin de siglo guardaba espacio para una reflexión ética del fenómeno. Esta servía para legitimar la hegemonía de la elite modernizadora y la ideología que buscaban imponer al resto de la sociedad. En este sentido, junto a los casos que podían ser catalogados como variantes de alienación mental o locura, aparecían otras situaciones que no parecían encuadrarse dentro de las categorías del saber médico, psiquiátrico y criminológico. El suicidio de Leandro N. Alem no lo trasladó a la órbita de los alienados, el estereotipo más común, junto a los románticos y 
los cansados de la vida. Por el contrario, una de las formas de representarlo era como un varón viril, que había llevado adelante su decisión, luego de una fría meditación, por medio de su razón, y motivado por la valiente intención de no ceder en su intransigencia política, manteniendo sin mancha su trayectoria. El discurso estoico fue el que dio sustento a la hora de presentar el suicidio de Alem desde una perspectiva heroica; sus adversarios, y quienes no aprobaban esta operación discursiva, lo presentaban como un cobarde, o, en su defecto, como un caudillo romántico y apasionado.

Como vemos en el trabajo de Gaché, Ramos Mejía, o de sus discípulos, no todo suicidio era igual en términos ideales. En los estudios del fenómeno aparecía más o menos explícito una especie de código social. Éste marcaba que para algunas situaciones el suicidio era un hecho -sino justificable y digno de admiración (un refugio supremo)-, al menos comprensible. El peligro de caer preso de la locura, y quedar despojado de las facultades mentales, era un ejemplo de esto último. También los casos de suicidio por el sufrimiento provocado por enfermedades graves. Sin embargo, la justificación ética, en estos casos, no era explícita. Los sujetos dignos de exaltación eran los que eran capaces de cumplir con sus roles: en el caso de los hombres, los que podían afrontar la lucha por la vida y convertirse en padres de familia, en el de las mujeres, ser madres y esposas. El sufrimiento, el cansancio o el hastío de la vida no eran móviles éticos válidos. El principal valor que aparecía era el honor individual, familiar y patriótico, en especial, del género masculino. La otra condición de un suicidio virtuoso, al igual que en el mundo antiguo, era la decisión basada en el pensamiento meditado y racional, alejado de cualquier indicio de cobardía, y no el desenlace trágico de pasiones desmedidas o de desgracias menores (como el desengaño amoroso) o el resultado del ansia desproporcionada de fortuna y bienes materiales. El ideal republicano moderno buscaba en el pasado antiguo sus modelos de lo que constituía el ciudadano virtuoso.

Por otra parte, fuera de esa minoría estoica selecta mencionada por Ramos Mejía, el resto de los suicidas eran considerados alienados o sujetos desesperados, apasionados y anormales, en ambos casos, privados de su libertad moral. La muerte por mano propia era un desenlace vergonzoso, característico de sujetos cuya estructura física y mental no era apta para la lucha por la vida, en el mundo civilizado. Como veremos en los próximos capítulos, la valoración de la acción era difícil de determinar. Se trataba de un hecho lamentable, sin duda, pero podía ser representado de distintas formas, de acuerdo a las circunstancias, en especial, a las causas, manifestadas o supuestas. Así la representación del suicida estaba lejos de ser unívoca y homogénea: 
loco o héroe estoico, ciudadano racional o romántico apasionado, hombre viril y honrado o cobarde débil y sin honor. Entre estas imágenes antagónicas parecía debatirse la sociedad sin llegar a definir una representación que las sintetizara. Las diferentes formas en las que era representado Alem, en los discursos pronunciados en su funeral y los producidos por los cronistas de la prensa, nos muestran el significado ambiguo que tenía el hecho de quitarse la vida para los contemporáneos. 


\section{Capítulo 6: Medir la desesperación}

Como mencionamos en el capítulo anterior, los intelectuales y médicos porteños analizaban el aumento de la tasa de suicidios en la ciudad de Buenos Aires. Según estos datos, en 1881, se registraron 36 actos suicidas (entre suicidios consumados y tentativas). En 1895, se contabilizaron 182. Si observamos los valores anuales de la Tabla 1 (en Anexo), podemos observar la evolución gradual del crecimiento de las cifras. Según Alberto Méndez Casariego (1888: 46), la población de la ciudad de Buenos Aires, entre 1882 y 1887 había crecido alrededor de un 53\%, mientras que los suicidios aumentaron un $47 \%$. Es decir, el crecimiento de la cantidad de suicidios era un correlato del acelerado incremento poblacional. Esta misma tendencia continuó con el paso de los años. A comienzos de la década de 1880 había, en la capital del estado argentino, alrededor de 290.000 habitantes, a fines de 1895 la población superaba el medio millón de habitantes (675.989), es decir, había crecido un 133\% (véase Tabla 2 en Anexo). De manera análoga, aumentaron los casos de muerte por mano propia: si los ocurridos en 1882 fueron 83 (alrededor de 28,62 cada 100.000 hab.), en 1895 la cantidad de casos fue 182 (26,92 cada 100.000 hab.), lo que equivale a un incremento absoluto del 119\%, proporcional a la evolución demográfica de la ciudad (véase Tabla 3 en Anexo). En este sentido, el demógrafo Francisco Latzina (1896), calculó una tasa promedio de 25,9 suicidios cada 100.000 habitantes para el período 1886-1895. Sin embargo, como ya mencionamos, la percepción, para muchos, era que los suicidios crecían de una forma alarmante, una inquietante epidemia.

La cantidad de expedientes judiciales consultados también muestra una tendencia al aumento de los casos de suicidio proporcional al crecimiento poblacional de la ciudad de Buenos Aires. Para llevar adelante nuestra investigación, hemos relevado 722 expedientes, en los que figuran un total de 724 casos de suicidio (500 consumados y 224 tentativas). ${ }^{142}$ Estos abarcan un período que va desde comienzos de

\footnotetext{
142 Estos fueron consultados en: AGN, FTC - Primera Entrega [en adelante, PE], Legajos: A5, A6, A7, B2, B4, C4, D2, D4, F2, F5, G2, I2, M3, M4, M6, N2, O3, O5, P2, P4, S2, U2, Z2 / W1.

AGN, FTC - Segunda Entrega [en adelante, SE], Legajos: A2, A3, A6, A9, A10, A11, A12, A13, A14, $\mathrm{A} 15, \mathrm{~A} 35, \mathrm{~B} 4$, B6, B8, B9, B11, B12, B13, B14, B15, B16, B17, B18, B20, B22, B23, B24, B25, B26, B27, B28, B29, B30, B32, B33, B34, B40, C2, C7, C10, C12, C15, C16, C18, C19, C21, C22, C23, C24, $\mathrm{C} 25, \mathrm{C} 26, \mathrm{C} 27, \mathrm{C} 28, \mathrm{C} 29, \mathrm{C} 30, \mathrm{C} 32, \mathrm{C} 33, \mathrm{C} 34, \mathrm{C} 35, \mathrm{C} 36, \mathrm{C} 37, \mathrm{C} 38, \mathrm{C} 40, \mathrm{C} 44, \mathrm{C} 46, \mathrm{C} 47, \mathrm{C} 87, \mathrm{D} 2, \mathrm{D} 4$, D6, D7, D9, D11, D14, D17, D18, D19, D21, D22, D24, D83, E3, E4, E5, E8, E9, E10, E13, E14, E15, F3, F5, F7, F8, F9, F10, F13, F17, F18, F19, F21, F23, F24, G4, G6, G8, G11, G12, G13, G14, G15, G17, G18, G20, G21, G22, G24, G25, G26, G29, G30, G31, G32, G35, G36, G 37, G38, G39, G40, G41, G43, H2, H6, H7, I2, I3, I4A, I5, J3, J5, J6A, J10, K1, K3, K4, L1A, L2, L6, L8, L9, L11A, L12A,
} 
la década de 1860 hasta 1888 . Entre 1859 y 1869, contamos con apenas 11 expedientes; a partir de 1870 y hasta 1879 identificamos 131 sumarios; por otra parte, entre $1880 \mathrm{y}$ 1888 la cantidad de casos disponibles se dispara: en total hallamos 582 actos suicidas (véase Tabla 4 en Anexo). Vale aclarar que no podemos asegurar que los documentos relevados constituyan la cantidad original de expedientes elaborados por las instituciones policiales y judiciales, mucho menos, que se trate de la cantidad efectiva de suicidios ocurridos en dichos períodos. Por otra parte, tenemos algunos indicios de que los sumarios judiciales relevados representan una parte significativa de los suicidios registrados por la policía, sobre todo para la década de 1880. En primer lugar, si comparamos la cantidad de casos anuales que figuran en las estadísticas de dicho período con el número de sumarios correspondientes a cada año, podremos observar que los valores se encuentran cercanos entre sí. Asimismo, la suma total de los casos de suicidio relevados a partir de los expedientes representa un número equivalente al $85 \%$ de los actos suicidas registrados en las estadísticas oficiales (véase Tabla 5 en Anexo). No contamos con datos estadísticos para los años anteriores a 1881, sin embargo, si comparamos la población estimada para la década de 1860 y 1870, no es extraño que la cantidad de muertes por mano propia registradas sean mucho menores. Sin embargo los números son muy bajos, en especial durante los años sesenta. ${ }^{143}$ Por esta razón, creemos que parte de la documentación se perdió, también consideramos probable que el registro de los casos fuera menos frecuente, dado que era un tema tabú para la sociedad de entonces; las leyes que protegían a los suicidas, desde el derecho civil y penal, fueron posteriores a 1869 y 1877, respectivamente; por lo tanto, es muy probable que la población guardara mayor reserva a la hora de dar a conocer lo sucedido a las autoridades.

L12B, L13A, L13B, L14, L15, L17, L18, L19, L20, L21, L22, L23, L24, L26, L27, L29, L31A, L31B, M4, M10, M11, M14, M15, M16, M17, M18A, M18C, M20, M21, M24, M25, M27, M28, M29, M31, M33, M34, M35, M37, M39, M40B, M41, M42, M43B, M44, N1, N2, N3, N4, N5, N6, N7, O2, O3, O7, P8, P9, P12B, P14, P18, P19, P20, P21, P22, P23, P25, P27, P28, P29B, P30, P31, P32, P33, P34, P35, P37, P39, P40, R2, R3, R9, R10, R16, R18, R19, R20, R21, R22, R23, R26, R27, R28, R29, R30, R34, R35, R36, R37, R38, S2, S4A, S7, S8, S9, S10, S15, S17, S19, S20, S21, S23, S24, S28, S30, S31, S34, S36, S37, S38, S39, S41, S44, S46, S49, S50, T3, T5, T9, T10, T11, T14, U2, U4, V1, V4, V5, V6, V8, V10, V11, V13, V14, V16A, V17, V18, V19, W1, W2, Z3.

Quiero agradecer en forma especial al equipo de trabajo del Departamento de Documentos Escritos del AGN por atender mis consultas y facilitar el acceso a la documentación necesaria para llevar adelante esta investigación.

143 Por ejemplo, en 1868, con una población de alrededor de 150.000 habitantes, hemos encontrado 3 expedientes de suicidios (1,90 suicidios cada 100.000 hab.), doce años después, en 1880, hallamos 29 sumarios, cuando Buenos Aires contaba con 290.000 habitantes (10 suicidios cada 100.000 hab.). De acuerdo con estos valores, la población se había duplicado y la tasa de suicidios se había multiplicado por cinco. 
Por otra parte, como ya mencionamos en capítulos anteriores, no nos proponemos estudiar las tasas de suicidio y las causas de sus fluctuaciones en el tiempo. Nuestro objetivo es la exploración de las representaciones del suicidio durante el último tercio del siglo XIX en la ciudad de Buenos Aires. Así, en este capítulo, partiremos de los datos de las estadísticas y los relevados en los expedientes judiciales con el objetivo de identificar aquello que resultaba verosímil para los contemporáneos. Dicho de otro modo: ¿qué características volvían verosímil un acto suicida? ¿Cómo imaginaban al sujeto que lo llevaba adelante? ¿Cuáles eran las circunstancias que resultaban más creíbles sobre el medio utilizado y el espacio donde sucedían los suicidios? ¿Qué variables, condicionantes, motivos, causas o factores daban sentido a las acciones de los suicidas? De todas estas cuestiones, nos interesa, en particular, la última, ya que la construcción de los distintos tipos narrativos se articulaba en base a diferentes explicaciones verosímiles que tenían sentido para los sujetos históricos que estudiamos. Por esta razón, dedicaremos una parte importante de este capítulo al análisis de las llamadas "causas determinantes", en especial, a la más ambigua de ellas: el cansancio / aburrimiento / hastío de la vida (también denominado por los intelectuales como “taedium vitae").

\subsection{Los suicidas a la luz de las estadísticas}

Si tomamos en cuenta los datos contabilizados por la policía entre 1881 y 1910, en cuanto al sexo de los que se quitaban la vida, de los 5.800 episodios (suicidios y tentativas), en más de 4.000 (71,25\%), se trataba de muertes por mano propia de varones y, en 1.681 (28,75\%), de mujeres (véase Tabla 6 en Anexo). Esto no resulta un hecho sorprendente. La ciudad de Buenos Aires tenía un alto índice de masculinidad y la mayoría de los inmigrantes eran hombres, lo que acentuaba la desproporción de ambos sexos en la población; es decir, la cantidad de suicidios y tentativas, masculino y femenino, era proporcional a la cantidad de varones y mujeres existentes. La misma proporción entre los sexos, la encontramos en los sumarios judiciales analizados. En la muestra total (724 suicidios, 500 consumados y 224 tentativas), hallamos 566 hombres (78,18\%) y 158 mujeres (21,82\%) (véase Tabla 7 en Anexo). De acuerdo con estos datos, Amílcar Luzuriaga (1909: 54), discípulo de Francisco de Veyga, estimaba que 
por cada 100 suicidas de sexo femenino había 300 varones que ponían fin a su vida. ${ }^{144}$ Para este estudiante de medicina, la "obligación de aportar a la sociedad el fruto de su trabajo" ponía a los hombres en una situación más difícil que a las mujeres. Sobre este punto había mayor acuerdo entre los intelectuales. Latzina (1896: 13), por ejemplo, también destacaba las exigencias que los varones debían enfrentar; las mujeres, por otra parte, contaban con dones naturales para enfrentar los desafíos y desengaños:

Las grandes diferencias entre uno y otro sexo, en cuanto a los suicidios respecta, se explican por las dificultades de la vida que para el hombre son mayores que para la mujer. Esta opone a los contrastes de la vida la resignación, la mayor de todas las virtudes femeninas; el hombre no tiene más que sus ímpetus, y si estos se quiebran, si quedan burladas sus ambiciones y codicias, no se resigna, sino que desespera de su suerte. La frecuencia de los suicidios femeninos aumentará a medida que las mujeres se emancipen de las tradiciones domésticas de antaño, y aumente la competencia económica entre ambos sexos.

En síntesis, desde la perspectiva de la elite intelectual, el lugar de los hombres en el mundo laboral los exponía a mayores presiones y preocupaciones, más intensas si sus deseos de amasar fortuna no tenían límites.

Teniendo en cuenta el alto índice de masculinidad ya mencionado, y el hecho de que la mayoría de los inmigrantes eran hombres solos, no es extraño que la mayoría de los suicidas fueran solteros $(3.366,58,4 \%)$, antes que casados $(34,73 \%)$, o viudos (6,87\%) (véase Tabla 8 en Anexo). En la mayoría de los suicidios registrados en los sumarios, también encontramos una proporción mayor de personas solteras, 366 (casi la mitad, 50,55\%), ya se trate de hombres (297 de 566), como de mujeres (69 de 158) (véase Tabla 9 en Anexo). Los casados y los viudos representaban el 25,41\% y el

\footnotetext{
${ }^{144} \mathrm{Al}$ igual que José Ingenieros, Francisco de Veyga fue discípulo de José María Ramos Mejía y uno de los principales representantes de la criminología positivista de entre siglos en Buenos Aires. Además de su labor académica, tuvo una activa participación como médico militar (para alcanzar su grado realizó sus prácticas en la Armada), llegando a General. De Veyga dirigió a un estudiante de la Facultad de Ciencias Médicas, P. Amílcar Luzuriaga, quien, en 1909, defendió su tesis para graduarse de Doctor en Medicina, que condensó varias de las ideas hasta aquí trabajadas y agregó otros elementos nuevos. Cabe mencionar que, antes de terminar sus estudios, Luzuriaga había sido alumno de la Escuela de Aplicación de Sanidad Militar y también había hecho prácticas como interno del Hospital Militar entre 1903 y 1909, período en el cual De Veyga, además de ser su profesor de Medicina Legal, era Inspector general de Sanidad del Ejército. Tras siete años de estudio, Luzuriaga, finalmente, se graduó y defendió su tesis. En su estudio sobre el suicidio en Buenos Aires, destacaba junto a los problemas morales también los económicos que atravesaba la sociedad en el mundo civilizado. Los habitantes, además de sufrir los efectos de la lucha por la vida, las pasiones y aspiraciones, estaban expuestos a las influencias de la corrupción, el alcoholismo y el juego, que enfermaban el alma. Junto a estos factores, Luzuriaga identificaba también el peso que tenía la aglomeración de la población en las ciudades y los males que venían como consecuencia (hacinamiento y miseria). Estos también eran responsables de generar "enfermedades morales", como el suicidio.
} 
3,31\%, respectivamente. Tanto para Méndez Casariego (1888: 55-56), como para Latzina, el matrimonio y la vida en familia tenían un efecto protector:

Como asociación duradera entre dos personas de distinto sexo, tiene el matrimonio la fuerza de servir de sostén en la lucha por la vida, de moderar las pasiones, de regularizar el género de vida, de aumentar la aptitud del hombre para el trabajo y, como base de la familia, es el matrimonio un medio eficaz para el perfeccionamiento de los hombres y la elevación del nivel general de cultura (LATZINA, 1896: 16).

Por otra parte, si bien el mayor número estaba entre los solteros, para Luzuriaga (1909: 55) había que tener en cuenta que la población célibe era mayor que la que estaba casada o había enviudado. En este sentido, este estudiante de medicina relativizaba el poder protector del matrimonio. Si bien, por un lado, el soltero, por su libertad, estaba expuesto al juego, la bebida ("del alcoholismo se espera todo") y una vida licenciosa (producto de las pasiones sin freno), el casado, por el otro, sufría la presión de atender las necesidades de su esposa e hijos (LUZURIAGA, 1909: 57).

De modo similar a lo que sucedía con el estado civil, la franja etaria en la que ocurría la mayoría de los suicidios (entre los 20 y los 25 años), se correspondía con las características de la población de la ciudad de Buenos Aires, compuesta, en su mayor parte, por individuos jóvenes (véase Tabla 12 en Anexo). A partir de los 25 años, las cifras absolutas descendían, sobre todo luego de los 40 (véase Tabla 10 en Anexo). Con respecto a las franjas etarias en los sumarios judiciales relevados, en la mayoría de los casos $(51,52 \%)$, los que se quitaban la vida tenían entre 20 y 40 años, es decir, eran más frecuentes entre la población joven y activa (véase Tabla 11 en Anexo). Esta pauta general variaba en hombres y mujeres. Entre estas últimas, la mayor cantidad de suicidios ocurrió entre los 16 y los 20 años y con menos frecuencia en las otras franjas etarias, mientras que en los varones la mayor cantidad de casos estuvo concentrada entre los 20 y los 30 años. En ambos sexos, la tendencia fue al descenso entre los $30 \mathrm{y}$ los 40 años, y de crecimiento a partir de esa edad en los hombres, algo que también está registrado en las estadísticas. Según Latzina, los frecuentes suicidios durante la adolescencia y el tránsito a la madurez (desde los 15 hasta los 30 años) eran causados por el temperamento romántico, la carencia de experiencia, "pero sobre todo, aquel fruto de una educación descabellada, de la lectura de novelas estrafalarias, y de la vista de espectáculos teatrales tontos e inmorales" (LATZINA, 1896: 13 y 14). En el caso de los mayores de 60 años, sus actos suicidas eran impulsados por los padecimientos del 
cuerpo en el trayecto final de la vida. Según Fermín Rodríguez, la etapa que iba de los 26 a los 30 años era la más calma. Los más fuertes y aptos en la lucha por la vida, para ese momento, habían consolidado la formación de un hogar bien constituido y cierta estabilidad material. Así, en esos años, hombres y mujeres encontraban el punto medio entre las emociones exaltadas de la juventud y los padecimientos de la vejez. Como consecuencia de esto último, estaban lejos del alcohol y del suicidio (RODRÍGUEZ, 1904: 17). Amílcar Luzuriaga, por otra parte, sostenía que la mayoría de los suicidios, de acuerdo con las cifras disponibles para la ciudad de Buenos Aires, en 1909, ocurría entre los 20 y 40 años. Para el autor, en esos veinte años, las personas tenían proyectos ambiciosos y, al mismo tiempo, eran más vulnerables a las decepciones que cuando ya habían alcanzado experiencia (aplacando las ambiciones desmedidas) y una situación más ventajosa (LUZURIAGA, 1909: 60). Dejando de lado si se trataba de una u otra franja etaria, lo cierto es que los datos que manejaban los médicos de la época indicaban que los casos ocurrían entre personas jóvenes y en edad productiva. Como contrapartida, era muy infrecuente que los menores de 10 años se suicidaran, sin embargo, cuando sucedía era considerado un indicador de las condiciones de vida inadecuadas al interior del grupo familiar; en estos entornos, los pequeños estaban expuestos a la degeneración y, en algunos casos, a quitarse la vida. En este sentido, el suicidio de los niños llamaba la atención de los contemporáneos, eran hechos que manifestaban la precoz aparición de las pasiones de los adultos (MÉNDEZ CASARIEGO, 1888: 53).

Con respecto a la división de los casos por grupo étnico, en el $25,14 \%$ de los sumarios consultados, los suicidas fueron argentinos (182 casos). El resto de los actos suicidas registrados fue llevado adelante, en orden de importancia, por los principales colectivos de inmigrantes europeos: italianos (26,24\%) y españoles (11,74\%), respectivamente (véase Tabla 14 en Anexo). Los inmigrantes europeos representaban alrededor del 56,22\% (407 suicidios). En los anuarios estadísticos, encontramos un panorama similar: 33,29\% de los suicidios ocurridos entre 1882 y 1910 fueron llevados a cabo por nativos, mientras que los extranjeros representaron el 66,71\% (véase Tabla 13 en Anexo). Estos datos no son llamativos, teniendo en cuenta que los inmigrantes, como ya mencionamos, eran el principal aporte al crecimiento demográfico de la ciudad de Buenos Aires. Según Latzina, la frecuencia de los suicidios, entre 1881 y 1895, era similar entre alemanes, franceses e ingleses y un poco menos entre españoles y más todavía entre italianos, si se tomaba en cuenta la representación proporcional de 
cada grupo étnico en la población total de la ciudad. Al mismo tiempo, no es extraño que los argentinos tuvieran las frecuencias de suicidios más bajas, ya que tenían la proporción más alta de niños, que son los que menos y muy raramente se suicidan (LATZINA, 1896: 15). Para Luzuriaga (que estudió las cifras entre 1890 y 1908), la cantidad de inmigrantes suicidas estaba en proporción directa con el número de extranjeros en la capital. Así, como la mayoría de los inmigrantes eran italianos y españoles, la mayor parte de los suicidas era de esas nacionalidades. Siguiendo dicha tendencia, les seguían, en número, franceses, alemanes e ingleses. Es decir, para Luzuriaga, no había una inclinación mayor de los extranjeros hacia el suicidio (LUZURIAGA, 1909: 55). Estos datos cuestionaban otras interpretaciones, como la de Víctor Arreguine, quien consideraba que la falta de homogeneidad e integración tendían a promover el aumento de los suicidios, o de quienes, en línea con el contexto finisecular y del centenario, miraban con desconfianza a los inmigrantes, a quienes consideraban más proclives al delito y a la locura y, por ello, eran un peligro para la constitución de la nación.

Además de las características sexuales, étnicas y etarias de los suicidas, los casos eran clasificados siguiendo otros criterios. Por ejemplo, la policía los catalogaba, de acuerdo a la fortuna de los individuos, en tres clases: elevada, media y humilde. La mayoría de los casos de suicidio correspondía a las clases humildes y, en segundo lugar, a la media. Latzina (1896: 11) destacaba que el criterio para distinguir los límites entre una y otra de estas categorías era poco preciso y difuso. De acuerdo con las cifras relevadas a partir de los sumarios judiciales, la mayoría de los suicidios ocurría entre trabajadores manuales (77), artesanos (71), comerciantes y propietarios de talleres (66), trabajadores especializados en un oficio determinado (59), desempleados (52), empleados domésticos (51), empleados de comercio (47), empleados (30), funcionarios y profesionales (18) (véase Tabla 15 en Anexo). Así, en el 49,3\% (357 casos) eran individuos de las clases trabajadoras (peones, jornaleros, empleados domésticos, trabajadores artesanales en relación de dependencia o por cuenta propia, empleados de comercio y desempleados), mientras que los individuos de los sectores medios (comerciantes, industriales, pequeños empresarios rurales, empleados de cuello blanco, funcionarios $\mathrm{y}$ profesionales) $\mathrm{y}$ los rentistas $\mathrm{y} / \mathrm{o}$ empresarios agropecuarios representaron, en forma respectiva, el 16,6\% (120 casos) y el 1,1\% (8 casos). 
Además de las características sexuales, étnicas, etarias, el estado civil y la ocupación de los suicidas, los casos eran clasificados siguiendo otros criterios. Por ejemplo, era tenido en cuenta el grado de instrucción de los que se quitaban la vida. En este sentido, se consideraba que la mayoría de los suicidas sabía leer y escribir (entre 1881 y 1895, el 83\% habían sido alfabetos) (LATZINA, 1896: 14). Según Méndez Casariego (1888: 57), esto indicaba que el suicidio era más frecuente entre la gente culta; Latzina, en cambio, veía a los suicidas como "individuos desequilibrados", abatidos moralmente y enfermos, no eran las personas de más inteligencia, por el contrario eran sujetos "vulgares"; así, destacaba que el grado de alfabetización no era sinónimo de desarrollo cultural, mental y moral; la mayoría de los alfabetizados eran también ignorantes, no poseían una mente cultivada, sólo una habilidad limitada de lecto-escritura. Entre otros datos sobre los suicidios también era relevada la dirección de los vientos, la religión de los suicidas, los medios empleados para darse muerte, las “causas determinantes" y los lugares donde sucedían los hechos.

\subsection{Las formas de la autodestrucción}

Con respecto a los medios empleados para quitarse la vida de forma más frecuente en la Ciudad de Buenos Aires, los datos que hemos relevado están detallados en la Tabla 16 (disponible en el Anexo). El uso de armas de fuego y el envenenamiento eran las maneras más habituales para suicidarse en el período que estudiamos $(44,61 \% \mathrm{y}$ $26,22 \%$ de los casos, respectivamente). Otras alternativas comunes eran el ahorcamiento por suspensión $(5,50 \%)$ y el lesionarse con objetos cortantes (cuchillos, navajas de afeitar, etc.) en el 11,56\% de los casos. En varias oportunidades fueron encontrados en plazas y parques, por ejemplo, en Palermo, suicidas colgados de los árboles o heridos. Menos común era morir aplastado por vehículos (trenes y tranvías, por ejemplo) o asfixiado por tirarse al río (2,23\%) o a los pozos de agua (1,39\%). En el conjunto de los 724 casos estudiados, el medio más utilizado para quitarse la vida fue también el arma de fuego $(352,48,62 \%) \mathrm{y}$, en segundo lugar, el envenenamiento $(154,21,27 \%)$. Los venenos eran utilizados de forma más habitual por individuos del género femenino, los hombres, por su parte, recurrían, con más frecuencia, al revólver u otro tipo de arma de fuego, y, en segundo lugar, a los objetos cortantes (véase Tabla 17 en Anexo).

En algunos casos, los medios utilizados para poner fin a la vida se relacionaban 
con los objetos de la vida cotidiana de los habitantes en el espacio urbano. Éste era el caso de los venenos utilizados, como la llamada "sal de limón" (ácido oxálico, utilizado por las lavanderas para sacar manchas) o las cerillas (fabricadas usando fósforo blanco, que era tóxico), o los objetos cortantes (de acuerdo al oficio del suicida, el zapatero recurría a su trincheta, el carnicero al cuchillo, etc.), como cuchillos, navajas de afeitar, etc. Lo mismo puede decirse de los que se tiraban a los pozos de las casas, de donde se sacaba agua, más común entre las mujeres. La modernización, además, amplió la gama de químicos, sustancias venenosas y drogas disponibles entre la población; y la aparición del ferrocarril proporcionó un nuevo medio para quitarse la vida, considerado propio de aquellos perseguidos por la pobreza, por lo fácil y barato que resultaba darse muerte de ese modo.

Según Méndez Casariego (1888: 9-50), la predilección por el arma de fuego no era algo general; la mayoría de las estadísticas de otros países las colocaban en tercer lugar. ${ }^{145}$ Según Latzina, esto tenía una explicación clara: “Como se ve, en Buenos Aires predomina entre los medios que se emplean para cometer el suicidio, el arma de fuego; en Europa la estrangulación y la sumersión. La cosa se explica. ¿Quién no tiene en Buenos Aires un revólver?" (LATZINA, 1896: 20). Las armas de fuego todavía estaban muy presentes en una sociedad donde las luchas facciosas continuaban (por ejemplo, el enfrentamiento ocurrido en 1880 por la cuestión de la federalización de Buenos Aires, o, más adelante, la Revolución del Parque y los levantamientos armados posteriores encabezados por los radicales) y muchos individuos hacían uso de la violencia para resolver sus conflictos. En estas circunstancias, no es algo sorprendente que las armas de fuego fueran las más utilizadas por quienes decidían quitarse la vida. La presencia cotidiana de éstas entre los habitantes despertaba preocupación entre los intelectuales y médicos, ya que atentaban contra el monopolio de la coerción por parte del estado y la policía y generaba las condiciones para los crímenes sangrientos, además de ser la causa de muchos accidentes, en los que jóvenes y niños salían heridos o morían. En este sentido, el predominio de éstas en los suicidios de la ciudad de Buenos Aires, según el médico Amílcar Luzuriaga (1909: 62), se debía a que su difusión la ponía "al alcance de todos", aunque destacaba que, entre las clases populares, "la gente baja", era más

\footnotetext{
145 Según BIALET MASSE (1885: 232), titular de la cátedra de Medicina Legal en la Universidad de Córdoba, los franceses no usaban los mismos medios que los empleados en Argentina. Mientras que en Francia era más común la muerte como consecuencia de la asfixia por suspensión o por sumersión, en el Río de la Plata era más frecuente la muerte por mano propia, causada por armas de fuego, objetos cortantes y envenenamiento, "más propios de nuestro carácter y costumbres".
} 
frecuente el uso de objetos cortantes que entre la "gente acomodada".

Al mismo tiempo, en la elección del medio y su interpretación había representaciones relacionadas con las identidades de género de los integrantes de la sociedad de la época. La forma con que ponían fin a la vida tenía un significado, eran gestos relacionados con lo que los contemporáneos entendían como atributos de lo masculino y lo femenino. En este sentido, arrojarse a los pozos de agua, según Luzuriaga (1909: 78), a comienzos del siglo XX, era un modo raro de suicidarse, éste estaba asociado con las mujeres que habían sido deshonradas. Al ser engañadas, sobrevenía un ataque de desesperación y, lamentando la honra perdida, se tiraban al pozo. Por otra parte, el uso del arma de fuego dotaba al que la utilizaba de un carácter viril, valiente y decidido. No era el método de un cobarde o de alguien que quería llamar la atención de sus familiares, de sus amigos o de los miembros de la comunidad. Se necesitaba de firmeza y vigor para darse un disparo con un revólver. Por todas estas razones, en general, el uso de armas de fuego solía estar asociado al género masculino, al que se lo relacionaba con la fuerza y la voluntad. Amílcar Luzuriaga, en su tesis de 1909, señalaba:

Esto es en lo que se refiere al hombre. La mujer más débil, de menos valor que él, tiene siempre aversión por las armas de fuego, y prefiere buscar un medio menos violento y más al alcance de su sexo, recurriendo a los tóxicos o al legendario brasero, que coloca en una pieza cerrada (LUZURIAGA, 1909: 62-63).

Los objetos cortantes compartían similar vinculación con el valor y la tenacidad. Al mismo tiempo, eran asociados con el mundo del delito: "el suicida por arma blanca, comete generalmente este acto, después de haber manchado el arma con la sangre de otra víctima asesinada por él, y se mata por eludir la acción judicial" (LUZURIAGA, 1909: 78). Al mismo tiempo, tanto los cuchillos, navajas y demás objetos cortantes compartían con las armas de fuego los efectos que dejaban en el cuerpo y la escena que creaban. En ambos casos eran muertes sangrientas, sucias, en la que parte de los fluidos, los sesos o las entrañas del difunto se esparcían a su alrededor o quedaban desparramados en el piso. El cuerpo o el rostro quedaban dañados y perdían su belleza, una de las cualidades que eran asociadas con lo femenino. El envenenamiento, la otra forma más común de poner fin a la vida, no tenía estas consecuencias, permitiendo conservar un cadáver angelical y bello. Por esta razón, era asociado con las mujeres, 
aunque muchas usaban también armas de fuego. En general, el sentido común interpretaba que las jóvenes románticas y los cansados/as de la vida se quitaban la vida por medio de los tóxicos. El envenenamiento era considerado el medio de personas débiles o afeminadas que no tenían la firmeza o el valor para utilizar un medio letal. Era presentado también como la forma más efectiva para llamar la atención por parte de aquellos que habían sufrido un desengaño amoroso o sufrían de celos, esa terrible enfermedad, ya que ampliaba considerablemente la posibilidad de ser salvado por alguien, en general el médico más cercano:

A estos [fósforos y otras sustancias tóxicas] corresponde el mayor número de tentativas, pues los dolores que causan se encargan de revelar muy pronto el secreto de la víctima, que es puesta muchas veces fuera de peligro mediante contravenenos oportunos. Es un medio empleado frecuentemente por la mujer (LUZURIAGA, 1909: 78).

\subsection{Un lugar para morir}

También hemos considerado relevante registrar los lugares donde sucedían los hechos. Con respecto a esto último, de acuerdo con los datos extraídos de la documentación judicial, predominan los episodios ocurridos en los domicilios particulares de los que se quitaban la vida (351 casos, 48,48\%), aunque también hemos registrado sucesos en la vía pública (14,78\%); en los lugares de trabajo $(8,7 \%)$; en espacios poco transitados $(6,22 \%)$, tales como los terrenos baldíos o entre las lápidas y bóvedas de los cementerios; alrededor de un $6 \%$ en espacios de sociabilidad (comercios, cafés, prostíbulos, etc.) y un 5,6\% en casas de familiares y amigos (véase Tabla 18 en Anexo). Sobre el lugar donde tenían lugar los actos suicidas, Luzuriaga (1909: 79) destacaba algo similar a lo observado en los sumarios judiciales:

[El suicida] Lo hace casi siempre en su casa o en la oficina donde trabaja, y las menos de las veces en la vía pública. La moda de suicidarse en coche, está hoy muy generalizada y las crónicas policiales has registrado meses en que han habido tres y hasta cuatro suicidios ejecutados de esta manera.

Las casas de hospedaje, suelen también ser buscadas por estos sujetos. Toman una pieza, y se dan orden de que no se les moleste, luego cierran la puerta y se entregan a la ejecución del plan.

Transcurre gran parte del día siguiente y el patrón entrando en sospechas, llama a la policía que violentando la puerta encuentra al 
cliente hecho cadáver.

Palermo por su soledad, es teatro habitual de estos sucesos y entre sus follajes permanecen muchas veces los cadáveres ocultos por varios días.

Estos datos ponen en evidencia que la mayoría de los actos suicidas tenían lugar en espacios donde se pudiera encontrar una mayor intimidad, algo difícil para los que vivían en pensiones y conventillos. El hecho de que los lugares de trabajo estén en tercer lugar apunta en la misma dirección; muchas veces, los trabajadores desarrollaban su jornada laboral, comían y dormían en los mismos espacios, es decir, era el ámbito de mayor privacidad al que podían acceder, en primera instancia. Otros, para poder terminar con su vida en soledad, se dirigían a los lugares menos concurridos, plazas y parques, por las noches, algún área del cementerio, o en descampados alejados de sus domicilios.

\subsection{Las "causas determinantes"}

Como mencionamos antes, en los sumarios, la policía de la época registraba, entre otros datos relacionados con el suicida, la causa principal que lo había llevado a quitarse la vida. A partir de esta información, se elaboraban estadísticas sobre las "causas determinantes" de los suicidios en la ciudad de Buenos Aires. Por ejemplo, en el "Anuario Estadístico de la Ciudad de Buenos Aires" del año 1891, que recopila los datos y la evolución de los suicidios durante la década de 1880, hallamos información sobre edad, sexo, estado civil, nacionalidad, etc. de los suicidas, y también un cuadro con las causas identificadas: aflicción, amores contrariados, celos, demencia, disgustos de familia, ebriedad, hastío de la vida, malos negocios, malos tratamientos, padecimientos físicos, pobreza, remordimiento. Dejando de lado las categorías más ambiguas y poco claras ("remordimiento", "aflicción" y "celos"), el resto de las denominaciones continuó en uso dentro de las tipologías que aparecieron en los textos y recopilaciones estadísticas sobre el tema (por ejemplo, Anuario (1906: 242), Luzuriaga (1909: 75) y Lancelotti (1914: 109). Los datos correspondientes a la frecuencia de cada "causa determinante", y su evolución, según las estadísticas de la época, puede encontrarse en la Tabla 19 (en Anexo). No debía resultar sencillo encontrar una tipología que contemplara todas las situaciones que podían llevar a un individuo a 
quitarse la vida. En este sentido, lo primero que se destaca al observar la Tabla 19 es la diversidad de explicaciones que podían ser enunciadas en los interrogatorios llevados adelante por los agentes de policía. Al revisar los sumarios judiciales sobre casos de suicidio en la ciudad de Buenos Aires durante la segunda mitad del siglo XIX, también identificamos un conjunto heterogéneo de explicaciones verosímiles: patologías mentales (103, 14,23\%); pobreza (53, 7,32\%); conflictos de pareja (40, 5,52\%); conflictos y asuntos de familia $(39,5,39)$; enfermedad o padecimientos físicos $(38$, 5,25\%); cansancio / aburrimiento / hastío de la vida (35,4,83\%); mal estado de los negocios (28, 3,87\%); desengaño amoroso (27, 3,73\%); alcoholismo (25, 3,45\%); asuntos de reputación $(23,3,18 \%)$; amores contrariados $(17,2,35 \%)$; muerte de un familiar (14, 1,93\%) (véase Tabla 20 en Anexo). ${ }^{146}$

De acuerdo con los datos estadísticos sobre la Ciudad de Buenos Aires, la representación de cada explicación verosímil varió dentro del conjunto de causas determinantes (Tabla 19). Así, entre 1884 y 1889, las mencionadas con más frecuencia en los interrogatorios fueron, en orden descendente: demencia (72 casos, 14,6\%); disgustos de familia (60 casos, 12,17\%); amores contrariados (44, 8,92\%); padecimientos físicos $(37,7,51 \%)$; hastío de la vida $(34,6,9 \%)$; pobreza $(27,5,48 \%)$; malos negocios $(19,3,85 \%)$. Durante la década de 1890, en cambio, éstas fueron: disgustos de familia $(315,17,2 \%)$, hastío de la vida $(210,11,47 \%)$, padecimientos físicos $(177,9,67 \%)$, demencia $(141,7,7 \%)$, pobreza $(119,6,5 \%)$, amores contrariados (114, 6,23\%) malos negocios (66, 3,6\%) (Tabla 19 en Anexo). Por último, desde 1900 hasta 1909, las que más se repitieron fueron: disgustos de familia $(663,20,43 \%)$; padecimientos físicos (582, 17,94\%); hastío de la vida (447, 13,78\%); amores contrariados (188, 5,79\%); demencia (161, 4,96\%); pobreza (125, 3,85\%); malos negocios $(71,2,19 \%)$. Si comparamos los datos entre las tres décadas, podemos afirmar que los casos de demencia reportados fueron cada vez menos frecuentes y que, por el contrario, los que mencionaban conflictos familiares aumentaron; al mismo tiempo, crecieron los que manifestaban sufrir dolores en sus cuerpos o los efectos de enfermedades, al igual que los que expresaban estar hastiados de la vida. La pobreza,

\footnotetext{
${ }^{146}$ Las variaciones que observamos al comparar los datos de los sumarios judiciales y los valores de los anuarios estadísticos sobre las causas determinantes se explican, en buena medida, a partir de las diferencias entre los criterios de clasificación de la policía, que no conocemos con precisión, y los utilizados por nosotros para diferenciar los tipos narrativos. Por ejemplo, es probable que muchos conflictos de pareja fueran catalogados como disgustos de familia. Al mismo tiempo, los desengaños amorosos eran incluidos entre los amores contrariados (aunque, en los relatos, hacían referencia a situaciones distintas).
} 
los amores contrariados y los malos negocios, con variaciones, mantuvieron una importancia relativa similar entre las causas determinantes registradas.

Por otra parte, cabe destacar que una buena parte de los casos registrados en las estadísticas quedaban catalogados dentro de la categoría "causa ignorada", en todas las décadas: el 33\% en la del ochenta, 36\% en los años noventa, y alrededor del $30 \%$ en la primera década del siglo XX. Del mismo modo, en un $24,59 \%$ de los sumarios consultados no se daba explicación de los motivos o variables que habían impulsado al suicida a quitarse la vida. Esto nos da cuenta del grado de reserva a la hora de revelar las razones o los móviles que habían llevado al sujeto a quitarse la vida. Según Méndez Casariego (1888:52): "Muchos motivos de suicidio no han podido ser determinados a consecuencia de la oposición que las familias presentan a suministrar el dato". Desde nuestra perspectiva, el hecho de que la mayoría de los casos quedara dentro del grupo “sin especificación” da cuenta de que muchas veces no se sabían los motivos o que los deudos no querían revelar aquello que el difunto no había dado a conocer. Como señala Luzuriaga:

Generalmente la justicia, sobre todo cuando el suicida es un individuo caracterizado, no hace hincapié por conocer la causa, evitando a los deudos explicaciones odiosas, y sólo le basta poder comprobar que el cadáver es de un suicida y no de una víctima de un crimen.

Es la razón porque encontramos cifras tan elevadas entre los suicidios por causa ignorada (LUZURIAGA, 1909: 70).

En muchos otros casos, los deudos directamente buscaban ocultar el suicidio en sí:

Luego puede admitirse que todas las cifras, en general, son algo inferiores a lo que en realidad debieran ser, porque no pocos suicidios, por razones que fácilmente se comprenden, se ocultan por los deudos, quienes los hacen pasar por defunciones naturales con la ayuda de un médico amigo de la casa (LATZINA, 1896: 5).

Por otra parte, en los casos que sí eran identificados como suicidas, Luzuriaga (1909) destacaba que los familiares siempre trataban de "mejorar la situación del muerto"; por otra parte, no se podía confiar en los escritos dejados por los suicidas, ya que muchas veces también buscaban ocultar la verdad. Incluso, el que sobrevivía luego de una tentativa frustrada, no sería capaz de brindar muchos detalles: "El mismo [el suicida], después de una tentativa, sería incapaz de determinar la verdadera causa de su 
resolución, pues más de una idea ha perturbado su cerebro, y no podría decir cuál de ellas ha primado" (LUZURIAGA, 1909: 70).

Latzina, por su parte, suponía que muchos de los suicidios, por causa ignorada en realidad, estaban relacionados con la pobreza o con el temor a la miseria (LATZINA, 1896: 19). La realidad de los trabajadores pobres y los desempleados distaba de los estereotipos folletinescos y románticos, asociados con los suicidios por amor, como en el caso ya mencionado del joven Werther, o con los que se suicidaban por la situación de sus negocios, como aparecía expresado en las novelas del Ciclo de la Bolsa. Tras el derrumbe financiero, la ruina y la deshonra estaban a la vuelta de la esquina y el suicidio se presentaba como la única vía de escape. Este fue el caso de los protagonistas de Quilito y Horas de Fiebre. En el caso de Glow, el protagonista de la obra de Julián Martel, éste había especulado con su suicidio y con el del joven Ernesto Lillo (su corredor), a partir de la crisis bursátil, pero terminaba preso de la locura, devorado por la Bolsa en sus sueños, loco para siempre. En el desenlace de "Bursatilidad", publicado por "La Prensa" (11/01/1892), su protagonista, Agaflauta, pensaba lo conveniente que sería quitarse la vida luego de la ruina en que la especulación lo había dejado. La honra del hombre de familia estaba ligada a su accionar en el espacio público. En este sentido, las quiebras o la condena por negocios ilícitos o especulaciones eran situaciones que afectaban gravemente el honor individual y familiar, al punto de que no resultaba inverosímil imaginar que alguien se quitaría la vida en esas situaciones desesperadas.

Los médicos e intelectuales tenían en cuenta estos estereotipos, sin embargo, consideraban que la mayoría de los suicidas eran alienados, si bien también se contemplaba la posibilidad de que hubiera individuos que se suicidaban en un estado anormal y apasionado. Así lo entendía Luzuriaga (1909: 43). Dejando de lado esta pauta general, este estudiante de medicina contemplaba que había un pequeño grupo de casos que comprendía a "quienes han asistido todas las razones para concluir con su vida", aquellos individuos que, con o sin responsabilidad, habían comprometido su honor, el de su familia o el de su patria sin vislumbrar otra alternativa para salvarlo que la muerte. Sin embargo, el autor recalcaba que estos casos eran una minoría. Además de los dementes (que actuaban bajo la pérdida de la razón), quienes eran mayoría eran los "nerviosos" y "apasionados". El enamorado que no era correspondido, el negociante que había fracasado, el desempleado que no encontraba trabajo, quien había sido despedido, tenían alterada su mentalidad a la hora de actuar (LUZURIAGA, 1909: 4243), víctimas del estado pasional. Como hemos visto al analizar las Tablas 19 y 20, entre 
las "causas determinantes", las enfermedades mentales figuraban dentro de una categoría específica (la demencia). Esto deja de manifiesto que para los contemporáneos el suicida no era siempre un alienado mental, en varios casos era identificado como tal y en muchos otros los testigos describían diversas situaciones verosímiles que permitían interpretar el trágico desenlace, sin considerar un demente al que se daba muerte. En este sentido, intelectuales como Francisco Latzina, alejados de las ideas alienistas consideraban que:

En la mayor parte de los suicidios se achaca el motivo, por ignorar el verdadero, a una momentánea alteración de las facultades mentales de la víctima. Pero con esto no se dice nada. [...] En el cerebro sano se origina acaso con la misma frecuencia que en el enfermo, la resolución para el suicidio. Los motivos morales, como el amor propio no satisfecho, la vanidad herida, las pasiones sensuales no correspondidas, los celos o la vergüenza que roen la conciencia, etc. pudieran alegarse para explicar el suicidio como el fruto de la voluntad libre de un cerebro sano, no son más que elementos de la atmósfera moral, y del ambiente social que envuelven al individuo y que le determinan a cometer los actos que comete (LATZINA, 1896: $18)$.

Es síntesis, para los que no estaban más cercanos al paradigma alienista, la línea que separaba a los locos de las personas que tenían sus facultades sanas no estaba del todo clara. En muchos casos, los raptos de locura momentánea eran asociados con el consumo de bebidas alcohólicas. Si bien, la "ebriedad" o el "alcoholismo" eran mencionados como causas separadas, era muy frecuente que aparecieran, en los sumarios, asociados con la enajenación mental por el estado de ausencia de juicio y responsabilidad en las acciones que generaban. Asimismo, la dipsomanía, era un tipo de manía asociada a este comportamiento vicioso.

La categoría más enigmática que hemos encontrado hasta ahora entre las causas determinantes es el llamado "hastío de la vida". De alguna forma, era diferente al resto (demencia, padecimientos físicos, pobreza, malos negocios, etc.), aunque su significado no nos queda claro. Sólo podemos interpretar que nos habla de un intenso estado de desesperación, pero sin estar asociado a un hecho concreto o a una variable particular. Latzina (1896: 19) destacaba que, si bien no era infrecuente la enorme cantidad de causas desconocidas en las estadísticas sobre suicidio, en el caso de la ciudad de Buenos Aires, era llamativo el peso importante que ocupaba el número 
correspondiente al "hastío de la vida". El "cansancio" o el "hastío" de la vida, más allá de las particularidades de cada caso, era interpretado, desde el discurso científico, como un signo de la falta de aptitud para encarar la lucha por la existencia en el desarrollo de la evolución social. José María Ramos Mejía (1896), por ejemplo, entendía esa falta de energía, ese desprecio por la vida (el taedium vitae), como el resultado de la selección natural que iba acabando con los seres de estructura física, mental y moral débil. Desde esta perspectiva, estos eran individuos poco útiles para el organismo social, ya que no podían soportar el alto grado de nerviosismo al que estaban expuestos los que vivían en el mundo civilizado. De acuerdo con el discurso médico, los casos que estaban agrupados bajo el calificativo "cansancio" o "hastío" de la vida, estaban en la frontera que separaba la locura de la razón. Es decir, no se trataba de alienados, sino más bien de locos morales.

No sólo los médicos buscaban respuestas al origen del "cansancio" o del "hastío", también los escritores y literatos, en sus obras, trataban de encontrar alguna interpretación para estos sucesos. Lejos de llegar a una clara comprensión de lo que movía a estos hombres y mujeres a terminar con sus vidas, los contemporáneos ensayaban explicaciones, tratando de empatizar con este estado de ánimo, como en la novela de Eugenio Cambaceres, Sin Rumbo, para lograr entender cómo el entorno, que promovía las pasiones sin freno, era el que llevaba a poner fin a la vida. En el caso de la obra de Cambaceres, Andrés, el personaje principal, era un estanciero rico que no encontraba un rumbo a su existencia y terminaba perdido en el mundo urbano de placeres y vicios, sólo para ver crecer su hastío hacia la vida y su deseo de morir, al tiempo que en su organismo avanzaba la degeneración. Los textos literarios trataban de brindar explicaciones verosímiles al enigma que muchos suicidios despertaban entre los habitantes.

El cansado de la vida, a los ojos de los contemporáneos, negaba directamente que la vida tuviera algún sentido para él. En algunos casos, los contemporáneos identificaban un cierto rencor, una especie de reproche, de quien se suicidaba, hacia el entorno, que no lograba saciar sus expectativas y deseos. Según Fermín Rodríguez (1904), discípulo de Ramos Mejía, estos últimos, los "hastiados de la vida", eran víctimas de un "estado psíquico enfermizo". Su principal característica era la búsqueda de generar dolor y tristeza en los que estaban a su alrededor, los culpables de sus 
desgracias, más allá de si era real o imaginaria su visión de los hechos. ${ }^{147}$ Ya fuera por cansancio o hastío, en ambos casos, los que se quitaban la vida impugnaban el entorno en el que se desenvolvían, eran antisociales. En este sentido, Latzina asociaba los casos de suicidio por "hastío de la vida" con los "disgustos de familia". Según Luzuriaga (1909: 76-77),

Los disgustos de familia, son los que más suicidios dan. Es tan elástico este acápite, que cobija entre sus números, muchos cadáveres de suicidas que debiera colocárselos entre amores contrariados, malos tratamientos, etc., y que el que va a suicidarse, por evitar confidencias que sabe se harán públicas, por un lado, y la justicia, por la causa antedicha, por otro, creen a bien tranzar por la frase sacramental "me mato o se mató por disgustos de familia. [...] El tercer puesto corresponde al hastío de la vida. Bien podríamos repetir aquí lo dicho a propósito de los disgustos de familia. El que no se mata por esta última causa, lo hace por estar cansado de la vida.

Así, tal vez, muchos de los testimonios brindados por los suicidas, en realidad buscaban preservar su reputación personal y la de su grupo familiar y evitar la difusión en público de detalles sobre su vida íntima.

\subsection{Los "cansados de la vida"}

Como ya mencionamos, entre los sumarios judiciales relevados, encontramos 35 actos suicidas que fueron explicados a partir del "cansancio" o "aburrimiento" de vivir, sin brindar mayor información acerca de la "extrema resolución”. ¿Cuáles fueron las circunstancias implícitas en este "hastío de la vida"? ¿Con qué dificultades y problemas se asociaba? ¿Quiénes apelaban a este justificativo para explicar sus acciones? ¿Cuál era la identidad de los “cansados y hastiados de la vida”? Para responder estas inquietudes, además de presentar la información relacionada con los 35 suicidios ya mencionados, incluiremos referencias de otros casos, en especial, de

${ }^{147} \mathrm{Al}$ reflexionar sobre el tema, Rodríguez trajo a colación el caso de un joven internado en el Hospital Rawson tras intentar poner fin a su vida: "Un jovencito de 15 años que había atentado contra su vida, desesperado ante las infidelidades de una actriz de baja ralea, estaba dos días más tarde en un lecho del $\mathrm{H}$. Rawson, rodeado de los diarios y sordamente indignado por que 'mi suicidio', como enfáticamente le llamaba, se hallaba relegado al último rincón de las crónicas policiales. Al hacerle algunas reflexiones, inspiradas en la profunda conmiseración que despertaba, contestome, en términos violentísimos, que era 'suficiente hombre para saber lo que hacía'. Dos meses más tarde no me sorprendía absolutamente la noticia en que se daba cuenta de su participación en un hecho sangriento. Ya era un anti-social completo" (RODRÍGUEZ, 1904: 10). 
aquellos episodios en los que el suicida manifestó estar "cansado de la vida" a los integrantes de su red vincular o a la policía, y cuyos dichos fueron explicados y/o contrastados más tarde con las versiones aportadas por los testigos, durante el interrogatorio, en los que se incluían distintas causas alternativas para interpretar lo sucedido.

Como ya mencionamos, existe un vínculo estrecho entre la desesperación y el quitarse la vida. Para el que no tiene más esperanza, cuando ya no es posible percibir una alternativa para poner fin al dolor, sólo resta "la única solución que es la ausencia de solución”: darse muerte (JANKÉLÉVITCH, 2006: 91-93). En general, en los casos estudiados, este es el sentimiento que transmitían los que se habían herido a sí mismos al ser interrogados. Muchas veces, los suicidas sólo manifestaban un desánimo profundo, un sufrimiento intenso y la ausencia de expectativas en su futuro, sin brindar más información sobre las circunstancias que los afligían. Antes de quitarse la vida, Magdalena Gervais, lavandera y planchadora francesa, dejó un mensaje de este tipo escrito en un cuaderno. Éste fue encontrado después que se tirara a la calle desde la ventana de su habitación (vivía en una casa de inquilinos), el 11 de diciembre de 1866. ${ }^{148}$ En esa hoja dejó anotado: "Hace algunos días que tengo una pena en el corazón que me fuerza a darme la muerte; adiós [ilegible] vida, yo me la quito con pla[ilegible]". En otro papel, que fue encontrado en el mismo libro de notas, escribió: "hace mucho tiempo que me fastidio sobre la tierra y hoy la dejo con placer. Lo poco que tengo lo dono a los dueños de casa”. En estos escritos, sólo hay indicios de la falta de perspectivas que tenía Magdalena de su futuro. Algo similar expresó Fortunato Lazarte (italiano, 30 años, soltero, propietario de un café), en las cartas que fueron encontradas después de su suicidio (se quitó la vida disparándose con un revólver en el pecho en su negocio). El contenido de una de las notas era el siguiente: "Adiós madre querida. Adiós mis amigos. Me quito la vida para dejar de padecer [ilegible] esa vida me es insufrible perdonen mi falta. Adiós. Fortunato Lazarte". ${ }^{149}$ Carmen Vidal, por su parte, sólo declaró estar "cansada de la vida" cuando la interrogaron sobre las razones que la

\footnotetext{
${ }^{148}$ AGN, FTC-PE, Legajo G2, Gervais, Magdalena.

${ }^{149}$ AGN, FTC-SE, Legajo L12B, Lazarte, Fortunato s/suicidio. La segunda carta de Lazarte parecía un testamento y estaba dirigida a uno de sus amigos de confianza. Según la transcripción registrada por el policía, el contenido era el siguiente: "Señor don Juan Tronconi haga como si fuera uno de mi familia. Hay en el banco la suma que esta indicada en la libreta, hágame un regular entierro y después que todo este arreglado manda a mi mamá en Italia y cóbrese su trabajo. Aparte el gran favor que me hace. Adios, Fortunato Lazarte".
} 
llevaron a envenenarse con kerosene el 26 de octubre de $1886 .{ }^{150}$ Así, muchos desesperados sólo comunicaban la pena que sentían en su corazón, el desánimo y el desengaño, pero no los motivos, circunstancias o "causas determinantes" de sus acciones. En varios casos, tanto en las cartas como en las declaraciones de muchos de los que habían sido salvados a tiempo de la muerte, encontramos expresiones tales como "cansado/a de la vida" o sus variantes (por ejemplo, "aburrido de la vida", "hastiado de la vida", "la vida era insoportable", "la vida era demasiado pesada", "la vida era fatigosa", etc.) que también hacían referencia a ese estado de desencanto y desesperanza. ¿Qué significaban estas frases ambiguas? ¿Quiénes las comunicaban? ¿Con qué objetivo?

En algunos casos, la desesperación que expresaban era asociada con los efectos de patologías mentales. Por ejemplo, Agustín Solari (argentino, 22 años, soltero, desocupado), el 4 de diciembre de 1885, al mediodía, manifestó a la policía que había intentado suicidarse por estar cansado de la vida (se había tirado a un pozo de agua, pero fue rescatado a tiempo por su familia y los vecinos). Sin embargo, según el padre de Solari, Agustín tenía sus facultades mentales algo alteradas y había estado internado en el Hospicio de las Mercedes. ${ }^{151}$ Los testigos del suicidio de Juan Martín (francés, 38 años, soltero, albañil), también declararon que este último padecía algún tipo de alienación. ${ }^{152}$ Según Martín, estaba aburrido de vivir, debido a que creía que había individuos que se burlaban de él y lo perseguían. Por esta razón, el 7 de junio de 1884, se hirió con una cuchilla en el vientre. Juan B. Oneto, dueño del almacén y fonda donde tuvieron lugar los hechos, declaró que tanto él como su esposa habían notado, desde hacía varios días, que Martín se comportaba como si sus facultades mentales estuvieran alteradas (por ejemplo, hablaba solo). Sin embargo, no siempre se asociaba la desesperación y el hastío de la vida con el universo de la locura. En el caso de Toribio Gayo (oriental, 39 años, casado, mayoral del servicio de tranvías), dejó una carta en la que expresaba lo siguiente: "Cansado de mi Triste Vida me quito la vida con mi sano juicio; un a Dios a mis amigos. Gayo. No le hecho las culpas a nadies". ${ }^{153}$ Gayo se suicidó por medio de un disparo de pistola que se dio en medio de la calle. Según su esposa, se trataba de la letra y la firma de su marido, pero desconocía los motivos que lo habían llevado a quitarse la vida; por otra parte, también destacó que no había ninguna

\footnotetext{
${ }^{150}$ AGN, FTC-SE, Legajo V16 A, Vidal, Carmen, s/suicidio.

${ }^{151}$ AGN, FTC-SE, Legajo S39, Solari, Agustín, Sumario relativo al suicidio de.

${ }^{152}$ AGN, FTC-SE, Legajo M27, Martín, Juan, su suicidio.

${ }^{153}$ AGN, FTC-SE, Legajo G43, Gallo, Toribio, su suicidio.
} 
clase de conflicto familiar. Así, si bien podía asociarse el sentimiento de desesperanza con los efectos de los distintos tipos de alienación y patologías mentales, en muchas otras narraciones, el individuo que se quitaba la vida no era caracterizado como un loco o alienado.

Si analizamos los casos en los que se daban detalles de las circunstancias que generaban desesperación, cansancio o hastío, encontramos un conjunto de explicaciones, motivos y "causas determinantes" que distaban de ser homogéneas. En algunos relatos, este sentimiento de desesperanza era asociado con los padecimientos de vivir en una situación de pobreza extrema, o el miedo a pasar por dicha experiencia. Por ejemplo, cuando Pedro Gallart (francés, 38 años, 17 años de residencia en el país, soltero), fue encontrado por el guardián de la Plaza de la Recoleta, se apuñalaba con un cortaplumas mientras repetía sin cesar, “ya está, no hay más remedio". Gallart declaró que no tenía trabajo ni recursos para mantenerse y por eso se había hastiado de la vida. ${ }^{154}$ Esto mismo manifestó José Martínez Pérez (español, 21 años, soltero) en la carta que dejó a su hermano. El 7 de noviembre de 1879, por la noche, antes de envenenarse con arsénico en el café donde era alojado, escribió una nota en la que se despedía y explicaba que estaba aburrido de vivir sin los medios para sustentarse. En este caso, como en el anterior, se trataba de un inmigrante sin bienes ni familia, que había visto sus expectativas frustradas, y estaba pasando por una situación material apremiante. ${ }^{155}$ Asimismo, en algunas narraciones, los suicidas también destacaban el malestar generado por la soledad y la falta de vínculos familiares en los que apoyarse. ${ }^{156}$

En otros relatos, el cansancio y el hastío vital eran explicados a partir de los padecimientos físicos de alguna enfermedad. Mercedes Luque (argentina, 24 años, soltera), intentó suicidarse tomando una disolución de fósforos en agua, el 14 de enero de 1886, en la habitación de la casa de inquilinos en la que vivía con su concubino, Ramón Castro, y sus dos hijos, uno de 9 meses y otro de 7 años. Cuando fue interrogada por los motivos de su acto suicida, Luque declaró que estaba cansada de la vida debido a los dolores que sentía. ${ }^{157}$ La misma explicación fue presentada en los relatos de las tentativas de suicidio de Matilde Lazardi y Hermenegilda Charras. Lazardi (argentina, 23 años, soltera), el 9 de julio de 1886, luego de ser encontrada experimentando los

\footnotetext{
${ }^{154}$ AGN, FTC-SE, Legajo G30, Pedro Gallart, tentativa de suicidio.

${ }^{155}$ AGN, FTC-SE, Legajo M16, Martínez Pérez, José.

156 Por ejemplo, AGN, FTC-SE, Legajo P21, Prado, José, por tentativa de suicidio; AGN, FTC-SE, Legajo T14, Torres, Juan, sumario su suicidio.

${ }^{157}$ AGN, FTC-SE, Legajo L24, Luque, Mercedes, por tentativa de suicidio.
} 
efectos de una intoxicación producida por tomar fósforos diluidos en agua, manifestó estar cansada de la vida, ya que sufría de una irritación en su estómago. ${ }^{158}$ Los hermanos de Charras (argentina, 22 años, soltera) explicaron al policía, el $1^{\circ}$ de julio de 1886, que Hermenegilda se había envenenado con arsénico debido al sufrimiento que le provocaba una enfermedad crónica. ${ }^{159}$ No podemos saber con certeza si estos motivos eran esgrimidos para tapar otros asuntos más escandalosos; o, en efecto, los que se suicidaron o se hirieron estaban padeciendo algún tipo de dolor físico o enfermedad. Sin embargo, nos interesa remarcar que estas explicaciones eran enunciadas como creíbles o posibles para revelar la desesperación y el hastío insoportable. Menos dudas quedan al leer el relato del suicidio de Francisco Gutiérrez (español, 42 años, casado, desempleado/cigarrero), que vivía con su concubina, Concepción Guerra (argentina, 44 años, soltera), en la pieza de una casa de inquilinos. Los dos estaban pasando por una situación material precaria, y Francisco, además, padecía de fuertes ataques de tos en los que vomitaba sangre. La noche que se quitó la vida, el 18 de marzo de 1882, alrededor de las 20:00hs, tuvo uno de esos episodios. Según los testigos, se le escuchaba exclamar con frecuencia frases tales como: "que estaba cansado de vivir, que deseaba morir, cuando le venían los vómitos de sangre”. También agregaron que Gutiérrez solía estar ebrio y, algunas veces, mientras estaba embriagado, le habían oído decir "que estaba tan aburrido de sufrir, que valía más quitarse la vida". El policía concluyó que "las causas determinantes del suicidio" habían sido "la extrema pobreza en que vivía y la grave enfermedad de que se hallaba aquejado [tuberculosis]". ${ }^{160}$ Así, en algunas narraciones, la desesperación y el hastío de vivir eran presentados como el desenlace provocado por los padecimientos físicos insoportables.

En otros relatos, los sujetos manifestaban estar hastiados de la vida debido a la frustración de sus expectativas de ascenso social. Los sujetos comunicaban cómo percibían la realidad que les tocaba vivir; ésta no expresaba un futuro promisorio de progresos, sino un presente de fracasos en sus intentos por alcanzar sus principales anhelos y deseos. La historia de José Viano ilustra muy bien este esquema narrativo. ${ }^{161}$ Viano (italiano, 30 años, soltero, comerciante), se quitó la vida el 24 de febrero de 1886, por medio de un veneno que tomó en una habitación del Hotel del Globo. Estaba alojado allí desde el 20 de febrero, día en que llegó a la ciudad de Buenos Aires en

\footnotetext{
${ }^{158}$ AGN, FTC-SE, Legajo L24, Lazardi, Matilde por suicidio.

${ }^{159}$ AGN, FTC-SE, Legajo C36, Charras, Hermenegilda, tentativa de suicidio.

${ }^{160}$ AGN, FTC-SE, Legajo G21, Francisco Vicente Gutiérrez, sumario sobre su suicidio.

${ }^{161}$ AGN, FTC-SE, Legajo V16, Viano, José, suicidio.
} 
vapor. En su nota suicida, explicaba que hacía tiempo que estaba en América del Sur, tratando de probar fortuna sin éxito; por esta razón, estaba cansado y aburrido de la vida. En el mismo escrito dejaba un inventario de sus pertenencias y a quienes las legaba, a modo de testamento. Por último, Viano se despedía deseando la felicidad que él no pudo conseguir y confesando que se había dejado llevar por la desesperación. Fermina Pupo (casada) también expresó este desengaño en sus expectativas, cuando fue interrogada por la policía. El 16 de mayo de 1883, Pupo se envenenó tomando una disolución de fósforos en su domicilio. Al declarar sobre los motivos de su autoagresión, comunicó que lo hizo por estar "cansada de ver que se lo pasaban trabajando todo el año con su marido sin conseguir nunca economizar un poco para ir formando una fortuna". Fermina fue salvada a tiempo al recibir un vomitivo que la hizo expulsar el tóxico que había ingerido.

También encontramos relatos en los que el cansancio / hastío era asociado con conflictos de diverso tipo. Por ejemplo, Fortunata Giménez (argentina, 26 años, soltera, cocinera) estaba enemistada con el dueño de la casa de inquilinos donde vivía, que, al parecer, le insistía para que se marchara de la habitación que ocupaba. ${ }^{162}$ El 9 de mayo de 1887, cuando fue interrogada por los motivos de su intento de suicidio (había tomado una disolución de fósforos en agua), declaró que estaba cansada de los disgustos con la gente de los conventillos donde había vivido. Según uno de los habitantes del mismo inquilinato, siempre amenazaba con quitarse la vida, diciendo "dispone de mi ropa o dadla a los pobres por que yo no vuelvo más".

En otros casos, la explicación del hastío hacia la vida y la desesperación estaba vinculada con asuntos familiares. Estos podían implicar conflictos, como el que tenía Carlos Preda (italiano, 34 años, soltero, mucamo). El 29 de enero de 1888 explicó a la policía que había intentado tirarse a las vías del tren para suicidarse por estar cansado de la vida, luego aclaró que ese estado de desesperación lo habían provocado las peleas que tenía con su cuñada. ${ }^{163}$ Esta declaró que, tras la discusión, Carlos le dijo que se iba a suicidar, pero, como estaba ebrio, no dio importancia a sus palabras. En otros relatos, la muerte de un familiar era presentada como el principio de un proceso de tristeza profundo y desesperante. Juana Baneti de Castro (argentina, 60 años, viuda, rentista) intentó, en reiteradas oportunidades, quitarse la vida después de la muerte de su esposo.

\footnotetext{
${ }^{162}$ AGN, FTC-SE, Legajo G40, Giménez, Fortunata, tentativa de suicidio.

${ }^{163}$ AGN, FTC-SE, Legajo P39, Preda, Carlos, sumario sobre la tentativa de suicidio.
} 
Juana manifestaba con frecuencia estar cansada de la vida. La empleada doméstica de la casa cuidaba de ella para evitar que intentara un nuevo acto suicida. ${ }^{164}$ Catalina Hamoud también estaba atravesando un proceso de duelo cuando intentó suicidarse. El 18 de diciembre de 1887 se encerró en un cuarto sin ventilación con el brasero de carbón encendido. ${ }^{165}$ Fue encontrada a tiempo por el doctor Verdier, médico de Hamoud. Catalina le había entregado a Verdier una carta en la que le comunicaba sus intenciones de suicidarse. Asimismo, en varias oportunidades, Hamoud le había informado a su médico que no podía superar la muerte de su hijo. Desde ese incidente, se sentía hastiada de la vida. Catalina sostenía un retrato de éste con sus manos cuando fue encontrada recostada en un sofá esperando asfixiarse.

Por otra parte, también encontramos historias de cansados de la vida que habían sufrido alguna clase de desengaño amoroso o que tuvieron un conflicto con sus parejas. Gregoria López (argentina, 20 años, casada), se quitó la vida, el 12 de marzo de 1886, al ingerir ácido oxálico en la habitación del conventillo donde residía con su marido. Éste señaló que tenía una buena relación con su esposa y que vivían en armonía. Lo único que resaltó fue que la noche anterior había bailado con otras mujeres de la casa y que esto podría haber despertado los celos de Gregoria. Una de las vecinas de la casa, a su vez, expuso que López le había contado que su esposa manifestaba con frecuencia (desde hacía tres años) estar cansada de vivir. ${ }^{166}$ Los conflictos de pareja también jugaron un papel clave en el desenlace de la historia de Laureana Peralta. ${ }^{167}$ Peralta (argentina, 22 años, viuda), fue encontrada sin vida por la policía, el 10 de abril de 1881, recostada en el piso de su domicilio y largando espuma por la boca; a su lado, había una taza quebrada con fósforos esparcidos a su alrededor. Según la nota que dejó, estaba hastiada de la vida y se sentía muy desgraciada, debido a una pelea que había tenido con Agustín Olivera, su novio. La carta estaba dirigida a este último, quien acusaba a Laureana de serle infiel, a pesar de que ella juraba, por la "hostia sagrada", lo contrario. En el caso de María Fernández (argentina, 18 años, soltera), su pareja, un agente de policía, pensaba abandonarla por su mal carácter. ${ }^{168}$ Éste, asimismo, le había manifestado que estaba agobiado por las peleas que tenían con frecuencia. El 29 de octubre de 1887, María intentó quitarse la vida tomando una disolución de fósforos.

\footnotetext{
${ }^{164}$ AGN, FTC-SE, Legajo B18, Baneti de Castro, Juana, tentativa de suicidio.

${ }^{165}$ AGN, FTC-SE, Legajo H6, Hamoud, Catalina, tentativa de suicidio.

${ }^{166}$ AGN, FTC-SE, Legajo L22, López, Gregoria, su suicidio.

${ }^{167}$ AGN, FTC-SE, Legajo P22, Peralta, Laureana, suicidio.

${ }^{168}$ AGN, FTC-SE, Legajo F19, Fernández, María, tentativa de suicidio.
} 
Cuando fue encontrada, en un principio, no quiso decir los motivos que la habían llevado a envenenarse. Más tarde, luego de que declarara su pareja, Fernández expresó que se había intentado suicidar por estar cansada de la vida, harta de las peleas con su compañero, y porque este pensaba abandonarla.

Otros manifestaban estar cansados de vivir angustiados por el peso de las deudas, las injurias lanzadas en público y otros asuntos que atentaban contra sus reputaciones personales y las de sus grupos familiares. En una nota, encontrada luego de su muerte, Adolfo Lamarque (argentino, 35 años, soltero, abogado), le comunicaba a su hermano que se suicidaba porque se sentía "cansado de pesadumbres" y "agobiado bajo el peso de calumnias viles y horribles"; para Lamarque, en dichas circunstancias, era preferible "buscar el abrigo de la tumba". ${ }^{169}$ En otros relatos, los cansados de la vida habían sufrido la quiebra de sus emprendimientos comerciales / artesanales, o tenían deudas y compromisos a los que no podían responder. Este tipo de situaciones generaban un intenso sentimiento de vergüenza, al imaginar la exposición pública de los hechos. Tomás Dotto, dueño de una peluquería, intentó quitarse la vida en dicho lugar el 30 de septiembre de 1887, utilizando para ello un revólver con el que se provocó una herida en la cabeza. ${ }^{170}$ En un primer momento, Dotto se resistió a dar testimonio, según la policía, y sólo expresó que estaba cansado de la vida. Uno de sus empleados explicó que su patrón tenía problemas con su negocio y, además, padecía de alguna clase de patología mental.

\subsection{El silencio de los desesperados}

Un primer análisis de los datos referidos a los suicidas "cansados de la vida" (35 casos, 23 suicidios consumados y 12 tentativas), tales como género, franja etaria, grupo ocupacional, nacionalidad o estado civil, no nos revela nada llamativo, sobre todo si los comparamos con la información del conjunto de los sumarios analizados. En 26 de estos relatos, los suicidas eran hombres $(74,3 \%)$ y en los 9 restantes mujeres (25,7\%). La mayoría tenía una edad que estaba entre los 20 y los 40 años (21 casos, $60 \%$ ). En cuanto a la nacionalidad, el 82,9\% (29 casos) eran extranjeros, inmigrantes europeos $(74,3 \%)$ y de países limítrofes $(8,6 \%)$, mientras que los nativos representaban

\footnotetext{
169 AGN, FTC-SE, Legajo L31, Lamarque, Adolfo, por suicidio. Sobre este caso, volveremos en el capítulo 10 .

${ }^{170}$ GN, FTC-SE, Legajo D21, Dotto, Tomás, tentativa de suicidio.
} 
el 14,3\% (5 casos). ${ }^{171}$ Los "cansados de la vida" identificados, en general, eran solteros (60\%); la proporción de los casados era el 20\% y viudos, sólo dos casos. ${ }^{172}$ Con respecto a la ocupación de los difuntos/heridos, la mayoría (17 casos, 48,6\%) eran trabajadores (peones, jornaleros, artesanos asalariados y por cuenta propia), si sumamos a los desempleados, representaban alrededor del 57\%. ${ }^{173}$ Estos datos tampoco son inesperados si tomamos en cuenta las características generales y la evolución de la población de la ciudad de Buenos Aires en la segunda mitad del siglo XIX. La llegada masiva de inmigrantes, además de generar un crecimiento demográfico inédito (de 95.000 habitantes en 1855, la ciudad pasó a albergar en 1885 a más de 395.000 habitantes y en 1890 superaba el medio millón), también contribuyó a aumentar la proporción de población extranjera, joven y de sexo masculino.

Sí encontramos una variación un poco más significativa a la hora de analizar los datos relacionados con los medios utilizados para suicidarse por los "cansados de la vida". ${ }^{174}$ En este sentido, hay una mayor proporción de envenenamientos $(34,3 \%)$ en los relatos sobre el hastío de la vida que en la muestra total de casos estudiados. ${ }^{175} \mathrm{El}$ tiempo que mediaba entre el momento del acto suicida y la muerte efectiva del sujeto era más extenso en una intoxicación que en otras formas de quitarse la vida. Este período más largo daba mayores posibilidades al entorno del suicida y a la policía para salvar al desesperado y/o preguntar por los motivos de la "extrema resolución". En este sentido, lo que tal vez caracterizaba a los "cansados de la vida" (o, por lo menos, a los que se envenenaban) es que tenían más tiempo para ser encontrados con vida o ser rescatados. Así, había más posibilidades de escuchar el testimonio de los intoxicados que el de los que habían intentado suicidarse utilizando, por ejemplo, un revólver u otro modo de autoagresión más letal.

En algunos casos, el suicida no brindaba detalles de lo sucedido a la policía. Así sucedió el 25 de marzo de 1883, luego de que Palmira Castro (oriental, 13 años,

\footnotetext{
171 En los 35 casos estudiados: 11 suicidas eran españoles, 8 italianos, 5 argentinos, 3 franceses, 3 orientales, 2 alemanes, 1 austríaco, 1 inglés. Sólo en un caso no se especificaba la nacionalidad.

17221 eran solteros, 7 casados y 2 viudos. Hay 5 casos sin especificar $(14,3 \%)$.

173 Entre los trabajadores urbanos $(57,1 \%)$, había 3 peones / jornaleros, 9 artesanos o especialistas en algún oficio, 2 dedicados al trabajo doméstico, 3 empleados de comercio y 3 sin ocupación. Dentro de los sectores medios (20\%), podemos ubicar a 2 empleados no manuales, 3 comerciantes y 3 profesionales. En 8 casos $(22,9 \%)$ no se especificaba información alguna sobre la ocupación.

174 Entre los suicidas "cansados de la vida", los medios utilizados fueron los siguientes: $16(45,7 \%)$ se dispararon con armas de fuego, 12 se envenenaron (34,3\%), 4 se hirieron con objetos cortantes $(11,4 \%), 2$ murieron sobre las vías cuando pasaba el tren / tranvía y uno se precipitó desde un edificio alto $(2,9 \%)$.

${ }^{175}$ En el conjunto de los 724 casos estudiados, el medio más utilizado para quitarse la vida fue el arma de fuego $(351,48,48 \%) \mathrm{y}$, en segundo lugar, el envenenamiento $(154,21,27 \%)$.
} 
soltera) intentara quitarse la vida tomando "sal de limón" (ácido oxálico usado para lavar y sacar manchas de la ropa). Según el redactor del sumario: "A pesar de las averiguaciones que le he hecho no he podido conseguir que me confiese la verdadera causa que la ha impulsado a tomar esta determinación, pues siempre decía que estaba aburrida de la vida". Quizás Palmira no deseaba exponer en público problemas o conflictos familiares (los hechos sucedieron en el domicilio donde vivía con sus padres). Sin embargo, el policía que recolectaba los datos del sumario, a veces, interrogaba al entorno de acuerdo con su propia interpretación de los hechos, a fin de descubrir aquello que el suicida no deseaba revelar. Mientras en la ciudad se festejaba el carnaval, el 17 de febrero de 1885 Benigno del Valle (argentino, 42 años, casado, jornalero) intentó suicidarse en su domicilio, usando como veneno fósforos diluidos en agua. ${ }^{176}$ Fue interrumpido por su comadre, quien lo vio cuando estaba envenenándose. En ese momento, su esposa y sus hijos habían salido a la vereda. Cuando Valle fue interrogado, alegó estar "cansado de la vida". Sin embargo, el policía que elaboró el sumario, en su informe, destacó lo siguiente: "Ignoro el grado de veracidad que esta afirmación pueda tener; pero tratándose de un individuo de las condiciones de este, es decir, de un ebrio consuetudinario, no creo aventurado suponer que tal atentado lo ha llevado a cabo esitado por la bebida, de la cual abusa en extremo". En el diario "La Nación" del 19 de febrero de 1885) fue dado a conocer el acto suicida de Del Valle, sin embargo, no encontramos más detalles sobre lo sucedido. En "La Prensa" del mismo día, por otro lado, figuraba la versión de los hechos de acuerdo a la óptica del policía. El cronista informaba que el "atorrante" Benigno del Valle, estando borracho, había intentado envenenarse cerca de Palermo. En ambos diarios no se mencionaba nada más referido a la causa del suicidio. En este caso, el policía dio una versión de acuerdo con lo que creía verosímil y esta fue la que circuló en los medios gráficos: ¿Había escuchado en alguna parte rumores acerca del gusto de Valle por las bebidas alcohólicas? ¿Fue algo que comentó alguno de los integrantes del grupo familiar? ¿Era una forma verosímil de dar sentido a lo sucedido? Tal vez conocía al suicida o alguno de los testigos le dio esta información al policía y éste la registró, sacando del silencio datos que Benigno no había revelado. Algo similar sucedió en el caso de Aida Guasconi (italiana, 30 años, separada, planchadora), quien sólo declaró estar hastiada de la vida y no tener conflicto con nadie. Sin embargo, el agente que interrogó a Aida, luego de que ésta intentara

\footnotetext{
${ }^{176}$ AGN, FTC-SE, Legajo V14, Valle del, Benigno, tentativa de suicidio.
} 
envenenarse sin éxito, agregó en su informe que hacía tres meses que Guasconi se había separado de su marido y, por esta razón, se había ido a vivir a una casa de inquilinato. El policía, de acuerdo con su punto de vista, completó la información que Aida había omitido en su versión de lo sucedido: ¿Imaginaba que la suicida sentía pudor por esta situación y a causa de ello no incluyó en su versión de los hechos dichos eventos? ${ }^{177}$

En otros casos, mientras que el suicida sólo mencionaba estar cansado de la vida, el resto de los testigos brindaban explicaciones más completas sobre los hechos. María Uranga (argentina, 18 años, soltera), por ejemplo, no reveló detalles de sus motivaciones para quitarse la vida. ${ }^{178}$ El 2 de abril de 1888, alrededor de las $21 \mathrm{hs,}$ Uranga fue encontrada en su domicilio padeciendo los efectos del arsénico que había ingerido; manifestó a la policía que la vida le era insoportable sin dar detalles del origen de su tedio. Uranga vivía en la casa de la familia Aguirre desde los 4 años. El tutor de María declaró que la joven intentó suicidarse por problemas en la relación que tenía con su novio; asimismo, remarcó que los integrantes del grupo familiar no eran responsables de lo sucedido. Esta última versión fue la que circuló en las páginas de "La Prensa" el 4 de abril de 1888. María había muerto luego de sufrir una "decepción amorosa". En "La Nación” del mismo día, en cambio, se señalaba que no se conocían los motivos. No sabemos qué motivaciones estaban detrás del acto suicida de la joven; sin embargo, es probable que para Uranga fuera vergonzoso revelar en público los conflictos que tenía con su pareja. Por otra parte, para la familia Aguirre era importante despejar sospechas sobre algún tipo de maltrato hacia su personal doméstico. Las situaciones de agresión física o abuso sexual hacia las sirvientas no eran desconocidas para los contemporáneos.

Severino López (español, 30 años, soltero, peón) tampoco quiso dar detalles de los motivos que lo incitaron a autoagredirse y terminar con su existencia. ${ }^{179}$ El 12 de marzo de 1888, por la mañana, fue encontrado convaleciente (se había envenenado con fósforos diluidos en agua), en el aserradero donde trabajaba. López sólo dijo a la policía que estaba cansado de la vida, nada más. Su patrón y la esposa de este lo notaban preocupado desde hacía un tiempo, pero no conocían las razones. La que aportó detalles sobre la desesperación que sentía Severino fue la mujer que lavaba y planchaba su ropa. Ésta declaró que, la noche anterior, López le había manifestado estar cansado de la vida por varios motivos: en primer lugar, las dos jóvenes que le interesaban como esposas

\footnotetext{
${ }^{177}$ AGN, FTC-SE, Legajo G41, Guasconi, Aida, por tentativa de suicidio.

${ }^{178}$ AGN, FTC-SE, Legajo U4 Uranga, María, sobre suicidio.

${ }^{179}$ AGN, FTC-SE, Legajo L29, López, Severino, suicidio.
} 
habían muerto; sus padres no se acordaban de él desde que estaba en la capital, y sus amigos no lo querían. Según los padres del suicida, López había abandonado la casa paterna 16 años atrás y estuvieron sin saber de él durante mucho tiempo. Trece años después, volvió a intentar la convivencia con sus parientes, pero, luego de un mes, tuvo una pelea con sus hermanos y decidió abandonar la residencia familiar. Tanto Severino López como María Uranga sólo comunicaron a la policía su estado de desesperación y desánimo, pero no dieron detalles de las circunstancias que implicaban estos sentimientos. Sin los relatos de los testigos, el policía no hubiera podido elaborar una explicación más amplia de lo sucedido. Por otra parte, en el caso de López, los medios gráficos consultados no dieron a conocer ninguno de estos detalles de la vida íntima del difunto. "La Nación" no reportó el hecho y en el caso de "La Prensa", en la edición del 13 de marzo de 1888, sólo mencionó que: "La causa del suicidio es según lo ha manifestado cansancio de la vida".

En este sentido, entendemos que los casos que figuran en las estadísticas como hastiados de la vida, son el resultado de expresiones ambiguas, que más que apuntar a alguna situación en particular sólo nos dan cuenta, en la mayoría de los casos, del pudor de aquellos que se quitaban la vida para informar a otros los motivos que los apenaban y angustiaban. Así, la gran cantidad de casos en los que el herido se negaba a declarar, y en los que no dejó carta o nota suicida dando explicaciones sobre la situación, dejan solamente el silencio. Las muertes violentas por mano propia no dejaban de tener un significado escandaloso, aunque el paradigma de las enfermedades mentales fuera el más legítimo para entender estos hechos. Si las penas a los suicidas (como la privación de entierro en el cementerio) ya no tenían legitimidad, la condena religiosa y, sobre todo, el escándalo social seguía generando inquietud en los individuos que se quitaban la vida y en los miembros de sus redes vinculares.

En síntesis, decir que se estaba cansado / hastiado / aburrido de la vida era también una manera de no decir las causas que habían movido al individuo a intentar quitársela. Era una forma de evadir aquello que resultaba vergonzoso relatar, de evitar comunicar a los otros lo que estaba sucediendo. También era un modo de no revelar detalles de la vida íntima del sujeto. Gregorio Izarrualde Ríos (argentino, 19 años, soltero), se suicidó el 25 de febrero de 1882 en la Plaza 29 de Noviembre (en la actualidad, Plaza Garay), utilizando un revólver con el que se disparó en la cabeza, a la 
altura de la sien derecha. ${ }^{180}$ El cronista de "La Nación" lo describía en su edición del 26 de febrero de 1882 como un "imberbe simpático". De acuerdo con los datos presentados por "La Prensa", Gregorio había trabajado un tiempo como policía y después como empleado en el estudio de un abogado, donde ganaba un salario muy bajo. Su madre y su hermana administraban una escuela. Estaba en pareja con una joven a la que mantenía con sus ingresos. Según el cronista, esos días se lo vio contento en los bailes de carnaval, junto con su novia, y dijo a sus amigos que asistiría a uno de esos eventos el día que se quitó la vida. Al revisar las ropas de Gregorio, la policía encontró tres cartas: dos cerradas, una dirigida a su madre, Hilaria R. de Izarrualde, y la otra a Francisca Moledeo; el sobre abierto era para el comisario. ${ }^{181}$ En la nota suicida que contenía, Izarrualde pedía lo siguiente:

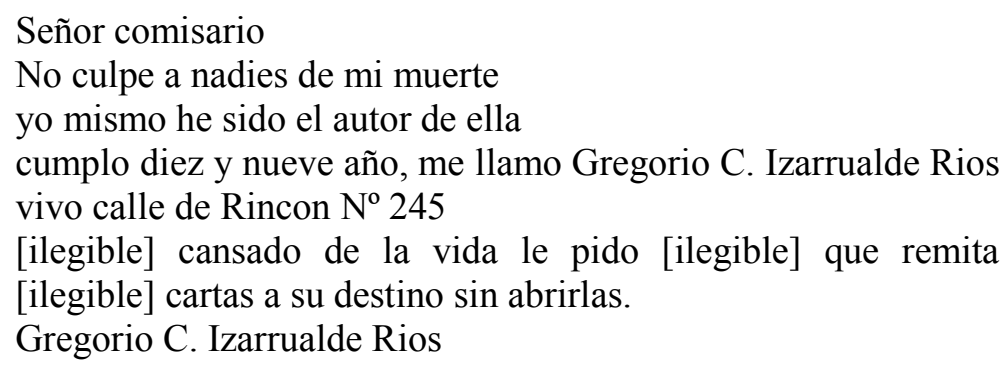

Gregorio, no deseaba compartir las razones, motivos o causas de su angustia con nadie más, sólo con aquellos a los que estaban destinadas sus cartas. Decir que uno estaba "cansado de la vida" permitía mantener los detalles de las circunstancias, sobre todo, si estas eran muy escandalosas, dentro del círculo privado más íntimo y reducir los rumores y comentarios sobre el hecho. Por esta misma razón, en otros casos, los que se habían quitado la vida, en lugar de dar las razones de sus actos, preferían negarse a declarar. Según lo revelado al comisario, en las dos cartas entregadas a sus respectivas destinatarias, Izarrualde comunicaba la decisión de quitarse la vida, cansado de ella, porque no contaba con suficiente dinero para mantenerse y pagar sus propios gastos; a Gregorio le avergonzaba sentir que era una carga para su familia. Los Izarrualde Ríos declararon que no sospechaban que éste fuera a suicidarse. Por otra parte, la misma tarde del suicidio, Gregorio les había manifestado “que no estaba lejana su muerte". Sin embargo, no habían dado importancia a sus palabras porque las había comunicado de un

\footnotetext{
${ }^{180}$ AGN, FTC-SE, Legajo I2, Izarrualde Ríos, Gregorio, su suicidio.

${ }^{181}$ Según la noticia publicada en "La Nación", el día 26 de febrero de 1882, una de las cartas estaba dirigida a la pareja de Gregorio.
} 
modo alegre y solía expresar este tipo de frases con frecuencia. En "La Nación", sólo se dio a conocer lo sucedido en una noticia titulada "Cansado de la vida"; en esta no daban detalles de los motivos de su acto suicida, aunque se daba a entender que las razones estaban vinculadas con la carta que dejó a su pareja. En la noticia publicada en la "La Prensa", el cronista mencionaba que Gregorio tenía discusiones con su familia y también con su amada. Tal vez, éstas eran las circunstancias que el suicida no quería exponer en público, o, quizás, el cronista rellenó con su imaginación los huecos de la historia.

Por otro lado, puede que la expresión simplemente fuera el llamado de auxilio de alguien que estaba sufriendo y no sabía muy bien lo que le estaba ocurriendo, o como explicarlo. Por ejemplo, el caso de Arístides Caldentey (oriental, 23 años, soltero, estudiante de $5^{\circ}$ año de ingeniería), nos da indicios que apuntan en esa dirección. ${ }^{182}$ Caldentey se suicidó en la calle Acosta, entre Charcas y Santa Fe, disparándose con un revólver, a la altura de la sien derecha, el día 2 de julio de 1881. Cuando fue encontrado herido, no quiso (o no pudo) decir nada a la policía. Según el cuñado de Caldentey, Eduardo Sousa (argentino, 24 años, casado), quien reconoció el cuerpo, Arístides había desaparecido de su casa el día anterior, alrededor de las 17hs. Antes de ausentarse, días atrás, Caldentey le había "manifestado [a Sousa] la idea de suicidarse, diciéndole que estaba cansado de la vida”, sin dar mayor información al respecto. ¿Caldentey intentaba pedir ayuda y se sentía avergonzado? ¿No sabía cómo comunicar lo que sentía a su red de vínculos más cercanos? ¿Sousa usó la expresión para no dar detalles relacionados con la vida íntima de su cuñado? En este sentido, creemos que este tipo de expresiones era también una forma de pedir auxilio, o hablar del tema, sin revelar lo que le causaba vergüenza. A la hora de buscar ayuda, a fin de soportar la desesperación, era necesario vencer la barrera del pudor y la incomodidad. Es probable que Gregorio Izarrualde, por ejemplo, bromeara sobre su propio dolor, porque le resultaba embarazoso tocar temas delicados con su red de vínculos afectivos, tal vez, porque imaginaba la preocupación que generaría en familiares y amigos escuchar estas palabras. En este sentido, hablar del suicidio propio, en sí, no debía resultar sencillo, aunque no se dieran a conocer las razones del sufrimiento intolerable. En esos diálogos, creemos que decir "cansado / hastiado / aburrido de la vida" también era un modo de comunicar al entorno que se necesitaba ayuda, sin entrar en los detalles engorrosos que podían trabar la

${ }^{182}$ AGN, FTC-SE, Legajo C21, Caldentey, Arístides, suicidio. 
comunicación.

\subsection{Consideraciones finales}

Como vimos en capítulos anteriores, los suicidios se convirtieron en objeto de estudio y preocupación para las disciplinas científicas, sobre todo, a partir de la década de 1880. A medida que la población de la ciudad de Buenos Aires crecía, ciertos fenómenos que no eran desconocidos cobraron mayor dimensión y se hicieron más notorios que en el pasado. Las cifras analizadas parecen evidenciar un aumento de los suicidios proporcional al crecimiento demográfico de la capital del estado argentino. Sin embargo, la dimensión alcanzada por el fenómeno, así como el análisis aislado de ciertos años en los que fueron registrados una mayor cantidad de casos, como en 1882, llevaron a imaginar que la epidemia de suicidios se expandía de forma alarmante.

Más allá de los análisis y conclusiones que podríamos sacar del estudio de la tasa de suicidios y su evolución, consideramos valioso conocer el perfil de suicida que construía el saber estadístico de la época. Es decir, además de lo que revelaban las cifras relacionadas con el género, la edad, el estado civil, la ocupación, el medio empleado, etc., nos ocupamos de relevar las interpretaciones que estas suscitaban. En este sentido, el hecho de que los suicidas fueran en su mayoría hombres se explicaba por las exigencias de la lucha por la vida; las presiones de garantizar el sustento familiar eran lo suficientemente poderosas como para llevar a muchos individuos a quitársela. La constitución de una familia armoniosa podía preservar a los varones de caer en la desesperación, en el vicio, el delito y, en último término, el suicidio. Por esta razón resultaba tan significativa la cantidad de solteros de sexo masculino. Estos estaban expuestos a mayores posibilidades de ceder ante el "hastío de la vida". Si bien algunos podían apuntar a los inmigrantes, como más proclives a suicidarse, en una ciudad con una proporción tan grande de extranjeros, no era algo sorprendente que fueran mayoría entre los suicidas. Tampoco era llamativo que fueran personas jóvenes y en edad productiva. Por otra parte, diferentes franjas etarias eran asociadas a distintos tipos de causas, más propensos a suicidarse por amor en la juventud (etapa de fuertes pasiones), mientras que los más ancianos lo hacían por los dolores provocados por la enfermedad y el malestar generado por las afecciones propias de la vejez.

Si el universo de casos y motivaciones mencionados en los sumarios judiciales 
era heterogéneo, los medios utilizados para quitarse la vida se repetían con bastante frecuencia. En el caso de las mujeres, era más común que utilizaran los venenos disponibles en el ámbito doméstico, que no dañaban el aspecto del cuerpo después de la defunción. Entre los hombres, la mayoría recurría a las armas de fuego, los objetos cortantes o medios más letales, eficaces y agresivos. Dentro de los elementos que integraban la representación de la masculinidad estaba el uso de la violencia física para defender la reputación personal y familiar. Dicho de otro modo, un hombre debía ser valiente para ganarse el respeto de sus pares. Desde esta perspectiva, las diferentes formas de quitarse la vida no tenían el mismo significado. Estas podían ser consideradas un signo de valentía y virilidad en unos casos, los medios más violentos, o una muestra de afeminamiento y de debilidad, por ejemplo, si se utilizaban fósforos. Por esta razón, resultaba más verosímil para los contemporáneos que los varones se quitaran la vida usando alguna pistola, un revólver, cuchillos y navajas, que por medio de venenos.

Asimismo, el estudio de las "causas determinantes" también nos muestra una serie de cuestiones para reflexionar sobre los diferentes tipos narrativos, y su relación con los valores y el marco axiológico, que trabajaremos en los próximos capítulos.

Lo primero que cabe remarcar, como vimos a lo largo del presente apartado, es la gran cantidad de casos en los que se desconocía el motivo o la "causa determinante". Esto último nos da cuenta del grado de reserva a la hora de revelar las razones o los móviles que habían llevado al sujeto a quitarse la vida, por parte de éste y de su red vincular. La vida social de un individuo trascendía el instante de la muerte biológica y el difunto continuaba presente en las prácticas funerarias y en el recuerdo de los deudos, guardianes de la memoria y defensores de la reputación del que estaba ausente. El suicidio no era el desenlace más frecuente de las historias personales de los habitantes de la ciudad de Buenos Aires. Era sinónimo de tragedia, escándalo y rumor indiscreto por parte de los vecinos/as, que trataban de descifrar los motivos de la "extrema resolución", más parecida al final de una novela "romántica" o a un relato de misterio. Bajo dichas circunstancias, no es extraño que sea poco lo que los suicidas dieran a conocer sobre lo que les estaba sucediendo. Si sus pasiones íntimas eran puestas en conocimiento era más bien por descuido o por decisión de los deudos. Los integrantes del grupo familiar del suicida también estaban en la mira, se sospechaba que los conflictos familiares eran los causantes del hastío y la desesperación. Así, los integrantes de la red vincular también debían dar testimonio de su participación en los 
hechos que culminaron en el acto suicida, es decir, estaban expuestos a la mirada del tribunal público que juzgaba la reputación personal. A partir de los casos presentados en este capítulo, y las apreciaciones de quienes analizaban las estadísticas, encontramos una primera forma de narrar los actos suicidas: el relato de una vida truncada, cuyo dramático desenlace no posee causa o motivo, el suicida se llevó a la tumba todas las razones que lo podrían haber impulsado a quitarse la vida. Al mismo tiempo, los deudos guardaron silencio, con la colaboración de los agentes policiales, que en muchos casos no buscaban ahondar la pena de los familiares y amigos del que se había quitado la vida. Así, este primer tipo de narración es un grado cero, no se mencionan elementos esenciales (del suicida) o situacionales (es decir, del contexto con el que interactuaba), que sean relevantes. Como hemos tratado de mostrar en este capítulo, los casos donde sólo se mencionaba el "cansancio / aburrimiento / hastío de la vida" eran variantes de este primer tipo narrativo, en el que la declaración de la desesperación era la acción comunicativa central.

Estas expresiones eran utilizadas para describir el estado de desesperación, ausencia de fuerza y falta de perspectivas acerca de su futuro que mencionaban los que se suicidaban, o los que habían intentado hacerlo sin éxito. Asimismo, este sentimiento de cansancio o hastío era clasificado por la policía con una categoría específica dentro del conjunto de "causas determinantes". Estos datos eran la base para confeccionar las estadísticas de la época. De alguna forma, era diferente al resto (demencia, padecimientos físicos, pobreza, malos negocios, etc.), aunque su significado no nos quedaba claro. A primera vista, sólo podemos interpretar que nos habla de un intenso estado de desesperación, pero sin estar asociado a un hecho concreto o a una variable particular. En algunos relatos, expresiones tales como estar cansado / hastiado / aburrido de la vida eran mencionadas acompañadas de otros factores o circunstancias que daban cuenta del origen de la desesperación (pobreza, enfermedad, locura, desengaños amorosos, asuntos familiares, cuestiones de reputación, etc.); en la mayoría, sin embargo, este tipo de causa verosímil era mencionada sin agregar más información. Entendemos que estas dos situaciones están conectadas entre sí. En este sentido, si bien podemos observar que en la mayoría de los casos la desesperación era asociada con una situación material apremiante, con padecimientos físicos y con patologías mentales, cabría pensar que estas eran las explicaciones que generaban menos pudor en los testigos. Más incómodo resultaba comunicar detalles íntimos de la vida del difunto, sobre todo si este no los había revelado (por ejemplo, cuestiones sentimentales, 
conflictos al interior del grupo familiar, sucesos escandalosos relacionados con la imagen en público del suicida y su familia, etc.).

Al observar lo que sucedía, parecía más bien que el suicida buscaba preservar la información que se revelaba en público. Muchos eran conscientes del escándalo que su acto suicida provocaría entre los que los conocían, y que serían el blanco de los comentarios y chismes dentro del microcosmos del conventillo, la casa de inquilinos y la cuadra; al mismo tiempo, dada la difusión de estos hechos en la prensa, los comentarios de sus muertes podían llegar a muchos otros lugares del territorio de la provincia de Buenos Aires o del territorio nacional. Las acciones de la red de amigos y familiares muchas veces también estaban orientadas a disimular u ocultar lo más posible lo sucedido. "Cansado / hastiado / aburrido de la vida" era una forma de comunicar la desesperación sin dar a conocer aquello que resultaba incómodo, vergonzoso o escandaloso tanto para el suicida como para los integrantes de su red vincular. El suicidio era un hecho que muchos consideraban infamante, signo de cobardía y de ausencia de fuerza para luchar por la vida. Por este motivo, había circunstancias que no eran comunicadas, o sólo eran transmitidas a familiares y amigos con mucha discreción, sin que esta información fuera escuchada por oídos mal intencionados y chismosos. Al mismo tiempo, también creemos que decir "cansado de la vida" o frases similares era una forma de pedir auxilio, es decir, era un modo de buscar ayuda entre los miembros de la red de vínculos afectivos del suicida. Como figura en algunos de los relatos, la incomodidad a la hora de dialogar sobre estos temas generaba confusiones y malos entendidos. Los enunciados o fórmulas que eran conocidos por todos, y formaban parte de la cultura general compartida, permitían comunicar el estado de desesperación al igual que el peligro potencial que corría quien decía estas palabras; así, podía superar la barrera que generaba el pudor de hablar sobre un tema tabú, como el suicidio, que impedía buscar contención afectiva y asistencia por parte de la red social de amigos, familiares y conocidos.

Los "cansados de la vida", así como los suicidas en general, no eran considerados alienados a priori. Si bien los profesionales de la salud entendían que la mayoría de los que se quitaban la vida lo hacían movidos por alguna clase de patología mental, o que estaban inmersos en un estado apasionado anormal, por otra parte, también contemplaban otras situaciones que podían conducir al suicidio de los habitantes: la enfermedad, la pobreza, la vida en un hogar mal constituido y en 
condiciones de hacinamiento, entre otros factores, podían provocar que incluso los niños se quitaran la vida. En este sentido, dentro de la diversidad de explicaciones que podían ser enunciadas en los interrogatorios llevados adelante por los agentes de la policía, las enfermedades mentales figuraban dentro de una categoría específica (la demencia). Esto dejaba de manifiesto que para los contemporáneos el suicida no era siempre un alienado mental, en varios casos era identificado como tal y en muchos otros los testigos describían diversas situaciones verosímiles que permitían interpretar el trágico desenlace, sin considerar un demente al que se daba muerte. Por esta razón, hemos dedicado el siguiente capítulo a estudiar aquellos casos que eran explicados a partir de la locura o la alteración de las facultades mentales, mientras que los otros tipos narrativos serán analizados en los capítulos sucesivos. 


\section{Capítulo 7: La locura}

Como mencionamos en el capítulo anterior, mientras que en una gran cantidad de los casos trabajados no se conocían las "causas determinantes" del acto suicida, en los sumarios donde sí eran mencionadas, en su mayoría, figuraban las patologías mentales como el elemento articulador de la explicación verosímil de los hechos (véase Tabla 20 en Anexo). Cabe destacar de nuevo que los expedientes trabajados corresponden en su mayoría a la década de 1880. Si consultamos las estadísticas de la época referidas a las causas de suicidio (véase Tabla 19 en Anexo), podemos observar que esto también fue registrado por la policía: la mayoría de los suicidios, entre $1884 \mathrm{y}$ 1889, había sido impulsado por la "demencia" de los que se quitaban la vida. Sin embargo, en las décadas siguientes, esta categoría perdió peso frente a otras: por un lado, los disgustos de familia y el hastío de la vida, que, para algunos intelectuales, estaban vinculadas entre sí, y las enfermedades y padecimientos físicos, por otro, sobre todo en la primera década del siglo XX. No hemos dado con una explicación para este cambio. Tal vez, los criterios para encasillar un caso en la categoría "demencia" se hayan determinado de una forma más precisa, dejando por fuera a otros individuos que eran incluidos en el pasado. Cabe destacar que, para el saber psiquiátrico, los dementes eran un subgrupo entre otros dentro del conjunto de los afectados por patologías mentales. Por otra parte, alegar demencia para explicar un acto suicida tuvo una función más trascendente en los períodos anteriores a la legislación moderna de los estados sobre los delitos y la administración de los cementerios. Mientras los entierros estuvieron regulados por el clero existía el riesgo de no ser enterrado en el cementerio. Sin embargo, como vimos en capítulos anteriores, el sujeto que no tenía juicio no podía ser castigado por sus actos. Así, es probable que muchos deudos y testigos hayan explicado que el suicida estaba demente, más allá de poder comprobar o no este estado, para evitar problemas a la hora de llevar adelante la inhumación de los restos. Esta estrategia es probable que haya perdurado en el tiempo, mientras se desarrollaban y consolidaban las instituciones y normativas estatales que eliminaron las penas y castigos de este tipo. Por otra parte, la instalación de un complejo psiquiátrico de encierro, donde se llevaban adelante las prácticas terapéuticas propuestas por el saber alienista (mediante chalecos de fuerza, duchas con agua helada y privación de la libertad), debe haber disuadido a muchos suicidas y miembros de la red de contención a alegar la 
locura de los que trataban de quitarse la vida. Es improbable que las personas estuvieran dispuestas a arriesgarse a recibir este tipo de tratamientos, o colaborar en llevar a un ser querido a tales espacios de encierro, si esto no era necesario. Tal vez, por este motivo, los casos en los que se manifestaba la locura como causa determinante descendieron y aumentaron los sujetos que decían estar "cansados de la vida" u otra causa que no implicara ser internado en un manicomio.

La alteración de las facultades mentales resultaba la explicación más verosímil a la hora de dar cuenta de un acto suicida entre muchos profesionales de la salud. Otros, en cambio, relativizaban la postura anterior y establecían una serie de matices que separaban alienados, sujetos apasionados de un modo anormal y una minoría de individuos que se quitaban la vida con pleno uso de su razón, como los grandes héroes del mundo antiguo greco-romano. Como veremos en este capítulo, las patologías psiquiátricas eran una causa determinante verosímil para los contemporáneos $\mathrm{y}$, como ya dijimos, aparecían mencionadas frecuentemente. Sin embargo, nos parece oportuno establecer matices entre, por un lado, las formas de la locura identificadas por el saber erudito y, por el otro, las maneras de representar a los locos por parte de otros actores sociales que no formaban parte del mundo académico. De este modo, partimos de preguntarnos los siguientes interrogantes: ¿De qué forma se podían reconocer a aquellos individuos que tenían sus facultades mentales alteradas? ¿Cuáles eran los indicios que caracterizaban a los locos? ¿Dónde estaba ubicada la línea que separaba a cuerdos de alienados? ¿Qué significado ético tenía el suicidio producido por una enfermedad mental? ¿Existían distintas formas de representar al enajenado mental?

Siguiendo con el análisis de los tipos narrativos, consideramos que la alteración mental tenía un significado particular a los ojos de la sociedad, dentro del marco axiológico de la época. En el momento crucial de explicar lo sucedido, de asignar la responsabilidad por un hecho traumático, la locura, en general, disculpaba a todos. Si bien no enaltecía al suicida, de hecho, lo transformaba en víctima de su propia condición, sin posibilidad de elección. Al mismo tiempo, desestimaba otras posibles hipótesis que construían una visión conflictiva del entorno familiar, causas determinantes menos halagadoras para la construcción de la memoria del difunto y sus deudos. Para los contemporáneos, como ya mencionamos, un ambiente familiar conflictivo era el principal origen del "hastío de la vida". Los comentarios y los chismes, así como las versiones difundidas en la prensa de la época, podían presentar a los familiares y miembros de la red social del suicida como responsables, en menor o 
mayor medida, de lo sucedido. En cambio, al narrar los hechos a partir de la alienación mental del suicida, los vínculos del sujeto no eran presentados como responsables o coautores del trágico y extremo desenlace. Las acciones de estos eran poco o nada efectivas frente a un individuo consumido por la obsesión de terminar con su existencia. Los suicidios motivados por la locura no eran hechos dignos de ser enaltecidos, como veremos, en el mejor de los casos, despertaban la compasión hacia el que se quitaba la vida y sus deudos. Así, estos suicidas no eran presentados como modelos éticos en los relatos de la prensa, salvo por excepciones. Una narración particular de este tipo era la que presentaba el suicidio del hombre que luchaba estoicamente contra la locura.

\subsection{Los suicidas alienados}

Distintos actores sociales (de acuerdo a su estrato social, género y franja etaria) explicaban los casos de suicidio apelando a las perturbaciones de la mente como variable explicativa. Era una idea que formaba parte del sentido común y por eso resultaba creíble. No encontramos una sola forma de explicar lo sucedido en este tipo de relatos. Muchas y variadas podían ser las causas de la locura. Por ejemplo, la dueña de la fonda donde estaba alojado Federico Ricardo Richter dio la siguiente versión de los hechos relacionados con su suicidio. Richter era nativo de Alemania, trabajaba allí como agricultor y venía con dichas expectativas a Argentina. Sin embargo, al ver sus anhelos frustrados, sus facultades mentales se desequilibraron y esto lo condujo a quitarse la vida el 13 de diciembre de $1885 .{ }^{183}$ Los testigos que declararon luego del suicidio de José Lozano (argentino, 62 años) explicaron que éste padecía de una enfermedad que le provocaba dolores intensos; como resultado, había desarrollado un cuadro de demencia y tenía problemas para hablar. Asimismo, había comunicado a varias personas que pensaba quitarse la vida (el 18 de julio de 1881 se disparó con un revólver a la altura de la sien derecha). ${ }^{184}$

En el caso de Bautista Piarrou (francés, 37 años, casado, comerciante), las declaraciones apuntaban a distintas circunstancias que abonaban para explicar el origen

\footnotetext{
${ }^{183}$ AGN, FTC-SE, Legajo R28, Richter, Federico Ricardo s/suicidio. Cabe mencionar que, en el sumario, consta que Richter se suicidó con un arma de fuego y se disparó seis veces para darse muerte. Estaba encerrado en un calabozo de la comisaría de la zona. Había sido detenido por andar con actitud sospechosa por la vía pública. De lo que se llega a saber por el resto del expediente, el suicidio de este hombre metió en un lío al policía que lo encarceló sin una justificación válida. No sabemos con seguridad qué fue lo que sucedió realmente, si Richter murió por su propia mano o en qué circunstancias.

${ }^{184}$ AGN, FTC-SE, Legajo L12 B, Lozano, José, s/suicidio.
} 
de su alienación mental y su acto suicida (se tiró en medio de las vías del tren en la Estación 11 de Septiembre, el día 18 de junio de 1886): los testigos mencionaban que tendía a abusar de la bebida, padecía de una enfermedad y su negocio no andaba bien. ${ }^{185}$ Si observamos la carta dirigida a Piarrou, que fue adjuntada en el expediente de su suicidio, podríamos agregar algunas circunstancias más que de seguro lo angustiaban. ${ }^{186}$ En dicho escrito (redactado en 1882), un viejo amigo suyo, llamado Barthélemy, que vivía en Olorón (Francia), su lugar de origen, le comentaba, entre otros asuntos, la situación en la que se encontraba su padre (que trabajaba como empleado para un estudio que llevaba adelante sucesiones). Según Barthélemy:

Su padre envejece, a pesar de su buena [ilegible, deduzco, "voluntad"], ya no puede trabajar como [ilegible, deduzco, "antes"] con la misma [ilegible] comienza a temblar $y$, además, la vista [ilegible, deduzco, "se debilita"] cada día, por consiguiente, los patrones [ilegible] hoy quienes poseen una devoción y un tacto notables, a veces dudan en pedirle que se ocupe de algunas tareas que su difícil estado [ilegible]. En consecuencia, él [ilegible], yo lo espero del deber de [ilegible] hijo agradecido de prestarle un poco de asistencia y, de este modo, procurarle algo de alivio.

Adiós mi querido amigo.

Barthélemy mencionaba que, en ese entonces, los negocios de Piarrou "marchaban de maravillas", por esta razón solicitaba a su amigo que enviara dinero para ayudar a su padre, quien encontraba cada día más dificultoso trabajar. Cuatro años más tarde, el panorama había cambiado y su situación económica no le permitía enviar fondos a su lugar de origen. Podemos imaginar que Piarrou quizás estaba preocupado por la seguridad de su progenitor, quien dependía cada vez más de sus ingresos.

Muchos suicidas eran enviados a hospitales para tratar sus heridas; allí eran vigilados para evitar cualquier tipo de reincidencia, y luego, algunos, eran internados en instituciones psiquiátricas. A modo de ejemplo, podemos mencionar el caso de Juan Bellagamba (italiano, 33 años, soltero, fabricante de licores), quien luego de envenenarse con ácido sulfúrico fue conducido al Hospicio de las Mercedes, el 6 de enero de 1886; ${ }^{187}$ allí también fue trasladado Eduardo Frula (italiano, 32 años, casado, jornalero), cuando intentó suicidarse la primera vez; en su segunda tentativa, murió

\footnotetext{
${ }^{185}$ AGN, FTC-SE, Legajo P34, Piarrou, Bautista s/suicidio.

186 Quiero agradecer a la Traductora Pública Natalia D'Aquino por llevar adelante la traducción de las cartas relevadas que estaban en francés.

${ }^{187}$ AGN, FTC-SE, Legajo B30, Bellagamba, Juan, s/tentativa de suicidio.
} 
ahorcado, el 15 de enero de 1888, en la pieza del conventillo que ocupaba. ${ }^{188} \mathrm{El}$ Hospicio de las Mercedes también recibió a Francisco H. Simons (norteamericano, 33 años, soltero, fabricante de sellos de goma), luego de un ataque de demencia, el 17 de octubre de $1875 .{ }^{189}$ Esta institución, creada en 1863, era dirigida, desde 1876, por el reconocido alienista Lucio Meléndez. Según Meléndez (1892), allí se brindaban los tratamientos utilizados en los manicomios de las naciones más adelantadas para curar las diferentes enfermedades mentales, por ejemplo, la hidroterapia (duchas con agua a distintas temperaturas que buscaban aquietar y sedar a los alienados). Resulta oportuno presentar el siguiente ejemplo, un caso de "manía aguda", mencionado por Vezzetti (1985: 61-62), atendido por Meléndez, que nos da una idea del tipo de atención que recibían los pacientes en dicha institución:

Luis B. es un actor italiano llevado al hospicio por la Policía, enchalecado y en medio de un cuadro de excitación aguda. [...] El marco clínico de aprehensión de la locura es esa imagen de excitación y desborde de las pasiones. Un "prolongado baño de duchas frías" es indicado para "robar un poco de calor a ese cerebro en completa ebullición nerviosa y sanguínea". Tratado con baños y cloral -inductor del sueño- fue dado de alta a los catorce días, curado de su episodio. Sin embargo, la prudencia y la observación del curso posterior van formando parte de los atributos necesarios del alienista: Meléndez aclara que el alta ha sido "condicional".

También era responsabilidad de los locos trabajar en los talleres del hospicio, por ejemplo, en la elaboración de calzado; el trabajo era considerado un agente moralizador que devolvía la salud al alienado, promovía las buenas costumbres y permitía llevar adelante las tareas para sostener la actividad del manicomio. En el caso de las mujeres,

\footnotetext{
${ }^{188}$ AGN, FTC-SE, Legajo F23, Frula, Eduardo, s/su suicidio. En el expediente fueron encontradas dos notas suicidas y dos cartas de familiares de Frula que vivían en Pésaro (Italia). En las escritas por Frula, en una (con fecha del 12 de enero de 1888), se despedía de una mujer llamada Anna Macchi y, en la otra (fechada el día 7 de julio de 1887, probablemente luego de la primera tentativa de suicidio), encomendaba a dos personas un dinero que tenía. Las cartas de los familiares tienen fechas cercanas. La primera, escrita el 21 de septiembre de 1887, fue enviada por una hermana de Eduardo Frula. En ella, le mencionaba que se alegraba de que estuviera recuperado y con un mejor estado de salud. También le comentaba que había pagado las cuentas y las cuotas con el dinero que le había enviado. Asimismo, le comentaba que tenía a una de sus hijas en el hospital, al tiempo que le informaba que sus hijos estaban todos bien y que seguiría cuidando de ellos, como le había encargado. La segunda carta fue enviada por el suegro de Eduardo, Giuseppe Rocchi. En ella, le manifestaba su preocupación por la herida que había recibido (en la primera tentativa de suicidio) y le proponía que volviera para trabajar, pero ya no como mozo, sino con su propio carro, y así podría vivir con su familia. Rocchi también le recordaba que ya estaba "entrado en edad", es decir, que ya no tenía las mismas energías para sostener al grupo familiar y cuidar de su hija y nietos. Agradezco a la traductora Claudia Debernardi por realizar la traducción de estos documentos.

${ }^{189}$ AGN, FTC-SE, Legajo S4A, Simons, H. Francisco, p/tentativa de suicidio.
} 
estas eran conducidas al Hospital de Mujeres Dementes, gestionado por la Sociedad de Beneficencia. ${ }^{190}$ Allí, la vida de las alienadas transcurría entre rezos y oraciones, la limpieza de las habitaciones y los ambientes del hospicio, las labores en los campos, el lavado de la ropa o el trabajo en los talleres de costura. En sus inicios, luego de su fundación, en 1854, la cantidad de alienadas estaba dentro de la capacidad del hospital. Con el correr de las décadas, el hacinamiento y la sobrepoblación se transformaron en problemas insoslayables para sus administradoras, al igual que en el manicomio para hombres. En esta institución estuvo internada Eusebia Platero (argentina, soltera, proveniente de una familia de "buena posición pecuniaria") varios años hasta que sus padres la trasladaron de nuevo a su hogar para que volviera a vivir con ellos. ${ }^{191}$ Eusebia tenía la costumbre de salir a pasear por las noches y por esta razón tapaban y cerraban el brocal del pozo de agua para evitar que en un descuido se cayera dentro. La noche del 3 de julio de 1883 olvidaron cerrarlo y su hija se arrojó allí. Los padres de Eusebia declararon que hacían todo lo que podían para volver más llevadera su vida; su intento de suicidio había sido provocado por su demencia.

Como mencionamos en el capítulo 5, entre los profesionales de la salud regía la discusión si los suicidios en sí mismos eran un signo claro de alienación mental, o, si quedaba un espacio para la muerte por mano propia dentro del terreno de la cordura. Según el médico alienista José Vásquez, existía una especie de zona de frontera, que separaba a los alienados de quienes hacían uso de sus facultades mentales en libertad, donde estarían los locos morales o semialienados.

José María Ramos Mejía, especialista también en patologías mentales, entendía el fenómeno de la alienación de una manera muy similar. Si bien existían enfermedades donde aparecía el delirio como característica notoria, en otras, los indicios eran menos evidentes. Para la mayoría de sus contemporáneos, según Ramos Mejía, no había locura sin la presencia de alucinaciones o exclamaciones incoherentes. Los locos morales o semialienados pasaban desapercibidos por esta razón y eran identificados como personas consumidas por el vicio o confundidos con los criminales. Según Ramos Mejía (1932: 148), el principal rasgo de esa locura moral era la "perversión completa de las facultades afectivas, de las inclinaciones, sentimientos, costumbres y de la conducta misma". Es decir, dentro de este grupo entraba todo tipo de comportamientos "anormales", que eran encuadrados dentro de diferentes categorías del saber

\footnotetext{
190 Sobre este tema, véase, PITA (2009 y 2012).

${ }^{191}$ AGN, FTC-SE, Legajo P27, Platero, Eusebia, p/tentativa de suicidio.
} 
psiquiátrico de la época.

Así, para el sentido común, había casos en los que era más evidente la presencia de una enfermedad mental. Si bien era difícil definir con precisión los límites de la razón, había algunas situaciones que quedaban dentro del reino de la locura. Por ejemplo, aquellos que sufrían alucinaciones o deliraban y los que habían cometido crímenes aberrantes como infanticidios, filicidios, parricidios y uxoricidios. Los casos de alteración de las facultades mentales más extremos y aterradores para la época eran los hombres y mujeres que atentaban contra los miembros de sus propias familias y luego se quitaban la vida. Estos casos generaban una serie de reacciones en cadena: escándalo, pánico, intriga y desconcierto.

Manuel Blancas, que fue titular de la cátedra de Medicina Legal, en su labor como médico de policía, tuvo que tratar casos como estos, sentando precedente en las autopsias y sumarios de esta índole. Samuel Gaché presentó, en su tesis de 1886, dos casos, donde su profesor había elaborado el informe. En primer lugar, el de Nicanora Fernández, esposa de un militar, en la ciudad de Buenos Aires. Al parecer, ésta había decidido asesinar a su hijo para luego suicidarse, pero fracasó. Blancas realizó el examen de las facultades mentales de Nicanora. En su informe al Juez del Crimen, mencionaba que, bajo la apariencia de no estar sus facultades alteradas, en la tranquilidad de su relato, en la melancolía de sus palabras, se ocultaba "algo extraño". Para éste, los celos eran la explicación de los hechos aberrantes que la mujer intentó llevar a cabo. Nicanora "es un ser que razona", sentenció Blancas. Oscilaba entre sus sentimientos de madre y sus celos. Éstos la podían haber conducido a cometer un triple crimen "moral, social y religioso". Para Blancas, Nicanora no podía estar presa de la sugestión romántica, ya que no conocía el lujo ni las tramas con intrigas amorosas, que consumían las mujeres de las clases más ricas en América y Europa. Sin embargo, ella sólo vivía para su amor, para amar a su marido. Frente a la idea del desamor de su esposo, traída por el comentario malicioso de otra mujer, Nicanora se sintió caer en la desgracia más absoluta. Así, el suicidio de Nicanora era sólo un acto de un ser pasional pero no enajenado. Por otra parte, el intento de filicidio, era un acto, para Blancas, sólo explicable como el producto de una patología mental; el amor maternal estaba implícito en la naturaleza femenina de Nicanora, su ausencia sólo podía explicarse por una alteración de sus facultades mentales, mientras que el carácter más "romántico" era una característica esencial de la mujer, más sensible al amor y a los sentimientos que los 
hombres, desde la perspectiva del saber de la época. ${ }^{192}$

En segundo lugar, Gaché incluía, en su tesis, un caso que provocó conmoción en el Buenos Aires finisecular, el de Eduardo Klappenback. Éste mató a su esposa y a sus dos hijos para luego suicidarse con un arma de fuego. Blancas, en su autopsia, se preguntaba cómo podía haber ocurrido semejante catástrofe: "La fría razón no alcanza", “el corazón no comprende” (GACHÉ, 1886: 137). El “desgraciado” Klappenback, “el matador", había puesto fin a su vida y aniquilado a su familia. Primero, mató a su esposa mientras dormía, si no, según el médico de policía, esta madre hubiera buscado oponerse al asesinato de sus hijos. De manera casi teatral, Blancas relataba la escena del crimen, con el tono de una trama policial, muy similar al usado por la prensa, cuando presentaba estos sucesos. Una cosa que llamó su atención fue que los cadáveres de la mujer y la hija estaban desnudos. La esposa bajo las sábanas, al lado del cadáver del marido, que tenía en su mano derecha el arma de fuego, que utilizó para llevar adelante los asesinatos y el suicidio. En otro cuarto, la niña, Elena, de nueve años, tenía "una espresión tranquila y dulcísima", según Blancas, "una fisonomía infantil, remedando mas que la muerte un sueño apacible y bienhechor", era descripta como un ángel. En otro cuarto, un niño de unos seis años yacía muerto, una bala había atravesado su cráneo. Su rostro contrastaba con el de su hermana, éste, según Blancas, todavía guardaba el espanto de los últimos momentos de su vida. La casa se encontraba en perfecto orden y limpia. Describió el comedor, el lugar de reunión de la familia, el cuaderno de deberes del niño y sus juguetes (GACHÉ, 1886: 135-139).

Toda la escena le indicaba a Blancas que se trataba de una familia bien constituida, ¿qué fue lo que pudo llevar al padre a cometer tan terribles y aberrantes actos? Blancas no dejaba de interrogarse sobre lo que éste pensó, sobre las emociones violentas y las perturbaciones que afectaron su pensamiento en ese momento:

¿Estaba sano? ¿Obedecía a un sentimiento delicado y tierno? ¿Pensaba que muriendo sólo, podrían su esposa e hijos esperimentar toda una inmensa suma de dolores y privaciones que el infortunio engendra? ¿Pensó que antes de librarlos a una vida precaria y miserable, era preferible lanzarse con ellos al abismo de la muerte, y buscar en otra vida posible una tranquilidad que en esta no le había sido dado alcanzar? (Blancas, cit. por GACHÉ, 1886: 140).

Blancas consideraba este razonamiento una locura, el producto de alguna alteración en

\footnotetext{
192 Este caso inspiró una de las historias contenidas en la obra de folletín "Amor Funesto", escrita por Eduardo Gutiérrez para el diario porteño La Patria Argentina, y publicada entre el 17 de abril y el 3 de mayo de 1883 .
} 
el cerebro, ya que se trataba de una aberración, de una "bárbara mutilación". Sin embargo, parecía dotar a los hechos de una cadena de sentido con sus interrogantes. Es decir, era la hipótesis "verosímil" que Blancas podía reconstruir sin entrar en el terreno de las patologías mentales o los problemas nerviosos. Sólo un desequilibrio brutal en el organismo y el cerebro de Klappenback podían explicar que un hombre destruyera a su familia, "lo que más ama sobre la tierra", en una sola noche (Blancas cit. por GACHÉ, 1886: 140), violando todas las leyes de la naturaleza. Nos resulta interesante cómo explicó, desde la medicina, el efecto que pensamientos e ideas tristes podían generar, las visiones que podían llevar al "abismo". Blancas asociaba la aparición de estos pensamientos funestos, en hombres sanos, a daños en ciertas partes del cerebro. Sólo el daño de este órgano y la locura podían explicar las aberrantes acciones de Klappenblack: "Desesperado, inconsciente, violento, exterminador, loco, en fin, destruyó lo que más había amado sobre la tierra, y presa del mismo vértigo cortó también el hilo de su vida". Blancas mismo confesaba, en su informe, que la forma de expresarse estaba fuera de lugar, pero que la impresión que le provocó lo que vio fue demasiado fuerte.

Los diarios de la época hacían hipótesis sobre el origen de los actos atroces y desconcertantes de Eduardo Klapenback. Según lo mencionado en el diario "La Prensa" del 3 de marzo de 1877, no había conflictos al interior del grupo familiar; la empleada doméstica que servía en la casa declaró que Klapenback no había discutido con su esposa; la noche anterior a la tragedia bebió una cerveza con su familia. El detonante del trágico suceso fue el siguiente: Eduardo había sido despedido de la compañía de tranvías en la que trabajaba como gerente hasta hacía pocos días. Sin este trabajo, no podía sostener el estilo de vida que llevaba su familia. Al día siguiente, el 4 de julio de 1877, "La Prensa" destacaba que Klapenback estaba quebrado y por eso debió vender propiedades que pertenecían a su familia. Más allá de los motivos o circunstancias que se pudieran acotar, al igual que Blancas, el cronista no dejaba de considerar lo sucedido como un desenlace inexplicable. La carta de Klapenback sólo servía para documentar el estado de locura que afectó al asesino suicida. Ésta decía lo siguiente:

Vosotros, mis queridos hijos y lo mismo vuestra desgraciada madre, son las victimas espiatorias que van a pagar una falta que no habeis cometido, $\mathrm{Si}$, es necesario que la familia Klapenback concluya, antes de perecer de hambre. ¡Hijos mios, morid con vuestra madre! 
Los medios gráficos dieron cuenta también de las particularidades del entierro y el importante cortejo fúnebre que lo antecedió. Según el cronista de "La Nacion", el 3 de marzo de 1877, los restos fueron trasladados en un cortejo con dos carros. En uno, iba solo Eduardo Klapenback; en el otro, su familia. Los restos de Eduardo fueron enterrados en el panteón de su padre. Como la esposa era familiar de Domingo Faustino Sarmiento, su cuerpo fue depositado en la bóveda de la familia Sarmiento, junto con los restos de sus hijos. El cronista acotaba: “¡Que profundo significado tenía esa separación establecida después de la muerte entre los restos de los que en vida formaron una sola y amorosa familia!" (“La Nación”, 04/03/1877).

Dejando de lado este tipo de casos más escandalosos y atípicos, los suicidios no siempre eran considerados actos de locura. Como ya mencionamos (y podemos inferir de lo expuesto por Blancas en el caso de Nicanora), existían zonas de frontera, como las de quienes estaban entre los jóvenes enamorados, o los cansados/hastiados de la vida. Además, había otra posible situación, casi excepcional, en la que los hombres, ciudadanos en defensa de su honra, podían hacer uso de su derecho a la muerte voluntaria con mayor legitimidad, como también explicamos. Por otra parte, dentro del universo de la locura, encontramos dos formas de representar a los suicidas en el saber médico que se corresponden con los relatos presentes en los sumarios judiciales: el individuo que padecía la manía suicida y el sujeto melancólico.

\subsubsection{La monomanía del suicidio}

Según el saber de la psiquiatría alienista (VÁSQUEZ, 1891: 92), la manía suicida o suicidiomanía tenía como característica principal el provocar una exaltación y un estado de hiperactividad. En estos maníacos, las alucinaciones, las ideas delirantes y las ilusiones que la mente les presentaba los excitaban y movilizaban de una forma extrema, al punto de llevarlos a poner fin a la vida. En muchos casos, esto ocurría sin razón aparente y de forma repentina. Para algunos especialistas en el tema, la herencia del sujeto era un factor clave, ya que determinaba las tendencias mentales alteradas que se desarrollarían con el paso de los años. En un momento, se desataban en el cerebro de éste y el maníaco actuaba de forma automática quitándose la vida. 
En varios otros casos, encontramos menciones acerca de esta manía suicida. Luis Vilani (italiano, 35 años, casado) trabajaba como peón en un aserradero. ${ }^{193}$ Hacía sólo tres días que estaba empleado. El 18 de julio de 1887 puso la cabeza en una sierra a vapor lo que le provocó dos heridas graves. Vilani declaró que sólo fue un accidente, producto de un resbalón que lo hizo caer en la sierra. Por otra parte, sus compañeros de trabajo expresaron que no podía tratarse de un hecho accidental bajo ningún punto de vista. La esposa de Vilani explicó que su marido expresaba con frecuencia la idea de suicidarse, por esta razón sospechaba que estuviera afectado por una manía. Para ejemplificar la situación, mencionó que ese día, a la mañana, se despidió de ella diciendo que no sabía si seguiría con vida cuando volviera. También explicó que había tratado de razonar con Vilani, pero que no tuvo ningún resultado y que éste continuaba manifestando sus ideas suicidas. La manía del suicidio dominaba a Vilani. Así también era presentado por los cronistas de "La Prensa" (18 de julio de 1887), un individuo que "hacia algún tiempo padecía de la manía del suicidio".

Una expresión similar aparece en el sumario que relata los hechos vinculados con el suicidio de Clemente Dagradi (italiano, 34 años, casado, sastre). Su cuerpo fue encontrado el 5 de diciembre de 1887 en el barrio de la Recoleta, estaba tendido en la vía pública, en la calle Ayacucho, con una herida de bala en la cabeza. En el interior del chaleco tenía una caja de fósforos; probablemente, el método para suicidarse que había elegido en un principio. Entre sus ropas también fue encontrada una carta con el siguiente contenido: "Inocente soy lo repito Dios por testigo. Si e buscado el modo de asconder mi cuerpo es porque es inocente". El policía estimaba que se trataba de uno de los tantos individuos afectados por la manía del suicidio; ésta alteraba las facultades mentales. Dos días más tarde, el 7 de diciembre, el cuerpo fue reconocido por Manrico Mezzadra, uno los amigos de Dagradi. Éste último le dejó una carta en la que, además de comunicarle que había decidido suicidarse, le encomendaba a sus hijos. ${ }^{194}$

La monomanía era la forma más frecuente de representar a los suicidas como dementes, las reiteradas señales e intentos de quitarse la vida, como si esta idea los dominara, era el tipo narrativo más frecuente que aparecía relatado; aunque no se aludiera con el término manía o monomanía, sí se dejaba en claro que este comportamiento era un signo claro del carácter alterado de las facultades mentales del

\footnotetext{
${ }^{193}$ AGN, FTC-SE, Legajo V17, Vilani, Luis s/tentativa de suicidio.

${ }^{194}$ AGN, FTC-SE, Legajo D24, Dagradi, Clemente, s/suicidio. Según las declaraciones de este último testigo, Dagradi tenía su familia, mujer y dos hijos, en Gualeguaychú (Entre Ríos).
} 
individuo. Por otra parte, desde el saber alienista se destacaba que no se trataba de una locura total, la monomanía suicida era un delirio parcial, es decir "las facultades manifiestamente lesionadas sobre un punto, un orden o varios órdenes de ideas o de afectos conservan aparentemente su integridad en todo lo demás" (BIALET, 1885: 143). Dicho de otro modo, un individuo podía comportarse normalmente en distintos ámbitos de la vida, pero sentirse irresistiblemente impulsado a quitarse la vida en ciertos momentos.

\subsubsection{Perseguidos hasta la muerte...}

Más allá de los matices y las áreas de frontera, en la época estaba claro que existían casos de suicidio causados por patologías psiquiátricas, tanto para los médicos como para la población en general. Una de las situaciones más estereotipadas era el delirio de las persecuciones.

Por ejemplo, Enrique Teytaud (francés, 38 años, albañil), se suicidó porque creía que lo perseguían los masones. Teytaud llegó a la Capital Federal el 15 de octubre de 1882, fue hasta la Fonda de los 3 Hermanos y pidió una habitación para pasar la noche. Luego de cenar un poco de queso, fue conducido a su alcoba. Allí se encerró y como no contestaba los llamados de los empleados, estos acudieron al policía que estaba en la esquina, a fin de que revisara que todo estuviera en orden en la habitación del huésped. Al entrar en el cuarto, encontraron al suicida ya fallecido (se había disparado un tiro de revólver, llevando el cañón hacia dentro de la boca). También hallaron los últimos escritos de Teytaud. Según el sumariante, el contenido de estas notas daba cuenta del estado mental alterado y patológico del suicida. En las mismas, además de solicitar que no se culpara a nadie de su muerte y pedir perdón a todos los que hubiera ofendido, expresaba frases como las siguientes: "me veo perseguido por todas partes...", "Los masones me buscan para meterme en prisión...”. Para el vigilante estaba claro que el suicida padecía de la monomanía de las persecuciones. ${ }^{195}$ Horas más tarde del suceso, un hombre que había sido compañero albañil de Teytaud informó que venía de Tandil y que tenía parientes en dicho lugar. 196

Entre las manías, éste era uno de los cuadros más comunes, en especial, en los

\footnotetext{
${ }^{195}$ AGN, FTC-SE, Legajo T9, Teitand, Enrique Francisco s/suicidio.

${ }^{196}$ El periódico tandilense El Eco de Tandil, el 19 de octubre de 1882, dio a conocer el caso de Teytaud. El cronista mencionaba que la manía que predominaba en los escritos de este suicida era la de las persecuciones, que, en general, terminaban con el suicidio del alienado.
} 
casos de suicidio y homicidio. En estos, como en el caso ya reseñado, las alucinaciones o ideas delirantes, expresadas a los que formaban parte del círculo más cercano al suicida, estaban relacionadas con el miedo a ser atrapados o con la persecución. Así lo expresaba Juana Garrido a su marido. Este declaró que su esposa estaba atacada por el delirio de las persecuciones y por el temor de ser atrapada se había envenenado el 7 de diciembre de 1882, al tomar fósforos diluidos en vinagre. ${ }^{197}$ Estos individuos paranoicos, sintiéndose acorralados, trataban de quitarse la vida. Máximo Morgenterry (danés, 28 años, soltero, agrimensor), por ejemplo, se disparó con un revólver el 24 de mayo de 1873; en sus cartas, explicaba que era perseguido por un magnetizador (practicante de la técnica terapéutica conocida como magnetismo animal o mesmerismo). ${ }^{198}$ Los perseguidores imaginarios podían ser muy variados: la autoridad, la justicia, asesinos, sombras, etc. En el caso de Nicolás Fablo (italiano, 41 años, soltero, peluquero), con frecuencia decía que lo perseguían enemigos invisibles; por este motivo, se tiró al pozo de agua del conventillo donde vivía, el 4 de junio de $1886 .{ }^{199}$

Como mencionaba Ramos Mejía, el sentido común de los legos asociaba frecuentemente a los locos con los delirantes, este tipo de patologías pasaba menos desapercibida que otras, por ejemplo, la melancolía.

\subsubsection{La ambigüedad de la tristeza}

Si el sentido común asociaba la locura con estos ataques a las facultades intelectuales, que se manifestaba en comportamientos extravagantes, en la distorsión de la realidad que dejaban entrever las acciones y los comentarios delirantes, el universo de patologías que identificaban los profesionales de la salud era mucho más amplio. El conocimiento médico de la época planteaba toda una clasificación de los cuadros mentales asociados al suicidio. Vásquez (1891) asociaba los suicidios con varias afecciones mentales, entre otras: el alcoholismo agudo (delirium tremens), el alcoholismo crónico (locura alcohólica), las manías (en general), la melancolía, el delirio de las persecuciones, la locura histérica, la locura religiosa, la locura epiléptica.

\footnotetext{
${ }^{197}$ AGN, FTC-SE, Legajo M20, M. de Garrido, Juana s/tentativa de suicidio.

${ }^{198}$ AGN, FTC-SE, Legajo M4, Morgenterry, Maximo.

${ }^{199}$ AGN, FTC-SE, Legajo F17, Fablo, Nicolás s/suicidio.
} 
Una forma menos notoria de locura, por ejemplo, era la melancolía o lipemanía. Si en las manías, como el delirio de las persecuciones, el sujeto era llevado por la idea recurrente y obsesiva hacia un estado de inquietud y actividad, esto no ocurría en todos los casos de suicidio. En otros, algunos individuos eran identificados por un estado de tristeza profundo, que no parecía tener explicación alguna.

Por ejemplo, Víctor Lepine (francés, 52 años, casado, dueño de una sastrería), manifestaba un estado de profunda tristeza, que era percibido por los dependientes de su negocio. Lepine tenía esposa (que estaba embarazada) y cuatro hijos. ${ }^{200}$ En la carta que dejó, se despedía de ellos sin explicar el origen de su pesar, según el informe de la policía; la nota no quedó en el expediente, ya que la señora de Lepine se la pidió al oficial.

Ramón Aloy tampoco dio a conocer los motivos de su sufrimiento el día que terminó con su vida. Aloy era un joven argentino de 21 años, soltero, que trabajaba como empleado doméstico en la casa de sus patrones. Según los testigos, la noche del 30 de enero de 1879 lo vieron muy triste, llorando desconsolado, y negándose a decirles qué le sucedía. Aloy les pidió que lo dejaran solo, pronto se iría a dormir. Cuando estaban todos acostados, escucharon un balazo; al buscar el lugar de donde provenía la explosión, encontraron a Ramón Aloy sin vida, con una herida de bala en la sien derecha. ${ }^{201}$ En el caso de Luis Gramilla (argentino, 19 años, soltero), cuando lo veían triste respondía que "nadie sabia lo que a él le pasaba". ${ }^{202}$ Según Carolina Baldizzoni, una joven que vivía en el café de la calle Libertad, con frecuencia lo notaban cabizbajo. El 7 de julio de 1881, Gramilla fue allí y le dijo que iba a suicidarse (señalando el revólver que llevaba consigo); acto seguido, le explicó que venía a tomar un trago de despedida y la invitó a compartir una bebida con él. Según uno de los testigos que observó lo sucedido, el joven tenía lágrimas en sus ojos. Pasada la medianoche, alrededor de la una de la madrugada, se quitó la vida dentro de un coche disparándose con un revólver en la cabeza.

Desde la perspectiva del saber médico, la tristeza era un signo de melancolía.

\footnotetext{
${ }^{200}$ AGN, FTC-SE, Legajo L14, Lepine, Víctor, s/su suicidio.

${ }^{201}$ AGN, FTC-SE, Legajo A3, Aloy, Ramón, s/ su suicidio. El diario La Prensa, del 30 de enero de 1879, dio a conocer el caso de Ramón, pero la noticia daba otra versión sobre la causa determinante. Según el cronista, fue encontrada una carta dirigida a Ramón, cerca de su cuerpo sin vida. De la misma se deducía que la causa habían sido amores no correspondidos. Sin embargo, en el sumario consultado no figura ni se menciona escrito alguno. Tal vez la versión difundida en los diarios provenía de rumores o de declaraciones de la familia que no fueron incluidas en el informe policial, o quizás, una vez más, la imaginación del periodista dio forma a una historia más atrapante.

${ }^{202}$ AGN, FTC-SE, Legajo G18, Gramilla, Luis p/su suicidio.
} 
Ésta era otra de las patologías que el saber alienista asociaba con la muerte voluntaria. El suicidio de los melancólicos, según Vásquez, era motivado por las alucinaciones que la tristeza despertaba en los que padecían la lipemanía, o melancolía suicida. Mientras que los maníacos eran agitados e impulsivos, los melancólicos eran calmos y reincidentes. Por esta razón, este alienista, recomendaba prestar especial atención, ya que: "Se sabe que los melancólicos se distinguen en una cuadrilla de alienados, porque manifiestan tal tranquilidad que simulan momias vaciadas en mármol, según la espresión de un alienista; se encierran en un mutismo absoluto, que parece mentira tengan tanta insistencia por acabar con su vida" (VÁSQUEZ, 1891: 97). Para Alejandro Korn (1883), la melancolía era la forma de locura que más promovía conductas delictivas o criminales en los individuos. Ésta tenía como rasgo característico la tristeza producida por el decaimiento de las capacidades intelectuales. Las oscuras reflexiones que nublaban el juicio del sujeto lo volvían sensible a cualquier acontecimiento adverso, y podían conducirlo a sentir un fuerte hastío hacia la vida, aunque no padeciera delirio o alucinaciones. Si el estado melancólico avanzaba en su desarrollo, podía desencadenar acciones violentas en los individuos afectados, como el homicidio o el suicidio (KORN, 1883: 45-47).

La tristeza era una emoción mencionada en los expedientes como signo del malestar interno del sujeto. Sin embargo, este estado emocional no era prueba suficiente, en la mayoría de los casos, para determinar si el individuo estaba cuerdo o no. Por esta razón, cuando se trataba de presentar el carácter patológico de un individuo, de representarlo como alienado, eran mencionados distintos indicios de su comportamiento "anormal".

\subsection{Los indicios de la ausencia del juicio}

La noche del 27 de febrero de 1887, alrededor de las 23:00hs, Marcelo Uralde (vasco-español, 23 años, soltero, dependiente de un almacén), entró en una casa de prostitución ubicada en la calle Viamonte $\mathrm{N}^{\circ} 356 .{ }^{203}$ Uralde solicitó pasar la noche con una mujer llamada Fatinitza Zackatz. En este prostíbulo también había otras siete personas: Bella Papovich, Maria Beker, Camila Strevel, Elisa Meyer, Berta Hauser, Isabel Steinhauser y Domingo Emilio. Nadie sospechaba que Uralde se quitaría la vida

\footnotetext{
${ }^{203}$ AGN, FTC-SE, Legajo U2, Uralde, Marcelo sumario s/su suicidio y heridas a Takatz, Fatinitza.
} 
allí. Según la policía: "Todas las personas que vieron entrar al suicida, la noche antes, manifestaron no haber notado en su semblante nada que les hiciera sospechar que abrigara tal resolución". Uralde presentaba un comportamiento normal, no respondía al estereotipo del suicida o del loco de sentido común: ¿Cuáles eran los indicios que esperaban reconocer en su rostro y su comportamiento? Tal vez algunos de los que percibió Fatinitza y declaró a la policía. Según la prostituta, ella estuvo en la cama con Uralde desde las 23:00hs hasta la cena y luego de comer volvió a subir y se acostó nuevamente a su lado. El comportamiento de este hombre despertaba cierta incomodidad: "en toda la noche no le habló casi nada, quedándose a ratos al parecer dormido". Todo parecía indicarle a Fatinitza que Uralde "no estaba en su estado normal, pues guardaba casi un completo silencio y su mirada era muy fría e inquieta". A las seis y media de la mañana, Zackatz despertó de forma abrupta a causa de un disparo y descubrió que su rostro tenía varias heridas (el médico de policía, en su informe, explicó que la lesión era seria y comprometía la mandíbula y parte de la lengua, además de que Fatinitza había perdido mucha sangre). Uralde estaba "medio sentado con el semblante descompuesto, mirándola de una manera estraordinaria”. Mientras Zackatz salió a pedir auxilio al patio, escuchó un nuevo disparo: Uralde se había disparado con un revólver en la cabeza. El policía concluía: "Por lo que resulta de lo expuesto presumo que Uralde ha cometido este hecho en un momento de locura".

El relato de los sucesos que llevaron a la muerte de Uralde presenta una serie de elementos que nos parece interesante señalar. En primer lugar, la cuestión de las expresiones del rostro, de la mirada, la forma de expresarse, eran presentadas como indicios para identificar la presencia de una perturbación mental. En un principio, este sujeto no despertó sospechas. Sin embargo, el relato de la prostituta que compartió la noche con él nos presenta otra imagen del suicida: un hombre anormal, que transmitía una sensación incómoda con su mirada y su silencio, esa mirada "estraordinaria" de su semblante delataba la pérdida de las facultades mentales, como si las facciones y los gestos revelaran el desequilibrio interno del individuo. Este era un rasgo observado también por los especialistas en medicina legal:

La mirada es el signo de más importancia en la fácies de los locos- En los maníacos los ojos están brillantes, vivos; la mirada se presenta en armonía con la tema del loco; así, unas veces es altiva, amenazadora, alegre; otras triste, abatida, desconfiada, inquieta. En el estupor la mirada es fija, inmóvil. En los dementes es vacilante, carece de 
expresión y a veces está temblorosa (BIALET, 1885: 101).

Así, los testigos daban por entendido que había características y acciones de los sujetos que les permitían identificar al que no estaba en su "sano juicio". Ahora bien: ¿había otras señales que permitían reconocerlos? ¿Cómo construían, los testigos de los hechos, la figura verosímil del alienado? Lejos de encontrar una tipología de cuadros psiquiátricos, la mayoría de las veces los testigos mencionaban aquellos elementos que permitían demostrar que el otro había perdido la razón, basándose en la observación y sus experiencias, sobre todo si conocían al suicida.

Está claro que ciertas actitudes eran más evidentes que otras. Por ejemplo, en algunos relatos, los suicidas alienados eran presentados padeciendo los efectos de las alucinaciones. Miguel Germán (alemán, 27 años, soltero, carpintero), caminaba sin rumbo por la vía pública, el 20 de noviembre de 1887, explicando que se había cortado las muñecas "porque las sombras le perseguían de noche". ${ }^{204}$ El esposo de Carmela Curcho (italiana, 30 años, casada, alpargatera), a la hora de explicar el suicidio de su mujer, declaró que padecía de alucinaciones relacionadas con seres demoníacos, signo de que tenía sus facultades mentales alteradas. ${ }^{205}$ Juan Stagnaro (italiano, 20 años, casado, sastre), en cambio, decía que veía espíritus. ${ }^{206}$ Hacía tiempo que Stagnaro venía manifestando a su familia (mujer y dos hijos), que pensaba quitarse la vida, tirándose al pozo de agua de la casa. El 9 de noviembre de 1886 llevó adelante su acto suicida y murió ahogado. Los testigos también mencionaron que el suicida ya había intentado, en otras oportunidades, pegarse un tiro, herirse con una navaja y tirarse al río. Su esposa, Luisa Garibotto, explicó que la preocupación por los espíritus y el alcohol lo llevaron a la demencia, no encontraba otra explicación, ya que "sus negocios iban en progreso y no tenía motivos de pena".

El consumo excesivo de bebidas alcohólicas era presentado como un elemento frecuente que iba asociado con los casos de locura y enfermedades mentales. De por sí, el discurso médico higienista alertaba sobre los peligros de las bebidas espirituosas que alteraban los ánimos y el nerviosismo de los individuos y los impulsaba a la locura, el delito y el suicidio. Además, era un hecho que permitía explicar los "raptos de locura", la pérdida momentánea del juicio. El $1^{\circ}$ de julio de 1881, María Carnevale (italiana, 28

\footnotetext{
${ }^{204}$ AGN, FTC-SE, Legajo G39, Germán, Miguel, por suicidio.

${ }^{205}$ AGN, FTC-SE, Legajo C24, Curcho, Carmela, s/tentativa de suicidio.

${ }^{206}$ AGN, FTC-SE, Legajo S37, Stagnaro, Juan, s/su suicidio.
} 
años, soltera, prostituta), se cortó la garganta con una navaja de afeitar en un prostíbulo, ubicado en la calle Necochea $\mathrm{N}^{\circ} 873$. Decía que el diablo se le había metido adentro. El policía explicaba en el sumario que María padecía de alguna monomanía o de esos males que entendía la ciencia, locura producida por un exceso de bebida. En este expediente, el médico afirmaba que la alienación de Carnevale había sido producida por el exceso de alcohol y citaba a uno de los alienistas franceses más reconocidos, Henri Legrand du Saulle. ${ }^{207}$ Santiago Luseli también solía beber en demasía, según el sumario levantado luego de su muerte. El 30 de marzo de 1884, se disparó con un arma de fuego debajo del maxilar inferior. ${ }^{208}$ Este hábito era un hecho que se sumaba a otros indicios expuestos por su esposa: Luseli le mencionaba con frecuencia que tenía deseos de suicidarse (por esta razón ella había escondido el revólver en una alacena), además, la letra de la nota suicida era muy ilegible y se notaba que había sido escrita en un estado de alteración de las facultades mentales. Según los especialistas en patologías mentales y medicina legal, los rasgos de la escritura eran un indicio claro del estado del juicio del suicida:

Los escritos de los locos se distinguen por el desorden, las repeticiones, la falta de ortografía, etc. Ponen a veces mayúsculas en las sílabas medias de las palabras, empiezan con minúsculas, etc.

Debe notarse, sin embargo, que hay locos que escriben bien y hablan desordenadamente y vice-versa (BIALET, 1885: 103).

Las expresiones orales y las amenazas reiteradas a familiares y amigos también podían despertar la alerta del entorno, si bien, por otro lado, a veces no eran tomadas en serio. En este sentido, lo que había dicho el suicida y el modo de expresarse eran un testimonio más de su alteración mental. Estos episodios eran seleccionados y articulados en la trama que iba de la locura a la muerte por mano propia. Luis Müller (francés, 27 años, soltero) fue encontrado tirado en la vía pública con una herida debajo de su pezón izquierdo. Müller confesó que había intentado suicidarse apuñalándose con una navaja y la razón que dio para ello es que sentía remordimientos por haber seducido a muchas niñas tanto en Estados Unidos como en Argentina. Tal vez, el suicida estaba tomándole el pelo al policía, sin embargo, este anotó que estas palabras eran propias de

\footnotetext{
${ }^{207}$ AGN, FTC-SE, Legajo C21, Carnevale, María, s/tentativa de suicidio.

${ }^{208}$ AGN, FTC-SE, Legajo L19, Luseli, Santiago, s/su suicidio.
} 
un loco con sus facultades mentales alteradas. ${ }^{209}$ No se trataba sólo del contenido del mensaje expresado por los suicidas, la forma de decir lo que querían comunicar, los gestos y el lenguaje corporal también eran mencionados en los relatos de los testigos. Agustín Larché (francés, 30 años, soltero, tipógrafo), se suicidó el 6 de octubre de 1882 disparándose con una escopeta en la cabeza en el dormitorio que alquilaba. El inquilino principal de la casa explicó a la policía que ese día notó algo raro en él cuando conversaron, su aspecto y su forma de expresarse le habían parecido extraños, Larché no estaba bien de la cabeza. ${ }^{210}$ Cuando Larché fue a pedirle que lo curara, pues se sentía enfermo, éste le respondió que fuera a ver a su sobrina porque no tenía ganas de levantarse. Santiago Rubia también se expresaba de una forma llamativa y anormal, según la propietaria de la casa de inquilinos donde vivía. ${ }^{211}$ En una ocasión, fue a pedirle el dinero del alquiler y éste le respondió que pronto irían a cobrarlo a la Chacarita. Rubia fue encontrado por la policía en la calle hablando solo palabras sin sentido. En la comisaría, aprovechó un descuido de los vigilantes para desnudarse y herirse en la garganta con un pequeño cortaplumas. Al mismo tiempo, hablar solo también podía ser considerado un signo de locura. El 28 de octubre de 1879, Pedro Ala (español, 36 años, soltero, alpargatero), se cortó con una navaja de afeitar las muñecas y el cuello. Generalmente esperaba a Antonia, su concubina, fuera de la casa donde trabajaba como empleada doméstica y volvían juntos a su hogar. Sin embargo, ese día fue encontrado por su pareja lastimado y tirado en el suelo de la habitación que ocupaban juntos en la casa de inquilinos. La compañera de Ala explicó que solía encontrarlo hablando solo y, por esta razón, le había sugerido que viera a un médico. Antonia sospechaba que su concubino se había herido como resultado de un ataque de demencia. ${ }^{212}$ Ala, por su parte, declaró que había intentado quitarse la vida por disgustos que lo abrumaban (¿habría de fondo algún conflicto entre los integrantes de la pareja?). Hermann Stubber (alemán, 35 años, soltero) vivía en una casa amueblada de la Legación de los Estados Unidos en Argentina; desde que estaba allí, no dormía por las noches y hablaba solo. ${ }^{213}$ Los médicos, por su parte, en sus diagnósticos, también tomaban en consideración las características de la expresión oral para clasificar los diferentes tipos de locura:

\footnotetext{
${ }^{209}$ AGN, FTC-SE, Legajo M27, Müller, Luis, tentativa de suicidio.

${ }^{210}$ AGN, FTC-SE, Legajo L13 A, Larché, Agustín, s/su suicidio.

${ }^{211}$ AGN, FTC-SE, Legajo R10, Rubia, Santiago por intento de suicidio.

${ }^{212}$ AGN, FTC-SE, Legajo A3, Ala, Pedro, s/tentativa de homicidio.

${ }^{213}$ AGN, FTC-SE, Legajo S17, Stubber, Hermann, por suicidio.
} 
En los maníacos la primera es rápida, desordenada y sin hilación. En los dementes es rara, lenta y repiten horas enteras palabras y frases. En los idiotas el vocabulario da la medida del grado: en el último grado apenas articulan sonidos ininteligibles.

Hay locos que guardan un mutismo absoluto, a causa muchas veces del temor de las persecuciones; estos se distinguen por la inteligencia y la vivacidad de su mirada cuando se les habla (BIALET, 1885: 103).

Así, mientras que unos hablaban incoherencias o solos, otros individuos no interactuaban con el entorno o sólo lo hacían para comunicar sus funestos pensamientos. Benjamín García (argentino, 56 años, soltero, empleado doméstico desempleado), era caracterizado, por los que lo conocían, por ser un hombre poco sociable, triste y solitario. Estaba así desde la muerte de su patrón, Julio Becker, tras lo cual quedó sin trabajo. ${ }^{214}$ Como no podía conseguir un nuevo empleo su desesperanza iba in crescendo. En una oportunidad, se le escuchó decir "que el suicidio era una salida valida para los que sufrían como él”. Este comportamiento extraño, la vida solitaria y la tristeza que transmitía fueron mencionados como indicios del trágico desenlace de la vida de García: el 4 de febrero de 1885, en la habitación del conventillo que alquilaba, se disparó en el pecho y en la cara con un revólver; falleció al poco tiempo. Francisco Salas (argentino, 41 años, soltero, cochero) fue representado de una forma similar. ${ }^{215} \mathrm{Su}$ hermano desconocía las causas que lo habían llevado a quitarse la vida, pero Salas estaba más taciturno y meditativo el último tiempo, algo que no era frecuente en él. Otros testigos declararon que les había manifestado sus intenciones de suicidarse, pero sin dar los motivos que lo llevaron a tan trágico final. El 10 de noviembre de 1886, en el cuarto del conventillo que alquilaba, Salas se disparó con su revólver, apuntando el arma hacia su sien derecha.

Félix Guyton y Vicente Nicolás llamaban la atención del entorno con su actitud pensativa y silenciosa. ${ }^{216}$ Guyton (francés, 35 años, soltero) trabajaba como peón en una mercería y se suicidó el 30 de marzo de 1882 arrojándose a un pozo de agua. Su patrón expuso que, si bien no estaba demente, algo le preocupaba, pues varias veces al día dejaba de hacer sus tareas y se quedaba solo, sumergido en sus pensamientos. Nicolás

\footnotetext{
${ }^{214}$ AGN, FTC-SE, Legajo G32, García, Benjamín, s/suicidio. Como veremos más adelante, Julio Becker también se suicidó (véase capítulo 10). AGN, FTC-SE, Legajo B24, Becker, Julio, su suicidio.

${ }^{215}$ AGN, FTC-SE, Legajo S39, Salas, Francisco, sumario sobre su suicidio.

${ }^{216}$ AGN, FTC-SE, Legajo G22, Guyton, Félix, Muerte (suicidio). AGN, FTC-SE, Legajo N3, Nicolás, Vicente, por tentativa de suicidio.
} 
(italiano, 26 años, soltero) trabajaba como empleado en una fábrica de masas). Sus compañeros de trabajo manifestaron que se ocupaba de su tarea, pero no hablaba con nadie, lo veían taciturno, cabizbajo, como si una idea lo dominara. El 23 de febrero de 1882, a las 11 hs de la mañana, Nicolás se hirió con un cuchillo en el costado derecho del torso. Cuando el policía lo interrogó, respondió "que por su placer se había herido". El suicida hablaba como balbuceando sus palabras, presentaba una "faz descarada", con los signos característicos de un hombre enfermo. A diferencia del caso Uralde, ya reseñado, Nicolás presentaba las actitudes, el aspecto y el semblante de un alienado, la locura se expresaba en su rostro. Entendemos que los testigos rememoraban de forma selectiva aquellos datos que les habían parecido curiosos y los utilizaban para dar sentido a lo sucedido. Lo interesante es que esperaban ver en el rostro, o en las actitudes, indicios anormales que anunciaran el desenlace trágico y extremo. Su ausencia también era desconcertante. En el caso de José Lauzani (italiano, 44 años, casado, carpintero), los miembros de su red social imaginaban que su extraño comportamiento (estaba triste y meditabundo, sin responder a las preguntas que se le formulaban), estaba relacionado con la separación de su esposa, madre y otros familiares que había dejado en su tierra natal para trabajar en Argentina. Hacía algunos meses que había llegado y lo único que hacía era sus tareas en el taller de su compadre, Pedro Asnaghi, y su tío, Angel Minotti. El 25 de septiembre de 1886 Lauzani apareció allí ahorcado. ${ }^{217}$

Por otra parte, en algunos relatos aparecían mencionados, como fundamento de la predisposición a la locura, los antecedentes familiares del suicida. Carlos Carlini (italiano, 27 años, soltero, sastre) se suicidó el 13 de junio de 1877. Fue encontrado ahorcado con su cinturón en un taller de herrería. Según los testigos de los hechos, paisanos de la misma región que el suicida, los tíos de Carlos padecían de demencia, estos precedentes permitían comprender el origen del ataque de locura repentino que había llevado a éste a quitarse la vida. ${ }^{218} \mathrm{El}$ factor hereditario de las patologías mentales era tenido en cuenta por la ciencia de la época. Los rasgos enfermizos podían ser transmitidos de una generación a la siguiente, repitiendo, en muchos casos, las mismas historias. Esta creencia también circulaba entre otros actores sociales, por fuera del círculo de la elite cultural erudita, y era un indicio que permitía explicar la alteración de las facultades mentales. Este tipo de casos ocurría en todas las clases sociales, según

\footnotetext{
${ }^{217}$ AGN, FTC-SE, Legajo L24, Lauzani, José.

${ }^{218}$ AGN, FTC-SE, Legajo C7, Carlini, Carlos, s/suicidio.
} 
Vásquez (1891: 31): “Conocemos familias distinguidas de esta capital, cuyos nombres no mencionamos, en el seno de las cuales se han producido varios suicidios por herencia neuropática”. César Medici, por ejemplo, hijo del Dr. Luis Medici, ${ }^{219}$ se quitó la vida el 26 de agosto de 1876, cerca de las 10hs de la mañana, con un disparó de arma de fuego en su corazón. Los hechos tuvieron lugar en su casa de familia. Al escuchar la detonación del arma de fuego, todos concurrieron a la habitación y encontraron al joven moribundo, quien les dijo: "Yo me he herido, ya no hay más remedio". Según la declaración de Luis Medici, su hijo padecía de una perturbación mental, por esta razón no podía concentrarse en los estudios, tenía cambios de ánimo abruptos y se negaba a salir de noche; todo esto denotaba que estaba enfermo de la cabeza. Al mismo tiempo, el padre de César destacó que la madre del suicida también había experimentado una enfermedad mental poco antes de fallecer. Por otra parte, el alienista Vásquez destacaba que, si el caso se repetía dentro de una misma familia, tendía a ocurrir en las personas del mismo género, en la misma edad que el antecesor y con el mismo medio.

\subsection{La responsabilidad y la memoria del suicida}

Antonio Rocatagliata era un comerciante italiano de 47 años, que vivía con su familia (su esposa, Josefa Carbonetti, y sus cuatro hijos) en la ciudad de Buenos de Aires, en una casa ubicada en la calle Callao $\mathrm{N}^{\circ} 201 .{ }^{220}$ Conocemos su historia gracias al testimonio de su hijo. En 1876, el negocio de Rocatagliata estaba pasando por momentos difíciles; ésta fue la primera vez que perdió la razón. Por este motivo fue trasladado a un manicomio donde estuvo internado tres meses. Se recuperó y regresó a su hogar, donde continuó viviendo tranquilamente hasta 1880, año en que tuvo un nuevo episodio de trastorno de sus facultades mentales. Frente a esta situación, Antonio fue enviado a Europa para recibir el tratamiento adecuado. Estuvo del otro lado del Atlántico durante un año, cuando regresó a la capital argentina parecía estar curado

\footnotetext{
${ }^{219}$ AGN, FTC-SE, Legajo M10, Medici, César, s/su suicidio. El caso fue dado a conocer en las páginas del diario La Prensa (26 de agosto de 1876). No se especificaba que la causa del suicidio se debiera a una patología mental. En cambio, el cronista mencionaba que el hijo de aquella respetable familia de Barracas al Sud había sido diagnosticado con una enfermedad difícil de sobrellevar y que por esta razón había empezado a pensar en la idea del suicidio.

${ }^{220}$ AGN, FTC-SE, Legajo R26, Rocatagliata, Antonio, s/suicidio.
} 
completamente de sus males. Sin embargo, los buenos tiempos no duraron mucho. En 1884, la monomanía del suicidio volvió: "El suicidio era una idea fija en su mente, y siempre se le oía decir que no podía vivir mas", explicaba su hijo a la policía. Las razones originales que lo habían desequilibrado, los problemas de sus negocios ocurridos en 1876, ya habían desaparecido para ese entonces y todo marchaba bien. Tampoco había conflictos al interior del grupo familiar. Rocatagliata vivía con su esposa e hijos en perfecta armonía. Pero Antonio repetía muy frecuentemente que no deseaba seguir viviendo. En una oportunidad fue sorprendido tratando de colgarse de un árbol en el Parque Tres de Febrero. La familia Rocatagliata estaba en estado de alerta y, por esta razón, vigilaban de forma constante a Antonio. Sin embargo, dormía en una habitación solo. El $1^{\circ}$ de abril de 1884 , mientras todos dormían, pudo burlar los controles y se suicidó durante la noche; fue encontrado ahorcado por uno de los empleados domésticos a la mañana siguiente. El policía que redactó el sumario agregó un detalle no menor al relato: en varias oportunidades actuó como mediador entre Rocatagliata y su familia, ya que éste deseaba continuar con la administración de su negocio; su familia se oponía, pues temían que afectara el estado de sus facultades mentales y los problemas que podía conllevar. En cierto modo, quizás, el agente policial cuestionaba el accionar de los integrantes del grupo familiar del suicida y rompía con la imagen de un hogar armonioso. Así, el relato del policía agregaba un elemento a la historia que modificaba la posible interpretación del mismo: el conflicto familiar detrás del relato de los otros significativos sobre la locura de Antonio Rocatagliata. El suicidio de un alienado, muerto por su propia condición, era un hecho escandaloso, pero no cuestionaba el rol cumplido por los miembros de la red afectiva de contención en lo sucedido, es decir, no ponía en tela de juicio la reputación de los deudos, como en otros casos que analizaremos más adelante.

Los medios gráficos difundieron el suicidio de Rocatagliata, presentándolo como el resultado de la manía suicida que afectaba al comerciante y padre de familia. En dos oportunidades, en 1870 y 1881, había corrido peligro su negocio, esto lo llevó a la desesperación y la locura; ver que el trabajo de una vida, la fortuna forjada se perdía, trastornó su razón y fue lo que hizo surgir la idea del suicidio. Nada se mencionaba sobre las potenciales peleas dentro del entorno familiar. El relato de lo sucedido estaba articulado, por un lado, a partir del estado mental de Rocatagliata, de la idea obsesiva, reiterada y frecuente de suicidarse que lo dominaba; y, por el otro, en la lucha de su familia por preservarlo de su propia autoaniquilación. En este sentido, la noticia 
publicada en "La Prensa" del 2 de abril de 1884 resaltaba que la familia había hecho todo lo posible para asistirlo en el tratamiento de su patología (había sido atendido en el Hospicio de las Mercedes y en Europa), y que lo habían salvado a tiempo, en varias oportunidades, de quitarse la vida. Desde que su razón se había desequilibrado, su mujer se hacía cargo de la tienda y mercería de la que eran propietarios. Del mismo modo, el cronista de "La Nación”, el 2 de abril de 1884, resaltaba el papel de la esposa y los hijos para vigilar a Rocatagliata y preservarlo de sí mismo: todas las noches revisaban que no llevara cuerda alguna a su cuarto, ya que el suicida les manifestaba que sólo se quitaría la vida de ese modo, ahorcándose. También destacaban que: "Era un hombre de fortuna y uno de los italianos mas laboriosos de Buenos Aires, así como unos de los comerciantes mas conocidos en el ramo de tienda y mercería”. Rocatagliata también era conocido por ser un importante especulador en la compra de tierras, después de 1871, aunque "se distinguió edificando muchísimas casas, lo cual lo diferenciaba ventajosamente de los demás especuladores que se limitaban a vender caros los terrenos que compraban baratos". Los restos del suicida fueron enterrados en el Cementerio de la Recoleta. En síntesis, el relato presentado en los medios gráficos resaltaba el papel de la enfermedad mental de Rocatagliata, provocada por los reveses de su fortuna, y el rol de su red de contención familiar para preservarlo de sí mismo. No había ninguna mención de las tensiones que afectaban el interior del grupo familiar.

Una estructura narrativa similar podemos encontrar en el caso de Juan Bayleg (argentino, 68 años, casado, rentista), quien se quitó la vida dándose un disparo de revólver en el lado derecho de la cabeza, en el comedor de su hogar, el 12 de agosto de 1886. Allí vivía con su esposa e hijas, quienes estaban en la pieza contigua al cuarto donde Bayleg se suicidó. Ellas acudieron de inmediato al oír el disparo y se encontraron con su cuerpo fallecido. Al declarar sobre lo sucedido, expresaron que desconocían las razones por las que Bayleg se había suicidado, aunque también explicaron que el comportamiento de éste había cambiado tras padecer una enfermedad. Así, los sufrimientos físicos habían alterado las facultades mentales del esposo y padre. Impulsado por su demencia, les había dicho, en varias oportunidades, que tenía la idea de quitarse la vida; en una de ellas, probó el revólver para que estuviera listo para el momento de darse muerte. Creemos relevante resaltar que la familia de Bayleg puso énfasis en remarcar que no había ninguna clase de disgusto en el hogar. Esta aclaración, como en otros relatos que hemos presentado, evidencia lo verosímil que resultaba imaginar las peleas dentro del grupo familiar como la "causa determinante" de los 
suicidios.

Por ejemplo, el 19 de diciembre de 1885, Avelino Silva Sandoval (oriental, 17 años, soltero), tuvo una acalorada discusión con su hermana que terminó en un desenlace sangriento: en medio de un "intercambio de palabras", Avelino, ebrio, sacó un cuchillo de la cintura, exclamó "me mato" y se lo clavó en el costado derecho del pecho. Los parientes del suicida declararon que éste venía expresando con frecuencia su deseo de quitarse la vida, sin conocer la causa. Avelino, por su parte, declaró que había tenido un ataque de epilepsia mientras sostenía el cuchillo, durante la cena. Las ideas científicas de la época solían asociar los casos de suicidio con los que padecían este trastorno del sistema nervioso. Avelino, tal vez, buscó justificar lo sucedido a partir de una patología que le quitaba su voluntad y su libre albedrío, al tiempo que no revelaba aquello que había estado discutiendo con su hermana. Esto explicaría las distintas versiones de lo sucedido. ${ }^{221}$

Desde nuestra perspectiva, la locura del sujeto suicida, como elemento explicativo dentro del relato de los hechos, daba lugar a una interpretación que era más benévola con la memoria del suicida y con la responsabilidad de los deudos que aquella que tenía de fondo los conflictos y resentimientos familiares. En el libro titulado El suicidio (1886), su autor, Pacífico Garelli, planteaba lo siguiente:

El estudio que en estos últimos años se ha hecho para declararlos [a los suicidios] todos y siempre como efecto de demencia, manifiesta el deseo de todos de disculparlos, pero a la vez prueba que todavía no se tiene el coraje de admirarlos a cara descubierta. Se tributan honras fúnebres civiles a los amigos aunque suicidas, pero no se ha llegado todavía al punto de tal hacer porque suicidas (GARELLI, 1886: 30).

Creemos que el párrafo anterior resume en gran medida la mirada sobre los suicidas y la imagen que la sociedad tenía de ellos. En este período, lo que era considerado una "buena muerte" estaba lejos de incluir un suicidio como causa de la defunción, menos entre los miembros de las elites. Por otra parte, tratar como alienado mental al suicida, si bien no lo enaltecía, era menos bochornoso que otros casos en los que había una responsabilidad del suicida o de sus deudos en lo ocurrido.

El caso de Santiago Onetto resulta ilustrativo de esto último. Onetto (italiano, 37

\footnotetext{
${ }^{221}$ AGN, FTC-SE, Legajo S34, Silva Sandoval, Avelino, antecedentes relativos a su tentativa de suicidio.
} 
años, casado), tenía un estaqueadero en sociedad con su suegro. ${ }^{222}$ El 18 de agosto de 1881 se disparó con una escopeta a la altura de la barba. Ese día se encontraba solo en su domicilio. Estaba separado de su esposa, quien vivía en otra casa con los hijos del matrimonio. La razón, el consumo de alcohol en exceso. Onetto volvía ebrio con mucha frecuencia a su casa y esta situación generaba conflictos y disgustos esperables y evidentes, según los testigos y el policía que redactó el sumario. Por otra parte, la expareja de Onetto declaró que, desde que se había separado, la relación entre ambos era mantenida en buenos términos, amigablemente, y visitaba a sus hijos todos los días. Los miembros de la familia explicaron que no estaba peleado con ninguno de ellos y que los negocios del suicida, por el momento, marchaban bien. Por esta razón, la única explicación que aventuraban era que se había suicidado en un momento de abuso de "bebidas espirituosas" que alteraron sus facultades mentales. El relato de lo sucedido buscaba dejar en claro que las relaciones entre Onetto, su ex-esposa y su familia política eran cordiales, a pesar de los probables conflictos que habían motivado la separación del primero y su grupo familiar. Por otra parte, la locura y el consumo de alcohol eran una combinación verosímil, que al tiempo que disculpaba, de forma parcial, al suicida por lo sucedido, presentaba a los vínculos del sujeto como armoniosos y carentes de cualquier resentimiento o discordia. Tal vez, sin dichas aclaraciones, podría pensarse que fue la separación familiar la causa determinante de la muerte del suicida; quizás, este relato era también una forma de presentarse a sí mismos como inocentes de un hecho trágico y traumático para el grupo familiar. En este sentido, si observamos cómo fue tratado el suicidio de Onetto en el diario "La Nación" (20/08/1881), veremos que este fue presentado de forma breve y telegráfica, en el que se explicaba que éste se había suicidado "dominado por espíritus alcohólicos".

En el caso de Mateo Luchessi (italiano, 33 años, casado, propietario de una marmolería), la alienación mental que padecía no sólo fue la "causa determinante" de su suicidio (se envenenó tomando una disolución de fósforos el $1^{\circ}$ de julio de 1886), sino también el justificativo de la separación de sus hijos y esposa, poniéndose ésta última al frente del negocio. ${ }^{223}$ Según lo informado por "La Prensa", Luchesi padecía el delirio de las persecuciones. En algunas ocasiones, para escapar de sus enemigos, salía y repartía dinero entre las personas que pasaban por la puerta. En varias oportunidades les había comunicado que se quitaría la vida. La esposa de Luchesi había pedido a la policía que

\footnotetext{
${ }^{222}$ AGN, FTC-SE, Legajo O2, Onetto, Santiago, por suicidio.

${ }^{223}$ AGN, FTC-SE, Legajo L23, Luchessi, Mateo, s/su suicidio.
} 
interviniera, para evitar, por un lado, el escándalo y la vergüenza, y por el otro, que Luchesi dilapidara los ingresos que su familia, esposa e hijas, necesitaban para vivir. En el relato, el cronista no hizo mención alguna a la separación de Luchesi, la narración sólo presentaba a un individuo afectado por el delirio de las persecuciones que comprometía la honra y el bienestar de su grupo familiar.

Muy diferente fue la narración del suicidio de Emilio Barceló (argentino, 50 años, separado). Barceló se quitó la vida el $1^{\circ}$ de agosto de 1882 a las $15: 30$ hs con un disparo de arma de fuego, debajo de la tetilla izquierda, en la habitación de una pensión donde vivía (Independencia $\mathrm{N}^{\circ} 165$ ). Según consta en el sumario, la noche anterior le había comentado a uno de sus sobrinos que "tenía deseo de tomar una cantidad de opio para quitarse la vida”. Barceló se había separado de su esposa hacía cinco años, tenía ocho hijos y una hija, y toda su familia residía en Barracas al Sud. El suicida dejó dos cartas. Domingo, uno de sus hijos, reconoció la letra de su padre. El policía que hizo el sumario dedujo, por el contenido de estas, que fueron "disgustos de familia" lo que motivó su suicidio. Lo que llegamos a entrever por el contenido de esas notas es que Barceló guardaba un profundo resentimiento hacia su familia. A continuación, reproducimos el contenido de la primera:

[Es]ta muerte deshonrosa me dan

[Parri]cidas, Parricidas, Parricidas

Gosedensen(?) en su obra

Que yo ruego a Dios por Ud.

Como podemos ver, el suicida, con su carta, llevaba adelante una acción comunicativa regulativa agresiva; buscaba culpar a los que lo habían conducido a ese deshonroso destino, es decir, condenaba a sus hijos y a su esposa por su muerte.

En la segunda carta, los acusaba más directamente de haberlo abandonado:

Porque más bien no me pego un tiro desde lo primero, si veo preferible a lo que e pasado porque no me matado an[tes]

Mi muger e hijos me echaron de [ilegible] casa, me persiguieron, me insultaron, desolleron mis suplcas. Me embargaron lo que les e querido dar, me ejecutaron me metieron pleitos calumniosos e injustos, me han asesinado, me redujeron a la caridad pública, me odian con rencor y sin piedad ni lastima, yo pido a Dios por ellos y por mi Dioslos allude los ampare los faboresca y los aga completamente felices, soy el Cristo de ellos, inocentes menores sean 
felices.

Gregorio, Emilio, Domingo y [ilegible] Barceló se han manchado y degradado Us. Mismos con su venganza. Una muerte: Parricidio, Parricidio, Parricidio [ilegible] ni saben lo que por [ilegible] de odio y benganza a quien no deven sino bienes. Sean muy felices, Dios y María Santísima los ampare los [ilegible] y los lleve a su reino, yo lo pido a Dios por Us. Acuerdense todo lo que han hecho conmigo para que Dios les de severo arrepentimiento, tomen con mi muerte lo que les ofrecí espontaneamente en vida [,] por morir al lado de Us. Les pesara tarde lo que han hecho conmigo, la soberbia, el orgullo, la colera, el abuso persecución y muerte que me han dado gosesen en su obra y [ilegible] toda su vida, no hablo sino pa Us. Recuerden mis humillaciones para arrepentirse [.] ante el mundo los declaro virtuosos conmigo [.] conmigo es el unico que se han robado hasta las heses, es el Diablo que los a tentado cotra mí únicamente, tan buenos para todos y para mi implacables enemigos.

Dios, los ampare, los haga felices, si[empre?]

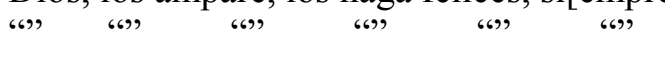

" " " " " " " " " $"$

“" “" y perdone a Us. y sea Misericordioso, Divino, Redentor, Virtuoso, Maestro, Padre Eterno

Feliz mis perseguidores y perdon [ilegible] a mi para siempre, me enlo[ilegigle] vos me enfermavas y me sui[ilegible] van, despues de todos los tor[men]tos de la vida me atormentaron, me desesperaron, me desonra[ron] y me han hecho pasar más de una muerte en humillaciones $\mathrm{y}$ tormentos, todos los tormentos, humillaciones $\mathrm{y}$ deshonras, desonras Gregoria, Emilio, Domingo y Laura [por] que no me mataron antes de esta persecución, mil muertes antes de tantos tormentos el redentor del mundo sufrió menos que yo. Cristo el Dibino Maestro, ese Virtuoso y Martir Peregrino su martirio fue mas corto que el mio, por eso [ilegible] hire a su lado.

Me han dado pasmoso martirio [ilegible], estudiado y cruel.

Gosen, Gosen, Gosen en mi triste fin

"" " " " " " " " " "

Toda la vida piensen en su obra, mis palabras, la perdida de mi razon, humillacion, caridad publica, mi suicidio, mi triste fin, mi muerte [,] todo ha sido pasmosa persecución [ilegible] Todos los motivos de[ilegible] ninguno sufrió como yo, [des]de el principio del mundo [ilegible] que pierde el juicio de sufrir y lo siguen perseguiendo haste el suicidio y Parricidio, [ejem]plo de esta pasmosa persecucion y martirio, mil muertes son [poco?] en comparación, meses de melancolia, monomania, tristeza, [ilegible], desesperación, desonras, miseria. Todos, todos, todos, los males [ileg] de la tierra espere aguardando caridad, clemencia, lastima, arrepentimiento nada, nada nada encontro, nadie sintio esto sin para [ileg] de lo que dejo, para los cuatro [ileg] mas sin nungun valor [ileg], Perdonalos Santo Padre mis [ileg] que $\mathrm{n}$ saben lo que acen, faborecelos iluminalos, amparalos, arrepentidos para siempre, hasta con la desgraciada victima que han hecho, no saben lo que acen, no saben lo que acen. Dios mio a mi llebame otro lado, perdoname, amparame, para siempre, Dios mio, porque te amo, te adoro, y en ti confio y confian para siempre contando con tu [ileg] Gloria que [ileg] mis cien mil martirios por todos, perdon diós mio, Perdon, Perdon, Perdon, no los castiguen con el [ileg] deshonra ni con mi [ileg] amis enemigos mencionados perdonadlos, perdonadlos. 
Entre los pedidos de perdón para sus hijos y los llamados a la intercesión divina, Barceló denunciaba la ingratitud y el abandono que había sufrido, algo que sentía como injusto por haber cumplido su rol como padre, proveedor material. Hacía responsable a su esposa e hijos por la miseria, la deshonra y los meses de sufrimiento en los que había padecido los efectos de la melancolía y la monomanía: tristeza y desesperación. Tanto "La Prensa" como "La Nación" del 2 de agosto de 1882 narraron lo sucedido bajo el mismo esquema. El cronista de "La Prensa" destacaba que la familia se negaba a dar detalles íntimos en público. Por otra parte, resaltaba el hecho de que Barceló se había separado de su familia por un conflicto, aunque había intentado regresar junto a ellos no lo logró. Desde entonces continuaba melancólico y meditabundo. Según el cronista, era probable que no hubiera podido superar el rechazo de su familia y la decepción que esto le generó. Esta última causa era la más verosímil. Del mismo modo fue presentada la noticia por "La Nación”. En el relato de lo sucedido, Barceló era presentado como una víctima de abandono por parte de su familia, lo opuesto al rol protector que esta debía ofrecer a los hombres en su lucha diaria para enfrentar la vida.

En síntesis, era más escandaloso relatar que los conflictos familiares fueron los que condujeron al sujeto a desear la muerte. En cambio, las narraciones articuladas a partir de la locura disculpaban al suicida ante el resto de la sociedad, al menos de forma parcial, ya que no era consciente de sus actos y dejaba sin responsabilidad por lo sucedido a familiares y amigos, el único victimario era la propia patología individual (o la predilección por el vicio) del alienado: no había nada que los miembros de la red social y familiar del sujeto pudieran hacer frente a un individuo que, en reiteradas oportunidades, había manifestado que deseaba suicidarse y/o había llevado adelante varios actos suicidas. Algunos, por pudor, tal vez, ocultaban las peleas familiares para preservar una imagen positiva frente a su red social de vínculos. Lo que nos interesa resaltar aquí es el valor ético diferenciado que tenían los casos de locura: la apreciación de los hechos era más compasiva y comprensiva con el suicida y su entorno que si mediara, en la trama, un hogar hostil y en constante discordia como contexto de lo sucedido.

\subsection{Luchar contra la locura estoicamente}


Federico Pujol (argentino, 26 años, soltero) llegó a Buenos Aires a fines del mes de marzo de $1885 .{ }^{224}$ Había llegado a la ciudad en un vapor proveniente de Carmen de Patagones para recibir tratamiento médico y psiquiátrico. En su lugar de origen le habían diagnosticado una clase de enajenación mental. Asimismo, su familia lo veía cabizbajo y pensativo. En la capital federal, sus familiares solicitaron un diagnóstico a los doctores Pirovano y Castilla, quienes, desafortunadamente, sólo pudieron recomendar a la familia de Pujol que mantuvieran a Federico distraído, era todo lo que podían hacer por el momento. Pujol informó a sus parientes que deseaba irse a vivir solo, a una casa, a la que finalmente se mudó. Diez días más tarde, el 23 de abril de 1885 fueron a verlo, pero, cuando golpearon la puerta, nadie respondió. Al temer lo peor, fueron a buscar a la policía. Al entrar en la casa, lo encontraron en la cama bañado en sangre, con un revólver en la mano derecha que apuntaba a la sien y la izquierda en el pecho. La familia del suicida adjudicó la extrema resolución de Pujol a su estado de alienación mental. Fue representado por los testigos como triste y meditabundo, pero sus acciones estaban lejos de la exaltación desmedida de las pasiones o la excitación exacerbada de las monomanías. Podría ser caracterizado como un melancólico. Lo cierto es que este relato nos presenta a un individuo que recibió la noticia de que no había un tratamiento preciso para el malestar psíquico que lo afectaba. No sólo percibía los primeros indicios de que sus facultades mentales no estaban del todo bien, sino que sabía que no había un pronóstico alentador para el futuro. ¿Cuál podía ser la actitud de un individuo que se encontraba en esta situación? Pujol dejó cartas a su familia, en las que, tal vez, daba alguna explicación sobre su decisión. Sin embargo, estas no quedaron conservadas en el expediente.

La reflexión de José María Ramos Mejía quizás pueda darnos algunos indicios de cómo se veía a sí mismo Federico Pujol. Como mencionamos en el capítulo 5, Ramos Mejía expuso en un artículo llamado "La tentación del suicidio" (1896) que la mayoría de los suicidas eran seres de complexión mental débil, hombres y mujeres que no soportaban las demandas de la vida en el mundo civilizado y sucumbían presos de la locura o terminando de forma abrupta con su vida. Sin embargo, el destacado médico alienista señalaba que existía un subgrupo de situaciones especiales y muy dolorosas, desgracias irreparables, en general, vinculadas con la virilidad masculina y con la deshonra en público. Frente a este tipo de circunstancias excepcionales, el suicidio

\footnotetext{
${ }^{224}$ AGN, FTC-SE, Legajo P31, Pujol, Federico, sumario levantado con motivo del suicidio de éste.
} 
podía ser un refugio supremo, haciendo referencia a la postura estoica sobre la muerte por mano propia. Una de estas tragedias sin remedio era la del hombre que podía percibir la llegada de la locura. La alienación mental era una forma de muerte en vida lenta y degradante; desde la perspectiva de Ramos Mejía, quitarse la vida con valor y serenidad, eligiendo una muerte temprana a una existencia sin el pleno uso de la razón, era un desenlace menos aterrador que la imagen de los individuos encerrados en las instituciones psiquiátricas.

El prestigioso profesional de la salud tal vez recordaba, entre otros pacientes que debió atender a lo largo de su carrera, al teniente de la Armada Juan C. Picasso. Picasso se suicidó el 23 de junio de 1888. Su cuerpo fue encontrado dentro de un carruaje con una herida de bala en la frente. Entre sus ropas fue hallada una receta escrita por Ramos Mejía con la última frase del suicida: "Silencio y olvido. Este es mi destino". ${ }^{225}$ Ramos Mejía pidió el cuerpo para hacerse cargo del entierro. Tal vez, sintió compasión o, quizás, vio en el teniente Picasso a uno de esos hombres que escapaba estoicamente de una vida degradante. Entre la locura y el suicidio, el segundo no era imaginado como el peor de los desenlaces.

La forma en la que fue presentado este suicidio en los medios gráficos es muy diferente al común de los casos. Ya desde el título de la noticia publicada el 24 de junio de 1888 en el diario "La Prensa", "Teniente de navío Juan Picasso", podemos apreciar que no se trató de la muerte por mano propia de cualquier individuo: "Juan Picasso ha muerto", "sobre su tumba puede decirse la verdad, era el primer oficial de la marina de guerra de la República”, expresaba el cronista. El suicida había sido un ilustre y joven oficial con una sólida formación científica en matemática y astronomía. Como miembro de la marina, había estado a cargo de comandar embarcaciones en diversos ejercicios y como parte de la comisión enviada a Misiones para resolver cuestiones relacionadas con los límites del territorio nacional. Ya había intentado suicidarse dos veces antes del último acto suicida. Gracias a la vigilancia de su red social habían podido prevenir su muerte hasta ese entonces. Estos estaban siempre atentos a sus bruscos cambios de ánimo: pasaba de estar alegre y comunicativo a permanecer callado, triste y reservado. Estos, con frecuencia, le preguntaban cómo se sentía. Sin embargo, Picasso negaba tener intenciones de suicidarse y cambiaba de tema, desviaba la conversación hacia temas científicos de los que hablaba con frecuencia. Para tranquilizar a sus amigos había

\footnotetext{
${ }^{225}$ AGN, FTC-SE, Legajo P40, PICASSO, Juan C., su suicidio.
} 
distribuido sus armas entre ellos. La noche anterior al día de su muerte estuvo conversando con un coronel de apellido Guerrico, quien lo notó calmado y de buen humor. Como figura en el sumario, el acto suicida tuvo lugar en un coche que tomó en la Plaza de la Victoria. Antes de subir, le pidió al cochero que se dirigiera a toda velocidad al Hospital San Roque. Poco antes de llegar, un disparo alertó al conductor del carruaje y al abrir éste la puerta del coche se encontró con el cadáver de Piccaso. Según el cronista, sólo dejó una carta de despedida para el coronel Guerrico, redactada en términos “vagos y a veces incoherentes". El velorio se realizó en la casa de Guerrico (los padres de Picasso habían fallecido) y sus restos fueron acompañados por amigos y gran parte de los miembros de la armada hasta el Cementerio del Norte. El Centro Naval, en reunión extraordinaria, había resuelto invitar a sus miembros a participar de la procesión, encomendando al teniente Manuel Domeq García a que pronunciara las palabras de despedida en el entierro. En su discurso, publicado en "La Prensa" el 26 de junio de 1888, Domeq se expresó en términos elogiosos sobre el difunto, apelando a los enunciados usados para adornar una "buena muerte":

Palpitante esta aun en nuestros corazones la impresión terrible que nos embarga, por la violenta separación de la vida del compañero de armas cuyos despojos inanimados venimos a depositar con profunda emoción en este recinto eterno descanso. Respetemos los misterios que encierran las resoluciones supremas e inclinémonos con religioso recogimiento ante la tumba prematura del hombre instruido e inteligente, del oficial pundonoroso y valiente que dejo ancho claro en las filas de nuestra joven marina, para no volverse a incorporar jamás a ella. La vida de las grandes inteligencias tiene un no se que de misterioso e inexplicable y, quien sabe si más allá en los velados arcanos de lo infinito no encuentren ancho campo para su desarrollo, aquí empequeñecido e insuficiente. Juan Picasso no es para ninguno de los presentes un nombre desconocido y ha sido el primer oficial que dejo las bancas de la Escuela Naval Argentina, fue su alumno fundador y por lo tanto el decano de todos los que a ella hemos pertenecido. [...] Su apología puede condensarse en esto Perfecto oficial de marina. Mas elogios no precisa, pues estas palabras sintetizan: la instrucción, la honradez, el valor y el patriotismo. [...] Teniente de navío don Juan Picasso. El Centro Naval, al cual pertenecíais, que encarna en si la mayoría de tus condiscípulos de antes, tus amigos de ayer y que, perdido, te lloramos hoy, -en nombre de quienes pronuncio estas palabras, os ha dedicado la modesta y pura ofrenda de esta cruz, símbolo de la paz eterna, que todos deseamos para tu alma. 
Mientras "La Prensa" presentaba este perfil modelo de Picasso, un prototipo ideal para los jóvenes de la armada, "un ejemplo digno de inspirar la conducta de la brillante juventud" dentro de la armada nacional, no daba detalles de su estado mental. En las noticias publicadas en el diario "La Nación”, en cambio, el discurso sobre el suicidio del joven teniente presentaba algunos matices dignos de ser rescatados. En primer lugar, se explicitaba la patología mental que lo afectaba: "Picasso tenía la monomanía del suicidio" (“La Nación”, 24/06/1888). No había motivos para los tres actos suicidas que había llevado adelante, "todo le sonreía”, sólo la influencia de la monomanía podía dar cuenta de lo sucedido. Así mismo, se mencionaba que el Dr. Ramos Mejía atendía al joven teniente, al cual apreciaba mucho, y le estaba administrando un tratamiento en el Hospital San Roque, durante los cinco días anteriores a que pusiera fin a su vida. Por otra parte, el titular de la noticia no era "suicidio", sino "Juan Picasso". En este sentido, al igual que en "La Prensa", también se mencionaban las cualidades destacadas del suicida, su trayectoria distinguida como oficial de la armada, así como su "vasta preparación” y "caballerescas cualidades". De esta manera, la enfermedad mental de Picasso no restaba mérito a sus logros. Por el contrario, aparecía integrada dentro del relato que exaltaba sus cualidades incluso al enfrentar la locura:

Después de aquella tentativa de suicidio [la segunda] y antes de someterse a la asistencia médica, Picasso tomó una determinación que revela tenía conciencia del estado anormal de sus facultades.

Debía contraer matrimonio y todo estaba ya dispuesto para ello cuando la víspera del día fijado para efectuarse la ceremonia se presentó en casa de los padres de la novia y les manifestó que iba a emprender un viaje a Europa y aplazaba el casamiento hasta su vuelta. Esta resolución que parece un acto de locura fue por el contrario inspirado por un momento de lucidez que le hizo comprender que su fatal monomanía acabaría en breve por vencerlo.

La narración del cronista presentaba un individuo que veía próxima su caída frente a la alienación mental, que aprovechaba sus últimos momentos de lucidez para prevenir daños y dolor a los que afectaría con su muerte, en este caso, su prometida. El mismo día (24/06/1888) que se dio a conocer la muerte de Picasso, "La Nación” publicó la siguiente nota:

El suicidio entre los militares - El Correo Español de ayer adjudica a un jefe español la siguiente orden del día, que antes de ahora hemos visto atribuida a un militar francés. 
"Orden del día, -Un individuo llamado Richer perteneciente a este regimiento en clase de educando musical, trató de envenenarse anoche y se ha disparado neciamente esta mañana a las siete un fusil cuya bala le ha atravesado el pecho, siendo la causa una mujer que otorgaba con largueza sus favores a otros.

El coronel no puede menos de condenar este acto, que si no es de un loco es de un cobarde. Un hombre, y un soldado español sobre todo, debe soportar con valor las pequeñas miserias de la vida y conservar su sangre para causa más noble.

El llamado Richer no será acompañado por nadie en su entierro."

Francés, español o ruso el que así habló, habló como hombre sensato.

La nota hablaba por contraste: el suicidio de Picasso no era el acto de un cobarde vencido por los desengaños amorosos y las pequeñas miserias de la vida. Cualquier soldado que se suicidara frente a infortunios frívolos merecía ser condenado a un entierro solitario, a una "mala muerte". Picasso, en cambio, había sido vencido en la lucha por preservar su juicio. Viendo próxima su derrota, había tomado las precauciones necesarias antes de verse dominado por la monomanía suicida. Su desgraciado final no ponía en duda sus múltiples logros y virtudes. Una prueba más de ello fue el destino dado a los bienes del difunto teniente. Según lo publicado días más tarde ("La Nación", 27/06/1888),

El coronel Guerrico ha firmado ayer un poder a favor del Sr. José Dibur estableciendo que una vez arreglada la testamentaría del capitán Picasso, cuyos bienes consisten en dos casas en esta capital y varias leguas de campo a que tenía derecho por haber tomado parte en la expedición al Río Negro, como lo deja dicho en su testamento, se done su importe al Centro Naval para que con los intereses del dinero que deberá ser depositado en un banco, se instituya un premio que se llamará Juan Picasso para el alumno que más se distinga en los exámenes de cada año.

El coronel Guerrico mandará además de Europa al Sr. Dibur un retrato del capitán Picasso para que sea colocado en el salón del citado centro, y donará igualmente una colección de libros por valor de mil pesos al hospital San Roque, al que, por empeños del Dr. Ramos Mejía, consintió Picasso a entrar para someterse al tratamiento que reclamaba su fatal monomanía.

Los libros de esa donación llevarán la inscripción siguiente: "El coronel Martín Guerrico a la biblioteca del hospital San Roque, en homenaje a la memoria del capitán Picasso que consagró su vida entera a la ciencia y a su patria, y en recuerdo a la institución que cariñosamente lo cobijó en su seno durante sus últimos días".

\subsection{Consideraciones finales}


Como señalamos en el capítulo anterior, en muchos casos, las enfermedades mentales eran mencionadas como "causa determinante". En el presente apartado, nos propusimos abordar una serie de cuestiones relacionadas con las representaciones del suicidio en aquellas narraciones que explicaban lo sucedido a partir de estas patologías.

Por un lado, buscamos indagar la relación entre el suicidio y la locura. Como vimos, si bien ya formaba parte del sentido común que muchos alienados se suicidaran, no todo acto suicida era considerado el resultado de una patología mental. Otros actos violentos eran considerados tan aberrantes que sólo podían emanar de una mente trastornada y enferma, como los asesinatos perpetrados por Eduardo Klappenback. Los suicidas, en cambio, si bien sujetos anormales, estaban ubicados en esa delgada y ambigua frontera entre los locos y los cuerdos.

En líneas generales, encontramos tres formas principales de representar al suicida. En primer lugar, la imagen del que padecía la manía suicida, aquellos individuos que tenían la idea recurrente de terminar con sus vidas y, por esta razón, intentaban, de forma reiterada, poner fin a sus existencias, sin que los miembros de su red social y familiar pudieran protegerlo de sí mismo. En segundo lugar, los suicidas alienados afectados por la idea obsesiva de que eran perseguidos, el delirio de las persecuciones. Por último, una forma menos evidente y más ambigua: la melancolía. La tristeza de la lipemanía podía confundirse con la aflicción que podían sentir todos los individuos.

En este sentido, a la hora de declarar, los testigos debían construir una imagen verosímil del demente. Algunos indicios eran más claros que otros, por ejemplo, si un sujeto experimentaba alucinaciones y/o escuchaba voces. El reiterado anuncio, por parte del suicida, de que se daría muerte también entraba entre las señales más frecuentes que los deudos recuperaban en la reconstrucción del hecho a posteriori (estas amenazas no siempre eran tomadas en cuenta). Otro de los principales argumentos para fundamentar la alteración de las facultades mentales era el abuso de la bebida. La relación casi lineal que se establecía entre el alcoholismo y los trastornos psíquicos favorecía que fuera invocada en muchos de los relatos. Los comportamientos excéntricos también eran presentados en las narraciones: si el sujeto no comía, no dormía, hablaba solo o, por el contrario, permanecía de manera frecuente en una actitud pensativa y con una mirada triste era probable que su cabeza no estuviera del todo bien. En este sentido, el tono, la forma de expresarse o de mirar, los gestos y el lenguaje corporal eran presentados como 
datos que permitían reconocer la locura. Los indicios de la enfermedad mental podían llegar a ser detectados por el ojo observador o, por lo menos, era verosímil que el comportamiento exterior y el semblante del suicida revelaran, en parte, si estaba desequilibrado. Estas imágenes y estereotipos de la locura volvían verosímil el relato de los hechos comunicado por los deudos.

Para los contemporáneos, la locura resultaba una explicación más comprensiva y benévola: en primer lugar, desviaba la responsabilidad del acto suicida de sus dos blancos potenciales. En primer lugar, del propio suicida. Este no podía ser juzgado como un sujeto racional, no era libre, era víctima de la patología que anulaba su posibilidad de elección racional. Al mismo tiempo, permitía a los integrantes de la red de lazos afectivos presentar una versión de los hechos que no los involucraba como colaboradores directos o indirectos del trágico desenlace. En este sentido, los miembros del grupo familiar buscaban representar una imagen de armonía en la convivencia. Como vimos, cuando versiones diferentes de los hechos se cruzaban, detrás del retrato familiar cargado de concordia surgían las sombras de los conflictos, resentimientos y cargos de conciencia. El que se suicidaba, de forma intencional o inconsciente, dejaba su marca en la memoria de los deudos, una herencia que podía ser pesada. La alienación, como decía Pacífico Garelli, era una "causa determinante" que permitía disculparlos a todos, a los suicidas y a su red de vínculos. Por otra parte, como explicaba Ramos Mejía, la locura era un destino cruel, una agonía lenta y larga en un estado indigno para cualquier sujeto. Terminar con la vida para evitarlo no parecía tan condenable, era más bien un supremo refugio, una salida estoica.

Las patologías mentales no agotaban el universo posible de explicaciones verosímiles, otros elementos esenciales y situacionales del suicida servían para dar cuenta de su acto y estos, a su vez, poseían un valor moral diferente. En el capítulo siguiente, presentaremos algunas causas de suicidio verosímiles para explicar el estado de desesperación, sin apelar a las enfermedades de la mente. Los desafíos que planteaba la lucha por la vida en el mundo civilizado ya eran motivos suficientes para explicar una muerte por mano propia. Si a esto se sumaba la falta de una red familiar que contuviera al sujeto frente a las dificultades, como sucedía en el caso de muchos inmigrantes que habían llegado a Buenos Aires en la época, no hacía falta imaginar que el sujeto estaba alienado para explicar su acto suicida. 


\section{Capítulo 8: La lucha por la vida}

En el capítulo anterior, analizamos las narraciones que explicaban las muertes por suicidio a partir de las patologías mentales. Como pudimos observar, el relato tenía un significado ético específico: dejar sin responsabilidad de lo sucedido al suicida y a su red social de contención y, en algunos casos, la situación podía ser presentada como la lucha heroica de un individuo y su entorno contra los crueles efectos de la alienación. Por otra parte, también observamos que no todos los suicidas eran considerados locos o enajenados. Para el saber psiquiátrico de la época, muchos actos suicidas eran llevados adelante por individuos que estaban en una zona de frontera, entre la cordura y el desequilibrio mental, o que sus facultades estaban parcialmente alteradas. En este capítulo, nos proponemos analizar cómo eran representados los vínculos del suicida como red social de contención.

Teniendo en cuenta las características de la población porteña en el período que estudiamos y las transformaciones que tuvieron lugar en Buenos Aires, consideramos relevante analizar la trama vincular de los inmigrantes que llegaron a la ciudad. Como mencionamos antes, la sociedad argentina, durante la segunda mitad del siglo XIX, recibió una importante cantidad de población proveniente de países europeos, en especial, italianos, españoles y franceses, que dejaron sus lugares de origen para aprovechar los altos salarios y las posibilidades de ascenso social. De este proceso de expansión demográfica, surgieron las clases medias y trabajadoras, en particular en los centros urbanos. Así, algunos migrantes lograron ascender socialmente mientras que otros no pudieron conseguirlo, y, en muchos casos, no regresaron a sus países de origen. Al mismo tiempo, como destacamos anteriormente, existía cierta preocupación entre la opinión pública por la cantidad de extranjeros que se suicidaban luego de asentarse en la capital del estado argentino.

En este capítulo, a partir de los sumarios judiciales disponibles, analizaremos algunos casos que narran suicidios de inmigrantes asolados por la pobreza y la falta de trabajo. En este sentido, prestaremos especial atención a las distintas formas de relatar los hechos, a las diferentes dificultades y circunstancias que los suicidas y los testigos aludían en sus declaraciones y las interpretaciones morales presentadas por la prensa. 
Asimismo, nos parece relevante rescatar los testimonios referidos a los diferentes integrantes de la red social del difunto / herido. Dicho de otro modo: ¿cuáles eran los vínculos que aparecían mencionados en los relatos cuando había dificultades para encontrar un nuevo puesto de trabajo? ¿A quiénes se dirigían los suicidas para pedir auxilio en estas narraciones? ¿De qué manera comunicaban a sus vínculos más cercanos, a sus otros significativos, los problemas y el dolor que experimentaban? ¿Cuáles eran las acciones verosímiles del entorno para contener al que perdía las esperanzas de mejorar su situación? ¿Había diferentes formas de representar a los que garantizaban la contención material y emocional de aquél que padecía un fuerte sentimiento de desesperación?

Como explicamos en capítulos anteriores, la creencia en las facultades protectoras de la familia tenía cierto consenso entre los intelectuales de las elites y los funcionarios del estado. Por ejemplo, Méndez Casariego (1888: 56) explicaba, citando al alienista francés Brierre de Boismont, que el aislamiento era un factor que predisponía al suicidio a muchos individuos solteros y viudos:

Hay muchas influencias de mayor o menor poder, factores del suicidio que actúan con más menos número de circunstancias diversas, pero que jamás obran por sí solos, como la nacionalidad, las estaciones, los vientos, el sexo, las profesiones, etc.- nadie se mata porque es argentino o porque es inglés, porque es varón o mujer, porque es sastre o carpintero,- si a esto no vienen incorporadas otras influencias de mayor intensidad determinante;-en cambio sí habrá quienes desistan de matarse aún cuando se sientan impulsados a ello, por la presencia de uno de sus hijos y por las reflexiones que a cada paso en el hogar, les sugiere el cariño a su familia que los vincula a la existencia con lazos "inquebrantables" (MÉNDEZ CASARIEGO, 1888: 55-56).

Así, el matrimonio y la vida en familias bien constituidas contribuía a poner límite a las pasiones desmedidas. Los vínculos familiares contenían a los varones que padecían los desengaños de la lucha por la vida, y, así, evitaban los casos de suicidio y el incremento de los delitos. Por otra parte, como también señalamos en el capítulo 6, otros, como Amílcar Luzuriaga (1909: 57), destacaban las múltiples presiones a las que estaba expuesto el hombre casado con hijos para atender las necesidades de los que dependían de él. Como veremos, ambas imágenes de la vida familiar aparecían representadas en los relatos y testimonios analizados. 
En este sentido, muchos inmigrantes que se quitaron la vida carecían de una red social de contención y manifestaban la falta de vínculos como un factor agravante de su desesperación. Así, la red social con la que contaba el sujeto (familiares, amigos y/o conocidos) era representada como un medio de protección, ya que proveía información, recursos y contención afectiva; todos estos eran considerados como factores que ayudaban a calmar y aliviar el malestar del que estaba desesperado. Por otro lado, las historias de los suicidas que tenían vínculos de contención nos brindan indicios de cómo eran presentadas las acciones de los miembros de la red social. En este sentido, creemos que los contemporáneos representaban roles diferenciados, de acuerdo con el género, a la hora de brindar contención afectiva. Así, de acuerdo con los relatos analizados, los hombres que experimentaban angustia por su situación económica y emocional buscaban consuelo en las mujeres de su red social, recurrían a ellas para pedir auxilio y comunicar sus intenciones de poner fin a su existencia. Por último, como contra-cara, también encontramos relatos en los que la red familiar era presentada como agravante del malestar y la preocupación que padecía el suicida.

\subsection{La "suprema desesperación"}

Francisco (o Francisqueti) Gilli era un inmigrante italiano (tenía diez años de residencia en Argentina), desempleado, soltero, de unos 30 o 40 años (en los sumarios, los policías dan datos diferentes), intentó quitarse la vida en dos oportunidades. En la primera (24 de octubre de 1882 a las 16hs), Gilli se tiró del Puente Alsina al riachuelo. ${ }^{226}$ Fue visto por un niño que pescaba en las inmediaciones, quien dio aviso al hijo del encargado del puente, Pedro Ridart, quien se tiró al agua para rescatar a Gilli, lo que logró con éxito. La segunda tentativa, ocurrió al poco tiempo, el 8 de diciembre de ese mismo año, según testigos, se tiró a las vías del tren, a la altura de las calles Catamarca y Caseros, pero fue rescatado a tiempo y llevado de nuevo al hospital. ${ }^{227}$ Según el agente que elaboró el sumario, Francisco declaró, luego de la primera tentativa, "que había tomado la determinación de quitarse la vida porque hacían ya cinco meses que no encontraba trabajo, careciendo hasta del alimento necesario para sostener su existencia: que no teniendo familia de ningún género se le había hecho más

\footnotetext{
${ }^{226}$ AGN, FTC, Legajo G22, Francisco Gilli, tentativa de suicidio.

${ }^{227}$ AGN, FTC, Legajo G22, Francisco o Francisqueti Gilli, por tentativa de suicidio.
} 
insoportable la vida. Que él en su extrema resolución ha procedido por inspiración propia”. El permanecer cinco meses desempleado, se había convertido, para Francisco, en una realidad insoportable motivo que lo llevó a tomar una "extrema resolución”.

El relato anterior no es un ejemplo aislado. Si sumamos los sumarios referidos a suicidas extranjeros desempleados y los expedientes de inmigrantes en los que figura la pobreza como causa determinante, tenemos un total de 68 casos. En 27 de estos, no figuran relaciones sociales que brinden apoyo material o emocional al sujeto desesperado por la pobreza y la falta de trabajo. ${ }^{228}$ En otros 11 casos, se mencionan vínculos con conocidos (sobre todo vecinos de las casas de inquilinos). ${ }^{229}$ En 5 casos, aparecen referencias a amigos que asistieron al que se quitó la vida o quedó lastimado. ${ }^{230} \mathrm{Y}$, por último, en 25 casos hay información de los familiares del que había intentado o consumado su suicidio, aunque en la mayoría se trata de hijos pequeños y esposas (o parejas), es decir, aquellos que dependían de los ingresos del padre y/o los varones del grupo familiar. ${ }^{231}$

\footnotetext{
${ }^{228}$ AGN, FTC-SE: Legajo B12, Juan Bapcena, s/tentativa de suicidio; Legajo B12, Fernando Boschi, s/su suicidio; Legajo B13, Alvino Broston, s/tentativa de suicidio; Legajo C28, Eduardo Chateau, s/tentativa de suicidio; Legajo D17, Domingo Dellacha, s/suicidio; Legajo D22, Clemente Domini, s/suicidio; Legajo E14, Teodoro Estopa, s/tentativa de suicidio; Legajo F3, Vicente Ferrari, por suicidio; Legajo F7, Luis Franchini, por tentativa de suicidio; Legajo F10, Manuel Fernández, por tentativa de suicidio; Legajo G22, Pedro Garaboto, s/su suicidio; Legajo G25, Vicente Gentile, por tentativa de suicidio; Legajo G30, Pedro Gallart, s/tentativa de suicidio; Legajo G35, José García, s/su suicidio; Legajo I3, Ignacio Yaller; Legajo L9, Carlos Leroi, por tentativa de suicidio; Legajo L12B, Enrique Leters, s/tentativa de suicidio; Legajo N1, Carlos Noesel, sumario levantado para averiguación del suicidio; Legajo O3, Agustín Olivier, s/su suicidio; Legajo P23, Juan Pier, s/tentativa de suicidio; Legajo P35, Antonio Parella, s/su suicidio; Legajo R16, Santiago Richoli, s/tentativa de suicidio; Legajo R22, Juan Righetti, s/tentativa de suicidio; Legajo R30, Juan Rodríguez, s/suicidio; Legajo R35, Fortunato Rosotto, s/suicidio; Legajo V14 Juan Vacca, por suicidio; Legajo W2, German Winklen, por tentativa de suicidio.

${ }^{229}$ AGN, FTC-SE: Legajo B6, Francisco Guillermo Beisola, s/tentativa de suicidio; Legajo E3, Jaime Estevan, s/suicidio; Legajo G29, José Ghiozz, s/su suicidio; Legajo G43, Mauricio Gastaud, s/tentativa de suicidio; Legajo $\mathrm{L} \mathrm{n}^{\circ}$ 14, Eugenio Lauvaseur, por tentativa de suicidio; Legajo L20, Antonio Lort, sumario s/su suicidio; Legajo L23 Luis Lagomarsino, por tentativa de suicidio; Legajo M16, José Martínez Pérez; Legajo M17, Angel Murriondo; Legajo P32, José Perretti, por suicidio de éste; Legajo S19, Ambrosio Sánchez González, s/suicidio.

${ }^{230}$ AGN, FTC-PE: Legajo O3, Ramón Otero y Pastoriza; Legajo P4, Segundo Pato; Legajo P4, Antonio Pérez. AGN, FTC-SE: Legajo A6, Miguel Aguirre, s/su suicidio; Legajo C18, José Eugenio Carbalho, s/suicidio.

${ }^{231}$ AGN, FTC-SE: Legajo B18, Luis Barbieri, s/tentativa de suicidio; Legajo B23, Lorenzo Bozzo, s/su suicidio; Legajo B23, Felipe Benesche, heridas y suicidio; Legajo C7, Carlos Carlini, s/suicidio; Legajo C25, Pedro Coquet, por tentativa de suicidio; Legajo C26, Vicente Carbonetti, s/su suicidio; Legajo C27, Antonio Conde, s/suicidio; Legajo C46, José Cros, s/suicidio; Legajo D6, Arístides Delage, s/suicidio; Legajo E5, José Esperanza, s/suicidio; Legajo F8, Otto Floete, por suicidio; Legajo G15, Antonio Gula, por sumario sobre el suicidio de este; Legajo G21, Francisco Vicente Gutiérrez, sumario sobre su suicidio; Legajo G22, Francisco Gillio, tentativa de suicidio; Legajo G24, Luis Ghiont, s/su suicidio; Legajo G31, Antonio Guioldi, s/su suicidio; Legajo G40, Gerónimo Grillo, s/su suicidio; Legajo H6, Alberto Henning; Legajo L14, Ignacio Lamadrid, s/su suicidio; Legajo M24, Francisco Marola, por tentativa de suicidio; Legajo M25, Ángel Mascheroni, s/tentativa de suicidio; Legajo P28, Francisco Pedroni, s/suicidio; Legajo P40, Carlos Pino, sumario s/el suicidio de éste; Legajo R21, Juan Rubio, suicida; Legajo S37, Juan Squiglia, s/su suicidio.
} 
Así, en la mayor parte de los sumarios de inmigrantes sin empleo que se quitaron la vida, no encontramos indicios de una red de contención que pudiera ayudar a sobrellevar las dificultades por las que pasaban en un momento angustioso y desesperante. En este sentido, Francisco expresó, como agravante de su situación, es decir, el padecimiento y sentimiento de desesperación que lo abrumaba, el no contar con el apoyo de una familia. Se trataba de las tentativas o suicidios de individuos que declaraban como motivo verosímil de sus acciones, además de la falta de empleo y una situación material precaria, la ausencia de relaciones familiares que los contuvieran.

En ciertos casos, el aislamiento y la desvinculación del individuo al momento de quitarse la vida era tal que costaba determinar su identidad. Cuando el cuerpo de un hombre de unos 40 años apareció colgado de un árbol, ninguno de los vecinos de la zona pudo identificarlo. ${ }^{232}$ En uno de los bolsillos, el médico de policía encontró una carta en la que su autor expresaba la desesperación que le provocaba la falta de medios para la subsistencia y que serían esas circunstancias las que le hicieron poner fin a su vida (la carta no fue adjuntada al expediente). También se encontró un pasaporte, que identificaba al fallecido como Agustín Olivier (italiano), quien, según el sello del documento, había pasado por el Hotel de Inmigrantes. ${ }^{233}$ En casos como este, los que se quitaban la vida, además de no contar con familia o deudos en la ciudad, se alejaban del lugar donde habían vivido o donde estaban los que podían reconocerlos; esto dificultaba aún más el esclarecimiento de su identidad. ${ }^{234}$

En otros casos, donde no había ni siquiera indicios del nombre del suicida, la identificación del cuerpo era más complicada. En el caso de Antonio Llort (español, 18 años), el policía encargado de hacer el sumario debió buscar a aquellos que habían conocido al difunto en su breve estadía en el Río de la Plata (venía de Cuba). Así, buscó información en cafetines y lupanares. En una casa de tolerancia, ubicada en la calle General Piamonte $N^{\circ} 331$, la gerente del establecimiento, Elena Silva, y una de las prostitutas, Estrella Benítez, le dieron algunos datos, ya que el joven Antonio había asistido allí al menos tres veces. Según éstas, era español, venía de Cuba y no tenía familia en la ciudad. Finalmente, fueron sus ex compañeros de trabajo, de su empleo en un comercio, "El Salto Argentino", los que dieron información y reconocieron el cuerpo de Antonio. El primero de los testigos, Francisco L. Hudson, fue contactado por las

\footnotetext{
${ }^{232}$ AGN, FTC-SE, Legajo O3, 1883, Agustín Olivier, s/su suicidio.

${ }^{233}$ AGN, FTC-SE, Legajo L20, 1885, Antonio Lort, sumario s/su suicidio.

${ }^{234}$ AGN, FTC-SE, Legajo R16, 1880, Santiago Richoli, s/tentativa de suicidio.
} 
prostitutas que declararon en primer lugar, ambos habían asistido al lupanar y eran conocidos por haber trabajado en el mismo lugar durante un año. El otro testigo, Santiago González, lo conocía del mismo medio y declaró que al estar quedándose sin recursos lo presentó al dueño de un café-restaurant, el "Saint Jean", para que le diera alojamiento por unos días. Según estos testigos, Llort se iba a ir a La Plata a buscar trabajo. De acuerdo con el relato elaborado por el policía, que tenía alma de detective y escritor al narrar los hechos, Llort estaba en una situación económica precaria, enfermo de sífilis, sin familiares en la ciudad y en estado de desesperación. Lo que terminó con sus expectativas fue el desengaño al ver que no había ganado la lotería (de acuerdo con el billete que le fue encontrado entre sus ropas). Según el agente, la suma de todas estas circunstancias fue lo que llevó a Llort a empuñar el arma de fuego y darse muerte en la Plaza Lavalle, donde su cuerpo sin vida fue encontrado el 16 de septiembre de 1885 a las 23:55hs. En el discurso del policía, la sumatoria de la enfermedad, la falta de empleo, las necesidades materiales insatisfechas, la falta de lazos familiares a los que recurrir y las esperanzas desengañadas de probar suerte fueron el conjunto de causas que llevaron a Antonio a tomar su drástica decisión. Lo que resulta interesante de este caso, más allá de la narrativa del autor del sumario, es la aparición de una serie de vínculos de contención, que, si bien no evitaron el desenlace final, dan cuenta de una serie de prácticas solidarias entre compañeros de trabajo, que además compartían espacios de ocio y divertimento masculino, como los cafés y los prostíbulos.

Estos hombres, sin vínculos fuertes con las redes sociales del lugar de llegada, en el momento de situaciones límite, recurrían a los últimos lazos que quedaban en esas circunstancias. En algunos casos, se trataba de sujetos aleatorios que transitaban por el mismo espacio que el sujeto había elegido para quitarse la vida, los desconocidos, aquellos que sólo veían a un individuo desesperado en medio de las calles de la ciudad. Clemente Domini (italiano, 30 años, desempleado), por ejemplo, antes de quitarse la vida el 18 de octubre de 1887 , entró al almacén de Jorge Mosetini. ${ }^{235}$ Como el dueño lo notó taciturno, le preguntó qué le sucedía. Domini le respondió que no tenía trabajo y tenía pensado suicidarse en el Paseo Colón. El dueño del almacén pensó que las facultades mentales de este hombre no estaban bien y, según su declaración, trató de disuadirlo, pero en vista de que no logró su cometido, lo echó de su negocio. Este se dirigió a Paseo Colón, allí, en plena vía pública, se clavó un cortaplumas debajo de la

\footnotetext{
${ }^{235}$ AGN, FTC-SE, Legajo D22, Clemente Domini, s/suicidio.
} 
tetilla izquierda. Su cuerpo fue remitido al depósito fúnebre de Lorea, ya que nadie se hizo cargo del mismo. Según las declaraciones levantadas por la policía, este inmigrante sin empleo tenía sus facultades mentales alteradas y una herida en la pierna derecha que lo hacía renguear. Domini había sido visto cuando buscaba trabajo y había amenazado con quitarse la vida a otros testigos. Según los datos de su pasaporte, había llegado el 4 de julio; en los tres meses que estuvo en la ciudad, no llegó a generar vínculos que pudieran socorrerlo.

Además de afrontar una precaria situación material en soledad, algunos padecían algún tipo de enfermedad o malestar físico. ${ }^{236}$ En el caso de Fortunato Rosotto (italiano, 25 años, cinco meses de residencia en el país, soltero, jornalero), fue alcanzado por la epidemia de viruela. ${ }^{237}$ Según la información contenida en el sumario, "ha intentado suicidarse pues al verse enfermo, sin familia en el país y sin recursos de ninguna clase quería concluir con su existencia; que de esto nadie era culpable". Fue descubierto por su compañero de cuarto, en la casa de inquilinato, cuando estaba cortándose la garganta con una navaja. Según la información del expediente, ambos fueron llevados a una casa de aislamiento por estar enfermos de viruela y no tener medios para atenderse. En el caso de Luis Lagomarsino (italiano, 42 años, soltero, jornalero desempleado), fue encontrado muerto en la licorería de su ex-patrón; el policía que elaboró el sumario consideró que, al estar enfermo, pobre y sin empleo, era probable que se hubiera quitado la vida en un "momento de desesperación". ${ }^{238}$ De modo similar se expresó Jacinto Benites (argentino, 33 años, soltero). Según su declaración, padecía una enfermedad crónica e incurable que le impedía trabajar y por eso intentó suicidarse con una disolución de fósforos en agua; y agregó “Que hoy sin embargo se siente arrepentido de su proceder, que juzga haberlo cometido en un momento de suprema desesperación". 239

En los casos de muerte por mano propia, en los que el difunto/herido había llevado adelante su autoagresión movido por el dolor que le provocaba alguna enfermedad, encontramos manifestaciones de compasión y solidaridad por parte del entorno, por ejemplo, de los vecinos de la casa de inquilinos, que estaban pendientes de lo que sucedía. En este sentido, la enfermedad del individuo que se había agredido a sí

\footnotetext{
236 AGN, FTC-SE, Legajo V14, Juan Vacca, por suicidio; Legajo B13, Alvino Broston, s/tentativa de suicidio; Legajo R35, Fortunato Rosotto, s/suicidio.

${ }^{237}$ AGN, FTC-SE, Legajo R35, Fortunato Rosotto, s/suicidio.

${ }^{238}$ AGN, FTC-SE, Legajo L23, Luis Lagomarsino, por tentativa de suicidio.

${ }^{239}$ AGN, FTC-SE, Legajo B18, Jacinto Benites, s/tentativa de suicidio.
} 
mismo servía para explicar el origen del malestar que lo atormentaba y las dificultades que tenía para continuar con el trabajo. En cambio, cuando el episodio de autoagresión estaba asociado con la ausencia de control en el consumo de bebidas alcohólicas, esta situación explicaba por qué el sujeto no podía conservar empleo alguno. Así, hemos encontrado este argumento en los discursos de los testigos y policías: el consumo de alcohol en exceso como variable que explica el desempleo, la locura y el suicidio, y la posible combinación de estos sucesos en el desenlace final de un mismo individuo. Por ejemplo, los testigos que declararon luego del suicidio de Domingo Dellacha (italiano, 30 años, soltero, herrero), desconocían la causa que lo había llevado a quitarse la vida (se había disparado con una pistola en la sien derecha). ${ }^{240}$ Sin embargo, destacaron que consumía licores en exceso; por esta razón, fue despedido de todos los talleres de herrería en los que trabajó, ya que el alcohol lo inutilizaba para llevar a cabo su tarea. En el sumario, también figuraba que Dellacha no tenía familia en el país y era pobre; por este motivo, no había persona que se hiciera cargo de su entierro.

En síntesis, hemos encontrado una serie de extranjeros en los que la ausencia de vínculos familiares, y de otro tipo, complicaba hasta la averiguación de sus identidades por parte de los policías encargados de elaborar el sumario luego de sus muertes. Para los contemporáneos, era verosímil imaginar lo difícil que podía ser encontrar canales para asentarse y buscar empleo en la ciudad de Buenos Aires y enfrentar los desafíos de la "lucha por la vida" sin tener una red de vínculos que apoyara al recién llegado. Así lo expresaba Luisa Sacatier, luego del suicidio de su marido, José Cros (francés, 37 años, zapatero). Éste llegó con Luisa a Buenos Aires, procedente del Departamento de Leroi (Francia), el 9 de noviembre de 1888, y ocuparon una pieza en una casa ubicada en la calle Callao $\mathrm{N}^{\circ} 493$. Según la declaración de su esposa, a pesar de solicitar trabajo en varios lugares no pudo conseguir nada, debido a que no conocían a nadie en la ciudad. La noche del 20 de noviembre, se acostaron en un colchón en el suelo, ya que no tenían dinero para comprar una cama. Durante la noche, Luisa notó que su esposo no estaba. Empezó a buscarlo en la oscuridad y sintió su cuerpo en el suelo, las manos estaban frías, empezó a gritar para pedir auxilio y los inquilinos de la casa acudieron de inmediato. Al alumbrar el cuerpo, vieron que Cros presentaba una herida profunda en el pecho de la que manaba sangre; según los testimonios, Luisa, en el acto, se tiró sobre su esposo desconsolada y le sacó la trincheta de zapatero que tenía

\footnotetext{
${ }^{240}$ AGN, FTC-SE, Legajo D17, Domingo Dellacha, s/suicidio.
} 
atravesada en el pecho. El agente de policía que elaboró el sumario agregaba que: "Nada ha dejado escrito, pero según su esposa, la pobreza en que se hallaban ha sido la causa de que su esposo cometiera ese acto, pues solos sin recursos, sin relaciones y en un país estraño, aquel siempre se quejaba de su suerte". ${ }^{241}$

\subsection{Asistencia material y últimas voluntades}

El caso anterior es un buen ejemplo de los problemas que podía encontrar un inmigrante al llegar a Buenos Aires y las consecuencias de no contar con una red vincular sólida que contuviera al recién llegado. En estos casos, a veces encontramos algunos lazos débiles, los "conocidos", personas que transitaban o habitaban un espacio físico y social común (alojamiento, lugar de trabajo -a veces, ambos eran lo mismo-, prostíbulos, cafés, fondas); en los relatos contenidos en los sumarios judiciales, estos testigos transmitían alguna información de cómo se habían relacionado con el suicida y cómo lo habían asistido en ese momento de intensa desesperación. En algunas narraciones, encontramos que comparten el alimento y conversan con el individuo que atravesaba una situación material difícil; en otros casos, les brindaban un techo donde pasar la noche, o unos días, e, incluso, hay relatos donde declaraban haberlos alojado en sus hogares por varios meses. Ex-compañeros de trabajo y otros testigos, que no dan detalles del vínculo que tenían con el suicida / herido, eran mencionados al narrar lo sucedido, dándole de forma solidaria auxilio y soporte al desempleado. José Pérez Martínez (español, 21 años, soltero) se suicidó el 7 de noviembre de 1879, por la noche, al tomar arsénico en el Café "Villa de Bayona" (Paseo de Julio N92). Dejó dos cartas: en la primera, explicaba a su hermano que estaba aburrido de vivir en condiciones materiales precarias y se despedía; y en la segunda, daba las gracias al dueño del café por hospedarlo allí en esos difíciles momentos y le dejaba un último "adiós para siempre". De acuerdo con los datos del sumario, José no tenía familia en la ciudad, ni bienes; sólo contaba con un hermano que vivía en otra parte del país, en una colonia. ${ }^{242}$

En el sumario levantado tras la muerte violenta de Ambrosio Sánchez, Celestino Carrera, dueño de la casa ubicada en la calle Lorea №533, declaró que Sánchez estaba sin trabajo hacía mucho tiempo y por esa razón lo tenía agregado en su

\footnotetext{
${ }^{241}$ AGN, FTC-SE, Legajo C46, José Cros, s/suicidio.

${ }^{242}$ AGN, FTC-SE, Legajo M16, José Martínez Pérez, suicidio.
} 
casa. $^{243}$ Carrera también declaró que hacía tiempo que Ambrosio manifestaba con frecuencia la idea del suicidio. Sánchez fue encontrado apoyado en la baranda de la Pirámide de Mayo, con una herida en el lado izquierdo del vientre, la que se infirió con un cuchillo. Lo vio un transeúnte que pasaba por la plaza a las 13:00hs del 14 de octubre de 1881 y dio aviso a la policía. Éste fue llevado a un hospital para que atendieran sus heridas. Según el diario "La Nación” (15/10/1881), los padres de Ambrosio vivían en Pontevedra (España). Estos lo enviaron con recomendación para encontrar un empleo. Luego de llegar a Buenos Aires, trabajó como mucamo en varias casas de la ciudad. Según el cronista, había despertado la compasión del subsecretario de la curia, el señor Rodríguez. Este le brindaba apoyo económico y lo recomendó para un nuevo empleo. Sin embargo, Sánchez era un sujeto atrapado por los vicios: "Hace dos o tres meses consiguió que este [Rodríguez] le diera doscientos pesos para un traje, que días después empeñaba por 35 pesos, que se convirtió en ginebra”. Pasaba por la curia varias veces a la semana y solicitaba auxilio, ya que pasaba hambre. Rodríguez trataba de alentarlo para que se dedicara a trabajar y luego de amenazarlo con quitarle su ayuda, le daba algo de dinero ("con que cualquiera que no fuese Ambrosio se hubiese remediado", según el cronista). El día de su suicidio, Ambrosio fue a la curia, pero Rodríguez no pudo atenderlo. Luego de no ser recibido, fue a la plaza e intentó suicidarse. La noticia del diario "La Prensa", titulada "Desesperación", presentaba un perfil similar del suicida. En este sentido, lo retrataba como sujeto vicioso, perezoso y poco trabajador: todo lo que ganaba lo gastaba en esas "mujeres de mal vivir", es decir, en los prostíbulos. Ningún trabajo lo satisfacía y todo lo cansaba; al mismo tiempo, había indicios de que Ambrosio estaba loco. En síntesis, la narración del acto suicida estaba orientada a presentar a un sujeto vago y vicioso (entregado a la bebida y a los placeres sensuales con las prostitutas), que abusaba de la caridad administrada por el funcionario de la curia. Los cronistas no buscaban dejar duda alguna de la reputación del señor Rodríguez, compasivo y benévolo benefactor. En la carta encontrada entre sus ropas (dirigida a Carrera, según las noticias, ex patrón de Sánchez), y adjuntada al expediente que contenía el sumario, Sánchez dejaba a todos su saludo de despedida y acusaba a Francisco Rodríguez y Abellán (el secretario) por sus intenciones de traicionarlo. También le expresaba a Carrera, "adbierta ud. ami familia" y agregaba "Dios me de la gloria y el descanso de mi cuerpo". Ambrosio se despedía "en nombre

\footnotetext{
${ }^{243}$ AGN, FTC-SE, Legajo S19, Ambrosio Sánchez González, s/suicidio.
} 
de Dios y el patriotismo argentino". En el sobre de la carta figuraba la frase "Adiós Pueblo Argentino". La forma en la que se despidió, y el destinatario de su nota, tal vez estaban vinculados con el desengaño de sus expectativas al migrar al Río de la Plata, la desesperación que le generaba el no encontrar empleo y la vergüenza que implicaba vivir a costa de la ayuda de terceros y la caridad.

Así, en varios sumarios judiciales, los que asistían al herido o al que iba a hacerse un daño mortal eran vínculos débiles, es decir, personas que no estaban altamente comprometidas con el sujeto que estaba desesperado. Por otra parte, muy raramente estaban solos. En la mayoría de los casos, encontramos relatos sobre los trabajadores más pobres y los marginados que habitaban espacios hacinados, en los que era menos sencillo encontrar soledad. Por esta razón, si buscaban privacidad para quitarse la vida, era muy poco probable que la encontraran en las habitaciones de las casas de inquilinos. En muchos casos, éstas eran ocupadas por una familia completa o por varios hombres solteros. Los suicidas podían esperar a estar solos o buscar alguna excusa para generar las condiciones necesarias y darse muerte sin ser interrumpidos. En otros casos, como el de Ángel Murriondo, la desesperación superaba cualquier clase de pudor y el sujeto no esperaba más ni buscaba otro lugar de mayor intimidad. Ángel (italiano, 42 años, 18 años de residencia, soltero, desempleado), se hirió a sí mismo de gravedad con un disparo de arma de fuego en la sien derecha, mientras su compañero de cuarto, José Bionda, dormía, alrededor de las 22:00hs del 25 de julio de 1880; al sentir la detonación, Bionda se despertó sobresaltado y fue a buscar auxilio. Según le dijo Murriondo en ese momento, se había herido, por accidente, al revisar el arma de fuego, y rechazó cualquier auxilio médico, curación o remedio. José, no convencido con los argumentos de Ángel, fue a dar aviso a la comisaría. Al declarar, Murriondo manifestó "que hayándose desesperado por la falta de recursos para su subsistencia, tomó la determinación de quitarse la vida". ${ }^{244}$

También, en algunos documentos, encontramos declaraciones donde los vecinos de la casa manifestaban cuidar al inquilino que sufría dolores por alguna enfermedad y se veía impedido de trabajar para ganarse el sustento. Los vecinos conocían las dificultades de los que habitaban el mismo domicilio y eran una posible fuente de consejo, contención y solución de las dificultades que encontraban los inmigrantes que buscaban integrarse en la sociedad argentina. En una pieza de la casa

\footnotetext{
${ }^{244}$ AGN, FTC-SE, Legajo M17, Angel Murriondo, tentativa de suicidio.
} 
ubicada en la calle Cerritos No229, habitaba Jaime Estevan (español). Allí fue encontrado sin vida el 11 de octubre de 1880 . De acuerdo con la herida y el arma que fue encontrada junto a su cuerpo, se había suicidado de un tiro de revólver en la sien izquierda. Jaime no dejó carta y se ignoraban las causas que lo llevaron al trágico desenlace, pero, según lo asentado en el sumario por el policía de turno, el resto de los inquilinos destacó "que este sujeto se encontraba gravemente enfermo en cama y sin tener recursos con qué asistirse. La noche anterior se hallaba bastante afectado y quejándose de las circunstancias que le obligaban a pasar al Hospital". De acuerdo con estos testimonios, Patricio Mayoral, que vivía en la misma casa, estuvo acompañándolo; éste estuvo a su lado hasta las 2:00hs de la madrugada, momento en que se retiró. A las 6:20hs se presentó en la habitación Francisco Vanosi (9 años), "que acostumbra prestarle algunos servicios todas las mañanas y hallándole tirado en el suelo creyó que estaba dormido y se retiró”. A las 8:30hs, Catalina Más, la dueña de casa, se acercó a ofrecerle sus servicios y lo encontró sin vida, sobre el suelo. José Más, dueño de la casa, se hizo cargo del cuerpo para darle sepultura. En síntesis, vemos que podían existir redes afectivas de contención y ayuda mutua entre los inquilinos de un mismo conventillo, los mismos estaban pendientes del estado de Jaime y colaboraron en su cuidado, además de hacerse cargo del entierro de sus restos. ${ }^{245}$

En algunos expedientes, aparecen individuos caracterizados como "amigos" de los suicidas/heridos, que asistían a los sujetos en la difícil situación de falta de empleo. Los amigos daban alojamiento y alimento en los momentos críticos, eran una red de contención que podía sostener al sujeto frente a la caída en desgracia. El 21 de marzo de 1887, José Eugenio Carbalho (brasileño, 45 años, soltero, jornalero) fue a la habitación de la casa de inquilinos donde vivía su amigo, José Martínez (portugués, 42 años, soltero, marinero). ${ }^{246}$ Según el testimonio de este último, esa noche, Carbalho había ido a comer a su casa, como de costumbre; sin embargo, no quiso probar bocado, a pesar de que Martínez le insistiera para que comiera. Él y José Eugenio charlaron armoniosamente durante la velada y luego se fueron a dormir. Mientras Martínez dormía, sintió ruidos y descubrió que Carbalho se había herido en el cuello con una navaja de afeitar. De inmediato, buscó auxilio y llamó a la policía. Cuando ésta llegó, el herido había fallecido. Para José, el que se hubiera quedado sin trabajo era la causa probable de que Carbalho se suicidara; según el testimonio de Martínez, su amigo había

\footnotetext{
${ }^{245}$ AGN, FTC-SE, Legajo E3, Jaime Estevan, s/suicidio.

${ }^{246}$ AGN, FTC-SE, Legajo C18, José Eugenio Carbalho, s/suicidio.
} 
sido despedido por problemas de alcohol, ya que se embriagaba con frecuencia e iba a trabajar en ese estado; por otra parte, aclaró que no estaba ebrio la noche en que se quitó la vida. Asimismo, manifestó que recibía a José Eugenio en su casa por la amistad que había entre ambos.

Contar con amigos también era una forma de recibir asistencia en caso de enfermedad. Antonio Pérez (mejicano, 34 años, soltero, cocinero) estaba desempleado, hacía un año que no tenía trabajo debido al reumatismo que padecía; se creía, de acuerdo con los testimonios recolectados, que esa fue la causa de su suicidio, aunque el suicida no había dejado ningún escrito. Antonio no tenía familia en el país y "vivía mediante el ausilio de un amigo nombrado Don Domingo Della Vadova", según lo asentado por el policía en el sumario levantado luego de su defunción. ${ }^{247}$

Los amigos también aparecen en los relatos como los depositarios de las últimas voluntades. El caso de Miguel Aguirre (español, 52 años, soltero, jornalero), nos sirve de ejemplo. ${ }^{248}$ Según Catalina Nemesia, su comadre, hacía diez años que ella y sus dos hijos vivían en la casa de su ahijado. Según su testimonio, negó que hubieran tenido disgusto alguno y agregó que Aguirre se había fracturado el brazo y que por ello no podía trabajar, cada tanto decía que estaba "cansado de la vida". Miguel se suicidó la noche del 13 de abril de 1882. La finca en la que ocurrió este desafortunado desenlace era propiedad del suicida. Los títulos que certificaban esto no fueron hallados por la policía. Estos habían sido entregados por Aguirre a un amigo de confianza, José Miguel Echeverría. Éste explicó que días antes había ido a la casa del suicida para alquilar una habitación y que éste le contestó que no tenía ninguna disponible. Durante la charla, le hizo entrega de los títulos de propiedad, encomendándole los enviara al cónsul español. Según Aguirre, había disgustos con su comadre, Catalina Nemesia, y, por esta razón, le pidió que, si se enteraba de alguna mala noticia, los llevara al consulado. Al ser informado por los hijos de Nemesia de la muerte por suicidio de Aguirre, Echeverría cumplió la última voluntad de su amigo. En el expediente, no hemos encontrado indicios que nos den más información del conflicto que había entre Miguel y su comadre. Quizás temía que Catalina y sus hijos se apropiaran de su vivienda y no respetaran el deseo de Aguirre de legar el inmueble a otros. En este caso, el lazo familiar fue una fuente de disgustos y conflictos; el contar con un amigo de confianza, por otra parte, sirvió para lograr que las disposiciones testamentarias de Aguirre no fueran

\footnotetext{
${ }^{247}$ AGN, FTC-PE, Legajo P4, Antonio Pérez.

${ }^{248}$ AGN, FTC-SE, Legajo A6, Miguel Aguirre, s/su suicidio.
} 
pasadas por alto. En "La Nación” (14/04/1882), fue publicado el caso de Aguirre, pero no se mencionaban los detalles de los conflictos familiares que comentamos más arriba; según un supuesto escrito del suicida, que no figura en el expediente, estaba "cansado de la vida".

Si bien hay relatos en los que aparecen mencionados familiares del individuo, como en el caso anterior, en la mayoría de estos, se trataba de la esposa y los hijos (menores de edad). La presencia de miembros de la familia a cargo del hombre sin empleo aumentaba la presión y la angustia que sentía. Otros miembros de su red familiar podían ayudarlo si se encontraban en la ciudad. En este sentido, en las narraciones de los hechos, son menos frecuentes las menciones a familiares adultos de género masculino. Vicente Carbonetti (italiano, 53 años, casado, marinero) pasaba por una coyuntura difícil: sin ocupación, pobre y enfermo de reuma articular. ${ }^{249}$ Para su subsistencia, dependía de su hermano Rafael. El 29 de diciembre de 1882, Vicente se encerró en la pieza de la casa de inquilinos donde vivía. Rafael habitaba en el cuarto de enfrente y fue a buscarlo para ir a almorzar. Como no recibió contestación, pensó que estaba enojado con él y pidió a otros vecinos que fueran a llamarlo. Tampoco hubo respuesta. Al temer que hubiera ocurrido una desgracia, pidieron auxilio a la policía. El oficial abrió la puerta con un corta-fierro y allí encontraron a Vicente sin vida, colgado de una faja que tenía anudada en el cuello. Según Rafael y los testigos creían que había "tomado esta determinación en vista de su mal estado de salud, pues estuvo en el Hospital durante diez y ocho días, enfermo de reumatismo articular, habiendo sido dado de alta sin estar completamente sano, influyendo también el no tener trabajo y vivir de lo que le daba su hermano". El cuerpo de Vicente le fue entregado a Rafael para darle sepultura. La explicación verosímil de la muerte por mano propia de Carbonetti incluía varios elementos: los dolores provocados por la enfermedad, la falta de empleo y la situación de dependencia en la que se encontraba. En este sentido, vivir de lo que le daba su hermano no era una situación aceptable, generaba malestar. La falta de trabajo atacaba su dignidad y autoestima. Como destacamos antes, el suicidio de un individuo no dependía sólo de la disponibilidad de una red de contención y sus características. En este sentido, jugaba un rol clave la forma en la que se percibiera el propio individuo y el estado de desesperación en el que se encontrara. En este caso, Vicente no toleró la situación. Por otra parte, las acciones de los familiares, como el hermano de Carbonetti,

\footnotetext{
${ }^{249}$ AGN, FTC-SE, Legajo C26, Vicente Carbonetti, s/su suicidio.
} 
generaban mejores condiciones para evitar el trágico final.

Al mismo tiempo, encontramos personas con familiares en la ciudad, pero que no actuaban como red de contención. Si analizamos el sumario levantado tras la tentativa de suicidio de Francisco Marola (italiano, 30 años, casado, silletero), podemos ver que la existencia de una relación de parentesco formal entre dos individuos no era garantía de ayuda mutua. ${ }^{250}$ Francisco fue encontrado herido en la vía pública, dentro de una zanja en la calle Armonía (entre Zeballos y Lorea), con tres cortes que se había autoinfligido en el brazo izquierdo con una navaja de afeitar. Cuando fue interrogado por las causas de su extrema resolución, declaró que llevaba cuatro días sin conseguir alimento y que estaba en un estado de pobreza desesperante; por ello, decidió quitarse la vida. Según el testimonio de Marola, la mayor parte de la familia residía en Europa y tenía un hermano llamado Manuel en la ciudad. El sumario, en este caso, no brinda más detalles sobre el tipo de relación que tenía Francisco con su hermano. Por la razón que fuere, Marola no recurrió a éste en busca de auxilio, asistencia material o contención emocional.

Este tipo de comunicación afectiva y empática no aparece mencionado con frecuencia en las descripciones de las interacciones masculinas presentes en las narraciones analizadas. Ramón Otero y Pastoriza (español, 34 años, soltero, lechero), trabajaba como peón en una cochería y dormía en el establecimiento. El 28 de diciembre de 1877, en un baldío (ubicado en la calle Belgrano, entre La Rioja y Catamarca), se dio muerte con un tiro de revólver en el cuello. ${ }^{251}$ Fue descubierto por un hombre que pasaba por allí, Luis Berton. Al sentir la detonación del arma de fuego, se dirigió al baldío y encontró el cuerpo de Ramón bañado en sangre, con una herida de bala debajo de la mandíbula. Según la declaración del cochero de Berton, Simón Navarro, amigo de Ramón: "momentos antes del suceso había estado conversando con él. Que le manifestó en la situación precaria que se encontraba y que se despidió dándole un adiós para siempre”. Ramón buscó dar a conocer sus intenciones a Simón: ¿Pedía auxilio? Tal vez esperaba, consciente o inconscientemente, que su amigo lo detuviera, que le brindara alguna ayuda, o simplemente quería compartir su dolor y su pena con alguien. En este caso, la interacción entre ambos no evitó el funesto desenlace. Ramón fue trasladado al Hospital de Hombres y falleció poco después.

En general, los amigos, conocidos y familiares de género masculino, aparecían

\footnotetext{
${ }^{250}$ AGN, FTC-SE, Legajo M24, Francisco Marola, por tentativa de suicidio.

${ }^{251}$ AGN, FTC-PE, Legajo O3, Ramón Otero y Pastoriza.
} 
en los relatos con un rol de sostén material, brindando información, alojamiento, comida, o como depositarios de las últimas voluntades de los hombres que se quitaban la vida. Por otra parte, no aparecían mencionados como fuente de consuelo y tampoco presentados como receptores de las quejas o las manifestaciones de dolor. El rol de contención afectiva y la comunicación de los pedidos de auxilio aparecían con más frecuencia en las descripciones de las interacciones con miembros del género femenino con los que estaba vinculado el varón que se autoagredía.

\subsection{La contención afectiva y el pedido de auxilio}

Muchos inmigrantes dejaron buena parte de su red de contención material y afectiva del otro lado del Atlántico. El caso de Juan Bapcena (español, 17 años, soltero, sin ocupación) ilustra muy bien esta situación. ${ }^{252}$ El hecho tuvo lugar en el café ubicado en Talcahuano $\mathrm{N}^{\circ} 195$. Allí, luego de tomar unas copas de anís, Juan intentó quitarse la vida. Antes de tratar de darse muerte, Bapcena leyó reiteradas veces una carta a los allí presentes. Tras leer su mensaje al público, sacó un revólver, lo puso en la sien derecha y disparó, pero el proyectil se desvió hacia la pared y provocó una herida de poca gravedad. El policía que se encontraba allí, Gabriel Gerpes, le quitó de inmediato el arma. El relato fue reconstruido por el agente de policía a través del testimonio del dueño del café y de uno de los dependientes. Bapcena, al ser interrogado, declaró que la carta que había leído iba dirigida a sus familiares en Europa (la que fue adjuntada al expediente estaba destinada a su madre). Asimismo, manifestó que la idea de suicidarse surgió como consecuencia de estar enfermo y cansado de sufrir el dolor que le producía ese estado. En este caso, hizo público, ante los desconocidos que se encontraban allí, quizás por la falta de inhibición que provoca el alcohol, el pedido de auxilio que estaba dirigido a sus familiares. Bapcena estaba desesperado y necesitaba contención, pero la red de vínculos que podía socorrerlo en ese momento estaba muy lejos. Este joven apeló a una de las mujeres del núcleo familiar más cercano para expresar su dolor. Finalmente, la carta no fue enviada y Bapcena optó por quitarse la vida en público antes de informar la situación a los integrantes de su red social. ¿Sentía vergüenza de su debilidad, de no

\footnotetext{
252 AGN, FTC-SE, Legajo B12, Juan Bapcena, s/tentativa de suicidio. La versión de los hechos que circuló en las páginas del diario La Prensa, el 9 de abril de 1878, es distinta a la que mencionamos antes. De acuerdo con ésta, la carta que leyó el suicida había sido enviada a éste por sus familiares. En dicha nota, le informaban a Bapcena "noticias terribles". El cronista, por su parte, no brindaba más detalles sobre estos traumáticos sucesos.
} 
poder valerse por sí mismo? ¿No veía posibilidad de que sus familiares pudieran prestarle algún tipo de ayuda y por ello cayó en la desesperación? El sumario no brinda más información sobre Juan y la relación con sus familiares del viejo mundo.

Lo relatado en el sumario que se levantó después del suicidio de Segundo Pato (español, 26 años, casado, vigilante), puede ofrecer algunos indicios sobre el doble papel que jugaba la red de vínculos familiares: si, por un lado, era fuente de contención, apoyo y ayuda mutua, por el otro, presionaba a los varones del grupo familiar. ${ }^{253}$ Pato trabajaba como vigilante en la ciudad de Buenos Aires. Se suicidó una noche, el 29 de enero de 1873, según testigos, a la una de la madrugada. Vivía en una casa de inquilinos (ubicada en la calle Venezuela N³0) y compartía una habitación con otras dos personas, Primitivo Gómez y Ramón Abal, también vigilantes. El cuerpo, encontrado en el segundo patio de la casa, presentaba una herida de bala en la sien derecha y tenía un revólver en la mano. Según los testimonios, al sentir la detonación, los otros habitantes de la casa fueron a ver qué ocurría y lo encontraron sin vida. De acuerdo con la inquilina que vivía en el último piso, Marcelina Paigo, hacía bastante tiempo que se lo notaba extraño. Un día le manifestó "que iba a escribir a su esposa que se hallaba en España, su estado deplorable de salud y pobreza, significándole al mismo tiempo que estaba aburrido de vivir. Que estas últimas palabras se le oían siempre”. Entre sus pertenencias se encontraron dos cartas. Una de ellas dirigida a un tal Ramón Zubizameta (el remitente era el abuelo de la esposa de Segundo), le solicitaba si podía conseguirle una colocación a Pato. También le explicaba que había fallecido su hijo, el suegro de Segundo, lo que había complicado la situación económica familiar. La otra carta era un borrador escrito por Pato a su esposa, en la cual le manifestaba que se encontraba mal de salud y que sólo había dado con un empleo de sereno, muy lejos de las expectativas con las que había viajado al Río de la Plata. Este último documento no fue enviado y figura en el expediente; lo que nos hace pensar que, tal vez, desistió de hacerlo, o envió una carta diferente. En cualquiera de los dos casos, cedió a la desesperación y se quitó la vida. Por un lado, los vínculos más fuertes de la red de contención afectiva estaban entre los miembros de su familia, del otro lado del Atlántico, quienes contaban con su éxito para mejorar la situación económica familiar. En este sentido, quizás desistió de pedir ayuda porque no quería defraudar a su esposa. Más allá de si llegó o no a solicitar auxilio, lo cierto es que este caso muestra que la red actuaba como fuente de apoyo,

\footnotetext{
${ }^{253}$ AGN, FTC-PE, Legajo P4, Segundo Pato.
} 
contención y ayuda, pero también generaba presiones. Es probable que Segundo sintiera la responsabilidad de contribuir con el sustento familiar, se representara a sí mismo como un proveedor, $\mathrm{y}$, al mismo tiempo, padeciera la decepción de un salario que no cumplía con sus expectativas, con el agravante de estar solo, no sentirse bien de salud y lejos de su esposa. Una vez más, el sujeto al borde de la desesperación buscó consuelo y contención en una persona de género femenino del núcleo familiar. Por lo que queda asentado en el expediente, cuando intentó compartir sus dificultades y expresar su malestar, se dirigió a una de las inquilinas de la casa, que fue la que declaró sobre el asunto.

Así, en los relatos que quedaron registrados en los sumarios judiciales, las mujeres con las que estaban vinculados los hombres inmigrantes sin empleo eran representadas como vínculos de contención emocional y afectiva, ya fuera que estuvieran presentes, en la ciudad de Buenos Aires, o muy lejos, en sus lugares de origen. Vale la pena volver a mencionar, de forma más detallada, el caso de Francisco Gutiérrez (español, 42 años, casado, desempleado / cigarrero), mencionado en el capítulo 6. Éste habitaba con su concubina, Concepción Guerra (argentina, 44 años, soltera), en una pieza de una casa de inquilinos (calle Europa $\mathrm{N}^{\circ} 370$ ). Concepción convivía con Francisco desde hacía ocho años. Este último tenía su legítima esposa y dos hijos en Fray Bentos. Como Gutiérrez estaba sin trabajo y en la última miseria, había comprado tabaco para hacer cigarros en su casa y vivir de su venta. La navaja con la que se dio muerte era la que usaba para picar las hojas. Además, Francisco padecía de fuertes ataques de tos en los que vomitaba sangre. La noche que se quitó la vida, el 18 de marzo de 1882, a las 20:00hs, aproximadamente, tuvo uno de esos ataques. Concepción le alcanzó un paño de agua fría y Gutiérrez lo rechazó diciendo "que no quería padecer más, que se iba a quitar la vida"; esto lo repetía desde hacía tiempo. Horas más tarde, a eso de las 23:00hs, los vómitos se volvieron más intensos. Concepción le ofreció buscar ayuda, pero Francisco tomó la navaja y amenazó con quitarse la vida. Cuando su compañera trató de disuadirlo, la amenazó con el arma levantada. Concepción pidió auxilio al resto de los vecinos. Cuando llegaron, ya se había herido y estaba sin vida en el piso. El relato de lo que aconteció fue hecho por la compañera de Gutiérrez, que fue la única testigo de lo sucedido. Los vecinos de la casa de inquilinato fueron los que aportaron credibilidad a la narración de Concepción con sus propias declaraciones. Estos manifestaron que siempre vieron a la pareja convivir en armonía; también dieron cuenta de los vómitos que padecía Francisco. Una de las 
inquilinas, Carmen Casares, declaró que una vez que pasó por su cuarto lo escuchó exclamar "que estaba cansado de vivir, que deseaba morir, cuando le venían los vómitos de sangre". Alberto Rombaratti (italiano, 36 años, casado, fotógrafo) y su esposa, Tomasa Patrón (italiana), domiciliados en la calle Defensa $\mathrm{N}^{\circ} 447$, declararon que Gutiérrez y Concepción habían vivido un tiempo en su casa y que siempre vieron armonía y mutuo cariño. También agregaron que Gutiérrez solía estar ebrio y, algunas veces, en tal estado, le habían oído decir "que estaba tan aburrido de sufrir, que valía mas quitarse la vida". El policía concluyó que "las causas determinantes del suicidio" habían sido "la extrema pobreza en que vivía y la grave enfermedad de que se hallaba aquejado". 254

En la narración de los hechos, su concubina, Concepción, era representada como una afectuosa compañera que atendía los dolores de Gutiérrez, escuchaba las manifestaciones de sufrimiento y las intenciones de terminar con su vida que su compañero le expresaba de manera frecuente. De esta forma aparecieron narrados los hechos en los diarios de la época. En la noticia publicada en "La Prensa" del 18 de marzo de 1882, el cronista destacaba el heroico esfuerzo de Gutiérrez, quien atravesaba los dolores de la fase terminal de una tuberculosis que lo aquejaba (según los médicos no habría sobrevivido mucho tiempo más aunque no se hubiera suicidado): hacía un “esfuerzo supremo" por trabajar vendiendo cigarros a pesar de que los ataques de tos lo hacían sufrir mucho, en contraste con los casos de sujetos consumidos por el vicio y que no podían encontrar o conservar sus empleos. Si bien no se mencionaba el nombre de Concepción, ya que no se trataba de la legítima esposa de Gutiérrez, el cronista no dejaba lugar a dudas de que se trataba de una leal mujer que estuvo al lado de su pareja hasta el final, vigilando que no se quitara la vida: "La muger que lo acompañaba desde tantos años conociendo tales propósitos lo vigilaba continuamente y con mayor celo en los momentos de fuertes ataques". Al mismo tiempo, sus cuidados eran la fuente de alivio para el desesperado afectado por la tisis: "El sábado tuvo otro ataque y los cuidados de su compañera lo aliviaron”. Concepción hacía todo lo que estaba a su alcance: "Su compañera que en ese momento había ido a traer agua del patio lo vio y trató de contenerlo, pero el enfermo en uno de esos arranques de cabeza propios de la enfermedad, la amenazó a ella, por lo cual corrió al cuarto de los vecinos a pedir auxilio". En síntesis, el relato de los hechos relacionados con el suicidio de Gutiérrez

\footnotetext{
${ }^{254}$ AGN, FTC-SE, Legajo G21, Francisco Vicente Gutiérrez, sumario sobre su suicidio.
} 
era una fábula moral en dos sentidos. En primer lugar, presentaba un suicida que buscaba sobrellevar hasta el final los dolores insoportables de una enfermedad terminal, es decir, trabajaba y sostenía la "lucha por la vida" en condiciones muy difíciles y precarias. En segundo lugar, las acciones y la actitud de Concepción eran exaltadas y representadas como un ejemplo de buena y dulce compañera, que cuida, vigila y contiene al desesperado.

Un relato similar encontramos en el caso de Lorenzo Graciano (casado, con tres hijos). Éste se quejaba constantemente de la falta de trabajo como jornalero y las dificultades que conllevaba: problemas para proveer lo necesario a su familia, pagar el alquiler y los impuestos. ${ }^{255}$ Según el testimonio de su esposa, Catalina Yales, en varias oportunidades conversó con su esposo sobre la situación económica que atravesaban, para tranquilizarlo había buscado convencerlo de que vendrían mejores épocas en el futuro. Sin embargo, a pesar de los esfuerzos de Catalina por apaciguar la desesperación de su marido, Lorenzo se quitó la vida el 24 de marzo de 1875. Dos meses antes del hecho, había sido encontrado por Catalina y otra vecina, María Rabena, en la cocina con un arma entre sus manos. Según la declaración de Rabena, fue descubierto con el cañón en la boca y fue ella quien se la sacó y se la entregó a su esposa. Lorenzo les dijo a ambas que sólo jugaba con la pistola. Su mujer, le retiró el arma y un cuchillo, que también tenía allí, y se lo dio a Rabena para que los guardara en su cuarto. Pasado este incidente, meses después, Lorenzo volvió a arremeter contra sí mismo, esta vez sin que su familia o los vecinos pudieran evitarlo. Ese día, el 24 de marzo, llegó del trabajo, cerca del mediodía, y como la comida no estaba lista, fue en busca de un poco de vino. Al volver, fue al cuarto y le pidió a su esposa, Catalina, que saliera. Esta le preguntó la razón y Lorenzo le respondió que estaba muy disgustado y quería descansar una media hora antes del almuerzo. Catalina recordaba todo lo que manifestaba su esposo, sus charlas y el episodio del arma de fuego en la cocina. Al sospechar sobre sus intenciones, le dijo que se iría sólo si le daba la pistola que guardaba detrás de la puerta del cuarto, ya que la inquilina había informado que no tenía más el arma en su poder y que se la había entregado. Al ver que su esposa no aceptaba irse de la habitación, Lorenzo la echó por la fuerza, cerró la puerta y la trabó con el pasador. Catalina y uno de sus hijos, un menor de 8 años, hacían fuerza desde el otro lado para entrar. La inquilina, Rabena, también se sumó a los esfuerzos de la familia para evitar que Lorenzo se suicidara. Con

\footnotetext{
${ }^{255}$ AGN, FTC-SE, Legajo G8, Lorenzo Graciano, por suicidio.
} 
el forcejeo rompieron un vidrio de la puerta. El suicida, en ese momento, tomó la pistola y se disparó en la sien derecha quitándose la vida en el acto. En ese momento, ingresaron al cuarto Catalina, su hijo y la inquilina. Lorenzo Ranea, dueño del almacén que quedaba en la misma esquina del domicilio donde ocurrieron los hechos, al sentir el estruendo corrió para ver qué había pasado. Encontró a la mujer de Graciano y a sus hijos llorando sobre su cadáver. Lorenzo no tenía bienes de ninguna clase, según la policía, dejaba a su mujer y tres hijos en la mayor pobreza.

Al leer el sumario, encontramos indicios del punto de vista del policía sobre este trágico incidente, que se manifiesta en la forma de narrar los hechos y sus comentarios al respecto. Graciano, como hombre cabeza de familia, era responsable de la trágica situación en la que dejaba a su grupo familiar: él debía ser el sostén material, garantizar la provisión de alimento y dinero para preservar el bienestar de su esposa e hijos. Su esposa, Catalina, fue presentada como la comprensiva compañera que trataba de calmar las angustias y las tormentas que alteraban al esposo, que cargaba con la lucha por la vida sobre sus hombros. Así aparecía representada la imagen de una esposa que contenía a su marido, brindaba su compañía y buscaba aliviar la preocupación y la incertidumbre. En este sentido, la falta de certezas sobre el futuro próximo debía ser una realidad difícil de sobrellevar para muchos hombres: ¿qué hacer cuando el miedo y las preocupaciones teñían todo lo que sucedía en el momento presente? En este caso, y varios de los anteriores, vemos aparecer familiares de género femenino, y otras mujeres del entorno del sujeto, que brindaban contención emocional: Catalina trató, según su testimonio, de alejar las ideas negativas y fortalecer un pronóstico optimista que ayudara a Lorenzo a transitar la época difícil que les tocaba vivir. Tal vez, en otros casos, este tipo de interacción habría logrado alejar, por tiempo suficiente, la inquietud sobre el futuro hasta que la situación material del grupo familiar mejorara.

\subsection{Consideraciones finales}

En el presente capítulo, nos propusimos analizar aquellos relatos que daban cuenta de los actos suicidas de personas que estaban sin empleo o padeciendo una situación de pobreza y/o enfermedad. Al explorar el significado ético de dichas narraciones, encontramos algunos matices de acuerdo a las circunstancias que figuraban en los testimonios recabados en los interrogatorios y en las versiones de los hechos 
dadas a conocer en la prensa de la época. En primer lugar, encontramos un primer conjunto de relatos en los que el suicida escapaba de una situación agobiante, sumido en la más profunda y suprema desesperación: pobre, en muchos casos enfermo, sin perspectivas de conseguir empleo y carente de familiares y amigos que pudieran proveerle asistencia y contención. En general, no había muchas circunstancias que pudieran justificar un suicidio; sin embargo, estos casos podían despertar la compasión de los observadores y generar empatía. Por otra parte, si el sujeto era caracterizado como "vicioso", el significado axiológico de lo sucedido era otro. El trabajador pobre consumido por el abuso de las bebidas alcohólicas y que empeñaba sus ingresos en los placeres sensuales de los prostíbulos era el protagonista de otro tipo de fábula moral. Era el ejemplo de las consecuencias que el vicio tenía en los varones y, al mismo tiempo, servía para dar cuenta de la dificultad para conseguir empleo o conservarlo. Por último, el padre y esposo que se dejaba arrastrar por la desesperación también era sinónimo de vergüenza. No se podía justificar que abandonara la lucha por la vida y dejara en una situación de desamparo a su esposa e hijos. Como mencionamos, de acuerdo a la representación del rol masculino, este debía garantizar el bienestar material de estos últimos, este deber debía ser el móvil para sostenerse y perseverar. Sin embargo, como se puede entrever en varios casos, muchas veces la presión era demasiada para algunos trabajadores pobres y/o sin empleo.

En este sentido, entendemos que las redes sociales eran vías por las cuales los actores podían ensayar distintas estrategias, articular contactos y vínculos para conseguir riqueza, prestigio y/o poder, o para obtener información y aventurarse en lo desconocido. En línea con lo anterior, desde nuestra perspectiva, pensamos este conjunto de relaciones vinculares como un posible marco de contención afectiva y material frente a potenciales desgracias y desengaños. Por esta razón, nos propusimos observar cómo eran representados los diferentes vínculos de un sujeto desesperado o al borde de perder toda esperanza de vida y las estrategias de los distintos actores sociales que interactuaban con este para preservarlo de sí mismo. Así, analizamos las redes de contención material y afectiva de los inmigrantes que llegaron a la ciudad de Buenos Aires.

A la hora de abordar estos casos, partimos de considerar que los migrantes que se quitaron la vida, en su mayoría, no poseían vínculos de contención material y afectiva o eran muy escasos. A veces, el tiempo que había permanecido el inmigrante no había sido suficiente para crear una sólida estructura de relaciones sociales o había encontrado 
dificultades a poco de arribar a suelo argentino. En este sentido, no contaba con nada, salvo su propia suerte, capacidad e iniciativa para sobrellevar cualquier situación, como buscar un nuevo empleo, conseguir alojamiento o encontrar consuelo para su desasosiego. Así, tenía menos probabilidades de resistir los desengaños y los imprevistos. Estos mismos sujetos llegaron a testificar lo dramática que era la situación en la que se concatenaban pobreza, falta de empleo y enfermedad, si encima no contaban con una familia en el país. Este era el rostro de la "desesperación" más intensa. Además de confirmar esta premisa, encontramos una gran variedad de situaciones que creímos relevante mostrar. En este sentido, la ausencia de vínculos era un escenario difícil, pero el del hombre con esposa e hijos, sin empleo, también era desolador. En ambos casos, la posibilidad de contar con una red social que proveyera apoyo económico, alojamiento, información, además de contención emocional, tenía mayores chances de proteger al individuo de la desesperación que despertaban la pobreza y el desempleo. En este sentido, cabría reflexionar sobre la importancia de contar con los lazos "débiles" (conocidos, patrones, compañeros de trabajo), amigos y otros tipos de vínculos familiares, que completaran la red de un mismo individuo. Por esta razón, decidimos presentar diferentes tipos de lazos. Al estudiarlos, pudimos acercarnos a marcos relacionales diversos, desde una red casi inexistente (donde el sujeto que se quitaba la vida sólo llegaba a vincularse con los desconocidos), pasando por una mínima (en la que intervenían vecinos, compañeros de cuarto y/o de trabajo, patrones y otros "conocidos") a una más amplia, que además de estos lazos débiles integraba otros más fuertes, amigos y familiares que podrían, en algunos casos, palear las complicaciones materiales, dar contención al que no tenía trabajo, ayudarlo con sus contactos a conseguir uno nuevo, si lo había perdido, y calmar su desesperación y desánimo, escuchando las penas que quería contar, cuando parecía no quedar otra salida que quitarse la vida.

Cabe destacar, una vez más, que partimos de entender el suicidio como un desenlace posible, no determinado: mientras algunos individuos no resistían la desesperación y el sufrimiento, muchos otros luchaban, soportaban el dolor y enfrentaban la adversidad. El desenlace final no dependía sólo de la disponibilidad de una red de contención. Desde nuestra perspectiva, ningún vínculo o conjunto de relaciones podía garantizar la prevención o intervención efectiva para evitar un suicidio; las circunstancias que estaban en juego en cada caso eran diversas y complejas y los lazos que había establecido el individuo con su entorno social eran un factor más, como 
el estado físico y psíquico del sujeto, pero no determinante. Es decir, una red de contención podía dar más posibilidades de superar la situación límite, de evadir o sobrellevar el estado de intensa desesperanza; sin embargo, en ningún caso podía evitar el suicidio del ego padeciente por sí misma. En este sentido, creemos que tenía un rol importante la forma en la que se percibía el propio individuo y cómo representaba a los que integraban su red de vínculos; estas representaciones podían contribuir a calmar o exacerbar la angustia, el malestar y el sufrimiento que sentían estos actores sociales; y a favorecer u obstaculizar la ayuda de la red de aliados que lo asistían en su lucha contra la "suprema desesperación".

Por esta razón, también hemos presentado las diferentes formas en las que eran representados los distintos lazos que tenía un individuo que pasaba por una situación de extrema desesperación. Como planteamos al comienzo del trabajo, partimos del supuesto de que existían roles diferenciados, de acuerdo con el género del sujeto, a la hora de contener al individuo. Los actores sociales de género masculino, vinculados al ego que padecía el sentimiento de la desesperación, eran presentados en los relatos, reconstruidos en el sumario, como proveedores de asistencia material (comida y alojamiento) y eran los guardianes de las últimas disposiciones expresadas por los que se quitaban la vida. En el caso de las mujeres con las que estaba relacionado el suicida / herido, eran representadas como las garantes del consuelo y la contención emocional, tal es así, que, en general, eran las que escuchaban o recibían los pedidos de auxilio y las manifestaciones vinculadas con el malestar que sentía el hombre sin empleo y desesperado.

En síntesis, el ámbito familiar del suicida era uno de los elementos situacionales claves a la hora de explicar una muerte por suicidio. Era verosímil imaginar que la ausencia de parientes y amigos que pudieran socorrer al desesperado agravara su condición. En varios casos, la situación de los inmigrantes era representada de este modo para dar cuenta de la frustrada inserción en el tejido social receptor. Por otra parte, un hogar carente de armonía y desarticulado no podía contribuir a calmar el sentimiento de desesperación. En ese caso, como ya vimos, el relato podía llegar a presentar al grupo familiar como la "causa determinante" de lo sucedido, algo mucho más difícil de sobrellevar para los deudos. Como contraparte, cuando estaba presente y no había peleas internas de por medio, la red familiar era representada como un soporte, un ámbito de contención frente a los desafíos de la lucha por la vida.

En las narraciones analizadas en este capítulo, el suicidio era presentado como 
el escape o la fuga de un sufrimiento intolerable, causante de una "suprema desesperación". En otros casos, el acto suicida podía ser interpretado como un medio para agredir a un otro significativo, la mayoría de las veces, la persona amada, aquel que no correspondía a los sentimientos del suicida o hacia aquellos que se oponían a la unión de los enamorados. Por esta razón, en el capítulo siguiente, analizaremos los casos de suicidio relacionados con el amor y el vínculo de pareja (desengaño amoroso, amores contrariados, conflictos conyugales). Así, en los apartados restantes de este trabajo, estudiaremos cómo eran narrados los actos suicidas de aquellos sujetos que intentaban condicionar a su entorno social y familiar, es decir, aquellos casos en los que el suicida llevaba adelante su autogresión como una acción comunicativa regulativa. 


\section{Capítulo 9: Las pasiones desenfrenadas}

En los capítulos anteriores observamos distintas formas de representar al sujeto que llevaba adelante el acto suicida. Había relatos en los que el suicida era un individuo desesperado por problemas materiales o por conflictos familiares; en otros, se trataba de sujetos que habían perdido el uso de la razón y tenían sus "facultades mentales alteradas" por diversos tipos de patologías mentales. En el presente capítulo, nos centraremos en las narraciones protagonizadas por suicidas apasionados, es decir, aquellas historias en las que estaba de por medio el amor o la relación de pareja.

Cabe destacar que muchas narraciones eran articuladas a partir de "causas determinantes" asociadas con las pasiones amorosas: "desengaño amoroso", "celos", "amores contrariados", etc., así como aquellos "dramas de amor" o "crímenes pasionales", según la prensa, los suicidios dobles y las tentativas de homicidio o agresiones físicas seguidas del acto suicida del asesino / agresor. Por esta razón, este capítulo está dedicado a estudiar los relatos de aquellos suicidios relacionados con sentimientos amorosos y conflictos conyugales.

El amor tenía un significado ambiguo dentro del discurso de las elites culturales del período que estudiamos. Desde la época de Rosas, la sociedad rioplatense valoraba y rescataba el amor romántico como un valor positivo en muchos casos. Tras el final del rosismo, esta sensibilidad romántica entró en su momento de auge; en palabras de Carlos Mayo (2004: 75): "El amor es celebrado en la poesía y la novelística, evocado en el cancionero, en las tertulias y vivido con gran intensidad por muchas parejas jóvenes". La prensa porteña se plagó de poemas y sueltos sobre este tema en la primera década de la segunda mitad del siglo XIX. De acuerdo con estos escritos, el amor verdadero era la "base de la civilización", es lo que une a los jóvenes esposos y los conduce a la felicidad. Por otra parte, el amor "ardiente e inmoderado" podía llevar a los celos, a una pasión destructora y enfermiza (MAYO, 2004: 94 y 95). Esta misma dualidad era resaltada por los médicos higienistas y alienistas de las décadas finales del siglo XIX: el amor era el fundamento de los matrimonios felices, por un lado, y, al mismo tiempo, podía generar celos, odio, etc., que impulsaba a los sujetos a cometer homicidios y/o suicidios, o promover la aparición de patologías mentales, de acuerdo con las ideas de los alienistas. 
Como señala Sandra Gayol (2004), la difusión de este tipo de sucesos en los textos de los criminólogos y medios gráficos de la época contribuyó a difundir la imagen de una ola de criminalidad en aumento. Las secciones de diarios como "La Prensa" y "La Nación", estaban pobladas de este tipo de notas (homicidios pasionales, asesinatos, duelistas, robos profesionales), bajo los subtítulos "Noticias de policía", "Noticias", etc. Por otra parte, como menciona Gayol (2004: 229), desde la perspectiva de las elites, el amor explicaba los delitos pasionales, salvo en el caso de las prostitutas:

\begin{abstract}
Los delitos pasionales anidan en el amor que, obviamente, sólo era concebido dentro del matrimonio. Sentimiento noble y altruista, hay quienes incluso hablaban de una ola de amor romántico; el amor presupone desinterés y, en palabras de Eusebio Gómez, "un sentido moral casi perfecto", difíciles de encontrar en una prostituta y un rufián. La prostitución no tenía retorno, representaba un estigma moral corporeizado e invalidaba el ingreso en el "imperio de los sentimientos.
\end{abstract}

Así, el amor era un sentimiento propio de mujeres fieles y honradas, que se entregaban al hombre amado. Las prostitutas en cambio, no podían sentir amor ni despertar una genuina pasión en los individuos de sexo masculino. Así, los sentimientos amorosos genuinos estaban asociados con el honor de los hombres y mujeres que establecían una relación de pareja. En este sentido, el marco axiológico de la época exaltaba la virginidad y la fidelidad de las mujeres, así como la supervisión de su sexualidad por parte de los varones.

Como veremos, las narraciones sobre suicidas apasionados que analizaremos a continuación también estaban articuladas siguiendo este tipo de principios morales. En este capítulo, presentamos el análisis de los discursos narrativos vinculados con el amor. Por esta razón, hemos seleccionado, del conjunto de los casos estudiados, aquellos que tuvieron como causa determinante alguna explicación afín a este eje temático. Asimismo, incluimos aquellas historias de muerte por mano propia, cuya trama estaba articulada alrededor del vínculo entre el suicida y su pareja. A partir de las historias protagonizadas por estos románticos desesperados, buscamos analizar dos cuestiones principales. En primer lugar, identificar distintos tipos narrativos de acuerdo con las explicaciones verosímiles elaboradas por el que se quitaba la vida y los integrantes de su red social. Como en los capítulos anteriores, comparamos estas versiones con las que circularon en los medios gráficos de la época y prestamos atención a los valores y 
creencias que daban sentido a las acciones de estos actores sociales, es decir, los elementos del marco axiológico.

El segundo objetivo de este capítulo fue analizar las interacciones entre el suicida y el otro significativo al que apelaba con sus acciones. En estos casos, la pareja (concubino/a, novio/a, amante, esposo/a) era, en la gran mayoría de los casos, el sujeto interpelado por los que se quitaban la vida; $y$, en menor medida, los padres del suicida o los de su amada/o. Entre los relatos analizados, encontramos diversas interacciones con diferentes intenciones por parte del que se suicidaba. Había quienes manifestaban su dolor por percibir que era imposible establecer un vínculo amoroso con la persona deseada. Algunos de ellos expresaban su deseo de reencontrarse en el más allá con el ser amado. Otros, en cambio, se suicidaban con intenciones más agresivas: trataban de chantajear al sujeto objeto de deseo; y, en varios, la aniquilación de la propia vida era una forma de generar culpa, escándalo y sufrimiento en alguno o varios de los supervivientes. En las narraciones presentadas en los capítulos anteriores, en general, los suicidas buscaban expresar las causas de su dolor o manifestar el intenso sentimiento de desesperación que los apenaba. Así, en la mayoría de estos relatos, los que se quitaban la vida eran representados llevando adelante acciones comunicativas expresivas y declarativas. En este capítulo, en cambio, encontramos más narraciones que muestran al suicida tratando de condicionar al entorno y a los otros significativos, a partir de la agresión hacia ellos mismos.

\subsection{Mujeres sensibles y jóvenes románticos}

En primer lugar, en estos relatos, identificamos una mayor proporción de hombres y mujeres de menos de 20 años (27,38\%); en el conjunto de los casos, esta franja etaria representó un porcentaje menor, 13,67\%. Al mismo tiempo, la proporción de personas mayores de 40 años que se quitaron la vida por amor $(5,95 \%)$ es menor que en el total $(18,09 \%)$. También cabe destacar que los quinquenios de "16 a 20" y "21 a 25 " tuvieron valores superiores a los de la generalidad de los casos analizados. Además, los quinquenios de "31 a 35" y "36 a 40" presentaron porcentajes (4,76\%, en el primero, y $5,95 \%$, en el segundo) que son equivalentes a la mitad de los valores de esos subgrupos etarios en el total de las narraciones consultadas (10,5\% y 11,05\%, respectivamente). Por otro lado, si observamos los valores al clasificar de acuerdo con 
el género a los que se suicidaron por cuestiones amorosas, también encontramos variaciones. Si estos últimos fueron en un $48,81 \%$ varones y un $51,19 \%$ mujeres, la representación de cada uno de los sexos en el total era más asimétrica $(78,18 \%$ y $21,82 \%$, respectivamente). Esta diferencia se acentúa más si comparamos a los hombres y mujeres de menos de 20 años. Los sujetos de sexo femenino en dicha franja etaria $(6,77 \%$ de los 724 suicidios relevados) representaban el 20\% de los 84 casos de suicidio por causas determinantes asociadas con el amor y los conflictos de pareja. En los varones, en cambio, los porcentajes casi no variaron: mientras en el total eran el 6,91\%, en los suicidios por cuestiones amorosas representaban el 7,14\%. Desde nuestra perspectiva, estos datos están vinculados con los distintos horizontes de expectativas que tenían los hombres y mujeres de acuerdo a la etapa de la vida que transitaran. Es probable que para las mujeres de entre 15 y 25 años, la esperanza de encontrar pareja y casarse fuera mayor que en años posteriores; en general, se consideraba que se quedarían para "vestir santos" si no lo conseguían antes de los 25. Del mismo modo, conocer al ser amado y formar un hogar en el cual encontrar la felicidad era un anhelo de muchos jóvenes de ambos sexos. Así mismo, los desengaños y frustraciones derivados de las relaciones amorosas eran más frecuentes entre estos.

La situación que mencionamos en el párrafo anterior no era desconocida por los intelectuales de las elites que estudiaron los suicidios en la época. Desde esta perspectiva erudita y científica, los jóvenes, en especial de género femenino, eran vistos como más propensos a quitarse la vida, arrastrados por sus pasiones, en especial, el amor. En este sentido, los médicos alertaban sobre la perniciosa influencia de las obras literarias en el estado mental de la juventud. Los folletines de la época tenían tramas violentas, dramáticas e inmorales que despertaban las pasiones más intensas entre los adolescentes. El resultado, una poderosa sugestión que hacía crecer el número de los suicidios y los delitos. Al tratar este punto no faltaba la referencia al personaje creado por Johann Wolfgang von Goethe, el joven Werther. Éste se había convertido, desde la aparición de la novela escrita por Goethe (a fines del siglo XVIII), en un estereotipo de los suicidios por amor, dramáticos y novelescos, referencia a la que aludían los profesionales de la salud cuando hacían comentarios irónicos respecto de los suicidios por "amores contrariados", inspirados en las tramas de la literatura por entregas. ${ }^{256}$

\footnotetext{
${ }^{256}$ En el pensamiento médico, la literatura romántica y folletinesca era considerada una pésima influencia por los ejemplos que proponía. El protagonista de la obra de Goethe, Werther, era el arquetipo del suicidio romántico por excelencia. Este personaje decidía poner fin a su vida frente a la imposibilidad de concretar
} 
Si bien el poder de sugestión de los periódicos y diarios, así como de la literatura "romántica" o "folletinesca", se mantendría como un factor de explicación en el pensamiento científico, la causa principal eran los fenómenos y transformaciones sociales que afectaban a los organismos particulares en su funcionamiento. El criminólogo Miguel Lancelotti reflexionó sobre el fenómeno de la imitación y el contagio en los casos de suicidio. Para éste, sólo era posible la sugestión si había terreno psíquico propicio. En palabras de Lancelotti:

[...] ningún esposo o amante afortunado; ningún hombre de costumbres morigeradas; ningún individuo que no tenga su cuerpo viciado, extenuado por las enfermedades y mil otros sufrimientos físicos o morales; ninguno que no tenga la imaginación exaltada [subrayado en el original], por más asiduo lector que sea de crónicas a lo Werther se le ocurrirá imitar a esos tristes héroes que ven en la propia existencia su mayor enemigo (LANCELOTTI, 1900: 579).

Sin que ocurriera un hecho desafortunado, como un desastre financiero; en ausencia de celos, ira, cólera, envidia y otras emociones destructivas; en un cuerpo que no había abusado de los placeres, de las bebidas alcohólicas, del juego; donde no había lugar para la ambición, la ociosidad, la soledad, la nostalgia, el terror, los remordimientos, la desesperación, no existía un terreno propicio para el suicidio. Si bien nadie planteaba la existencia de un "suicida nato", de forma análoga a la concepción lombrosiana del delincuente, entendían que había ciertos individuos, de constitución física y mental más débil, que encontraban dificultades para adaptarse a la vida en el mundo civilizado. La civilización multiplicaba las necesidades y sobreexcitaba el sistema nervioso, en mayor o menor grado, de acuerdo al temperamento y a la personalidad de los individuos (LANCELOTTI, 1900: 579).

su amor hacia Lotte, quien estaba casada con otro hombre, Albert, a quien Werther estimaba. Para terminar con el sufrimiento que le provocaban estos sentimientos, este artista se quitaba la vida. Werther era la referencia más frecuente presentada por los médicos a la hora de denunciar los efectos dañinos de la literatura romántica y novelesca. La novela de Goethe había generado, a fines del siglo XVIII, preocupación y consternación, ya que era acusada de haber provocado una serie de suicidios de jóvenes que decían haberse inspirado en el protagonista de la obra. El propio autor pidió disculpas públicamente, convencido de los males que su creación había desencadenado. Todo esto promovió que los sufrimientos del joven Werther fueran conocidos en el mundo occidental y que éste se transformara en un estereotipo de la sensibilidad romántica. El suicidio del protagonista estaba motivado por sus intensos sentimientos y el sufrimiento interno que le provocaban. Este ejemplo literario era comparado por los médicos con los casos que encontraban en la prensa y en las obras de ficción de su época. Estos podían ser el vehículo de la sugestión de mujeres y jóvenes enamorados. 
Para José Vásquez (1891: 48), discípulo del alienista Lucio Meléndez, era fundamental promover la domesticación de las pasiones a través de la educación. Para construir al ciudadano virtuoso era necesario dar, desde la infancia, una formación integral, intelectual y moral, que incluyera la reflexión sobre los sentimientos. Esta instrucción era el contrapeso necesario frente a ciertas influencias nocivas, por ejemplo, la literatura romántica y los folletines. Ésta atentaba contra el control de las pasiones, en especial, entre las mujeres (VÁSQUEZ, 1891: 65-66). En línea con el pensamiento de Esquirol, Vásquez explicaba que ciertas emociones, algunas depresivas, otras violentas, provocaban episodios de locura transitoria; por ejemplo, el orgullo, los celos, el odio, la preocupación por la pobreza, etc. Lo que nos resulta interesante destacar sobre este punto es que este alienista decidió dejar de lado el análisis de cada una y concentrarse en el amor. Para Vásquez, esta emoción era la causa principal del suicidio en las mujeres. Al mismo tiempo, eran los sentimientos amorosos hacia el sexo femenino el principal responsable de los crímenes, los duelos y las prácticas suicidas en los hombres.

En este sentido, uno de los fenómenos que despertaban la curiosidad, el asombro y el rechazo de estos intelectuales era el llamado "doble suicidio", en el cual dos enamorados decidían poner fin a sus vidas:

\begin{abstract}
Como consecuencia se desprende, que muchos suicidios dobles, se realizan bajo la influencia de enfermedades mentales determinadas generalmente por las emociones pasionales; y creemos, abriendo opinión, que en los casos en que obra el amor, interviene un grado de sugestión hipnótica estimulada por el sentimiento de lo bello, por la afinidad de los seres en la simpatía del cariño delirante y, en fin, por las neurosis que determina la exaltación del sentimiento pasional (VÁSQUEZ, 1891: 81).
\end{abstract}

Esta situación era percibida como un hecho frecuente en el marco de la sensibilidad romántica y si alguno de los amantes llegaba a sobrevivir planteaba un dilema. Sobre esta situación, escribió un artículo Ricardo del Campo (1898), vicedirector de la revista “Criminología Moderna". En este trabajo, titulado "Los crímenes románticos", Del Campo también denunció la perniciosa influencia de la literatura de la época en los jóvenes. Para argumentar sobre este tema, relató y analizó el caso de Casimiro Tapia, un joven oriental de 19 años que el 24 de noviembre de 1898 degolló a su amante, Hortensia Marsi, atentando luego contra su propia vida, aunque sin resultado. Al 
parecer, ambos habían decidido suicidarse debido a que la familia de Hortensia se oponía a su amor. A la hora de explicar las causas de este suceso, Del Campo destacó que se trataba de un "celoso por literatura", retomando un concepto del escritor francés Paul Bourget. El autor justificaba su hipótesis en el hecho de que Tapia era un asiduo lector de historias románticas, con preferencia de aquellos relatos con finales trágicos. Según Del Campo, la sugestión de este tipo de literatura habría hecho exagerar la realidad y los obstáculos que tenía para continuar su relación con Hortensia. ${ }^{257}$

En este sentido, al consultar los sumarios judiciales, hemos encontrado indicios de algunas de estas representaciones estereotipadas que formaban parte de la cultura general y del sentido común acerca de los jóvenes y su sensibilidad. En algunos de los relatos, aunque no se conociera la causa, se presentaba a los protagonistas como jóvenes sensibles y románticos, al estilo "Werther". Manuel Martínez (auxiliar del inspector de telégrafos de la policía), el 29 de agosto de 1887, entró en la comisaría y pidió a uno de sus compañeros un libro de poesías y comenzó a leer la que tenía por título "El suicidio". Uno de los presentes interrumpió a Manuel y se ofreció a continuar leyendo. Otro de los policías que estaba allí escuchó a Martínez decir por lo bajo, "así se hace", momentos antes de que se disparase con un revólver en la sien derecha. ${ }^{258}$ Según el comisario y sus compañeros nada parecía indicar que éste tomara la resolución de suicidarse, siempre había tenido un carácter jovial y agradable y se desempeñaba de forma responsable y comprometida en sus labores. Quizás imaginaban a un suicida como alguien melancólico y triste.

Así describieron a Leandro García los que respondieron el interrogatorio de la policía. ${ }^{259}$ El 15 de octubre de 1879, el agente dejó asentado que Leandro (español, 27 años, soltero, dependiente de una ropería), era callado y poco comunicativo, sus compañeros de trabajo también destacaron que se lo veía con frecuencia cabizbajo. Asimismo, en el relato de lo sucedido, se destacaba que García leía un libro de poesías antes de dispararse con un arma de fuego en la cabeza, lo que denotaba el carácter sensible del joven.

\footnotetext{
${ }^{257}$ En otro artículo, Pío VIAZZI (1899), quien sería autor de La lucha entre los sexos (1902), abogado y corresponsal externo de Criminología, trataba de explicar estos dobles suicidios como el resultado del decaimiento fisiológico que traía la actividad sexual, en especial, aquella que tendía a la degeneración de los sujetos. Cuando el individuo había cumplido su rol en la reproducción podían aparecer tendencias de odio, tanto hacia sí mismos como hacia el objeto amado. La actividad sexual, ya sea por exageración o por carecer de energías suficientes, por el agotamiento o por males, como la epilepsia o ciertas neurosis, podían favorecer estos tipos de actos violentos.

${ }^{258}$ AGN, FTC-SE, Legajo M39, Martínez, Manuel, su suicidio.

${ }^{259}$ AGN, FTC-SE, Legajo G14, García, Leandro suicida.
} 
Este mismo carácter novelesco aparecía en el relato de las circunstancias del suicidio de Rodolfo Sepúlveda (peruano, 25 años). ${ }^{260}$ Este joven venía de Europa y se quitó la vida el 18 de noviembre de 1881, en los Bosques de Palermo, disparándose con un revólver en el corazón. De acuerdo con la narración elaborada por el policía que llevó adelante la investigación de su muerte violenta, la nota encontrada entre sus ropas tenía escrita una poesía romántica. Según lo publicado en los diarios "La Nación” y "La Prensa", el 20 de noviembre de 1881, en su último escrito, el suicida expresaba lo siguiente:

Lloré, no se porqué. Aun siento en mis mejillas ardientes huellas de un amargo llanto. Llore al ver desaparecer entre las ramas del sauce llorón, que cubrirá mi lecho mortuorio, los últimos rayos de sol. Llore al sentir pasar en el cercano paseo un carruage, el mismo que vi poco ha llevando a una niña hermosa como la juventud y a dos niñitas que se rieron de ver corretear por estas soledades a un caballero de galera de media vara; Llore al oír la alegre gritería de los muchachos bañándose en la playa de mas allá, llore en fin sin saber porque. Ahora ya no lloro, La noche esta cayendo. Todo esta tranquilo.... No ahí pasa otro carruage, lo oigo y sonrío... Los últimos reflejos del sol se pierden en las nubecillas del horizonte, lo veo y tranquilo admiro las variantes formas que les da el viento que carece de fuerza. ¿Si habrá tempestad? Para mi no!

Según los cronistas, el joven Rodolfo provenía de una prestigiosa familia de Lima que había quedado en la ruina como consecuencia de la Guerra del Pacífico. Había sido enviado con cartas de recomendación para conseguir empleo en la ciudad. De acuerdo con lo informado en el diario "La Prensa" (20/11/1881), la biblioteca del suicida contenía las siguientes obras, que daban cuenta del estado mental alterado del sujeto: "La princesa saltinbanqui”, de Alexis Bonvier; "Guía de la conversación Español Francés"; "Rimas", de Gustavo A. Bécquer; "Marianela", de Pérez Gáldos; "Memoramdum de medicina y cirujia"; "Le Bave de Paris", de Bongolez; y "Obras poéticas" de Espronceda. Los libros del suicida eran un indicio de su sensible e inestable carácter: la obra de Pérez Gáldos tenía como desenlace el suicidio de la protagonista; "La princesa saltinbanqui" era una novela dramática francesa de folletín; al mismo tiempo, Bécquer y Espronceda eran poetas románticos. Sepúlveda fue enterrado en el Cementerio de la Chacarita y en su tumba se colocó una cruz con su nombre, para que su familia pudiera encontrar el lugar donde descansaban sus restos,

\footnotetext{
${ }^{260}$ AGN, FTC-SE, Legajo S21, Sepúlveda, Rodolfo por su suicidio [Dos cartas legibles].
} 
según lo relatado en el diario "La Nación” (20/11/1881).

Algunos sumarios narraban situaciones que se asemejaban a las tramas de relatos literarios. La historia de Paulo Piati, así como el epitafio que dejó escrito en un papel, parecía extraída de una novela o folletín con desenlace trágico. Piati (italiano, 24 años, dos años de residencia en Argentina, soltero, tenedor de libros) intentó quitarse la vida al beber láudano en su habitación (vivía en una casa de inquilinos). ${ }^{261}$ Manifestó estar agobiado por todas sus desdichas, infamias y desengaños. De acuerdo con los testimonios recolectados por el policía, Paulo estaba enfermo de tisis (tuberculosis), no tenía recursos para cubrir sus necesidades básicas y había sido abandonado por su amor. A continuación, transcribimos el contenido de la nota suicida que dejó (traducido por la policía de la época):

\author{
1886-1888 \\ Años infames y terribles \\ 12 / Agosto
}

Hoy todo concluye para mí, tengo 24 años justos de edad y por ser mi cumple-años pienso concluir con esta vida infame y miserable inútil para mi y los demás, una vida llena de sinsabores y estupideces, he sufrido bastante desengaños, iras, he padecido sin cuento, estoy aburrido, cansado de todo y de todos. Muero. Quién sabe si en la muerte no encontraré algún alivio a mis males?

Escribo estas últimas líneas con el corazon despedazado, con el alma moribunda con mi imajinación convulsa por el último golpe sufrido.

No me quedaba más que el supremo placer del amor con un ser que me hacía feliz y al que adoraba con locura, bien también esto lo tengo, todos los caprichos.

Cuando te cansaras Oh Dios Poderoso de atormentar a esta tu criatura?

Según el mensaje que nos transmite en su carta, Paulo representaba el cariño de su amada como el único aliento para soportar los dolores que experimentaba. Para él, la vida era una sucesión de desencantos constantes (enojo, equivocaciones, desengaño, insatisfacción), que no ofrecía otra posibilidad más que disfrutar del amor (el "supremo placer”) o morir. La fecha no era casual, el día de su cumpleaños parecía un buen momento para hacer un recuento de lo vivido. De acuerdo con el balance vital de los últimos años, ya no había más posibilidad de encontrar la felicidad, sólo sufrimiento; la balanza se inclinó hacia la muerte. La desesperación y el sentimiento de estar aislado de su red de vínculos eran completos: estaba "aburrido, cansado de todo y de todos" y, al

\footnotetext{
${ }^{261}$ AGN, FTC-SE, Legajo P40, Piati, Paulo, por tentativa de suicidio.
} 
mismo tiempo, sentía que su existencia "infame y miserable" era "inútil” para sí mismo y para sus otros significativos. Si bien cargado de un tinte novelesco, biografías con desenlaces como el de Piati eran creíbles.

Era verosímil imaginar que las personas podían perder la razón como resultado del amor y las intensas pasiones románticas. Leopoldo Faba (argentino, 30 años, soltero) explicó a la policía que atentó contra su vida porque estaba "mal de la cabeza", como consecuencia de las peleas que tenía con su concubina. Tanto en el relato de Faba, como en el del policía que lo dejó registrado en el sumario, aparecía la asociación entre el malestar en las relaciones amorosas y la aparición de patologías mentales, que tenían como desenlace, en algunos casos, la aparición de ideas suicidas o la puesta en práctica de intentos de autoagresión. ${ }^{262}$

En algunos sumarios no se incluían mayores detalles de lo sucedido, el estereotipo quedaba sobreentendido sin brindar mucha información. Así lo encontramos expuesto en el informe relacionado con la muerte violenta de Rosa Chautemps. Rosa intentó quitarse la vida bebiendo láudano en su domicilio el día 10 de enero de 1887. El policía que confeccionó el sumario se limitó a mencionar que la causa del acto suicida de Chautemps eran "amores...". ${ }^{263}$ No eran necesarias mayores explicaciones, era un hecho dado que las mujeres eran, en teoría, seres más sensibles y apasionados, en especial, si eran jóvenes, como Isabel Flores (argentina, 17 años, soltera, prostituta). Isabel trató de suicidarse el $1^{\circ}$ de octubre de 1882 tomando fósforos diluidos en agua. En el sumario levantado por el policía, éste sólo acotó que la causa de su intento de suicidio era "afecciones del corazón". ${ }^{264}$

En el caso de los hombres, suicidarse por tales motivos representaba una actitud vergonzosa, digna de permanecer en el misterio. Miguel Honoré (francés, 23 años, soltero, dependiente), intentó darse muerte el 13 de abril de 1884, a las 19:30hs, utilizando un revólver con el que disparó en dirección a su propio vientre. Honoré se negó a declarar a la policía los motivos de su desesperada determinación; sin embargo, el agente dejó sentado que era probable que la causa fuera algún "amor desgraciado". ${ }^{265}$ Miguel no quiso declarar los motivos de su pesar. Ángel Mascheroni (italiano, soltero, sin ocupación) tampoco demostró interés en comunicar a las autoridades los detalles del

\footnotetext{
${ }^{262}$ AGN, FTC-SE, Legajo F19, Faba, Leopoldo, su suicidio.

${ }^{263}$ AGN, FTC-SE, Legajo C35, Chautemps, Rosa, s/tentativa de suicidio.

${ }^{264}$ AGN, FTC-SE, Legajo F9, Flores, Isabel, s/tentativa de suicidio.

${ }^{265}$ AGN, FTC-SE, Legajo H7, Honoré, Miguel, s/tentativa de suicidio.
} 
desengaño amoroso que lo había impulsado a quitarse la vida. ${ }^{266}$ El 25 de enero de 1883, Mascheroni ingirió pasta para matar ratones y cloroformo. Ángel era hermano de dos escultores. Estos declararon que Mascheroni sólo se ocupaba de la bebida, y no buscaba trabajo, desde que había sufrido un desengaño amoroso. Al principio, Ángel no quería declarar, pero, más tarde, manifestó que había tomado veneno porque había sido engañado por una mujer.

Estos suicidios de varones apasionados que se quitaban la vida por problemas amorosos eran los más cuestionados dentro del marco axiológico de las elites. Así lo resaltó el diario "La Nación", el 31 de marzo de 1881, al informar sobre un acto suicida ocurrido el día anterior:

Los suicidios están tomando un notable incremento entre nosotros.

Parece que estos hechos lamentables tienden a propagarse de un modo alarmante, en vez de limitarse como fuera de desear.

Jóvenes que apenas nacen a la vida, que tienen en perspectiva un porvenir risueño, que son necesarios a los suyos, se quitan la vida, las más de las veces por causas frívolas, acaso por los desdenes de una mujer coqueta, como si de una mujer se compusiera el mundo.

El suicidio, como recurso extremo de la desesperación, puede acaso disculparse, no justificarse, en una persona combatida por los sufrimientos, perseguida por la inclemencia, o acosada por la miseria; pero nunca en jóvenes inexpertos todavía por su corta edad, que no han tenido tiempo de sentirse impotentes para hacer frente a la adversidad.

En síntesis, desde la mirada del discurso científico y la perspectiva de las elites culturales, muchos de los suicidios eran la expresión de pasiones románticas exaltadas, que debían ser condenadas como frívolas y vergonzosas. Este romanticismo, que proponía exaltar los sentimientos de los hombres y mujeres sensibles, también era interpretado como uno de los responsables de que muchos, que ya estaban predispuestos al suicidio, terminaran llevando adelante esta extrema resolución por peleas o incidentes menores, o que se batieran a duelo para defender su honra, por medio de la violencia. El amor o el desengaño amoroso, además, podían arrastrar a las personas al vicio, la ambición desmedida y otras actitudes que no eran consideradas virtuosas. Por esta razón, aparecía la necesidad de una adecuada educación moral de los sentimientos que preparara a los futuros ciudadanos para enfrentar la vida y sirviera para prevenir la aparición de conductas desviadas, peligrosas y precoces.

\footnotetext{
${ }^{266}$ AGN, FTC-SE, Legajo M25, Mascheroni, Ángel, s/tentativa de suicidio [Cartas - dos].
} 
A continuación, presentaremos las distintas variantes de tipo narrativo protagonizados por estos suicidas apasionados, de acuerdo con las diferentes explicaciones verosímiles elaboradas por el que se quitaba la vida y los integrantes de su red social.

\subsection{Los suicidas apasionados}

\subsubsection{El Desengaño}

En un primer conjunto de casos, podemos agrupar los relatos cuya trama gira en torno al amor no correspondido, es decir, al dolor provocado por el rechazo del individuo deseado por el suicida. Dentro de éste, podemos incluir la historia de León Barnatti. León (italiano, 23 años, soltero, electricista) se quitó la vida el 15 de junio de 1888 en la vía pública. De acuerdo con el sumario de su muerte, se disparó en varias partes del cuerpo y el disparo letal fue dirigido al corazón. Según lo averiguado por la policía, se había suicidado "a causa de estar enamorado de una mujer que no le correspondía". ${ }^{267}$ El relato de Federico Kuhleman (dueño de una fonda, "La Merced") también sirve a modo de ejemplo de esta primera variante de tipo narrativo. Federico se suicidó el 15 de junio de 1859 por medio de un disparo de arma de fuego en la boca. De acuerdo con las cartas que dejó (una estaba dirigida a la joven que amaba), la policía dedujo que se trataba de un "desengaño amoroso". ${ }^{268}$ Una causa determinante similar estructura la narración del intento de suicidio llevado adelante por Benito Correa (argentino, 22 años, soltero, albañil). Benito intentó darse muerte el 23 de junio de 1882 clavándose una daga en el vientre. El suceso ocurrió en un boliche (despacho de bebidas), situado en la calle Caseros, entre Catamarca y La Rioja. Los testigos declararon que Correa se hirió debido a que había sido rechazado por Ángela Coria; ambos habían tenido un romance en el pasado. Benito expresó que sentía un gran cariño por su ex-pareja, sin embargo, Coria lo había "burlado". Según los testigos, Ángela se

\footnotetext{
${ }^{267}$ AGN, FTC-SE, Legajo B40, Barnatti, León, s/su suicidio.

${ }^{268}$ AGN, FTC-SE, Legajo K1, Kuhleman, Federico s/su suicidio. La carta que fue adjuntada en el expediente contiene las últimas voluntades del suicida: "Buenos Aires, 15 de junio. Mi estimado Sr. Arning. Por medio de la presente le transfiero a usted todo mi negocio y le pido amablemente que me entierren de manera decente y que venda todo mi negocio al mejor precio posible, en caso de que quedara un excedente se lo envíe a mi madre domiciliada en Markstrasse 47, Hannover. Su leal servidor, Friedrich Kuhleman". Quiero agradecer a la Traductora Pública Marina Inés Brunotto por hacer la traducción de este documento.
} 
negaba a restablecer el vínculo amoroso con Correa. ${ }^{269}$

En muchos otros sumarios, no se daban a conocer las circunstancias que contrariaban a los enamorados. José Santiago Foa, inmigrante italiano, intentó quitarse la vida el 22 de enero de 1887. Para llevar adelante su acto suicida eligió una habitación del Hotel Génova. Allí, tomo una dosis de láudano. Fue rescatado a tiempo por el Dr. Manuel Blancas. Blancas le administró un antídoto que dejó a Foa fuera de peligro. Cuando fue interrogado por la policía, José se negó a revelar los detalles y los motivos que lo habían impulsado a tomar una determinación tan extrema. Sin embargo, de acuerdo con lo asentado en el sumario, la carta que fue encontrada en la habitación del hotel (no adjuntada al expediente) revelaba las circunstancias que Foa no quería dar a conocer. Según la policía, del contenido de la nota se deducía que fueron "amores contrariados" los que llevaron al suicida a intentar darse la muerte. ${ }^{270}$ Esta misma causa determinante fue mencionada en el sumario levantado luego del suicidio de Lina Pirola. ${ }^{271}$ Pirola (italiana, 38 años, viuda), también intentó envenenarse con láudano, sin embargo, no llegó a ser auxiliada a tiempo. Fue encontrada en la pieza de la casa de inquilinos que habitaba, ya sin vida, el 29 de octubre de 1886. Según algunos de los testigos que la conocían, en Europa ya se había querido suicidar por "amores contrariados" y sospechaban que esta fue la causa de su acto suicida. Elena Cada también intentó quitarse la vida por similares frustraciones amorosas. ${ }^{272}$ Para ello, recurrió a un medio más contundente, sin atentar contra su rostro, se disparó con un revólver en el costado izquierdo de su cuerpo. Los hechos ocurrieron en la Confitería del "Gas". A partir de los testimonios recolectados, se llegó a la conclusión que la motivación de su autoagresión provenía de amores que habían sido frustrados. En los relatos anteriores, no encontramos más explicaciones ni detalles de lo sucedido. ¿Qué circunstancias impedían el éxito de sus relaciones de pareja? ¿Se trataba de desengaños amorosos? ¿Qué otros obstáculos podían contrariar a los que estaban enamorados?

En este tipo de casos, muchas veces no había un mensaje explícito para el entorno vincular del sujeto. En varias ocasiones, no declaraban ni dejaban nota, primaba el pudor del suicida en estos asuntos. Por ejemplo, Juan Castelleti (italiano, 30 años, marinero), sólo dejó una carta para el comisario, haciéndose responsable de su

\footnotetext{
${ }^{269}$ AGN, FTC-SE, Legajo C23, Correa, Benito, s/tentativa de suicidio.

${ }^{270}$ AGN, FTC-SE, Legajo F21, Foa, José Santiago, sumario sobre la tentativa de suicidio de éste.

${ }^{271}$ AGN, FTC-SE, Legajo P34, Pirola, Lina, Su muerte.

${ }^{272}$ AGN, FTC-SE, Legajo C12, Cada, Elena, por tentativa de suicidio.
} 
muerte. ${ }^{273}$ Se quitó la vida el 18 de agosto de 1879. No dejó explicaciones de sus motivos, ni argumentos para justificar su acto suicida. Los testigos, por su parte, explicaron que Castelletti les había confesado que estaba enamorado de una joven a la que no podía olvidar. El diario "La Prensa" (20/08/1879), dio a conocer este caso y para explicar lo sucedido difundió lo declarado por Pedro Lameli, amigo del suicida. Según Lameli, Castelleti le había dicho que estaba "enamorado ardientemente". Estos detalles íntimos fueron revelados por terceros. Juan no dejó nada de esto asentado en su carta. No podemos descartar que se dieran a conocer estos datos de la vida sentimental del suicida para dar mayor credibilidad a la hipótesis de que se trataba de un suicidio, y, así, alejar las sospechas de un homicidio. En este sentido, muchas veces eran miembros de la red social del suicida los que revelaban alguna información sobre las desventuras amorosas del difunto. Así lo hicieron los que conocían a Héctor Semini (italiano, 21 años, un año de residencia, soltero, corredor de una casa introductora). El suicidio de Semini también apareció publicado en "La Prensa" (20/08/1879), en una noticia muy breve que informaba que la causa fue "amores contrariados", sin brindar muchos más detalles al respecto. De acuerdo con el sumario, este joven cortejaba a Luisa Gatti, para que accediera a casarse con él. ${ }^{274} \mathrm{Al}$ momento de explicar el acto suicida de Héctor, los que declararon informaron que Gatti había declinado la propuesta de aquél y creían que éste era el suceso que lo había motivado a quitarse la vida (se disparó con un revólver en la sien derecha en la Plaza Vicente López). Otras veces, si se trataba de amigos y familiares, y no había que convencer al vigilante de turno de que se trataba de una muerte por mano propia, no había razón para inventar una excusa o para comunicar datos de la vida privada del muerto. Si el suicida dejaba alguna nota, en muchos casos estaba en un sobre cerrado para evitar que otros pudieran curiosear su vida sentimental e íntima.

En el caso de Miguel Iglesias, el origen de sus penas eran las dificultades que tenía para contraer matrimonio. ${ }^{275}$ Esto último fue averiguado por el policía que levantó el sumario luego de su muerte el 11 de octubre de 1888 (se disparó con una pistola cerca del pezón izquierdo). En la habitación de la casa de inquilinos donde hallaron su cuerpo sin vida, también encontraron varias cartas. Todas estaban en sobres cerrados, salvo la dirigida al comisario que estaba abierta. En ésta, Miguel expresaba que no se culpara a

\footnotetext{
${ }^{273}$ AGN, FTC-SE, Legajo B40, C16, Castelletti, Juan, s/suicidio.

${ }^{274}$ AGN, FTC-SE, Legajo S46, Semini, Héctor, s/suicidio.

${ }^{275}$ AGN, FTC-SE, Legajo I4A, Iglesias, Miguel s/su suicidio.
} 
nadie de su muerte y solicitaba dos cosas: en primer lugar, que por favor no publicaran en la prensa su nombre, ya que su madre era una mujer mayor y podría impresionarse demasiado si la noticia la tomaba por sorpresa; en segundo lugar, solicitaba que enviaran las cartas que quedaban a sus destinatarios, confiando que respetarían su voluntad.

Hemos encontrado varios relatos similares al de Iglesias, varones desesperados por no tener los medios para unirse en matrimonio con la mujer amada, como el de Felipe Pedro Martínez (oriental, 18 años, soltero, tipógrafo). Martínez intentó quitarse la vida el 19 de noviembre de 1878, alrededor de las 23:15hs. ${ }^{276}$ La policía intentó averiguar las razones que habían llevado a Felipe a cortarse la garganta, el pecho y el vientre. Descubrieron que su acto suicida estaba relacionado con la falta de medios materiales para casarse y formar un hogar. Según los testigos, Martínez estaba enamorado de una joven y le pidió que lo esperara y le fuera fiel, mientras ahorraría los recursos necesarios para concertar el matrimonio. Sin embargo, su amor se desligó del compromiso. Le envió una carta en la que se desdecía de la palabra que le había dado, alegando problemas de familia. En su nota suicida, Felipe le reclamaba por esta traición a su confianza.

Los relatos de las circunstancias que llevaron a estos jóvenes al acto suicida, da cuenta de la presión que debieron haber sentido para poder cumplir con el horizonte de expectativas masculinas de la época. La forma en la que fue interpretado el suicidio de Felipe Brust da cuenta de ello. ${ }^{277}$ El 4 de junio de 1886, Felipe (oriental, 28 años, soltero, dependiente de una casa de comercio) se quitó la vida en la habitación que alquilaba. El dueño de la propiedad salió desesperado al escuchar la detonación del arma de fuego: Brust se había disparado con un revólver en la cabeza, mientras estaba sentado en una silla, y cayó al piso luego de perder el conocimiento. Allí fue encontrado por la policía. En una de las sillas del cuarto del suicida, encontraron la carta dirigida a su prometida, Catalina Cantoni. Encima de la misma había un papel que rezaba lo siguiente: "no quiero que nadie se entere de esta carta sino ella". Brust también dejó una carta para su hermano, Pedro. Tanto éste último como Catalina retiraron sus respectivas notas. Cantoni también pidió a la policía una foto suya que había quedado entre los papeles de Felipe, que la policía recolectó como parte del inventario. ¿Cuál sería el contenido de la carta de Felipe a Catalina? De acuerdo con lo informado en el diario "La

\footnotetext{
${ }^{276}$ AGN, FTC-SE, Legajo M15, Martínez, Felipe Pedro, Tentativa de suicidio.

${ }^{277}$ AGN, FTC-SE, Legajo B27, Brust, Felipe, s/su suicidio.
} 
Prensa" (05/06/1886), en esta nota, Brust se despedía de ella tiernamente y le pedía perdón por el dolor que iba a causarle con su muerte. A diferencia de otras noticias que narraban suicidios por cuestiones amorosas, en este caso abundaban los detalles sobre lo sucedido, ya que Brust se suicidó el día de su boda:

Desde hace tres meses proximamente, el carácter de Brust sufrió una mudanza radical, su jovialidad genial se torno en una acentuada melancolía, se le veía triste y pensativo, buscando los sitios solitarios en los que se le veía taciturno y meditabundo.

¿Que causa era la que influía de esa manera en su animo?

Brust había concebido halagadoras esperanzas, había alimentado la pasión que ardía en su pecho, esperando que el día que se uniera para siempre con la dueña de su pensamiento, contaría con una fortuna para contribuir a la dicha de la mujer amada.

Pero sus esperanzas le salieron fallidas, y veía con temor aproximarse la hora de realizar su casamiento sin contar más que con el escaso sueldo que obtenía de su trabajo. [...]

La tormenta se desató en su alma, y antes que hacer desgraciada a su futura, según sus estraviados (sic) raciocinios, prefirió darse la muerte. $[\ldots]$

Mientras se hacían los preparativos para inhumar los restos del suicida, la novia recibía los obsequios de boda.

Sarcasmo cruel del destino!

El suicidio de Brust fue un escándalo y no es sorpresivo que hubiera llamado la atención de los cronistas. El origen del desengaño, en este caso, no fue explicado a partir del rechazo de la mujer que amaba, sino de su propio horizonte de expectativas. No era justificable que alguien en su sano juicio tomara la decisión de quitarse la vida en estas circunstancias, sin embargo, era verosímil imaginar la angustia que le generaba al "joven suicida" no poder proveer a su amada de una vida de abundancia y riqueza con sus precarios ingresos. Al mismo tiempo, este relato moral remarcaba el terrible efecto de las pasiones. Sin un adecuado control de éstas, los jóvenes podían ser arrastrados a la melancolía y la muerte.

De manera similar fue presentado el caso de Eduardo Chateau (francés, 40 años, soltero, desocupado). En las páginas del diario "La Nación” (2/7/1884). Chateau intentó suicidarse el $1^{\circ}$ de julio de 1884 en el hotel donde se alojaba (Hotel des Postes). Al principio, se negó a declarar las razones de su "extrema resolución”, pero el policía dedujo, por la carta que había dejado el suicida, que una mujer era la causa de sus pesares; en su nota, se despedía cariñosamente de ella. ${ }^{278}$

\footnotetext{
${ }^{278}$ AGN, FTC-SE, Legajo C28, Chateau, Eduardo, s/tentativa de suicidio.
} 
Amigos: No busquen [ilegible - ningún] papel, todos están en Europa desde [ilegible] solicito al Sr. Comisario que los 100 nacionales que estarán en mi bolsillo sean dados a mi [ilegible] amada 58 calle Cuyo, serán para [ilegible] mi [ilegible - duelo]. Muero porque no quiero o no puedo vivir más. Todas mis pertenencias del baúl para Camilo mi [ilegible] y el mejor de mis amigos.

Adiós a todos y a vos, mi dulce amiga, el mejor de los besos.

Perdón por todas las penas que te pude causar.

Adiós querida mía, adiós tesoro. Desde mi corazón, mil veces adiós.

Eduardo. ${ }^{279}$

Esta nota fue incluida, traducida del francés al español, como parte de la noticia publicada al día siguiente de lo sucedido. De acuerdo con "La Nación” (02/07/1884), la joven que Eduardo amaba se llamaba Augusta, y trabajaba de niñera en la casa de José Pacheco. En esa misma residencia, había trabajado Chateau como mucamo y había conocido a Augusta. Chateau deseaba casarse con ella, pero, según el cronista, esto no fue posible debido a que los papeles necesarios para tramitar el enlace estaban en Europa y el novio no tenía dinero suficiente para traerlos. En síntesis: "Esta imposibilidad de llegar pronto a la realización de sus deseos y no otra causa ha sido la que ha impulsado a Chateau a atentar contra su vida". Al igual que en el caso de Felipe Brust, las pasiones nublaron el juicio del apasionado Chateau; éstas no le permitieron enfrentar los obstáculos para casarse con Augusta y ser feliz.

Por otro lado, tanto Eduardo Chateau como Felipe Brust buscaron expresar su afecto y su sufrimiento, despedirse cariñosamente de las personas amadas y pedir perdón por el dolor que causarían con sus actos. Como veremos más adelante, otros mensajes tenían fines más agresivos. En algunos casos, la carta buscaba despertar la culpa en el receptor. Era un ajuste de cuentas, una última palabra que dejaba establecidos a la víctima y al victimario. Un medio para transmitir el resentimiento del suicida al que culpaba de su dolor.

\subsubsection{Sentimientos prohibidos}

En otros relatos, con más detalles de las circunstancias que "contrariaban" los amores de los suicidas, encontramos que los padres de alguno de los miembros de la pareja se oponían al matrimonio de estos o a que continuaran con su relación. Pedro

\footnotetext{
${ }^{279}$ Quiero agradecer a la Traductora Pública Natalia D'Aquino por realizar la traducción de este documento.
} 
León Carricoba (17 años, soltero), por ejemplo, tenía dicho predicamento. ${ }^{280}$ Cuando fue encontrado con una herida de bala en el corazón, en un principio, se negó a dar explicaciones de sus actos: “yo mismo me he herido, no me pregunte más”, declaró al policía y al médico que lo atendió. Según el hermano de Carricoba, Pedro estaba triste y sin ánimo de beber; la causa, ya no podía seguir cortejando a la joven que le gustaba, debido a que la madre de ésta se oponía a la relación entre ambos. No era casual el lugar elegido por el joven Carricoba. Su acto suicida fue llevado adelante el 26 de junio de 1887, justo en frente de la casa donde vivía su amada. De acuerdo con la noticia publicada en el diario "La Prensa" (27/06/1887), Carricoba estaba enamorado de una muchacha de 15 años llamada María, que vivía en la misma casa que uno de sus hermanos. Éste último le pidió a Pedro que no fuera más a verlo, ya que la familia de la joven se oponía a la relación entre ambos. Según el cronista, lo relatado era "uno de esos dramas por desgracia arto frecuentes".

La narración de los sucesos que culminaron con el suicidio de Ovidio Canesse sigue una trama similar y tiene el mismo desenlace trágico y violento: apareció colgado de un tirante de su habitación (en un conventillo), el 2 de octubre de $1887 .^{281}$ Ovidio (italiano, 21 años, soltero, marinero), estaba prometido a una joven llamada Ida. Sin embargo, como declararon los testigos (entre los que se contaba el padre de su novia), la madre de Ida se oponía a este matrimonio. Así, se sospechaba que este fuera el móvil del acto suicida del joven Canesse. Según el diario "La Nación" (03/10/1887) fue "inducido al suicidio por unos amores contrariados". La noticia de lo sucedido también fue publicada por "La Prensa" (03/10/1887), con el habitual titular: "Amores contrariados". El escritor de la nota traía a colación otro intento de suicidio reciente, el de la novia de Canesse, Ida Gambedotti. Días atrás, Ida había intentado envenenarse al tomar una disolución de fósforos; la causa: amores contrariados por sus tutores. Según la versión de los hechos informada por el diario, dentro de la caja de cigarros que se encontraba en el baúl de Ovidio Canesse había cartas, en su mayor parte escritas por Ida, y otra del suicida, dirigida al comisario, en la que le manifestaba que "a nadie se culpara de su muerte, pues el se había suicidado porque la señorita Ida Gambedotti no lo quería ya". Además de lo mencionada en la noticia, Ovidio dejó varias cartas que fueron adjuntadas al sumario judicial levantado con motivo de su muerte. Una de éstas estaba dirigida a la madre de Ida, la "Despreciada Señora" Luigina. Entre otras cosas, Canesse

\footnotetext{
${ }^{280}$ AGN, FTC-SE, Legajo C35, Carricoba, Pedro León, s/tentativa de suicidio.

${ }^{281}$ AGN, FTC-SE, Legajo C38, Canesse, Ovidio, s/suicidio.
} 
culpaba a esta "vil mujer" de todo lo que sucedía y de su suicidio. Le recordaba que, aunque él ya no estuviera vivo, Dios continuaba presente y le preguntaba, de forma retórica, quién llevaba más honor en la cara, ella, "una aristocrática", o un "mísero marinero". Al mismo tiempo, le expresaba que la perdonaba y la odiaba "hasta más allá de la tumba". La razón de su resentimiento: había acusado a Ida de ser una puta, cuando ella era un ángel. También le señalaba que, si él hubiera querido, habría podido hacerla suya. Finalmente, se despedía: "Adiós oh vil mujer. La odio por siempre. El difunto, Invidio Canese". 282

Está demás aclarar que no todos los adolescentes en situaciones similares recurrieron a la autoagresión. En otros casos, por ejemplo, la fuga y el rapto fueron también una alternativa, si los padres no cedían a los deseos de los enamorados. La historia de Florentino Maggi y Mariana Preston muestra un conjunto de alternativas también verosímiles en la época. ${ }^{283}$ Maggi (argentino, 22 años, soltero, empleado de una carpintería) tenía un romance con Preston (oriental, 16 años, empleada doméstica). La primera vez que se fugaron, luego de ser capturados, Florentino fue llevado preso y liberado después de prometer que en cuatro meses él y Mariana estarían casados. Maggi no cumplió con su palabra y volvió a desaparecer acompañado de Preston. Esta vez se llevaron dinero que Florentino había pedido a su patrón como adelanto. Para evitar que los encontraran cambiaron sus nombres y alquilaron una pieza. Sin embargo, la relación de la pareja encontró dificultades; las declaraciones coinciden en que no se los veía bien. El 6 de marzo de 1886 fueron encontrados los cadáveres de ambos en el cuarto donde convivían. De acuerdo con el sumario levantado, Maggi, quien se hacía llamar José Rodríguez, había asesinado a Mariana y luego se quitó la vida utilizando un arma de fuego. De acuerdo con las cartas que fueron encontradas en la escena del crimen, Florentino empezó a sospechar que su compañera le era infiel. En las notas pedía perdón por lo sucedido y confesaba que se quitaría la vida. En este relato, encontramos dos tipos narrativos combinados, que también identificamos en otras historias por separado. En primer lugar, la fuga de los enamorados frente a las resistencias parentales a su amor. En segundo lugar, la agresión impulsada por los celos y el suicidio casi inmediato del asesino.

\footnotetext{
${ }^{282}$ En otra de las cartas, Cannese se despedía de uno de sus tíos, de apellido Passerini. Allí le solicitaba que depositara dinero suyo (17.500 liras) en donde ya le había indicado con anterioridad. También le explicaba que para no vivir en deshonor era necesaria su muerte, lamentando los hechos que evitaron que pudiera "vivir feliz junto al objeto que amo más que a mí mismo". Quiero agradecer, nuevamente, a la Traductora Claudia Debernardi por realizar la traducción de estos documentos.

${ }^{283}$ AGN, FTC-SE, Legajo, R30, Rodríguez, José o Maggi, Florentino, s/suicidio.
} 
También podía darse otra variante, la fuga y el doble suicidio o el acto suicida en pareja. Sólo hemos encontrado un sumario con un relato de este tipo, el que narra la trágica muerte de Victorino Belmonte y Malvina Mernes. ${ }^{284}$ Belmonte era un jornalero argentino de 21 años, estaba enamorado de Malvina, una joven huérfana oriental, que tenía 18 años y trabajaba como empleada doméstica. De acuerdo con las declaraciones relevadas por la policía, Mernes se fugó del domicilio en el que estaba colocada junto con Belmonte. Ambos habían pactado suicidarse tomando arsénico y así lo hicieron en un café de la ciudad. Según las declaraciones que llegó a dar Victorino, luego de fugarse, Malvina le confesó que quería poner fin a su vida. En un gesto de romanticismo apasionado, Belmonte le propuso morir juntos.

Los suicidios de Belmonte y Mernes fueron informados por "La Nación" en una noticia titulada: “¡Amor, sublime amore!”. Según el cronista, la historia de estos enamorados recordaba a los "trágicos dramas de amor" de las obras literarias, como la pieza teatral "Los Amantes de Teruel", "tan amado por los jovenes y que tanto armoniza con sus sentimientos". ${ }^{285}$ Victorino trabajaba como agente de policía el día que conoció a una "muchacha no mal parecida y bien arreglada" que pasaba por la esquina que vigilaba: "Su vista frecuente no tardó en encender en él el fuego de una pasión amorosa". Malvina, "la heroína" del relato (de 15 años de edad, según los cronistas), "atendió las amorosas querellas del galante vigilante y una dulce intimidad se estableció entre ambos". Según el relato, Belmonte abandonó su trabajo como vigilante y raptó a su amada; planeaban huir al campo para evadir a la policía. En medio del escape, Malvina le propuso a Victorino quitarse la vida y este accedió a su pedido. Ésta compró veneno, con la excusa de matar ratones, en una botica. Cenaron juntos esa noche y más tarde fueron a un café. Allí bebieron el tóxico que depositaron con disimulo en sus tazas. De aquel lugar se fueron a las fiestas de San Cristóbal, en las que bailaron en diferentes carpas. Alrededor de las doce, quedaron solos y se sentaron en un banco, allí

\footnotetext{
${ }^{284}$ AGN, FTC-SE, Legajo B23, Belmonte, Victorino y Mernes, Malvina s/suicidios.

285 "Los amantes de Teruel" es una leyenda medieval turolense. La trama transcurre en el siglo XIII y gira en torno al amor de la bella Isabel de Segura, hija de un rico mercader, y Diego de Marcilla, un joven pobre pero honrado. Diego debe juntar dinero para poder casarse con su amada y parte hacia Siria a luchar contra los infieles, de donde vuelve con una importante fortuna. Sin embargo, pasados varios años de su partida, Isabel es forzada a casarse con Don Rodrigo de Azagra, otro de sus pretendientes. Al final, luego de varios entuertos y obstáculos, los protagonistas se reencuentran. Sin embargo, el desenlace es trágico: Diego cae muerto, luego de que su amada Isabel se niega a besarlo, y ésta última fallece luego de ver morir a su amor. De esta leyenda existen varias adaptaciones. Una de las más conocidas es la pieza teatral escrita por el dramaturgo y poeta romántico español, Juan Eugenio Hartzenbusch Martínez (18061880), titulada "Los amantes de Teruel" y que data de 1837. Disponible en: https://es.wikipedia.org/wiki/Los_amantes_de_Teruel; $\underline{\text { https://es.wikipedia.org/wiki/Juan_Eugenio_ }}$
} Hartzenbusch 
comenzaron a padecer los efectos del arsénico. Según lo averiguado por los periodistas, la nota dejada por Malvina, en la que se despedía del mundo, era una carta propia de una novela del conocido escritor de folletines, Enrique Pérez Escrich. ${ }^{286}$ El cronista, probablemente, se refería a otro escrito encontrado en el expediente, que contenía el siguiente texto:

$+[$ cruz $]$

Recuerdo de Malvina Mernes

Adios...

Recuerdo cuando tu mano desato[furi]bundo el raudal [ilegible] las cuerdas [ilegible]la onda sonora palpitando elevo la oración de la armonia [ilegible] como un celeste arrobamiento [ilegible] en mi alma el alma del sonido [ilegible] ala replegó mi pensamiento

[ilegible] el corazón lo cobijo dormido. [ilegible] como tu tal vez el algún dia

[ilegible] el afán de la plegaria [ilegible] llegan los ecos [ilegible] [ilegible] bóveda del templo solitario.

+ [una cruz] mi tumba querido te pido que venga, que me quiero despedir de tí. [a]seme ese fabor; yo quiero despedir de ti quiero mi [co]raje, que no [ilegible] [a]dios, como para darte mi [mu]erte [tachado] Avrazo y un veso para que tu seas dichosa con quien ama, este papel [ilegible] Adios [ilegible]

Asimismo, en la noticia se informaba que Victorino también había dejado una nota que decía que "ellos se amaban y que preferían morir juntos a vivir separados". La carta que fue anexada al expediente judicial decía lo siguiente:

Buenos Aires, Febrero 15 de 1884

Adios Todo el mundo

Me despido de todos /

mis amigos y mis /

enemigos nos emos

muerto por que

nos queremos

por que antes

\footnotetext{
${ }^{286}$ Enrique Pérez Escrich (1829-1897), fue un dramaturgo y escritor español, muy reconocido por ser autor de numerosos y populares folletines, que circularon durante el siglo XIX y el primer tercio del XX. Entre los más famosos están: "El cura de la aldea"; "Los desgraciados: cuadros sociales"; "El último beso"; "El matrimonio del Diablo"; "Historia de un beso"; "La mujer adúltera"; "Escenas de la vida"; "El infierno de los celos"; "El amor de los amores"; "Las redes del amor"; "Los que ríen y los que lloran"; "Alumbra a tu víctima". Véase: https://es.wikipedia.org/wiki/Enrique P\%C3\%A9rez_Escrich
} 


\begin{abstract}
de bela padeser
mi querida Mal

vina que reirnos

padecer los dos

con muy biengus[to]

[ilegible] Mi madre es

Bernardina Salomon
\end{abstract}

Victorino Belmonte y Malvina Mernes

El relato de lo sucedido publicado en "La Prensa" (19/02/1884) también daba a entender que se trataba de jóvenes ofuscados por las tramas de las obras literarias y folletinescas:

Saben que se les busca, especialmente a la menor, y antes de exponerse a una separacion, llenas las cabezas de ideas novelescas, copia Malvina una carta apropiada al acto de una obra de Perez Escrich y se toman en dos tazas de café una cantidad de arsénico que les produce la muerte.

Como mencionamos, no hemos encontrado otro relato como éste, lo que da cuenta de lo poco frecuente que era este final. Sin embargo, algunos casos similares, más allá de su poco peso numérico, generaban revuelo y escándalo en la época, el artículo que mencionamos antes sobre el trágico desenlace de la relación entre Casimiro y Hortensia, escrito por Ricardo del Campo, también da cuenta de ello. En el relato de los hechos que culminaron con el suicidio conjunto de Malvina y Victorino, los cronistas caracterizaron a los jóvenes dentro del estereotipo que presentamos antes: los jóvenes apasionados y románticos. Por otra parte, sobre todo en el caso de "La Nación", se dejaba entrever que los sinceros sentimientos de amor expresados por la juventud tenían un valor positivo, aunque se rechazaran acciones extremas de los que llegaban a quitarse la vida por ello. En este sentido, como menciona Carlos Mayo (2004), durante el transcurso del siglo XIX, y sobre todo a partir de la influencia del romanticismo, el amor ganó legitimidad como valor y como fundamento de las relaciones de pareja, $\mathrm{y}$, en paralelo, los criterios coloniales, que anteponían la conveniencia, el poder patriarcal, el linaje y la pureza de sangre, como condiciones para elegir esposo/a, perdieron peso. Así, el hecho de que los jóvenes que se amaban buscaran la forma de estar juntos no dejaba de resultar heroico y su amor un sentimiento noble. 
Luzuriaga (1909: 97-98) también menciona un caso similar al de Belmonte y Mernes al referirse a las cuestiones legales relacionadas con los suicidios. A modo de ejemplo de una instigación al suicidio, exponía el siguiente relato:

Se trata de un individuo que intenta suicidarse infiriéndose una herida grave en el vientre, después de haber muerto en la pieza de un hotel a su novia, con la cual no podía contraer matrimonio por razones pecuniarias.

Es un reincidente por tercera vez. La primera trató de pegarse un tiro en presencia de su novia, pero ésta se lo impidió; salió ese día de la casa obcecado con la idea de matarse y se echa bajo las ruedas de un tren a causa de lo cual se le tiene que amputar las dos piernas. Una vez curado, y desesperado por su situación, agravada sobre antes por la imposibilidad de trabajar, habla y convence a su prometida de la necesidad de un doble suicidio. Se resuelven, llegan al hotel, tiran a suerte, y es a ella a quien toca matar primero. No se cree capaz, y cede, implorando, su derecho al novio. Este toma el arma y la descarga varias veces sobre la infeliz mujer, que muere en el acto. Vuelve el revolver contra sí y se hiere de gravedad en el vientre. Es conducido al Hospital donde después de muchos cuidados reacciona y cura más tarde.

El proceso sigue su curso y el doctor Tomás de Veyga que entiende en la causa absuelve al inculpado de la imputación de homicidio.

Se apela la sentencia por el Fiscal, y la Cámara de Apelaciones, revoca el fallo, confirmando la falsa imputación de homicidio, pero condena al procesado a cuatro años y medios de prisión por el delito de instigación al suicidio.

Es un caso, como se ve, muy interesante, tanto bajo el punto de vista dramático, como Médico Legal y Penal, pues sienta jurisprudencia.

Belmonte, de haber sobrevivido, tal vez habría sido juzgado siguiendo este mismo criterio (todavía no se había sancionado el Código Penal de 1886, que no mencionaba el suicidio en ninguno de sus artículos), y condenado por una instigación al suicidio. El doble suicidio de los enamorados despertaba sentimientos encontrados: por un lado, se condenaba el desenlace extremo trágico y violento; por el otro, muchos se horrorizaban y conmovían, al mismo tiempo, al ver en lo sucedido los nobles sentimientos de amor propios de la juventud y los dramas románticos.

\subsubsection{Celos e infidelidad}

Ruperta Nagrado (española, 26 años, soltera, empleada doméstica) intentó quitarse la vida el 5 de noviembre de 1878. Llevó adelante su acto suicida en su domicilio, utilizando una disolución de fósforos con la que se intoxicó. Como en 
muchos otros casos de este tipo, el tiempo que daba el veneno antes de tener un efecto letal solía ser suficiente para que él o la desesperado/a fuera encontrado a tiempo. El sumario sobre este episodio es breve, sin detalles. El policía sólo acotó que Ruperta había tenido un "disgusto con su concubino". ${ }^{287}$

Tampoco tenemos más datos sobre las historias de Mercedes Montes y Aurelia González, ambas prostitutas. ${ }^{288}$ Montes intentó quitarse la vida en el prostíbulo donde ejercía su actividad. El informe del policía también es muy breve, como en el caso de Nagrado, y sólo nos revela que vivía con su pareja, con el que tuvo un disgusto ese mismo día, 22 de enero de 1881. Según el relato de los testigos, en plena discusión, Mercedes tomó la daga de su concubino y se la clavó en el vientre. Aurelia González (alemana, 22 años, soltera) llevó adelante su acto suicida en el prostíbulo donde vivía con otras compañeras. Fue encontrada padeciendo los efectos de la disolución de fósforos que había ingerido. Cuando la policía interrogó a González, le expresó que había llevado adelante este acto desesperado luego de recibir malas noticias sobre su familia, que vivía en Europa. Sin embargo, otra de las prostitutas de la casa mencionó otros sentimientos como responsables de la extrema resolución de Aurelia. Esta última tenía peleas y discusiones con su "querido”, German Fisch. ¿Cuál fue la verdadera motivación de la desesperación de Aurelia? Es probable que ambas fueran creíbles, por ello el policía registró las dos explicaciones en su sumario. Así, era verosímil que los problemas que tenía González con su amado fueran también una "causa determinante" de lo sucedido.

En muchos casos, el miedo al abandono era presentado como el origen del sentimiento de desesperación. Así lo expresó Ana Paulici a su concubino, Joaquín Cabral. ${ }^{289}$ Este declaró que hacía seis meses que vivía con Ana. La había conocido en una casa de tolerancia (calle Corrientes $\mathrm{N}^{\circ} 506$, administrada por una tal Suisa N.), donde era conocida por su otro nombre, "Berta”. Según Cabral: "hasta el presente había vivido en la mejor armonía con aquella i que ahora debido a los pocos recursos que tenía había manifestado a Ana su deseo de separarse; que aquella por repetidas veces se negó a ello pues decía que no tenía donde ir si salía de su lado”. Joaquín quería dejar a Ana, ésta tal vez imaginaba que debía volver a prostituirse para salir adelante; sus expectativas de una vida diferente habían empezado a derrumbarse. El sábado $1^{\circ}$ de

\footnotetext{
${ }^{287}$ AGN, FTC-SE, Legajo N2, Nagrado, Ruperto, por tentativa de suicidio.

${ }^{288}$ AGN, FTC-SE, Legajo M18, A Montes, Mercedes por tentativa de suicidio; AGN, FTC-SE, Legajo G14, González, Aurelia por tentativa de suicidio.

${ }^{289}$ AGN, FTC-SE, Legajo P34, Pauluci, Ana, por tentativa de suicidio.
} 
mayo de 1886, Ana salió sin decir a Joaquín a donde iba. Al día siguiente, el domingo por la mañana, le confesó a su concubino, mientras este todavía estaba recostado en su lecho, "que no sabía donde ir i que si la abandonaba se mataría". Frente a este llamado de auxilio, Cabral (según su testimonio) se comprometió a llevarla a una casa amueblada para que estuviera allí hasta que consiguiera un nuevo alojamiento y medios para sostenerse. Le indicó que podía esperar en su domicilio, que entre las cinco y las seis de la tarde mandaría un carruaje para que la llevara a su nuevo hogar. Cabral salió y al regresar, alrededor de las $19 \mathrm{hs}$, dos vecinas de la misma casa de inquilinos, María Miguet (argentina, 31 años, casada) y Carlota Marichi (italiana, 28 años) le informaron que, al parecer, Ana había intentado envenenarse. Cuando subió a su habitación, Cabral encontró otro escenario: Ana estaba recostada en su cama, al correr su cobija descubrió una herida de bala debajo de su seno izquierdo. Paulici había tomado la determinación desesperada de quitarse la vida y para ello se había disparado con una pistola. Sólo seis meses atrás Ana había abandonado el mundo de la prostitución y empezado una nueva vida, que debía dejar de repente, con el desalentador horizonte de regresar a la casa de tolerancia. No podemos saber qué fue lo que realmente ocurrió, no sabemos qué fue lo que Joaquín prometió o dijo a Paulici. Lo que resulta claro es el sentimiento de desesperación frente al abandono de la pareja, y, en este caso, la vuelta a una realidad que parecía pertenecer al pasado de Ana.

El caso de ésta atrajo la atención de los medios gráficos y fue publicado en las páginas del diario "La Prensa" (04/05/1886). La narración de los hechos construida por el cronista estaba cargada del discurso axiológico de la elite cultural de la época. En primer lugar, Ana era presentada como una de esas tantas jóvenes inocentes, confinadas en los prostíbulos, que habían sido separadas de sus familias, en Europa, con engaños y falsas promesas. En este sentido, la historia de Paulici era un relato moral que denunciaba, ante las autoridades, el tráfico de mujeres, "que mercaderes sin conciencia explotan con cínica desvergüenza”. Según los datos de la noticia, Ana (una "joven agraciada", de 22 años) había llegado hacía un año desde Hungría. Luego de seis meses pudo alcanzar sus "deseos honrosos": un joven la sacó de esa casa de tolerancia y la llevo a vivir con él a un hotel. Sin embargo, estaba sin recursos suficientes y pensaba separarse de Ana. Temiendo volver al mundo de donde provenía si era abandonada, le propuso ir a vivir juntos a donde fuera, ella haría todo lo posible para reducir los gastos. Se fueron a vivir juntos a un conventillo. Pero ese hombre no amaba a Ana, señalaba el cronista narrador, este sujeto se volvió frío y severo con ella y terminó por pedirle que 
se separaran y la echó del cuarto que alquilaban. "Si me abandonas me mato!", le dijo Ana, "con firme acento y salió enjugando las lagrimas que surcaban sus mejillas". El joven no le hizo caso, pensó que no cumpliría su palabra. Ana fue alojada en la casa de unos amigos. De acuerdo con la versión expuesta por el periodista: "No falto quien le insinuara que volviera a adoptar la vida que anteriormente había llevado, pero la desgraciada tenia sano el corazón y rechazo con energía esos consejos". La narración continuaba con un recuento del suicidio de Ana, muy similar al mencionado en el sumario judicial. Ana era la heroína de este relato, una joven valiente que no estaba dispuesta a deshonrarse, una vez más, para sobrevivir, prefiriendo la muerte a la prostitución:

La desgraciada hacia el sacrificio de su vida, a sus nobles sentimientos; la corrupción le tendía los brazos y ella prefirió la muerte. [...]

¡Cuantas infelices se encontraran en la situación que motivo a Ana a matarse!

La autoridad debía averiguarlo.

El cronista de "La Prensa" no ocultaba la admiración que despertaba la estoica Ana, que anteponía su honra incluso antes que su vida, dispuesta a entregar su corazón al hombre equivocado. Además de hacer campaña en post de la intervención y el control de los prostíbulos, el relato moral elaborado a partir del suicidio de Paulici enfatizaba el valor del honor en las mujeres, y su preservación, a partir de un ejercicio de la sexualidad femenina dentro del ámbito de las relaciones entre los esposos.

Ilusiones similares a las de Ana Paulici, tal vez, guardaba Ana Grana. Esta joven prostituta italiana de 23 años estaba detenida en la comisaría por ejercicio clandestino de la prostitución. En la pieza donde estaba confinada, fue encontrada por los policías revolcándose en el suelo, dando quejidos, y con un líquido azulado que salía de su boca. Según lo asentado en el sumario, el hombre con el que tenía un amorío la había abandonado por otra mujer, por esta razón, Ana lloraba sin consuelo. ${ }^{290}$

Melania Reymond de Gondran también sucumbió frente a su propia desesperación: imaginaba que su compañero, Musiliar Lanci, la abandonaría. ${ }^{291}$ Melania había dejado a su marido, un hombre de apellido Gondran, que vivía en Francia, para

\footnotetext{
${ }^{290}$ AGN, FTC-SE, Legajo G41, Grana, Ana, s/tentativa de suicidio.

${ }^{291}$ AGN, FTC-SE, Legajo R21, Reymond de Gondran, Melania, por suicidio.
} 
seguir a su amado, Lanci. Éste era músico de profesión y vivía junto a su pareja y el hijo de Reymond. Éste tenía 6 años y había nacido de la unión de Melania y su ex marido. La familia de Reymond no aprobaba los "amores ilícitos" que tenía con Lanci, como los denominó la madre de Melania cuando fue llamada a declarar. Ésta última también destacó que su hija se había separado de su esposo con autorización de las autoridades eclesiásticas. El 22 de febrero de 1882, Reymond prendió el brasero de la pieza que habitaba con su familia, dejó el cuarto cerrado y murió asfixiada. Cuando Lanci declaró, entre sollozos y un dolor manifiesto, según lo relatado en el sumario, explicó que había pedido a Melania que le confesara ciertos detalles de su vida. Melania accedió y le contó lo que quería saber, pero quizás la reacción de su compañero la desestabilizó; Lanci sospechaba que Reymond se había suicidado por miedo a ser abandonada. ¿Qué secretos guardaba Melania? ¿Por qué pensaba que Lanci la dejaría librada a su suerte? ¿Algún episodio de infidelidad? Al parecer, el desgraciado artista se sentía arrepentido de su reacción y demostró estar lleno de tristeza por el trágico desenlace. Las dos cartas que dejó Melania, escritas detrás de una de las partituras de su compañero, tampoco nos brindan muchos indicios; éstas fueron publicadas en el diario "La Nación" (24/02/1882), días después de su muerte. Una de las notas dejadas contenía el siguiente mensaje:

Una hora antes de morir declaro que M Laug no tiene culpa alguna de mi suicidio y que siempre ha sido para mi un hombre bueno y honrado. Le suplico me perdone el sentimiento que le voy a hacer experimentar.

Perdon una y mil veces y si me has amado conservaras un piadoso recuerdo para esta Melania que te ha querido.

Melania Reymond. ${ }^{292}$

La otra, dirigida a la madre de la suicida, daba alguna otra información sobre lo sucedido:

Querida Madre: Te recomiendo a mi pobre hijo, con quien, si yohubiera sido ua buena madre, debiera vivir para protegerlo $\mathrm{y}$ formarlo un hombre.

Sabes que voy por el camino de la desgracia; hoy, vencida por los remordimientos, con la deshonra en perspectiva, que es mas grande

\footnotetext{
${ }^{292}$ La traducción de las cartas publicadas en el diario "La Nación" es fiel al contenido de las notas adjuntadas en el expediente que contiene el sumario. Quiero agradecer a la Traductora Pública Natalia D'Aquino por hacer la traducción de estos documentos.
} 
que todo, pues que el que se llama mi esposo va a abandonarme y no veo para mi mas camino que la muerte.

Tu me perdonaras y a el tambien porque yo sola soy la unica culpable - solamente yo.

Adiós, mi querida madre; perdona a esta hija que te ha dado no solo todos los disgustos, sino también toda la deshonra.

Un ultimo adios, madre; vuélveme a perdonar, $\mathrm{y}$, sobre todo, te recomiendo a mi hijo.

Melania Reymond.

Melania pedía, entre otras cosas, perdón a su madre por toda la deshonra, ella era la única responsable de todo lo sucedido. Sin embargo, no explicitaba qué clase de acciones la habían llevado a comprometer su honor, el de su pareja y el de su familia. En las noticias publicadas en el diario "La Prensa" y "La Nación" se explicitaba que trataban la información sobre el caso con suma discreción: "Las causas del suicidio son de carácter tan intimo que no ha creído conveniente la familia autorizar su publicidad" ("La Prensa", 23/02/1882). El cronista de "La Nación" (23/02/1882) acotaba: "Hay en las causas que han motivado este suicidio hechos de importancia y de verdadero interés, que omitimos por pertenecer a la vida íntima de aquella desgraciada”. Tal vez, Melania confesó a su pareja alguna clase de infidelidad que comprometía la honra de éste y, por esta razón, tal vez Lanci mostró intenciones de terminar la relación entre ambos.

En el caso de Laureana Peralta (argentina, entre 22 y 25 años, viuda), como mencionamos en el capítulo 6, su pareja, Agustín Olivera, sospechaba de su fidelidad y, por esta razón, había abandonado a su compañera en más de una oportunidad. Peralta llevó adelante varios actos suicidas. La primera vez, el 10 de abril de 1881, Laureana intentó quitarse la vida al tomar una disolución de fósforos en agua. Luego de hacerlo, se arrepintió y mandó llamar a su familia. En la misma casa vivían Adelina Leiva (prima de Laureana) y los miembros del matrimonio Cairo, Dolores y José. Estos explicaron que, ese día, Laureana fue a llevar una carta a Olivera; al volver, manifestó deseos de acostarse y se retiró a su habitación. Al entrar allí, Dolores encontró a Laureana recostada, largando espuma por la boca; cerca, en el suelo, estaba la taza quebrada con los fósforos esparcidos a su alrededor. De acuerdo con las declaraciones de los testigos, los motivos detrás de este incidente eran las peleas entre Olivera y Laureana. ${ }^{293}$ Peralta escribió tres cartas antes de intoxicarse. Una estaba dirigida a Adelina. A través de esta nota, le comunicaba sus intenciones de envenenarse "para dejar de sufrir". Al mismo tiempo, le pedía que buscara a Agustín y le entregara en mano un mensaje dirigido a

\footnotetext{
${ }^{293}$ AGN, FTC-SE, Legajo P22, Peralta, Laureana, s/suicidio.
} 
éste (tal vez cambió de opinión y decidió enviar la carta ella misma, como mencionaron los testigos). Asimismo, Laureana le pedía a su prima, en nombre de las cenizas de la madre de Adelina, que diera aviso a su padre de lo sucedido. Por último, le pedía perdón y le deseaba a su pariente toda la felicidad. La segunda nota suicida era más breve. Estaba dirigida a José y Dolores; además de explicar que se suicidaba para dejar de sufrir, les pedía que, en cuanto la encontraran, llamaran a Agustín y le dieran a conocer lo sucedido. La carta destinada a Agustín Olivera también fue incluida en el expediente. Por la riqueza de este documento, lo transcribimos a continuación:

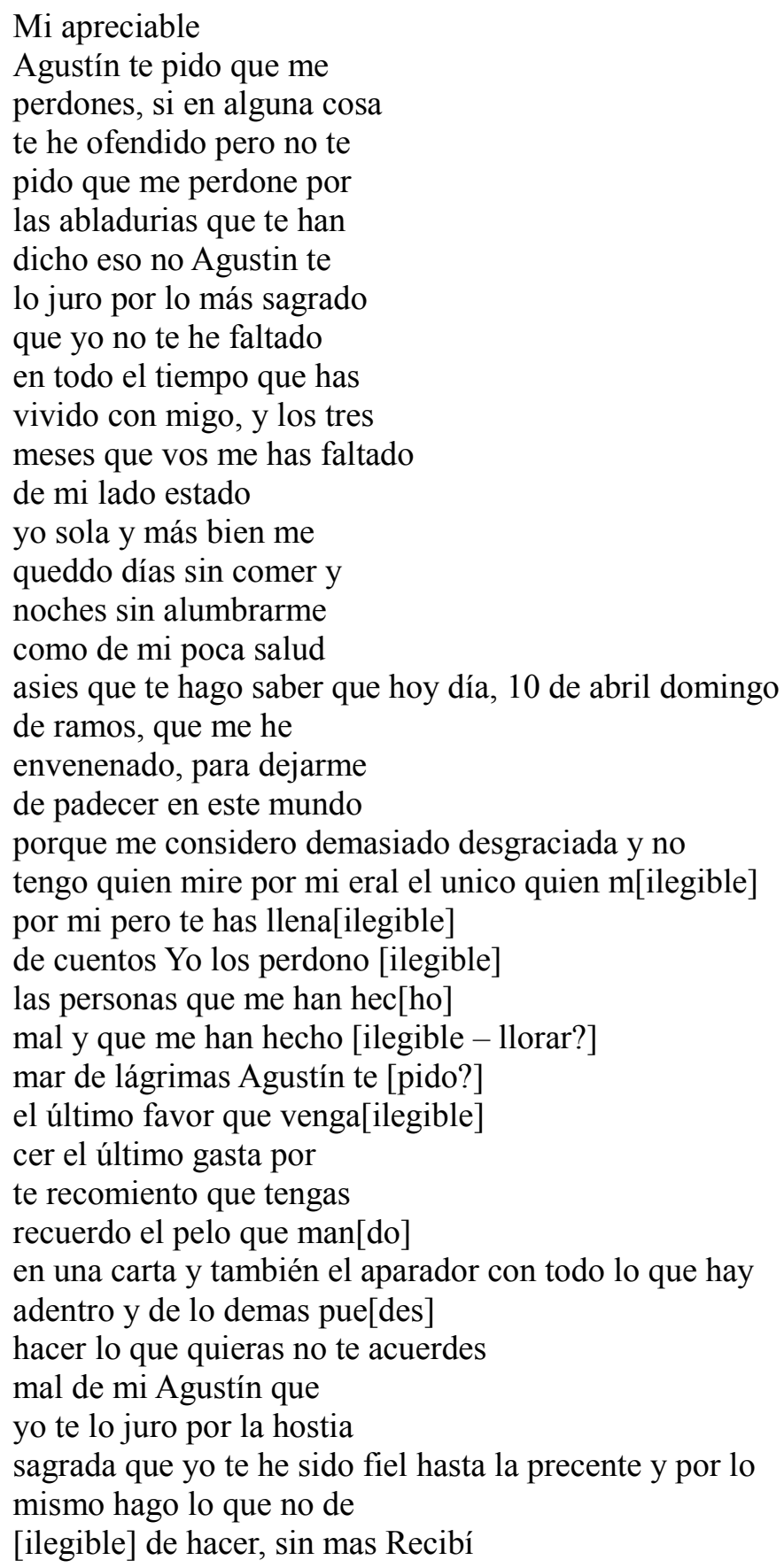


el último adiós se despide de vos, la desgraciada, Lauriana Peralta.

Por lo que Laureana relata en esta nota, su compañero la acusaba injustamente de serle infiel, por esta razón, estaban separados desde hacía tres meses. Ella, por su parte, le juraba a Agustín lo contrario, "por la hostia sagrada". Asimismo, pedía perdón si lo había ofendido, pero no se disculparía por chismes y rumores falsos. En su mensaje, además de darle el último adiós, también le pedía que no la olvidara, que conservara sus cabellos en un sobre. Laureana se posicionaba como la víctima del relato, la "desgraciada", abandonada por su pareja, había padecido hambre y frío por su ausencia, mientras ella había permanecido siempre a su lado.

La segunda vez que encontramos noticias de Laureana Peralta fue en un expediente que relata sucesos ocurridos el 18 de marzo de $1882 .{ }^{294}$ A pesar de los celos y sentimientos posesivos, la relación de Peralta y Olivera continuó y, en algún momento, ambos volvieron a vivir juntos; sin embargo, habían vuelto a separarse y Laureana vivía en otra casa de inquilinos. Allí bebió una disolución de fósforos en kerosén. En esta oportunidad, fue descubierta por Juana Salvadores, una amiga, a la que estaba dirigida una de las cartas que dejó la suicida. En ésta le expresaba sus últimas disposiciones:

\author{
Juana \\ Me quito la vida por que \\ me encuentro demaciado \\ desesperada y avandonada \\ completamente sin saber \\ lo que he de hacer como \\ V. lo save el estado mio \\ cual es Juana siento \\ mucho de darle un disgusto \\ tan grande el último \\ favor que le pido \\ es que no de a saber a \\ nadie en su casa ni en \\ la mia \\ lo que deben procurar es de ir a la \\ imprenta a buscarlo \\ Agustín que el savra \\ lo que no de hacer sin \\ mas no tengo mas que \\ decirle que me perdone si
}

${ }^{294}$ AGN, FTC-SE, Legajo P23, Peralta, Laureana, por tentativa de suicidio. 
en alguna cosa le he ofendido

su amiga

Laureana Peralta.

En las páginas del sumario, también encontramos una nota dirigida a Agustín Olivera. En dicho escrito, nuevamente podemos identificar el intento de Peralta por generar culpa y remordimiento en su ex-pareja: "hoy 18 de marzo de 1882 es el último día de mi vida causa tulla y de mi quirido compadre Carranza". Frente a los rumores maliciosos y falsos, la joven suicida respondía: "Agustín yo muero con mi conciencia lipia por que creo de no averte ofendido a vos de ningun modo por que si es respeto a la gran calunia que me ha levantado mi compadre no lo es cierto y lo apruebo con mi vida". No sabemos con certeza la relación de Laureana con Carranza o el vínculo de parentesco que los unía, pero a éste también lo responsabilizaba de su muerte, aunque manifestaba que le daba su perdón. Al mismo tiempo, Peralta pedía a su ex-pareja que le hiciera una serie de favores. En primer lugar, que no diera a conocer lo sucedido a su familia (eran muy "ingratos" con ella). En segundo lugar, solicitaba que avisara a su madrina para que se hiciera cargo de sus restos. También le pedía a Olivera que pagara sus deudas ("te pido de favor que le pagues a Juana docientos pesos para que pague su relo[reloj] que lo empeño para darme a mi para que me mudara y también le pagaras a lopes catorce pesos que le pedí emprestado"). Por último, le solicitaba que le diera el último adiós el día de su entierro. Como en el relato de lo sucedido el año anterior, en las peleas entre Olivera y Peralta había de por medio sospechas de infidelidad. Al parecer, estos rumores habían vuelto a llegar a oídos de Agustín. De nuevo, la narración de lo sucedido, contada desde la perspectiva de la suicida, la posicionaba como la víctima: acusada injustamente, abandonada por su compañero, con necesidades materiales y deudas a las que no podía responder. Al mismo tiempo, queda explícito el deseo de generar culpa en Olivera por lo sucedido y por los términos de la separación. En este sentido, en la nota suicida también figuraba lo siguiente: "Agustín hasta donde ha llegado tu ingratitu de haber permitido que yo me quite la vida antes de pagarme una triste y micerable pieza sin mas me despido de vos para siempre y te deceo toda la felicidad". Al parecer, Agustín tal vez se negó a dar socorro a su ex-pareja y no dio relevancia a las amenazas que ésta última le expresó. Esta carta quizás era parte de la venganza final de Laureana: generar remordimiento y culpa en aquél que la había abandonado, cuando la leyera. Tal vez, sólo era parte de un acto suicida que tenía como 
fin, consciente o inconsciente, retener a Olivera. A diferencia de otros relatos, la carta quedó en el expediente. Agustín no consideraba importante o valioso este documento, quizás tampoco creía que su honra o su reputación estuvieran en duda. En este sentido, la madre de Olivera declaró que Laureana debía estar padeciendo de la manía del suicidio, ya que este era el tercer intento que la joven llevaba adelante. ¿Qué credibilidad podía tener una persona con sus facultades mentales alteradas?

La versión de lo sucedido acerca de esta última tentativa de Laureana es distinta en los diarios “La Nación” y "La Prensa" (18/03/1882). En la noticia publicada en "La Prensa", bajo el título "Triste suceso", Laureana era presentada como la víctima de las circunstancias: abandonada por su pareja, que no le brindaba los medios materiales para pagar la habitación que habían ocupado juntos; y acusada injustamente por su compadre que ponía en cuestión su honor. Por fortuna, Laureana fue atendida a tiempo, su situación no era grave según los médicos. En cambio, el relato de los hechos presentado en "La Nación" daba una visión diferente. El cronista explicaba que la pareja había tenido peleas constantes y por esta razón se habían separado:

Con él [Agustín Olivera] ha mantenido año y medio relaciones amorosas, habiéndose disgustado varias veces y en todas ellas atentado contra su vida, valiéndose siempre del fósforo.

Hará tres meses, los amantes tuvieron un serio disgusto y desde entonces el regente [Agustín Olivera], aunque atendía a las necesidades de Laureana, no la visitó más.

Esto causó un profundo disgusto a la joven, que, desde entonces, se tornó triste y taciturna.

Varias veces manifestó a sus amigas que la vida le era insoportable, y que estaba decidida a no sobrellevarla más.

Esta versión de lo sucedido, hacía hincapié en el estado emocional y mental anormal de Laureana, una mujer que había intentado suicidarse en reiteradas oportunidades. Asimismo, el cronista destacaba el "temperamento nervioso bastante pronunciado" de la joven. Esta caracterización se asemejaba a la brindada por la madre de Olivera en sus declaraciones. Al mismo tiempo, en la noticia de lo sucedido se dejaba aclarado que Agustín atendió las necesidades de su ex-pareja, aunque no la visitaba como antes. Dos formas de narrar lo sucedido, con significados morales diferentes para cada uno de los miembros de la pareja. En un caso, el victimario era un hombre que abandonaba a su compañera y la dejaba sin sustento material; en el segundo, una mujer con sus facultades mentales alteradas que reincidía en sus intentos de quitarse la vida, frente al 
alejamiento del hombre con el que había tenido una relación, pero que se hacía cargo de atender sus necesidades.

Hombres y mujeres podían ser abandonados. Agustín León (italiano, 29 años, casado, jornalero), por ejemplo, no pudo superar la traición de su esposa, María Boima. ${ }^{295}$ Ambos vivían juntos en una habitación que alquilaban, pero, según los testimonios, la convivencia no era buena: según Agustín, María no lo trataba bien. Al clima tenso entre ambos contribuía la presencia frecuente de un hombre de apellido Alejandri. Este último visitaba asiduamente a María, según Agustín, con intenciones deshonestas. Las sospechas de León resultaron acertadas: su esposa se fugó con Alejandri y se llevó también la cama y otros bienes con ella. Agustín había quedado solo, enfermo y sin trabajo. Este último revés lo había superado, no podía tolerar el disgusto. El 27 de julio de 1876, se dirigió a la rivera, por la bajada que quedaba en el barrio de la Recoleta. Allí, se disparó con un arma de fuego a la altura del oído, sin que el impacto lo matara de forma instantánea. La policía llegó a tomarle declaración al suicida y a los testigos de lo sucedido. La forma en la que están narrados los hechos nos presenta a un hombre damnificado por la adversidad y la traición de una mala mujer, ésta había sido infiel y lo había abandonado por otro. Tanto Agustín como el policía que asentó lo sucedido en el sumario dejaron en claro quién tenía el papel de la víctima y quién el del victimario. No hubo intención de callar lo sucedido. León expuso las circunstancias que lo habían llevado a cometer su acto suicida.

En muchos otros casos era difícil conocer las razones por las cuales discutían las parejas que aparecen mencionadas en los sumarios judiciales. En general, no daban a conocer los detalles escandalosos de lo sucedido o sólo mencionaban parte de la información. Por ejemplo, no comprendemos los motivos que tenían para pelearse José Mambretti (italiano, 29 años, soltero, albañil) y su pareja, María Brusetti (italiana), dueña de un bodegón / fonda. ${ }^{296}$ Ambos vivían en el establecimiento de Brusetti. El 17 de septiembre de 1878, a las 9hs de la mañana, tuvieron una fuerte discusión que terminó en un episodio de violencia entre ambos: José lanzó varias puñaladas a su compañera y la hirió en la espalda; acto seguido, se encerró en su habitación y sonó un disparo. La bala provocó una herida en el cuello de José. Cuando la policía interrogó a ambos, estos dieron dos versiones diferentes sobre las razones que habían llevado a Mambretti a cometer semejante acto de violencia. Según la versión de María Brusetti,

\footnotetext{
${ }^{295}$ AGN, FTC-SE, Legajo L8, León, Agustín, s/su suicidio.

${ }^{296}$ AGN, FTC-SE, Legajo M14, Mambretti, José, heridas y conato de suicidio.
} 
su concubino se negaba a darle un retrato que tenía en su poder; de acuerdo al relato de José, su pareja le había robado dinero. Como en otras narraciones que implicaban cuestiones afectivas o familiares, no había muchos detalles acerca de los motivos de la discordia. En este caso, además, las versiones de los hechos no coincidían. Alguna situación vergonzosa o escandalosa estaba implicada.

Una versión de lo sucedido fue publicada por el diario "La Prensa" (18/09/1878) en una noticia titulada "Otro drama sangriento". Según el cronista, se trataba de uno de esos "crímenes movidos por el impulso de las pasiones", "una escena sangrienta”. De acuerdo con lo relatado, María Brusetti amaba a su compatriota, José Mambretti. La armonía reinaba entre ellos y Mambretti amaba cada día con más pasión a María. Sin embargo, las cosas se complicaron cuando otro pretendiente empezó a cortejar a María, "al cual no le negaba su simpatía". Cuando Mambretti supo esto empezó a sufrir celos terribles, "queriéndola cada día más a medida que ella lo despreciaba". El día que tuvo lugar el trágico suceso, María pidió a Mambretti que viniera a verla, para "despedirlo y hacerlo renunciar a sus amores". Así mismo, le solicitó un retrato y algunos objetos suyos. Si bien parecía estar tranquilo oyendo todo, Mambretti lanzó de imprevisto una puñalada con su cuchillo, que sólo llegó a herir superficialmente a María. Ésta salió de la fonda a pedir auxilio, entretanto, Mambretti se pegó un tiro con una pistola. Según el cronista, el suicida quedó herido de gravedad, mientras que su amada sólo sufrió daños leves. Lo más interesante, es el retrato que hizo el diario de Mambretti:

El desgraciado José era hombre honrado y trabajador. En uno de los estantes de una cómoda se encontró una libreta del Banco de la Provincia por valor de 4000 pesos $\mathrm{m} / \mathrm{c}$. a su orden.

Esta en inminente peligro de muerte.

Esta forma de presentar al suicida, minimizaba la gravedad de un intento de homicidio y ponía el énfasis en el estado apasionado del sujeto agresor, el “desgraciado José” era un hombre honrado y trabajador corrompido por los celos y el desengaño amoroso. Así, los actos violentos de Mambretti eran producto de sus pasiones y de la traición de su amada que lo abandonaba y lo dejaba sin hogar. 
En síntesis, podemos encontrar distintas circunstancias que podían disparar los conflictos en una pareja. Sin embargo, en los casos de suicidio, hay un elemento que se repite con más frecuencia: los celos. Estos eran el origen de las disputas amorosas en varios de los relatos estudiados y eran un motivo verosímil para explicar los comportamientos suicidas de algunos individuos apasionados como Alberto Truffi. Truffi, llegó a Buenos Aires en 1874. Este joven italiano venía de un poblado situado en la provincia de Pavia, llamado Zavattarello, donde vivían sus parientes. Venía acompañado por Napoleón Pochintesta, antiguo amigo de su familia. Napoleón decía que quería a Alberto como si fuera su propio hijo. Luego de su llegada a suelo argentino, Truffi trabajó durante los siguientes seis meses como dependiente en la botica de Benjamín Pochintesta, hijo de Napoleón. El día 5 de febrero de 1875, alrededor de las dos de la tarde, entró en la residencia de la familia Pochintesta (que también funcionaba como botica). Allí estaban los miembros de la familia, entre otros, Ida Pochintesta, también hija de Napoleón. Cuando quedó a solas con Alberto, éste tomó el arma y exclamó: "ha llegado el momento de la venganza". Sacó un revólver y disparó contra la joven, quien resultó herida por el roce de una de las balas. El ruido del disparo atrajo a Napoleón y a Benjamín que estaban en la casa, le sacaron el arma a Alberto y salieron a pedir auxilio. En medio de la conmoción, Truffi recuperó el revólver, subió las escaleras y se disparó en la cabeza. Si bien resultó herido, estaba con vida cuando llegó la policía y fue interrogado. Alberto confesó que él había herido a la joven Pochintesta; también declaró que se había disparado a sí mismo para darse muerte. Así mismo, expresó que todo esto lo había hecho movido por la pasión de los celos. Los testigos explicaron que Truffi amaba a Ida y ella le correspondía; sin embargo, los celos habían invadido la cabeza y el corazón del "temerario amante". 297

En este tipo de relatos, la agresión física era descargada contra el ser deseado, antes de volverse hacia el propio individuo. De este modo, en los expedientes relacionados con el amor y los vínculos de pareja, encontramos una serie de historias en las que el suicidio era precedido por un asesinato o intentos de dañar físicamente al otro. En todos los casos, estos actos violentos eran llevados adelante por hombres y sus víctimas eran sujetos del género femenino. Por ejemplo, Josefa Rodríguez era acosada por Luis Enrique (mejicano, 28 años, soltero, policía). La noche del 30 de junio de

\footnotetext{
${ }^{297}$ AGN, FTC-SE, Legajo T3, Truffi, Alberto, por haber herido a Ida Pochintesta y atentar contra su vida después de herida esta, decerrajándose un tiro el 5 de Febrero.
} 
1888, Rodríguez salía de la casa de su patrón para dirigirse a la suya. ${ }^{298}$ En el camino, encontró a Enrique. Josefa y Luis habían sido novios y él le había insistido para que contrajeran matrimonio. Sin embargo, ella había decidido poner fin a la relación y, desde entonces, él la perseguía. Esa noche, su agresivo pretendiente la forzó a dirigirse a la Plaza Vicente López. En medio del trayecto, Josefa trató de escapar e intentó meterse en la casa de un conocido de ella, pero Enrique se interpuso y le dijo: "te mato", apuntó al rostro de su víctima y disparó un tiro. Sin embargo, aunque la hirió, el daño no fue letal. Tras llevar adelante este acto de violencia, Enrique puso fin a su vida. Se disparó dos veces en el pecho, del lado izquierdo, apuntando a su corazón. Los detalles del relato fueron aportados al policía por la propia Josefa y un joven menor de edad que estaba cerca del lugar donde ocurrió esta trágica y dramática escena. Las declaraciones de ambos coincidían. En los bolsillos del pantalón de Luis Enrique se encontró un cuaderno que contenía el siguiente texto: "Esta noche vamos a perecer quiera ono quiera y no se sorprenda de nada de lo que va a pasar porque no corre ningún riesgo - mas al primer grito que de o que trate de correr, tire 5 tiros para ud. y uno para mi”.

Según el cronista del diario "La Prensa” (01/07/1888), Enrique era un hombre que poseía cualidades valiosas:

Sus aptitudes eran regulares, pero en un país extraño, sin amigos, dedicose a ocupaciones distintas de aquellas en que podía ejercitar sus conocimientos.

Por fin, su estrella llevole a ocupar un puesto de vigilante en la comisaria de la sección 13 y allí sus superiores comprendieron que se trataba de un hombre que debía ocupar otro puesto y le miraron con consideración.

Los hechos vinculados con el acoso y la agresión de Enrique hacia Josefa Rodríguez coinciden con los eventos narrados en el sumario judicial. Asimismo, la nota suicida de Enrique fue reproducida fielmente en la noticia publicada. Sin embargo, lo que debemos destacar es la interpretación de los móviles del suicida; como Josefa lo rechazaba, "el debió sin duda suponer que ella amaba a otro, y entonces los celos se apoderaron terribles de su corazón”. Al día siguiente, "La Prensa" (02/07/1888) publicó una carta escrita por Luis Enrique y dirigida a uno de sus más íntimos amigos, el oficial de Marina Pedro Santillán, que, según el cronista, daba mayor información sobre las preocupaciones del suicida. Entre otros asuntos, Enrique comentaba lo siguiente:

\footnotetext{
${ }^{298}$ AGN, FTC-SE, Legajo E15, Enrique, Luis.
} 
Muy señor mio:- Si recuerda U. ciertas confidencias mías, no se le ocultara lo mortificado que estoy con este oficio. Los cuarenta pesos son relativamente buenos, pero el menosprecio con que a uno se le ve, exaspera. Los hombres nos halagan y algunos pocos mas despreocupados hasta llegan a comprender lo noble de nuestra misión: mas las muchachas dicen "es un vigilante" y ese es el fallo de divorcio con el sexo amoroso.

Quiero mucho a las muchachas y por ellas seria capaz de decir que Newton era un tonto y que Espronceda no sintió lo que escribió, mas ¿que hacer? irme a trabajar diez y ocho o veinte horas para ganar menos y perder libertad, vida y muchachas?

Enrique era un hombre que se sentía menospreciado por el sexo opuesto, debido al estigma que cargaba por trabajar de policía. Las constantes frustraciones amorosas y su ardiente amor por las muchachas hacían crecer su desasosiego. En síntesis, Enrique era presentado como víctima de sus constantes desengaños y de sus celos, generados por las actitudes de la joven que lo despreciaba.

El caso anterior, como muchos de los que analizamos en esta investigación, era representado como una reacción extrema y desmedida. No consideramos que sea representativo de lo que sucedía en la mayoría de las relaciones de pareja que se terminaban. Muchos otros expresaban su enojo y frustración de otros modos. Sin embargo, sí encontramos un elemento común con el resto de las historias, el sentimiento de posesión. En algunos individuos este alcanzaba un grado de obsesión extremo y muy enfermizo. Este fue el caso de Luis Javanaud (francés, 26 años, soltero, panadero). ${ }^{299}$ Javanaud había dejado su tierra natal para fugarse con Magdalena Jary (francesa, 24 años, casada), quien abandonó a su esposo. Ambos decidieron viajar a Argentina. Los dos consiguieron trabajo. Sin embargo, los celos de Javanaud la forzaron a renunciar al suyo. Al poco tiempo, Luis también dejó de trabajar. Con el dinero que les quedaba se alojaron en un hotel. Al terminarse los recursos, pidieron auxilio a unos conocidos para que los alojasen en las habitaciones que estos alquilaban. Según Magdalena, su amante era muy celoso y no la dejaba ir a ninguna parte sola. La obsesión que sentía por Jary era muy intensa. Esta, por su parte, le recriminaba a Javanaud que era urgente empezar a trabajar para subsistir. Javanaud se negaba a hacerlo. Había pasado un mes desde su llegada y como la actitud de Luis no cambiaba, Magdalena escribió a su esposo y le solicitó que le enviara dinero para regresar a Francia. Según lo que declaró más tarde a la policía, el $1^{\circ}$ de octubre de 1881 , comunicó esto a Luis. Éste, lleno de cólera, tomó un

\footnotetext{
${ }^{299}$ AGN, FTC-SE, Legajo J6A, Javanaud, Luis, s/suicidio.
} 
cortaplumas e hirió a su amante en el cuello. Inmediatamente, se cortó la garganta.

La versión de lo sucedido que narramos hasta aquí es la que Magdalena narró a la policía. La publicada en el diario "La Nación" (01/10/1881) incluye una narración alternativa de los dramáticos eventos. En primer lugar, incluye los motivos de la pelea entre los amantes. Según el relato del cronista, luego de llegar a Buenos Aires, Luis buscó trabajo en la ciudad, pero pronto decidió irse al campo a trabajar. Magdalena se oponía a esto:

Magdalena le renovo los juramentos de amor pero le protesto que ella, habituada a la vida de las ciudades, no podria salir de Buenos Aires, y que por grande que fuera su pasion, lo dejaria partir solo si el se obstinaba en salir al campo.

De acuerdo con el relato de la noticia, este fue el inicio de las peleas, insultos y recriminaciones, que terminaban con accesos de ira por parte del inexperto Luis. En estas peleas, Magdalena llegó a decir que "ganaría la vida por cualquier medio, con tal de no salir de la ciudad". El día de los sangrientos eventos, "Magdalena dijo que tenia dinero y que regresaría a Francia antes que salir al campo". En la crónica de la noticia, Magdalena fue caracterizada como un personaje arrastrado por sus impulsos pasionales e inmorales; por esta razón no había opuesto resistencia a los encantos del joven Luis, que logró seducirla:

Probablemente cansada de su marido, Magdalena acepto los galanteos de Luis, que la asediaba con las protestas de un profundo amor por ella inspirado.

En la obsesión vituperable de la pasión criminal, Magdalena se rindió y fue hasta concertar con su amante una fuga a América, para vivir tranquilos, en donde la ignorancia de su delito les permitiera una existencia libre.

Al mismo tiempo, al narrar el desenlace, el cronista representa a Magdalena como una mujer fría, oportunista e interesada, carente de un genuino amor hacia su difunta pareja:

Magdalena, completamente indiferente, aunque algo asustada a causa de sus heridas, se mantuvo en la comisaria impasible como una piedra y se encogió de hombros cuando le dijeron que Luis había muerto.

En el momento en que se le notificaba que podía salir en libertad, se presento un garçon de café, que, según parece, reemplazara a Luis en el engagement contraído por ella ante el cadáver todavía tibio de su 
amante. Salio con el de la comisaria y volvió al mismo cuarto en que había tenido lugar el suceso horrible que hemos narrado.

Queda claro que el caso de Magdalena y Luis fue narrado a modo de fábula moral para los lectores. Según el cronista, los protagonistas de este drama venían de familias bien colocadas y podrían haber vivido en ellas "si el crimen no los hubiera dominado con su vértigo". Así, este relato con moraleja advertía a los jóvenes solteros que cuidaran sus acciones, ya que podían ser arrastrados a la desesperación, el crimen y el suicidio por mujeres frías y manipuladoras, como en el caso de Luis. El villano: la mujer que impedía el progreso del joven y lo cambiaba, sin pena ni dolor, por un nuevo amante.

Por otra parte, si observamos la trama narrada en el expediente judicial, volvemos a reconocer un elemento común con otras historias ya analizadas: los celos. Estos eran el elemento que articulaba la sucesión de los eventos, la variable explicativa que permitía entender el paso del enamoramiento apasionado al desencanto, la violencia y el suicidio. No todos los hombres recurrían a la violencia sin medida, pero era verosímil imaginar hombres celosos, que podían llegar a agredir a la persona que los desvelaba y obsesionaba.

La agresión física hacia uno mismo y hacia los demás era representada como un medio desesperado de los varones apasionados para retener a su lado a la persona que los abandonaría o los rechazaba. No hemos encontrado casos de mujeres que recurrieran a actos violentos contra otros y luego se suicidaran. Más frecuentes, en los relatos sobre sujetos de género femenino, eran las tentativas de envenenamiento en lugares donde podían ser encontradas y salvadas de su trágico destino a tiempo o los intentos de suicidio delante de sus parejas. El policía que redactó el informe relacionado con el intento de suicidio de Nemesia Sora (argentina, 19 años, soltera) pensaba que la suicida había buscado ser rescatada por su pareja, Carlos Llanulo. ${ }^{300}$ Carlos trabajaba en una cigarrería y convivían con Nemesia desde hacía cuatro años. El 30 de marzo de 1881, a las nueve y media de la mañana, Nemesia tomó la disolución de fósforos y esperó allí, en la habitación del conventillo que compartía con Carlos. Sin embargo, su compañero tardaba en llegar y Nemesia comenzó a sentirse nerviosa. El policía ironizó al respecto: "[Nemecia declaró] que había tomado las cajas de fósforos disueltos en agua tibia con el propósito inquebrantable de quitarse la vida; pues no podía vencer ciertas contrariedades que venía sufriendo hacía tiempo; que después de una hora de

\footnotetext{
${ }^{300}$ AGN, FTC-SE, Legajo S20, Sora, Nemesia, por tentativa de suicidio.
} 
haberlas tomado y cuando creyó que era imposible que le salvasen la vida, mandó llamar a Carlos Llanulo, con quien vive en concubinato”. ¿Cuáles fueron las intenciones de Nemesia? ¿Habían sido “inquebrantables” sus intenciones? ¿Quería ser encontrada y salvada? ¿O, tal vez, intentaba morir delante de su pareja, como en otros casos que ya hemos presentado? No conocemos más datos sobre sus penas, sí sabemos que fue salvada a tiempo gracias a un vomitivo que le hizo tomar el Dr. Manuel Blancas, médico de policía. Esto la puso fuera de peligro y Carlos la acompañó al hospital para que continuaran tratando a su compañera.

Los sentimientos posesivos llevaron a Justa López a atentar contra sí misma en varias oportunidades: el 9 de febrero de 1883, fue la primera tentativa frustrada; el 26 de abril y el 31 de agosto, respectivamente, del mismo año tuvieron lugar la segunda y tercera tentativas. ${ }^{301}$ En todos estos episodios se había envenenado con fósforos diluidos en agua, debido a supuestas "presunciones sobre la fidelidad de su esposo", según consta en el sumario. En el último de estos incidentes, Justa trató de envenenarse delante de su marido, Bruno Sánchez (sargento de policía). Éste le quitó el veneno en el acto y cansado de repetir por tercera vez la misma escena, se dirigió a la comisaría a hacer la denuncia de todo lo sucedido. Si bien López dudaba de su esposo, los vecinos de la casa de inquilinos declararon en favor de este último, negando cualquier fundamento a las acusaciones que Justa le hacía a Sánchez.

En algunos relatos, las sospechas de infidelidad se habían transformado en certeza. Juana Cepeda (argentina, 20 años, soltera) tomó una disolución de fósforos en aguardiente, el 25 de enero de $1886 .{ }^{302}$ Según los testimonios que recolectó la policía, la joven suicida estaba convencida de que su concubino tenía una relación con otra mujer. Fue rescatada a tiempo por otra inquilina que buscó auxilio; mientras llegaba asistencia médica, le hizo tomar a Cepeda varias cucharadas de aceite de cocina. El diario "La Prensa" (27/01/1886) informó los hechos narrados hasta aquí y presentó como causa de lo sucedido los celos que Cepeda sentía hacia su amante. Fortunata López también tenía serias sospechas de que su pareja, Santiago Juárez, no le era fiel. ${ }^{303}$ El 9 de agosto de 1882, López tomó una disolución de fósforos en su domicilio. Cuando llegó Juárez, encontró a Fortunata dolorida, ésta le confesó que había tomado veneno. Cuando la policía interrogó a López por su acto suicida, explicó que "sospechando en la

\footnotetext{
${ }^{301}$ AGN, FTC-SE, Legajo L15, López, Justa, por tentativa de suicidio. ${ }^{302}$ AGN, FTC-SE, Legajo C34, Cepeda, Juana, s/tentativa de suicidio.

${ }^{303}$ AGN, FTC-SE, Legajo L13A, López, Fortunata, s/tentativa de suicidio.
} 
infidelidad de Juárez se había propuesto suicidarse sin que nadie concurriera ni tuviera conocimiento de su intento". Estas fueron las palabras textuales del policía que dejó asentado lo sucedido en el sumario. El agente, quizás, desconfiaba de las verdaderas intenciones de Fortunata; tal vez, podía entrever que la suicida, en lugar de poner fin a su existencia, buscaba ser encontrada por Juárez y rescatada a tiempo. Además, según el sumario, Fortunata no llegó a absorber el veneno y su cuerpo pudo evacuarlo naturalmente. ¿Había tomado el veneno realmente? ¿Tomó la dosis suficiente para que fuera mortal? El que redactó el sumario intuía que, tal vez, en este episodio, más que un intento de suicidio letal se trataba de un llamado de atención movido por los celos. El caso de Fortunata fue dado a conocer en "La Nación” y "La Prensa" (11/08/1882). En el primero, se evitaba mencionar las causas de lo sucedido: éstas eran "de carácter privado, y no hay para que hacerla pública". Fortunata se recuperaba en el hospital, con perspectivas de estar sana de nuevo; quizás el hecho de que la joven pudiera vivir, daba mayores razones para no exponer sus desgracias íntimas. En el segundo, en cambio, se brindaban más detalles de lo ocurrido. Según el cronista, Fortunata padecía la enfermedad crónica e incurable de los celos. Al mismo tiempo, daba a entender que las actitudes de su compañero no ayudaban a calmar estas pasiones:

El gendarme, que sin ser marido travieso tiene en el cumplimiento de su deber que andar mirando y conversando con sirvientitas de la manzana que vigila, daba inocentemente, así debemos suponerlo, continuos motivos para que la enfermedad se agravara.

El cronista daba a entender que, tal vez, los celos de Fortunata estuvieran justificados, aunque su pareja no fuera infiel. Su "inocente" comportamiento era inadecuado si quería evitar que su compañera estuviera celosa. En cierto modo, el cronista avalaba, siguiendo el marco axiológico de la época, la construcción de un vínculo de pareja exclusivo y posesivo. Como hemos visto, este apego podía llegar a extremos obsesivos y enfermizos, como ejemplifican las historias que hemos presentado aquí.

En síntesis, era verosímil imaginar estos sentimientos en las relaciones de pareja conflictivas: el juego constante entre los celos, el miedo al abandono y a la traición, el resentimiento por la infidelidad. Eran emociones intensas; en algunos individuos eran tan fuertes que los conducía a perder la cordura, a herirse a ellos mismos o a lastimar a quienes deseaban apasionadamente. 


\subsection{Consideraciones finales}

En este capítulo, nos propusimos analizar los relatos de suicidios vinculados con el amor, como eje temático. Asimismo, incluimos también aquellas historias que presentaban datos sobre las interacciones entre los miembros de la pareja. En este sentido, nos parecía central rescatar la relación del suicida con la persona amada, como otro significativo.

Cabe destacar que la mayoría de los suicidas en estas historias dramáticas y novelescas eran adolescentes y adultos jóvenes. Esto no resultaba sorpresivo para los contemporáneos; los médicos alertaban sobre los peligros de ese romanticismo mortal, que promovía las pasiones desenfrenadas. Los más jóvenes y las mujeres eran los más propensos a dejarse arrastrar por estos sentimientos exaltados, en especial, el amor. Era muy verosímil imaginar a sujetos con estas características de sexo y edad quitándose la vida por este tipo de "causas determinantes": era esperable que fueran más proclives a caer en la desesperación por influencia de dilemas amorosos o sentimientos asociados, como los celos; o estar envueltos en combates relacionados con asuntos del corazón. En síntesis, había un preconcepto sobre el carácter de los jóvenes, imaginados como individuos sensibles y apasionados, como el Werther de Goethe, que se refleja en las declaraciones de los testigos y en los informes de la policía.

A partir de las historias de estos héroes y heroínas románticos, este capítulo estuvo orientado a analizar dos cuestiones principales. Por un lado, nos propusimos indagar los diferentes tipos narrativos identificados a través de la lectura de los sumarios seleccionados. Así, encontramos tres tipos de tramas que se repetían con mayor frecuencia. En primer lugar, relatos que tenían como protagonistas a los y las jóvenes que sufrieron una decepción de sus anhelos románticos. Al sufrir de un amor no correspondido, estos individuos se quitaban la vida, arrastrados por su falta de madurez para sobrellevar el dolor que producía este infortunio. En otros relatos, los enamorados se profesaban afecto, pero los principales opositores a la unión de estos eran sus padres o tutores. Los genuinos sentimientos de los jóvenes enamorados despertaban cierto grado de empatía por parte de los periodistas de los diarios como "La Prensa" y "La Nación", la influencia del romanticismo perduraba y el amor era un valor positivo, a pesar de los problemas que podía llegar a ocasionar. Por un lado, era el fundamento de las relaciones amorosas felices y anheladas. Por el otro, era sinónimo de pasión, de celos y de violencia. En este sentido, el tercer tipo de trama frecuente tenía como 
protagonistas a la pareja ya conformada, pero en disputa constante. En algunas narraciones, el conflicto daba lugar a la separación o a la amenaza de abandono. Esta situación también era imaginada como potencial generador de intensa desesperación. Sin embargo, en la mayoría de los casos analizados, los celos eran la emoción enervante y agresiva que movilizaba los actos suicidas de muchos de los sujetos apasionados. En este sentido, el amor que se profesaban los amantes, como en la mayor parte del siglo XIX, seguía siendo un sentimiento posesivo, que, en algunos individuos, se convertía en una obsesión enfermiza. Tal es así, que algunos enamorados podían responder de forma muy agresiva (contra ellos mismos o contra otros) si sospechaban alguna infidelidad por parte de la persona amada. Estos excesos no eran la norma, pero el anhelo de posesión exclusiva de la pareja sí era un aspecto de la personalidad que podía ser reconocido en una franja más importante de la población juvenil y adulta.

Como segundo objetivo, nos propusimos analizar las interacciones entre los que se quitaban la vida y sus parejas, como otros significativos. Al indagar estas tramas con final dramático, nos encontramos con algunas actitudes y acciones que se reiteraban. En primer lugar, como en muchos otros suicidios, no sólo los de este eje temático, identificamos la determinación de guardar silencio y no revelar lo que estaba sucediendo o lo que el suicida sentía. Si dejaban cartas, estas eran dirigidas a miembros de la red de vínculos más cercanos en sobre cerrado. En algunos, el mensaje se resumía en un último adiós, un pedido de perdón o una expresión del dolor y la desesperación por percibir que era imposible establecer un vínculo amoroso con la persona deseada. En ciertas ocasiones, el destinatario de la misma era el ser amado, y, a veces, también odiado con la misma intensidad. En este sentido, encontramos actos suicidas e interacciones que tenían objetivos más agresivos. Así, por ejemplo, vimos, de forma reiterada, expedientes que relatan tentativas de envenenamiento o de autolesión que fueron ensayadas delante de la pareja o el individuo deseado. A veces, el mensaje estaba dirigido a alguno de los padres o tutores que se oponía a la relación amorosa de sus hijos. En algunos casos, parecía haber una intención de chantaje. Es decir, el objetivo de forzar al entorno a ceder a los deseos del suicida; por ejemplo, en el caso del sujeto que estaba por ser abandonado, retener a su amado. En varios otros, la aniquilación de la propia vida era una forma de generar culpa, escándalo y sufrimiento en alguno o varios de los supervivientes. La expresión más extrema de este tipo de acciones era el intento de lastimar o asesinar al sujeto deseado y a la vez culpado de la decepción amorosa, antes de quitarse la vida. El objetivo de estos actos suicidas iba más allá de lo expresivo 
o lo afectivo, eran suicidios con la intención de sembrar remordimiento en otros.

Así, encontramos que la mayoría de los actos suicidas en los que el sujeto buscaba condicionar y agredir a sus otros significativos estaban asociados con el amor y las relaciones de pareja. Por esta razón, en este capítulo nos concentramos en los casos que narraban acciones comunicativas regulativas agresivas y, en algunos casos, de violencia hacia terceros por parte de los suicidas, caracterizados como individuos apasionados. En el capítulo siguiente, nos detendremos en aquellos suicidas que representaban su acto como una acción oblativa o defensiva para proteger su reputación personal y la de sus familias. 


\section{Capítulo 10: Honor y sufrimiento moral}

En el capítulo anterior, analizamos los relatos protagonizados por los suicidas apasionados. Estas historias giraban en torno a individuos movidos por sus estados emocionales anormales, impulsados por el amor, el desengaño amoroso o los celos. En muchas de estas narraciones, aparecían llevando adelante acciones comunicativas regulativas agresivas. En éste, por otra parte, abordamos aquellos actos suicidas que fueron presentados como sacrificios o acciones defensivas para salvaguardar la reputación personal y el recuerdo que construirían los deudos.

En este sentido, nos abocaremos al estudio de los relatos de suicidios en los que se hacía referencia al tema de la honra. Como mencionamos antes, las cuestiones de honor y reputación fueron parte de la construcción de las identidades masculinas de la época y, como tales, eran motivos verosímiles para explicar el sufrimiento que conducía a la desesperación más intensa, a la locura y, en última instancia, al suicidio. ${ }^{304}$ Así, hemos encontrado individuos que se quitaron la vida y dejaron asentadas en sus cartas frases y enunciados referidos a la importancia de su honra, y, en otros casos, de su contracara, el sufrimiento provocado por un sentimiento de profunda vergüenza. Por esta razón, en este capítulo, enfocaremos el análisis en aquellas historias en las que aparecía este discurso sobre el honor.

En estos relatos morales de lo sucedido, nos propusimos, por un lado, identificar a quienes interpelaban a los que se quitaban la vida, con sus notas y sus actos suicidas, es decir, los otros significativos a los que dirigían sus mensajes. En segundo lugar, estudiaremos la intención que el propio suicida manifestaba en sus declaraciones, antes de morir, o en los escritos legados a los deudos. Así mismo, también tuvimos en cuenta los sentidos que podían identificar los miembros de su red social a la hora de dar cuenta de los hechos a la policía.

Desde nuestra perspectiva, pensamos que los actos suicidas podían ser representados como acciones comunicativas regulativas defensivas, orientadas a proteger el honor personal y/o familiar. Si bien, en la mayoría de los casos, los suicidas eran considerados locos, desesperados y apasionados, estimamos que existía un pequeño grupo de relatos en los que el que se quitaba la vida esperaba salvar o defender su reputación con su autoagresión. En este sentido, no existía un código social que

\footnotetext{
304 Sobre el honor en la cultura durante el proceso de formación de la Argentina Moderna, véase, entre otros, GAYOL (2000 y 2008) y CICERCHIA (2001).
} 
determinara situaciones en las que los individuos debían suicidarse. Sin embargo, resultaba comprensible y verosímil que algunos sujetos consideraran terminar voluntariamente con su existencia frente a una deshonra pública con consecuencias intolerables. Para algunas personas, en determinadas circunstancias, era un acto de coraje y valor que hablaba de la calidad personal del sujeto que descargaba la violencia sobre sí mismo. Al mismo tiempo, creemos que los suicidas apelaban al discurso de la honra como una de las estrategias que contribuía a preservar su recuerdo en la memoria de los deudos. Presentarse como hombres de honor y defender su reputación era una forma de hacerlo.

\subsection{El deber, la vergüenza y la desesperación}

Julio Becker (65 años, soltero) era un comerciante de origen alemán. ${ }^{305}$ El día que se quitó la vida, el 15 de septiembre de 1884, se encontraba en su domicilio (ubicado en la calle Venezuela $\mathrm{N}^{\circ} 171$ ); vivía en su hogar, junto a sus empleados domésticos, no tenía familiares en la ciudad. Su habitación estaba alfombrada y "decentemente" amueblada. Fue encontrado a las 17:00hs. por su socio comercial, José Costa, sin vida, en su cama, arropado hasta la mitad de su cuerpo con una cobija. El informe del médico de policía confirmaría que su muerte fue provocada por un disparo de revólver en el costado izquierdo del tronco y que la bala quedó alojada en el corazón. De acuerdo con la reconstrucción posterior de lo sucedido, la noche anterior había intentado envenenarse con láudano y cloroformo. Todavía padecía los efectos de estas sustancias cuando en la mañana (a las 7:00 horas) fue a despertarlo su empleado doméstico, Benjamín García (argentino, 54 años, soltero), quien vivía en la casa de Becker. Al entrar al cuarto, García sintió un fuerte olor a cloroformo, su patrón no respondía a sus llamados y permanecía inmóvil en su lecho. De inmediato llamó a otro de los que trabajaban allí y juntos le insistieron que fuera a ver a un doctor, Becker se negó y alegó que su estado se debía a una descompostura que lo aquejaba desde la noche anterior. García y su compañero desoyeron estas indicaciones y buscaron a un médico para que lo atendiera. Por la mañana, el Dr. Carlos Cristiani hizo el diagnóstico y recetó algunos remedios y una purga. El médico volvió a visitarlo en la tarde y notó que el intoxicado estaba mejor. Éste le confesó que había intentado suicidarse debido al

\footnotetext{
${ }^{305}$ AGN, FTC-SE, Legajo B24, Becker, Julio, su suicidio.
} 
"mal estado de sus negocios" y que estaba arrepentido de sus actos. Asimismo, Becker le pidió reserva a Cristiani sobre lo sucedido, ya que sería una vergüenza si se enteraban las personas que lo conocían.

La biografía póstuma de Becker, reconstruida por el cronista de "La Prensa" (15/09/1884), presenta el perfil de un hombre de honor, ejemplo de una "vida laboriosa y honrada”. Desde su llegada a Argentina, este inmigrante alemán, luego de trabajar muchos años para la familia Cambaceres como dependiente, les compró el saladero de su propiedad. Con este negocio había amasado una fortuna respetable. Sin embargo, en el último tiempo, el saladero había empezado a dar pérdidas:

Personas que conocían al suicida nos hacen saber que ha sido victima de su delicadeza y tal vez del desaliento que le causo la perspectiva de quedarse sin recursos para vivir, después de una vida laboriosa que le proporcionó una fortuna respetable. [...] En estos días tenían algunos vencimientos de importancia para los que no contaba con efectivo disponible: pero deja tres propiedades libres de carga, cuyo valor escedera de cincuenta mil pesos fuertes, cantidad sobrada para pagar todas sus obligaciones en plaza.

Según lo relatado por el cronista, Becker dejó ocho cartas. Una de estas estaba dirigida a su ex-patrón, Antonino Cambaceres:

Un detalle que demuestra la prolijidad serena conque tomo esa fatal determinación, es que la carta dirigida al señor Cambaceres le enviá cuidadosamente envueltos en papeles de seda los retratos de cada uno de los miembros de la familia de aquel que durante los veinti tantos años que estuvo de cajero, tanto con el padre de D Antonino Cambaceres como con este mismo señor, había recibido.

El contenido de las otras cartas dejadas por el suicida también era signo de su carácter imperturbable y frío, propio de una mente serena, que deja en orden sus asuntos antes de poner fin a su existencia: "En las cartas indicadas se revela la tranquilidad de animo con que dicto su ultima voluntad". En todas hablaba de sus negocios, sobre todo, en la dirigida a su socio, Costa. En sus últimos escritos también se mostró preocupado por la suerte de su empleado doméstico: "Se ha cuidado de la suerte de García con verdadero interés, y en una de las cartas recomienda al dependiente para que le proporcionen colocación". Asimismo, según el cronista, le dejó a su sirviente tres meses de salario 
adelantado. $^{306}$ Por último, en la dirigida a García lo alentaba a seguir adelante con firmeza: "Póngase a las órdenes del señor Señorans y tenga sangre fría como corresponde a un viejo soldado como Vd.”. Por último, en las notas suicidas, Becker pedía un entierro sencillo y sin invitación. Según el cronista, esto fue respetado por los deudos: "Cumpliendo su último deseo, hoy sera conducido modestamente a su última morada". Becker fue presentado en este recuento biográfico como un ejemplo de laboriosidad y honradez, antes que incumplir con el pago de sus deudas, respondía con su vida y con las propiedades que le quedaban. Sus actos no eran los de un desesperado, un apasionado o un loco; eran las acciones de un hombre tranquilo, que había tomado su resolución con serenidad. Al mismo tiempo, en la desgracia, demostraba preocupación por su empleado y gratitud hacia sus antiguos patrones, aquellos que le brindaron las posibilidades para crecer y progresar. En suma, era el relato de un "gran hombre" que había caído en desgracia y terminaba su vida estoicamente, siguiendo los valores del marco axiológico de las elites, que mencionamos en el capítulo 5.

El caso de Adolfo Becker ejemplifica otras situaciones narradas en los sumarios judiciales, que podríamos agrupar dentro un mismo tipo narrativo: individuos que se quitaron la vida al ver que habían quebrado o que estaban endeudados y no podían responder a las demandas de sus acreedores, como una forma de compensar con su sangre los compromisos asumidos. Algunos interpretaban que era su deber responder con la vida. Manuel Pastor (español, 41 años, casado, ropavejero), antes de suicidare por medio de un disparo en la cabeza (el 23 de septiembre de 1879), dejó una nota con el siguiente texto: "A las autoridades todas en general les suplico que no molesten a nadie por mi determinación que no hago nada más que cumplir con mi deber. Sin mas Manuel Pastor". ${ }^{307}$ Según los testigos, la ropavejería de Pastor no andaba bien. "La Prensa" y "La Nación”, el 24 de septiembre de 1879, dieron a conocer el triste desenlace de la biografía de este inmigrante español. De acuerdo con la noticia de "La Nación", Pastor había llegado exiliado de su país, ya que había sido condenado a muerte por participar de un atentado contra Amadeo de Saboya (rey de España entre 1870 y 1873). ${ }^{308}$ Llegado al Río de la Plata, se ocupó de atender a su familia, que lo siguió más tarde. Según se decía, daba señales de tener sus facultades mentales alteradas el último tiempo. Sin

\footnotetext{
${ }^{306}$ Desconocemos el rumbo que tomó la vida de Benjamín García luego de la muerte de su patrón. Sin embargo, como señalamos en el capítulo 6, García tuvo el mismo desenlace trágico que Becker.

${ }^{307}$ AGN, FTC-SE, Legajo P19, Pastor, Manuel, por suicida.

${ }^{308}$ Este atentado tuvo lugar el 18 de julio de 1872, en la calle del Arenal de Madrid, mientras el rey paseaba junto con su esposa. Véase: https://es.wikipedia.org/wiki/Reinado_de_Amadeo_I_de_Espa\%C3 $\% \mathrm{~B} 1^{\mathrm{a}}$
} 
embargo, la carta que dejó Pastor no presentaba indicios de trastorno mental alguno, según el cronista:

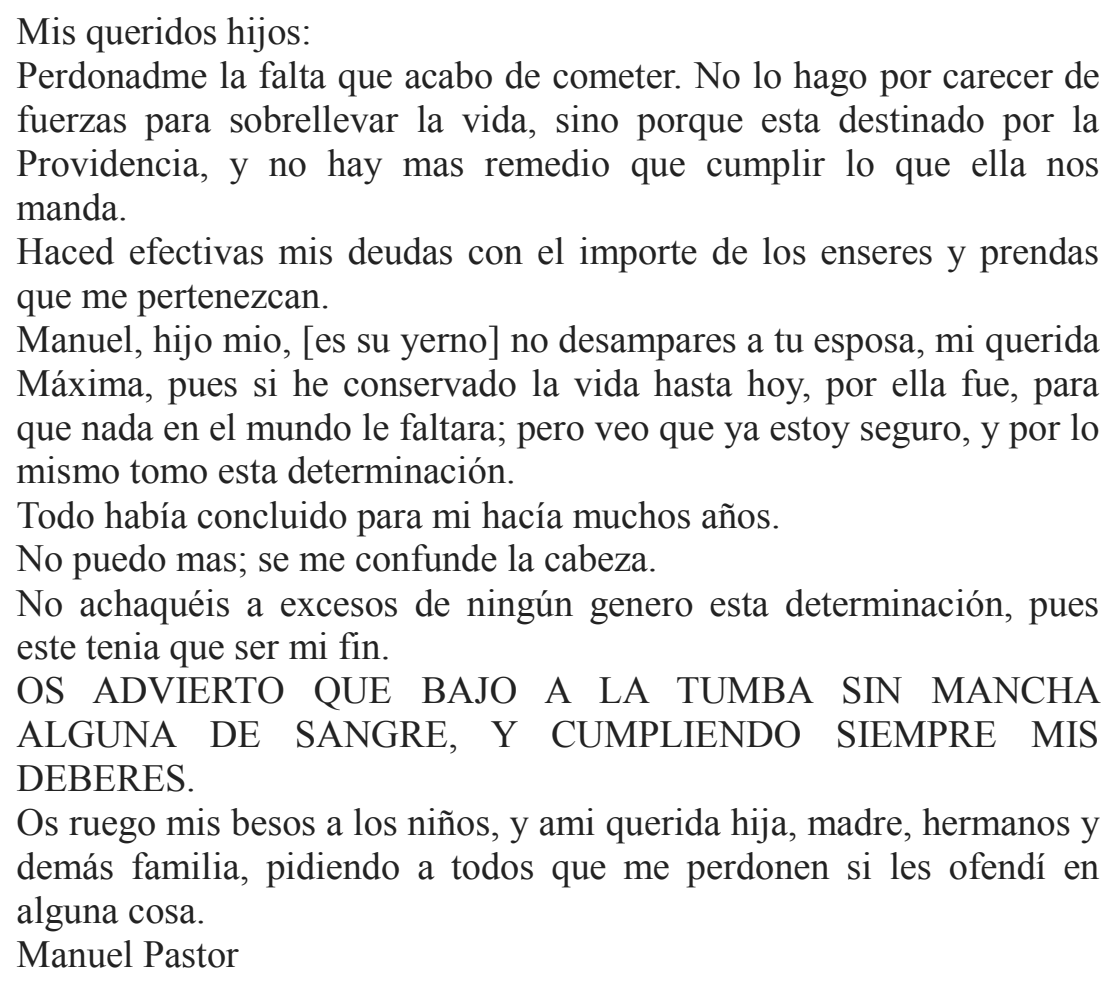

En esta nota, el suicida se representaba como un hombre honrado que cumplió con su deber hasta el final, legando un buen nombre a su familia. No era un "cansado de la vida" o un individuo consumido por los vicios, había luchado hasta ese entonces por su hija, que encomendaba a su yerno. Sólo le quedaba solicitar perdón a sus familiares y que pagaran sus deudas con los bienes que quedaran de su negocio. La carta de Manuel Pastor funcionaba de la misma forma que las necrológicas elogiosas y afectuosas, dejaba una imagen más amable que recordar a sus deudos, guardianes de la memoria del suicida.

Por otra parte, otros suicidas no manifestaban el estado de serenidad y tranquilidad de espíritu con el que fue caracterizado Becker. De acuerdo con la nota suicida que dejó Edgardo Moreno (argentino, 41 años, casado, dos hijos, ingeniero), los últimos momentos de su existencia estuvieron cargados de una fuerte desesperación. Moreno se quitó la vida en su domicilio, el 3 de agosto de 1888, cerca de las 7:30hs de la mañana. ${ }^{309}$ Según los testimonios de la familia (tenía esposa y cuatro hijos), creían

\footnotetext{
${ }^{309}$ AGN, FTC-SE, Legajo M42, Moreno, Edgardo, su suicidio.
} 
que se había suicidado después de tener una serie de pérdidas como consecuencia de sus operaciones bursátiles, aunque recalcaban que para ese entonces habían solucionado estas dificultades con éxito. En su carta, Moreno expresaba cómo se sentía:

Soy el único autor y responsable de mi muerte. Cedo a la fatalidad y a mi cruel destino. Perdonenme mi virtuosa y leal esposa, mis inocentes hijos, mis hermanos y los que me honraron con su amistad. Presa del delirio del insomnio, me siento loco, desesperado! agosto 3/88 Edgardo Moreno.

En este caso, el suicida se hacía responsable de sus faltas y del final de su vida. Al mismo tiempo, buscaba el perdón de su familia y de aquellos que habían confiado en él, entre otros, los que probablemente le habían prestado dinero. Así, hemos encontrado testimonios del intenso sentimiento de vergüenza y remordimiento que sentían aquellos hombres que no podían cancelar sus deudas. De acuerdo con la versión de los hechos narrada en "La Prensa" (04/08/1888), el suicida era hermano de Enrique B. Moreno, ministro argentino de relaciones exteriores en Rio de Janeiro. Edgardo Moreno se había desempeñado, la mayor parte de su vida como ingeniero, y sólo en el último tiempo se dedicó a las especulaciones bursátiles, de acuerdo con lo mencionado en la noticia. Las fuertes pérdidas en la Bolsa, durante los meses de junio y julio de ese mismo año, habían obligado a Moreno a entregar, en pago de lo que debía, todo lo que poseía y, además, también, firmó papeles que lo comprometían a pagar en plazos el resto de lo adeudado. Al mismo tiempo, Moreno se negó a recibir el auxilio de sus amigos, que se ofrecieron a ayudarlo para saldar sus deudas. La nota que dejó a su familia y amigos no fue reproducida, pero el cronista mencionaba su existencia y aclaraba que, en este escrito, pedía perdón a su esposa y amigos por su resolución y expresaba su deseo de que nadie tuviera que ocuparse de su muerte. Por último, la noticia concluía con estas últimas líneas:

Eran bien conocidas sus cualidades, como hombre honrado y trabajador, que le granjearon amigos y simpatías merecidas.

Es una perdida verdaderamente lamentable, a cuyo pesar nos asociamos sinceramente. 
En suma, la noticia de "La Nación" buscaba resaltar la honradez y la laboriosidad de Moreno por sobre el escándalo de sus fallidos negocios en la Bolsa y su suicidio. Al igual que en el caso de Becker, el texto publicado en la prensa actuaba como una suerte de necrológica que enaltecía al difunto ante sus deudos y el público lector.

En el caso de Juan Masironi (italiano, 40 años, viudo, 4 hijos), según el médico de policía, la mala situación económica de su lechería llegó a afectar sus sentidos y le provocó un rapto de locura, lo que motivó que intentara suicidarse dándose golpes con un vaso en la frente. ${ }^{310}$ Así, los contemporáneos consideraban verosímil que los individuos endeudados o al borde de la quiebra sintieran una profunda desesperación y se quitaran la vida. Esto nos permite entrever la presión que sentían los individuos de género masculino en relación con el éxito económico y material y, como contraparte, la angustia que generaba la incertidumbre de no poder cumplir con los compromisos monetarios pautados. Ver el negocio propio quebrar era una pesadilla que podía trasladar la mente hacia el terreno de la locura. Carlos Jackson estaba solo y no tenía familia en la ciudad (se creía que estaba en Inglaterra), en el momento que se quitó la vida. ${ }^{311}$ Sólo dejó una carta con los nombres de los apoderados para que se les entregaran unas llaves. Según Eugenio Berdan (francés, 36 años, casado), propietario de la casa amueblada "La Universal” (San Martín N¹48), hacía dos meses y medio que ocupaba una habitación allí. En dicha pieza, Jackson (50 años, casado, comerciante) se quitó la vida. Según el informe médico, el cuerpo estaba rodeado de un charco de sangre y presentaba una herida de bala en la cabeza, a la altura de la sien derecha; la pistola con la que se dio muerte estaba entre sus muslos. El Dr. Blancas, médico de la policía, concluía que se trataba de un suicidio. El policía aclaraba en su informe: "Se supone que la causa que lo ha inducido a Jackson a quitarse la vida es el quebranto de su fortuna". Berdan declaró que desde el momento en que conoció al suicida, notó un comportamiento extraño: "parecía un loco tanto por la incoherencia de sus palabras cuanto por su habitual tristeza". La ruina económica era una situación desesperante, el sentimiento de angustia era tan intenso que podía llevar a los individuos a un estado de alienación mental.

Ahora bien, ¿cómo explicaban ese malestar los contemporáneos? Es probable que en el caso de los hombres casados y con hijos, el bienestar de la familia fuera fuente de desvelos para el cabeza del grupo familiar. Así lo expresó Luis Giani (italiano, 44

\footnotetext{
${ }^{310}$ AGN, FTC-SE, Legajo M28, Masironi, Juan, sumario tentativa de suicidio.

${ }^{311}$ AGN, FTC-SE, Legajo J3, Jackson, Carlos, su suicidio.
} 
años, casado, 4 hijos, dueño de un almacén), en la nota que dejó antes de quitarse la vida. ${ }^{312}$ Giani se suicidó mientras todos dormían, el día 9 de mayo de 1886, en la letrina de su almacén (que también era el domicilio donde residía con su familia). Según declaró su esposa, Catalina Ganatti, ya había intentado quitarse la vida en otras oportunidades. ${ }^{313}$ Esa noche, Giani se acercó al lecho, cuando ella dormía, y la despertó para dejarle una carta que debía enviar al señor Juan Capello (domiciliado en calle

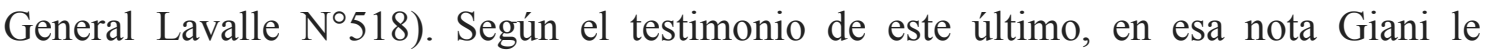
manifestaba que se suicidaba porque "sus negocios marchaban mal" y le encomendaba el cuidado de su familia. ${ }^{314}$

Sin embargo, la intensa desesperación también era percibida por los hombres solteros, como el caso ya mencionado de Adolfo Becker, quien sentía vergüenza de su situación y sus actos. En este sentido, si el sujeto estaba agobiado por deudas, esta circunstancia sumaba más presiones para el propietario de un emprendimiento. Este fue el caso de Luis Morigini (italiano, 32 años, soltero), dueño de la cigarrería ubicada en la calle Victoria $\mathrm{N}^{\circ} 34 .{ }^{315}$ Como todos los días, el 10 de abril de 1877 , se dirigió al altillo de su negocio a dormir la siesta. El ruido de un balazo quebró el ritmo cotidiano de los que habitaban la casa; parecía provenir del lugar donde suponían que Morigini dormía. De inmediato, se dirigieron allí y encontraron su cuerpo sin vida, tendido en un catre, con una herida en la sien derecha. Según la hermana del suicida, Luisa, y el peón que trabajaba en la cigarrería, el negocio no marchaba bien y Morigini tenía deudas que no podía saldar. Los acreedores, a su vez, reclamaban que se les pagara lo adeudado. De hecho, este fue el evento que los testigos identificaron como el detonante: "Dicen que esta mañana fue un individuo a cobrarle una cuenta y el peón se lo hizo saber a Morigini, quien contestó: diga U. a esa persona, que voy a vestirme y que entre pocos momentos pasaré por su casa". También debía dinero a un primo suyo, Constantino Morigini, quien, frecuentemente, le reclamaba por ello. En síntesis, la presión del mal estado de su emprendimiento y las sucesivas demandas vinculadas con sus deudas eran los motivos verosímiles para imaginar el suicidio de este sujeto. Quizás había un

\footnotetext{
${ }^{312}$ AGN, FTC-SE, Legajo G37, Giani, Luis, su suicidio.

${ }^{313}$ Catalina también declaró que días antes había encontrado a su marido probando el arma en donde fue encontrado el cuerpo, corroborando así que la detonación podía ser oída por los habitantes de la casa. Al encontrarlo en esa situación, le sacó el arma y la guardó. La noche anterior a su muerte, Giani le solicitó con insistencia que le regresara el revólver. Ganatti, en un principio, se negó a ceder, pero terminó por dársela después de muchas insistencias, según lo que expuso a la autoridad. De acuerdo con la versión de Catalina, intentó vigilar a Luis, pero este se rehusaba de forma agresiva y por eso decidió irse a dormir. ${ }^{314} \mathrm{La}$ carta no fue incluida en el expediente.

${ }^{315}$ AGN, FTC-SE, Legajo M11, Morigini, Luis por suicidio.
} 
mensaje implícito de parte de Morigini para sus acreedores. Tal vez trataba de demostrar su vergüenza y atenuar su falta entregando la vida. Posiblemente, también intentaba, consciente o inconscientemente, generar un sentimiento de culpa en aquellos que lo aquejaban con sus reclamos. El expediente no nos brinda más detalles y como señala el policía: "No se ha encontrado documento escrito que haya dejado el suicida al tomar la suprema determinación".

En general, la mayoría de los relatos vinculados con la idea del honor y la reputación giraban en torno a cuestiones relacionadas con robos y deudas. Sin embargo, en algunos casos, hemos encontrado el discurso referido a la honorabilidad en otro tipo narrativo ya analizado, cuando mencionamos la deshonra que el comportamiento sexual de la pareja de un individuo de género masculino podía traerle a este último. Este fue el caso de José Fontauas (español, 58 años, jornalero), quien intentó quitarse la vida con un tiro de revólver (22 de febrero de 1886), por sospechar que su pareja le era infiel. ${ }^{316}$ Éste declaró a la policía: "yo he sido quien me he herido, con el animo de suicidarme para quitarme tanta vergüenza sobre mi”. Según su mujer, Petrona Ferreira, su marido la celaba mucho. Ese mismo día, a las 3 de la madrugada, alguien tocó a la puerta de la habitación en la que vivían y la llamó por su nombre, cuando abrieron no había nadie; por esta razón, sospechaba que alguien quería generar discordia en la pareja. Según Ferreira, estos fueron los eventos que motivaron una nueva escena de celos con Fontauas. La violencia era presentada como un modo de limpiar la reputación personal, de que se era un hombre viril y honrado a pesar de la falta, en este caso, del comportamiento de su pareja. Más allá de que las suposiciones de Fontauas fueran reales o ilusorias, él se sentía angustiado por la posibilidad de que eso estuviera ocurriendo, las relaciones ilícitas de su mujer ponían en cuestión su propia respetabilidad y hombría. Cabe aclarar que no fue algo que el herido expresara en un escrito, sólo lo manifestó al policía que lo interrogó, buscando cierta empatía por su dolor emocional. Había más casos de suicidio en situaciones similares a esta, motivadas por los celos y las sospechas de infidelidad, pero es probable que muchos fueran ocultados, que no se dieran a conocer estos detalles, por pudor y por la exposición y el escándalo que traían, tanto para el que se quitaba la vida como para su pareja, como vimos en el capítulo anterior.

\footnotetext{
${ }^{316}$ AGN, FTC-SE, Legajo F18, Fontauas, José, tentativa de suicidio.
} 
Volviendo a los casos relacionados con endeudamientos y el cumplimiento de los "compromisos sagrados", de acuerdo con varios testimonios relevados de los casos, imaginar la quiebra del negocio propio implicaba una exposición pública que dañaba la reputación personal y resultaba muy dolorosa. Por ejemplo, Pedro Capdevila (francés, 25 años, soltero, propietario de una tintorería) declaró, en la comisaría, que había intentado quitarse la vida y la causa de su acto suicida (llevado adelante el 29 de enero de 1880) era "el mal estado de sus negocios y el no querer sufrir la afrenta ante sus amigos de ser ejecutado en sus bienes", según dejó sentado el policía sumariante. ${ }^{317}$ Este tipo de testimonios dan cuenta del sufrimiento que provocaba verse expuesto públicamente ante el imaginario "tribunal del honor" que mediaba y valuaba la reputación de cada miembro de la comunidad. En este sentido, la vergüenza era representada como desesperante e insoportable.

El contenido de las notas que dejó Francisco David (español, 39 años, soltero, comerciante), antes de quitarse la vida, ilustra muy bien cómo se representaba a sí mismo y a los demás. ${ }^{318}$ El 20 de junio de 1875, uno de los empleados del local, José Manuel López (español, 25 años, soltero), amigo íntimo de David, volvía de comer con su primo y al entrar en el negocio encontró a su patrón sentado en el sillón de su escritorio, fallecido, con una herida de bala en la cabeza. David era copropietario de su comercio con Pedro Imeda (español, 35 años, soltero, comerciante). Al mismo tiempo, tenía otros negocios con Nemesio Zanoletti (español, 46 años, casado, agente judicial), relacionados con la compra de terrenos. Las circunstancias no quedan claras en el expediente, pero la situación de los compromisos que David y Zanoletti tenían por su cuenta se habían complicado de forma grave, lo que, además, comprometía el emprendimiento que tenían junto con Imeda. ${ }^{319}$ Transcribimos la carta dejada por el suicida a Zanoletti:

\footnotetext{
${ }^{317}$ AGN, FTC-SE, C19, Capdevila, Pedro.

${ }^{318}$ AGN, FTC-SE, D2, David, Francisco. Tanto Nemesio Zanoletti como José M. López solicitaron que se les devolvieran las cartas que la policía había recolectado, pues estaban dirigidas a ellos. El Juez de primera instancia en lo criminal indicó que les fueran devueltas luego de concluido el sumario y que su contenido fuera registrado por escrito. A partir de dicha transcripción, pudimos acceder al contenido de las notas originales que no quedaron contenidas en el expediente.

${ }^{319}$ David no tenía ninguna clase de parientes en territorio argentino; era español, oriundo de la provincia de San Luis (departamento de San José del Moro), allí tenía dos hermanos y, en Pontevedra, dos hermanas. Su socio, Pedro Imeda, le dio sepultura. Este último quedó al frente del negocio.
} 
Querido Zanoletti: Cuando U. reciba esta, ya habrán concluido mis penas. No me compadezca: entre vivir mártir y sufrir una hora por siempre, creo que la elección de la última es preferible. Convenga que si usted no tuviera los deberes que tiene, haría lo mismo. La idea de que me llaman ladrón no puedo soportarla. Por otra parte, si es verdad que he sido desgraciado, muy desgraciado, no desconozco mis desaciertos y errores, y hay errores y faltas en la vida, que sin reparar solo se pueden atenuar con el suicidio. No me compadecerán siquiera; pues que si perdí lo ageno también perdí lo mio, y con ello la vida, que es harto fuerte perderla de esta manera. Le ruego que haga por Imeda y López lo que pudiera hacer por mí. En el cajón del escritorio de mi cuarto dejo un testamento ológrafo de cuatro renglones, sólo nombrando albaceas para evitarle a Imeda trastornos con los tribunales. Mi último abrazo a Rosa Clotilde y los niños, que después de sus padres nadie los ha querido tanto como yo, y usted querido Zanoletti, valor, y al recibir con mi último abrazo mi último adiós le pido perdón por este golpe que le doy.

\section{F. David}

junio veinte, mil ochocientos setenta y cinco.

Le suplico haga lo que este en su mano para evitar que este suceso se publique en los diarios. También le pido haga dar sepultura a mi cadáver en la tierra y ponga junto a él, el de mi hijita. Y por último, que lo adjunto vaya por mano segura y la entreguen en mano propia.

En la carta anterior, David manifestaba el malestar que le generaba sólo imaginar que lo llamaran ladrón. Como mencionamos antes, este era considerado un insulto grave en la época que atentaba contra la reputación personal y familiar. También expresaba la preocupación que le despertaba pensar que los hechos relacionados con su muerte aparecieran mencionados en la prensa, una exposición en público que dañaría de forma severa su reputación y la de sus socios. Al mismo tiempo, David se hacía responsable de lo sucedido y entendía el suicidio como una forma de disminuir el peso de sus faltas; la muerte por mano propia era representada en esta nota como un modo de atenuar el remordimiento y la vergüenza y de resarcirse por los errores y sus consecuencias ("si perdí lo ageno también perdí lo mio, y con ello la vida”). Zanoletti, por su parte, declaró que el jueves anterior al domingo en que David puso fin a su vida, se reunió con él. Su socio y amigo le comunicó que sentía una intensa preocupación por no poder pagar las deudas a sus acreedores y también le confesó su preocupación de que murmuraran que tenía más bienes sin declarar. En esta misma conversación, le comunicó sus intenciones de suicidarse. Según Zanoletti, lo reprendió por estos pensamientos. Por lo revelado a su socio y lo comunicado en la carta, a David le preocupaban los rumores, los comentarios 
maliciosos sobre sus negocios y su fallecimiento y que circularan calumnias y acusaciones injustas. Por esta razón, entendemos, le pedía a Zanoletti que no se divulgara información alguna sobre los detalles de su muerte y los motivos que lo llevaron a quitarse la vida.

La otra carta estaba dirigida a José Manuel López y allí expresaba lo siguiente:

\author{
Querido López \\ sido tu padre. \\ Perdóname pues y recibe mi último abrazo. \\ F. David \\ Junio veinte, mil ochocientos setenta y cinco.
}

Todo el bien que le quise hacer resultó en mal. Tu que quieres, hasta ahi llegó mi fatal destino. Pero llevo la confianza, que tu has conocido mis intenciones, que no hubieran sido otras si como sin tutor hubiese

Por lo que se deja entrever, David sentía un profundo afecto por López y temía que sus acciones hubieran perjudicado al joven de algún modo (no encontramos más información al respecto en el expediente). Lo que sí podemos identificar es el remordimiento que expresaba David en sus cartas por haber comprometido el bienestar de sus socios y amigos. Asimismo, sufría por la imagen que sería construida en público, por el escándalo de su situación económica y por haberse quitado la vida en dichas circunstancias. En este sentido, el suicidio era representado como una acción que comunicaba la vergüenza y el arrepentimiento por las faltas cometidas.

A pesar de los pedidos de David, el caso fue publicado en el diario "La Prensa" (23/06/1875). El relato de lo sucedido presentado en el cuerpo de la noticia sigue la línea de eventos que figuran en el expediente. Sin embargo, hay dos cuestiones a resaltar. En primer lugar, no se incluyó la carta dirigida a Nemesio Zanoletti, sólo se reprodujo la destinada a José Manuel López. En segundo lugar, no se dieron detalles de las deudas y problemas económicos de David. Solo se mencionó que el mal estado de sus negocios era producto de una especulación; ésta, en lugar de darle fortuna había acortado su vida... algo que "sólo a Dios incumbe señalar término", concluía el cronista. No todos compartían la perspectiva estoica acerca de la muerte voluntaria. 


\subsection{EI lenguaje de la honra y la defensa de la reputación}

Los casos presentados hasta ahora son en su mayoría de comerciantes. Teniendo en cuenta que la honra en el mundo moderno se defendía cumpliendo los compromisos comerciales y monetarios, no es extraño que estén afectados por el destino de sus negocios. Sin embargo, no eran los únicos que recurrían al discurso del honor. En este sentido, hemos encontrado diferentes actores sociales, con perfiles ocupacionales diversos, que apelaban a la honra, la vergüenza o asuntos de reputación, para explicar sus acciones y las de los hombres y mujeres que se quitaban la vida. Por ejemplo, un abogado, Adolfo Lamarque (35 años, argentino, soltero). El día 18 de junio de 1888, alrededor de las 22:00hs, Lamarque caminaba con su hermano, Facundo, y en el trayecto por la vía pública se suicidó con un disparo de revólver en la sien derecha. ${ }^{320}$ Este último declaró que Adolfo y él estuvieron tomando cerveza en el "Café de la Linterna" y que no notó nada raro ni en el rostro ni en los modos de su hermano. En una de las cartas que dejó, Lamarque manifestaba a su hermano que "cansado de pesadumbres, agobiado bajo el peso de calumnias viles y horribles, busca el abrigo de la tumba”. En el sumario, figura también que entre sus pertenencias encontraron un papel que tenía un poema titulado "La hora suprema". Si bien queda claro que consideraba que otros podían entender el dolor generado por la exposición pública, no sabemos de qué lo acusaban o cuál era la injuria que lo angustiaba, el expediente no revela más detalles. Tal vez le achacaban algún hecho deshonesto, por ejemplo, un mal desempeño en su profesión.

En las noticias publicadas el 20 de junio de 1888 en los diarios "La Prensa" y "La Nación", por otro lado, no se mencionó nada acerca de las calumnias que mencionaba el sumario judicial. La causa era "absolutamente desconocida", según el primero. En el caso de "La Nación", es probable que el autor de la nota sea Bartolomé Mitre, y señaló que el suicidio de Lamarque era uno producido por esos "insondables misterios del corazón”, difíciles o imposibles de comprender con la razón; al mismo tiempo, destacaba: “Todas las cartas son de despedida, rebosantes de ternura y cariño, pero sin una palabra que explique la causa de su fatal resolución". Sólo se citaba algo mencionado en la carta dirigida a un "amigo predilecto", su ex jefe, el Dr. Molina Arrotea: "Desde la muerte de mi hermana, he muerto moralmente, y sólo vivo para

${ }^{320}$ AGN, FTC-SE, L31 A, Lamarque, Adolfo, por suicidio. 
algunos amigos". Mitre acotó al respecto: "Esa idolatría la que Adolfo tenía por aquella hermana a quien vio extinguirse no ha mucho en la lenta y lucida agonía de la tisis pulmonar", lo que hacía suponer, de forma implícita, que tal vez el duelo por la muerte de este familiar había contribuido a turbar su estado de ánimo. Nada que comprometiera el buen nombre de Lamarque apareció mencionado en las noticias. Por el contrario, el perfil del suicida construido, en ambos casos, fue muy elogioso. El cronista de "La Prensa" destacaba que:

El Dr. Lamarque era secretario del Juzgado de lo Civil del doctor Molina Arrotea, puesto que desempeño con honorabilidad y competencia hasta hace un mes en que ese magistrado fue ascendido a Camarista. [...]

Lamarque era querido de todos los que le conocían.

En el colegio y la Universidad era sin duda el estudiante más sinceramente estimado por sus compañeros, la dulzura y suavidad de su carácter eran proverbiales.

Adolfo Lamarque, poeta en los primeros años de su juventud, tenía un talento claro y bien contrapesado.

Espíritu profundamente honrado, tuvo el respeto de todos.

Su digno padre tenía idolatría por su hijo Adolfo y gozaba con el cariño que todos le profesaban.

Es un misterio su terrible resolución, que ha de marcar un día de luto para los numerosos amigos que lo querían.

Hombre honrado y capaz, de agradable carácter y dotado de sensibilidad poética, era querido y respetado por todos los que lo conocían, no había razones para que se quitara la vida. Las palabras dedicadas por Mitre, en “La Nación”, no fueron menos elogiosas:

El Dr. Adolfo Lamarque era un hombre que hacía honor a su generación.

Poeta, periodista, abogado, funcionario público, afiliado desde los albores de su juventud al gran partido que ha afianzado la nacionalidad argentina, y en el que formaba en primera línea por sus talentos y por la elevación de su carácter, dejó por doquiera a su paso huellas luminosas, labrándose una posición distinguida. [...]

Con estos factores, del lado de su haber, en la cuenta corriente con la sociedad, en las intimidades de su existencia parecía que esta debía deslizarse placentera, entre el trabajo honrado y honroso a que vivía dedicado, y al cultivo de los afectos más caros al alma.

Sin embargo, ha sucedido lo que ha sucedido.

Con su propia mano ha cortado aquella vida tan rica en elementos de felicidad. [...]

La Nación, que lo contó un día entre sus obreros más leales y entusiastas, deplora su temprana, incomprensible muerte. 
El fundador del diario "La Nación” cerraba el texto con una poesía:

La muerte es la verdad. Cae marchito

Todo laurel ante su soplo helado;

Su silencio es la voz del infinito

Y su misterio un mundo revelado.

En la choza y en medio a la opulencia.

Con su destino igual nos encontramos.

Una frase resume la existencia:

Venimos, padecemos... y nos vamos!

No supo sino amar. El era bueno

Porque jamás prostituyó su alma.

Y bien! en vez de miel hallo veneno

Y lucha en vez de la anhelada calma.

No vivió con su edad. Causó fastidio

Todo a su fatigado pensamiento...

$\mathrm{Y}$ canto la sirena del suicidio

En la hora sin luz del desaliento.

Yo sé que el esperaba en otra vida

De justicia, de paz y de ventura;

El mundo para él era escondida

Fuente de iniquidades y tortura.

Todos adoraremos su memoria

De su talento en las hermosas perlas

Pues renunció a la vida y a la gloria

Cuando otros van recién a comprenderlas.

Según Mitre, "estas eran las palabras que habían sido pronunciadas por un poeta suicida ante la tumba de otro poeta suicida, joven, bueno, inteligente como él". El autor del poema, aunque no se mencionara, no era otro que el propio Adolfo Lamarque. ${ }^{321}$

${ }^{321}$ La poesía ("En la muerte de J. M. Mitre") formaba parte de la obra de Adolfo Lamarque, "Ensayos Poéticos" (1871). Ésta fue publicada un año después del suicidio de Jorge Mariano Mitre. Ambos eran íntimos amigos desde su adolescencia, así lo mencionaba Lamarque en una carta enviada a Enrique S. Quintana, editor de la obra literaria del difunto hijo de Bartolomé Mitre, e incluida en el prólogo de la obra: "En las largas veladas del invierno que pasábamos juntos, escribíamos siempre, y cuando el cansancio nos invadía, nos leíamos mutuamente nuestros ensayos". Jorge Mariano Mitre (1871: 47) también había dedicado un poema a su amigo en el pasado:

"A mi querido amigo Adolfo Lamarque"

Ecos de libertad, ecos de gloria,

De este libro las hojas atesoran:

De fiera esclavitud cuentan la historia 
Originalmente, fue dedicada al hijo de Bartolomé Mitre, Jorge Mariano, joven escritor literario que se suicidó en $1870 .{ }^{322} \mathrm{El}$ director del diario "La Nación" recordaba la escena: "La corona que el colocó sobre aquella frente querida, lamentando con toda el alma la insensata idea que mató tantas ideas generosas, sea también la que hoy coloquemos sobre la suya, helada en medio del calor del aprecio y de las simpatías”.

En síntesis, nadie puso en cuestión la honra y la reputación de Adolfo Lamarque en el relato de su suicidio. Por el contrario, su triste desenlace fue adornado con una variante del discurso de la "buena muerte", utilizado en las necrológicas de los hombres de las elites. No justificaban su acto suicida, pero este no desmerecía los méritos y el aprecio que el muerto se había ganado en vida. Así, los deudos exaltaron el buen nombre de Lamarque y preservaron la memoria del querido poeta suicida.

Lo relatado en el sumario judicial referido al suicidio de Lamarque, por otra parte, da cuenta de la preocupación obsesiva que despertaba en muchos individuos el imaginar la pérdida del respeto y la honra ante sus pares. En este sentido, la narración de los sucesos relacionados con el suicidio de Elías González (argentino, 21 años, soltero), nos brida más indicios sobre la autoagresión como una forma de buscar el perdón y la redención tras haber manchado la propia honra personal y/o familiar. ${ }^{323}$ González fue encontrado en el Cementerio de la Recoleta, ahorcado en una reja con un pañuelo enrollado, el 10 de diciembre de 1885, cerca de las 16:00 horas. Según los testigos, debía llevar una suma de dinero a Nemesia Leguizamón de parte de Juan Viñales. Según

\footnotetext{
Y la desdicha de la patria lloran.

Tu, que amarla supiste con anhelo,

Tu, que adoras sus hechos inmortales,

Compartirás sus dichas y su duelo

En sus pájinas gratas o fatales.
}

\begin{abstract}
322 Jorge Mariano Mitre se suicidó el 17 de octubre de 1870, mientras se encontraba en Río de Janeiro, como parte de una misión diplomática en Brasil, liderada por Wenceslao Paunero. Jorge Mariano fue presentado en círculos de alta sociedad y se enamoró de una joven que provenía de una de las familias de la elite carioca. La muchacha lo invitó a su casa, pero debía entrar furtivamente. Al ser descubierto por uno de los integrantes del servicio doméstico, el padre de la muchacha llamó a la policía. Paunero no vio otra solución que enviarlo de regreso a Buenos Aires. Jorge se resistía, entre otras cosas, porque le dolía la desilusión que generaría a su madre. Antes de ser devuelto, se quitó la vida. Fue encontrado en su cama, donde se dio un disparo en la sien, vestido con su traje de calle. A los pies, estaba el retrato de su padre, el que de seguro miró antes de quitarse la vida. El suicidio de su hijo dejó una fuerte marca en la vida de Bartolomé Mitre y su esposa, Delfina. Mitre partió en busca de los restos de Jorge Mariano el 21 de octubre de 1871. En este primer viaje, sólo pudo visitar su tumba, ya que la legislación del Brasil demandaba una espera de cinco años antes de exhumar el cuerpo. En julio de 1872, Sarmiento lo nombró diplomático argentino en Río. A partir de entonces, reanudó las gestiones para trasladar los restos de su hijo. Regresó con estos a Buenos Aires el 7 de julio de 1873. Para un relato pormenorizado de las circunstancias relacionadas con el suicidio de Jorge Mariano Mitre, véase, entre otros: JIJENA (1992).

${ }^{323}$ AGN, FTC-SE, Legajo G31, González, Elías, antecedentes relativos a su suicidio.
\end{abstract}


consta en el sumario, la familia Leguizamón lo había criado; probablemente, había formado parte del servicio doméstico (González no tenía familiares ni recursos según el informe policial), y, por esta razón, se le confió la tarea de llevarles el dinero. Sin embargo, este nunca llegó a destino. Viñales pidió a la policía que capturara a González. Cuando este último fue interrogado en la comisaría, confesó que había gastado el dinero, pero que se comprometía a devolverlo con el salario que le pagaban en la cigarrería en la que trabajaba. A juicio del comisario, se trataba más de un abuso que de un robo y por eso dejó en libertad a González, recomendándole que, de alguna manera, pagara lo adeudado. El policía que realizó el sumario acotaba lo siguiente sobre el suicidio de González:

De lo relatado deduzco, pues, que la resolución tomada por este individuo no reconoce otra causa que la de que, arrepentido quizá por el mal paso que diera, cometido talvez en un momento de estravio, y no encontrando el perdón que solicito, resolvió terminar así con su vida, creyendo con esto lavar la mancha que el mismo arrojara sobre su reputación.

Nunca sabremos en qué gasto el dinero González, qué significado daba a sus acciones y a su propia autoagresión, pero para el agente policial que registraba los hechos resultaba verosímil imaginar que el suicida trató de enmendar su falta y de limpiar el buen nombre que él mismo había deshonrado, era un modo de demostrar arrepentimiento, de exteriorizar la vergüenza que lo atormentaba. De nuevo, no podemos saber qué sentía Elías, pero su acto suicida tenía este significado para el espectador que registró lo sucedido.

En este punto, cabe recordar que los insultos que comprometían el honor personal y familiar eran ofensas graves, por ejemplo, acusar a alguien de ladrón. Así lo manifestó Santiago Kyleurz (suizo, 28 años, soltero), quien trabajaba como tenedor de libros en una casa de comercio de los Sres. Martínez de Hoz. ${ }^{324}$ Una de las vecinas que ocupaba una pieza en la misma casa, Leucadia Sasso, contó al policía encargado de elaborar el sumario que tras un robo en dicha sociedad comercial las sospechas recayeron sobre Kyleurz, lo que enojó a este último. Tras este episodio, el 23 de junio de 1876, alrededor de las 18:30hs, Santiago Kyleurz tomó un revólver y se disparó en la frente, en su habitación. En la nota que dejó dirigida a su familia (que no residía en la

\footnotetext{
${ }^{324}$ AGN, FTC-SE, K3, Kyleurz, Santiago, por suicidio.
} 
ciudad o en territorio argentino), declaraba: "Mi querido caro, caro Padre y hermanos. Muero con Honor. Yo no soy ladron. Dios y vosotro, mi queridos, perdonadme. Santiago Kyleurz. Buenos Aires 23 de junio de 1876". 325

El caso de Santiago Kyleurz fue dado a conocer en los diarios. En las noticias, se remarcaba la actitud generosa de los señores Martínez de Hoz con su empleado (se encargaron de lo necesario para garantizar el entierro del suicida); al mismo tiempo, los cronistas aclaraban que las acusaciones de robo resultaban de una mala interpretación del suicida. Según “La Nación” (27/06/1876):

La causa que lo condujo a suicidarse es la que damos a conocer en seguida.

Hacia varios días que le habían robado a los señores antes dichos (Martínez de Hoz) una fuerte suma de dinero.

Este hecho le causo una profunda melancolía y un gran disgusto.

Se retiro completamente de la sociedad y solo salia de su casa para asistir con la puntualidad que lo caracterizaba a su trabajo.

El día 24 había tenido un disgusto, a causa del robo mencionado.

Creyose ofendido en su delicadeza y terriblemente impresionado, tomo la peor de las determinaciones: arrancarse la vida.

Una vez en su casa y recostado en la cama, disparo el revolver sobre su frente.

En "La Nación", el suicida era descripto como una persona meticulosa y delicada, proclive a caer en la melancolía. En "La Prensa" (25/06/1876), fue representado como un ser "de caracter silencioso y tétrico, y de genio corto y pusilánime, en una palabra, era uno de esos sujetos excesivamente susceptibles pero faltos de energía moral", un trabajador minucioso y perfeccionista, frío para llevar adelante sus actos, como los alemanes e ingleses, incluso a la hora de darse muerte. Según el cronista, sus patrones tenían plena confianza en este eficiente y honesto empleado suizo, que trabajaba con ellos desde hacía cinco años. En suma, el relato construido a partir del suicidio de Kyleurz tenía como objetivo salvaguardar la reputación de sus empleadores. Si bien no se ponía en duda la honestidad y el buen nombre del suicida, su carácter era representado como melancólico, sensible y frágil.

\footnotetext{
${ }^{325}$ Esta es la traducción que la policía elaboró a partir del original en alemán. Al comparar ambos textos, se comprueba que lo traducido, en líneas generales, es fiel a lo expresado en la carta dejada por Kyleurz. Quiero agradecer a Tim Oliver Sander, profesor de alemán, quien comparó y comprobó que el mensaje era el mismo en los dos escritos.
} 
Al igual que en el caso de Kyleurz, en otros sumarios, encontramos suicidios de individuos que, en lugar de demostrar su remordimiento y sincero deseo de ser perdonados o de limpiar la deshonra, rebatían acusaciones o injurias y denunciaban injusticias que atentaban contra sus reputaciones personales y familiares. Al igual que Elías González, algunos fueron acusados de ladrones. Sin embargo, a diferencia de éste adoptaron una actitud particular: manifestaban su inocencia y respondían a las denuncias para desmentirlas. En este sentido, sus suicidios tenían un significado distinto y por eso los englobamos en un tipo narrativo diferente. A modo de ejemplo, podemos mencionar el trágico devenir de Martín Echenique (argentino, 19 años, soltero, empleado), que trabajaba para Juan Rozas cobrando los alquileres de las propiedades de este último. ${ }^{326}$ Rozas había tomado a Echenique como su empleado porque era huérfano. Según el informe de la policía, habían tenido una discusión por la falta de dos recibos y el dinero correspondiente. El cuerpo de Echenique fue encontrado el 29 de mayo de 1885 en la vía pública, en una zanja, con una herida de bala en la sien derecha. En su nota suicida, declaraba que moría por creerse "acusado injustamente". En la carta que dejó a su patrón, el suicida manifestaba que se sentía muy desgraciado por la recriminación que le había hecho y el castigo que iba a darle, ya que sólo había pagado con el dinero confiado a quienes lo reclamaban. Asimismo, aclaraba que podría haber tomado el dinero que hubiese querido, "como un estafador", o pagar la suma que faltaba y "mandarme mudar de su casa, pero veo que es una iniecuidad hacerlo haci, despues de haberle servido tanto". También dejaba sentados los nombres de los que debían pagar el monto motivo de discordia. En síntesis, podemos entrever que Martín Echenique alegaba que había dado dinero de Rozas a quienes lo habían solicitado, actuando de buena fe y que no era una persona deshonesta o un ladrón. Juan Rozas, por su parte, interpretaba que su empleado doméstico se había suicidado después de que su robo fuera descubierto, como consecuencia de la vergüenza y el remordimiento. Tanto "La Nación” como "La Prensa", el día 30 de mayo de 1885, mencionaban que Echenique decidió suicidarse para evadir un castigo injusto en su carta, aunque no había testimonios que respaldaran las acusaciones del suicida sobre dicha sanción. Así, los diarios daban fundamento a la versión de Juan Ortiz de Rosas, quien negaba las últimas palabras escritas por su difunto empleado.

\footnotetext{
${ }^{326}$ AGN, FTC-SE, Legajo E8, Echenique, Martín, suicidio.
} 
Próspero Galliard (francés, 30 años, soltero, empleado en una tienda), también alegó, en su nota suicida, que había sido culpado de robar a sus patrones. ${ }^{327}$ El 22 de abril de 1873, se degolló con una navaja de afeitar en su cuarto. Según el informe policial, en un cuaderno de memorias, que estaba a su lado, dejó escrito que se suicidaba porque lo acusaban de un robo. Sus patrones, al igual que Juan Ortiz de Rozas, desmintieron esto y declararon que lo habían notado raro a Galliard e interpretaron que estaba alienado.

Ser tildado de ladrón dañaba la reputación personal y la propia autoestima. Es probable que muchos hayan sido denunciados en público como delincuentes sin honra y que no se quitaran la vida. La violencia en sí era una forma de demostrar virilidad y honradez. En estas historias, la autoagresión aparecía como un modo de dar veracidad a lo expresado en las notas; es decir, rebatir las palabras injuriosas oponiendo las que pronunciaban los hombres de honor, dispuestos a jugarse la vida para probar la falsedad de las calumnias lanzadas sobre sus nombres.

En este sentido, la honra y la vergüenza no formaban parte sólo del vocabulario de los comerciantes, abogados o miembros de las elites, los trabajadores también manifestaban en sus declaraciones la importancia que el honor tenía para ellos. Tobías Seccature (italiano, 46 años, casado, jornalero) vivía con su esposa en una casa de inquilinos, ubicada en la calle Tucumán No366. ${ }^{328}$ Como Tobías estaba enfermo, vivían del trabajo de su esposa. Se quitó la vida el 25 de mayo de 1884, alrededor de las 14:00hs, clavándose un hacha de mano en la cabeza, de acuerdo con el sumario de su muerte, en la casa de uno de sus amigos más íntimos, Vicente Castellanos. Según los testigos, antes de fallecer, expresó: "lo he hecho por el honor". Vivir de los ingresos de su compañera parecía deshonrar a Seccature y resultaba verosímil que en este contexto se quitara la vida. No tenemos más detalles sobre el tipo de trabajo que desempeñaba la esposa del suicida. Pero el hecho en sí, de ver los roles invertidos, mantenido por una mujer, debió resultar chocante para un individuo que se representaba como el sostén familiar.

De acuerdo con la versión de los hechos presentada en "La Nación" (27/05/1884), Seccature había llegado a Buenos Aires años atrás, junto con su esposa, Ana della Casa Rosina. No tenían casi dinero, sin embargo, gracias a la constancia y el trabajo duro había conseguido reunir ahorros suficientes para abrir un pequeño

\footnotetext{
${ }^{327}$ AGN, FTC-SE, Legajo G4, Galliard, Próspero.

${ }^{328}$ AGN, FTC-SE, S31, Seccature, Tobías.
} 
despacho de bebidas en Lomas de Zamora. Este establecimiento le permitió ganar más fortuna y el matrimonio tenía perspectivas de crecer y progresar. Desgraciadamente, Seccature fue estafado por un amigo que le hizo perder una importante suma y, por ello, se vio obligado a vender su negocio y trasladarse a la ciudad de Buenos Aires. Enfermo y arruinado empezó a trabajar como peón en una colchonería. Debido a su grave estado de salud y a la falta de recursos fue internado en el hospital. Al tiempo, salió casi curado, según el cronista. Desde entonces:

$\mathrm{Su}$ esposa y algunos amigos que le han visto dicen que había cambiado notablemente; de alegre y espansivo que era se había tornado triste y taciturno. Lloraba a veces y otras, cabizbajo y meditabundo, paseábase por el fondo de la casa, tomándose la cabeza con ambas manos, como si una idea tenaz y abrumadora lo persiguiera.

El día de su muerte, había ido a visitar a Vicente Castellanos, para que le diera un nuevo trabajo, ya que quería abandonar la colchonería. En un momento que quedó sólo, intentó quitarse la vida, dándose golpes en la nuca con un hacha, como fue registrado por el policía en el expediente. Castellanos le sacó el hacha y Seccature cayó al suelo, exclamando: "Déjame morir, que estoy aburrido de la vida". Cuando fue interrogado por el oficial de policía, como figura en el sumario, le expresó que "se daba muerte por salvar su honor". Murió a pesar de los esfuerzos llevados adelante por parte de los médicos que lo atendieron para salvarlo. Como vemos en este relato, no resultaba sorpresivo que un trabajador pobre hablara acerca de su honra, este valor era compartido por la población masculina que vivía en la ciudad de Buenos Aires, nativos y extranjeros podían comprender la importancia que tenía para Seccature.

El caso de José Marcos también nos sirve para ejemplificar la presencia del discurso vinculado con el honor en un trabajador inmigrante. ${ }^{329}$ Marcos (italiano, 36 años, soltero, albañil) se quitó la vida el 31 de octubre de 1883, en la pieza del conventillo en la que vivía, a eso de las 17:00 hs, por medio de un cuchillo con el que se hirió en el cuello y se apuñaló bajo el pezón izquierdo. Mientras era interrogado por la autoridad, hizo señas de que quería escribir algo, lo que el policía transcribió en el expediente:

${ }^{329}$ AGN, FTC-SE, M28, Marcos, José, sumario su suicidio. 
Señor, yo confeo que yo mismo me e matado por la causa de dodo esto vecino que dodo lo dia estavan ablando de mí, tratandome de mal hombre, o a decir mejor tratádome de ladrone a lo qual todo el mundo puede decir que hombre á sido yo porque hombre de onor siendo mucho de tratarle deste modo y yo poresto mi é matado, por que tambien el dueño puede decir que ombre á sido yo, llamame a poquito el dueño. [el policía solicitó al dueño que viniera y el suicida continuó escribiendo]. Todo este queestan aqui principiando del $n^{\circ} 2$ y 3 y fin dodo segido lo que vino aquí, fue del dueño de casa por que bien sabe que soy yo, por esto mi e matado porque hombre de onor siente mucho de tratarlodeste modo.

Lo que podemos entrever en este mensaje, es que Marcos creía que lo trataban de ladrón, esta injuria lo ofendía mucho, este insulto cuestionaba que fuera hombre de honor, como él se representaba a sí mismo, y aspiraba a ser visto de ese modo por el resto de los miembros de su red social. Los testigos negaron todo lo manifestado por Marcos, nadie lo había acusado ni se conocían disgustos entre él y la gente del lugar. Para los vecinos que declararon, José tenía sus facultades mentales alteradas. Uno de los inquilinos interrogados declaró que Marcos le comentó que estaba enfermo y que percibía que todos se burlaban de él.

En síntesis, el discurso de la honra y la vergüenza no formaba parte sólo del vocabulario utilizado para explicar los suicidios de los comerciantes, abogados y los integrantes de las elites. Por ejemplo, acusar a alguien de ladrón atentaba contra el capital de honor de un individuo, más allá de su procedencia social. En los casos anteriores, encontramos indicios de que, en "la hora suprema", trabajadores inmigrantes expresaban ser hombres de honor y desmentían las calumnias e injurias, reales o imaginarias, para todos los que presenciaban sus muertes por mano propia.

\subsection{Limpiar la mancha y legar un buen nombre}

En los casos que integran el subtema "honra / vergüenza", hemos analizado, por un lado, quiénes eran los otros significativos a los que se dirigían los que se quitaban la vida; y, por el otro, la intención, explícita o implícita, con la que llevaban adelante el acto suicida. En primer lugar, encontramos casos en los que el suicida interpelaba a los familiares con sus acciones y en la nota que dejaba escrita. En muchos casos, la apelación podía estar implícita en los gestos, como en el caso de Manuel 
Villamayor (argentino, 26 años, soltero, empleado bancario). ${ }^{330}$ Villamayor se quitó la vida el 25 de febrero de 1888, en la casa de su hermano, donde él también residía en esos momentos; con un arma de fuego, se disparó en la sien derecha. Transcribimos el siguiente fragmento del sumario:

Villamayor ha comido esa tarde como de costumbre, en su casa; después de comer ha salido al patio con todos y minutos mas tarde, solo, ha entrado en la antesala y sentándose en un sofá, debajo del retrato de su señor padre, se ha arrebatado la existencia con un revolver Smith Wesson, de 9 milimetros. Al matarse oprimia en la mano izquierda una pantalla y un número de "El Diario", que se han salpicado con su sangre. He recorrido las columnas del diario buscando alguna noticia que pudiera ofrecer algún dato o luz sobre el suceso y no he encontrado nada.

No sabemos qué fue lo que pensaba o leía, qué lo angustiaba, pero sí podemos entrever lo verosímil, los gestos con significado para el entorno y para el policía. Éste imaginó que debía haber alguna noticia que había exaltado a Villamayor y lo motivó a quitarse la vida, bajo el retrato de su padre. La familia no conocía las causas de lo sucedido, o decidió no revelar detalles; sólo lo notaban triste desde hacía un mes. ¿Manuel sentía que había defraudado a su padre y que había manchado el buen nombre de la familia? ¿Había alguna noticia que comprometía la reputación familiar y se sentía responsable por ello? ¿Había violado el mandato paterno de una forma que le era muy vergonzoso y penoso revelar? El sumario no brinda más detalles, pero el gesto fue relevado por el policía. Quizás no significara algo para Manuel Villamayor, pero sí fue identificado como tal por el que registró los detalles relacionados con su muerte. También fue mencionado por "La Prensa" y "La Nación” al comunicar el hecho el 26 de febrero de 1888. Las dos noticias que dieron cuenta del suicidio de Villamayor destacaron que este se quitó la vida sentado bajo el retrato de su padre. Así mismo, también remarcaban el cambio en el estado de ánimo de Manuel: de alegre y comunicativo pasó a melancólico y reconcentrado, según "La Nación”. El retrato de las figuras paternas y maternas tenía un significado especial, representaba la línea de continuidad entre las generaciones familiares y el buen nombre legado por los antepasados a las actuales, era responsabilidad de los hijos preservar el honor de los padres.

\footnotetext{
${ }^{330}$ AGN, FTC-SE, Legajo V18, Villamayor, Manuel s/suicidio.
} 
Presentamos el caso anterior para compararlo con el de Domingo Eiras (español, soltero, dueño de un almacén). ${ }^{331}$ Eiras fue encontrado sin vida por el empleado que trabajaba en su local, que al mismo tiempo era su domicilio personal. Según este último, Celestino Picerilli, la noche anterior, su patrón llegó alrededor de las 22:30hs de su paseo. Entró sin decir una palabra y se retiró a su pieza, que estaba contigua a la de Picerilli. Este se fue a dormir, sin sentir ruidos en la noche y, al despertarse, abrió el almacén como todos los días. Al notar que eran las 10:30hs y Eiras no se levantaba, fue a ver qué sucedía, golpeó y como no respondían decidió entrar en el cuarto. Allí lo encontró muerto, bañado en sangre, con una herida de bala en la sien derecha; a su lado, estaba el revólver que había utilizado para quitarse la vida. Según el sumario levantado por el policía, el difunto dejó tres cartas. Una para su padre, Carlos Eiras, quien se encontraba en España (Ayuntamiento de Valga, provincia de Pontevedra, Galicia); ésta estaba abierta y fue conservada en el expediente. Por la riqueza de este testimonio, transcribimos su contenido:

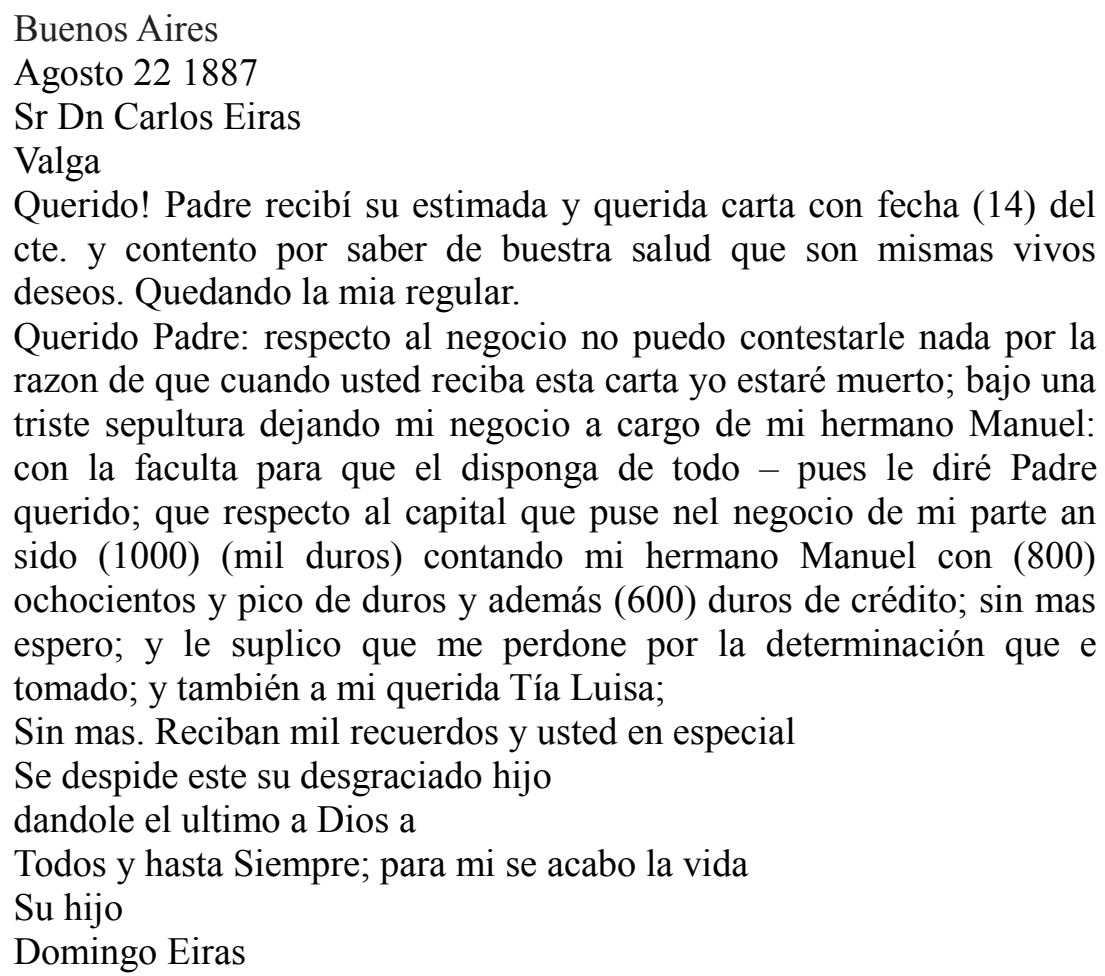

${ }^{331}$ AGN, FTC-SE, Legajo E13, Eiras, Domingo s/suicidio. 
Del contenido de la nota podemos entrever la importancia que tenía para Eiras comunicar a su padre el estado de su negocio, que, si bien era desgraciado por el estado de salud en el que se encontraba, manifestaba que podría traspasar el almacén a sus hermanos, tras dejar de existir. Aunque no quedaron conservadas en el expediente, las otras dos cartas estaban cerradas y dirigidas a estos, Lino y Manuel. No se detalla el contenido de estos documentos en el sumario, pero el policía explica en su informe: “Abiertas estas en presencia de los dos, de ellas se desprende claramente que Eiras tomó esta resolución por una enfermedad que lo aquejaba y no por el mal estado de su negocio". Así también fue presentado en el diario "La Prensa" (30/08/1887): "El suicida deja dos cartas cerradas, dirigidas a sus hermanos Miguel y Lino, y otra abierta al autor de sus días, en la que le manifiesta que se suicida por el mal estado de su salud, y le pide perdón por el disgusto que le proporciona". Domingo quizás temía los comentarios malintencionados y los rumores; sin embargo, en su carta, dejaba en claro que no fue su negocio la fuente de su desesperación, sino su estado de salud. En este caso, como en el de Santiago Kyleurz, o el de Adolfo Lamarque, mencionados antes, los otros significativos a los que se apelaba era a la figura paterna y a los hermanos varones, a los que se les daba garantía de que el nombre de su familia no había sido deshonrado.

Asimismo, creemos que existía una preocupación por la forma en que serían recordados luego de sus muertes. Eduardo Lavezzari (argentino, 19 años, soltero) comunicó lo que sentía a su prima, Emilia, antes de quitarse la vida. ${ }^{332}$ El 16 de agosto de 1876, Cipriana Sánchez de Rubio (argentina, 77 años, abuela de Eduardo,) junto a Emilia Rubio (argentina, 14 años), su nieta, estaba en el comedor; en la casa sólo estaban ellas y las empleadas domésticas. Alrededor de las 14:00hs, sintieron una detonación que provenía de uno de los cuartos de la casa. Al llegar a la habitación, encontraron a Eduardo, sin vida, con una herida de bala en el pecho, a la altura del corazón, y el revólver de uno de sus hermanos, Marcelo, en el piso. Según la señora Sánchez de Rubio, "su nieto tenía un carácter muy variable, pues a veces se le veía muy alegre, y otras triste sin saber la causa, oyéndoselo hablar siempre con desprecio de la vida, y que en cuanto a la causa cree que haya sido algunos compromisos que no podía cumplir". Lavezzari dejó una nota dirigida a su prima, Emilia. Ésta se negó a entregar la carta original, por eso en el expediente figura una transcripción del contenido hecha por el policía que llevó adelante el sumario y que transcribimos a continuación:

\footnotetext{
${ }^{332}$ AGN, FTC-SE, Legajo L8, Lavezzari, Eduardo, su suicidio.
} 
Emilia esta determinación de suicidarme que no es sino una villanía, lo hago por salvar mi honor, pues hoy tengo una letra y como me es imposible el pagarla antes que falle a mi firma dejo de existir cosa que lo que vengan a cobrar se encuentren con un cadáver. Emilia mi ultimo deseo es que te resignes.

En este caso, vemos que Eduardo Lavezzari decidió dar cuenta de lo sucedido a un pariente por el que sentía afecto, que suponía lamentaría su muerte. Al mismo tiempo, dejaba testimonio del significado de su última acción: salvar su honor. Respondía con su sangre y con su vida a los compromisos que no podía cumplir. En este sentido, creemos que la intención de los que dejaban sus notas antes de llevar adelante el acto suicida era trascender la muerte a través del recuerdo de los integrantes de sus redes afectivas, de los otros significativos. Así, pensamos que Emilia, tal vez, deseaba preservar el último adiós de un ser querido $\mathrm{y}$, al mismo tiempo, retirar evidencia que contribuyera al escándalo público y a la circulación de rumores mal intencionados sobre su primo. "La Prensa" (18/08/1876) informó el caso de Lavezzari e incluyó en el cuerpo de la noticia la reproducción de una carta encontrada en la mesa de luz de su habitación:

Padre mio:

Hay situaciones en la vida que no tienen mas solución posible que este terrible remedio: el suicidio.

Perdoname, pero yo no puedo seguir viviendo. He contraído bajo mi palabra compromisos sagrados que hoy no puedo cumplir y prefiero la muerte antes que la deshonra.

Eduardo Lavezzari

No resultaba inverosímil imaginar el suicidio de un individuo en la situación que se encontraba Eduardo Lavezzari; el significado que daba a su acto suicida podía ser reconocido por otros, aunque no hubiera un claro acuerdo sobre el valor ético del mismo. En este sentido, Lavezzari representaba su suicidio como una forma de redimirse y evadir la pérdida de su honor. Al igual que en el caso de Francisco David, el suicida hacía explícita la intención de su autoagresión: buscaba condicionar al entorno para obtener el perdón por su falta. En suma, en este contexto, el suicidio era representado como una acción comunicativa regulativa defensiva por parte del que se quitaba la vida y esperaba que otros compartieran su interpretación moral del mismo. En este sentido, "La Prensa" contribuyó a construir esta imagen romántica y heroica; presentó la carta en la noticia, y sólo dicha nota, entre otras. 
Asimismo, en estos casos, encontramos, entre otras motivaciones, el deseo de trascendencia, de sobrevivir en la memoria de los otros significativos a los que iban dirigidas las cartas y los gestos. En este sentido, los amigos del que se quitaba la vida eran interpelados con esta intención. Por ejemplo, Juan Hipólito Martins (brasileño, 20 años, soltero, empleado comercial) buscaba reconciliarse con su amigo, Francisco. ${ }^{333} \mathrm{El}$ 30 de enero de 1886, alrededor de la 12:00hs, Martins se presentó en la pieza de la casa de inquilinato que aquel ocupaba. Al llegar a la habitación, este último estaba con Rafael García. Martins pidió quedarse a solas con su amigo. Antes de que García se fuera, el recién llegado le presentó unas cartas y el primero le indicó que las dejara encima de la mesa y se retiró. Un instante después de dejarlos a solas, Rafael oyó el ruido de un arma de fuego que provenía de la habitación. Según Francisco, le estaba dando la espalda a Martins cuando sintió el disparo, se dio vuelta y vio caer a éste sin vida en el piso, con una herida en la sien derecha. De inmediato, salió en busca de auxilio y a llamar a la policía. Más tarde, declaró que había conocido a Martins en Brasil. Este último era el hijo de un hacendado y había conseguido empleo en una casa de comercio gracias a la recomendación de su amigo, pero había sido despedido de su puesto por "haber dispuesto indebidamente de algunos fondos". Su actitud deshonesta había comprometido la honra propia y la reputación de un miembro de su red social. Como vimos en otros casos, las relaciones de amistad facilitaban la búsqueda de auxilio material, información y contactos y eran los depositarios de las últimas voluntades (hemos visto cartas en las que el suicida encomendaba el bienestar de su familia a un amigo). Asimismo, los lazos amicales podían cimentar una sociedad comercial, de lo que ya hemos presentado algunos ejemplos. Por otra parte, la falta o la acción deshonesta de uno de los integrantes del vínculo, comprometía la reputación de ambos ante su red vincular. Las cartas que Martins dejó dan cuenta de esto: manifestaba que no soportaba más la vergüenza de sus acciones. Pedía disculpas y que acompañaran su cuerpo al cementerio (había dejado preparada su ropa lista para el velorio y el cortejo fúnebre), también solicitaba que asistiera la madre de Francisco al entierro. La acción y el mensaje expresado por el suicida buscaban, por un lado, redimirlo por sus faltas y, por el otro, ganar la compasión de su amigo. No parece haberlo conseguido, ya que el policía dejó sentado que no había quien se hiciera cargo del entierro del cuerpo y éste fue trasladado a la morgue.

${ }^{333}$ AGN, FTC-SE, Legajo M33, Martins, Juan Hipólito, su suicidio. 
José Picena (italiano, 30 años, soltero) dejó por escrito, de forma aún más explícita, sus intenciones y las reflexiones sobre su acto suicida. ${ }^{334}$ Éste se quitó la vida el 10 de enero de 1886, cerca de las 13:30hs, en los bosques de Palermo. En un primer momento, la policía no podía dar con la identidad del difunto. El cuerpo fue reconocido por Romeo Campari y Carlos Chiola, quien compartía la misma habitación de la casa de inquilinos con Picena. Chiola notó la ausencia de su compañero y empezó a buscar algún indicio de su paradero y encontró las cartas que fueron adjuntadas en el expediente. ${ }^{335}$ También comentó que el difunto no tenía padres y el único familiar que le quedaba era una hermana en su país de origen, además de parientes lejanos. Picena trabajaba como reconocedor de vinos y no le alcanzaba con lo que ganaba para vivir. Una de estas notas decía lo siguiente:

\begin{abstract}
Mis saludos a mi querido Pezio a la familia Tuzano, Soria, Russo, Mariglio, Carlo su mujer y familia, en suma a todos mis paisanos y todos los vecinos de casa especialmente ala patrona, como tambien me hareis el servicio de ir personalmente a saludar al patron de la botelleria donde comia y su hermano e imponedles y a ms compañeros de vida que me han hecho pasar dias alegres y demandadles a todos perdon para mi. N. B. Creo bien el avisarle que de esta mi deciion ya he advertido por medio de una carta a mi hermana, pero si vos creis bien confirmarle mi aviso lo hareis en pocaslineas sin extenderos mucho. He elejido para el suicidio un lugar lejos de la casa por no daros disturvios y fastidios que seriandel caso. Si no os mando la carta por correo fue por el simple motivo que no desearia empieses la cosa hasta que yo estuviese bajo la tierra. Adios a todos y por siempre - Un beso a loshijos - J. Picena, Buenos Aires, horas 11 de la noche del dia 8 vispera de mi muerte - Enero 1886.
\end{abstract}

El mensaje tiene una intención similar a la de otras notas que presentamos antes: comunicar la despedida, pedir perdón por las consecuencias de sus actos y dejar un recuerdo lo más benévolo posible a los deudos, dando gracias y explicando las precauciones tomadas para evitarles molestias relacionadas con la investigación de su muerte por mano propia. Otras cartas fueron entregadas a sus destinatarios y quizás tenían un contenido similar: el último testimonio del que abandonaba la vida y dejaba su huella en la memoria de los que lo habían conocido y querido. Ser recordado era una forma de prolongar la propia existencia.

\footnotetext{
${ }^{334}$ AGN, FTC-SE, Legajo P33, Picena, José, suicidio.

335 Dejó varias cartas, pero sólo dos quedaron conservadas en el expediente, están el original y la transcripción realizada por el policía. De las cartas que Picena legó, una estaba dirigida a Chiola y otra a Campari. Estos manifestaron a la policía el deseo de conservarlas. Sin embargo, la nota de Chiola quedó guardada en el expediente; el original en italiano y una traducción del contenido realizada por el policía.
} 
La segunda carta (dirigida a Carlos Chiola), conservada en el expediente, transmite un mensaje similar, resulta muy rica por el discurso sobre el suicidio que manifestó su autor. Éste está relacionado con los sentimientos encontrados y los significados polémicos que tenía esta extrema resolución para Picena y para su entorno social y afectivo:

\begin{abstract}
Amigo Carlos y familia: Adios para siempre. Cuando recibais estos mis ultimos renglones ya no estaré mas en este mundo, habré resuelto asi el problema de la vida. No se si me será a mi mas penoso escribirlos quea vos el leerlos, con todo me era penoso el partir sin daros el ultimo adios en compañia de Rosalia y familia, donde yo siempre he recibido pruebas no dudosas de estimacion y sincera amistad. Habia debido y querido tronchar la vida de tiempo atras pero la esperanza me entretenia y no fue mas que desilucion mi esperar. Después de doce meses de espectativa, recibí hoy una carta, una de aquellas cartas que hacen el efecto de un puñal sumerjido en un corazón enfermo, digo enfermo por que estoy bien seguro de no errar. Muero contento perdonando a todos y pidiendo a todos perdón. Muero sin odio ni superticion, no teniendo otras ideas que las que he profesado en vida. Algunos han dicho que el suicidio es debilidad, otros que es fuerza de espíritu, ahora no es para mi el tiempo para polémicas sobre ello, diré solamente que no todos los suicidas son locos como el vulgo generalmente cree y en prueba de ello os digo que no tengo ningun temor a la muerte cuando me seria doloroso el deber manchar en lo mas minimo mi honor y el de mi familia. Perdoname y compadeceme y quiera la naturaleza acordar a vuestra familia aquella felicidad de que sois meritorios. Lo repito, perdoname y acepta en compañia de vuestra señora y familia un beso y un apreton de manos que os mando por la ultima vez vuestro dmo y affmo amigo. Jose Picena. ${ }^{336}$
\end{abstract}

En esta nota, Picena se despedía, pedía perdón y buscaba generar un sentimiento de compasión en el entorno, al igual que en la primera que presentamos. Sin embargo, en esta carta también expresaba el complejo significado que tenía su acto suicida. Por un lado, afirmaba que no eran todos alienados los que se quitaban la vida, él no lo era; por el otro, dejaba abierta la cuestión de si el suicidio era un acto valiente y viril o una muestra de debilidad y cobardía. Sin embargo, reafirmaba su valor, el no temer a la muerte y, por ende, ser un hombre de honor, que no teme jugarse la vida. El mensaje no daba mayores explicaciones de la razón por la que ponía fin a su existencia.

\footnotetext{
336 Transcribimos la nota traducida al castellano por la policía. Al comparar el contenido con la versión original, encontramos que esta, en general, es fiel. Quiero hacer un agradecimiento especial a la Profesora de Italiano, Maria Claudia Debernardi, quien revisó los dos escritos y corroboró que el mensaje era el mismo en ambos.
} 
Picena no dejó explicitado el origen de sus dolores y del sufrimiento físico y/o emocional que padecía. En el expediente, figura también la carta que encontraron entre sus ropas en el bosque de Palermo, la que tal vez daba algún indicio de la fuente de sus pesares. Esta estaba escrita detrás de una foto y su contenido era el que sigue:

Perdone mi atrevimiento, pero con una persona educada como Ud. espero no desdeñará aceptar la simple fotografía de aquella que afortunada se dice de haber hecho en ta pocos dias la honrada relacion de Ud., pero también feliz se diría si aunque de lejos pudiera tener de Ud. un simple escrito y asi asegurarse que alguna vez me recuerda... Esta es mi dirección - Eloisa Daloso - Val D'Aosta - per Donnas. ${ }^{337}$

¿Sería un desengaño amoroso lo que había afectado el estado de ánimo de Picena? Los diarios consultados así presentaron el caso. "La Prensa" (17/01/1886), en la noticia de lo sucedido, reprodujo las cartas que hemos transcripto antes. A su vez, incluía una última carta que no estaba en el expediente, la dirigida a Romeo Campari:

\begin{abstract}
Amigo Campari - Doy a V. mi ultimo adios - Cuando lea V. este escrito mio ya no estare en este mundo. Es doloroso, pero es necesario. Disgustos de familia que seria inutil querer narrar y una pena al corazón que hace mucho tiempo lo destroza me hacen insoportable la vida. Vd. me perdonara y compadecera esta es mi ultima voluntad.

Mis saludos Campari, tanto a Zappa como a todos los amigos. Si yo he elegido un paraje lejos de la casa epara suicidarme ha sido por no darle los disturbios y el fastidio que son del caso.

Muchos saludos a la patrona de la casa y a su hija, rogandoles me perdonen por si impensadamente los hubiera ofendido.

Acepte un ultimo adios y apreton de manos de su affmo amigo firmado - Jose Picena
\end{abstract}

De acuerdo con esta última nota, las causas del suicidio de Picena habían sido disgustos de familia y "una pena al corazón" de la que no quería hablar. El texto de la noticia concluía mencionando el retrato de la mujer, que fue encontrado en sus bolsillos, y la carta de amor escrita detrás, en la que se destacaba la tierna dedicatoria de su amada, E. D. El diario "La Nación” (17/01/1886) también hizo hincapié en este último escrito: "En uno de los bolsillos del saco que tenía Picena se encontró un retrato de su prometida, con una dedicatoria por cuyos conceptos se conoce que fue escrita antes de interrumpir

\footnotetext{
${ }^{337}$ Esta es la traducción de la carta que estaba detrás de la foto. La versión original estaba en italiano y no se conserva en el expediente.
} 
sus relaciones con Picena".

Las ideas esbozadas por Picena en una de sus notas, nos deja una muestra de lo polémico que podía resultar un suicidio para la sociedad de la época, un acto violento de significado ambiguo: ¿Valiente o cobarde? ¿Desesperado? ¿Signo de locura? Algo parecido manifestó Celestino Rho en la carta que dejó dirigida al comisario de la zona donde vivía:

\begin{abstract}
Señor comisario, dele escribo a usted no para darle explicaciones queno debo, sino porque siendo que los cobardes que aun rechazando de una vida insoportable y no teniendo el extremo valor de poner termino con sus propias manos a sus vida han dado por revestir su vileza con los despojos de la virtud, en llamar crimen a un acto tan natural como el suicidio, a usted como representante de la justicia le toca mezclarse en el asunto. $\mathrm{L}$ ruego pues no culpe a nadie de mi muerte, por que si me mate fue por que tuve las ganas de hacerlo asi y me crei en el derecho de hacerlo. Soy de usted. D. I. Celestino Rho 25 de mayo $214 .{ }^{338}$
\end{abstract}

Rho era un joven italiano de 19 años, empleado, que vivía con sus padres en una pieza de una casa de inquilinato. Allí se quitó la vida, el 18 de marzo de 1887, alrededor de las 23:30hs. Momentos antes, Celestino jugaba con su familia a las cartas y luego de concluida la partida salió al patio. Francisco Rho, el padre del suicida, salió a mirar por el balcón y sintió un disparo que provenía de adentro de la habitación. Entró y encontró a su hijo, Celestino, recostado en un catre bañado en sangre. El suicida dejó varias cartas (una al padre, varias a la novia y una al comisario); en el expediente sólo quedó conservada la que transcribimos. Por otra parte, de acuerdo con el informe del policía, que sí pudo acceder al contenido de las otras notas, la causa del suicidio de Rho fueron amores contrariados. Rho, al igual que Picena, expuso en su carta algunas ideas del debate acerca del suicidio: si un individuo experimentaba un sufrimiento intolerable, si la vida era insoportable, ¿no tenía derecho a quitársela? ¿No era este un acto de coraje? ¿Por qué debía ser considerado un crimen? De nuevo, el autor de la nota obvió mencionar en su alegato en favor de la muerte por mano propia los motivos que lo llevaron a quitarse la vida. En este sentido, al igual que en el de Picena, los desengaños amorosos no eran una circunstancia que pudiera ser considerada intolerable para los contemporáneos. Por esta razón, quizás, omitían esta información que los presentaba como hombres débiles en lugar de exaltar la virilidad con la que buscaban connotar su

\footnotetext{
${ }^{338}$ AGN, FTC-SE, Legajo R34, Rho, Celestino.
} 
autoagresión.

Los suicidios eran sucesos escandalosos que abrían la polémica entre los miembros de la sociedad que se enteraban de lo sucedido, por los rumores que circulaban en las conversaciones o a través de las noticias de la prensa. Pastor Anabia (empleado del Banco de la Provincia de Buenos Aires) dio cuenta de las charlas que mantenía con su amigo, Esteban B. Pelerán, en la nota que fue encontrada en sus ropas. ${ }^{339}$ Ésta estaba dirigida a Pelerán y su contenido era el siguiente:

El objeto de esta es despedirme para siempre de mi amigo intimo.

$\mathrm{Tu}$ reprochabas el suicidio cuando conversavamos de esto, pero hermano llega el momento en que se encuentra entre la espada y la pared como dice un refrán, y no se puede esperar por más tiempo.

Si te llegan a preguntar si tu sabe por que me maté, les dices que por que me dio la gana.

Me despides de Dn Víctor Martinez y tu recibes el último adios de tu amigo que te queria.

Pastor Anabia.

B. A. Nov 2 de 1887.

El cuerpo de Anabia fue encontrado sin vida, en medio de un charco de sangre, en la entrada del Parque Tres de Febrero por los empleados del mismo, el 3 de noviembre 1887, con una herida de bala en la sien derecha. Las circunstancias hicieron suponer al policía que se trataba de un suicidio, pero no aparecía el arma, lo que sembraba la duda de que se tratara de un homicidio. Sin embargo, el informe del médico forense destacaba que Anabia presentaba un rostro tranquilo; esto lo diferenciaba de las expresiones de horror de los muertos de forma violenta en otras circunstancias. Asimismo, la letra de la carta suicida fue reconocida por los testigos que declararon, entre otros, el hermano del suicida, Juan B. Anabia, y sus amigos. Según el testimonio de Pelerán, a quien iba dirigida la nota, el suicida, Jacinto F. Guzmán, D. Nemecio Villar y él jugaron a la baraja hasta cerca de las 23:30hs de la noche anterior en el Café "San Martín” y destacó que:

[...] no notó nada extraño en él, que por el contrario estuvo muy contento y hasta cierto punto más comunicativo que nunca: que únicamente recuerda si, una circunstancia que en ese momento no le dió importancia, y es la de que al despedirse de él no le dijo hasta mañana como acostumbraba, sino que se despidió con un simple "adios" y apretandole al mismo tiempo fuertemente la mano: que

\footnotetext{
${ }^{339}$ AGN, FTC-PE, Legajo A6, Anabia, Pastor.
} 
cuando Anabia se le separó serían proximamente las doce: que Anabia jamas le habia manifestado que tuviese la idea de suicidarse, pero que si habían conversado, incidentalmente del suicidio, a proposito de Alberto Gaché quien hace algún tiempo se suicidó, habiéndose expresado el declarante, cada vez que se hablaba de eso, en el sentido de que el suicidio era un acto de cobardía.

Nemecio Villar estuvo con Anabia ese día desde las 18:00 horas, "pudiendo notarle cierta alegría exagerada que le hizo le preguntara si había sacado alguna lotería grande o había recibido alguna buena noticia, respondiéndole Anabia que por el momento no le quería decir lo que motivaba su alegría, pero que uno o dos días después lo sabría”. El hermano de Anabia, Juan, destacó que él y su familia habían notado que Pastor había estado en su cuarto rompiendo papeles el día antes de su muerte. No dieron importancia a este acontecimiento, pero visto en retrospectiva, era una clara señal de que Anabia estaba "dominado" por la idea de suicidarse días antes de que lo hiciera.

En síntesis, al igual que en los casos de Picena y Rho, la historia del trágico desenlace de Pastor Anabia da cuenta de que la noticia de un suicidio podía abrir la polémica sobre el valor ético de este acto. La carta de este último y la declaración de Pelerán apuntaban en esa dirección. Era un acto de violencia, se necesitaba suficiente coraje para apuntar un arma y dispararse a uno mismo; al mismo tiempo, era una cobardía huir de las dificultades que aparecían en la vida. Sin embargo, Anabia, al igual que Celesino Rho, destacaba que había momentos de intenso sufrimiento en los que quitarse la vida era un derecho y una posibilidad.

Tanto los que buscaban saldar la responsabilidad por sus faltas, como los que denunciaban falsas acusaciones se dirigían a un otro indefinido, representaban la violencia contra sí mismos, para que fuera observada por el "otro" colectivo que juzgaría su buen nombre y preservaría su memoria. Por esta razón, llevaban adelante gestos (como quitarse la vida en espacios públicos), dejaban cartas explicando sus motivos o los declaraban al ser interrogados por la policía. En este sentido, encontramos una intención, que emerge en los relatos y en las notas de los suicidas, que analizamos en este trabajo: la preocupación por la trascendencia. Muchos de los que se quitaron la vida, al mismo tiempo que manifestaban el discurso viril de la defensa del honor o la demostración de vergüenza, solicitaban perdón, daban gracias y se despedían. En síntesis, manifestaban, consciente o inconscientemente, el deseo de ser recordados. Cuando estamos frente a la muerte, resulta ineludible tomar consciencia de la finitud de nuestra experiencia individual. El único modo de continuar vivo, de alguna forma, era a 
través de la memoria de los deudos. En este sentido, el discurso en defensa del honor y la reputación personal era un medio para construir una imagen más amable para los otros significativos que serían los que preservarían el recuerdo del suicida. El hecho de que muchos hayan solicitado conservar las cartas dejadas por los difuntos da cuenta de que este era un deseo mutuo y compartido.

\subsection{Consideraciones finales}

El honor era uno de los valores que daba sentido a la experiencia cotidiana y a la construcción de la propia identidad. En el caso de los sujetos de género masculino, la honra estaba vinculada con un conjunto de características individuales. Al mismo tiempo, si la reputación personal era amenazada, el insulto, ofensa, injuria o agravio debía ser respondido con la violencia, con la posibilidad (aunque fuera lejana) de perder la vida en el enfrentamiento (por ejemplo, en duelos, peleas o riñas, de acuerdo con el grupo social al que perteneciera el sujeto). Estos combates estaban guiados por este sentimiento de honra, por la importancia que tenía defender un buen nombre ante el imaginado tribunal del honor, es decir, el resto de los miembros de la sociedad que observaban y juzgaban lo que sucedía en público. Así, la agresión física dirigida hacia los otros en defensa de la reputación individual tenía, en líneas generales, un valor positivo y dotaba ante los demás de hombría y virilidad al que la ejercía con autocontrol y $\sin$ rastro de cobardía. Nuestro objetivo fue indagar el significado que tenía la violencia para los actores sociales del período, pero cuando ésta era dirigida hacia ellos mismos, es decir, la representación de los actos suicidas y su relación con el discurso acerca de la honra y la vergüenza.

De los relatos rescatados de los sumarios judiciales estudiados, podemos observar, en primer lugar, que, en la mayor parte de los casos, el suicidio era considerado un acto vergonzoso y escandaloso. En general, era asociado a las personas endeudadas o que habían visto quebrar sus negocios y, por ello, estaban sumidas en el remordimiento, atormentadas por la humillación pública que imaginaban e, incluso, presas de la locura que su propia desesperación les había generado. Así, en la mayoría de los casos que hemos estudiado, la muerte por mano propia estaba asociada con la vergüenza y la debilidad.

Al mismo tiempo, del análisis de las notas suicidas y algunos comentarios publicados en la prensa de la época, pudimos encontrar una variedad de significados 
polémicos relacionados con los suicidios. En este sentido, algunos de los sujetos que no podían responder a sus compromisos comerciales y financieros se quitaban la vida y expresaban que lo hacían para atenuar o saldar la deuda entregando la propia vida. Del mismo modo, encontramos hombres que habían sido deshonrados por negocios o acciones deshonestas que interpretaban su suicidio como un modo de redimirse por su falta, de limpiar la mancha sobre sus nombres y el de sus familias. Por otra parte, también encontramos narraciones de los hechos y cartas de los que se quitaban la vida en los que aparecía la intención de denunciar una acusación injusta. Si bien encontramos algún caso de deshonra por el comportamiento sexual de la pareja, en general, en la gran mayoría de los casos, se trataba de reafirmar que no se era un "ladrón" (ya fuera porque se debía dinero o porque había una denuncia de robo). Este tipo de injurias afectaba la reputación en público y la estima personal del que la recibía. De acuerdo con lo expresado por los suicidas en sus cartas y en los relatos elaborados por la policía, pareciera que el uso de la violencia, arriesgando su vida, era un argumento en favor de la calidad de la persona y la credibilidad de lo que afirmaba. Entendemos que no existía algo parecido a un código de honor, que estipulara con precisión el rol de la violencia dirigida hacia uno mismo. Ésta tenía un significado polémico, como expresaban algunos individuos en sus cartas, para muchos el suicidio era un acto de cobardía, otros consideraban que, en ciertas circunstancias, podía ser una acción valiente. Lo que nos queda claro es que los actores sociales, tanto los que se quitaban la vida como los testigos que reconstruían los hechos, podían comprender el dolor que la exposición en público producía, sobre todo, en los hombres de la época. No todos los que vieron quebrar sus negocios o fueron acusados de ladrones se quitaron la vida, pero es probable que el dolor generado por estas experiencias fuera imaginado como profundo, dañino y potencialmente intolerable.

Para finalizar, nos parece importante resaltar una inquietud que encontramos detrás del discurso sobre la honra y la vergüenza: la preocupación por la trascendencia después de la muerte. El uso del lenguaje del honor cumplía una función retórica; es decir, tenía un fin regulativo: el que dejaba la nota buscaba, consciente o inconscientemente, condicionar, de alguna manera, la memoria de los otros significativos. Éste no era el único recurso argumentativo usado para ello: daban el último y afectuoso adiós, agradecían y pedían perdón por sus faltas, etc. Sin embargo, posicionarse como hombres de honor también podía ser un recurso para pervivir más allá de la existencia e influir en la representación que los demás construirían luego de la 
muerte. Es decir, al igual que el relato de las necrológicas, que mostraba un retrato idealizado del difunto, el suicida intentaba dejar una imagen menos escandalosa, violenta y sangrienta, y más heroica, para que sus seres queridos lo conservaran en el recuerdo. En este sentido, el miedo al olvido por parte de los otros significativos era un temor compartido por muchos más de los que se quitaban la vida. 


\section{Conclusión}

En esta investigación, partimos de la siguiente hipótesis de base: los suicidios son acciones sociales que siempre comprometen el marco axiológico, o sea, los valores de una sociedad. En este sentido, como hemos observado, los actos suicidas eran acciones individuales que poseían un significado social, es decir, eran inteligibles a la luz de la cultura compartida por los suicidas, su red de vínculos y la sociedad en la que vivían. Al mismo tiempo, pudimos inferir que los suicidios constituían acciones comunicativas, ya que los suicidas transmitían un mensaje al entorno, que podía ser interpretado de diferentes formas. Cada acto suicida era representado a partir de un discurso axiológico que se expresaba en la narración moral de los eventos. En este sentido, no todo suicidio tenía el mismo valor ético, a priori. Como hemos fundamentado en los capítulos que componen esta tesis, los elementos situacionales del contexto y los esenciales del sujeto, narrados a la hora de reconstruir los hechos, le atribuían un carácter moral específico a la acción de poner fin a la vida.

En este sentido, el estudio cualitativo de los casos consultados nos aportó valiosa información sobre las categorías que usaban distintos actores para entender los suicidios, cuáles eran las explicaciones para la sociedad de la época que estudiamos y qué valores, explícitos e implícitos, estaban en juego a la hora de reflexionar sobre la muerte voluntaria. Así, al consultar la documentación, partimos de considerar que existían distintas causas y motivaciones verosímiles para explicar una muerte por suicidio, y que éstas, a su vez, tenían un valor moral específico para los habitantes de Buenos Aires del último tercio del siglo XIX.

La ciudad creció de forma sostenida durante este período, en términos demográficos y en cuanto a las áreas ocupadas. Asimismo, la llegada masiva de inmigrantes modificó las características de la población de la urbe. No es casual que la cantidad de suicidios haya aumentado en este período como detectaron los miembros de la elite cultural porteña, ni que muchos de los suicidas fueran hombres inmigrantes jóvenes; todo esto respondía a la dinámica evolución demográfica de la ciudad que dejaba atrás su pasado de gran aldea.

En el marco de estas transformaciones, los integrantes de la sociedad de la época, sobre todo los miembros de las elites políticas e intelectuales, tomaron mayor conciencia de una serie de fenómenos. En algunos casos, estos eran novedosos, como la llegada de población inmigrante; los debates sobre los problemas de hacinamiento; la 
llamada cuestión obrera; y la construcción de una identidad nacional. Mientras que otras situaciones, sin ser desconocidas, iban adquiriendo una proporción y una naturaleza no vista hasta entonces, como las epidemias, los delitos y los casos de suicidio. Estos últimos fueron descubiertos por parte de la elite cultural porteña como un problema novedoso traído por los cambios producidos por el proceso de modernización (la civilización) en el marco del mundo urbano, ambiente que promovía las pasiones exaltadas y las ambiciones sin frenos.

Por otra parte, consideramos que si bien el suicidio fue objeto de estudio del saber médico legal y psiquiátrico, como discurso erudito y hegemónico sobre el fenómeno, $\mathrm{y}$, en nuestro período, era asociado a la enfermedad, el delito y, en especial, a la locura, creemos que seguía vigente, incluso entre los miembros de la elite cultural, un debate axiológico sobre la legitimidad o no de la muerte voluntaria en distintas circunstancias y para ciertos actores. El ideal del pensamiento moderno y positivista era formar ciudadanos que fueran capaces de hacer uso de su razón y que civilizaran sus pasiones, adoptando sus roles de acuerdo a su género, la mujer en el espacio privado (como madre y esposa) y el hombre desempeñando sus actividades en el mundo del trabajo y en la política. Nuestra hipótesis de trabajo es que la reflexión ética sobre el suicidio estuvo permeada por estos valores y principios de cómo debía ser la vida social: una visión sobre el lugar de las emociones y los sentimientos en una sociedad capitalista, con un estado nacional consolidado y un régimen político democrático en construcción. En síntesis, buscaban promover el ideal de hombres y mujeres que controlaran sus pasiones románticas y violentas, e hicieran uso de su razón, cumpliendo con sus obligaciones hacia el colectivo y garantizando, así, el orden. El suicidio de Leandro N. Alem da cuenta de las distintas y polémicas formas de representar un suicidio por parte de los miembros de las elites. Como hemos argumentado a lo largo del desarrollo de nuestra exposición, este discurso ético, expresado en los textos académicos y la interpretación de los suicidios como una epidemia social, circulaban en las páginas de la prensa de la época.

En los medios gráficos consultados, al igual que en los relatos relevados de los sumarios judiciales, encontramos diferentes tipos de narraciones de acuerdo a la "causa determinante" que articulaba el recuento de lo sucedido. En éstas, los suicidas y sus actos eran representados de distintas formas, según los principios del marco axiológico preponderante. Así, lo que queremos rescatar de nuestro recorrido es la presencia de un debate ético sobre la muerte voluntaria diferente a los que ocurren en el presente. En 
cada suicidio había muchas representaciones entremezcladas, había sentidos para las circunstancias en las que ocurría (sobre todo las causas imaginadas), y, a partir de esto, los contemporáneos trataban de descifrar su significado, cuando había uno; en otros casos, sólo quedaba el desconcierto y el horror.

Así, como resultado de nuestro estudio, llegamos a la conclusión de que existían imágenes ambiguas y contradictorias para representar a los que se quitaban la vida. Por un lado, en la mayoría de los casos, el suicidio era motivo de vergüenza y escándalo. La gran cantidad de casos en los que no figura la causa, o que los suicidas heridos se negaban a declarar, nos da cuenta de ello. Del mismo modo, las frases evasivas "cansado / aburrido / hastiado de la vida" son muestras de este pudor a la hora de revelar los dramas y miserias que desesperaban al que trataba de quitarse la vida. Así, sobre una franja importante de suicidios sólo conocemos el intenso silencio que quedó, luego del estruendo del arma de fuego disparada, los gritos y el llanto de los familiares y amigos desconsolados y las preguntas de la policía por los hechos. A partir de estos casos, encontramos una primera forma de narrar los hechos: el relato de una vida truncada, cuyo dramático desenlace no poseía causa o motivo, el suicida se llevó a la tumba todas las razones que lo podrían haber impulsado a quitarse la vida.

En otras historias, encontramos un conjunto de causas verosímiles que los testigos mencionaban. Si bien el discurso médico presentaba a los suicidas como sujetos desesperados y débiles, que no podían enfrentar la lucha por la vida, algunos relatos despertaban mayor compasión y comprensión. Muchos suicidas no tenían una red de vínculos que pudiera contenerlos, como en los casos de los inmigrantes sin empleo. La carencia de un entorno familiar armonioso era un indicio importante para explicar el origen del malestar interno del sujeto. El ámbito familiar del suicida era uno de los elementos situacionales claves a la hora de explicar una muerte por suicidio. Era verosímil imaginar que la ausencia de parientes y amigos agravaba la condición del desesperado; del mismo modo, un hogar carente de armonía y desarticulado no podía contribuir a calmar el sentimiento de desesperación que angustiaba al suicida. Si había conflictos en el grupo familiar, estos podían ser considerados el origen del malestar que llevó al suicida a quitarse la vida. En ese caso, el relato tendería a presentar a los vínculos familiares como la "causa determinante" de lo sucedido, algo mucho más difícil de sobrellevar para los deudos, y que afectaba aún más la reputación de la familia en su conjunto. Es comprensible que el policía no hiciera demasiadas preguntas en estos casos. 
La pobreza, la enfermedad, la falta de trabajo y la ausencia de vínculos afectivos eran los ingredientes de la "suprema desesperación". Muchos de los relatos giraban en torno a estas dificultades que enfrentaban los miembros de las clases trabajadoras y las acciones que los otros significativos ensayaban para protegerlos de sí mismos. Por otra parte, la asistencia brindada por la red social del suicida no era homogénea. Como argumentamos en el capítulo 8, consideramos que existían formas diferentes de representar los roles de acuerdo al género de los miembros de la trama vincular. Mientras que los hombres eran los depositarios de las últimas voluntades y asistían materialmente a otros individuos de género masculino, las mujeres eran las encargadas de llevar adelante la contención emocional de los desesperados, escuchando sus problemas.

Por otra parte, muchas muertes por suicidio eran explicadas apelando a las patologías mentales. Esto da cuenta de lo instalada que estaba en el sentido común la representación del suicida como alienado, enajenado, loco, etc. y la influencia del paradigma médico en el tema. Sin embargo, el quitarse la vida no era una prueba clara de alienación mental, al menos, no para todos, ni siquiera para los profesionales de la salud sin distinción. Si bien numerosos casos eran explicados a partir de los efectos de la locura, muchos otros no hacían referencia a las facultades mentales del sujeto. En cambio, explicaban hechos más vergonzosos, como los desengaños amorosos o los conflictos familiares. Los suicidas eran anormales que estaban situados en esa delgada y ambigua frontera entre locos y cuerdos.

Como hemos fundamentado antes, sostenemos que las patologías mentales, como elemento de la narración, modificaban la interpretación moral del acto suicida. El suicidio como tal ya no era resultado de un individuo que hacía pleno uso de su razón, era la acción desesperada de un sujeto carente de juicio y, por ende, de responsabilidad. Al mismo tiempo, disculpaba al entorno familiar por lo sucedido: era difícil contener a los alienados que intentaban quitarse la vida de forma reiterada, las acciones de los miembros de la red social del suicida eran aún más limitadas en estos casos.

Muchos suicidas, aprovechaban sus últimas palabras, orales y/o escritas, para llevar adelante un conjunto de acciones comunicativas: despedirse afectuosamente, pedir perdón o perdonar, dar las gracias, dar a conocer sus últimas voluntades, etc. Sin embargo, varios también adoptaban actitudes agresivas. Sus muertes o intentos de autoagresión estaban dirigidos a condicionar a los otros significativos que formaban parte de su red de vínculos. Esto fue más frecuente en los casos referidos al amor y las 
relaciones de pareja. Un sentimiento posesivo era expresado por estos suicidas, abrumados por los celos y las sospechas de infidelidad. En algunos relatos, amenazaban con quitarse la vida para condicionar al otro; en otros, las acciones estaban orientadas a generar remordimiento en los miembros de la red social del que se autoagredía. En las historias más agresivas, el suicidio tenía como preludio el ataque del individuo deseado. Si bien eran expresiones extremas, casos límites, los que narraban los hechos podían reconocer las emociones y el sentir de los suicidas. La obsesión y las pasiones amorosas de los suicidas eran un reflejo anormal de sentimientos que podían ser identificados en muchos otros que no se quitaban la vida. El dolor del desengaño amoroso, la preocupación despertada por los celos, el miedo a perder el amor de la pareja, a la infidelidad de esta o a ser abandonado eran escenarios verosímiles desgraciados que podían ser comprendidos empáticamente. Por otra parte, estos actos eran condenados por la moral positivista de la época: seres románticos y sin freno para sus pasiones, se mataban por motivos frívolos, actitudes propias de jóvenes y de sujetos de género femenino.

Por otra parte, el debate ético sobre los actos suicidas no estaba cerrado. Estos también podían ser presentados como sacrificios o acciones defensivas para salvaguardar el honor personal y familiar. Si bien no existía un código social estricto que estableciera cuándo era un deber quitarse la vida, había situaciones que despertaban mayor empatía. Así, resultaba comprensible y verosímil que algunos sujetos consideraran suicidarse frente a una deshonra pública con consecuencias intolerables, por ejemplo, como consecuencia de la quiebra de sus negocios o la imposibilidad de responder a las deudas contraídas. Al mismo tiempo, consideramos que los suicidas apelaban al lenguaje del honor, entre otros recursos, para preservar el mejor recuerdo posible en la memoria de los deudos.

Para un mundo en transición, que llevaba el legado de la era de guerras y combates del siglo XIX, el suicidio tenía un significado ambiguo. Desde la perspectiva positivista, representaba un acto "romántico" de pasiones sin freno o el resultado de las patologías mentales. Sin embargo, el mundo civilizado y su materialismo generaban resistencia, incluso en aquellos miembros de las elites comprometidos con el avance del proceso de modernización. En este marco, el ideal masculino de un hombre valiente, viril y heroico, que defendía su reputación, sin dudar en recurrir a la violencia física para hacerlo, incluso contra sí mismo, despertaba un sentimiento ambiguo entre los actores sociales de la época. Ese heroísmo forjado por el romanticismo decimonónico, 
el proceso de construcción de una identidad republicana y la experiencia de sucesivos enfrentamientos en el campo de batalla, perduraba como anhelo en una sociedad en acelerado proceso de transformación. 


\section{ANEXO}

Tabla 1

Suicidios y tentativas de suicidio. Buenos Aires, 1881-1910

$\begin{array}{lrrrrr}\text { Años } & 1881 & 1882 & 1883 & 1884 & 1885 \\ \text { Suicidios } & 24 & 41 & 26 & 30 & 35 \\ \text { Tentativas } & 12 & 42 & 21 & 42 & 37 \\ \text { Totales } & 36 & 83 & 47 & 72 & 72 \\ & & & & & \\ \text { Años } & 1886 & 1887 & 1888 & 1889 & 1890 \\ \text { Suicidios } & 52 & 68 & 62 & 76 & 71 \\ \text { Tentativas } & 50 & 52 & 52 & 52 & 54 \\ \text { Totales } & 102 & 120 & 114 & 128 & 125 \\ & & & & & \\ \text { Años } & 1891 & 1892 & 1893 & 1894 & 1895 \\ \text { Suicidios } & 78 & 79 & 73 & 93 & 98 \\ \text { Tentativas } & 72 & 58 & 73 & 84 & 84 \\ \text { Totales } & 150 & 137 & 146 & 177 & 182 \\ & & & & & \\ \text { Años } & 1896 & 1897 & 1898 & 1899 & 1900 \\ \text { Suicidios } & 103 & 144 & 104 & 98 & 110 \\ \text { Tentativas } & 126 & 141 & 103 & 97 & 94 \\ \text { Totales } & 229 & 285 & 207 & 195 & 204 \\ & & & & & \\ \text { Años } & 1901 & 1902 & 1903 & 1904 & 1905 \\ \text { Suicidios } & 143 & 132 & 139 & 126 & 149 \\ \text { Tentativas } & 109 & 111 & 111 & 113 & 101 \\ \text { Totales } & 252 & 243 & 250 & 239 & 250 \\ & & & & & \\ \text { Años } & 1906 & 1907 & 1908 & 1909 & 1910 \\ \text { Suicidios } & 171 & 173 & 206 & 208 & 189 \\ \text { Tentativas } & 110 & 170 & 187 & 209 & 179 \\ \text { Totales } & 281 & 343 & 393 & 417 & 368 \\ & & & & & \end{array}$

Fuente: Elaboración propia a partir de los Anuarios Estadísticos de la Ciudad de Buenos Aires (1892: 481; 1899: 254; 1906: 239); Latzina (1896: 5); Luzuriaga (1909: 52); Lancelotti (1914: 103); Méndez Casariego (1888: 19). 


\section{Tabla 2}

Población total al inicio de cada quinquenio, Buenos Aires (1810-1914)

Quinquenios

1810-14

1815-19

1820-24

1825-29

1830-34

1835-39

1840-44

1845-49

1850-54

1855-59

1860-64

1865-69

1870-74

1875-79

1880-84

1885-89

1890-94

1895-99

1900-04

1905-09

1910-14
Población al inicio del quinquenio
45.000
47.918
51.831
54.945
55.108
60.004
65.794
72.983
82.492
94.937
122.869
157.982
198.129
250.404
292.893
396.771
560.449
675.989
837.864
999.632
1.313 .151

Fuente: Lattes, Andrada, y Caviezel (2010: 156) 
Tabla 3

Evolución de la tasa de suicidios (cada 100000 hab.) en Buenos Aires (1882-1910)

$\begin{array}{lccr}\text { Años } & \begin{array}{l}\text { Número de } \\ \text { suicidios }\end{array} & \begin{array}{l}\text { Población } \\ \text { estimada }\end{array} & \text { Tasa de suicidi } \\ 1882 & 83 & 292.893 & 28,34 \\ 1895 & 182 & 675.989 & 26,92 \\ 1910 & 368 & 1.313 .151 & 28,02\end{array}$

Fuente: Elaboración propia a partir de los Anuarios Estadísticos de la Ciudad de Buenos Aires (1892: 481; 1899: 254; 1906: 239); Latzina (1896: 5); Luzuriaga (1909: 52); Lancelotti (1914: 103); Méndez Casariego (1888: 19) y Lattes, Andrada, y Caviezel (2010: 156). 
Tabla 4

Casos de suicidios encontrados en los sumarios judiciales por año

(Buenos Aires, 1859-1888)

\begin{tabular}{lccc} 
AÑO & Masculino & Femenino & Total \\
$\mathbf{1 8 5 9}$ & 1 & 0 & 1 \\
$\mathbf{1 8 6 0}$ & 2 & 0 & 2 \\
$\mathbf{1 8 6 1}$ & 0 & 0 & 0 \\
$\mathbf{1 8 6 2}$ & 0 & 0 & 0 \\
$\mathbf{1 8 6 3}$ & 1 & 0 & 1 \\
$\mathbf{1 8 6 4}$ & 0 & 0 & 0 \\
$\mathbf{1 8 6 5}$ & 0 & 0 & 0 \\
$\mathbf{1 8 6 6}$ & 1 & 1 & 2 \\
$\mathbf{1 8 6 7}$ & 0 & 0 & 0 \\
$\mathbf{1 8 6 8}$ & 3 & 0 & 3 \\
$\mathbf{1 8 6 9}$ & 2 & 0 & 2 \\
$\mathbf{1 8 7 0}$ & 0 & 0 & 0 \\
$\mathbf{1 8 7 1}$ & 2 & 1 & 3 \\
$\mathbf{1 8 7 2}$ & 3 & 0 & 3 \\
$\mathbf{1 8 7 3}$ & 8 & 1 & 9 \\
$\mathbf{1 8 7 4}$ & 9 & 1 & 10 \\
$\mathbf{1 8 7 5}$ & 14 & 2 & 16 \\
$\mathbf{1 8 7 6}$ & 21 & 2 & 23 \\
$\mathbf{1 8 7 7}$ & 19 & 7 & 26 \\
$\mathbf{1 8 7 8}$ & 12 & 7 & 19 \\
$\mathbf{1 8 7 9}$ & 20 & 2 & 22 \\
$\mathbf{1 8 8 0}$ & 29 & 1 & 30 \\
$\mathbf{1 8 8 1}$ & 32 & 10 & 42 \\
$\mathbf{1 8 8 2}$ & 57 & 27 & 84 \\
$\mathbf{1 8 8 3}$ & 43 & 16 & 59 \\
$\mathbf{1 8 8 4}$ & 47 & 16 & 63 \\
$\mathbf{1 8 8 5}$ & 46 & 12 & 58 \\
$\mathbf{1 8 8 6}$ & 64 & 22 & 86 \\
$\mathbf{1 8 8 7}$ & 74 & 22 & 96 \\
$\mathbf{1 8 8 8}$ & 56 & 8 & 64 \\
Total & $\mathbf{5 6 6}$ & $\mathbf{1 5 8}$ & $\mathbf{7 2 4}$ \\
& & & \\
$\mathbf{1 8 5 6}$ & & 0 & 0 \\
\hline
\end{tabular}
Años
$1859-186$
1870-1879
1880-1888 Total
N. ${ }^{\circ}$ de casos
11
131
582
724

Fuente: Elaboración propia a partir de los sumarios judiciales contenidos en los legajos del AGN, FTC PE y SE. 


\section{Tabla 5}

Suicidios entre 1881 y 1888, en sumarios judiciales y anuarios estadísticos de la Ciudad de Buenos Aires

$\begin{array}{lcc}\text { Años } & \mathbf{N}^{\circ} \text { de casos en sumario } & \mathbf{N}^{\circ} \text { de casos en Anuarios E. } \\ 1881 & 42 & 36 \\ 1882 & 84 & 83 \\ 1883 & 59 & 47 \\ 1884 & 63 & 72 \\ 1885 & 58 & 72 \\ 1886 & 87 & 102 \\ 1887 & 96 & 120 \\ 1888 & 63 & 114 \\ \text { Total } & 552 & 646\end{array}$

Fuente: Elaboración propia a partir de los sumarios judiciales contenidos en los legajos del AGN, FTC PE y SE y el Anuario Estadístico de la Ciudad de Buenos Aires (1892: 481). 
Tabla 6

Suicidios según género, en Buenos Aires 1881 a 1910

$\begin{array}{lrrrrr}\text { Años } & 1881 & 1882 & 1883 & 1884 & 1885 \\ \text { Hombres } & 30 & 60 & 40 & 54 & 55 \\ \text { Mujeres } & 6 & 23 & 7 & 18 & 17 \\ \text { Totales } & 36 & 83 & 47 & 72 & 72 \\ & & & & & \\ \text { Años } & 1886 & 1887 & 1888 & 1889 & 1890 \\ \text { Hombres } & 75 & 90 & 99 & 102 & 106 \\ \text { Mujeres } & 27 & 30 & 15 & 26 & 19 \\ \text { Totales } & 102 & 120 & 114 & 128 & 125 \\ & & & & & \\ \text { Años } & 1891 & 1892 & 1893 & 1894 & 1895 \\ \text { Hombres } & 118 & 110 & 102 & 126 & 126 \\ \text { Mujeres } & 32 & 27 & 44 & 51 & 56 \\ \text { Totales } & 150 & 137 & 146 & 177 & 182 \\ & & & & & \\ \text { Años } & 1896 & 1897 & 1898 & 1899 & 1900 \\ \text { Hombres } & 168 & 195 & 154 & 142 & 145 \\ \text { Mujeres } & 61 & 90 & 53 & 53 & 59 \\ \text { Totales } & 229 & 285 & 207 & 195 & 204 \\ \text { Años } & & & & & \\ \text { Hombres } & 1901 & 1902 & 1903 & 1904 & 1905 \\ \text { Mujeres } & 180 & 179 & 171 & 167 & 172 \\ \text { Totales } & 72 & 64 & 79 & 72 & 78 \\ & 252 & 243 & 250 & 239 & 250 \\ \text { Años } & & & & & \\ \text { Hombres } & 1906 & 1907 & 1908 & 1909 & 1910 \\ \text { Mujeres } & 201 & 221 & 264 & 270 & 244 \\ \text { Totales } & 80 & 122 & 129 & 147 & 124 \\ & 281 & 343 & 393 & 417 & 368\end{array}$

$\begin{array}{lcc}\text { Sexo } & \mathbf{N}^{\mathbf{0}} \text { de casos } & \text { \% } \\ \text { Hombres } & 4166 & 71,25 \\ \text { Mujeres } & 1681 & 28,75 \\ \text { Total } & 5847 & 100\end{array}$

Fuente: Latzina (1896: 5); Luzuriaga (1909: 53); Anuario (1892: 478); Anuario (1899: 254); Anuario (1906: 240); Lancelotti (1914: 105). 
Tabla 7

Casos de suicidio según sexo (Buenos Aires, 1859-1888)

\begin{tabular}{|l|c|c|c|}
\hline \multicolumn{1}{|c|}{ Género } & Masculino & Femenino & Total \\
\hline Cantidad de casos & 566 & 158 & 724 \\
\hline Porcentaje & 78,18 & 21,82 & 100 \\
\hline
\end{tabular}

Fuente: Elaboración propia a partir de los sumarios judiciales contenidos en los legajos del AGN, FTC PE y SE. 
Tabla 8

Suicidios según estado civil, Buenos Aires 1882 a 1910

Hombres

Años

1882

1883

1884

1885

Solteros

Casados

Viudos

Totales

24

32

36

1

17

17

60

5

2

54

55

Mujeres

Años

1882

1883

1884

1885

Solteros

Casados

Totales

23

$\begin{array}{ll}- & 7 \\ - & 9\end{array}$

Totales

Hombres

Años

Solteros

1886

1887

Viudos

1

3

75

90

1888

1889

1890

62

Totales

Mujeres

Años

1886

1887

1888

1889

1890

15

Solteros

9

21

11

15

10

3

Viudos

Totales

27

8

3

1

15

8

3

26

Hombres

Años

1891

1892

1893

1894

1895

67

Casados

37

59

65

79

80

8

44

32

39

40

112

110

102

8

6

Totales

Mujeres

Años

Solteros

1891

1892

1893

1894

1895

14

32

31

Casados

10

6

16

22

38

4

Totales

27

44

3

51

3

56 
Hombres

Años

Solteros

Casados

Viudos

Totales

$\begin{array}{rrrrr}1896 & 1897 & 1898 & 1899 & 1900 \\ 95 & 124 & 97 & 80 & 79 \\ 62 & 61 & 48 & 48 & 48 \\ 11 & 10 & 9 & 14 & 18 \\ 168 & 195 & 154 & 142 & 145\end{array}$

Mujeres

Años

Solteros

Casados

Viudos

Totales

1896

1897

1898

1899

1900

42

44

29

24

28

17

22

28

7

7

3

61

53

53

59

Hombres

Años

Solteros

1901

1902

1903

1904

1905

88

106

96

91

100

Casados

60

61

67

55

17

14

Viudos

180

13
179

171

17

167

172

Mujeres

Años

1901

1902

1903

1904

1905

Solteros

35

36

52

Casados

23

36

31

19

9

3

8

5

7

Totales

72

64

79

72

78

Hombres

Años

Solteros

1906

$$
1907
$$

128

1908

1909

1910

140

142

165

149

Casados

54

79

103

88

85

Viudos

201

14

19

17

10

Totales

Mujeres

Años

1906

221

264

270

244

Solteros

1907

1908

1909

1910

Casados

23

73

71

44

83

67

41

14

55

54

$7 \quad 8$

129

9
147

3
124

Totales

80

122

Total

3.366

$\%$

Estado civil

Hombres
2.432
1.397
261
4.090

Mujeres
934
605
135
1.674

2.002

58,40

Casado

605

396

34,73

6,87

Total

1.674

5.764

100

Fuente: Elaboración propia a partir de los datos relevados del Anuario Estadístico de la Ciudad de Buenos Aires (1899: 256); Luzuriaga (1909: 53); Lancelotti (1914: 105). 
Tabla 9

Casos de suicidio según estado civil (Buenos Aires, 1859-1888)

$\begin{array}{lrrrr}\text { Estado civil } & \text { Hombres } & \text { Mujeres } & \text { Total } & \text { \% } \\ \text { Soltero } & 297 & 69 & 366 & 50,55 \\ \text { Casado } & 144 & 40 & 184 & 25,41 \\ \text { Viudo } & 15 & 9 & 24 & 3,31 \\ \text { Separado } & 4 & 2 & 6 & 0,83 \\ \text { Concubinato } & 1 & 3 & 4 & 0,55 \\ \text { No } & & & & \\ \text { especificado } & 105 & 35 & 140 & 19,34 \\ \text { Total } & 566 & 158 & 724 & 100\end{array}$

Fuente: Elaboración propia a partir de los sumarios judiciales contenidos en los legajos del AGN, FTC PE y SE. 
Tabla 10

Suicidios según franja etaria, Buenos Aires (1882 a 1910)

\section{Hombres}

\section{Edad}

Menos de 15

15 a 20

20 a 25

25 a 30

30 a 35

35 a 40

40 a 50

50 a 60

Más de 60

Sin espec.

1882
$3-$
$4-$
$5-$
$12-$
$11-$
$9-$
$7-$
$6-$
$3-$
$0-$

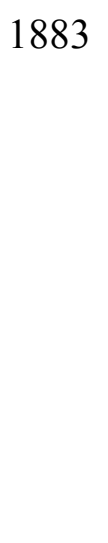

$\begin{array}{rr}1884 & 1885 \\ 1 & 0 \\ 2 & 7 \\ 10 & 12 \\ 9 & 10 \\ 8 & 4 \\ 10 & 8 \\ 7 & 8 \\ 2 & 4 \\ 5 & 2 \\ 0 & 0\end{array}$

\section{Mujeres}

\section{Edad}

Menos de 15

15 a 20

20 a 25

25 a 30

30 a 35

35 a 40

40 a 50

50 a 60

Más de 60

Sin espec.

$\begin{aligned} 1882 & - \\ 1 & - \\ 6 & - \\ 5 & - \\ 3 & - \\ 3 & - \\ 3 & - \\ 1 & - \\ 1 & - \\ 0 & - \\ 0 & -\end{aligned}$

\section{Hombres}

\section{Edad}

Menos de 15

15 a 20

20 a 25

25 a 30

30 a 35

35 a 40

40 a 50

50 a 60

Más de 60

Sin espec.

\begin{tabular}{rrl}
1886 & 1887 & \multicolumn{1}{l}{1888} \\
1 & 0 & - \\
8 & 12 & - \\
12 & 21 & - \\
10 & 16 & - \\
12 & 10 & - \\
16 & 10 & - \\
12 & 13 & - \\
2 & 5 & - \\
2 & 4 & - \\
0 & 0 & -
\end{tabular}

$\begin{array}{rr}1889 & 1890 \\ 1 & 1 \\ 10 & 10 \\ 20 & 23 \\ 16 & 24 \\ 14 & 11 \\ 12 & 11 \\ 20 & 17 \\ 8 & 9 \\ 1 & 0 \\ 0 & 0\end{array}$




\section{Mujeres}

Edad

Menos de 15

15 a 20

20 a 25

25 a 30

30 a 35

35 a 40

40 a 50

50 a 60

Más de 60

Sin espec.

\section{Hombres}

\section{Edad}

Menos de 15

15 a 20

20 a 25

25 a 30

30 a 35

35 a 40

40 a 50

50 a 60

Más de 60

Sin espec.

\section{Mujeres}

\section{Edad}

Menos de 15

15 a 20

20 a 25

25 a 30

30 a 35

35 a 40

40 a 50

50 a 60

Más de 60

Sin espec.

$\begin{array}{rrrrr}1886 & 1887 & 1888 & 1889 & 1890 \\ 0 & 3 & - & 1 & 0 \\ 9 & 8 & - & 4 & 5 \\ 7 & 12 & - & 9 & 8 \\ 3 & 2 & - & 5 & 2 \\ 3 & 3 & - & 2 & 2 \\ 3 & 1 & - & 2 & 2 \\ 2 & 0 & - & 2 & 0 \\ 0 & 0 & - & 1 & 0 \\ 0 & 0 & - & 0 & 0 \\ 0 & 0 & - & 0 & 0\end{array}$

1891

1892

1893

1894

1895

12

20

29

18

12

13

10

4

0

12

14

23

16

7

19

12

4

2

1

11

13

23

15

6

17

12

3

1

0

16

17

20

14

21

19

10

7

4

1893

1894

1895

4

10

8

6

5

5

2

3

1

0

\section{4}

18

2

15

$\begin{array}{ll}9 & 17\end{array}$

6

9

3

2

1

6

0

0

$\begin{array}{ll}0 & 0 \\ 0 & 0\end{array}$

0




\section{Hombres}

\section{Edad}

Menos de 15

15 a 20

20 a 25

25 a 30

30 a 35

35 a 40

40 a 50

50 a 60

Más de 60

Sin espec.

\section{Mujeres}

\section{Edad}

Menos de 15

15 a 20

20 a 25

25 a 30

30 a 35

35 a 40

40 a 50

50 a 60

Más de 60

Sin espec.

\section{Hombres}

\section{Edad}

Menos de 15

15 a 20

20 a 25

25 a 30

30 a 35

35 a 40

40 a 50

50 a 60

Más de 60

Sin espec.

$\begin{array}{rr}1896 & 1897 \\ 0 & 1 \\ 16 & 25 \\ 20 & 27 \\ 25 & 23 \\ 30 & 25 \\ 18 & 18 \\ 24 & 42 \\ 23 & 20 \\ 9 & 10 \\ 3 & 4\end{array}$

1898

1899

1900

1

25

27

23

25

18

42

20

10

4

0

19

23

17

18

20

26

15

9

7

1897
4
30
21
11
8
6
6
2
2
0

1898

1899

1900

2

18

14

10

7

3

3

2

2

0

16

$\begin{array}{r}16 \\ \hline\end{array}$

10

9

4

3

1

0

1

1

16

9

12

1

4

6

1

3

0

1904

1905

3

22

18

27

15

20

26

21

19

0
0

10

17

26

25

19

19

17

12

0

1
16
15
12
7
3
2
3
0
0

0




\section{Mujeres}

Edad
Menos de 15
15 a 20
20 a 25
25 a 30
30 a 35
35 a 40
40 a 50
50 a 60
Más de 60

$\begin{array}{rrrrr}901 & 1902 & 1903 & 1904 & 1905 \\ 2 & 3 & 4 & 1 & 2 \\ 20 & 17 & 19 & 25 & 23 \\ 17 & 15 & 15 & 16 & 27 \\ 10 & 4 & 12 & 8 & 8 \\ 5 & 9 & 7 & 7 & 5 \\ 6 & 8 & 10 & 5 & 4 \\ 6 & 3 & 5 & 6 & 3 \\ 1 & 2 & 4 & 3 & 3 \\ 5 & 3 & 3 & 1 & 3 \\ 0 & 0 & 0 & 0 & 0\end{array}$

\section{Hombres}

\section{Edad}

Menos de 15

15 a 20

20 a 25

25 a 30

30 a 35

35 a 40

40 a 50

50 a 60

Más de 60

Sin espec.

\section{Mujeres}

\section{Edad}

Menos de 15

15 a 20

20 a 25

25 a 30

30 a 35

35 a 40

40 a 50

50 a 60

Más de 60

Sin espec.

$\begin{array}{rr}1906 & 1907 \\ 2 & 2 \\ 25 & 23 \\ 28 & 29 \\ 29 & 43 \\ 16 & 18 \\ 24 & 25 \\ 37 & 36 \\ 15 & 23 \\ 25 & 22 \\ 0 & 0\end{array}$

1906

$$
1907
$$

3

38

30

18

9

7

11

4

2

1908

3

26

33

31

52

40

27

39

16

17

1908
1
38
39
20
3
11
9
5
3
0

1909

1910

4

32

47

43

23

30

44

23

24

0

1909

\section{5}

49

41

23

11

6

6
6

3

3

0

\section{0}

\section{4}

41

32

13

14

6

7

7

0

0 


\begin{tabular}{lrrrrrr} 
Edad & Hombres & \multicolumn{1}{c}{ \% } & Mujeres & \% & Total & \% \\
Menos de 15 & 39 & 0,69 & 61 & 1,08 & 100 & 1,76 \\
15 a 20 & 434 & 7,65 & 489 & 8,62 & 923 & 16,28 \\
20 a 25 & 584 & 10,30 & 408 & 7,19 & 992 & 17,49 \\
25 a 30 & 612 & 10,79 & 236 & 4,16 & 848 & 14,95 \\
30 a 35 & 521 & 9,19 & 136 & 2,40 & 657 & 11,59 \\
35 a 40 & 467 & 8,23 & 122 & 2,15 & 589 & 10,39 \\
40 a 50 & 597 & 10,53 & 97 & 1,71 & 694 & 12,24 \\
50 a 60 & 406 & 7,16 & 65 & 1,15 & 471 & 8,31 \\
Más de 60 & 286 & 5,04 & 35 & 0,62 & 321 & 5,66 \\
Sin espec. & 75 & 1,32 & 1 & 0,02 & 76 & 1,34 \\
& \multicolumn{7}{c}{ Total }
\end{tabular}

\section{Franjas}

\section{etarias}

15 a 40

20 a 40

40 en

adelante

Menos de 20

años
Hombres

2.618

2.184

1.289

473
$\%$

46,16

38,51

22,73

8,34
Mujeres

1.391

902

197

550

Fuente: Elaboración propia a partir de los datos del Anuario Estadístico de la Ciudad de Buenos Aires (1899: 257-258), Luzuriaga (1909: 58), Lancelotti (1914: 108).

$\begin{array}{ccc}\mathbf{\%} & \text { Total } & \text { \% } \\ 24,53 & 4.009 & 70,69 \\ 15,91 & 3.086 & 54,42 \\ & & \\ 3,47 & 1.486 & 26,20 \\ & & \\ 9,70 & 1.023 & 18,04\end{array}$

18,04 
Tabla 11

Casos de suicidio según edad (Buenos Aires, 1859-1888)

$\begin{array}{lrrrrrr}\text { Edad } & \text { Hombres } & \text { \% } & \text { Mujeres } & \text { \% } & \text { Total } & \text { \% } \\ 15 \text { o menos } & 5 & 0,69 & 16 & 2,21 & 21 & 2,90 \\ 16-20 & 45 & 6,22 & 33 & 4,56 & 78 & 10,77 \\ 21-25 & 86 & 11,88 & 31 & 4,28 & 117 & 16,16 \\ 26-30 & 85 & 11,74 & 15 & 2,07 & 100 & 13,81 \\ 31-35 & 62 & 8,56 & 14 & 1,93 & 76 & 10,50 \\ 36-40 & 70 & 9,67 & 10 & 1,38 & 80 & 11,05 \\ 41 \text { o más } & 95 & 13,12 & 10 & 1,38 & 105 & 14,50 \\ 60 \text { o más } & 23 & 3,18 & 3 & 0,41 & 26 & 3,59 \\ \text { No espec. } & 95 & 13,12 & 26 & 3,59 & 121 & 16,71 \\ \text { Total } & 566 & 78,18 & 158 & 21,82 & 724 & 100,00 \\ & & & & & & \\ \text { Franjas etarias } & \text { Hombres } & \text { \% } & \text { Mujeres } & \text { \% } & \text { Total } & \text { \% } \\ \text { 15 a 40 } & 353 & 48,76 & 119 & 16,44 & 472 & 65,19 \\ \text { 20 a 40 } & 303 & 41,85 & 70 & 9,67 & 373 & 51,52 \\ 40 \text { en adelante } & 118 & 16,30 & 13 & 1,80 & 131 & 18,09 \\ \text { Menos de 20 años } & 50 & 6,91 & 49 & 6,77 & 99 & 13,67\end{array}$

Fuente: Elaboración propia a partir de los sumarios judiciales contenidos en los legajos del AGN, FTC PE y SE. 
Tabla 12

Estructura por grandes grupos de edad y sexo en años seleccionados Ciudad de Buenos Aires, 1855-1915

Años / Grupos de edad 0-14

\begin{tabular}{lllll} 
& \multicolumn{1}{c}{$45-64$} & \multicolumn{2}{c}{$65 \mathrm{y}+$} & \multicolumn{2}{c}{ Total } \\
29,3 & 54,7 & 12,8 & 3,1 & 100 \\
32,1 & 55,7 & 10,5 & 1,7 & 100 \\
30,5 & 55,5 & 11,8 & 2,2 & 100
\end{tabular}

Varones

Años / Grupos de edad 0-14

1855

$29,5^{15-44} 55$,

45-64

$12,5^{65 y+}$

Total

1885

28,4

59

11,1

100

1915

28,5

57,5

12,1

1,4

100

Mujeres

Años / Grupos de edad 0-14

29,2
36,8
33

15-44

54,3
51,4
53,1

1,9

100

1855

1885

33

13,2
9,7
11,5

3,3
2
2,5

100

100

100

Fuente: Lattes, Andrada y Caviezel (2010: 145). 
Tabla 13

Suicidios según nacionalidad - Buenos Aires, 1882 a 1910

\begin{tabular}{|c|c|c|c|c|c|}
\hline Nacionalidad & 1882 & 1883 & 1884 & 1885 & \\
\hline Italianos & 19 & - & 20 & 23 & \\
\hline Argentinos & 27 & - & 25 & 22 & \\
\hline Españoles & 12 & - & 8 & 16 & \\
\hline Franceses & 16 & - & 10 & 5 & \\
\hline Alemanes & 0 & - & 0 & 0 & \\
\hline Ingleses & 2 & - & 1 & 0 & \\
\hline Otras nacionalidades & 7 & - & 4 & 6 & \\
\hline Nacionalidad & 1886 & 1887 & 1888 & 1889 & 1890 \\
\hline Italianos & 34 & 36 & 29 & 30 & 43 \\
\hline Argentinos & 37 & 30 & 39 & 37 & 32 \\
\hline Españoles & 14 & 19 & 17 & 17 & 18 \\
\hline Franceses & 7 & 13 & 13 & 13 & 5 \\
\hline Alemanes & 0 & 3 & 4 & 8 & 10 \\
\hline Ingleses & 0 & 2 & 2 & 4 & 2 \\
\hline Otras nacionalidades & 10 & 9 & 10 & 19 & 15 \\
\hline Nacionalidad & 1891 & 1892 & 1893 & 1894 & 1895 \\
\hline Italianos & 47 & 47 & 45 & 53 & 55 \\
\hline Argentinos & 43 & 46 & 51 & 40 & 56 \\
\hline Españoles & 18 & 11 & 15 & 24 & 34 \\
\hline Franceses & 27 & 20 & 14 & 14 & 7 \\
\hline Alemanes & 4 & 6 & 2 & 21 & \\
\hline Ingleses & 2 & 4 & 3 & 4 & 4 \\
\hline Otras nacionalidades & 9 & 13 & 16 & 21 & 23 \\
\hline Nacionalidad & 1896 & 1897 & 1898 & 1899 & 1900 \\
\hline Italianos & 62 & 98 & 70 & 63 & 69 \\
\hline Argentinos & 62 & 76 & 66 & 59 & 67 \\
\hline Españoles & 31 & 41 & 27 & 28 & 33 \\
\hline Franceses & 28 & 25 & 20 & 9 & 11 \\
\hline Alemanes & 16 & 10 & 0 & 6 & 3 \\
\hline Ingleses & 2 & 8 & 1 & 1 & 2 \\
\hline Otras nacionalidades & 27 & 27 & 23 & 29 & 19 \\
\hline Nacionalidad & 1901 & 1902 & 1903 & 1904 & 1905 \\
\hline Italianos & 66 & 77 & 68 & 68 & 51 \\
\hline Argentinos & 87 & 81 & 88 & 76 & 109 \\
\hline Españoles & 46 & 32 & 40 & 36 & 32 \\
\hline Franceses & 22 & 8 & 13 & 24 & 16 \\
\hline Alemanes & 5 & 5 & 14 & 4 & \\
\hline Ingleses & 3 & 9 & 1 & 1 & 3 \\
\hline Otras nacionalidades & 23 & 31 & 26 & 30 & 34 \\
\hline
\end{tabular}


Nacionalidad

Italianos

Argentinos

Españoles

Franceses

Alemanes

Ingleses

Otras

Nacionalidad

Italianos

Argentinos

Españoles

Franceses

Alemanes

Ingleses

Otras nacionalidades
1906

67

94

44

22

3

8

43
1907

99

122

51

18

3

2

48
1908

112

139

66

27

6

0

43

1909

1910

92

92

157

57

11

7

4

40

$\begin{array}{rrrrr}1882-1889 & 1890-1899 & 1900-1910 & \text { Total } & \% \\ 191 & 583 & 861 & 1635 & 28,38 \\ 217 & 531 & 1170 & 1918 & 33,29 \\ 103 & 247 & 515 & 865 & 15,01 \\ 77 & 169 & 195 & 441 & 7,65 \\ 15 & 78 & 72 & 165 & 2,86 \\ 11 & 31 & 46 & 88 & 1,53 \\ 65 & 203 & 381 & 649 & 11,27\end{array}$

Nativos

Extranjeros

Total

217

531

1.170

1.918

33,29

462

1.311

2.070

3.843

66,71

679

3.240

5.761

100

Fuente: Elaboración propia a partir de los datos del Anuario Estadístico de la Ciudad de Buenos Aires (1899: 254-255); Luzuriaga (1909: 54) y Lancelotti (1914: 104). 
Tabla 14

Casos de suicidio según nacionalidad (Buenos Aires, 1859-1888)

\begin{tabular}{|c|c|c|}
\hline Nacionalidad & Cantidad & Porcentaje \\
\hline Italianos & 190 & 26,24 \\
\hline Argentinos & 182 & 25,14 \\
\hline Españoles & 85 & 11,74 \\
\hline Franceses & 70 & 9,67 \\
\hline Alemanes & 22 & 3,04 \\
\hline Orientales & 20 & 2,76 \\
\hline Británicos & 11 & 1,52 \\
\hline Suizos & 8 & 1,10 \\
\hline Norteamericanos & 4 & 0,55 \\
\hline Portugueses & 4 & 0,55 \\
\hline Austríacos & 4 & 0,55 \\
\hline Brasileros & 3 & 0,41 \\
\hline Mexicanos & 2 & 0,28 \\
\hline Indígenas & 2 & 0,28 \\
\hline Vasco-francés & 1 & 0,14 \\
\hline Vasco-español & 1 & 0,14 \\
\hline Chilenos & 1 & 0,14 \\
\hline Paraguayos & 1 & 0,14 \\
\hline Rusos & 1 & 0,14 \\
\hline Dinamarqueses & 1 & 0,14 \\
\hline Belgas & 1 & 0,14 \\
\hline Peruano & 1 & 0,14 \\
\hline Extranjero (N/E) & 4 & 0,55 \\
\hline $\mathrm{N} / \mathrm{E}$ & 105 & 14,50 \\
\hline Total & 724 & 100,00 \\
\hline Extranjeros europeos & 407 & 56,22 \\
\hline Nativos & 182 & 25,14 \\
\hline Extranjeros A. Latina & 28 & 3,87 \\
\hline Indígenas & 2 & 0,28 \\
\hline $\mathbf{N} / \mathbf{E}$ & 105 & 14,50 \\
\hline Total & 724 & 100,00 \\
\hline
\end{tabular}

Fuente: Elaboración propia a partir de los sumarios judiciales contenidos en los legajos del AGN, FTC PE y SE. 
Tabla 15

Casos de suicidio según ocupación (Buenos Aires, 1859-1888)

\section{Profesión / ocupación}

Peones / Trabajadores / Jornaleros

Trabajadores artesanales indep.

Comerciantes - industriales

Especialistas urbanos

Desempleados

Trabajadores domésticos

Empleados de comercio

Empleados públicos

Funcionarios y Profesores

Rentistas y empresarios

Pequeños empresarios (agro)

Varios

Sin especificar

Total

\author{
$\mathbf{N}^{0}$ de casos $\%$
}

$\begin{array}{rr}77 & 10,64 \\ 71 & 9,81 \\ 66 & 9,12 \\ 59 & 8,15 \\ 52 & 7,18 \\ 51 & 7,04 \\ 47 & 6,49 \\ 30 & 4,14 \\ 18 & 2,49 \\ 8 & 1,10 \\ 6 & 0,83 \\ & \\ 38 & 5,25 \\ 201 & 27,76\end{array}$

724

100,00

Fuente: Elaboración propia a partir de los sumarios judiciales contenidos en los legajos del AGN, FTC PE y SE. 
Tabla 16

Medios empleados en los suicidios y tentativas de suicidio

(Buenos Aires, 1884-1908)

Medio / Años

Armas cortantes y punzantes

Armas de fuego

Arrojándose a pozos

Arrojándose de la azotea

Arrojándose del balcón

Arrojándose al agua

Fósforos

Otras sustancias tóxicas

Aplastamiento (vehículos)

Caídas

Asfixia por inmersión

Asfixia por estrangulación

Asfixia por carbón

Quemaduras

Otros

Sin especificar

Total

Medio / Años

Armas cortantes y punzantes

Armas de fuego

Arrojándose a pozos

Arrojándose de la azotea

Arrojándose del balcón

Arrojándose al agua

Fósforos

Otras sustancias tóxicas

Aplastamiento (vehículos)

Caídas

Asfixia por inmersión

Asfixia por estrangulación

Asfixia por carbón

Quemaduras

Otros

Sin especificar

Total

1884
12
27
0
0
0
0
9
5
1
0
4
9
0
0
1
0
68

1889

15

67

0

0

0

0

8

14

5

0

2

8

0

0

0

8

127

1885
8
32
0
0
0
0
12
5
2
3
5
4
0
0
0
1
72

1890

15

78

0

0

0

0

7

9

4

0

4

6

0

0

0

2

125
1886

1887

$13 \quad 14$

$45 \quad 57$

0

0

0

0

15

10

4

4

6

4

0

0

0

0

101

1891

25

90

0

0

0

0

10

9

3

1

3

6

0

0

0

3

150
1888

12

56

0

0

0

0

0

19

7

0

3

4

0

0

0

13

114

1893

20

67

0

0

0

0

22

10

4

8

9

5

0

0

0

1

146 
Medio / Años

Armas cortantes y punzantes

Armas de fuego

Arrojándose a pozos

Arrojándose de la azotea

Arrojándose del balcón

Arrojándose al agua

Fósforos

Otras sustancias tóxicas

Aplastamiento (vehículos)

Caídas

Asfixia por inmersión

Asfixia por estrangulación

Asfixia por carbón

Quemaduras

Otros

Sin especificar

Total

Medio / Años

Armas cortantes y punzantes

Armas de fuego

Arrojándose a pozos

Arrojándose de la azotea

Arrojándose del balcón

Arrojándose al agua

Fósforos

Otras sustancias tóxicas

Aplastamiento (vehículos)

Caídas

Asfixia por inmersión

Asfixia por estrangulación

Asfixia por carbón

Quemaduras

Otros

Sin especificar

Total
1895 
Medio / Años

Armas cortantes y punzantes

Armas de fuego

Arrojándose a pozos

Arrojándose de la azotea

Arrojándose del balcón

Arrojándose al agua

Fósforos

Otras sustancias tóxicas

Aplastamiento (vehículos)

Caídas

Asfixia por inmersión

Asfixia por estrangulación

Asfixia por carbón

Quemaduras

Otros

Sin especificar

Total

$\begin{array}{rrrrr}\mathbf{1 9 0 4} & \mathbf{1 9 0 5} & \mathbf{1 9 0 6} & \mathbf{1 9 0 7} & \mathbf{1 9 0 8} \\ 27 & 25 & 27 & 36 & 43 \\ 98 & 111 & 122 & 145 & 159 \\ 5 & 3 & 3 & 3 & 3 \\ 5 & 5 & 5 & 3 & 9 \\ 0 & 0 & 0 & 0 & 0 \\ 0 & 0 & 0 & 0 & 0 \\ 2 & 0 & 0 & 1 & 0 \\ 62 & 63 & 87 & 118 & 118 \\ 11 & 19 & 14 & 5 & 14 \\ 0 & 0 & 0 & 0 & 0 \\ 3 & 2 & 2 & 7 & 7 \\ 19 & 16 & 21 & 20 & 28 \\ 3 & 2 & 0 & 1 & 5 \\ 0 & 0 & 0 & 0 & 0 \\ 0 & 0 & 0 & 0 & 3 \\ 4 & 4 & 0 & 4 & 4 \\ 239 & 250 & 281 & 343 & 393\end{array}$

\begin{tabular}{lrr}
\multicolumn{1}{c}{ Medio / Años } & Total & \% \\
Armas de fuego & 2.181 & 44,61 \\
Fósforos y otros tóxicos & 1.282 & 26,22 \\
Armas cortantes y punzantes & 565 & 11,56 \\
Asfixia por estrangulación & 269 & 5,50 \\
Asfixia por inmersión & 109 & 2,23 \\
Aplastamiento (vehículos) & 155 & 3,17 \\
Arrojándose a pozos & 68 & 1,39 \\
Arrojándose de la azotea & 65 & 1,33 \\
Caídas & 46 & 0,94 \\
Arrojándose al agua & 8 & 0,16 \\
Arrojándose del balcón & 2 & 0,04 \\
Asfixia por carbón & 18 & 0,37 \\
Quemaduras & 1 & 0,02 \\
Otros & 5 & 0,10 \\
Sin espec. & 115 & 2,35 \\
Total & 4.889 & 100,00
\end{tabular}

Fuente: Elaboración propia a partir de los datos del Anuario Estadístico de la Ciudad de Buenos Aires (1899: 260); Luzuriaga (1909: 61). 
Tabla 17

Casos de suicidio según medio utilizado (Buenos Aires, 1859-1888)

Medio empleado / Sexo

Arma de fuego

Envenenamiento

Objeto cortante

Asfixia por suspensión

Arrojarse a un pozo de agua

Tirarse en las vías del tren / tranvía

Precipitación (desde lugar elevado)

Asfixia por sumersión

Asfixia (bracero)

Otros

No especifica

Total

\begin{tabular}{crrrrr} 
Hombres & \multicolumn{1}{c}{$\%$} & Mujeres & \multicolumn{1}{c}{$\%$} & Total & \multicolumn{1}{c}{$\%$} \\
331 & 58,48 & 21 & 13,29 & 352 & 48,62 \\
56 & 9,89 & 98 & 62,03 & 154 & 21,27 \\
94 & 16,61 & 6 & 3,80 & 100 & 13,81 \\
33 & 5,83 & 8 & 5,06 & 41 & 5,66 \\
9 & 1,59 & 13 & 8,23 & 22 & 3,04 \\
18 & 3,18 & 0 & 0,00 & 18 & 2,49 \\
7 & 1,24 & 7 & 4,43 & 14 & 1,93 \\
6 & 1,06 & 1 & 0,63 & 7 & 0,97 \\
1 & 0,18 & 4 & 2,53 & 5 & 0,69 \\
4 & 0,71 & 0 & 0 & 4 & 0,55 \\
7 & 1,24 & 0 & 0 & 7 & 0,97 \\
566 & 100,00 & 158 & 100,00 & 724 & 100,00
\end{tabular}

Fuente: Elaboración propia a partir de los sumarios judiciales contenidos en los legajos del AGN, FTC PE y SE. 
Tabla 18

Casos según el lugar donde tuvo lugar el acto suicida (Buenos Aires, 1859-1888)

\section{Espacio}

Domicilio personal

Vía pública

Lugar de trabajo o negocio

Espacios poco transitados

Espacios de sociabilidad

Casa de familiares y amigos

Alojamiento temporario

Lugares de encierro

Otros

Sin especificar

Total

\begin{tabular}{rr}
$\mathbf{N}^{\mathbf{0}}$ de casos & \multicolumn{1}{c}{$\%$} \\
351 & 48,48 \\
107 & 14,78 \\
63 & 8,70 \\
45 & 6,22 \\
44 & 6,08 \\
41 & 5,66 \\
24 & 3,31 \\
13 & 1,80 \\
15 & 2,07 \\
21 & 2,90 \\
724 & 100,00
\end{tabular}

Fuente: Elaboración propia a partir de los sumarios judiciales contenidos en los legajos del AGN, FTC PE y SE. ${ }^{340}$

340 Criterios: si especifica que el suicidio ocurrió en la habitación personal, más allá de que se trate de su negocio o espacio laboral, fue contabilizado como domicilio personal. Si no se aclara, fue contado como lugar de trabajo. En el caso de los empleados domésticos, los menores de edad fueron considerados como domicilio personal. En el caso de los mayores de edad que eran servicio doméstico, si el hecho ocurrió en el domicilio de su patrón, y no hay aclaración de espacio o habitación donde dormía, se consideró como lugar de trabajo.

Espacios poco transitados (baldíos, cementerio, parques, quintas, potreros, cerca de la rivera, el bajo, obra en construcción).

Vía pública (calles, plazas, tren). Alojamiento temporario (hotel, fonda). Espacios de sociabilidad (comercios, cafés, prostíbulos, restaurant, capilla).

Lugares de encierro (hospitales, asilos, cárceles).

Otro (casa del patrón, coche). 
Tabla 19

Causas determinantes de los suicidios, Buenos Aires (1884-1910)

$\begin{array}{lrrrrrrrr}\text { CAUSAS } & \mathbf{1 8 8 4} & \mathbf{1 8 8 5} & \mathbf{1 8 8 6} & \mathbf{1 8 8 7} & \mathbf{1 8 8 8} & \mathbf{1 8 8 9} & \mathbf{1 8 9 0} & \mathbf{1 8 9 1} \\ \text { Aflicción } & 4 & 6 & 1 & 0 & 0 & 0 & 0 & 0 \\ \text { Amores contrariados } & 9 & 4 & 7 & 9 & 0 & 7 & 11 & 9 \\ \text { Celos } & 1 & 0 & 4 & 3 & 0 & 0 & 0 & 0 \\ \text { Demencia } & 15 & 17 & 22 & 10 & 0 & 8 & 11 & 15 \\ \text { Disgustos de familia } & 13 & 6 & 9 & 17 & 0 & 15 & 12 & 20 \\ \text { Ebriedad } & 4 & 4 & 1 & 6 & 0 & 0 & 0 & 0 \\ \text { Hastío de la vida } & 4 & 4 & 9 & 6 & 0 & 11 & 12 & 11 \\ \text { Malos negocios } & 3 & 2 & 1 & 5 & 0 & 8 & 8 & 7 \\ \text { Malos tratamientos } & 1 & 0 & 1 & 0 & 0 & 2 & 1 & 0 \\ \text { Padecimientos físicos } & 5 & 6 & 6 & 12 & 0 & 8 & 8 & 14 \\ \text { Pobreza } & 7 & 3 & 7 & 1 & 0 & 9 & 5 & 17 \\ \text { Remordimiento } & 0 & 3 & 2 & 2 & 0 & 0 & 0 & 0 \\ \text { Causa ignorada } & 6 & 16 & 32 & 49 & 0 & 60 & 57 & 57 \\ \text { Totales } & 72 & 71 & 102 & 120 & 0 & 128 & 125 & 150\end{array}$

\section{CAUSAS}

Amores contrariados

Demencia

Disgustos de familia

Ebriedad

Hastío de la vida

Malos negocios

Malos tratamientos

Padecimientos físicos

Pobreza

Causa ignorada

Totales

$\begin{array}{lllllll}1890 & 1891 & 1892 & 1893 & 1894 & 1895 & 1896\end{array}$

$\begin{array}{rrrrrrr}11 & 9 & 14 & 13 & 11 & 15 & 17 \\ 11 & 15 & 11 & 10 & 9 & 12 & 24 \\ 12 & 20 & 16 & 28 & 27 & 31 & 55 \\ 0 & 0 & 1 & 5 & 4 & 1 & 1 \\ 12 & 11 & 13 & 6 & 14 & 28 & 26 \\ 8 & 7 & 12 & 2 & 7 & 6 & 2 \\ 1 & 0 & 0 & 1 & 2 & 1 & 0 \\ 8 & 14 & 7 & 14 & 15 & 15 & 26 \\ 5 & 17 & 12 & 7 & 13 & 8 & 11 \\ 57 & 57 & 51 & 60 & 75 & 63 & 67 \\ 125 & 150 & 137 & 146 & 177 & 180 & 229\end{array}$

CAUSAS

Amores contrariados

$\begin{array}{lllllll}1897 & 1898 & 1899 & 1900 & 1901 & 1902 & 1903\end{array}$

Demencia

Disgustos de familia

Ebriedad

Hastío de la vida

Malos negocios

Malos tratamientos

Padecimientos físicos

Pobreza

Causa ignorada

Totales

$\begin{array}{rrrrrrr}7 & 8 & 9 & 6 & 11 & 17 & 13 \\ 24 & 16 & 9 & 13 & 16 & 10 & 17 \\ 56 & 30 & 40 & 39 & 38 & 43 & 45 \\ 2 & 4 & 4 & 8 & 2 & 6 & 2 \\ 52 & 31 & 17 & 23 & 37 & 27 & 30 \\ 10 & 6 & 6 & 0 & 13 & 7 & 5 \\ 2 & 0 & 0 & 0 & 1 & 1 & 0 \\ 27 & 23 & 28 & 27 & 29 & 26 & 44 \\ 17 & 16 & 13 & 9 & 13 & 26 & 10 \\ 88 & 73 & 69 & 79 & 92 & 80 & 89 \\ 285 & 207 & 195 & 204 & 252 & 243 & 255\end{array}$


CAUSAS

Amores contrariados

Demencia

Disgustos de familia

Ebriedad

Hastío de la vida

Malos negocios

Malos tratamientos

Padecimientos físicos

Pobreza

Causa ignorada

Totales

CAUSAS

Amores contrariados

Demencia

Disgustos de familia

Ebriedad

Hastío de la vida

Malos negocios

Malos tratamientos

Padecimientos físicos

Pobreza

Causa ignorada

Otras causas

Totales $\begin{array}{lllllll}1904 & 1905 & 1906 & 1907 & 1908 & 1909 & 1910\end{array}$

$\begin{array}{lllllll}22 & 21 & 17 & 17 & 19 & 19 & 26\end{array}$

$\begin{array}{lllllll}14 & 19 & 18 & 9 & 13 & 11 & 21\end{array}$

$\begin{array}{lllllll}48 & 50 & 55 & 79 & 85 & 100 & 81\end{array}$

$\begin{array}{rrrrrrr}2 & 1 & 1 & 2 & 3 & 1 & 5\end{array}$

$\begin{array}{lllllll}36 & 32 & 39 & 46 & 63 & 70 & 44\end{array}$

$\begin{array}{lllllll}4 & 4 & 11 & 4 & 10 & 8 & 5\end{array}$

$\begin{array}{lllllll}0 & 2 & 0 & 0 & 0 & 1 & 1\end{array}$

$\begin{array}{lllllll}42 & 44 & 53 & 73 & 86 & 84 & 74\end{array}$

$\begin{array}{rrrrrrr}8 & 12 & 5 & 12 & 16 & 8 & 6\end{array}$

$\begin{array}{lllllll}63 & 65 & 82 & 101 & 98 & 115 & 105\end{array}$

$\begin{array}{lllllll}239 & 250 & 281 & 343 & 393 & 417 & 368\end{array}$

1884-1889

\section{\% 1890-1899}

$\%$ 1900-1910

\% Total \%

$\begin{array}{llllllll}44 & 8,92 & 114 & 6,23 & 188 & 5,79 & 346 & 6,21\end{array}$

$\begin{array}{llllllll}72 & 14,60 & 141 & 7,70 & 161 & 4,96 & 374 & 6,72\end{array}$

$\begin{array}{llllllll}60 & 12,17 & 315 & 17,20 & 663 & 20,43 & 1038 & 18,64\end{array}$

$\begin{array}{llllllll}15 & 3,04 & 22 & 1,20 & 33 & 1,02 & 70 & 1,26\end{array}$

$\begin{array}{llllllll}34 & 6,90 & 210 & 11,47 & 447 & 13,78 & 691 & 12,41\end{array}$

$\begin{array}{llllllll}19 & 3,85 & 66 & 3,60 & 71 & 2,19 & 156 & 2,80\end{array}$

$\begin{array}{rrrrrrrr}4 & 0,81 & 7 & 0,38 & 6 & 0,18 & 17 & 0,31\end{array}$

$\begin{array}{llllllll}37 & 7,51 & 177 & 9,67 & 582 & 17,94 & 796 & 14,29\end{array}$

$\begin{array}{llllllll}27 & 5,48 & 119 & 6,50 & 125 & 3,85 & 271 & 4,87\end{array}$

$\begin{array}{llllllll}163 & 33,06 & 660 & 36,05 & 969 & 29,86 & 1792 & 32,18\end{array}$

$\begin{array}{llrlrrrr}18 & 3,65 & 0 & 0,00 & 0 & 0,00 & 18 & 0,32\end{array}$

$\begin{array}{llllllll}493 & 100 & 1831 & 100 & 3245 & 100 & 5569 & 100\end{array}$

Fuente: Elaboración propia a partir de los Anuarios Estadísticos de la Ciudad de Buenos Aires (1891: 481; 1899: 259; 1906: 242); Luzuriaga (1909: 75); Lancelotti (1914: 109). ${ }^{341}$

341 Aclaración sobre los cambios en la tipología (Agrupación de remordimiento y aflicción en "otras causas"). 
Tabla 20 - Motivaciones y causas registradas en los sumarios, Buenos Aires 1859-

1888

Causas mencionadas

Patologías mentales

Pobreza

Conflictos con la pareja

Conflictos y asuntos de familia

Enfermedad o padecimientos físicos

Cansado / Aburrido / Hastiado de la vida

Mal estado de los negocios

Desengaño amoroso

Alcoholismo

Asuntos de reputación

Amores contrariados

Muerte de un familiar

Tristeza

Conflictos laborales

Otros Conflictos

Maltrato

Otros motivos o causas

Causas varias

No se especifica

Total
Número de casos

$\%$

103

14,23

53

7,32

40

5,52

39

5,39

38

5,25

35

4,83

28

3,87

27

3,73

25

3,45

23

3,18

17

2,35

14

1,93

7

0,97

6

0,83

3

0,41

0,41

19

2,62

9,12

66

24,59

178

100,00

Fuente: Elaboración propia a partir de los sumarios judiciales contenidos en los legajos del AGN, FTC PE y SE. ${ }^{342}$

342 En varios casos encontramos combinaciones de diferentes causas determinantes del acto suicida. Estas fueron agrupadas en la categoría "causas varias". A veces, las distintas variables eran presentadas (por el mismo o distintos testigos) como explicaciones alternativas o complementarias para dar cuenta de lo sucedido. En algunos casos, por ejemplo, los que declaraban explicaban que el suicida era pobre y sufría de alguna enfermedad. En otros, se hacía referencia a la combinación de la alienación mental y los efectos nocivos del consumo excesivo de bebidas alcohólicas. Asimismo, algunos suicidios eran explicados a partir de la acción conjunta de la miseria y el alcoholismo, que hacía perder el juicio, de forma momentánea, y agravaba el estado de desesperación. Éstas tres eran las combinaciones más frecuentes, entre otras. 
Tabla 21

Género de los suicidas en los casos cuya causa determinante está relacionada con el amor ("Desengaño amoroso", "Conflicto con la pareja", "Amores contrariados")

\begin{tabular}{lrrrr} 
Género & General & \% & Amor & \multicolumn{1}{c}{$\%$} \\
Hombres & 566 & 78,18 & 41 & 48,81 \\
Mujeres & 158 & 21,82 & 43 & 51,19 \\
Total & $\mathbf{7 2 4}$ & $\mathbf{1 0 0}$ & $\mathbf{8 4}$ & $\mathbf{1 0 0}$
\end{tabular}

Fuente: Elaboración propia a partir de los sumarios judiciales contenidos en los legajos del AGN, FTC PE y SE. 
Tabla 22

Edad de los suicidas en los casos cuya causa determinante está relacionada con el amor ("Desengaño amoroso", "Conflicto con la pareja", "Amores contrariados")

Datos del conjunto de los sumarios relevados

\begin{tabular}{lrrrrrr} 
Edad & Hombres & $\mathbf{\%}$ & Mujeres & \multicolumn{1}{c}{ Total } & \% \\
15 o menos & 5 & 0,69 & 16 & 2,21 & 21 & 2,9 \\
$16-20$ & 45 & 6,22 & 33 & 4,56 & 78 & 10,77 \\
$21-25$ & 86 & 11,88 & 31 & 4,28 & 117 & 16,16 \\
$26-30$ & 85 & 11,74 & 15 & 2,07 & 100 & 13,81 \\
$31-35$ & 62 & 8,56 & 14 & 1,93 & 76 & 10,5 \\
$36-40$ & 70 & 9,67 & 10 & 1,38 & 80 & 11,05 \\
41 o más & 95 & 13,12 & 10 & 1,38 & 105 & 14,5 \\
60 o más & 23 & 3,18 & 3 & 0,41 & 26 & 3,59 \\
No espec. & 95 & 13,12 & 26 & 3,59 & 121 & 16,71 \\
Total & $\mathbf{5 6 6}$ & $\mathbf{7 8 , 1 8}$ & $\mathbf{1 5 8}$ & $\mathbf{2 1 , 8 2}$ & $\mathbf{7 2 4}$ & $\mathbf{1 0 0}$ \\
& & & & & & \\
15 a 40 & 353 & 48,76 & 119 & 16,44 & 472 & 65,19 \\
20 a 40 & 348 & 48,07 & 103 & 14,23 & 451 & 62,29 \\
40 en & & & & & & 131 \\
adelante & 118 & 16,30 & 13 & 1,80 & & 18,09 \\
Menos de 20 & & & & & & \\
años & 50 & 6,91 & 49 & 6,77 & & 13,67 \\
Total & 724 & 100 & & & &
\end{tabular}


Datos de los casos cuya causa determinante está relacionada con el amor

$\begin{array}{lrrrrrr}\text { Edad } & \text { Hombres } & \mathbf{\%} & \text { Mujeres } & \mathbf{\%} & \text { Total } & \text { \% } \\ 15 \text { o menos } & 1 & 2,44 & 2 & 4,65 & 3 & 3,57 \\ 16-20 & 5 & 12,20 & 15 & 34,88 & 20 & 23,81 \\ 21-25 & 10 & 24,39 & 11 & 25,58 & 21 & 25 \\ 26-30 & 8 & 19,51 & 3 & 6,98 & 11 & 13,10 \\ 31-35 & 1 & 2,44 & 3 & 6,98 & 4 & 4,76 \\ 36-40 & 3 & 7,32 & 2 & 4,65 & 5 & 5,95 \\ 41 \text { o más } & 3 & 7,32 & 0 & 0 & 3 & 3,57 \\ 60 \text { o más } & 1 & 2,44 & 1 & 2,33 & 2 & 2,38 \\ \text { No espec. } & 9 & 21,95 & 6 & 13,95 & 15 & 17,86 \\ \text { Total } & \mathbf{4 1} & \mathbf{1 0 0} & \mathbf{4 3} & \mathbf{1 0 0} & \mathbf{8 4} & \mathbf{1 0 0} \\ & & & & & & \\ 15 \text { a 40 } & 28 & 33,33 & 36 & 42,86 & 64 & 76,19 \\ 20 \text { a 40 } & 27 & 32,14 & 34 & 40,48 & 61 & 72,62 \\ 40 \text { en } & & & & & & 5 \\ \text { adelante } & 4 & 4,76 & 1 & 1,19 & 55 \\ \text { Menos de } 20 & 6 & 7,14 & 17 & 20,24 & 23 & 27,38 \\ \text { años } & \mathbf{8 4} & \mathbf{1 0 0} & & & & \end{array}$

Fuente: Elaboración propia a partir de los sumarios judiciales contenidos en los legajos del AGN, FTC PE y SE. 


\section{REFERENCIAS BIBLIOGRÁFICAS}

\section{- FUENTES INÉDITAS}

* Expedientes judiciales:

Archivo General de la Nación - Fondo Tribunal Criminal

Primera Entrega (Legajos):

A5, A6, A7, B2, B4, C4, D2, D4, F2, F5, G2, I2, M3, M4, M6, N2, O3, O5, P2, P4, S2, $\mathrm{U} 2, \mathrm{Z} 2$ / W1.

Segunda Entrega (Legajos):

A2, A3, A6, A9, A10, A11, A12, A13, A14, A15, A35, B4, B6, B8, B9, B11, B12, B13, B14, B15, B16, B17, B18, B20, B22, B23, B24, B25, B26, B27, B28, B29, B30, B32, B33, B34, B40, C2, C7, C10, C12, C15, C16, C18, C19, C21, C22, C23, C24, C25, C26, C27, C28, C29, C30, C32, C33, C34, C35, C36, C37, C38, C40, C44, C46, C47, C87, D2, D4, D6, D7, D9, D11, D14, D17, D18, D19, D21, D22, D24, D83, E3, E4, E5, E8, E9, E10, E13, E14, E15, F3, F5, F7, F8, F9, F10, F13, F17, F18, F19, F21, F23, F24, G4, G6, G8, G11, G12, G13, G14, G15, G17, G18, G20, G21, G22, G24, G25, G26, G29, G30, G31, G32, G35, G36, G 37, G38, G39, G40, G41, G43, H2, H6, H7, I2, I3, I4A, I5, J3, J5, J6A, J10, K1, K3, K4, L1A, L2, L6, L8, L9, L11A, L12A, L12B, L13A, L13B, L14, L15, L17, L18, L19, L20, L21, L22, L23, L24, L26, L27, L29, L31A, L31B, M4, M10, M11, M14, M15, M16, M17, M18A, M18C, M20, M21, M24, M25, M27, M28, M29, M31, M33, M34, M35, M37, M39, M40B, M41, M42, M43B, M44, N1, N2, N3, N4, N5, N6, N7, O2, O3, O7, P8, P9, P12B, P14, P18, P19, P20, P21, P22, P23, P25, P27, P28, P29B, P30, P31, P32, P33, P34, P35, P37, P39, P40, R2, R3, R9, R10, R16, R18, R19, R20, R21, R22, R23, R26, R27, R28, R29, R30, R34, R35, R36, R37, R38, S2, S4A, S7, S8, S9, S10, S15, S17, S19, S20, S21, S23, S24, S28, S30, S31, S34, S36, S37, S38, S39, S41, S44, S46, S49, S50, T3, T5, T9, T10, T11, T14, U2, U4, V1, V4, V5, V6, V8, V10, V11, V13, V14, V16A, V17, V18, V19, W1, W2, Z3.

* Prensa:

El Nacional

Año: 1856

\section{La Nación}

Años: 1870, 1872, 1873, 1875-1879, 1881-1892, 1895, 1896, 1898, 1904, 1905.

\section{La Prensa}

Años: 1870, 1872, 1873, 1875-1879, 1881-1892, 1895, 1896, 1898, 1904, 1905. 


\section{- FUENTES EDITAS}

- Anuario Estadístico de la Ciudad de Buenos Aires, Año I - 1891, Buenos Aires, Dirección General de Estadística Municipal, 1892.

-----, Año VIII - 1898, Buenos Aires, Dirección General de Estadística Municipal, 1899.

-----, Año XV - 1905, Buenos Aires, Dirección General de Estadística Municipal, 1906.

- ARREGUINE, Víctor (1898), "El suicidio”, en Criminología Moderna, Buenos Aires, Tomo I, pp. 5-10.

----- (1899), “El suicidio”, en Estudios Sociales, Buenos Aires.

---- (1905), "El suicidio", en Archivos de Psiquiatría Criminología y Ciencias Afines, Buenos Aires, Tomo IV, pp. 695-706.

- BECCARIA, César (1955 [1764]), De los delitos y de las penas, Buenos Aires, Arayú.

- BIALET MASSÉ, Juan (1885), Lecciones de medicina legal: aplicada a la legislación de la República Argentina, La Velocidad, Córdoba.

- BLANCAS, Manuel (1884), "Carta al Círculo Médico Argentino", en Anales del Círculo Médico Argentino, Buenos Aires, vol. 7.

- BRIERRE DE BOISMONT, Alexandre (1865 [1856]), Du Suicide et de la Folie Suicide, París, Librarie Germer Baillièré.

- Código Penal de la Provincia de Buenos Aires (1996 [1877]), Madrid, A-Z editora.

- Código penal reformado y leyes complementarias de la República Argentina en vigencia desde el 1 de marzo de 1887 (1919), Buenos Aires, M. A. Rosas.

- CONI, Emilio R. (1891), Código de Higiene y Medicina Legal, Librería de Juan Etchepareborda, Buenos Aires.

- DEL CAMPO, Ricardo (1898), "Los crímenes románticos”, en Criminología Moderna, Buenos Aires, Tomo I, pp. 42-43.

- ESPINOSA, Mariano (1905), "Pastoral sobre el suicidio", en Revista Eclesiástica, Año V, Buenos Aires, Escuela Tipográfica del Colegio Pio IX de Artes y Oficios.

----- (1915), "Pastoral sobre el suicidio", en Revista Eclesiástica, Año XV, Buenos Aires, Escuela Tipográfica del Colegio Pio IX de Artes y Oficios.

- GACHÉ, Samuel (1884), "Patogenia del suicidio en Buenos Aires", en Anales del Círculo Médico Argentino, Buenos Aires. Vol. 7.

(1886), Estudio de Psicopatología, Universidad de Buenos Aires, Facultad de Ciencias Médicas, Buenos Aires, Imprenta de M. Biedma.

- GARELLI, Pacífico (1886), El Suicidio: Examinado en si y en sus causas. Estudio filosófico, histórico, social sobre las huellas de los más ilustres escritores antiguos y modernos, Buenos Aires, La Nación.

- INGENIEROS, José (1962 [1911]), "La piedad homicida", en Obras Completas, Tomo I, Buenos Aires, Ediciones Mar Océano.

- KORN, Alejandro (1883), Locura y Crimen, Tesis de la Facultad de Ciencias Médicas de la Universidad de Buenos Aires, Buenos Aires, Imprenta de La Nación. 
- LAMARQUE, Adolfo (1871), Ensayos Poéticos, Buenos Aires, Imprenta de Pablo E. Coni.

- LANCELOTTI, Miguel (1900), "La imitación en el delito y en el suicidio", en Criminología Moderna, Buenos Aires, Tomo II, pp. 575-580.

----- (1914), La criminalidad en Buenos Aires, al margen de la estadística (1887-1912), Buenos Aires, Librería Jurídica.

- LATZINA, Francisco (1896), "Los suicidios en Buenos Aires, durante el último quindenio (1881-1895)", en Anuario de la Dirección General de Estadística (1895), Buenos Aires, Compañía Sud-americana de Billetes de Banco.

- LUZURIAGA, P. Amílcar (1909), El suicidio en Buenos Aires, Universidad de Buenos Aires, Facultad de Ciencias Médicas, Buenos Aires.

- MATA, Pedro D. (1866), Tratado de Medicina y Cirugía Legal. Teórica y práctica. Seguido de un compendio de toxicología, Madrid, Universidad Central, Carlos Bailly Bailliere.

- MELÉNDEZ, Lucio (1892), “La Locura en Buenos Aires”, en Anuario Estadístico de la Ciudad de Buenos Aires, Año I - 1891, Buenos Aires, Dirección General de Estadística Municipal.

- MÉNDEZ CASARIEGO, Alberto (1888), La criminalidad de la ciudad de Buenos Aires en 1887, Buenos Aires, Imprenta del Departamento de Policía de la Capital.

- MITRE, Jorge Mariano (1871), Poesías, Buenos Aires, Imprenta y librería de Mayo.

- MORSELLI, Enrico (1882 [1879]), Suicide: An Essay on Comparative Moral Statistics, New York, D. Appleton and Company.

- QUESADA, Ernesto (1907), Herbert Spencer y sus doctrinas sociológicas, Buenos Aires, Librería de J. Menéndez, Talleres Gráficos de la Penitenciaría Nacional.

----- (1926), La época de Rosas, Artes y Letras, Buenos Aires.

----- (2011), Las doctrinas sociológicas de Augusto Comte, Buenos Aires, Urbanita.

- RAMOS MEJÍA, José María (1896), “La tentación del suicidio", en Anales del Departamento Nacional de Higiene, Año VII, $\mathrm{n}^{\circ} 23$, Buenos Aires.

----- (1952 [1899]). Las multitudes argentinas, Buenos Aires, Kraft

----- (1932 [1878]), Las Neurosis de los hombres célebres en la historia argentina, Buenos Aires, Talleres Gráficos Argentinos L. J. Rosso.

- RODRÍGUEZ, Fermín (1897), Alcoholismo y suicidio. Tesis doctoral. Buenos Aires, Universidad de Buenos Aires, Facultad de Ciencias Médicas, Imprenta de Pablo E. Coni e hijos.

----- (1903), "Determinantes lógicas del suicidio", en Archivos de Psiquiatría y criminología aplicadas a las ciencias afines, año II, nº V, mayo 1903.

----- (1904), "Estudios sobre el suicidio en Buenos Aires. La influencia de la edad y del sexo", en Archivos de Psiquiatría y Criminología aplicadas a las ciencias afines, año III, enero-febrero 1904.

----- (1905), "Influencia del estado civil sobre el suicidio en Buenos Aires", Archivos de Psiquiatría y Criminología aplicadas a las ciencias afines, año IV, julio-agosto 1905. 
(1905), "Influencia del alcoholismo sobre el suicidio en Buenos Aires", Archivos de Criminología, Medicina Legal y Psiquiatría, T. IV, 1905.

- SARMIENTO, Domingo F. (1951 [1856]), "La comunidad de la tumba", en Obras completas, T.XXIV, Buenos Aires, Editorial Luz del Día, pp. 308-309.

- TEJEDOR, Carlos (1866), Proyecto de código penal para la República Argentina trabajado por encargo del gobierno nacional, Buenos Aires, Imprenta del Comercio del Plata.

----- (1871 [1860]), Curso de Derecho Criminal, segunda edición, Buenos Aires, Librería de Cl. M. Joly.

- VÁSQUEZ, José T. (1891), Suicidio y Locura, Facultad de Ciencias Médicas, Universidad Nacional de Buenos Aires, Buenos Aires, Imprenta Europea.

- VÉLEZ SÁRSFIELD, Dalmasio (1971 [1856]), "Sepultura de los suicidas", en Colección de Textos y Documentos para la Historia del Derecho Argentino, T. XI, Buenos Aires, Facultad de Derecho y Ciencias Sociales, Instituto de Historia del Derecho Ricardo Levene.

- VIAZZI, Pio (1899), “El amor y el dolor en la criminalidad”, en Criminología Moderna, Buenos Aires, Tomo I, pp. 166-168.

- VUCETICH, Juan (1903), "Diez años de suicidio en Buenos Aires", en Archivos de psiquiatría, criminología y ciencias afines, Buenos Aires. Tomo II.

- WILDE, Eduardo (1917), “Apuntes para un Tratado de Jurisprudencia Médica”, en Obras Completas, Peuser, Buenos Aires, Vol. 4.

- Congreso Nacional, Diario de Sesiones de la Cámara de Senadores, período de 1903, Buenos Aires, Establecimiento Tipográfico "El Comercio", 1904, pp. 131-132.

- Diario de Sesiones de la Cámara de Diputados de la Provincia de Buenos Aires, Buenos Aires, Imprenta de "El Nacional", 1876, pp. 770-790.

- VILlegas, S., UGARRIZA, A., y GARCÍA J. A. (1881), Proyecto de Código Penal, Buenos Aires, Imprenta de El Nacional.

* Novelas:

- Lucio V. LÓPEZ, La gran aldea (1884). Versión electrónica en formato pdf disponible en: $\quad$ http://www.elaleph.com/presenta datos pago.cfm? $\mathrm{id}=672 \&$ identifica $=870 \& \mathrm{w}$ gratuito $=1$

- Eugenio CAMBACERES, Sin rumbo (1885). Versión electrónica en formato pdf disponible en: http://es.scribd.com/doc/218508698/17756908-Cambaceres-Eugenio-Sin -Rumbo

- Julián MARTEL, La Bolsa (1891). Versión electrónica en formato pdf disponible en: http://www.elaleph.com/presenta_datos_pago.cfm?id=708\&identifica $=905 \&$ wgratuito $=$ $\underline{1}$

- Carlos María OCANTOS, Quilito (1891). Versión electrónica en formato pdf disponible en: http://espanol.Free-eBooks.net

- Segundo VILlaFAÑE, Horas de fiebre (1891). Buenos Aires, Universidad de Facultad de Filosofía y Letras Buenos Aires, 1960. 
- J. W. GOETHE (2004 [1774]), Las desventuras del joven Werther, Barcelona, Editorial Juventud.

\section{BIBLIOGRAFÍA}

- ABRIC, J. C. (2001), Prácticas sociales y representaciones, México, Ediciones Coyoacán.

- ADAMOVSKY, Ezequiel (2009), Historia de la clase media argentina, Buenos Aires, Planeta.

----- (2012), Historia de las clases populares en la Argentina: Desde 1880 hasta 2003, Buenos Aires, Sudamericana.

- ALONSO, Paula (1997), "<<En la primavera de la historia $>>$. El discurso político del roquismo de la década del ochenta a través de su prensa", en Boletín del Instituto de Historia Argentina y Americana "Dr. Emilio Ravignani", Tercera serie, no 15.

(2000), Entre la revolución y las urnas. Los orígenes de la Unión Cívica Radical y la política argentina de los años '90, Buenos Aires, Sudamericana.

- ÁlVAREZ, Adriana (1996), "Ramos Mejía: salud pública y multitud en la Argentina finisecular”, en Mirta Z. Lobato (ed.), Política, médicos y enfermedades. Lecturas de historia de la salud en la Argentina, Buenos Aires, Biblos.

- ALZATE ECHEVERRI, Adriana María (2015a), "Francisco Felipe del Campo y Rivas (1802). Homicidio de sí mismo en Santa Fe de Bogotá", en Microhistorias De La Transgresión, Colombia, Centro De Estudios Sociales (Ces), Universidad Nacional De Colombia.

---- (2015b), “'El escandaloso delito de matarse'. Proceso criminal contra el esclavo Ambrosio Mosquera, Nuevo Reino de Granada, 1775", en Una Obra Para La Historia: Homenaje A Germán Colmenares, Colombia, Editorial Universidad del Rosario.

- ANSALDI, Waldo (2004), “¿Clase social o categoría política? Una propuesta para conceptualizar el término oligarquía en América Latina”, en Anales, Nueva Época, Instituto Iberoamericano, Universidad de Göteborg, $n^{\circ}$ 7/8, 2004/2005, pp. 157-169. Disponible en: http://geshal.sociales.uba.ar/libros-de-waldo-ansaldi/\#sthash. RZPC1ORe.dpuf [Consultado el 12/08/2015].

- ARIÈS, Philippe (1996), "El suicidio”, en Ensayos de la memoria 1943-1983, Bogotá, Norma.

----- (2000), Morir en Occidente: desde la Edad Media hasta la actualidad, Buenos Aires, Adriana Hidalgo Editora.

----- (2011), El hombre ante la muerte, Buenos Aires, Taurus.

- ARMUS, Diego (2000), "El descubrimiento de la enfermedad como problema social", en Mirta Lobato (dir.), Nueva Historia Argentina, Buenos Aires, Sudamericana. Tomo $\mathrm{V}$.

----- (2005), "Legados y tendencias en la historiografía sobre la enfermedad en América Latina moderna", en (ed.), Avatares de la medicalización en América Latina 1870-1970, Buenos Aires, Lugar Editorial.

---- (2010), “¿Qué historia de la salud y la enfermedad?”, Salud Colectiva, nº 6, pp. 510 . 
- ARROYO, Julián (2015) Cansados de la vida, locos apasionados y ciudadanos estoicos: representaciones del suicidio en la Provincia de Buenos Aires. Tandil (18811910), Universidad Nacional del Centro de la Provincia de Buenos Aires, Facultad de Ciencias Humanas, Tesis de Grado, Tandil.

----- (2017) “Aliados para vencer a la "suprema desesperación”: las redes sociales en los casos de suicidio de los trabajadores inmigrantes desocupados (Buenos Aires, 18641888)", en Andrea Reguera (Dir.), Los vínculos que forman redes. Las dimensiones relacionales de lo social y sus articulaciones a escalas diferenciadas, Buenos Aires, Editorial Teseo.

- AVELLANEDA, Andrés (1980), "El naturalismo y E. Cambaceres", en Historia de la literatura argentina: del romanticismo al naturalismo, Buenos Aires, Centro Editor de América Latina.

- AYROLO, Valentina (2009), "Reflexiones sobre el proceso de 'secularización' a través del 'morir y ser enterrado'. Córdoba del Tucumán en el siglo XIX”, Dimensión Antropológica, vol. 46, Instituto Nacional de Antropología e Historia, México, mayoagosto.

- AZPEITIA MARTÍN, María (2008), "Historiografía de la "historia de la muerte", Studia historica, Historia Medieval, vol. 26, Salamanca, Ediciones de la Universidad de Salamanca.

- BAECHLER, Jean (1975), Les suicides, Paris, Calmann-Lévy.

- BARRENECHE, Osvaldo (1999), "Fuentes judiciales", en Jornadas La Fuente Judicial en la Construcción de la Memoria, Mar del Plata, Universidad Nacional de Mar del Plata y Departamento Histórico Judicial.

- BASTIAN, Jean-Pierre (2004), "Introducción: Aprender a descentrar la mirada sobre la modernidad religiosa" en (coord.), La modernidad religiosa: Europa y América Latina en perspectiva comparada, México, FCE.

(1990), "Introducción", en (comp.), Protestantes, liberales y Francmasones, Sociedades de ideas y modernidad en América Latina, México, FCE.

- BELMAR, D. (2015a) "Dame mi anillo o mátame". Suicidio y afectividad en registros judiciales de Santiago y San Felipe, 1920-1937”, Revista Historia y Justicia, $\mathrm{n}^{\circ}$ 4, Santiago de Chile, pp. 103-137.

(2015b) “"Mire, Papá"-Notas para un estudio microhistórico del suicidio en tiempos de crisis económica. El caso de Julio Antolín Alfaro, Santiago de Chile, 1930”, en Nuevo Mundo Mundos Nuevos [en línea], Coloquios, Puesto en línea el 25 noviembre 2015, consultado el 06 septiembre 2016. Url: http://nuevomundo.revues.org/ 68642; DOI: 10.4000/nuevomundo.68642

- BELTRÁN ABARCA, F. (2015), "La construcción de la epidemia de suicidios: interpretaciones y confrontaciones de los letrados en torno a sus causas sociales. Ciudad de México, 1830-1876", Trashumante. Revista Americana de Historia Social, n ${ }^{\circ}$, pp. 60-82.

- BERTONI, Lilia Ana (1992), "Construir la nacionalidad: héroes, estatuas y fiestas patrias, 1887-1891”, en Boletín del Instituto Ravignani, n5, setiembre 1992.

----- (1996), "Nacionalidad o cosmopolitismo, la cuestión de las escuelas de las colectividades extranjeras a fines del siglo XIX”, Anuario del IEHS, n¹, Tandil.

---- (2001), Patriotas, cosmopolitas y nacionalistas. La construcción de la 
nacionalidad argentina a fines del siglo XIX, Buenos Aires, Fondo de Cultura Económica.

- BERTRAND, Michel (2016), "Del actor a la red: análisis de redes e interdisciplinaridad", Nuevo Mundo Mundos Nuevos. Disponible en: http://nuevomundo.revues.org/57505.

- BIAGINI, Hugo (comp.) (1985), El movimiento positivista argentino, Buenos Aires, Editorial de Belgrano.

- BIANCHI, Susana (2005), Historia social del mundo contemporáneo. Del feudalismo a la sociedad contemporánea, Quilmes, Universidad Nacional de Quilmes Editorial.

- BLAKEMORE, Harold (1992), "Chile, desde la guerra del Pacífico hasta la depresión mundial, 1880-1930", en Leslie Betthell (ed.), Historia de América Latina, Barcelona, Editorial Crítica. Tomo X.

- BLASCO FERNÁNDEZ de MOREDA, F. (1962), "Instigación al suicidio", Enciclopedia Jurídica Omeba, Buenos Aires, Bibliográfica Omeba, Tomo XVI.

- BONALDI, Pablo (2002), "Evolución de las muertes violentas en la Argentina, 19801999”, en Sandra Gayol y Gabriel Kessler (comps.) Violencias, delitos y justicias en la Argentina, Buenos Aires, Manantial.

- BONDAR, César Iván (2012a), "Tanatosemiosis: comunicación con los niños difuntos. Tumbas, colores, epitafios, exvotos y memoria(s)", RUNA, XXXIII (2), Buenos Aires, FFyL - UBA, pp. 193-214.

----- (2012b), "Muerte, ritualización y memoria. Imágenes sobre la (re)memoración de los angelitos. Corrientes. Argentina", Corpus. Archivos virtuales de la alteridad americana, vol. $2, \mathrm{n}^{\circ} 1$, Mendoza.

- BOTANA, Natalio (2000), "Pensamientos y proyectos políticos 1880-1914", en Nueva Historia de la Nación Argentina, la configuración de la República independiente, Buenos Aires, Academia Nacional de la Historia. Tomo V, 1814-1914.

----- y GALLO, Ezequiel (2007), De la República posible a la República verdadera (1880-1910), Buenos Aires, Emecé Editores.

- BRAUDEL, Fernand (1979), La Historia y las ciencias sociales, Madrid, Alianza. Capítulo 3: "La larga duración", pp. 60 a 106.

- BRAZ Saraiva, Carlos (2011), "Suicídio: de Durkheim a Shneidman, do determinismo social à dor psicológica Individual”, Psiquiatria Clínica, nº 31, pp. 185-205.

- BURGUIÈRE, André (2009), La Escuela de los Annales. Una historia intelectual, Valencia, Universidad de Valencia. Capítulo 7: "Historia de la muerte. Antropología del cuerpo y conciencia de uno mismo".

- BURKE, Peter (1990), La revolución historiográfica francesa. La Escuela de los Annales: 1929-1989, Barcelona, Gedisa. Introducción y capítulos 1-4, pp. 11 a 109.

----- (2004), ¿Qué es la Historia cultural?, Barcelona, Paidós.

- CAGGIANO, María; ADAM, Sandra; PONCIO, Gabriela; FLORES, Olga y GARAY, Víctor Hugo (2005), "Historias de uso y desuso de cementerios en la Provincia de Buenos Aires", en Patrimonio cultural en cementerios y rituales de la muerte, Buenos Aires, Comisión para la Preservación del Patrimonio Histórico Cultural de la Ciudad de Buenos Aires, t. II. 
- CAIMARI, Lila (2009), "La antropología y la recepción de Lombroso en América Latina”, en Silvio Montaldo y Paolo Tappero (eds.), Cesare Lombroso cento anni dopo, UTET.

- CAMINOTTI, Daniel (2010), "Morir en el territorio de Neuquén: una aproximación al estudio del suicidio (1903-1957)", en Gabriel Rafart (comp.), Historia social y política del delito en Patagonia, Neuquén, Educo.

- CAMUS, Albert (2010), El mito de Sísifo, Buenos Aires, Losada.

- CANCIANI, Leonardo (2012), De las comandancias de frontera a las guardias nacionales. El liderazgo del coronel Don José Benito Machado en el sur de la campaña Bonaerense, Tesis de Licenciatura, Tandil, UNCPBA.

(2013), La identidad bonaerense. La expansión de la frontera: expediciones al “desierto”, Tandil, Ediciones del CESAL-UNCPBA.

- CANCIK LINDEMAIER, Hildegard (1997), "La muerte de Lucius Annaeus Seneca", en Auster, Centro de Estudios Latinos, Facultad de Humanidades y Ciencias de la Educación, Universidad Nacional de La Plata.

- CARETTA, Gabriela y ZACCA, Isabel (2007), "Lugares para la muerte en el espacio meridional andino, Salta en el siglo XVIII", Memoria Americana, $\mathrm{n}^{\circ} 15$, Buenos Aires, Instituto de Ciencias Antropológicas- UBA.

----- (2010), "Deambulando entre las Eusapias: lugares de entierro y sociedad tras la ruptura independentista en Salta”, en Cynthia Folquer y Sara Amenta (eds), Sociedad, Cristianismo y Política, Tucumán, CEPIHA-UNSA.

----- (2011), "Itinerarios de un cuerpo. Los segundos funerales de Güemes en el proceso de construcción de memorias", en Sara Mata y Zulma Palermo (comps.), La travesía de los discursos. Representaciones identitarias en Salta (siglos XVIII-XXI), Rosario, Prohistoria.

- CARETTA, Gabriela Alejandra (2015) "Y el Cielo se tiñó de rojo... Muerte heroica y Más allá en las Provincias Des-Unidas del Río de la Plata (1820-1852)", Locus: revista de história, Juiz de Fora, v. 21, n 2, p. 319-338.

- CARIDE BARTRONS, Horacio (2011) “Cuerpo y ciudad. Una metáfora orgánica para Buenos Aires a fines del siglo xix”, Anales del IAA, n 41(1), pp. 37-52.

- CASTILlO TRONCOSO, A. (2001) "Notas sobre la moral dominante a finales del siglo XIX en la Ciudad de México. Las mujeres suicidas como protagonistas de la nota roja", en C. Agostini y E. Speckman Guerra (coord.), Modernidad, tradición y alteridad. La ciudad de México en el cambio de siglo (XIX-XX), México, UNAM.

- CEVA, Mariela (2012), "El ciclo de la inmigración”, en Hernán Otero (dir.), Historia de la provincia de Buenos Aires, Tomo 1: Población, ambiente y territorio, Buenos Aires, Unipe.

- CHARTIER, Roger (1992), El mundo como representación, Barcelona, Gedisa.

- CHÁVEZ-HERNÁNDEZ, Ana-María y LEENAARS, Antoon (2010), "Edwin S Shneidman y la suicidología moderna", Salud Mental, nº 33.

- CHÁVEZ, Pablo y OVALLE, Alex (2015), ““Vengo en tomar por resolución única, la conclusión de mi fatal y asaroza escistencia": Justicia Y Voluntad Suicida. Arica, 19001930”, Revista Historia y Justicia, n 4, Santiago de Chile, p. 38-65.

- CHESNAIS, Jean-Claude (1992), "Historia de la violencia: el homicidio y el suicidio 
a través de la historia", Revista Internacional de Ciencias Sociales, $\mathrm{n}^{\mathrm{o}}$ 132, Barcelona, UNESCO.

- CIBOTTI, Ema (2000), "Del habitante al ciudadano: la condición del inmigrante”, en Mirta Lobato (dir.), Nueva Historia Argentina, Buenos Aires, Sudamericana. Tomo V.

- CICERCHIA, Ricardo (1998), Historia de la vida privada en la Argentina, Buenos Aires, Troquel. Tomo I.

----- (2001), Historia de la vida privada en la Argentina, Buenos Aires, Troquel. Tomo II.

- CLEMENTI, Hebe (1985), "José María Ramos Mejía”, en Hugo Biagini (comp.), El movimiento positivista argentino, Buenos Aires, Editorial de Belgrano.

- COHEN AGREST, Diana (2007), Por mano propia. Estudio sobre las prácticas suicidas, Buenos Aires, Fondo de Cultura Económica.

- CORTES CONDE, Roberto (1979), El Progreso Argentino, Buenos Aires, Sudamericana. Cap. II.

----- (1992), "El crecimiento de la economía argentina, c. 1870-1914”, en Leslie Bethell (ed.), Historia de América Latina, Barcelona, Crítica. Tomo 10.

---- (2000), “Finanzas públicas, moneda y Banco, 1810-1899”, en Nueva Historia de la Nación Argentina, la configuración de la República independiente, tomo V, 1814-1914, Buenos Aires, Academia Nacional de la Historia.

- CUTOLO, Vicente Osvaldo (1968), Nuevo Diccionario Biográfico Argentino (17501930), Buenos Aires, Editorial Elche.

- DAL CASTELLO, David (2014), "Dejar la casa. Espacios de los velorios en Buenos Aires. 1868-1903”, Anales del IAA, 44 (2), pp. 161-174. Consultado el 1/11/2017 en: www.iaa.fadu.uba.ar/ojs/index.php/anales/article/viewFile/146/134 .

----- (2016), La ciudad circular, espacios y territorios de la muerte en Buenos Aires, 1868-1903, Tesis de Maestría, Buenos Aires, Programa de Posgrado en Historia de la Facultad de Arquitectura, Diseño y Urbanismo de Universidad de Buenos Aires.

- DE CRISTÓFORIS, Nadia y FERNÁNDEZ, Alejandro (eds.) (2008), Las migraciones españolas a la Argentina. Variaciones regionales (siglos XIX y XX), Buenos Aires, Biblos.

- DE LUCA, Rubén Mario (2008), Funcionarios bonaerenses: 1810-1950, Buenos Aires, Dunken.

- DE PAZ TRUEBA, Yolanda (2010), Mujeres y esfera pública: la campaña bonaerense entre 1880 y 1910, Rosario, Prohistoria Ediciones.

- DELER, Jean-Paul (2008), "Transformaciones del espacio en América Latina", en Historia General de América Latina, Ediciones UNESCO, Tomo VII.

- DEVOTO, Fernando y MADERO, Marta (1999), Historia de la vida privada en la Argentina, Buenos Aires, Taurus, Tomo II.

- DEVOTO, Fernando (2000), "La inmigración”, en Nueva Historia de la Nación Argentina, la configuración de la República independiente, Buenos Aires, Academia Nacional de la Historia. Tomo IV (1814-1914).

----- (2005), Historia de la inmigración en la Argentina, Buenos Aires, Sudamericana. 
- DI GRESIA, Leandro (2011), "De los expedientes judiciales a las fuentes judiciales: reflexiones sobre las posibilidades y limitaciones de su uso en la investigación histórica", en Actas III Jornadas de Investigación en Humanidades, Bahía Blanca, Universidad Nacional del Sur.

----- (2014), Instituciones, prácticas y culturas judiciales. Una historia de la Justicia de Paz en la Provincia de Buenos Aires. El Juzgado de Paz de Tres Arroyos (1865-1935). Tesis de Doctorado, Universidad Nacional de La Plata. Capítulo XIII.

- DIAS, Maria Luiza (1991), Suicídio: Testemunhos de Adeus, Sao Paulo, Editora Brasiliense.

- DÍAZ COUSELO, José María (2014), "Delitos contra la religión y el culto en la codificación penal argentina (1853-1941)", Revista de Historia del Derecho Sección Investigaciones, $\mathrm{n}^{\circ}$ 48, Buenos Aires, INHIDE.

-DILLMANN, Mauro (2014), "El reposo de la "caveira bem vestida". Cementerios y representaciones de la muerte en Brasil y Argentina (siglos XIX y XX)", en Eliane Cristina Deckmann Fleck y Andrea Reguera (comp.), Variaciones en la comparación: procesos, instituciones y memorias en la historia de Brasil, Uruguay y Argentina, s. XVIII-XXI, Tandil, Universidad Nacional del Centro de la Provincia de Buenos Aires.

- DIODATI, Lilian y LIÑAN, Nora (1993), "Gestualidad y sentido de la muerte en el siglo XIX”, en Cristina Godoy y Eduardo Hourcade (comps.), La muerte en la cultura: ensayos históricos, Rosario, Universidad Nacional de Rosario.

- DI STÉFANO, Roberto y ZANATTA, Loris (2000), Historia de la Iglesia Argentina. Desde la Conquista a finales del siglo XX, Buenos Aires, Grijalbo-Mondadori.

- DI STÉFANO, Roberto (2010), Ovejas negras. Historia de los anticlericales argentinos, Buenos Aires, Sudamericana.

----- (2011), "Por una historia de la secularización y de la laicidad en la Argentina", Quinto Sol, vol. 15, n 1, Santa Rosa (La Pampa), pp. 1-32.

----- (2012), "El pacto laico argentino", PolHis. Boletín Bibliográfico Electrónico del Programa Buenos Aires de Historia Política, $\mathrm{n}^{\circ}$ 8. Dossier: "Catolicismo, sociedad y política: nuevos desafíos historiográficos”, editado por Miranda Lida y Diego Mauro, pp. 80-89. Disponible en: http://historiapolitica.com/boletin8/

- DONNA, Edgardo Alberto (1999), Derecho Penal. Parte Especial, Buenos Aires, Rubinzal - Culzoni Editores, Tomo I, pp. 94-99.

- DOUGLAS, Jack D. (1967), The social meanings of suicide, Princeton, Princeton University Press.

- DURKHEIM, Emile (2004), El suicidio. Estudio de sociología, Madrid, Editorial Losada [1 ${ }^{\mathrm{a}}$ ed. 1897].

- ELIAS, Norbert (2009), La soledad de los moribundos, México, Fondo de Cultura Económica.

- ETTE, Ottmar (2000), "Hacia una conciencia universal. Ciencia y ética en Alejandro de Humboldt", Debate y perspectivas, $\mathrm{n}^{\circ}$ 1, Madrid.

- FABREGAT PEREDO, M. (2015a) "La muerte bajo sospecha: procedimientos judiciales frente al suicidio, Chile, 1832-1920", en Nuevo Mundo Mundos Nuevos. URL: http://nuevomundo.revues.org/68654

---- (2015b) “El suicidio: exégesis judicial, reconstrucción estadística y caracterización. 
Provincia de Santiago, 1900-1920", Revista Historia y Justicia, nº4, Santiago de Chile, pp. 66-102.

- FALK, Pedro Frederico (2011), Retratos sombrios da modernidade. Memórias do suicídio no Recife durante a década de 1920, Recife, Tesis de Maestría.

- FALCÓN, Ricardo (1984), Los orígenes del movimiento obrero (1857-1899), Buenos Aires, CEAL.

----- (2000), "Los trabajadores y el mundo del trabajo", en Nueva Historia Argentina, Buenos Aires, Sudamericana. Tomo IV.

- FERREIRA, Jackson (2004), Loucos e pecadores: suicídio na Bahia no século XIX, Universidade Federal da Bahia, Tesis de Maestría.

- FIQUEPRON, Maximiliano Ricardo (2015), "Cadáveres, epidemias y funerales en Buenos Aires (1856-1886)", en Sandra Gayol y Gabriel Kessler (Editores), Muerte, politica y sociedad en la Argentina, Buenos Aires, Edhasa.

- FITZPATRICK, Scott (2011), "Looking Beyond the Qualitative and Quantitative Divide: Narrative, Ethics and Representation in Suicidology", Suicidology Online, vol. 2, pp. 29-37. Disponible en: http://www.suicidology-online.com/pdf/SOL-2011-2-2937.pdf

---- (2014a), “(Re)Moralizing the suicide debate”, Journal of Bioethical Inquiry, 11(2), pp. 223-232. Disponible en: http://link.springer.com/article/10.1007/s11673-014-9510-y

----- (2014b), "Stories worth telling: Moral experiences of suicidal behavior", Narrative Inquiry in Bioethics, 4(2), pp.147-160. Disponible en: http://muse.jhu.edu/journals/nib/ summary/v004/4.2.fitzpatrick.html

- FLORES, Alexis (2015), "Soy enfermo de cuerpo y alma y mejor muerto que vivir así'. Justificar el suicidio ante la justicia, Punta Arenas 1894-1899”, Revista Historia y Justicia, n ${ }^{\circ}$, Santiago de Chile, p. 38-65.

- FOUCAULT, Michel (2008), Historia de la Sexualidad, Argentina, Siglo XXI Editores. Tomo I.

- FRADKIN, Raúl (1999), "Fuentes judiciales", en Jornadas La Fuente Judicial en la Construcción de la Memoria, Mar del Plata, Universidad Nacional de Mar del Plata y Departamento Histórico Judicial.

- GALAFASSI, Guido (2001), "Las preocupaciones por la relación Naturaleza-CulturaSociedad. Ideas y teorías en los siglos XIX y XX. Una primera aproximación", Revista Theomai, $\mathrm{n}^{\circ} 3$.

- GALEANO, Diego (2007), "Mens sana in corpore sano: José M. Ramos Mejía y la medicalización de la sociedad argentina", Salud Colectiva, mayo-agosto, año/vol. 3, $\mathrm{n}^{\circ}$ 2, Buenos Aires, Universidad Nacional de Lanús.

- GALEANO, Diego (2009), Escritores, detectives y archivistas: la cultura policial en Buenos Aires, 1821-1910, Buenos Aires, Teseo.

- GALLARDO, Milagros y MARTINS, Patricia C. M. (2014), "La formación del clero en América. Los colegios seminarios de Córdoba (Argentina) y São Paulo (Brasil) en la segunda mitad del siglo XIX. Una perspectiva comparada", en Eliane Cristina Deckmann Fleck y Andrea Reguera (comp.), Variaciones en la comparación: procesos, instituciones y memorias en la historia de Brasil, Uruguay y Argentina, s. XVIII-XXI, Tandil, Universidad Nacional del Centro de la Provincia de Buenos Aires. 
- GALLO, Ezequiel y CORTÉS CONDE, Roberto (1984), La república conservadora, Buenos Aires, Paidós.

- GALLO, Ezequiel (1992), "Política y sociedad en Argentina, 1870-1916", en L. Bethell (ed.) Historia de América Latina, Barcelona, Crítica, Tomo 10.

----- (2000), "La consolidación del Estado y la Reforma política: 1880-1914”, en Nueva Historia de la Nación Argentina, la configuración de la República independiente, Buenos Aires, Academia Nacional de la Historia. Tomo IV (1814-1914).

- GANDOLFO, Rómolo (1999), "Las Sociedades italianas de socorros mutuos de Buenos Aires: cuestiones de clase y etnia dentro de una comunidad de inmigrantes 1880-1920", en Fernando Devoto y Eduardo Míguez, Asociacionismo, Trabajo e Identidad Étnica. Los italianos en América Latina en una perspectiva comparada, Buenos Aires, CEMLA-CSER-IEHS.

- GARCÍA BASALO, Juan Carlos (1998), "La codificación penal provincial argentina (1876-1886)", Revista de Historia del Derecho "Ricardo Levene”, n³ 34, Buenos Aires, pp. 125-223.

- GARDELLA, Lorenzo A. (1968), "Suicidio", Enciclopedia Jurídica Omeba, Buenos Aires, Bibliográfica Omeba, Tomo XXV.

- GARDETTE, Joëlle (2001), "Le ou les suicides? Entrevue avec Jean Baechler", Aspects sociologiques, vol 8, no 1-2, printemps 2001, pp. 64-71. Disponible en: http://www.fss.ulaval.ca/cms_recherche/upload/aspectssociologiques/fichiers/gardette e ntrevue2001.pdf, consultado el 12/08/2015.

- GAYOL, Sandra (2000), Sociabilidad en Buenos Aires. Hombres, honor y cafés, $1862-$ 1910, Buenos Aires, Ediciones del Signo.

----- (2002), "Elogio, deslegitimiación y estéticas de las violencias urbanas: Buenos Aires, 1870-1920", en Sandra Gayol y Gabriel Kessler, Violencias, Delitos y Justicias en la Argentina, Buenos Aires, Manantial, pp. 41-63.

---- (2004), “Sociabilidades violentas o el imposible amor popular”, en Hugo E. Biagini y Arturo A. Roig (dir.), El pensamiento alternativo en la Argentina del siglo XX, Tomo I, Buenos Aires, Biblos, pp. 219-232.

----- (2007), "Calumnias, rumores e impresos: las solicitadas en La Prensa y La Nación a fines del siglo XIX”, en Lila Caimari (comp.), La ley de los profanos. Delito, justicia y cultura en Buenos Aires (1870-1940), Buenos Aires, Fondo de Cultura Económica, pp. 67-98.

----- (2008), Honor y duelo en la Argentina moderna, Buenos Aires, Siglo XXI.

----- (2012), "La celebración de los grandes hombres: funerales gloriosos y carreras post mortem en Argentina”, Quinto sol, vol.16, n², Santa Rosa (La Pampa).

---- (2016), "La muerte en espejo: movilizaciones, emociones y política de masas", Anuario del Instituto de Historia Argentina, vol. 16, $\mathrm{n}^{\circ}$ 2, e 019, Universidad Nacional de La Plata, Facultad de Humanidades y Ciencias de la Educación, Centro de Historia Argentina y Americana.

- GAYOL, Sandra y KESSLER, Gabriel (2011), "La muerte en las ciencias sociales: una aproximación”, Persona y Sociedad, vol. XXV / no 1, Universidad Alberto Hurtado, Santiago de Chile, pp. 51-74.

- GAYOL, Sandra y KESSLER, Gabriel (2015), Muerte, política y sociedad, Ciudad 
Autónoma de Buenos Aires, Edhasa.

- GEERTZ, Clifford (1991), La interpretación de las culturas, México, Gedisa. Capítulo 4: "La religión como sistema cultural".

- GERALD, Martín (1991), "La literatura, la música y el arte de América Latina, 18701930”, en Leslie Bethell (ed.), Historia de América Latina, Barcelona, Crítica, Tomo 8.

- GERÉS, Osvaldo (2011), “Con el muerto a otra parte... consideraciones sobre la piedad mortuoria y sus espacios en la ciudad de Jujuy entre fines de la colonia y los primeros años independientes", Andes no 21, Salta, CEPIHA-UNSa.

-GINZBURG, Carlo (2004), "Huellas. Raíces de un paradigma indiciario", en Ginzburg, Carlo, Tentativas, Rosario, Prohistoria.

----- (2007), "O inquisidor como antropólogo", en O fio e os rastros: verdadeiro, falso, fictício, São Paulo, Companhia das Letras.

- GIRBAL-BLACHA, Noemí y QUATROCCHI-WOISSON, Diana (dir.) (1999), Cuando opinar es actuar. Revistas argentinas del siglo XX, Buenos Aires, Academia Nacional de la Historia.

- GODOY, Cristina y HOURCADE, Eduardo (comps.) (1993), La muerte en la cultura: ensayos históricos, Rosario, Universidad Nacional de Rosario.

- GONZÁLEZ GÓMEZ, Carmen Imelda y BASALDÚA HERNÁNDEZ, Manuel (2007), "La formación de redes sociales en el estudio de actores y familias. Perspectiva de estudio en historia y antropología", REDES- Revista hispana para el análisis de redes sociales, vol. 12, $\mathrm{n}^{\circ}$ 8, Junio 2007. Disponible en: http://ddd.uab.cat/pub/redes/ $15790185 \mathrm{v} 12 / \mathrm{Vol12} 8 . \mathrm{htm}$

- GONZÁLEZ LEANDRI, Ricardo (1996), "La profesión médica en Buenos Aires: 1852-1870", en Mirta Z. Lobato (ed.), Política, médicos y enfermedades. Lecturas de historia de la salud en la Argentina, Buenos Aires, Biblos.

----- (2004), "Notas acerca de la profesionalización médica en Buenos Aires durante la segunda mitad del siglo XIX", en Juan Suriano (comp.), La cuestión social en Argentina: 1870-1943, Buenos Aires, La Colmena.

----- (2006), "La consolidación de una inteligentzia médico profesional en Argentina: 1880-1900", Diálogos. Revista Electrónica de Historia, febrero-agosto, año/vol. 7, n 1 , Universidad de Costa Rica, pp.36-78.

- GRANOVETTER, Mark S. (1973), "The strength of weak ties", American Journal of Sociology, vol 78, $\mathrm{n}^{\circ}$ 6, pp. 1360-1380.

- GRINBERG, Keila (2009), “A História nos porões dos arquivos judiciários”, en Carla Bassanezi Pinsky y Tania Regina de Luca (orgs.), O historiador e suas fontes, São Paulo, Contexto.

- GUERRA, Diego Fernando (2010a), “La muerte 'chic': consumo, modernidad y cultura visual en las publicidades de empresas funerarias en Buenos Aires, 1898-1904", Bogotá, Ponencia presentada en el XV Congreso Colombiano de Historia.

----- (2010b), "Con la muerte en el álbum. La fotografía de difuntos en Buenos Aires durante la segunda mitad del siglo XIX”, Revue Trace 58: Las ciencias sociales y la muerte, Guatemala, CEMCA.

---- (2014), “Civilizar por el horror”, Amerika, n 11. Disponible en: http://amerika. revues.org/5716 
----- (2015), "Images et chroniques du bien et mal mourir", Amerika, n 12. Disponible en: http://amerika.revues.org/6426.

- GUTIÉRREZ, Leandro H. (2000), "Los trabajadores y sus luchas", en Romero, José Luis y Romero, Luis Alberto, Buenos Aires, Historia de cuatro siglos, Buenos Aires, Altamira. Tomo II.

----- (2000b), "La mala vida", en Romero, Jose Luis y Romero, Luis Alberto (2000), Buenos Aires, Historia de cuatro siglos, Buenos Aires, Altamira. Tomo II.

- GUTIÉRREZ, Leandro y SURIANO, Juan (2006 [1985]), "Vivienda, política y condiciones de vida de los sectores populares. Buenos Aires 1880-1930", en La vivienda en Buenos Aires (Jornadas de Historia), Buenos Aires, Instituto Histórico de la Ciudad de Buenos Aires.

- GUY, Donna (1994), El sexo peligroso, la prostitución legal en Buenos Aires, 1875 1955, Buenos Aires, Editorial Sudamericana.

---- (2014), "Prostitución y suicidio en Buenos Aires, 1880-1900”, en D. Barrancos, D. Guy y A. Valobra, Moralidades y comportamientos sexuales: Argentina, 1880-2011, Ciudad Autónoma de Buenos Aires, Biblos.

- HABERMAS, Jürgen (1993), El discurso filosófico de la modernidad, Madrid, Taurus, pp. 11-35.

- HABIF, Enrique (2005), El suicidio: Una lectura socio-psicoanalítica desde la salud pública, Buenos Aires, Ediciones en Salud Mental.

- HALE, Charles A. (1991), "Ideas políticas y sociales en América Latina 1870-1930", en Leslie Bethell (ed.), Historia de América Latina, Barcelona, Crítica. Tomo 8.

- HERNANDEZ SAMPIERI, Roberto, FERNANDEZ COLLADO, Carlos, BAPTISTA LUCIO, Pilar (1991), Metodología de la investigación, México, Mc. Graw-Hill. Cap. 4.

- HJELMELAND, Heidi (2010) "Cultural Research in Suicidology: Challenges and Opportunities”, Suicidology Online, n 1, pp.34-52.

- HJELMELAND, Heidi y KNIZEK, Birthe Loa (2011), “"What do they say?" Understanding suicidal behaviour in the framework of communication". Disponible en: http://www.inter-disciplinary.net/wpcontent/uploads/2011/10/knizekhjelmelandspaper. pdf

- HOURCADE, Eduardo (1993), "La muerte del tribuno", en Cristina Godoy y Eduardo Hourcade (comps.), La muerte en la cultura: ensayos históricos, Rosario, Universidad Nacional de Rosario.

- IMÍZCOZ, José María (2004), “Actores, redes, procesos: reflexiones para una historia más global”, Revista da Faculdade de Letras, Historia, Porto, III Serie, vol. 5, pp. 115140 .

- IRURZUN, Josefina (2014), La identidad bonaerense. Colectividades y asociaciones: espacios de encuentro, Tandil, Ediciones del CESAL - UNCPBA.

- ISAIS CONTRERAS, M. (2005), "Historias de melancolía y frenesí. Una aproximación al estudio del suicidio en la Guadalajara porfiriana”, Clío, vol. 5, n 34, pp. 61-80.

----- (2007a) "Suicidio y opinión pública en la Guadalajara de fines del siglo XIX: representaciones y censuras", Anuario del Seminario de Estudios Regionales, Tepatitlán de Morelos, pp. 107-133. 
----- (2007b) "Del homicidio voluntario a la monomanía suicida: perspectivas históricas y explicativas de un mismo fenómeno", Estudios Sociales, n 1, Guadalajara, pp. 133164.

- JANKÉLÉVITCH, Vladimir (2006), Pensar la Muerte, Buenos Aires, Fondo de Cultura Económica.

- JAUREGUI, Andrea (1993), "Imágenes e idea de la muerte en Buenos Aires", en Cristina Godoy y Eduardo Hourcade (comps.), La muerte en la cultura: ensayos históricos, Rosario, Universidad Nacional de Rosario.

- JIJENA, Ada (1992), "Gloria y Tragedia de Jorge Mariano Mitre", Todo es Historia $\mathrm{n}^{\circ}$ 302, Buenos Aires, pp. 38-48.

- JITRIK, Noé (1980), "El ciclo de la Bolsa”, en Historia de la literatura argentina: del romanticismo al naturalismo, Buenos Aires, Centro Editor de América Latina.

- KORN, Francis (2000), "La aventura del ascenso", en José Luis Romero y Luis Alberto Romero, Buenos Aires, Historia de cuatro siglos, Buenos Aires, Altamira. Tomo II.

- FERNÁNDEZ LABBÉ, M. (2004), “Ansias de tumba y de la nada: prácticas sociales del suicidio en el mundo pampino. Chile, 1874-1948”, en Marcos Fernández Labbé y otros, Arriba quemando el sol. Estudios de Historia Social Chilena: experiencias populares de trabajo, revuelta y autonomía (1830-1940), Santiago, LOM Ediciones.

----- (2006) "Incapaz de soportar ya esta vida. Suicidio femenino en Chile. 1884-1948", Nuevo Mundo Mundos Nuevos [en línea], Coloquios, Puesto en línea el 19 de noviembre de 2006.

- LACLAU, Ernesto (2005), "Le Bon: sugestión y representaciones distorsionadas", en La razón populista, Buenos Aires, FCE.

- LAPLAZA, Francisco P. (1978), "El proceso histórico de la Codificación Penal Argentina", Revista de Historia del Derecho Ricardo Levene, $\mathrm{n}^{\circ} 24$, Buenos Aires, Instituto de Investigaciones Jurídicas y Sociales A.L. Gioja, UBA.

- LATTES, Alfredo E. (1973), "Las migraciones en la Argentina entre mediados del siglo XIX y 1960”, Desarrollo Económico, vol. 12, n 48, pp. 849-865.

- LATTES, Alfredo E. y RECCHINI DE LATTES, Zulma (comp.) (1975), La población de Argentina, Buenos Aires, C.I.C.R.E.D. Series.

- LATTES, Alfredo E., ANDRADA, Gretel E., y CAVIEZEL, Pablo "Dinámica demográfica", en Lattes Alfredo E. (coord.), Dinámica de una ciudad: Buenos Aires 1810-2010, Buenos Aires, Dirección General de Estadística y Censos, Gobierno de la Ciudad de Buenos Aires, 2010, pp. 128-131, 138-146.

- LATTES, Alfredo E. y ANDRADA, Gretel E. (2012), "La población entre 1870 y 2000: una dinámica diferente", en Hernán Otero (dir.), Historia de la provincia de Buenos Aires, Tomo 1: Población, ambiente y territorio, Buenos Aires, Unipe.

- LE GOFF, Jacques (2005), Pensar la historia. Modernidad, presente, progreso, Barcelona, Paidós.

- LEFEBVRE, Henri (2006), La presencia y la ausencia. Contribución a la teoría de las representaciones, México, FCE. 
- LEVI, Giovanni (1990), La herencia inmaterial: la historia de un exorcista piamontés del siglo XVII, Madrid, Nerea.

- LIERNUR, José Francisco (1992), "Una ciudad efímera. Consideraciones sobre las características materiales de Buenos Aires en la segunda mitad del siglo XIX", Estudios Sociales, $\mathrm{n}^{\circ} 2$.

----- (2000) "La construcción del país urbano", en Mirta Lobato (dir.), Nueva Historia Argentina, Buenos Aires, Sudamericana. Tomo V.

- LIONETTI, Lucía (2005), "La función republicana de la escuela pública: la formación del ciudadano en Argentina a fines del siglo XIX", Revista Mexicana de Investigación Educativa, vol. X, n 27, México, Consejo Mexicano de Investigación Educativa.

(2007), La misión política de la escuela pública. Formar ciudadanos de la república (1870-1916), Buenos Aires, Miño y Dávila.

- LIONETTI, Lucía y MÍGUEZ, Daniel (comp.) (2010), Las infancias en la historia argentina. Intersecciones entre prácticas discursos e instituciones (1890-1960), Rosario, Prohistoria Ediciones.

- LOBATO, Mirta Z. (1996), "Lecturas de historia de la salud en la Argentina. Una introducción", en (ed.), Política, médicos y enfermedades. Lecturas de historia de la salud en la Argentina, Buenos Aires, Biblos.

----- (2000a), “Estado, gobierno y política en el régimen conservador”, en (dir.) Nueva Historia Argentina, Buenos Aires, Sudamericana. Tomo V.

----- (2000b), "Los trabajadores en la era del 'progreso", en (dir.), Nueva Historia Argentina, Buenos Aires, Sudamericana. Tomo V.

----- (2007), Historia de las trabajadoras en la Argentina, Buenos Aires, Edhasa.

- LOPES, Fábio Henrique (1998), O suicídio sem fronteiras: entre a razão e a desordem mental, Universidade Estadual de Campinas, UNICAMP, Brasil, Tesis de Maestría.

----- (2003), A experiência do suicídio: discursos médicos no Brasil, 1830-1900, Universidade Estadual de Campinas, UNICAMP, Brasil, Tesis de Doctorado.

- LÓPEZ MATO, Omar (2002), "Morir en Buenos Aires. Entierros, velatorios y cementerios en la vieja ciudad", Todo es Historia, n 424, Buenos Aires.

- LOSADA, Leandro (2006), "Sociabilidad, distinción y alta sociedad en Buenos Aires: los clubes sociales de la elite porteña (1880-1930)", Desarrollo Económico, n 180 , vol. 45, IDES, Buenos Aires.

----- (2008), La alta sociedad en la Buenos Aires de la belle epoque, Buenos Aires, Siglo XXI.

----- (2009), Historia de las elites en la Argentina, Buenos Aires, Sudamericana.

- LUCA, Tania Regina de (2008), "História dos nos e por meio dos periódicos", en Carla Bassanezi Pinsky (org.), Fontes históricas, São Paulo, Contexto, pp. 111-153.

- MACDONALD, Michael (1989), "The Medicalization of Suicide in England: Laymen, Physicians, and Cultural Change, 1500-1870", The Milbank Quarterly Vol. 67, Supplement 1, pp. 69-91. URL: http://www.jstor.org/stable/3350186

---- (1986) “The secularization of suicide in England, 1660-1800”, Past \& Present, $\mathrm{n}^{\circ}$ 111. 
- MAILHE, Alejandra (2013), "Histeria y sugestión en Argentina y Brasil. Redes intelectuales y trama de ideas en la psiquiatría y en la criminología de entre siglos", en XIV Jornadas Interescuelas/Departamentos de Historia, Departamento de Historia de la Facultad de Filosofía y Letras, Universidad Nacional de Cuyo, Mendoza.

- MALLIMACI, Fortunato (2004), "Catolicismo y liberalismo: las etapas del enfrentamiento por la definición de la modernidad religiosa en América Latina”, en Jean-Pierre Bastian (comp.), La modernidad religiosa. Europa Latina y América Latina en perspectiva comparada, México, FCE.

(2008), "Nacionalismo católico y cultura laica en Argentina", en Roberto Blancarte (coord.), Los retos de la laicidad y la secularización en el mundo contemporáneo, México, El Colegio de México.

- MALlO, Silvia (1999), "Fuentes judiciales", en Jornadas La Fuente Judicial en la Construcción de la Memoria, Mar del Plata, Universidad Nacional de Mar del Plata y Departamento Histórico Judicial.

----- (2000), "La sociedad entre 1810 y 1870", en Nueva Historia de la Nación Argentina, Buenos Aires, Academia Nacional de la Historia, Editorial Planeta, Tomo IV.

- MANDRINI, Raúl (1992), "Indios y fronteras en el área pampeana (siglos XVI-XIX), balance y perspectivas", Anuario IEHS, n 7, Tandil.

- MARQUIEGUI, Dedier Norberto (2012) "Un final no buscado: Los inmigrantes europeos entre la frustración del proyecto migratorio, el control estatal y la locura. Un acercamiento desde los libros de la colonia de alienados de Open Door (Inicios del siglo XX).”, Claroscuro. Revista del Centro de Estudios sobre Diversidad Cultural, $\mathrm{n}^{\mathrm{o}} 11$, pp. 149-174.

---- (2014), "Las mil caras de Lombroso en Argentina, Fotografía, “estigmas" físicos y condena social desde los libros de historias clínicas de la colonia nacional de alienados de Open Door, 1901-1930", Revista de Historia Bonaerense, $\mathrm{n}^{\circ}$ 43, Buenos Aires, IAHMM.

- MARTÍNEZ PÉREZ, José (2001), "Suicidio, crisis política y medicina mental en la Francia del siglo XIX (1801-1885)", FRENIA, vol. I-2, Madrid, AEN. Disponible en: http://www.revistaaen.es/index.php/frenia/article/view/16362/16208 [Consultado el 06/12/2014].

- MARX, Karl (2011), Acerca del suicidio, Buenos Aires, Las Cuarenta. Estudio preliminar de Ricardo Abduca [ $1^{\mathrm{a}}$ ed. 1846].

- MAYO, Carlos, MALLO, Silvia y BARRENECHE, Osvaldo (1989), "Plebe urbana y justicia colonial: las fuentes judiciales. Notas para su manejo metodológico", Estudios Investigaciones, $\mathrm{n}^{\mathrm{o}}$ 1, La Plata, pp. 47-80.

- MAYO, Carlos (1999), "La fuente judicial", en Jornadas La Fuente Judicial en la Construcción de la Memoria, Mar del Plata, Universidad Nacional de Mar del Plata y Departamento Histórico Judicial.

----- (2004), Porque la quiero tanto. Historia del amor en la sociedad rioplatense (1750-1860), Buenos Aires, Biblos.

- MAZZEO, Victoria (1998), "Mortalidad por suicidio en la Ciudad de Buenos Aires. Su magnitud y características. Transformaciones en el período 1980-1995", en Jornadas Nacionales de Debate Interdisciplinario en Salud y Población. Salud y población: cuestiones sociales pendientes, Buenos Aires, Espacio. 
- MEYER-MINNEMANN, Klaus (1997), La novela hispanoamericana de fin de siglo, México, FCE.

- MíGUEZ, Eduardo (2008), Historia económica de la Argentina. De la Conquista a la crisis de 1930, Buenos Aires, Sudamericana.

- MINOIS, Georges (1995), Histoire du suicide. La société occidentale face à la mort volontaire, Paris, Fayard.

- MORIN, Alejandro (2001), "Suicidas, apóstatas y asesinos. La desesperación en la Séptima Partida de Alfonso El Sabio", Hispania. Revista española de historia N²07, Madrid, CSIC. Disponible en: hispania.revistas.csic.es/index.php/hispania/ article/viewFile/310/310. [Consultado el 27/08/2015].

- MORON, Pierre (1980), El suicidio, Buenos Aires, Editorial Ábaco.

- MOSCOVICI, S. (1979), El psicoanálisis, su imagen y su público, Argentina, Huemul.

- MURRAY, Alexander (1998), Suicide in the Middle Ages, Oxford University Press.

- NIEVES SOSA, Emilce (2005), "La Creación del Cementerio Público de Mendoza", en Patrimonio cultural en cementerios y rituales de la muerte, Buenos Aires, Comisión para la Preservación del Patrimonio Histórico Cultural de la Ciudad de Buenos Aires, t. II.

- OTERO, Hernán (2006), Estadística y Nación: una historia conceptual del pensamiento censal de la Argentina Moderna, 1869-1914, Buenos Aires, Prometeo.

- OTERO, Marcelo Víctor (1991), El suicidio en la ciudad de Buenos Aires: su nacimiento como problema social, Buenos Aires, Facultad de Filosofía y Letras, UBA, Tesis de Licenciatura.

----- (2004), "Le suicide a Buenos Aires: la contribution des médecins à sa $<<$ thématisation $>>$ comme problème social", Canadian Bulletin of Medical History, vol. 32, no 2, Canadá, Canadian Society for the History of Medicine. Disponible en: http://www.cbmh.ca/index.php/cbmh/article/view/1297/1288.

- OWENS, Christabel, y LAMBERT, Helen (2012), "Mad, Bad or Heroic? Gender, Identity and Accountability in Lay Portrayals of Suicide in Late Twentieth-Century England", Culture, Medicine, and Psychiatry An International Journal of CrossCultural Health Research, VOL 36. Disponible en: https://www.researchgate.net/ profile/Christabel_Owens/publication/221877679_Mad_bad_or_heroic_Gender_identit y_and_accountability_in_lay_portrayals_of_suicide_in_late_twentiethcentury_England/ links/00b7d51b9 fac6efe 6 f000000.pdf

- OWENS, Christabel, OWEN, Gareth, BELAM, Judith, LAMBERT, Helen, DONOVAN, Jenny y RAPPORT, Frances (2012), "Suicide communication events: Lay interpretation of the communication of suicidal ideation and intent", Social Science \& Medicine 75, pp. 419-428. Disponible en: http://www.academia.edu/download/ 41916922/Suicide_communication_events_lay_interpr20160202-3950-14vnxfq.pdf

- PALACIO, Juan Manuel (1999), "Juicios e historias: algunas reflexiones metodológicas acerca del uso de la fuente judicial en la investigación histórica", en Jornadas La Fuente Judicial en la Construcción de la Memoria, Mar del Plata, Universidad Nacional de Mar del Plata y Departamento Histórico Judicial.

---- (2005-2006), “Hurgando en las bambalinas de 'la paz del trigo': algunos problemas teórico-metodológicos que plantea la historia judicial”, Quinto Sol, no 9-10, Santa Rosa (La Pampa), pp. 99-123. 
- PARDINAS, Felipe (1984), Metodología y técnicas de investigación en ciencias sociales, México, Siglo XXI. Caps. 3, 4 y 6.

- PARISE, Lidia y GONZÁLEZ, Abel (1971), La fin del mundo, Buenos Aires, Centro Editor de América Latina.

- PEÑA, David (1960), “Los cementerios, su secularización”, en La materia religiosa en la política argentina, Buenos Aires, Editorial Bases.

- PEÑA, José María (1998), "El luto, la pompa y los bemoles silenciosos”, en AAVV, El diario íntimo de un país. 100 años de vida cotidiana, Buenos Aires, La Nación.

- PEREYRA, Diego (2008), "Sociología e investigación social en la obra de Ernesto Quesada...", Políticas de la Memoria, Buenos Aires, CeDinci.

- PEREYRA, Liliana (1999), La muerte en Córdoba a fines del siglo XIX, Córdoba, Alción Editora.

- PINGUET, Maurice (1987), A morte voluntaria no Japao, Rio de Janeiro, Editorial Rocco.

- PIÑERO RAMÍREZ, Silvia L (2008), "La teoría de las representaciones sociales y la perspectiva de Pierre Bourdieu: Una articulación conceptual”, Revista de Investigación Educativa, $\mathrm{n}^{\circ} 7$, julio-diciembre, Instituto de Investigaciones en Educación, Veracruz (México), pp. 1-19.

- PITA, Valeria Silvina (2009), La Sociedad de Beneficencia en el manicomio La experiencia de administración y tutela del Hospital de Mujeres Dementes, Buenos Aires, 1852-1890, Tesis de Doctorado, Universidad de Buenos Aires, Facultad de Filosofía y Letras.

----- (2012), La casa de las locas. Una historia social del Hospital de Mujeres Dementes. Buenos Aires 1852-1890, Rosario, Prohistoria.

- PITT-RIVERS, Julian (1999), "La enfermedad del honor", Anuario IEHS, no 14, Tandil.

- PLOTKIN, Mariano Ben y ZIMMERMANN, Eduardo (comp.) (2012), Los saberes del estado, Buenos Aires, Edhasa.

- PLUMED, Domingo José Javier y ROJO MORENO, Luis (2012), “La medicalización del suicidio en la España del siglo XIX: aspectos teóricos, profesionales y culturales", Asclepio, Revista de Historia de la Medicina y de la Ciencia, vol. LXIV, $\mathrm{n}^{\circ} 1$, Madrid, Instituto de Historia / CSIC, 2012. Disponible en: http://asclepio.revistas.csic.es/ index.php/asclepio/article/viewFile/516/ 518. Consultado el 06/12/2014.

- PRATT, Mary Louise (2011), Ojos Imperiales. Literatura de viajes y transculturación, Buenos Aires, FCE.

- Preventing suicide: a global imperative (2014), World Health Organization. Disponible en: http://apps.who.int/iris/bitstream/10665/131056/1/9789241564779 eng. pdf?ua $=1$

- RAMELLA, Franco (1995), "Por un uso fuerte del concepto de red en los estudios migratorios", en Hernán Otero y María Bjerg (comps.), Inmigración y redes sociales en la Argentina moderna, Tandil, CEMLA/IEHS.

- RAMOS MEJÍA, Enrique (1988), Los Ramos Mejía. Apuntes históricos, Buenos Aires, Emecé. 
- REGUERA, Andrea (2006a), Patrón de Estancias. Ramón Santamarina: una biografía de fortuna y poder en la pampa, Buenos Aires, Eudeba.

----- (2006b), "Presentación. La modernidad de la transición. Las diferentes vías al capitalismo en Europa y América Latina", en (comp.), Los rostros de la modernidad: vías de transición al capitalismo: Europa y América Latina: siglos XIX y XX, Rosario, Prohistoria Ediciones.

---- (2007), "La multiplicidad de los posibles. Las formas del empresario rural en la Argentina del siglo XIX. Contrapunto de casos", en Jorge Schvarzer, Teresita Gómez y Marcelo Rougier (comps.), La empresa ayer y hoy. Nuevas Investigaciones y Debates, Buenos Aires, Universidad de Buenos Aires, Facultad de Ciencias Económicas.

---- (2013), La identidad bonaerense. Estancias con historia: historia de las estancias, Tandil, Ediciones del CESAL - UNCPBA.

---- (2017), “Introducción”, en Andrea Reguera (Dir.), Los vínculos que forman redes. Las dimensiones relacionales de lo social y sus articulaciones a escalas diferenciadas, Buenos Aires, Editorial Teseo.

- REGUERA, Andrea y GALLARDO, Milagros (2014), La identidad bonaerense. En la mirada de los viajeros europeos: relatos, imágenes e impresiones, Tandil, Ediciones del CESAL - UNCPBA.

- REVEL, Jacques (1995), "Microanálisis y construcción de lo social”, Anuario IEHS n ${ }^{\circ}$ 10, pp. 125-143.

- RÍOS, Julio Cesar y TALAK, Ana María (1999), "La niñez en los espacios urbanos", en Fernando Devoto y Marta Madero (comps.), Historia de la vida privada en la Argentina, Buenos Aires, Taurus, Tomo II.

- ROCCHI, Fernando (2000), "El péndulo de la riqueza: la economía argentina en el período 1880-1916", en Mirta Lobato (dir.), Nueva Historia Argentina, Buenos Aires, Sudamericana. Tomo V.

- ROCCHI, Femando (1999), "Inventando la soberanía del consumidor, publicidad, privacidad y revolución del mercado en Argentina, 1860-1940", en Fernando Devoto y Marta Madero, Historia de la vida privada en la Argentina, Buenos Aires, Taurus, Tomo II.

- ROCK, David (1977), El radicalismo argentino 1890-1930, Buenos Aires, Amorrortu.

- ROMERO, José Luis (2000), "La ciudad burguesa”, en José Luis Romero y Luis Alberto Romero, Buenos Aires, Historia de cuatro siglos, Buenos Aires, Altamira. Tomo II.

(2006), “La ciudad patricia”, en José Luis Romero y Luis Alberto Romero, Buenos Aires, Historia de cuatro siglos, Buenos Aires, Altamira. Tomo I.

----- (2010), “La conformación de la Argentina aluvial", en Las ideas políticas en Argentina, Buenos Aires, FCE.

- RUIBAL, Beatriz (1990), "El control social y la policía de Buenos Aires 1880-1920", Boletín del Instituto de Historia Argentina y Americana "Dr. E. Ravignani", Tercera Serie, $\mathrm{n}^{\circ} 2,1^{\mathrm{er}}$ semestre de 1990.

----- (1996), "Medicina legal y derecho penal a fines del siglo XIX”, en Mirta Z. Lobato (ed.), Política, médicos y enfermedades. Lecturas de historia de la salud en la Argentina, Buenos Aires, Biblos. 
- SÁENZ, Jimena (1973), "Los suicidas argentinos", Todo es Historia, no 73, Buenos Aires.

- SALESSI, Jorge (1995), Médicos, maleantes y maricas. Higiene, criminología y homosexualidad en la construcción de la nación Argentina (Buenos Aires: 1871-1914), Rosario, Beatriz Viterbo Editora.

- SABATO, Hilda (1989), Capitalismo y ganadería en Buenos Aires: la fiebre del lanar 1850-1890, Buenos Aires, Editorial Sudamericana.

- SÁBATO, Jorge (1987), La clase dominante en la formación de la Argentina moderna, Buenos Aires, CISEA/GEL.

- SAÍTTA, Sylvia (1998), Regueros de tinta. El diario Crítica en la década de 1920, Buenos Aires, Sudamericana.

- SALVATORE, Ricardo (2004), "Criminología positivista, reforma de prisiones y la cuestión social/obrera en Argentina”, en Juan Suriano (comp.), La cuestión social en Argentina: 1870-1943, Buenos Aires, La Colmena.

- SAN FRANCISCO, Alejandro (2006), "La apoteosis de Balmaceda. Desde la tumba solitaria a la gloria (Santiago, 1896)", en Carmen Mc Evoy (comp.), Funerales republicanos en América Latina: tradición, ritual y nación 1832-1896, Santiago de Chile, CIP-Centro de Estudios Bicentenario- Pontificia Universidad Católica de ChileInstituto de Historia.

- SARRAILH, Eduardo (2006), “Lámparas y adoquines", en José Luis Romero y Luis Alberto Romero, Buenos Aires, Historia de cuatro siglos, Buenos Aires, Altamira. Tomo I.

- SCHMITT, Jean-Claude (1976), "Le suicide au Moyen Age", Annales E.S.C., n 6.

- SCOBIE, James (1977), Buenos Aires. Del centro a los barrios. 1870-1910, Buenos Aires, Ediciones Solar.

---- (1991) "El crecimiento de las ciudades latinoamericanas", en L. Bethell (ed.), Historia de América Latina, Barcelona, Crítica, Tomo 7.

- SCOBIE, James y RAVINA DE LUZZI, Aurora (2000a), "El puerto y los ferrocarriles", en José Luis Romero y Luis Alberto Romero, Buenos Aires, Historia de cuatro siglos, Buenos Aires, Altamira. Tomo II.

----- (2000b), "El centro, los barrios y el suburbio", en José Luis Romero y Luis Alberto Romero, Buenos Aires, Historia de cuatro siglos, Buenos Aires, Altamira. Tomo II.

- SEDEILlAN, Gisela (2008), El proceso de conformación y consolidación de la institución policial en Tandil: 1872-1901, Tesis de Licenciatura en Historia, Tandil, UNICEN.

----- (2012), La justicia penal en la provincia de Buenos Aires: instituciones, prácticas y codificación del derecho (1877-1906), Buenos Aires, Biblos.

- SEOANE, Maria Isabel (2006), Un salvoconducto al cielo, prácticas testamentarias en el Buenos Aires indiano, Buenos Aires, Instituto de Investigaciones de Historia del Derecho.

- SESTO, Carmen (1999), "El refinamiento del vacuno y la vanguardia terrateniente bonaerense, 1856-1900", Anuario lEHS, n 14.

- SNYDER, Terri L. (2010), "Suicide, Slavery, and Memory in North America", The 
Journal Of American History, ${ }^{\circ} 1$.

- SOLER, Ricaurte (1968), El positivismo argentino, Buenos Aires, Paidós.

- STAGNARO, Juan Carlos (1997), "Lucio Meléndez y la primera matriz disciplinar de la Psiquiatría en Argentina", Temas de historia de la Psiquiatría Argentina, no 1. Disponible en: http://www.investigacion.cchs.csic.es/rihp/Temas1/1parte

- SURIANO, Juan (2004), "Introducción: una aproximación a la definición de la cuestión social en Argentina", en (comp.), La cuestión social en Argentina: 1870-1943, Buenos Aires, La Colmena.

- SWEENEY, L., OWENS, C., y MALONE, K. (2015), "Communication and interpretation of emotional distress within the friendships of young Irish men prior to suicide: A qualitative study.", Health \& Social Care in Community, 23(2), pp.150-158. Disponible en: https://ore.exeter.ac.uk/repository/bitstream/handle/ 10871/17803/HSCC $\% 20-\% 20$ Final $\% 20$ accepted $\% 20$ manuscript.pdf? sequence $=1$

- SZLAJEN, Fernando Fishel (2012), Suicidio y Eutanasia: en la filosofía occidental y en lo normativo y filosófico judio, Buenos Aires, Edición del autor.

- TERÁN, Oscar (2000), “Ernesto Quesada. Sociología y Modernidad", en Vida intelectual en Buenos Aires fin-de-siglo (1880-1910), Buenos Aires, FCE, pp. 207- 287.

----- (2010), Historia de las ideas en Argentina. Diez lecciones iniciales, 1810-1980, Buenos Aires, Siglo XXI.

- TRONCOSO, Oscar (2000), "Las formas del Ocio", en José Luis y Luis Alberto Romero, Buenos Aires, Historia de cuatro siglos, Buenos Aires, Altamira. Tomo II.

- VAN HAUVART, Carlos Alberto, Homicidio y suicidio, perspectivas y enfoques de la antropología para la construcción de la historia social, el caso de la provincia de Buenos Aires 1880-1900, Mar del Plata, UNMDP, mimeo.

- VASILACHIS DE GIALDINO, Irene (1993), Métodos cualitativos. Los problemas teóricos epistemológicos, Buenos Aires, CEAL, n 32, Tesis 5, 6 y 7, pp. 43-70.

- VEZZETTI, Hugo (1985), La locura en la Argentina, Buenos Aires, Paidós.

- VEYNE, Paul (1981), "Suicide, fisc, esclavage, capital et droit romain”, Latomus, XL.

- VILARDO, Fernando Pablo, "Víctor Arreguine ante el progreso humano". Disponible en: http://www.cecies.org/articulo.asp?id=102 [Consultado el 31/01/2018].

- VOVELLE, Michel (1985), Ideologías y mentalidades, Barcelona, Ariel.

- WADI, Yonissa M. (2008), “A escrita além da vida e da morte: mensagens de adeus de suicidas na Comarca de Toledo/PR (1980/1993)”, Espaço Plural, nº 18.

- WEAVER, John C. (2009), A Sadly Troubled History: The Meanings of Suicide in the Modern Age, Montreal, McGill-Queen's University Press.

- WEISSMANN, Patricia (1999), "Francisco de Veyga y los comienzos de la clínica criminológica en la Argentina", Temas de historia de la Psiquiatría Argentina, no 7. Disponible en: http://www. polemos.com.ar/docs/temas/Temas7/1a.\%20\%20parte\% 20Francisco\%20de\%20Veyga.htm.

- WILLIAMS, Raymond (2000), Marxismo y literatura, Barcelona, Ediciones Península.

- YAMPEY, Nasim (1973), “El suicidio en Buenos Aires”, en et al, La fascinación de la 
muerte: Panorama, dinamismo y prevención del suicidio, Buenos Aires, Paidós, 1973.

- ZAPICO, Hilda Raquel (2005a), "El rey y sus reinos: poder y ceremonias funerarias en el Buenos Aires del siglo XVII", en Patrimonio cultural en cementerios y rituales de la muerte, Buenos Aires, Comisión para la Preservación del Patrimonio Histórico Cultural de la Ciudad de Buenos Aires, t. II.

----- (2005b), "Una demostración pública de honor, fama y notabilidad en el Buenos Aires del siglo XVII: las honras fúnebres", en Patrimonio cultural en cementerios y rituales de la muerte, Buenos Aires, Comisión para la Preservación del Patrimonio Histórico Cultural de la Ciudad de Buenos Aires, t. II.

- ZEBERIO, Blanca (2000), "Un mundo rural en cambio", en Nueva Historia Argentina, Buenos Aires, Sudamericana. Tomo IV.

- ZIMMERMANN, Eduardo (1995), Los liberales reformistas. La cuestión social en la Argentina, 1890-1916, Buenos Aires, Editorial Sudamericana-Universidad de San Andrés.

----- (1998), "La prensa y la oposición política en la Argentina de comienzos de siglo: el caso de "La Nación" y el Partido Republicano", Estudios Sociales, n ${ }^{\circ}$ 15, Segundo Semestre, 1998.

----- (2000), "La sociedad entre 1870 y 1914", en Nueva Historia de la Nación Argentina, la configuración de la República independiente, Buenos Aires, Academia Nacional de la Historia. Tomo IV (1814-1914). 